\title{
Real-Time Water Quality Management in the Grassland Water District
}

\author{
Nigel W.T. Quinn PhD, P.E. \\ W. Mark Hanna, PhD \\ Jeremy S. Hanlon \\ Josephine R. Burns \\ Christophe M. Taylor \\ Lawrence Berkeley National Laboratory \\ 1 Cyclotron Road, 70A-3317H \\ Berkeley, CA 94720

\section{Don Marciochi} \\ Scott Lower \\ Veronica Woodruff \\ Diane Wright \\ Grassland Water District \\ 22759 Mercey Springs Road \\ Los Banos, CA 93635 \\ Tim Poole \\ Salinas Duck Club \\ c/o Grassland Water District \\ 22759 Mercey Springs Road \\ Los Banos, CA 93635
}

HydroEcological Engineering Advanced Decision Support

November 15, 2004 


\section{ACKNOWLEDGEMENTS}

This project was supported by the CALFED Ecosystem Restoration Program and administered by the US Bureau of Reclamation under U.S. Department of Interior Interagency Agreement No. 3-AA-20-10970, through US Department of Energy Contract No. DE-AC03-76SF00098. The first author would like to thank CALFED and the US Bureau of Reclamation for their financial support and in particular Ms Diane Buzzard, the project COTR, who provided excellent support and was able to secure funds for additional work in the last year of the project. The project wouldn't have been possible without the courage and foresight of Don Marciochi, Grassland Water District General Manager who decided to take a proactive position well in advance of the announcement of salt and boron TMDL's for the Grasslands Basin. Don's sound judgment has been rewarded in a successful pilot project. Tim Poole (Salinas Duck Club) and Scott Lower (Grassland Water District) both made significant investments in educating and advising graduate students and technicians working on the project including Mark Hanna, Jos Burns and Sara Feldmann (Berkeley National Laboratory). This effort was greatly appreciated. A final word of thanks to Mark Hanna whose $\mathrm{PhD}$ thesis formed the backbone of this final report. I could not have found a better helper, colleague and friend to take on this project - much of the project's success is a direct result of Mark's dedication and the energy he brought to his work. Thanks also to Susan Hubbard (Earth Science Division, Berkeley National Laboratory) who reviewed the report and provided useful comments.

This project was supported by the CALFED Ecosystem Restoration Program and managed both by the U.S. Bureau of Reclamation under US Department of Interior Interagency Agreement No. 3-AA-20-10970 and by the U.S. Department of Energy under Contract No. DE-AC03-76F00098. 


\begin{abstract}
The purpose of the research project was to advance the concept of real-time water quality management in the San Joaquin Basin by developing an application to drainage of seasonal wetlands in the Grassland Water District. Real-time water quality management is defined as the coordination of reservoir releases, return flows and river diversions to improve water quality conditions in the San Joaquin River and ensure compliance with State water quality objectives. Real-time water quality management is achieved through information exchange and cooperation between shakeholders who contribute or withdraw flow and salt load to or from the San Joaquin River. This project complements a larger scale project that was undertaken by members of the Water Quality Subcommittee of the San Joaquin River Management Program (SJRMP) and which produced forecasts of flow, salt load and San Joaquin River assimilative capacity between 1999 and 2003. These forecasts can help those entities exporting salt load to the River to develop salt load targets as a mechanism for improving compliance with salinity objectives. The mass balance model developed by this project is the decision support tool that helps to establish these salt load targets.
\end{abstract}

A second important outcome of this project was the development and application of a methodology for assessing potential impacts of real-time wetland salinity management. Drawdown schedules are typically tied to weather conditions and are optimized in traditional practices to maximize food sources for over-wintering wildfowl as well as providing a biological control (through germination temperature) of undesirable weeds that compete with the more proteinaceous moist soil plants such as swamp timothy, watergrass and smartweed. This methodology combines high resolution remote sensing, ground-truthing vegetation surveys using established survey protocols and soil salinity mapping using rapid, automated electromagnetic sensor technology. This survey methodology could be complemented with biological surveys of bird use and invertebrates to produce a robust long-term monitoring strategy for habitat health and sustainability. 


\section{TABLE OF CONTENTS}

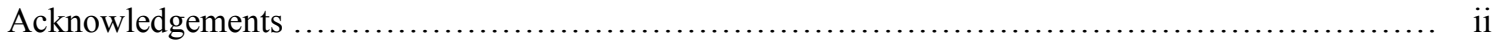

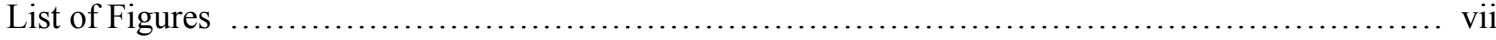

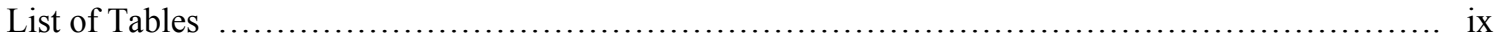

\section{CHAPTER 1 INTRODUCTION}

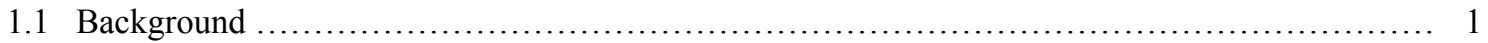

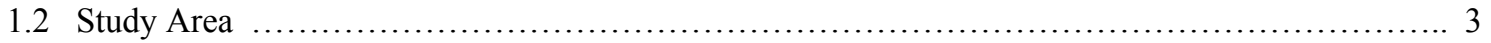

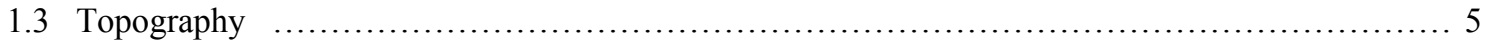

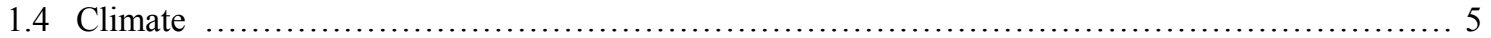

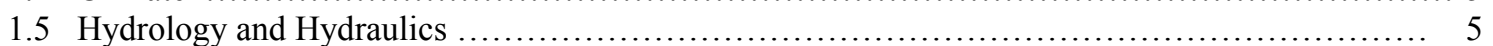

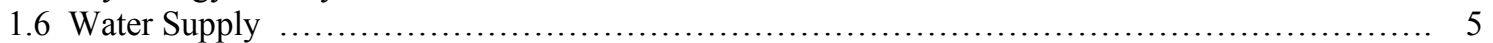

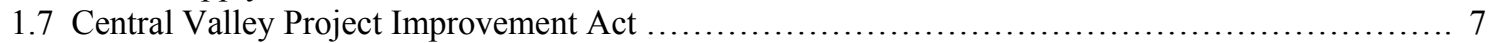

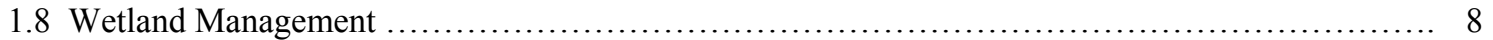

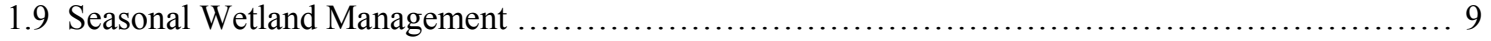

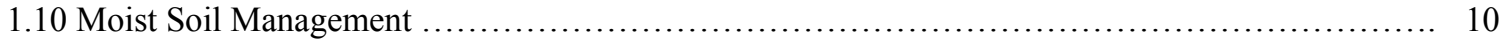

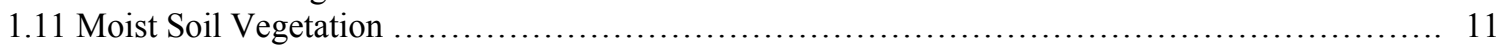

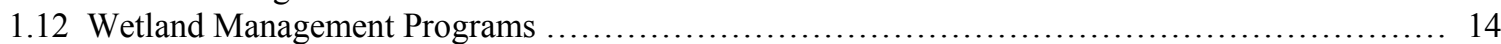

1.13 Impacts of Wetland Management on the San Joaquin River ................................ 15

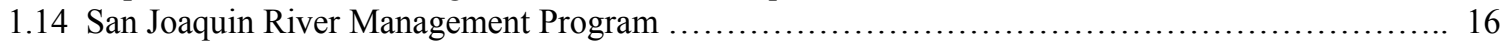

1.15 Coordination between Wetland Management and the San Joaquin River ........................ 17

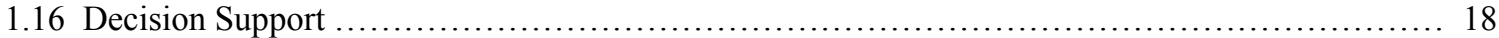

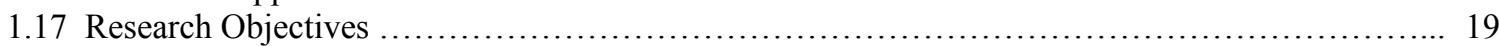

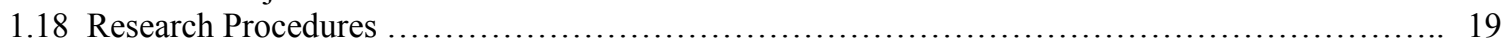

\section{CHAPTER 2 REAL TIME WETLAND WATER QUALITY MONITORING}

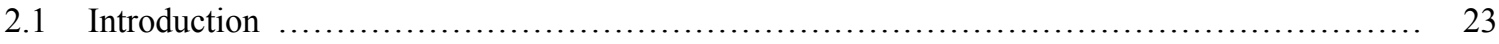

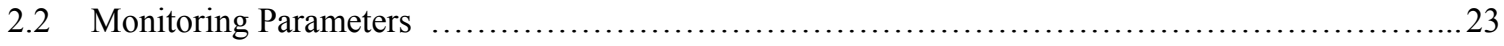

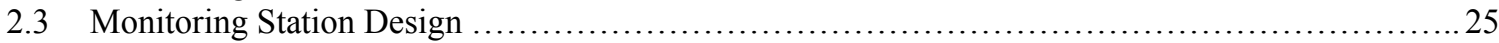

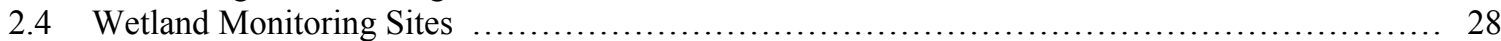

2.4.1 Mud Slough at Gun Club Road ...................................................... 29

2.4.2 Fremont Canal above Mud Slough ................................................ 30

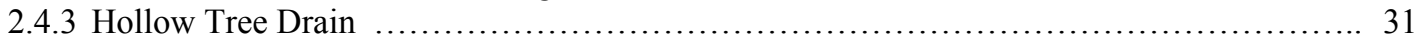

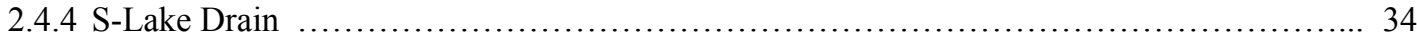

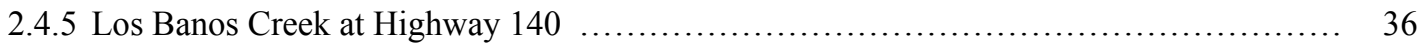

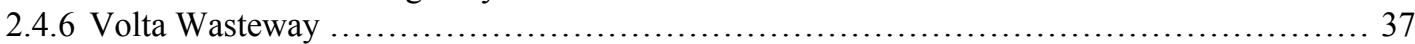

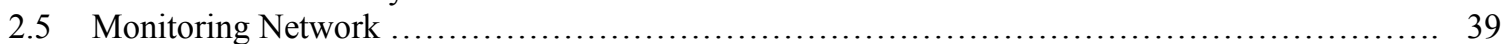

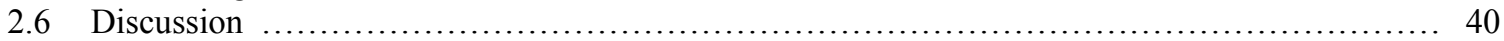

CHAPTER 3 DEVELOPMENT AND APPLICATION OF A REAL-TIME WETLAND WATER QUALITY MODEL

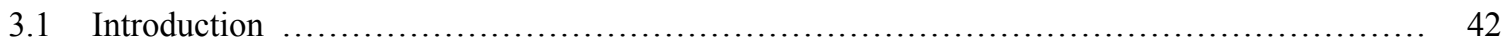

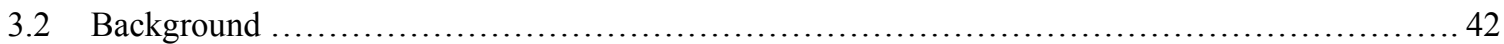

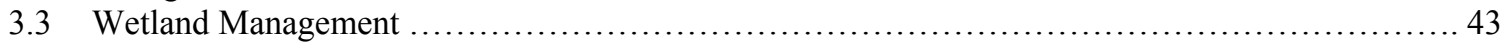

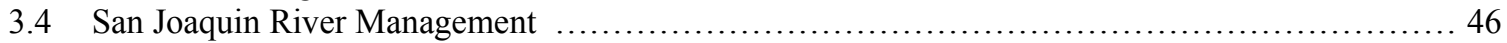

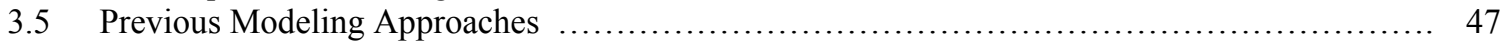

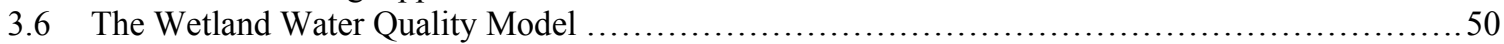

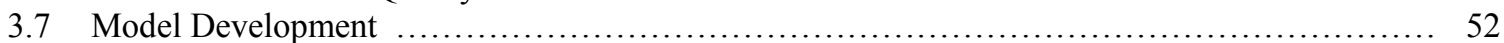

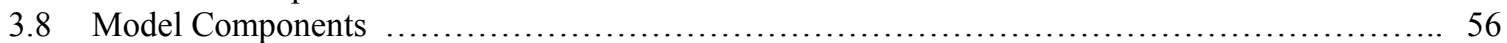

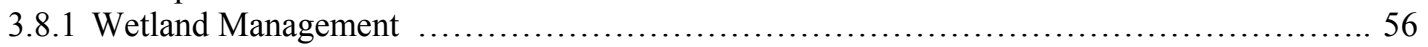

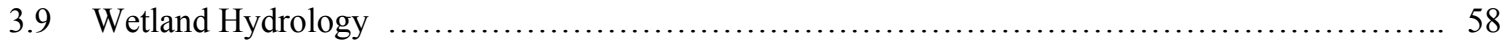

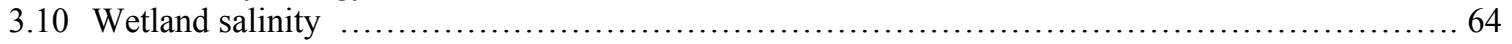

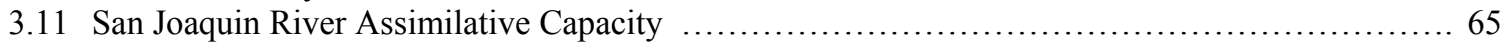




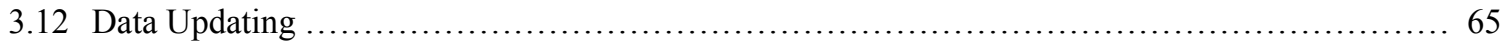

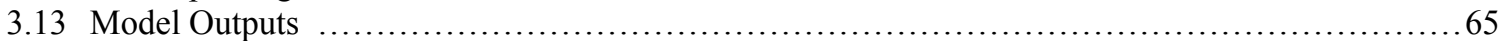

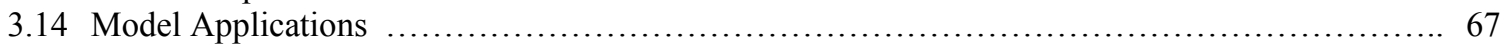

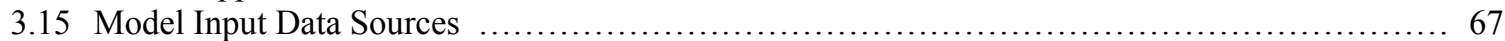

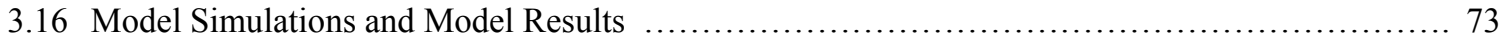

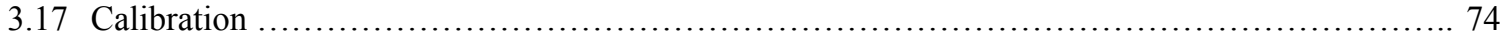

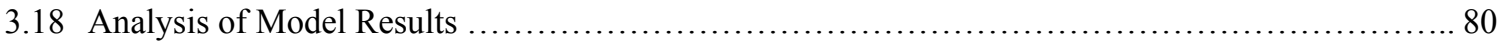

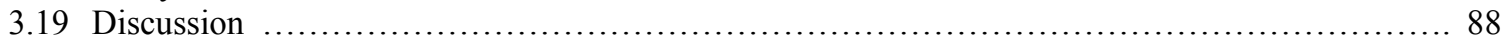

\section{CHAPTER 4 REMOTE SENSING HABITAT ASSESSMENT METHODOLOGY}

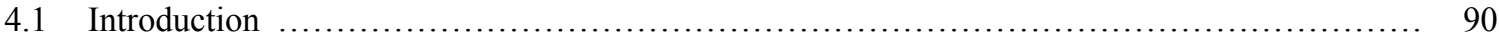

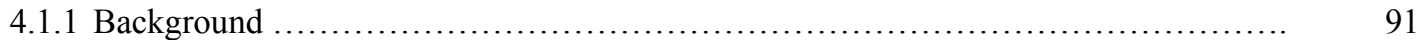

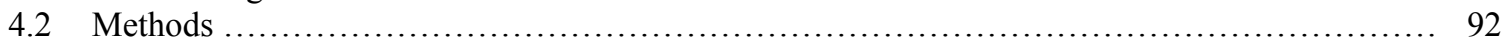

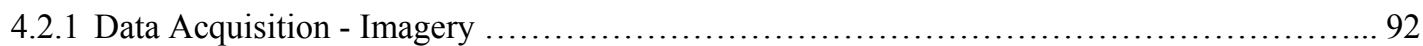

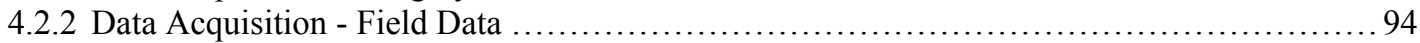

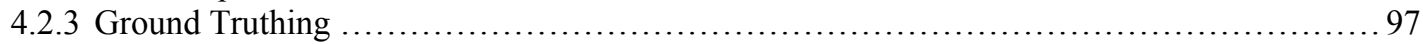

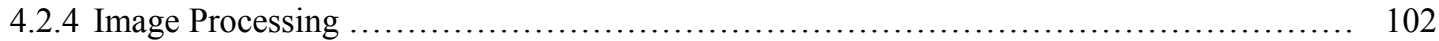

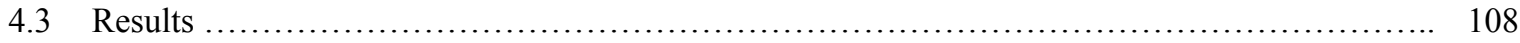

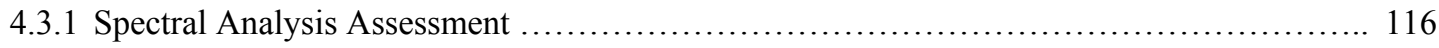

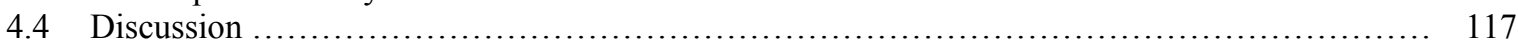

\section{CHAPTER 5 ESTIMATING SOIL SALINITY IN WETLANDS}

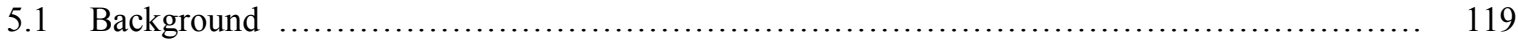

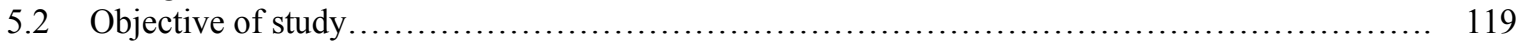

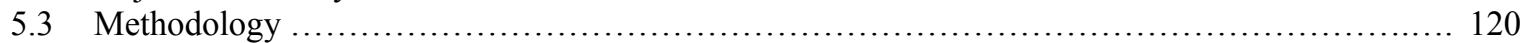

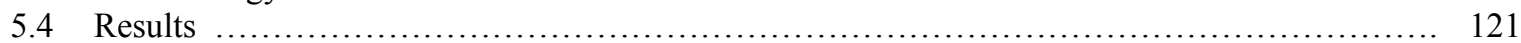

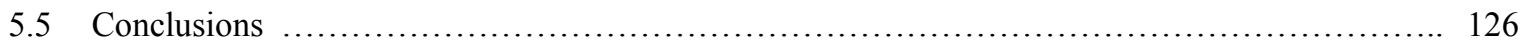

\section{CHAPTER 6 CONCLUSIONS}

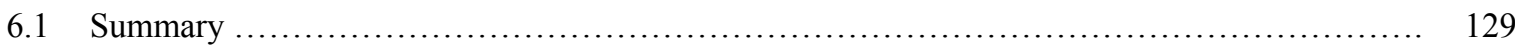

6.2 GWD - Project Geographic Information System........................................... 130

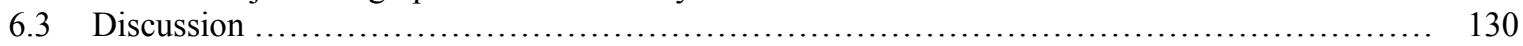

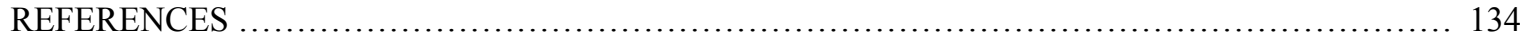

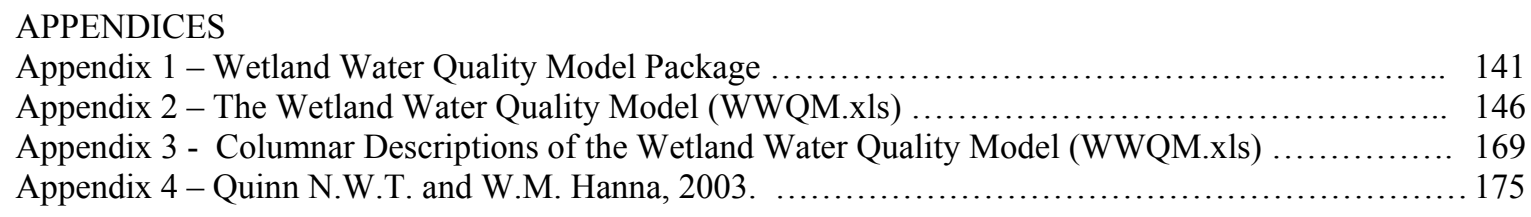




\section{LIST OF FIGURES}

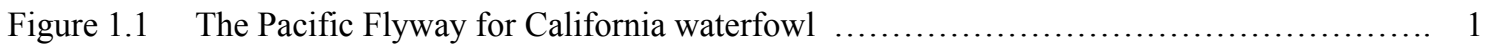

Figure 1.2 The Grassland Ecological Area within the San Joaquin River Basin. .................... 2

Figure 1.3 Grassland Water District split into Northern and Southern Divisions $\ldots \ldots \ldots \ldots \ldots \ldots \ldots \ldots . \ldots$

Figure 1.4 Surface water supply canals and drainage service to GWD $\ldots \ldots \ldots \ldots \ldots \ldots \ldots \ldots \ldots \ldots \ldots \ldots \ldots \ldots \ldots \ldots \ldots \ldots$

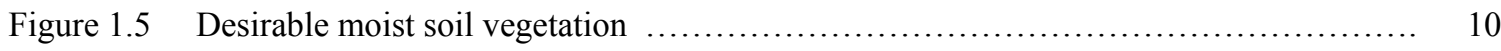

Figure 1.6 Recommended irrigation schedules for certain desirable moist soil plants ............... 11

Figure 1.7 Seasonal wetland drawdown practice in the GWD ............................... 12

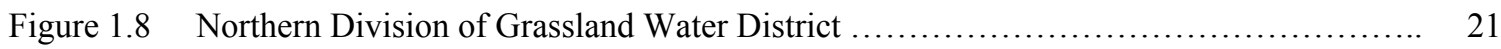

Figure 2.1 Ramp weir at Hollow Tree showing phases of construction ........................ 27

Figure 2.2 Mud Slough and Fremont Canal monitoring station ............................... 28

Figure 2.3 Stage to discharge rating curve for Mud Slough at Gun Club Road ...................... 29

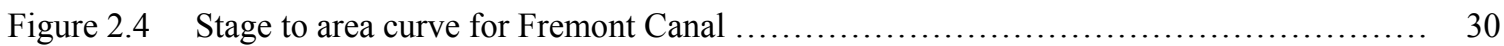

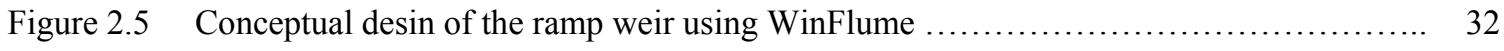

Figure 2.6 Hollow Tree and S-Lake Drain Monitoring Stations ............................... 33

Figure 2.7 Stage to discharge rating curve for Hollow Tree Drain ramp weir ....................... 33

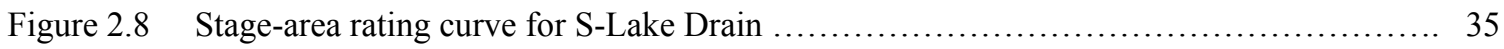

Figure 2.9 Los Banos Creek at the Highway 140 monitoring station .......................... 36

Figure 2.10 Stage -discharge rating curve for Los Banos Creek .............................. 36

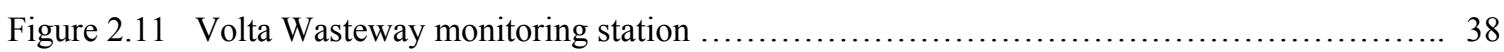

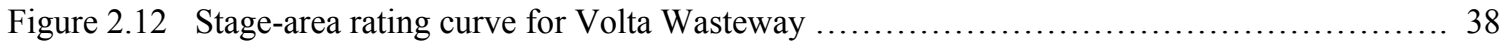

Figure 2.13 Reporting of real-time stage, flow, EC and temperature at Mud Slough ................. 40

Figure 3.1 Scheduling of San Joaquin River salinity, assimilative capacity versus NGWD loading ... 45

Figure 3.2 Flow and electrical conductivity in the SJR between Jan 15 and Mar 1, $1996 \ldots \ldots \ldots \ldots .48$

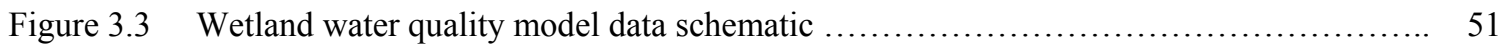

Figure 3.4 Flow and assimilative capacity forecasts for the San Joaquin River, June 2001_.......... 53

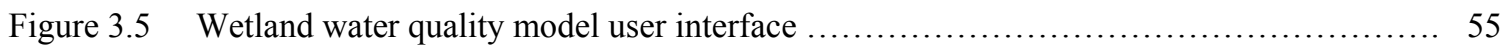

Figure 3.6 The Salinas Land and Cattle Club - an example of a mid-depth seasonal wetland unit ..... 56

Figure 3.7 Hydrologic inputs and outputs for seasonal wetlands ............................... 59

Figure 3.8 The crop coefficient Kc for emergent wetland vegetation in the San Joaquin Valley ........ 63

Figure 3.9 Results from the WWQM calibration runs for Sept 292000 to Apr 12, $2001 \ldots \ldots \ldots \ldots \ldots \ldots$

Figure 3.10 Seasonal wetland management practice with year types incorporated .................... 77

Figure 3.11 Accuracy of modeled versus observed salinity for the 2000-2001 flooded season ........ 78

Figure 3.12 Results from the WWQM calibration runs for Oct 5, 2001 through Apr 8, 2002 ......... 79

Figure 3.13 Accuracy of modeled versus observed salinity for the 2001-2002 flooded season ........ 80

Figure $3.14 \quad 2002-2003$ flooded season scattergram ............................................. 81

Figure 3.15 Results from the WWQM calibration run from Sept 22 to Apr 16, 2003 ................. 82 
Figure 3.16 Comparison of modeled versus observed EC from Feb 24, 2003 model application 84

Figure 3.17 Results of SJRIO assimilative capacity forecast incorporating Feb 24, 2003 model results .. 84

Figure 3.18 Comparison of modeled versus observed EC from March 24, 2003 model application ..... 86

Figure 3.19 Results of SJRIO assimilative capacity forecast incorporating Feb 24, 2003 model results .. 86

Figure 3.20 Results from WWQM calibration runs for Sept. 28, 2003 through Apr 12, 2004 ........87

Figure 4.1 Project imagery from May 2003 (IKONOS) and April 2004 (Quickbird) .................. 95

Figure 4.2 Project imagery from May and June 2004 (Quickbird) ........................... 96

Figure 4.3 The 2003 ground truth locations, Salinas Club, Merced Co., CA..................... 100

Figure 4.4 The 2004 ground truth locations , Salinas Club, Merced Co., CA. ...................... 101

Figure 4.5 Histograms for bands 1,2,3 and 4 in the May 14, 2004 multispectral imagery $\ldots \ldots \ldots \ldots \ldots 103$

Figure 4.6 Mean values of the training signatures of three land cover classes .................... 104

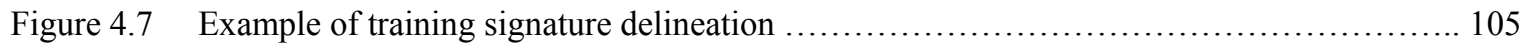

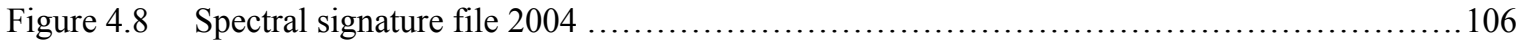

Figure 4.9 Feature space analysis of separability of three land cover classes in bands 2 and $4 \ldots \ldots \ldots 107$

Figure 4.10 Separability matrix showing transformed divergence values for first ten land over classes .. 108

Figure 4.11 Maximum likelihood classification result for Salinas Club, 2003.................. 109

Figure 4.12 Maximum likelihood classification result for NGWD, $2003 \ldots \ldots \ldots \ldots \ldots \ldots \ldots \ldots \ldots$

Figure 4.13 Final map showing delineation of entire North Grassland WD into land use categories..... 112

Figure 4.14 April and May, 2004 maximum likelihood classification of NGWD.................... 114

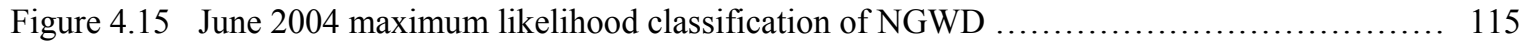

Figure 4.16 Spectral signature validation, 2003 RHAM $\ldots \ldots \ldots \ldots \ldots \ldots \ldots \ldots \ldots \ldots \ldots \ldots \ldots \ldots \ldots$

Figure 5.1 Location of sites surveyed at the SLNWR San Luis Unit ......................... 120

Figure 5.2 Location of sites surveyed at the Salinas Duck Club .............................. 120

Figure 5.3 EM38 dual mode meter placed in a carrier sled that was attached to the rear of an ATV ... 121

Figure 5.4 Soil salinity estimated at 0-6 inches depth at two sites surveyed at the San Luis Refuge .... 124

Figure 5.5 Soil salinity estimated at 6-12 inches at two sites surveyed at the San Luis Refuge 2004 .. 125

Figure 5.6 Soil salinity estimated at 0-6 inches depth at two sites surveyed at the Salinas Duck Club .. 125

Figure 5.7 Soil salinity estimated at 6-12 inches at two sites surveyed at the Salinas Duck Club 2004126

Figure 5.8 Soil salinity estimated at 0-12 inches at two sites surveyed at the Salinas Duck Club , 2004127

Figure 6.1 Geographic Information System (GIS) for the Northern Division grassland Water District 131

Figure 6.2 Modeled San Joaquin River salinity under different drawdown schedules ............... 133 


\section{LIST OF TABLES}

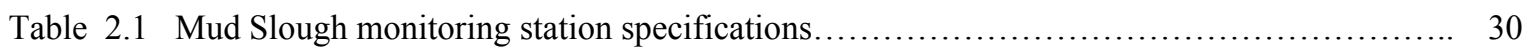

Table 2.2 Fremont Canal monitoring station specifications..................................... 31

Table 2.3 Hollow Tree Drain monitoring station specifications................................... 34

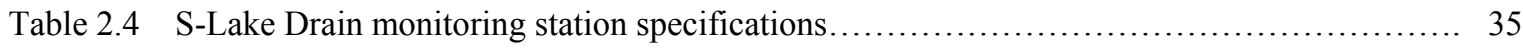

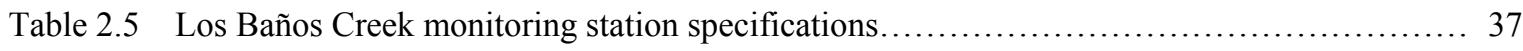

Table 2.6 Volta Waste Way monitoring station specifications..................................... 39

Table 3.1 Wetland management decision tree ..................................................... 44

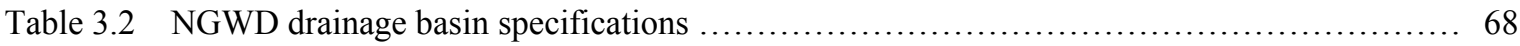

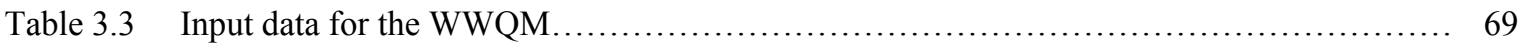

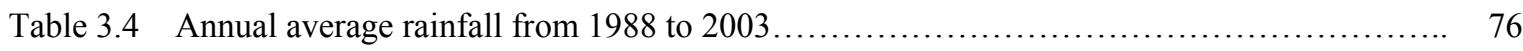

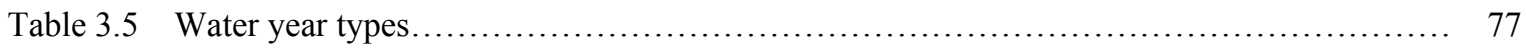

Table 3.6 Tabular results of February 24, 2003 model application .............................. 83

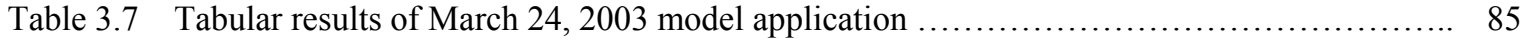

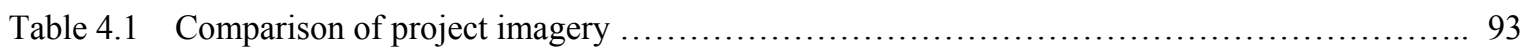

Table 4.2 Field data from modified CNPS Rapid Assessment Protocol ............................... 99

Table 4.3 Land use acreages for the Salinas Duck Club and the Northern Grassland Water District .... 111

Table 4.4 Land use acreages (2004) for the Northern Grassland water District..................... 113

Table 5.1 Soil electrical conductivity $(\mathrm{ds} / \mathrm{cm})$ for samples collected at all survey sites................ 122

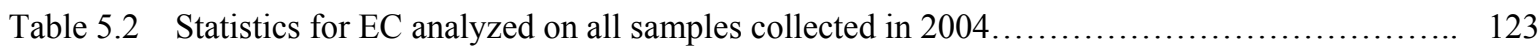

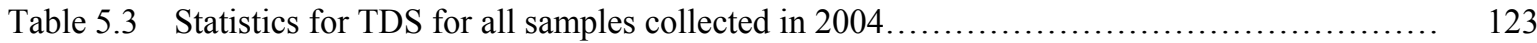

Table 5.4 Statistics for EC and TDS analyzed for all soil samples collected at the Salinas Duck Club ... 126 


\section{CHAPTER 1 INTRODUCTION}

\subsection{Background}

California's Central Valley is the most important wintering area for migratory waterfowl within the Pacific Flyway (Figure 1). However, over 90\% of California's wetlands have been eliminated through agricultural expansion and urban development (Campbell, 1988; USFWS, 1999). Historically, much of California's Central Valley was an arid plain dominated by grasses and low shrubs. In the lower-lying areas adjacent to the San Joaquin River large wetland complexes existed. During the wet season, much of the area was transformed into marshes. These wetlands supported an abundance of native vegetation, migratory waterfowl, shorebirds, and other wildlife (Stoddard \& Associates, 1986; Campbell, 1988; Isola, 1998).

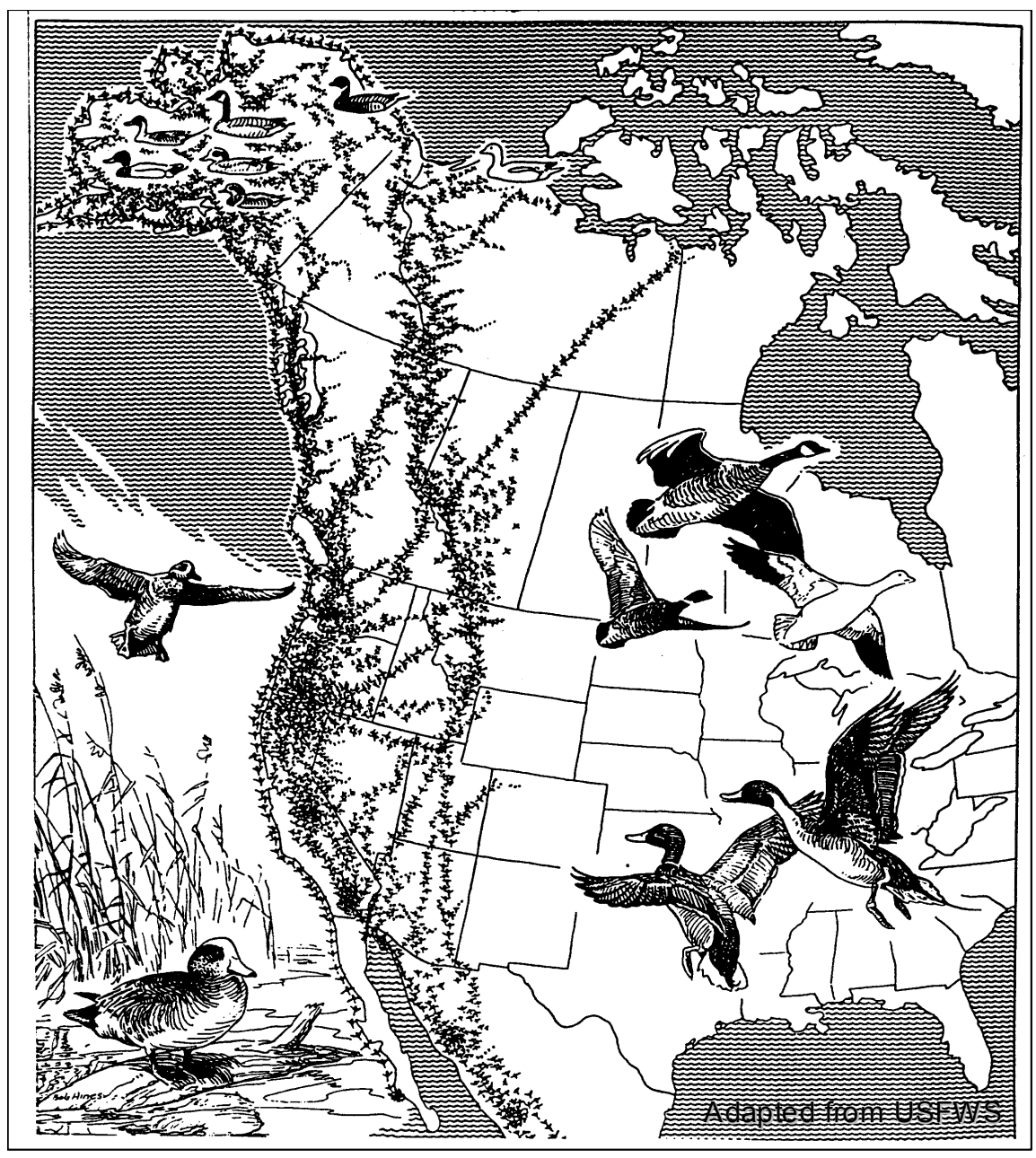

Figure 1.1 The Pacific Flyway for California waterfowl. 
Over time, as more people immigrated to California, land in California was rapidly acquired by settlers. One of California's largest land owners in the early 1900's was the Miller and Lux Cattle Corporation (Miller and Lux). The area encompassing the present day Grassland Basin was once a part of the Miller and Lux land holdings (Grassland Water District, 1986) When Miller and Lux began selling portions of its land holding to market hunters and

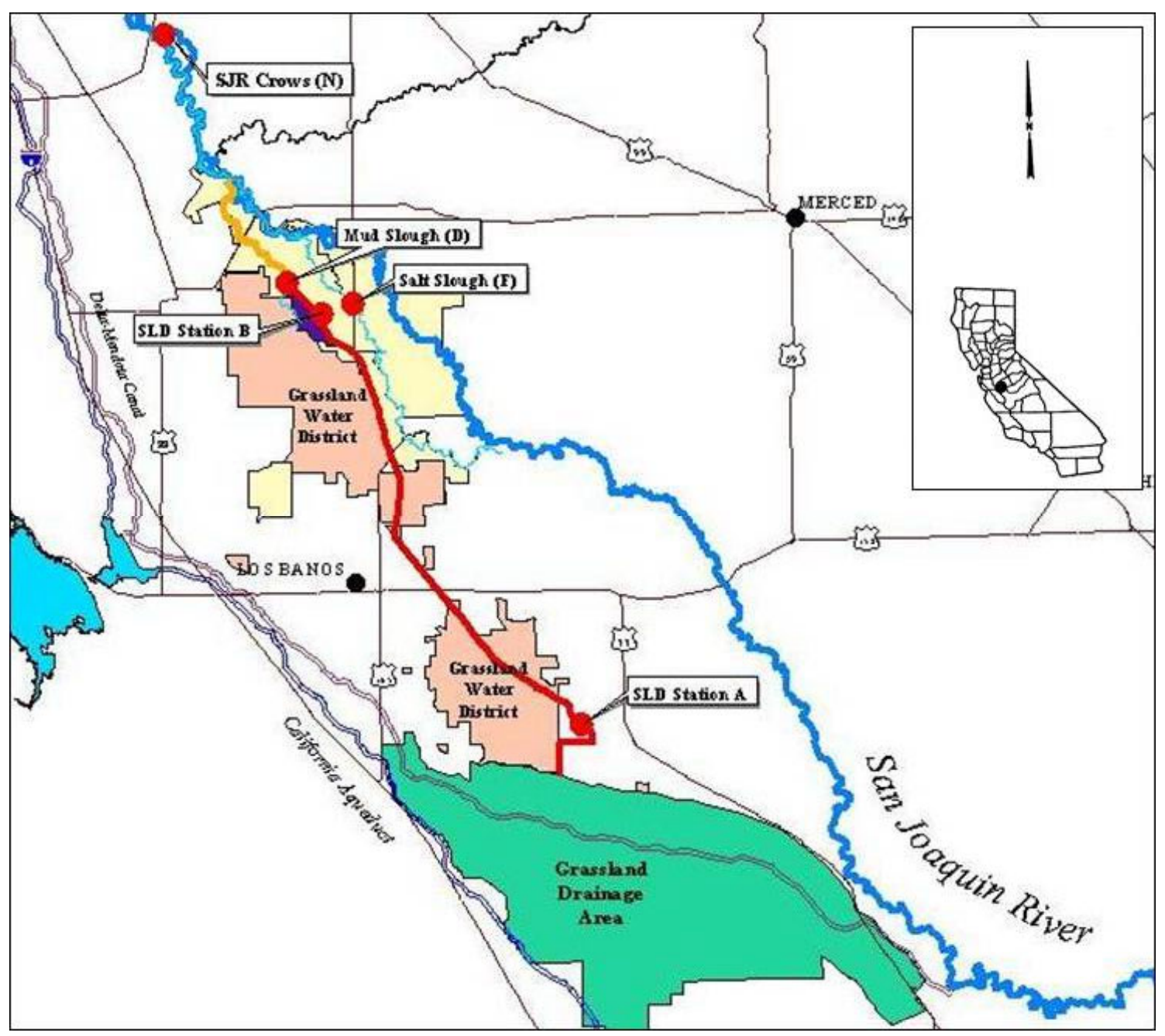

Figure 1.2. The Grassland Ecological Area within the San Joaquin River Basin.

recreational hunters in 1926, the corporation retained most water rights, thus centralizing this vast resource under one entity (Grassland Water District, 1986; Stoddard \& Assoc., 1998). In 1939, the U.S. Bureau of Reclamation acquired the water rights from the Miller and Lux Company to develop the Central Valley Project (CVP), which allowed reclamation to expand 
irrigation service to the southern san Joaquin Valley by trading San Joaquin River water supply with surface water pumpage from the South Delta.. Throughout its history the Grassland Water District GWD has received insufficient water supply to meet demand and to restore the wetlands within the District to a pre-development condition. The problem of inadequate water supply has been compounded in recent years by concerns over supply water quality and most recently by environmental constraints to salt loading to the san Joaquin River.

\subsection{Study Area}

The San Joaquin River, flowing northward through California's Central Valley, is a major hydrologic contributor to the Sacramento-San Joaquin Delta. The SJR system, including the river and its associated drainage basin, provides significant social, environmental, and economic benefits (Grassland Water District, 2001). The river system also provides water supply and drainage conveyance for agriculture, wetlands, upland and riparian areas, municipalities and industries. Current uses have resulted in a significant degradation of water quality, the loss of fish and wildlife habitat, a reduction in flood protection capacity, and a shortage of recreational opportunities. The San Joaquin River is a highly constrained system (i.e. over allocated and heavily regulated), hence uncoordinated actions often pit some beneficial uses of the river against others, resulting in deterioration of the overall health of the river system.

The Grassland Water District (GWD) is divided into two major land areas. The Northern Division of the GWD (NGWD) is located roughly between the town of Gustine to the northwest and Los Baños to the south. The San Luis National Wildlife Refuge borders the NGWD to the north and east. The western boundary of NGWD consists of the Volta Wildlife Management Area, uplands and agricultural lands between the towns of Gustine and Los Baños. Henry Miller Road and the town of Los Baños roughly constitute NGWD's southern boundary. The Southern Division of the GWD (SGWD) lies between Los Baños to the northwest and the Fresno County Line to the southeast. Highway 152 and the town of Los Baños border the SGWD to the north. The towns of Dos Palos and South Dos Palos 
border it to the east, and the southern and western boundary lies roughly along the main canal.

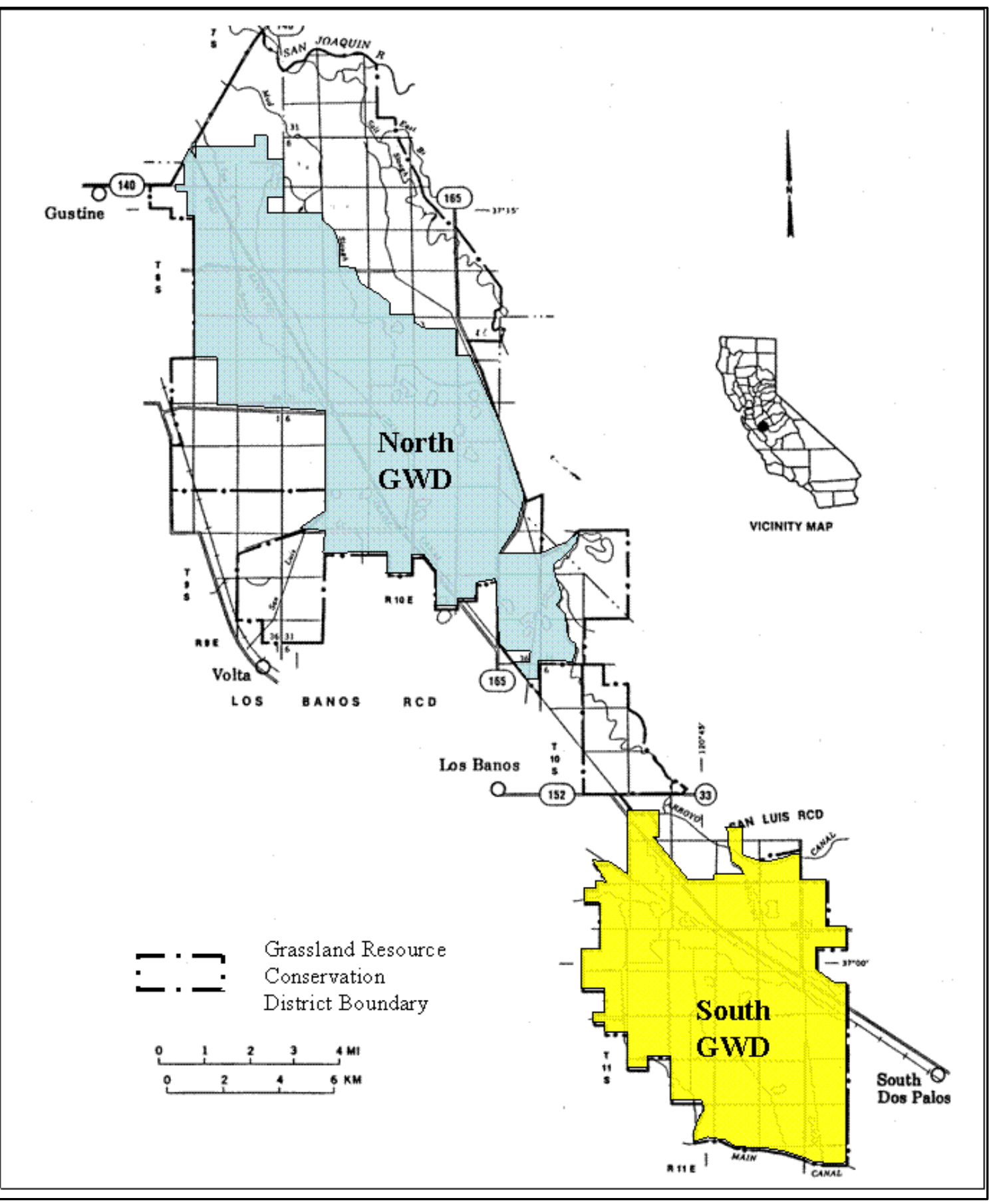

Figure 1.3. Grassland Water District split into Northern and Southern Divisions 


\subsection{Topography}

The topography of the GWD appears flat, with an average slope of less than $2 \%$. There is a general downward slope toward the northeast. The GWD has a peak elevation of 130 feet above sea level at the southern boundary and drops to 74 feet at the northern boundary near the SJR (Stoddard \& Assoc., 1986).

\subsection{Climate}

Regional climate in the San Joaquin Valley resembles Mediterranean conditions - warm, dry summers and cool, damp winters (Rundel and Vankat, 1989). During the summer temperatures often exceed 100 degrees Fahrenheit and produce an evaporation potential of $90+$ inches per year, although average precipitation at the valley floor is only ten inches (Grassland Water District, 1986). California's precipitation and streamflow are highly variable - climatic anomalies induced by El Nino and la Nina conditions cause extreme events and anomalies in California's weather patterns. California is affected by pressure systems generated over the Pacific Ocean (Kahya and Dracup, 1994; Piechota et al., 1997).

\subsection{Hydrology and Hydraulics}

Wetland hydrology is dictated by the regional flooding regime. Within the GWD, this regime is managed artificially to maintain standing water from mid-September through midto late-April (Grober et al., 1995; Quinn et al., 1997; Quinn and Karkoski, 1998). Historically, floodplain inundation and wetland hydrology was more variable, caused by flood flows in the San Joaquin River resulting from from winter rains and spring snowmelt. Surface and groundwater regional flow in the GWD is from the south-west to the north-east, following the regional topography. The area includes three natural drainages. These drainages are Mud Slough and Los Baños Creek in the northern region and Salt Slough in the southern region. In addition to these historic drainages, there are numerous constructed channels, ditches, drains, culverts, gates, and siphons throughout the GWD.

\subsection{Water Supply}

The Grassland Water District is the entity responsible for supplying water and drainage capacity to approximately 50,000 acres of privately owned historical wetlands, uplands, and 
agricultural lands west of the San Joaquin River and uses the River for conveyance of wetland drainage during the spring months (March - May) each year. The GWD, together with the adjacent State and Federal refuges, constitute the largest contiguous wetland complex remaining in the State of California $(\sim 160,000$ acres) (Grassland Water District, 1986; Shuford et al., 1998). These wetlands are remnants of a much larger wetland complex that extended throughout California's Central Valley. As more and more of California's wetlands are lost to development, this area's value to wildlife increases proportionately (USFWS, 1999). In turn, as the area's wildlife value increases, so must the intensity of wetland management.

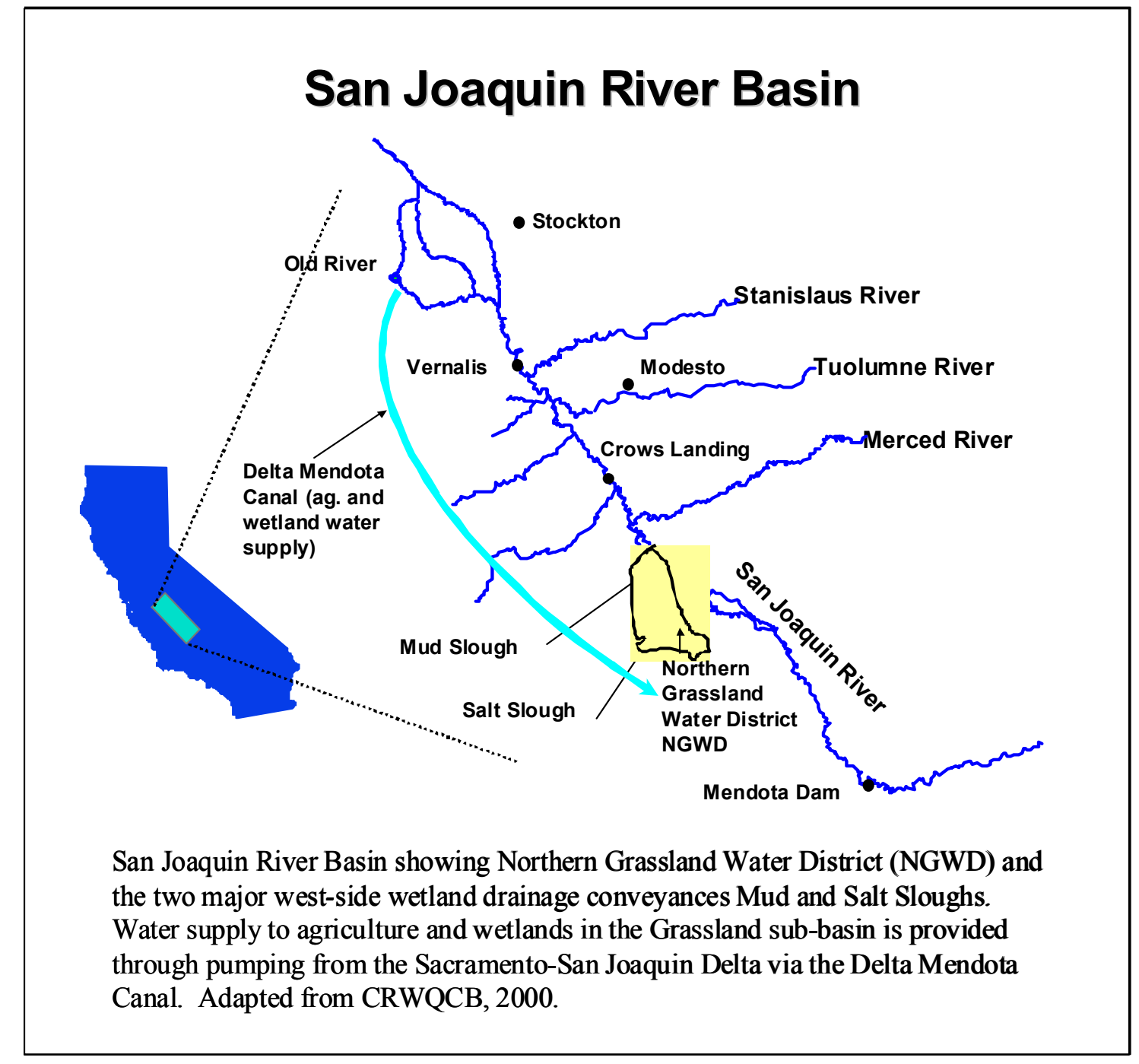

Figure 1.4. Surface water supply canals and drainage service to Grassland Water District. 
The GWD receives most of its water supply from the Central Valley Project (CVP) (Grassland Water District, 1986; Stoddard \& Assoc., 1998; Letey, 2001). Canals originating in the Sacramento - San Joaquin Delta now feed an area that once was flooded by the San Joaquin River. Prior to the Central Valley Project Improvement Act (CVPIA) in 1992, the CVP provided the GWD with 50,000 acre feet of water per year--roughly one foot of water per acre per year. In the past, during dry and critically dry water years the GWD often could experience reductions of up to $75 \%$ of its annual supply (Grassland Water District, 1986). Hence the GWD was forced to secure necessary maintenance water from local agricultural drainage. These supplies often contained additional pollutants including salts, selenium, and boron. Use of these agricultural return flows ceased in 1985 by mandate after the recognition of selenium toxicosis in migratory waterfowl nesting in what was once Kesterson Reservoir. The selenium issue brought about a significant change in the way environmental water quality was considered in California and helped to bring about one of the largest reforms in water allocation policy in the nation's history.

\subsection{Central Valley Project Improvement Act}

In October 1992, Congress passed a Western water bill that included, as a major provision, the CVPIA. The CVPIA mandated major changes in the operation of the Central Valley Project (CVP). The CVP was constructed by the U.S. Bureau of Reclamation in 1935 to permit surface water to be diverted from both the Sacramento and San Joaquin Rivers for farmland in the San Joaquin Valley. In addition to supplying agricultural irrigation water, other benefits such as flood control, navigation, power generation, and municipal and industrial water supply were realized by the CVP. Shasta and Keswick dams on the Sacramento River as well as Friant Dam on the San Joaquin River were among the first units built. Canals such as the Friant-Kern, the Madera, the Delta Cross Channel, and the DeltaMendota Canal were designed to transport and deliver surface water supplies throughout the San Joaquin Valley. With the CVP the origin of water supply for entities such as the Grassland Water District (and later - the State and Federal refuges) was transferred from the Sierra Nevada mountain range and the San Joaquin River to the Sacramento-San Joaquin River Delta and pumped south through the Delta Mendota Canal. 
One of the key provisions of the 1992 CVPIA legislation was a recognition that the CVP water allocations to San Joaquin Basin wetlands were inadequate to provide sustainable wetland habitat. Hence the Act dedicated 800,000 acre-feet of water from the CVP primarily for fish and wildlife purposes. A goal of the legislation was to increase wetland supply water from a Level II maintenance allocation to a Level IV optimal allocation. The GWD and the surrounding State and Federal wildlife refuges have been recipients of some portion of this reallocated water supply.

Increased water supply allocations under the CVPIA have improved wildlife habitat but have also resulted in increased seasonal wetland drainage, producing more flow and salt loading to the San Joaquin River. This has, in turn, created opportunities to coordinate the release of seasonal wetland drainage with the assimilative capacity of the San Joaquin River. Coordinated releases of west-side agricultural and wetland drainage with east-side reservoir releases can potentially help to achieve salinity objectives in the main stem of the San Joaquin River and and improve fish habitat in the Sacramento-San Joaquin Delta. Improved scheduling of west-side discharges can assist in avoiding water quality violations and remove an important stressor leading to improvements in the San Joaquin salmon fishery

\subsection{Wetland management}

Preservation and enhancement of wetlands in California's Central Valley is important to ensuring wildlife and habitat diversity. The regional wetlands are home to millions of waterfowl and shorebirds, a diverse community of moist-soil vegetation, and other common and endangered wildlife (Mason, 1969; Small, 1974; Cogswell, 1977; Grassland Water District, 1986; Stoddard and Associates, 1998; Shuford et al., 1998; Sibley, 2000). Because of the great importance of this wildlife, management practices (BMPs) for wetland management have been developed. Depending on the goals, these BMPs can include grading, discing, mowing, grazing, burning, herbicide application, dry season irrigations, and the timing of wetland flood-up and drawdown. By timing flood-up and drawdown in the San Joaquin Valley, managers mimic the wet/dry seasonal cycle that these historical wetlands once experienced. This seasonal cycle aids life's processes and can be adapted to promote desired species (Frederickson and Laubhan, 1995). 
Under "natural" conditions, this diversity would be supported through seasonal flooding and natural disturbances (drought, fire) that historically followed the seasonal cycle. However, due to anthropogenic effects (water projects, agricultural and urban development, etc.), the hydrologic regime that once defined these annual cycles in the Central Valley no longer exists. To mimic these natural processes, research has been undertaken to understand the role of water manipulation, irrigation, waterfowl habitat requirements and both vegetation and waterbird responses to different management techniques. Altering wetland drainage schedules affects the timing and rate of drawdown of wetland ponds and hence the forage value of the wetlands for migrating and wintering shorebirds and waterfowl. Wetland salinity management measures also affect the productivity and diversity of vegetation that can be grown in the watershed (Rosenberg and Sillett, 1991; Mushet et al., 1992).

\subsection{Seasonal wetland management}

Wetland management, as practiced in California's Central Valley, covers a broad range of activities. These activities may include various intensities of land grading, vegetation discing and burning, the application of herbicides and pesticides, agricultural activities such as grazing cattle or growing rice, and irrigation. Due to anthropogenic alterations in natural hydrology, these wetlands are flooded artificially with Central Valley Project water supplies delivered through GWD canals. The fall flood-up occurs during the months of September and October, and the spring drawdown occurs during the months of February, March, and April.

Wetland drawdowns are timed to make seed and invertebrate resources available during peak waterfowl and shorebird migrations and to correspond with optimal germination conditions (primarily soil moisture and temperature) for naturally occurring moist-soil plants (Smith et al., 1995). Spring drainage that is timed for optimal habitat conditions occurs at a sensitive time for agriculture in the South Delta in that these drainage releases occur during the time crops are being irrigated or the first time and are germinating - potentially affecting crop yields. Studies suggest that approximately $10 \%$ of the San Joaquin River's annual flow, and $30 \%$ of its annual salt load, passes through wetlands within the Grasslands Basin, which 
includes the Grassland Water District (Grober et al., 1995; Karkoski et al., 1995; Quinn et al., 1997; Quinn and Karkoski, 1998).

\subsection{Moist-Soil Management}

The wetland "best management practice" (BMP) specific to this research project focuses on water level manipulation and is most often called "moist-soil management". Moist-soil management refers to a process of water level manipulations to promote productive habitat conditions and beneficial vegetation such as smartweed (Polygonum punctatum), watergrass (Echinochloa crusgalli), and swamp timothy (Heleochloa schoenoides) for foraging

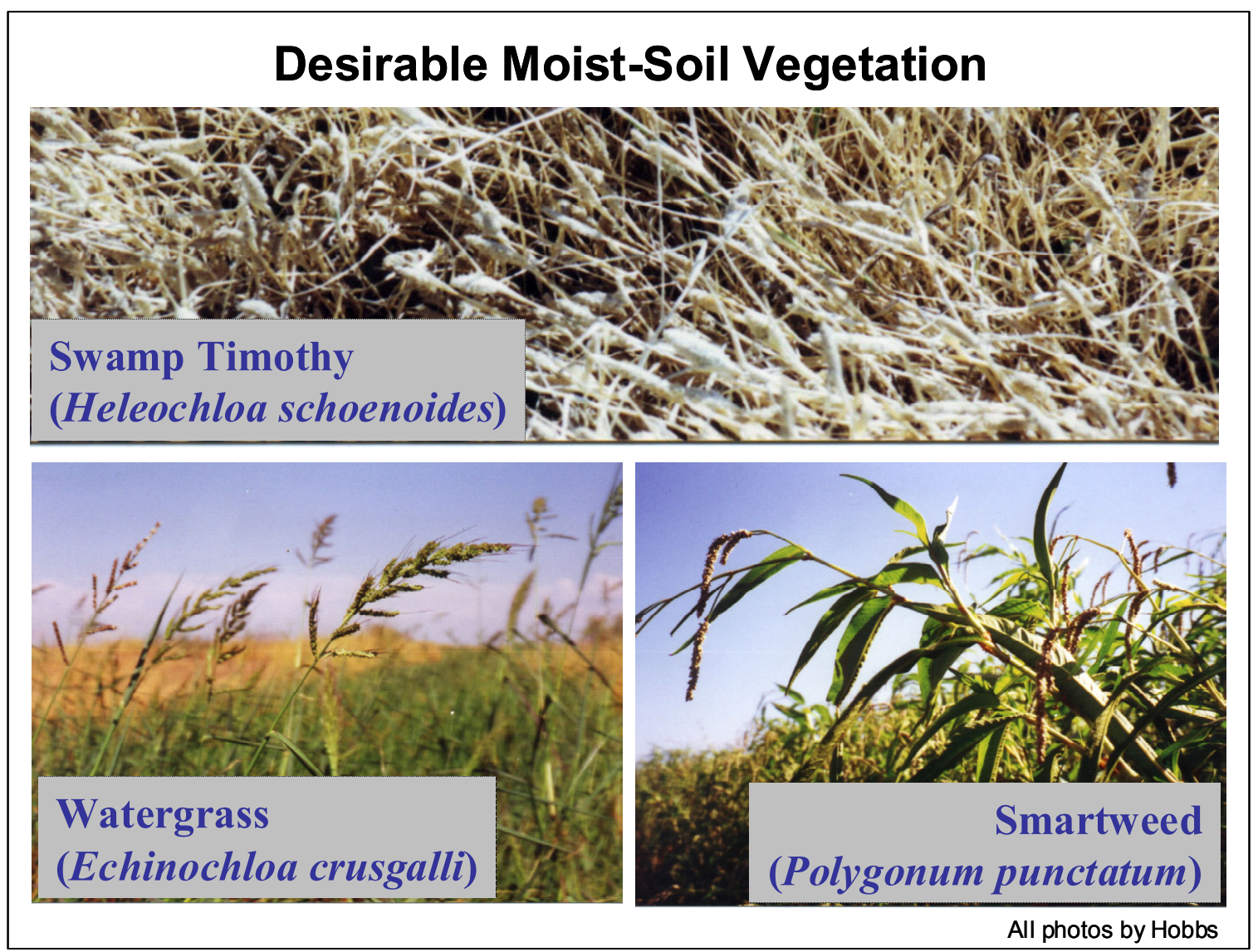

Figure 1.5 Desirable moist-soil plant vegetation.

waterfowl (Figure 1.5). Water-level manipulations include flood-up in the fall and wetland drawdown in the spring, and provide optimal conditions at each stage of vegetation development. In addition to flood-up and drawdown, several summer irrigations are 


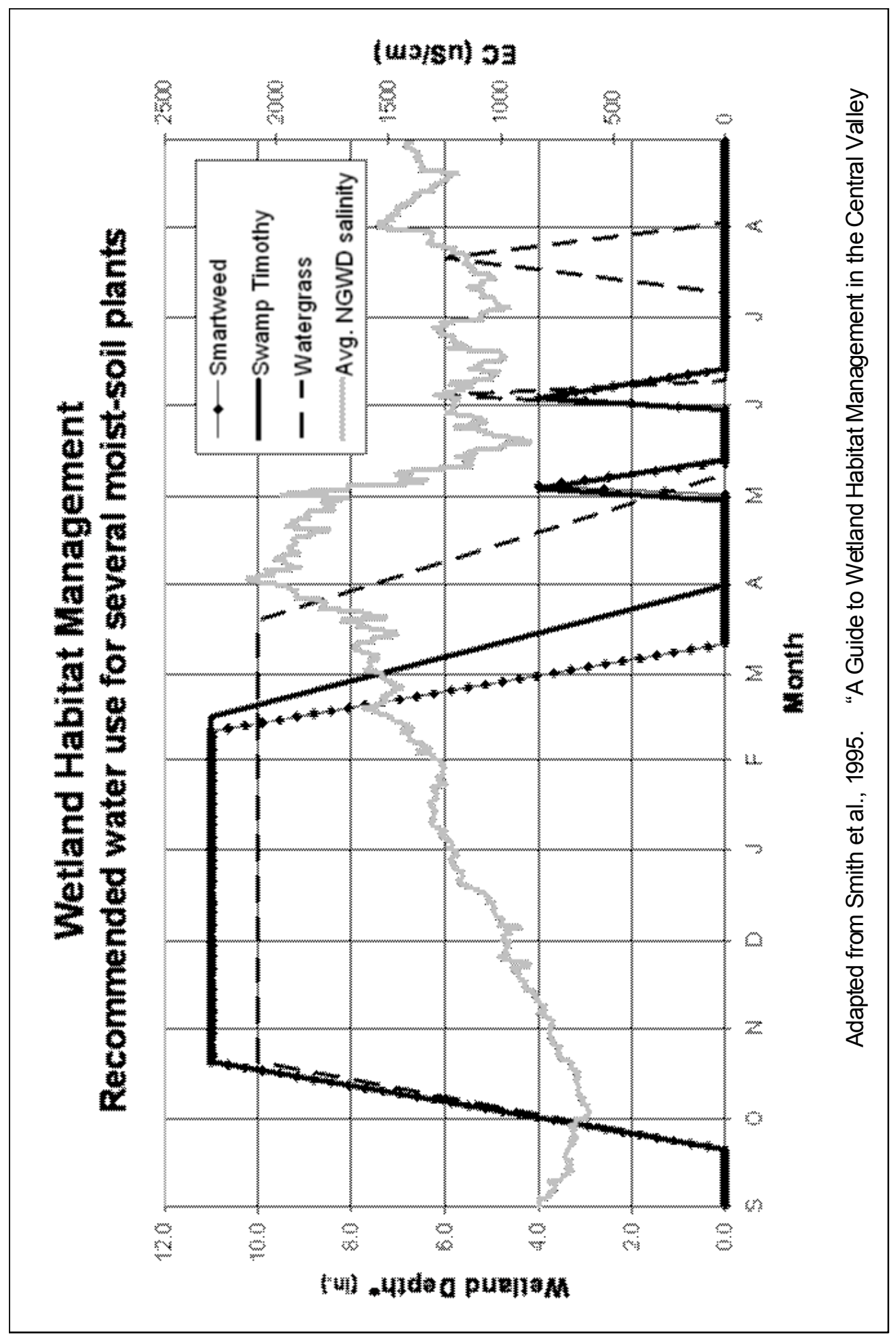

Figure 1.6. Recommended irrigation schedules for certain desirable moist soil plants. 
conducted by wetland managers to sustain and improve growth characteristics of the desired vegetation (Figure 1.6). The seeds of moist-soil plants are recognized as a critical waterfowl food source, providing essential nutrients and energy for wintering and migrating birds (Fredrickson and Taylor 1982; Bundy, 1997; Shuford et al. 1998). Not only does the desirable vegetation provide direct nutritional value through consumption, but it also encourages healthy invertebrate populations, a high-protein food source at critical times of the year (Swanson, 1988; Mushet et al., 1992; Smith et al., 1995; Bundy, 1997; Stoddard and Associates, 1998).

\section{Seasonal Wetland Management Drawdown Practice}

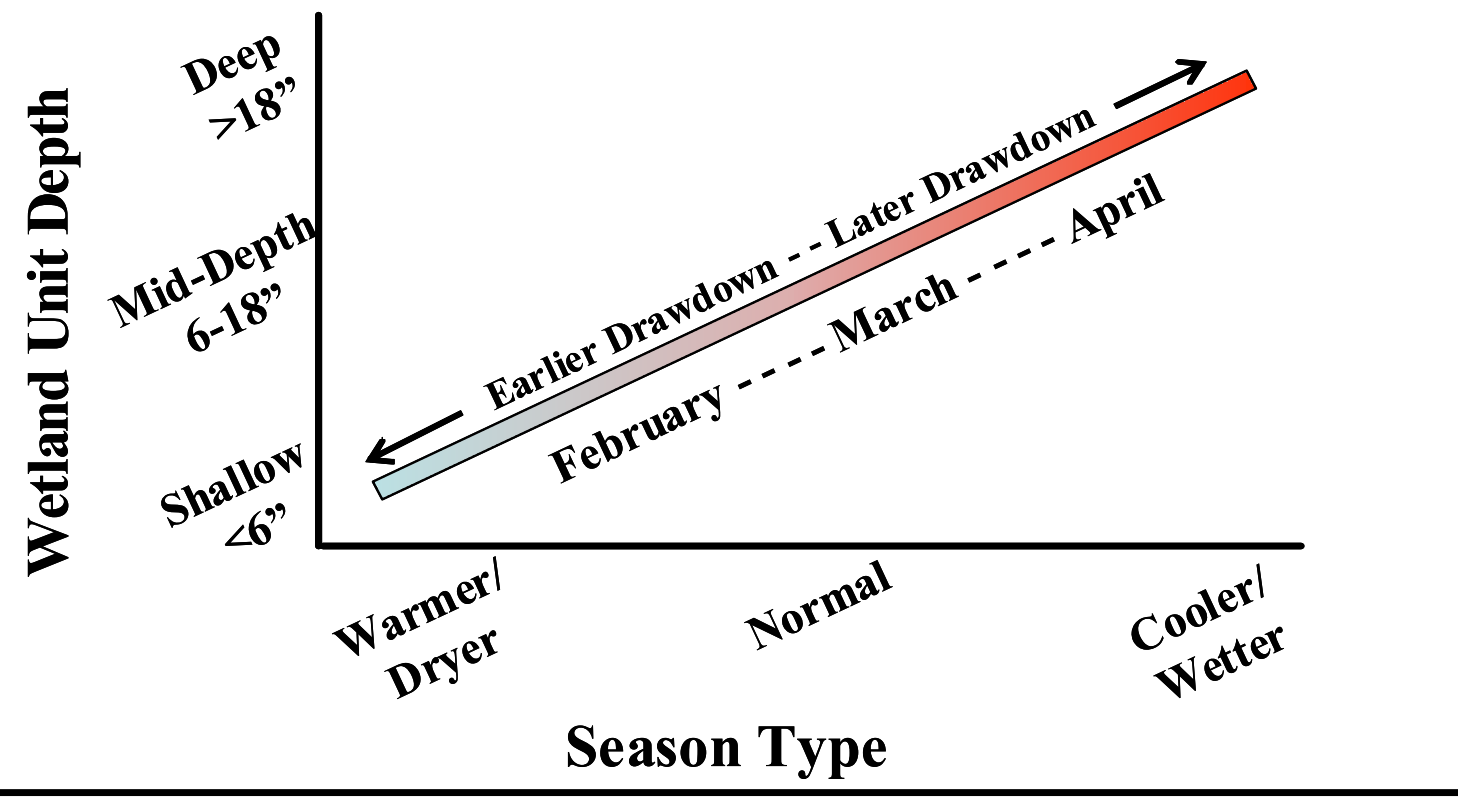

Figure 1.7 Seasonal wetland drawdown practice in the Grassland Water District.

It is generally accepted by wetland managers that during cool wet years, and for wetlands of greater depth, it is better to drain them later because the optimal conditions of soil temperature and soil moisture tend to occur later. Conversely, during warm dry years, and for shallower type wetlands, it is better to drain them earlier because the optimal conditions of soil temperature and soil moisture tend to occur earlier. However, in intensively managed 
wetland complexes such as the GWD, the heterogeneity of wetland soils, year to year variations in the weather and the complex dynamic ecology of the wetland resource require constant hydrologic manipulation and fine tuning of management decisions by wetland biologists.

\subsection{Moist-Soil Vegetation}

Many different species of vegetation grow within the GWD. Together they form a mosaic of vegetation communities that provide the habitat required to sustain wildlife. Wetland managers often classify this vegetation, either native or naturalized, into two categories: desirable or non-desirable. Desirable plants include native species that form a healthy mixed marsh or that can provide shelter or food stores to migratory waterfowl and shorebirds. Nondesirable plants are often invasive/introduced species and may consume resources (such as light and soil) that otherwise would go to desirable species.

There are generally three major desirable moist-soil plant communities that are targeted for waterfowl forage potential. These targeted communities are found in a mixed marsh setting and are either dominated by smartweed, swamp timothy, or watergrass. A healthy mixed marsh for the San Joaquin Valley could include several other desirable species such as sprangletop (Leptochloa fascicularis), brass buttons (Cotula coronopifolia), and alkali heath (Frankenia grandifolia). While targeting one of the highly desirable plants in the mixed marsh such as swamp timothy, wetland mangers also promote the other listed species (Smith et al, 1995). Several other acceptable plants work well in a mixed marsh community and can include, but are not limited to, tule or hardstem bulrush (Scirpus acutus), cattail (Typha latifolia), spikerush (Haleocharis palustris), purple ammannia (Ammannia coccinea), alkali bulrush (Scirpus robustis), fat-hen (Atriplex patula), and beggar-ticks (Bidens spp.).

The three desirable plants above, swamp timothy, watergrass, and smartweed, have a tendency to grow in large stands, bordered by mixed marsh consisting of desirable plants along with other acceptable plants. As conditions change (drainage plans, for instance), so does the composition of the stands and border areas. Wetland mangers target species by 
means of water manipulation and other management practices (i.e. flood-up and drawdown plans, disturbance, dry season irrigation, alternative land use).

However, there are several non-desirable plants that tend to establish a stronghold when conditions are not ideal for the more desirable plants. These non-desirable plants include, but are not limited to, aster (Aster spp.), cocklebur (Xanthium strumarium), salt grass (Distichlis spp.), Bermuda grass (Cynodon dactylon), and dock (Rumex spp.). These species grow in dense stands and can dominate the more desirable wetland species if unchecked (Smith et al, 1995).

\subsection{Wetland Management Programs}

The wetlands of the GWD are managed from an institutional perspective under different programs to achieve certain policy goals. The nearly 100 individual properties in the GWD are managed to attract waterfowl during the migratory season, particularly during the months when waterfowl hunting occurs (October through January). However, when the hunting season ends, different management strategies are employed. Some waterfowl clubs, during the off-season, provide grazing for cattle. Management of a "cattle club" necessitates early drawdown in late January to early February to promote the emergence of grasses for livestock. Although this management objective is sub-optimal for avian food production in seasonal wetlands, it has benefits for salinity management by allowing salt load to be exported earlier than would be typical in the Basin. More traditional duck clubs, managed specifically for their habitat resource, encourage desirable plant species for food and cover vegetation for migratory waterfowl. This management objective more closely mimics the wet/dry cycle needed to promote desired wetland species, and thus is recognized as being "wildlife friendly" by public, private, and non-profit entities alike (US Department of Agriculture [USDA], the California Department of Fish and Game [DFG], the California Waterfowl Association [CWA], and Ducks Unlimited [DU]).

Two habitat management programs provide funding for wetlands in the Grassland Water District. The Pressley Program is sponsored by the California Department of Fish and Game and Waterbank (soon to be the Conservation Resource Program or CRP) is managed by the 
US Department of Agriculture. Both the State and Federal programs promote managing wetlands for optimal habitat conditions while paying the landowner an annual allowance per acre included in the program. Historically, the Pressley Program tends to put slightly more emphasis on over-wintering conditions and food supply for migratory waterfowl, whereas Waterbank emphasizes brood water habitat to provide spring breeding water.

\subsection{Impacts of Wetland Management on the San Joaquin River}

The wetlands of the GWD are flooded in the fall with water supplied by the Delta-Mendota Canal. These water supplies for the GWD contain varying concentrations of salt, with a dissolved salt concentration (measured as electrical conductivity) in the range of 500 to 1,000 microSiemens per centimeter [uS/cm] (375 to $750 \mathrm{mg} / \mathrm{L}$ ). As the flooded season progresses, the ponded water increases in salinity as a result of the processes of direct evaporation and evapotranspiration from emergent wetland vegetation as well as through contact with the environment (soil residues, ground water inputs, bird usage, etc.). When the flooded season ends spring releases are discharged into tributaries of the Lower San Joaquin River. These releases, along with agricultural and municipal return flows, contain varying loads of total dissolved solids (TDS) and boron. These constituents have been identified as stressors that lead to frequent exceedance of water quality objectives established for the San Joaquin River by State and Federal agencies (Grober et al., 1995; Quinn et al., 1997).

This spring drawdown in the seasonal wetlands is timed for optimal germination conditions for the most desirable moist-soil vegetation. However, at times these spring releases coincide with higher salt concentrations in the SJR during lower flows and with downstream agricultural withdrawals from the SJR. Peak assimilative capacity typically occurs between the months of January and April. This period is often earlier than the traditional wetland drawdown period (February - April). The response of moist-soil plants and of migratory waterfowl and shorebirds to an altered drawdown regime that would coincide with the highest San Joaquin River assimilative capacity for salt is unknown. Experimentation necessary to determine these impacts will help to identify potential impacts on seed germination rates, waterbird foraging rates, habitat availability, and species diversity and abundance. It is possible that early, experimental drawdown may make food sources 
available to wildlife without negatively effecting wetland vegetation community and plant species diversity, hence benefiting both wildlife and the health of the San Joaquin River.

\subsection{San Joaquin River Management Program}

To improve flow and water quality conditions in the San Joaquin River system, the California Department of Water Resources formed the San Joaquin River Management Program (SJRMP), a stakeholder group representing many of the agencies, landowners and other parties interested in improving the San Joaquin River ecosystem. One of the SJRMP's mandates was to reconcile and coordinate the various uses and competing interests along the river. The SJRMP created a number of working subcommittees - one of which was the Water Quality Subcommittee. This subcommittee applied for grants, one of which supported early work on real-time water quality management in the SJR. One of the Water Quality Subcommittee's initial tasks was to develop solutions to address the occurrence of high salinity levels in the lower San Joaquin River at certain critical times of the year such as the onset of pre-irrigation in Delta agricultural lands.

Studies conducted initially under the SJRMP and subsequently by Berkeley National Laboratory, have suggested that wetland drainage from the GWD could be scheduled to coincide with peak assimilative capacity in the San Joaquin River to help improve downstream water quality (Grober et al., 1995; Quinn et al., 1997; Quinn and Karkoski, 1998). Increased surface water supply allocations under the Central Valley Project Improvement Act (CVPIA) have created greater opportunity than existed previously to coordinate the release of seasonal wetland drainage with the assimilative capacity of the San Joaquin River. Coordinated releases will help achieve salt and boron water quality objectives and improve both downstream agricultural draws and fish habitat in the main stem of the San Joaquin River and Sacramento-San Joaquin Delta. Improved scheduling of west-side discharges can assist in avoiding conflict with critical time periods for early season irrigation as well as fish rearing and remove an important stressor leading to improvements in the San Joaquin salmon fishery (Quinn and Delamore, 1994; Grober et al., 1995; Karkoski et al., 1995; Quinn et al., 1997; Quinn and Karkoski, 1998). 
The research conducted as part of the "Real-Time Adaptive Wetland Water Quality Management in the Grassland Water District" project focused on better coordinating salt loading from the Grassland Water District with the assimilative capacity for salts in the SJR. To assess the feasibility of such a reconciliation, experiments have been conducted within the 30,000 acres of seasonal wetlands in the Northern Division of the GWD (NGWD). Management of wetland drainage through scheduling of releases to coincide with periods of SJR assimilative capacity can improve the river's water quality. This project provides a systematic data collection program to evaluate the short and long-term consequences of realtime wetland drainage management.

\subsection{Coordination between Wetland Management and the San Joaquin River}

Management of wetland drainage, through scheduling of releases to coincide with periods of San Joaquin River assimilative capacity, can help improve San Joaquin River water quality and improve compliance with water quality objectives. These objectives were set by the California State Water Quality Control Board (SWQCB) as a result of a lawsuit between the South Delta Water Agency and the USBR that showed the need for salinity objectives to protect south delta agricultural interests. Hence, these objectives were set to protect downstream riparian irrigators who use the San Joaquin River as their sole water supply and to protect the salmon fishery (Grober et al., 1995; Quinn et al., 1997; Quinn and Karkoski, 1998). However, these actions may need to be considered relative to potential biological impacts of changes to traditional wetland management practices. Increased CVPIA water allocations, while increasing the flexibility of the operation of seasonal wetlands and improving the quality of seasonal wetland return flows, also increase the total salt load discharged to the San Joaquin River.

Late season wetland releases (April) containing high salt loads can impact salinity levels in the lower San Joaquin River system. The negative impacts are twofold:

- High salinity releases that coincide with agricultural pre-season irrigation downstream can inhibit germination and reduce crop yields; and

- Salmon can become confused during their annual migration when high flows from sloughs carry high volumes of drainage water. 


\subsection{Decision Support}

Depending on the water year type (wet, normal, dry, etc.), wetland drawdown from the NGWD and adjacent refuges can contribute significant salt load to the SJR. The real-time wetland water quality management project was conceived to complement the salinity assimilative capacity forecasting project led by the SJRMP Water Quality Subcommittee during the 2002 ands 2003 drawdown periods. Since there was no continuous monitoring of salt loads leaving the GWD at the onset of the project, the project required the installation of a series of wetland monitoring stations at the inlet to the NGWD and the multiple drainage outlets from the NGWD. A decision support system (DSS) was developed to help manage this information and readily provide it in a form wetland managers could use. This DSS helps wetland managers to make drawdown scheduling decisions and to manage salt export to coincide with periods of significant San Joaquin River assimilative capacity.

With the installation and operation of the water quality monitoring network, real-time wetland water quality data were collected and the results disseminated and used to calibrate a wetland water quality model (WWQM) developed specifically for this project. The WWQM, which is described in more detail in Chapter 3, was used in conjunction with two-week flow and salinity forecasts for the main stem of the San Joaquin River, to allow the impacts of different wetland drawdown schedules to be simulated and compared. These simulations have allowed GWD staff to play "what-if" games, working through the constraints imposed by the Grassland WD conveyance system while exploring potential benefits to salinity conditions on the San Joaquin River leading to potential long-term improvements in coordination.

A common concern among wetland managers is the impact of potential long-term adjustments to drawdown schedules on the propagation of desirable moist soil plants and the ecological health of the wetland ecosystem. In response to this concern a remote habitat assessment methodology (RHAM) was devised and integrated into the monitoring and assessment program to guide drawdown planning decisions and to ultimately protect the wetland resource. The RHAM uses high-resolution satellite imagery and pattern recognition 
routines to quantify wetland and upland vegetation. By taking a succession of images, a time series of vegetation conditions can be compiled, and spatial changes in vegetation conditions easily tracked. These long-term changes in vegetation communities can then be related to management decisions to better understand the extent of their impact. The RHAM is discussed in Chapter 4.

\subsection{Research Objectives}

This CALFED sponsored study had the following objectives:

1. To develop, construct, and maintain a real-time flow and salinity data acquisition network to aid seasonal wetlands drainage management.

2. To develop a wetland water quality model (flow and salinity mass balance) focusing on exports from the Grassland Water District to the San Joaquin River.

3. To experiment with adaptive wetland drawdown schedules to better coordinate salt loading from the Grassland Water District with the assimilative capacity of the San Joaquin River.

4. To develop a habitat assessment methodology for measuring the impacts of changes in seasonal wetland drawdown schedules on moist-soil plant production and habitat health.

\subsection{Research Procedures}

These objectives are accomplished in this study as follows :

1. To develop, construct, and maintain a real-time flow and salinity data acquisition network to aid seasonal wetlands drainage management.

A real-time wetland water quality network was established to measure flow, salinity (in the form of electrical conductivity, or EC), and temperature at the major inlets and outlets of the North Division of the GWD (NGWD. The main inlet, supplying water to more than $80 \%$ of the wetlands in the NGWD, is the Volta Wasteway. The Wasteway fills the San Luis Holding Reservoir that supplies the three main NGWD distribution canals: Mosquito Ditch, Spillway Ditch, and the Melia Ditch. After being diverted from 
the distribution canals to individual wetland units, wetland drainage is exported through through the main NGWD drainage outlets which include Mud Slough, Los Baños Creek, S-Lake Drain, Hollow Tree Drain, and Fremont Canal. Dataloggers collected data continuously at each of these stations and transmitted the data through phone and satellite telemetry to Berkeley National Laboratory where it was processed, made available on the project website and used to calibrate the WWQM.

\section{To develop a wetland water quality model (flow and salinity mass balance) focusing on} exports from the Grassland Water District to the San Joaquin River

The wetland water quality model (WWQM), was constructed using a combination of tools including Microsoft Excel, Microsoft Access, and Environmental Systems Research Institute's (ESRI) ArcGIS. The WWQM accepts daily time step data for water supply and water quality, climate, vegetation indexes, and land use classifications to simulate wetland water and salinity mass balance. The model was manipulated to test different wetland drawdown schedules for salinity discharge to the San Joaquin River. These simulated manipulations, or "games", allowed wetland managers to test the impacts of several different drawdown management schedules on the salinity of the SJR. Alternative wetland drawdown management scenarios include:

- An early wetland drawdown schedule;

- A reference management schedule (traditional drawdown);

- A late drawdown schedule; and

- A pre-flushing schedule that results in lower salinity drainage later in the season.

3. To experiment with adaptive wetland drawdown schedules to better coordinate salt loading from the Grassland Water District with the assimilative capacity of the San Joaquin River.

Development of target salt loads and exploration of the means by which these are achieved through adaptive wetland management and drawdown scheduling was accomplished through the use of the WWQM for the spring 2003 drawdown. By 
modeling the wetland salinity levels and comparing them to SJR assimilative capacity, the model assisted the GWD water master to better coordinate wetland salt loading with the prevailing assimilative capacity of the San Joaquin River.

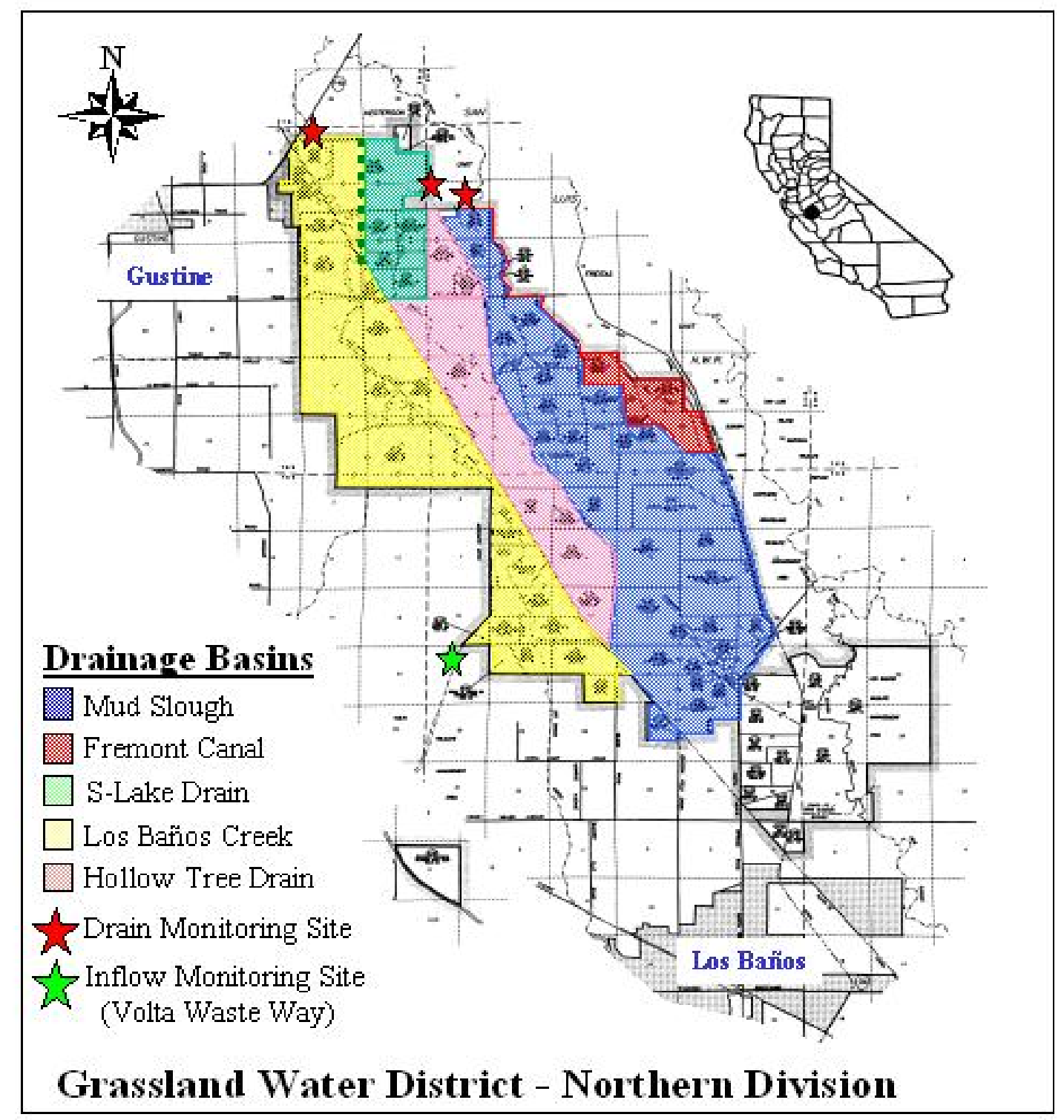

Figure 1.8. Northern Division of the Grassland Water District showing how this area was divided into distinct drainage management areas. Monitoring was designed to provide drainage flow and water quality information for each of these units. 
5. To develop a habitat assessment methodology for measuring the impacts of changes in seasonal wetland drawdown schedules on moist-soil plant production and habitat health.

Habitat impact assessment, was accomplished through the development of a remote habitat assessment methodology (RHAM). The RHAM was used to monitor the wetland vegetation communities as a means of assessing long term impacts of salinity management to meet San Joaquin River water quality objectives . The methodology employs remote sensing and pattern recognition technologies. One of these technologies, high-resolution satellite imagery, utilizes multi-spectral digital images of the wetland areas and associated uplands in panchromatic (black and white), red, green, blue, and near-infrared bandwidths. The images are then processed using an image classifier, which separates the different signals and in turn clusters regions with similar attributes. Once calibrated (i.e. which signal represents which type of vegetation), the classifier can provide quantifiable results on where as well as to what coverage and extent these different vegetation communities exist. Each subsequent time this process is repeated, changes from one set of images to another can be assessed, tracked, and quantified.

The habitat-monitoring methodology was designed to answer questions directly related to seasonal wetland management in the GWD. Principally, how do the wetlands respond to timing of wetland drainage that is different from traditional drainage schedules? More specifically, how would the wetlands in the GWD respond to an earlier, or later, than normal drawdown as salinity assimilative capacity in the San Joaquin River requires? 


\section{CHAPTER 2 REAL-TIME WETLAND WATER QUALITY MONITORING}

\subsection{Introduction}

The California Regional Water Quality Control Board (CRWQCB) recently announced salinity and boron Total Maximum Daily Loads (TMDL's) for the San Joaquin River - a regulatory procedure to encourage compliance with river water quality objectives. The TMDL requires that all dischargers to the River monitor their drainage return flows as well as the salt loading contained in these return flows (CRWQCB, 2002). The GWD has been recording daily observational flowrate readings and salinity grab samples since the early 1990's. However analysis has shown that continuous data provides a more accurate record of flow and salt loading. To aid in the data collection, organization, and reporting tasks for continuous flow and electrical conductivity monitoring, a real-time wetland water quality network ("network") was developed for the Northern Division of the GWD (NGWD). This real-time data network has been developed using state-of-the-art sensors, datalogging and telemetry equipment to ensure accurate data and convenient access to the data in real-time.

Data obtained by telemetry from the monitoring network has been stored in a project database. GWD staff can access the database to assess conditions without costly and time consuming trips into the field. In addition, the database helps satisfy the Regional Board's data collection requirements, and can be used to develop and calibrate water quality models for meeting water needs, explore salinity trading possibilities, and aid in wetland drainage management.

\subsection{Monitoring Parameters}

The main objectives of the monitoring program are:

Measure the flow and the salinity of wetland water supply and drainage, and calculate the total salt load entering and leaving the GWD.

Report these data on a real-time basis, through the use of the Internet, to a database capable of advancing wetland modeling efforts and providing decision support to wetland managers allowing them to make timely drainage management decisions. 
To accurately measure the flow rate at individual monitoring sites, several methods were employed. These methods depend upon the site characteristics for the individual supply channels, conveyances and drainage outlets and commonly require the development of a relationship between stage and discharge using a flow rating curve or, in instances where velocity is measured directly, between stage and cross-sectional area. In the latter case the cross sectional area of flow is multiplied by the mean velocity to obtain discharge. Direct measurement of velocity, where possible, is valuable, especially in system subjected to seasonal backwater conditions. Under these conditions water backs up in the channel causing high stages that are unrelated to discharge.

Salinity content is estimated by sampling the electrical conductivity of the water. Electrical conductivity (EC), measured in micro-Siemens per centimeter $[\mathrm{uS} / \mathrm{cm}]$, is a measure of the ions present in the water. The ions consist mainly of Calcium $\left(\mathrm{Ca}^{+}\right)$, Magnesium $\left(\mathrm{Mg}^{+}\right)$, Sodium $\left(\mathrm{Na}^{+}\right)$, and Potassium $\left(\mathrm{K}^{+}\right)$cations and Bicarbonate $\left(\mathrm{HCO}_{3}{ }^{-}\right)$, Sulfate $\left(\mathrm{SO}_{4}^{-}\right)$and Chloride $\left(\mathrm{Cl}^{-}\right)$anions. There is a direct relationship between EC in $\mathrm{uS} / \mathrm{cm}$ and TDS in $\mathrm{mg} / \mathrm{L}$. The flow and EC data can be used for the computation of the total salt loading to and from the GWD. The computation to convert the flow and EC readings in $\mathrm{cfs}$ and $\mathrm{uS} / \mathrm{cm}$ respectively, to total salt load in tons of salt per day [tpd] follows:

$$
\text { SaltLoad }=M \times Q \times E C
$$

where $\boldsymbol{Q}$ is in cubic feet per second [cfs], $E C$ is in microSiemens per centimeter $[\mathrm{uS} / \mathrm{cm}]$ and $\boldsymbol{M}$ is the ratio of $T D S[\mathrm{mg} / \mathrm{L}]$ to $E C[\mathrm{uS} / \mathrm{cm}] . M$ is determined experimentally and is typically 0.75 in the Grassland Basin (California Environmental Protection Agency, 2002). Converting salt load into tons per day [tpd] Error! Reference source not found. becomes:

$$
\text { SaltLoad }[\text { tpd }]=\frac{M\left[\frac{m g / L}{u S / c m}\right] \times Q\left[\frac{c u . f t .}{\mathrm{sec}}\right] \times E C\left[\frac{\mathrm{uS}}{\mathrm{cm}}\right] \times 28.32\left[\frac{\mathrm{L}}{\mathrm{cu} . f t .}\right] \times 2.2046\left[\frac{\mathrm{lb} .}{\mathrm{kg}}\right] \times 86,400\left[\frac{\mathrm{sec}}{\mathrm{day}}\right]}{1,000,000\left[\frac{\mathrm{mg}}{\mathrm{kg}}\right] \times 2,000\left[\frac{\mathrm{lb}}{\mathrm{ton}}\right]}
$$

or, simplified, it becomes: 


$$
\text { SaltLoad }[t p d]=Q[c f s] \times E C\left[\frac{u S}{c m}\right] \times 0.002023
$$

\subsection{Monitoring Station Design}

Flow transducers and electrical conductivity (EC) sensors were installed at control structures within the NGWD. These sampling devices take measurements every 15 minutes to provide an accurate measurement of salt loading into and out of the NGWD boundary. Flow and EC data at each site are collected on a battery-powered datalogger that communicates through a telemetry system (either telephone or satellite), allowing these data to be accessed 24 hours a day.

At the sites where a simple stage measurement and reliable stage - discharge relationship could be developed, pressure transducers were installed to estimate flows in inlet and drainage channels. Mud Slough at Gun Club Road (MSG) and Los Baños Creek at Highway 140 (LBC) are examples of sites where flow rating curves were used to estimate discharge directly from measured stage in addition to the use of an acoustic velocity sensor. At the MSG site, a pressure transducer was installed within a stilling well. The stilling well allows for minimal noise to be registered by the sensor from occurrences such as pressure variations from velocity changes and turbulence. At the LBC site, Design Analysis H355 Smart Gas bubbler system was used. Depending on the force necessary to push the air through the bubbler apparatus, a pressure value is recorded, converting the reading to a depth measurement. At both these sites the direct stage measurement was redundant used as a secondary estimate and check - often useful if the primary measurement fails or is compromised.

Flow measurements at the inlet site, Volta Wasteway (VWW), and two of the outlet sites, Fremont Canal (FRC) and S-Lake Drain (SLD), were recorded using the same state-of-theart acoustic velocity transducers used at MSG and LBC These transducers utilize the Doppler principle whereby during operation each transducer produces short pulses of sound at a known frequency along two different axes. Sound from the outgoing pulses is reflected ("scattered") in all directions by particulate matter in the water. Some portion of the 
scattered energy travels back along the beam axes to the transducer. These return signals have a frequency shift proportional to the velocity of the scattering material. This frequency change (Doppler shift), as measured by the circuitry within the transducer, is proportional to the projection of the water velocity onto the axis of each acoustic beam. By combining data from both beams, and knowing the relative orientation of those beams, the device measures velocity in the two-dimensional plane defined by its two acoustic beams.

When mounted on an underwater structure, these devices measure velocity in a userprogrammable sampling volume located up to $75 \mathrm{ft}(23 \mathrm{~m})$ from the transducer. A major advantage of this technology is that the transducer never requires calibration because measurements are made in a remote sampling volume free from flow distortion and the velocity data are free from drift. Additionally, Doppler technology has no inherent minimum detectable velocity, performing well at low flows ranging from $0.01 \mathrm{ft} / \mathrm{s}$ to $30 \mathrm{ft} / \mathrm{s}(0.003 \mathrm{~m} / \mathrm{s}$ to $9.2 \mathrm{~m} / \mathrm{s}$ ) -- velocities often found in wetland slough environments. Data collected by each transducer, which are equipped with two stage measurement sensors, a vertical beam and a pressure are used to calculate the stream cross-sectional area for use in the flow computation. At the Hollow Tree Drain (HTD) monitoring site where a high gradient rendered it unsuitable for either a simple stage measurement or the Doppler system, a ramp weir was designed and installed. The ramp weir, equipped with a pressure transducer, was designed using WinFlume ${ }^{\mathrm{TM}}$, which produces an exact rating curve for the dimensions of the weir (Clemmens et. al., 2001)

The location of the monitoring stations-- at all the major inlets and outlets throughout the GWD-- were determined by a global positioning system (GPS) survey and located on the set of GIS maps of the study area. The GIS maps were prepared for locating water delivery and drainage turnouts in the GWD drainage system. These maps also document drainage hydrology within individual wetland basins. These monitoring sites were placed strategically within wetland channels so as to allow computation of salt loads in real-time from different drainage subbasins of the North Grassland Water District (Figure 1.9). 


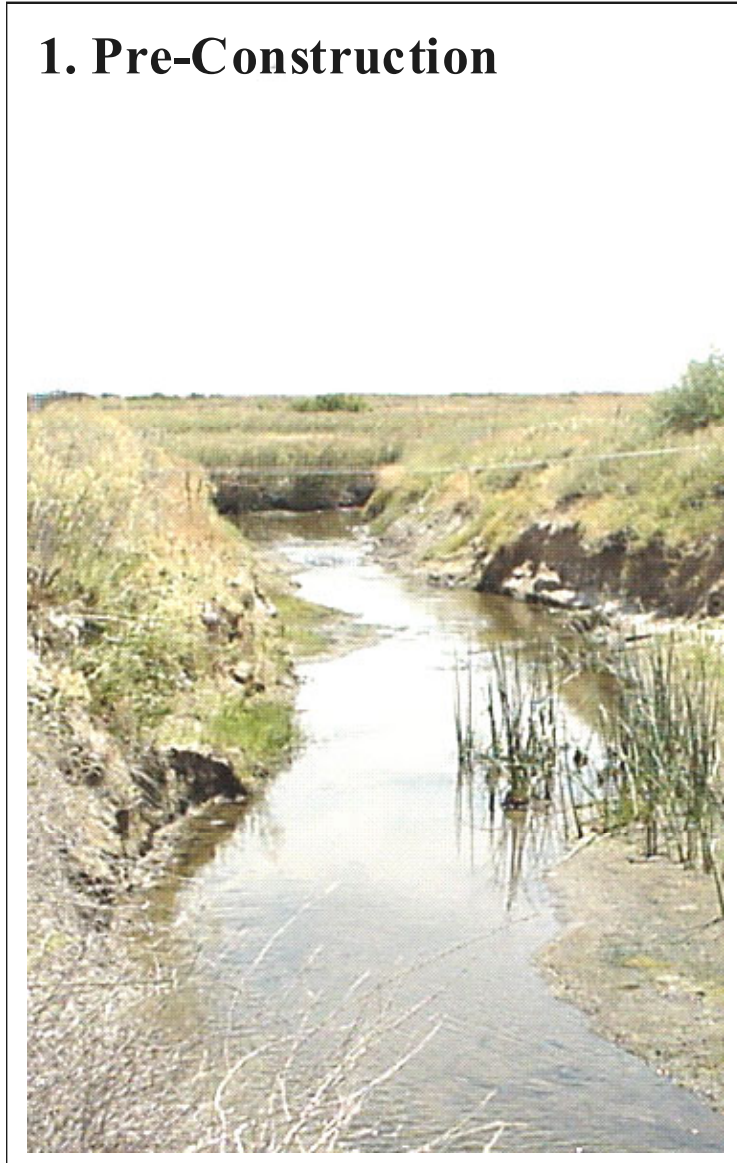

\section{Construction}

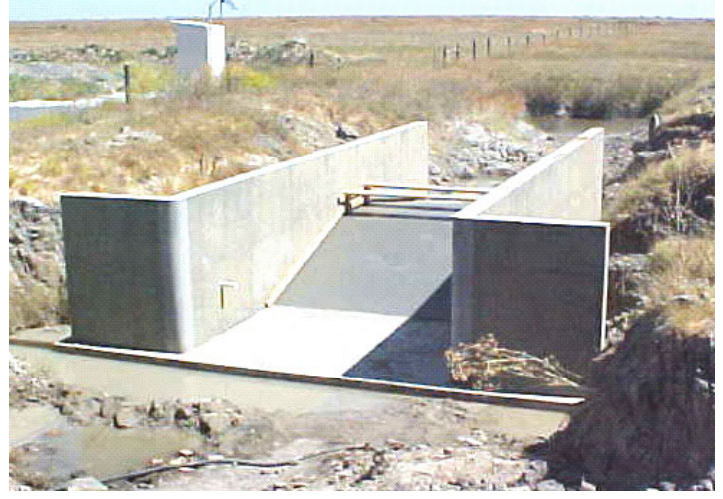

\section{Post-Construction}

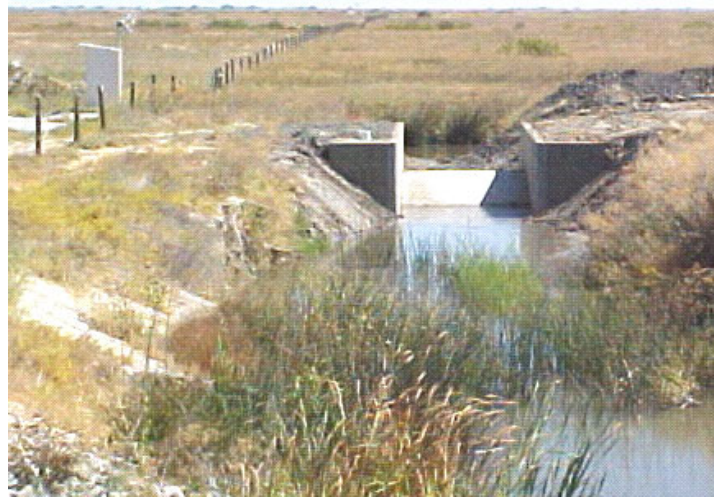

\section{Operation}

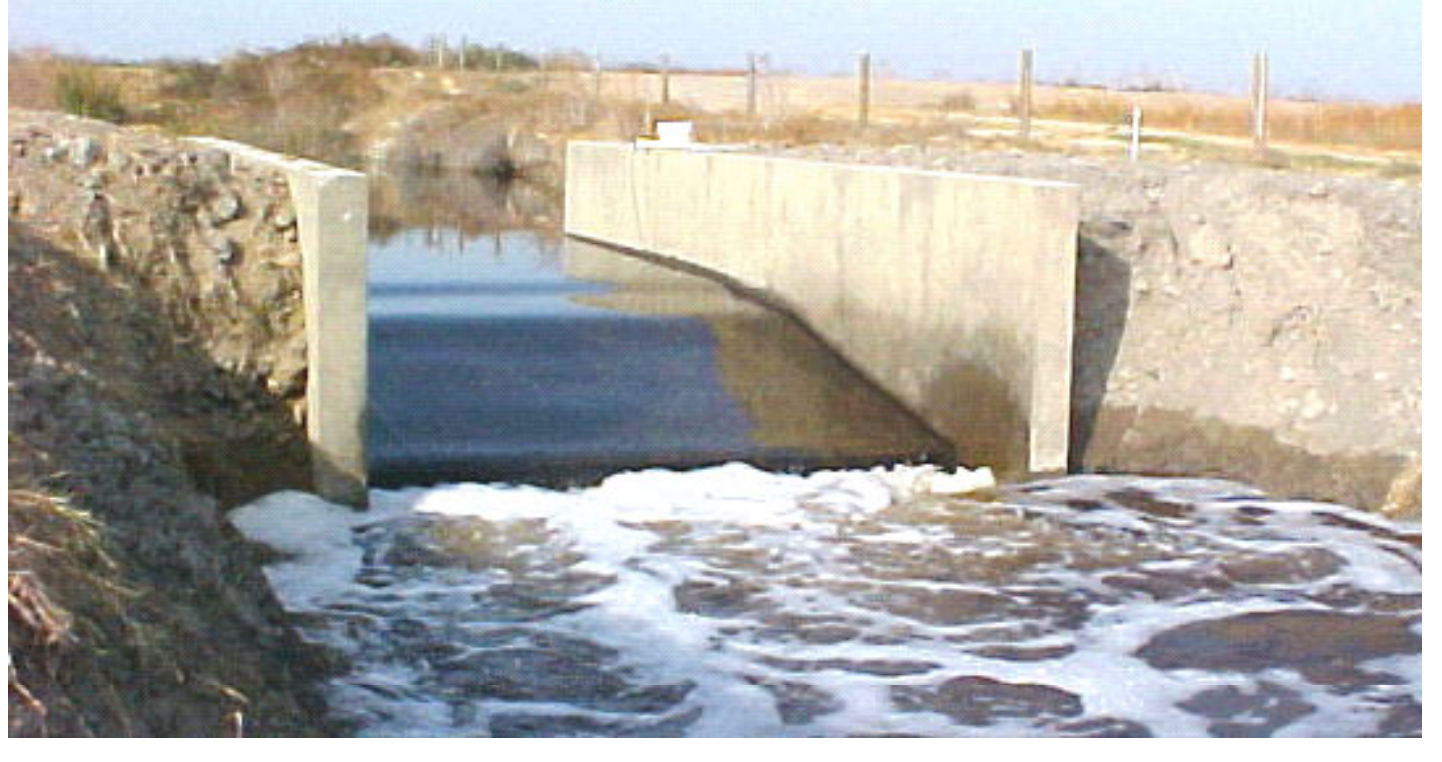

Figure 2.1. - Ramp weir at Hollow Tree Drain showing phases of construction. 
Temperature-compensated EC sensors manufactured by Campbell Scientific, Inc. were used to obtain real-time salinity and temperature data at each site. Monthly data quality assurance assessment at each of these sites was performed in accordance with the Project Quality Assurance Plan, developed for the Grassland Bypass Project, to ensure data accuracy and reliability.

\subsection{Wetland Monitoring Sites}

Four monitoring stations serving five drainage outlets and one supply inlet were constructed to monitor the seasonal wetland discharges and water quality in the NGWD. The inlet station was located on the Volta Wasteway, downstream from the San Luis Holding Reservoir, which supplies more than $80 \%$ of the surface water to the NGWD. The five drainage outlet stations are Mud Slough at Gun Club Road (MSG), Fremont Canal at Mud Slough (FRC), Hollow Tree Drain (HTD), S-Lake Drain (SLK), and Los Baños Creek at Highway 140 (LBC). Monitoring stations were co-located where a single gauge house was sufficient to

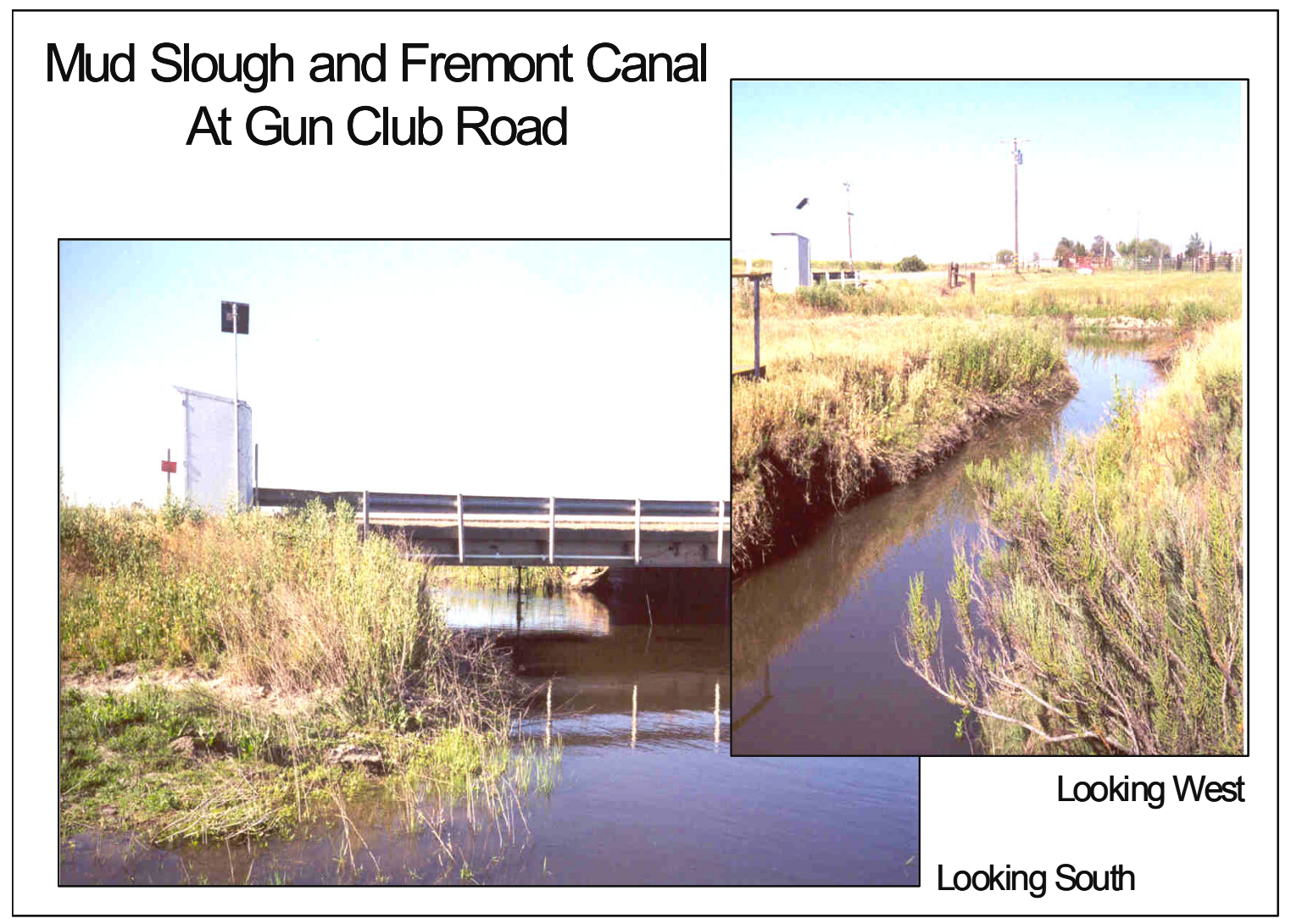

Figure 2.2 - Mud Slough and Fremont Canal monitoring stations. 
service flow and water quality sensors from both sites.

\subsubsection{Mud Slough at Gun Club Road (MSG)}

The monitoring station located on Mud Slough at the Gun Club Road bridge was the first one constructed given its importance as the primary drainage conveyance for GWD. The datalogger at MSG acquires data from sensor arrays at both Mud Slough and Fremont Canal. To calculate drainage discharge, a rating curve was developed that relates stage to cross sectional area of flow. Direct velocity readings were multiplied by the calculated cross sectional area to compute discharge. A Keller pressure transducer was also deployed at MSG and a separate stage-discharge rating developed for this sensor. The reason for this redundant measurement was to provide discharge measurements during low flow episodes when the stage was too low to cover the SONTEK acoustic velocity meter. The SONTEK was mounted approximately 1 foot above the thalweg of the stream channel so as to allow the acoustic beam an unimpeded path across at least $50 \%$ of the channel width.

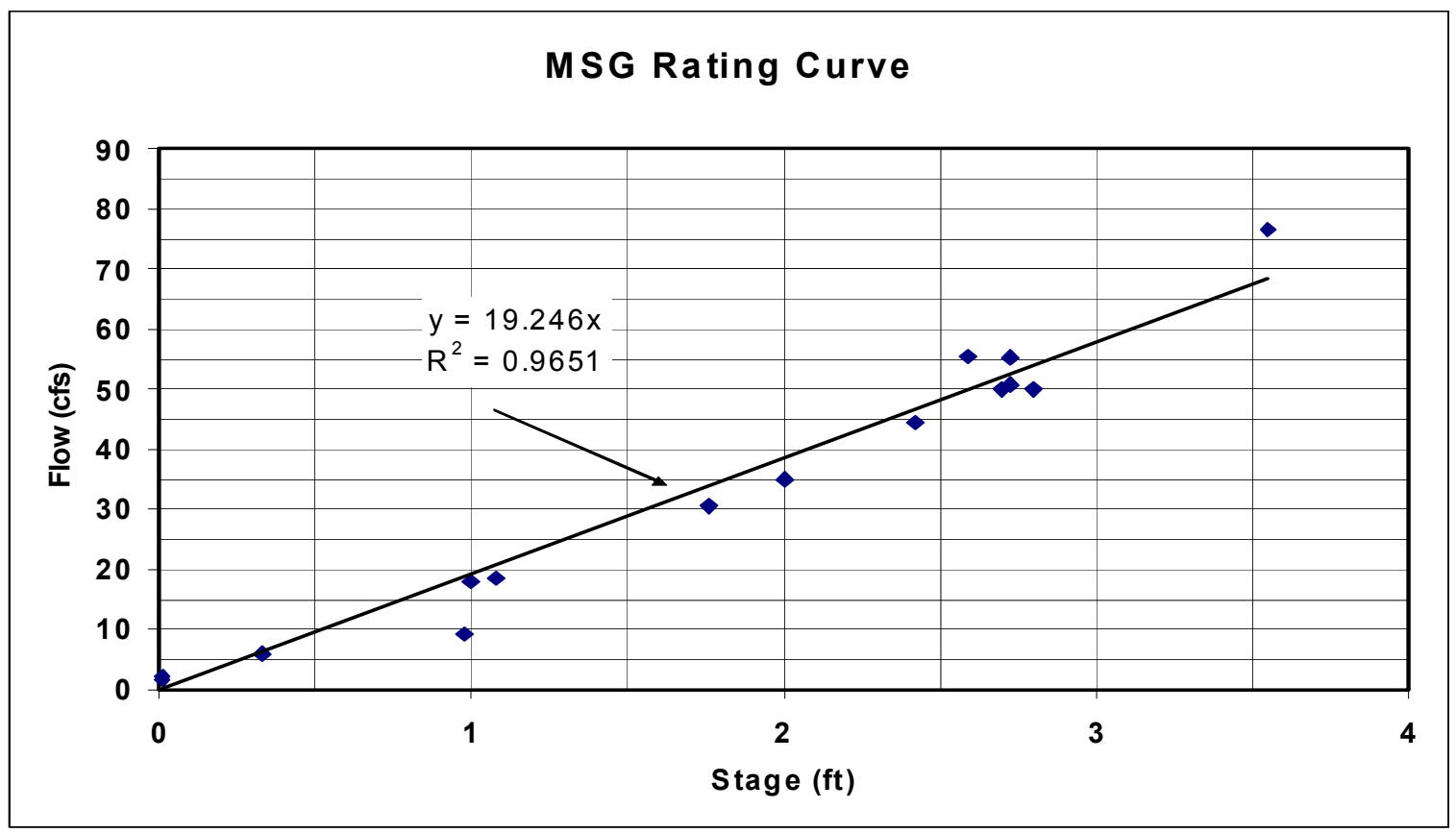

Figure 2.3. - Stage to discharge rating curve for Mud Slough at Gun Club Road (MSG) 
The site specifics for the Mud Slough monitoring station are shown below in Table 2.1.

Table 2.1 - Mud Slough monitoring station specifications

\begin{tabular}{|l|l|}
\hline Site Summary & $\begin{array}{l}\text { Mud Slough accounts for roughly 60\% of the discharge from } \\
\text { the North Grassland Water District. }\end{array}$ \\
\hline Power & Solar Panel with 12-volt battery \\
\hline Datalogger & CSI 10X Datalogger \\
\hline EC Sensor & CSI temperature compensated EC probe \\
\hline Flow Measurement & $\begin{array}{l}\text { Mud Slough at Gun Club Road sometimes is affected by a } \\
\text { backwater condition cause by high inflow from the Fremont } \\
\text { Canal. Use of the SONTEK acoustic sensor at MSG measures } \\
\text { velocity directly and can be used to obtain accurate discharge } \\
\text { estimates even in backwater conditions. }\end{array}$ \\
\hline$\bullet \quad$ Depth & Sontek SL pressure transducer \\
\hline • Velocity & Sontek SL \\
\hline Telecommunications & Landline telephone \\
\hline
\end{tabular}

\subsection{2 .Fremont Canal above Mud Slough (FRC)}

Fremont Canal and Mud Slough are both monitored using a single datalogger housed in the Mud Slough gauge house. A SONTEK YL is used at this site. This acoustic velocity sensor

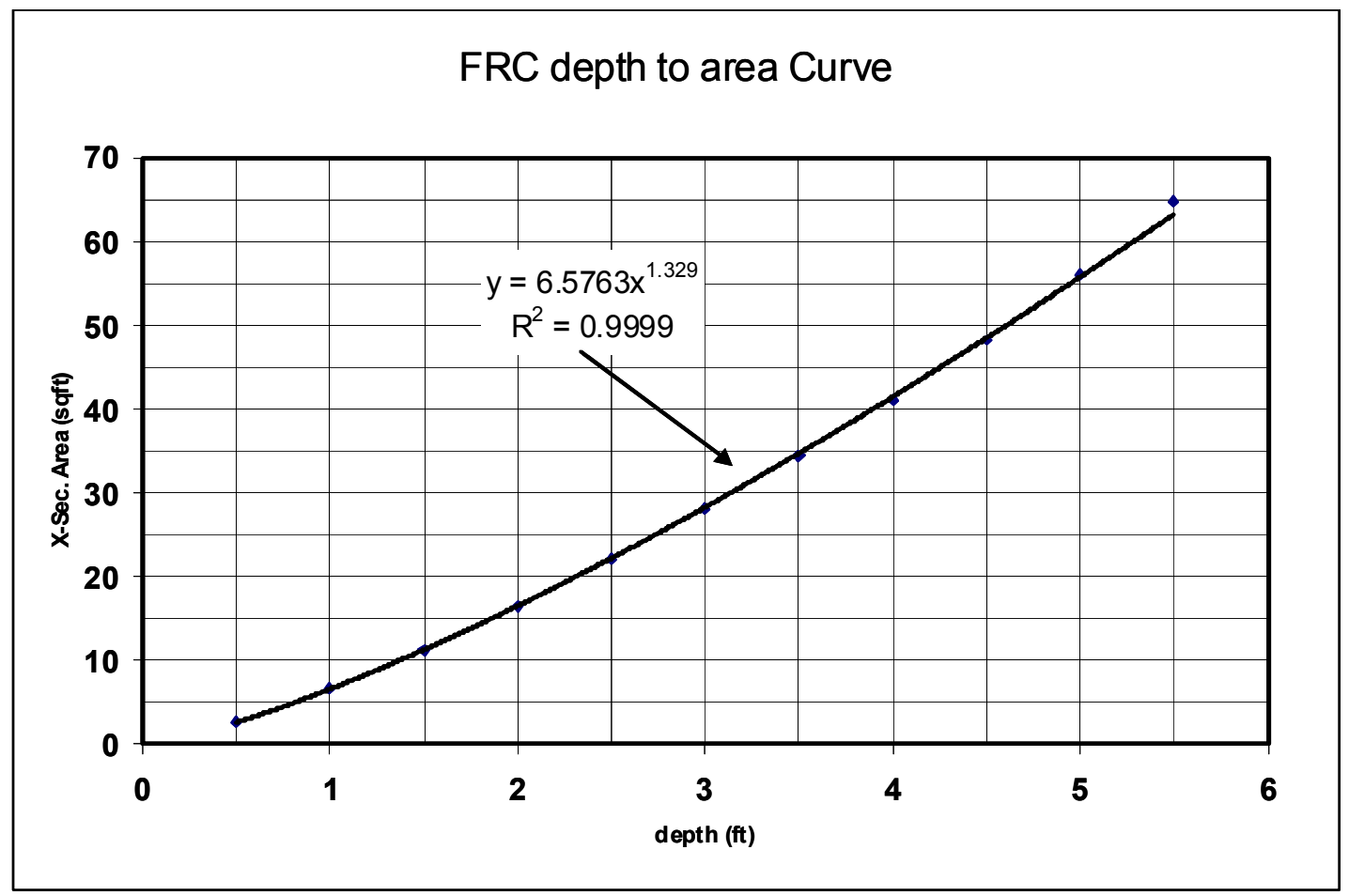

Figure 2.4 - Stage to area curve for Fremont Canal. 
measures flow velocity at a point rather than along a path and is suitable for narrow channels where the SONTEK SL's have too short a path length. A flow adjustment is required at this site and other SONTEK acoustic velocity meter sites to account for the location of the sensor at elevations either above or below the $0.6 *$ depth which is typically used to obtain an average discharge measurement.

The site specifics for Fremont Canal monitoring station are shown below in Table 2.2.

Table 2.2 - Fremont Canal monitoring station specifications

\begin{tabular}{|l|l|}
\hline Site Summary & $\begin{array}{l}\text { Fremont Canal accounts for roughly 2-3\% of the discharge from } \\
\text { the North Grassland Water District. }\end{array}$ \\
\hline Power & Solar Panel with 12-volt battery \\
\hline Datalogger & CSI 10X Datalogger \\
\hline EC Sensor & CSI temperature compensated EC probe \\
\hline Flow Measurement & $\begin{array}{l}\text { Fremont Canal at Mud Slough sometimes can be affected by } \\
\text { downstream influences creating a backflow condition. Because } \\
\text { of these constraints in this system, it is important to have both a } \\
\text { relative depth measurement and a relative velocity } \\
\text { measurement. A stage-velocity-discharge rating curve for FRC } \\
\text { has been established. }\end{array}$ \\
\hline$\bullet \quad$ Depth & Sontek YL pressure transducer \\
\hline \multicolumn{1}{|c|}{ Velocity } & Sontek YL \\
\hline Telecommunications & Landline telephone \\
\hline
\end{tabular}

\subsubsection{Hollow Tree Drain (HTD)}

Hollow Tree Drain is monitored from a gauge house located at the confluence of Hollow Tree Drain and S-Lake Drain. The existing site was poor for both flow and water quality monitoring on account of the highly variable flow, the steepness of the grade and the irregular channel cross section. To obtain good flow and water quality data, a ramp weir was designed and installed during the summer of 2002. The ramp weir was designed using WinFlume ${ }^{\mathrm{TM}}$, a commercial water structure design software package. This software requires input of elevations and expected flowrates in order to design suitable flume dimensions. A simple box cross-section was chosen for simplicity of construction with a ramp rising off the flume floor and tapering downstream of the throat of the flume. WinFlume ${ }^{\mathrm{TM}}$ produced a stage-discharge rating for the flume. This relationship was applied to the stage measurement 
obtained from a Keller pressure transducer located in an adjacent stilling well, to estimate discharge. The flume has worked very well since its installation.

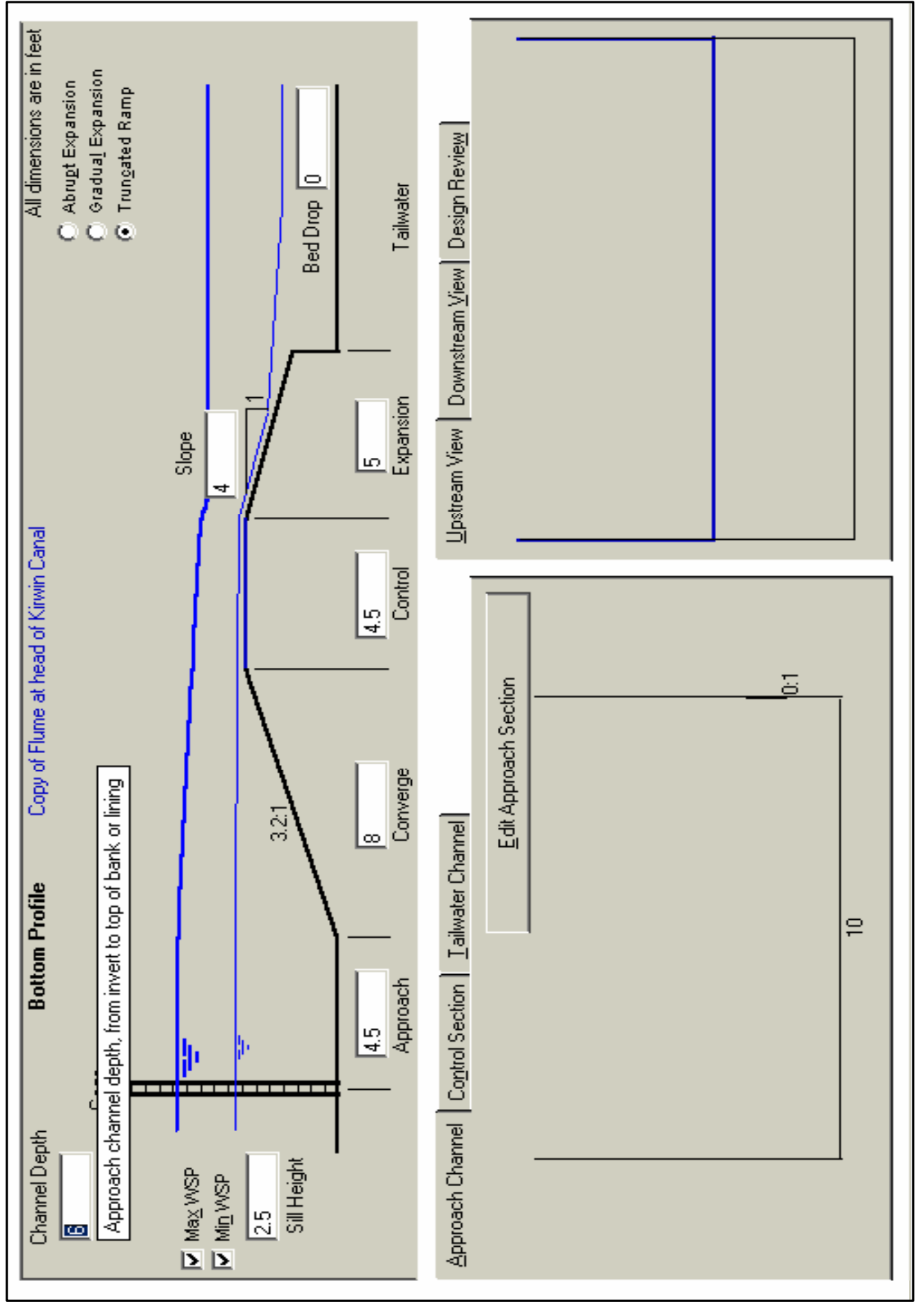

Figure 2.5 Conceptual design of the ramp weir using WinFlume ${ }^{\mathrm{TM}}$ (Clemmens et. al., 2001). 


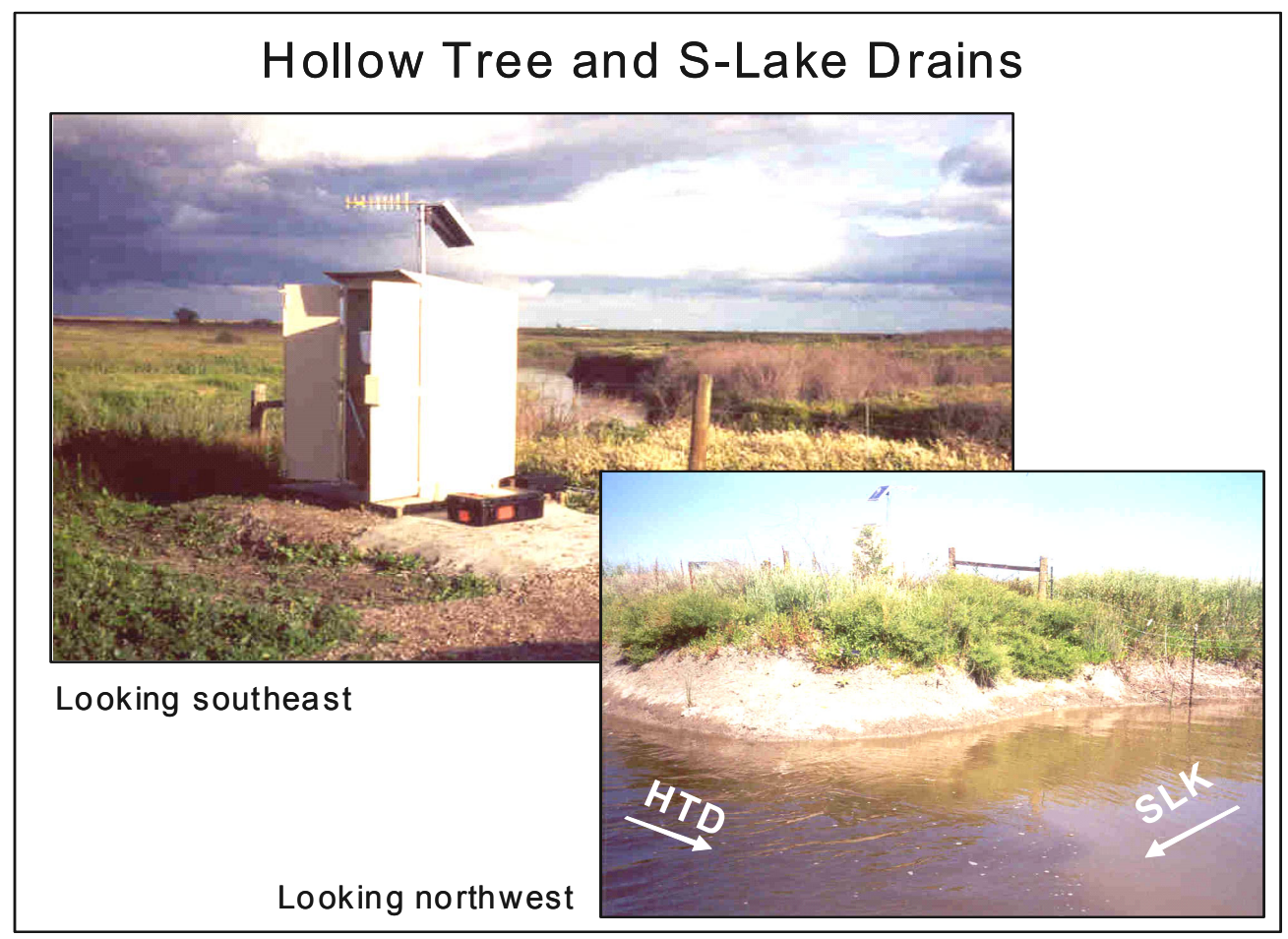

Figure 2.6. Hollow Tree and S-Lake Drain monitoring stations

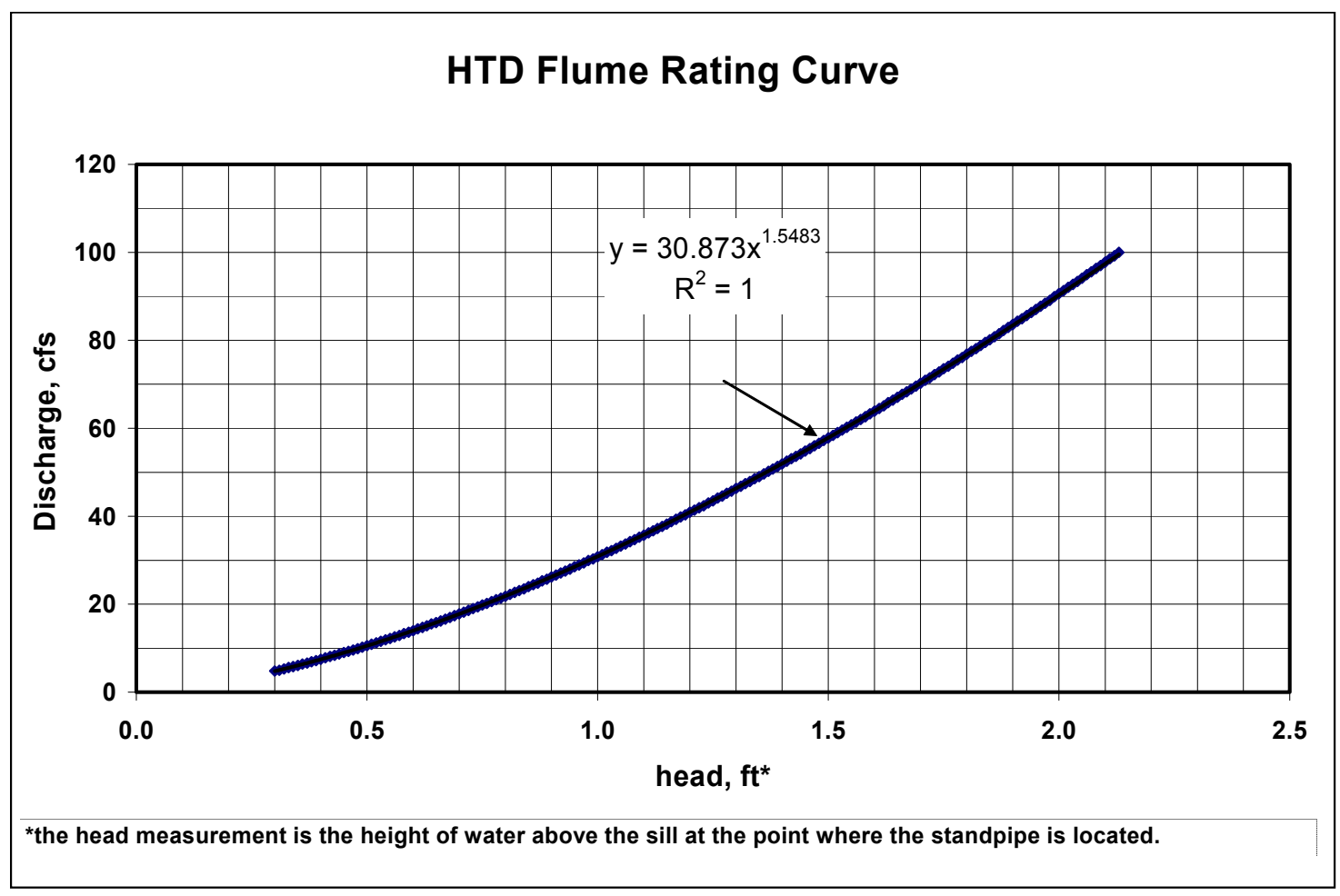

Figure 2.7. Stage to discharge rating curve for the Hollow Tree Drain ramp weir. 
The site specifics for Hollow Tree Drain monitoring station are shown below in Table 2.3.

Table 2.3 - Hollow Tree Drain monitoring station specifications.

\begin{tabular}{|l|l|}
\hline Site Summary & $\begin{array}{l}\text { Hollow Tree Drain at S-Lake Drain accounts for roughly 10\% } \\
\text { of the discharge from the North Grassland Water District. }\end{array}$ \\
\hline Power & Solar Panel with 12-volt battery \\
\hline Datalogger & CSI 10X Datalogger \\
\hline EC Sensor & CSI temperature compensated EC probe \\
\hline Flow Measurement & $\begin{array}{l}\text { The portion of the Hollow Tree Drain where the monitoring } \\
\text { station is located (at the confluence of HTD and SLK) was } \\
\text { steep. As a result, water depth was often shallow making stage } \\
\text { and/or velocity measurements extremely difficult. Therefore a } \\
\text { ramp-weir type flume was designed and installed along with a } n \\
\text { integral stilling well for depth measurements. The flume has a } \\
\text { very precise formula relating depth of water above the sill to } \\
\text { actual flowrate. }\end{array}$ \\
\hline \multicolumn{1}{|c|}{ Depth } & Keller Pressure Transducer \\
\hline Telecommunications & n/a \\
\hline
\end{tabular}

\subsubsection{S-Lake Drain (SLD)}

S-Lake Drain shares a gauge house with Hollow Tree Drain. S-Lake Drain is a typical backwater drainage site where the stage is influenced by flow in Hollow Tree Drain. The drainage area served by Hollow Tree Drain is not large and drain flows are sluggish. At time of high flow from Hollow Tree Drain flow can be zero and even negative for short periods at this site. The only means of obtaining good quality data for S-Lake Drain was through the use of a SONTEK acoustic velocity meter. A stage- cross sectional area relationship was established from survey data and was programmed into the SONTEK. Hence discharge was calculated using stage and velocity data and the stage-area rating. The relationship was shown to be quite stable over time and is shown in Figure 2.8. 


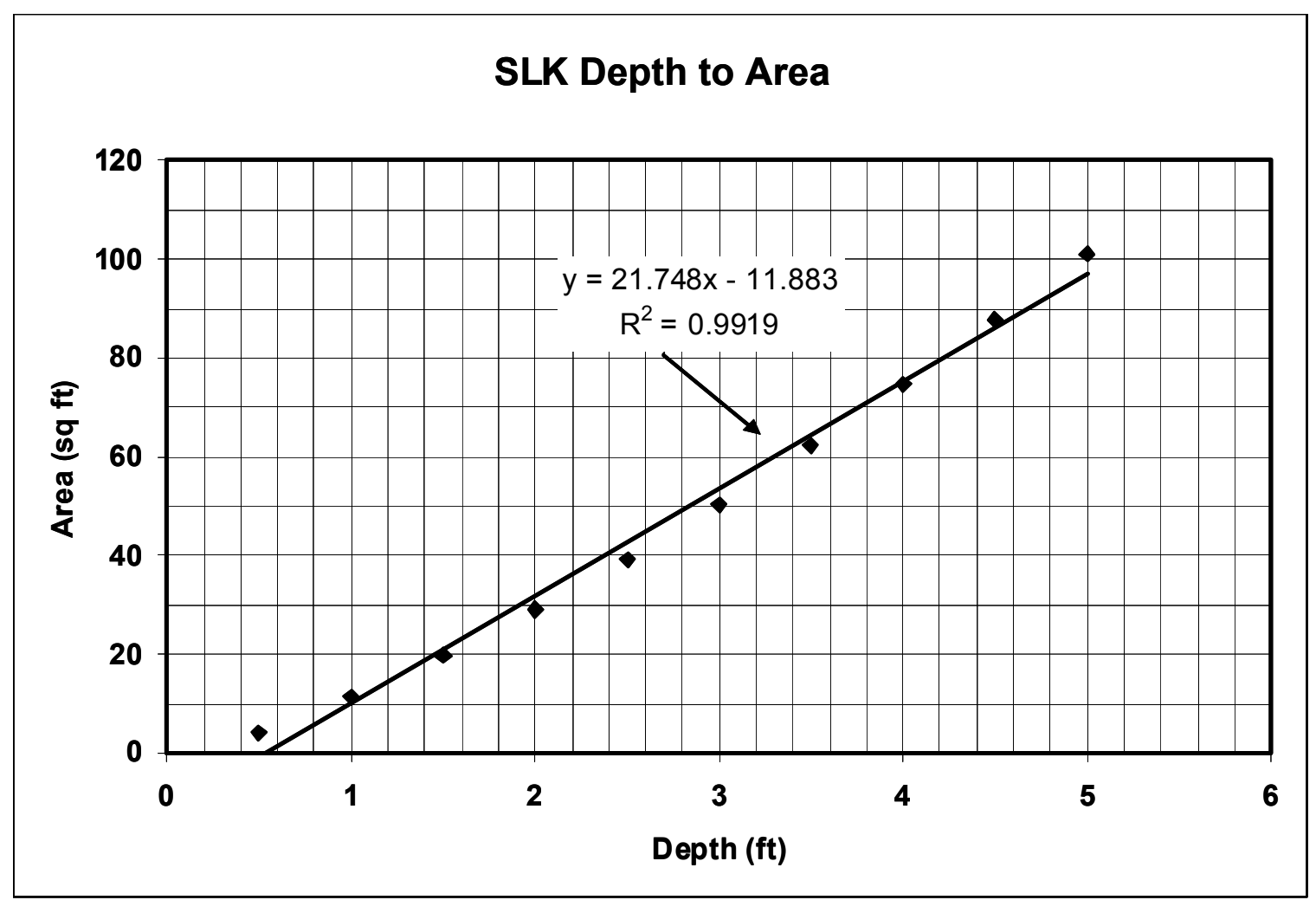

Figure 2.8. Stage-area rating curve for S-Lake Drain.

The site specifics for the S-Lake Drain monitoring station are shown below in Table 2.4.

Table 2.4. S-Lake Drain monitoring station specifications

\begin{tabular}{|l|l|}
\hline Site Summary & $\begin{array}{l}\text { S-Lake Drain accounts for roughly 10\% of the drainage flow } \\
\text { from the North Grasslands Water District. }\end{array}$ \\
\hline Power & Solar Panel with 12-volt battery \\
\hline Datalogger & CSI 10X Datalogger \\
\hline EC Sensor & CSI temperature compensated EC probe \\
\hline Flow Measurement & $\begin{array}{l}\text { S-Lake Drain at Hollow Tree Drain oftentimes is affected by } \\
\text { downstream influences, creating a backflow condition. } \\
\text { Because of these constraints in this system, it is important to } \\
\text { have both a relative depth measurement and a relative velocity } \\
\text { measurement. A stage-velocity-discharge rating curve for } \\
\text { FRC has been established. }\end{array}$ \\
\hline$\bullet \quad$ Depth & Sontek SL pressure transducer and vertical beam \\
\hline$\bullet \quad$ Velocity & Sontek SL \\
\hline Telecommunications & GOES Telemetry \\
\hline
\end{tabular}




\subsubsection{Los Baños Creek at Highway 140}

The Los Baños Creek at Highway 140 monitoring station was the final station to be constructed. This monitoring station is located in Kesterson Wildlife Refuge. Accordingly,

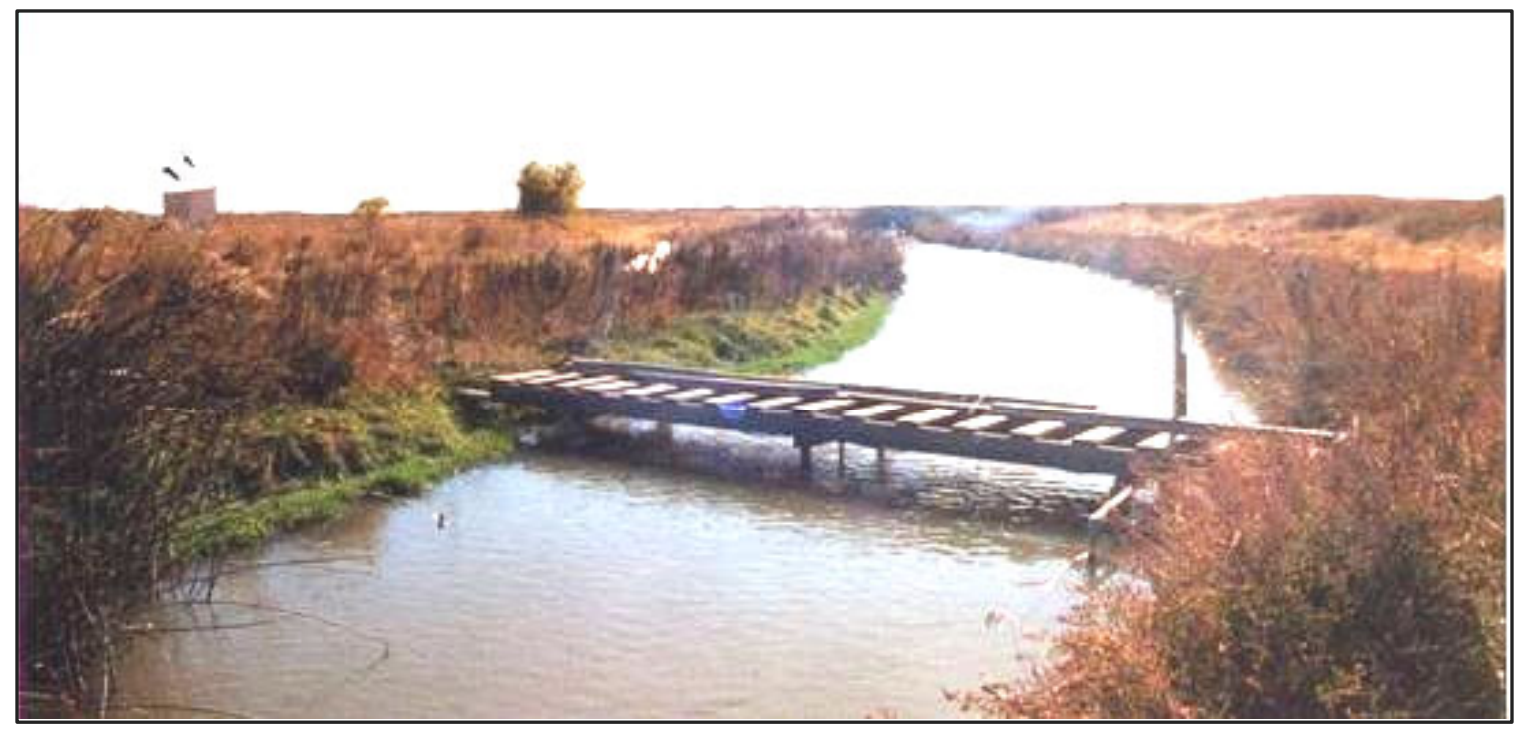

Figure 2.9. Los Baños Creek at the Highway 140 monitoring station.

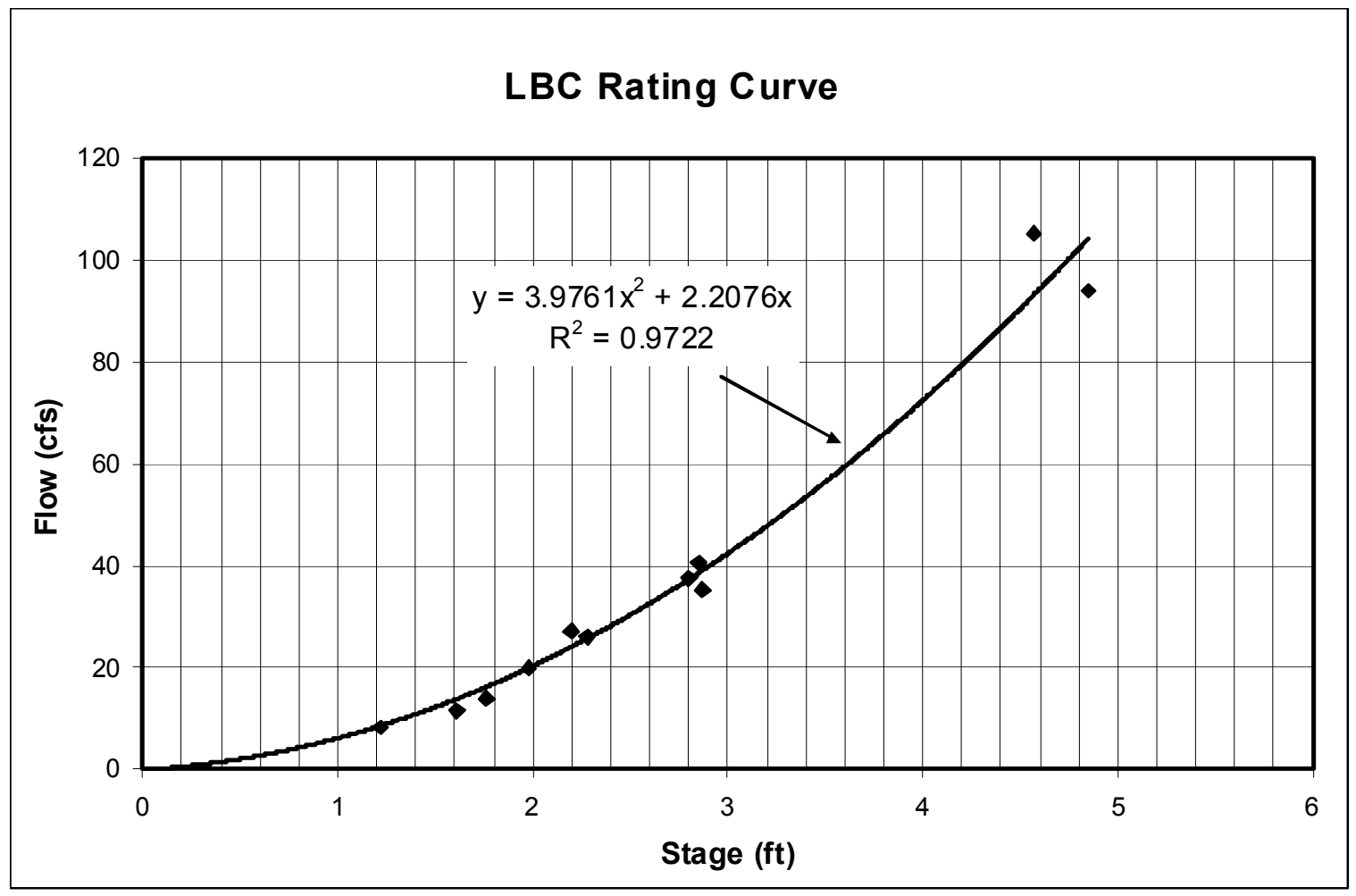

Figure 2.10. Stage - discharge rating curve for Los Baños Creek 
special permission was granted for access to the station by the United States Fish and Wildlife Service. The flow at this station is monitored using a Design Analysis Smart Gas System $^{\mathrm{TM}}$ air bubbler and a stage to discharge rating curve frequently updated during the project.

The site specifics for Los Baños Creek monitoring station are shown below in Table 2.5.

Table 2.5 - Los Baños Creek monitoring station specifications

\begin{tabular}{|c|c|}
\hline Site Summary & $\begin{array}{l}\text { Los Baños Creek at Hwy } 140 \text { accounts for roughly } 30 \% \text { of the } \\
\text { discharge from the North Grassland Water District }\end{array}$ \\
\hline Power & Solar Panel with 12-volt battery \\
\hline Datalogger & CSI 10X Datalogger \\
\hline EC Sensor & CSI temperature compensated EC probe \\
\hline Flow Measurement & $\begin{array}{l}\text { Los Baños Creek at Hwy } 140 \text { is not commonly affected by } \\
\text { backwater conditions. A duplicate pressure (bubbler) sensor } \\
\text { was located at the site in order to develop and test the reliability } \\
\text { of a stage-discharge relationship. The SONTEK deployment } \\
\text { was not ideal, being on a shallow bend in Los Banos Creek. } \\
\text { However the streambed is stable in this location.. }\end{array}$ \\
\hline - Depth & Design Analysis Smart Gas Bubbler \\
\hline - Velocity & $\mathrm{n} / \mathrm{a}$ \\
\hline Telecommunications & GOES Telemetry \\
\hline
\end{tabular}

\subsubsection{Volta Wasteway (inlet site)}

The Volta Wasteway is the major inlet site to the NGWD, supplying approximately $80 \%$ of the surface water. The monitoring station at Volta was difficult to keep operational, as vandalism was a major factor. However, after several design upgrades, the station is now secure (Figure 2.11). The Volta Wasteway is difficult to monitor for flow because it feeds, and is heavily influenced by, the San Luis Holding Reservoir. Backwater conditions are common in the Wasteway and hence a SONTEK velocity sensor was required to obtain a good discharge measurement. As with the previous installations installing a system to record the depth and the velocity requires the use of a stage- cross-sectional area rating curve. The measured stage (SONTEK pressure) defines the cross sectional area which is multiplied with the velocity to give an estimated discharge. 


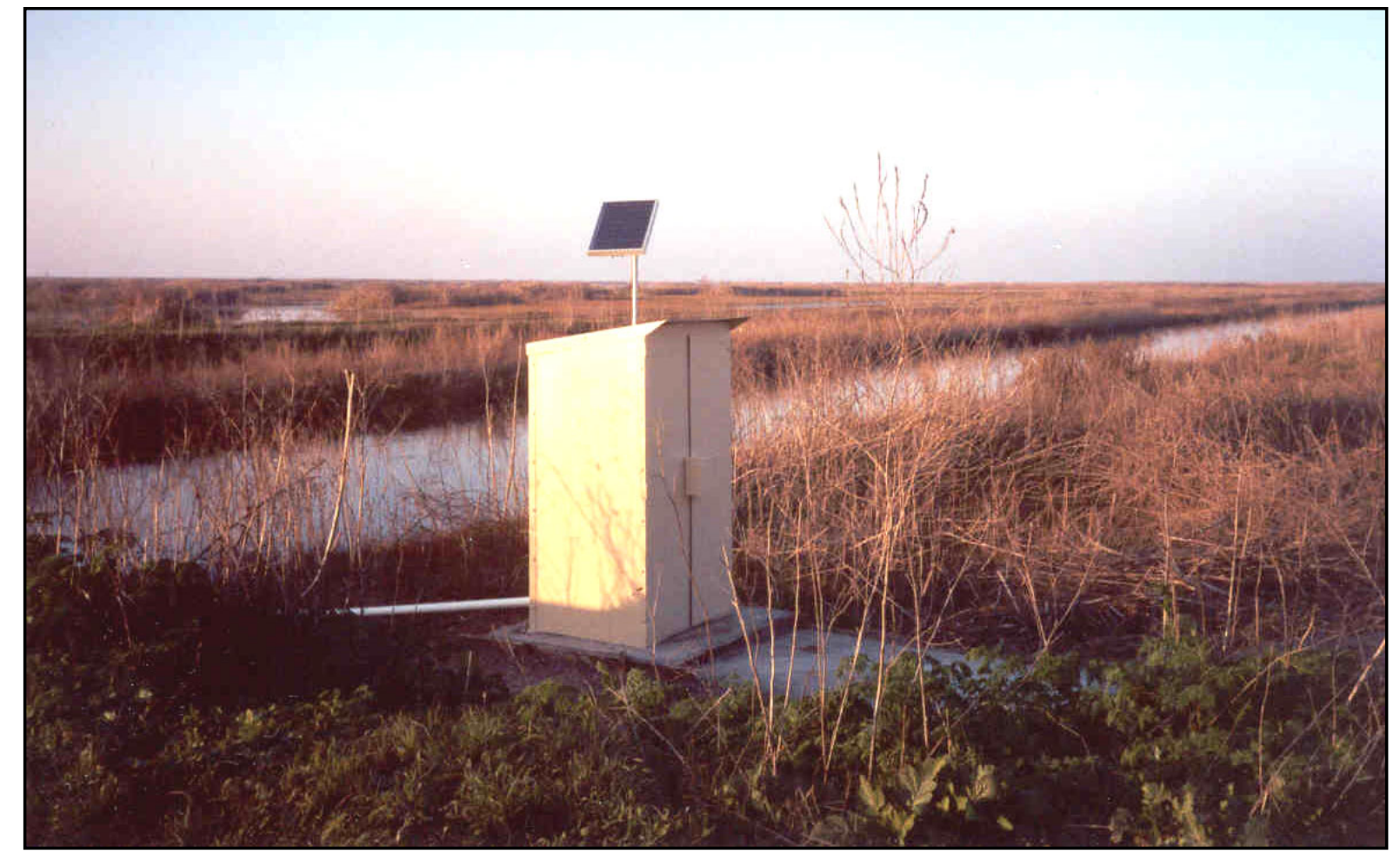

Figure 2.11. Volta Wasteway monitoring station.

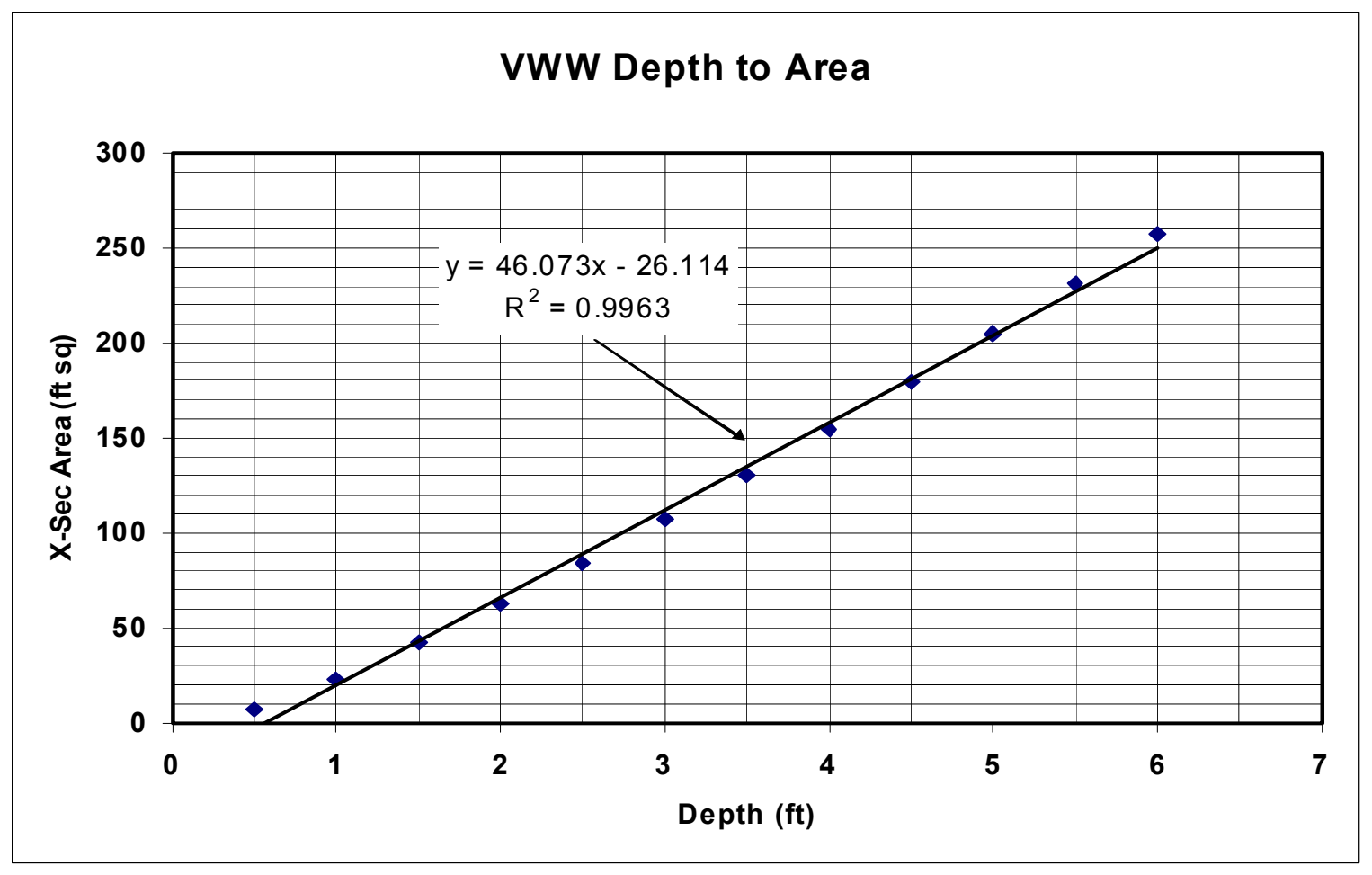

Figure 2.12 Stage - area rating curve for Volta Wasteway.

The site specifics for Volta Wasteway monitoring station are shown below in Table 2.6. 
Table 2.6 - Volta Wasteway monitoring station specifications.

\begin{tabular}{|c|c|}
\hline Site Summary & $\begin{array}{l}\text { Volta Wasteway accounts for roughly } 80 \% \text { of the inflow } \\
\text { volume to the NGWD. }\end{array}$ \\
\hline Power & Solar Panel with 12 -volt battery \\
\hline Datalogger & CSI 10X Datalogger \\
\hline EC Sensor & CSI temperature compensated EC probe \\
\hline Flow Measurement & $\begin{array}{l}\text { The Volta Wasteway downstream from the DFG water control } \\
\text { structure almost always is affected by backwater conditions } \\
\text { from the presence of the San Luis Holding Reservoir located } \\
\text { at the end of the Wasteway. Because of these constraints in } \\
\text { this system, it is important to have both a relative depth } \\
\text { measurement and a relative velocity measurement. }\end{array}$ \\
\hline - Depth & Sontek SL pressure transducer and vertical beam \\
\hline - Velocity & Sontek SL \\
\hline Telecommunications & GOES Telemetry \\
\hline
\end{tabular}

\subsection{Monitoring Network}

The six wetland water quality monitoring stations described above are connected through a real-time network. This network, which comprises the six monitoring stations, a GOES satellite telemetry system, a database, and the Internet - provides real-time data to wetland managers and supplies hydrologic data to a water quality model. The monitoring stations collect and store wetland drainage flow, EC and temperature data. These data are then distributed either via land line to a central database, or through Geostationary Operational Environmental Satellite (GOES) telemetry to the NESDIS data repository in Wallops, Washington. The downloaded information is compiled and error-checked using proprietary data management software and parsed standard report formats. The data are presented on the Internet in graphical and tabular formats. The real-time data is updated weekly, and can be found at http://esd.lbl.gov/people/nwquinn/Grassland_website/grasslandwd/index.html. These data are used in two ways. Their primary use is to help wetland managers monitor and manage salt loads present in seasonal drainage. The data is also useful for calibration of a real-time wetland water quality model developed for the NGWD wetlands. The utility of the model is to develop a better understanding of salinity mass balance in these wetlands - once calibrated the model can assist future scheduling of wetland drainage. 


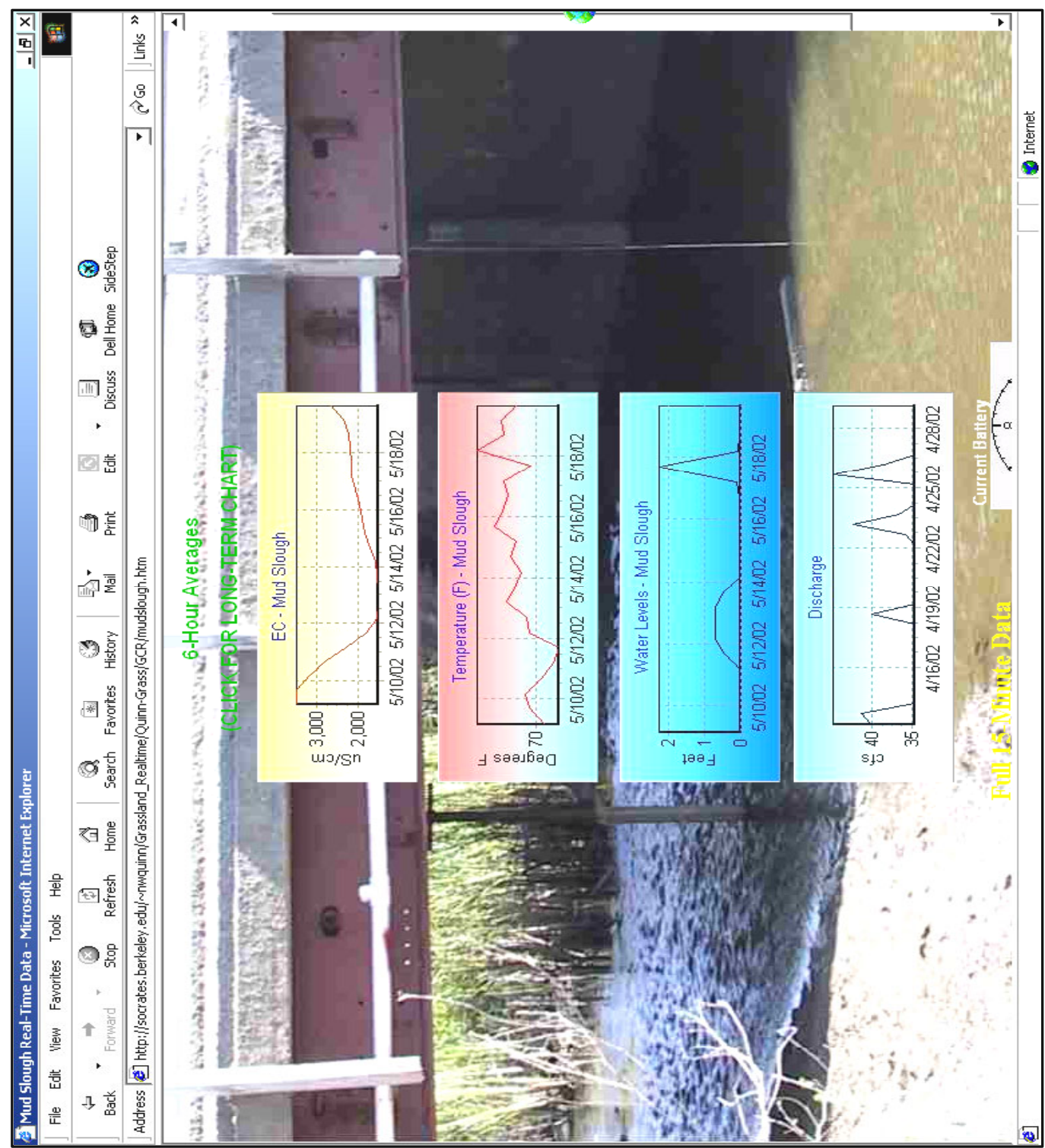

Figure 2.13. Reporting of real-time stage, flow. EC and temperature at the Mud Slough monitoring station in NGWD.

\subsection{Discussion}

The real-time wetland water quality monitoring project has demonstrated the feasibility of operating and maintaining a network of telemetered flow and water quality stations in drainage canals discharging into the San Joaquin River. In addition to providing continuous real-time flow and water quality data for use in adaptive salinity management the data has also proved useful in the development of a wetland water quality model. This model 
provides tributary input to the San Joaquin River Input Output Daily Model (SJRIODAY) operated by the SJRMP Water Quality Subcommittee. The SJRMP Water Quality Subcommittee was funded until the year 2002 to enhance the existing network of real-time monitoring stations along the main-stem of the San Joaquin River and to improve the coordination of agricultural return flows and scheduled east-side fish flows (Quinn et al. 1997).

The real-time flow and water quality monitoring data from key locations in the NGWD helps provide decision support to wetland managers scheduling drawdowns and irrigations. Mean daily salinity loading from the NGWD is calculated from the monitoring data and is compared with the daily assimilative capacity determinations on the SJR. The GWD now can evaluate wetland discharge opportunities during the spring months (when the majority of saline discharges from seasonal wetlands occur) and make relevant decisions based upon the real-time data. In addition, this network can provide the backbone for further monitoring efforts to help alleviate other problems within the San Joaquin Basin such as elevated concentrations of nitrates, dissolved organic carbon, and dissolved oxygen. 


\section{CHAPTER 3 DEVELOPMENT AND APPLICATION OF A REAL- TIME WETLAND WATER QUALITY MODEL}

\subsection{Introduction}

A wetland water quality model (WWQM) was developed for the seasonal wetlands in the San Joaquin River Basin (SJR). Once developed, it was applied to the wetlands of the Grassland Water District (GWD) as part of the real-time adaptive wetland water quality management research project. The WWQM, a salt and water balance box-type model, utilizes wetland management practices, daily climatic data, land use values, and daily surface water supply data to forecast wetland drainage salinity levels. These forecasts, when used in conjunction with assimilative capacity forecasts for salts in the SJR, can assist wetland managers to better coordinate salt loading from the GWD to the SJR. The main objective of the WWQM is to simulate and forecast seasonal wetland salinity levels for wetlands in the SJR Basin. However, it also has the ability to compare these wetland salt loads with assimilative capacity forecasts for salts in the SJR. This linkage allows the user to estimate the effects of salt loading to the SJR during spring wetland drawdown (February-April), and hence make better decisions regarding salt export.

The WWQM was successfully applied to the seasonal wetlands of the Northern Division of the GWD (NGWD) during the spring 2003 drawdown season. The model was calibrated and validated continually using actual wetland drainage salinity data collected by the monitoring stations in the NGWD. The WWQM resides with the water master of the GWD and is updated weekly or on an "as needed" basis. This application assisted the GWD water master in advising the individual managers of desired drawdown dates to better coordinate salt export from the wetlands.

\subsection{Background}

The California Regional Water Quality Control Board (CRWQCB) is the policing arm of the U.S. Environmental Protection Agency. The Central Valley Regional Water Quality Control Board regulates water quality in the SJR. Among other constituents of concern, the CRWQCB regulates salinity discharges from point and non-point sources. Using a 
procedure known as the Total Maximum Daily Load (TMDL), the CRWQCB can allocate the assimilative capacity of a water body such as the SJR for salts and other pollutants among watershed sources in order to maintain water quality. However, if watershed sources develop the ability to better coordinate their pollutant exports through real-time management, more management flexibility is possible. In the case of a traditional TMDL, minimal flexibility is possible and these TMDL's tend to be very restrictive since they are based on a $10 \%$ exceedence hydrology and a fixed frequency of violation. However, under real-time management, more salt export would be allowed during periods of high assimilative capacity. Conversely, during periods of low assimilative capacity for salts in the SJR, exports would need to be curtailed. The management of sources of salt load through real-time control requires the development of monitoring systems, more integrative management strategies and coordination with all entities. For the real-time concept to work, releases from west-side agricultural sources and east-side reservoir releases must be coordinated.

\subsection{Wetland Management}

Wetlands in the SJR Basin seasonally contribute salinity to the SJR because they are flooded in the fall and drawn down in the spring to mimic the natural wet-dry cycle these wetlands once experienced. As the flooded season progresses, the salinity in the wetlands increases. This salinity increase is due to many different factors, foremost among them the quality of the water supply and secondly the further concentration of the salts from evaporative and evapotranspirative losses. Other factors contributing to the salinity increase, but not yet quantified, are groundwater infiltration, bird usage, and water resource management at the regional level. Quantification of these and other possible salinity sources require study outside the scope of this research.

Management of wetland drainage, through scheduling of releases to coincide with periods of SJR assimilative capacity, can help improve SJR water quality. However, these actions may need to be considered relative to potential biological wetland impacts of changes to traditional wetland management practices. Seasonal wetlands in the SJR Basin are intensively managed to provide optimal conditions for waterfowl habitat. One set of wetland "best-management practices" (BMPs) is presented in the publication A Guide to Wetland 
Habitat Management in the Central Valley (Smith et al., 1995). This guide was produced through a cooperative effort between the California Department of Fish and Game and the California Waterfowl Association. In it water management plans for optimal productivity are presented for three very desirable moist-soil plants - smartweed (Polygonum punctatum), swamp timothy (Heleochloa schoenoides), and watergrass (Echinochloa crusgalli) (Figure 1.6). Using the guide to help direct BMPs, wetland managers conduct drawdown during the months of February through April. In practice, wetland mangers try to drawdown the wetlands earlier when it is unseasonably warm or dry, and try to drawdown their wetlands later in the season when it is unseasonably cool or wet (Table 3.1).

Table 3.1. Wetland Management Decision Tree

\begin{tabular}{|llll|c|}
\hline \multicolumn{5}{c}{ Theoretical Decision Tree for Wetland Drainage } \\
Moisture Regime & Temp. Regime & Drawdown Type & SJR Assim. Cap. & Mis-Match? \\
\hline Very Dry & Cold & Traditional & Early & $\mathbf{X}$ \\
Very Dry & Normal & Traditional & Early & $\mathbf{X}$ \\
Very Dry & Warm & Early & Early & \\
Dry & Cold & Traditional & Early & $\mathbf{X}$ \\
Dry & Normal & Traditional & Early & $\mathbf{X}$ \\
Dry & Warm & Early & Early & $\mathbf{X}$ \\
Normal & Cold & Late & Average & \\
Normal & Normal & Traditional & Average & $\mathbf{X}$ \\
Normal & Warm & Traditional & Early & \\
Wet & Cold & Late & Late & \\
Wet & Normal & Late & Late & \\
Wet & Warm & Traditional & Average & \\
\hline
\end{tabular}

Note: Mis-Match refers to the wetland drawdown type not coinciding with SJR assimilative capacity.

However wetland salinity levels are highest during this wetland drawdown period. In addition, peak assimilative capacity for salts in the SJR typically occurs between the months of January and March (Figure 3.1). This time period is often earlier than the traditional wetland drawdown period (February-April). Hence, the response of wetland habitat 


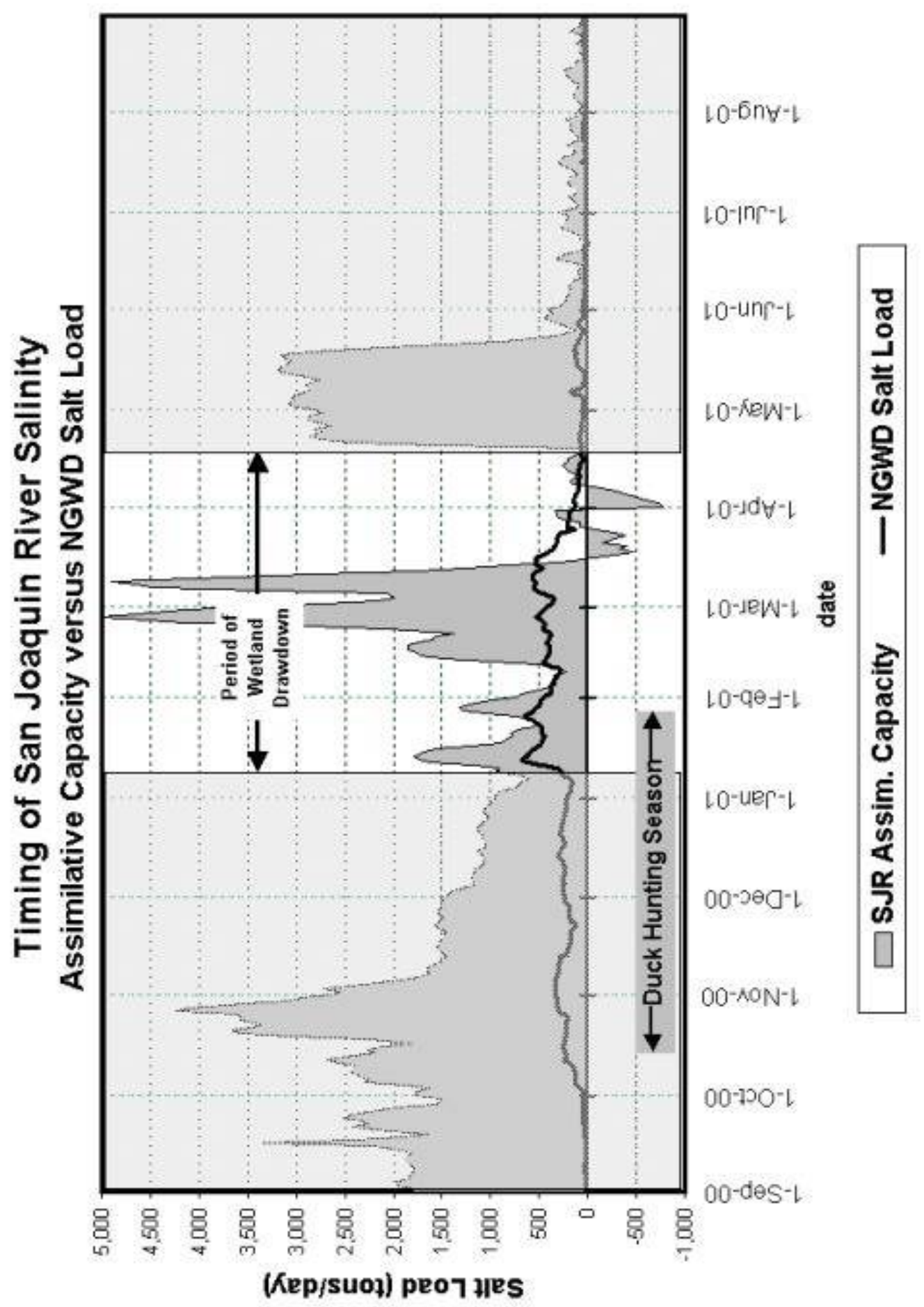

Figure 3.1. Scheduling of San Joaquin River salinity, assimilative capacity versus NGWD salt loading. The majority of NGWD salt load occurs between January and mid-April, coinciding with periods of low assimilative capacity on the San Joaquin River. 
conditions to an altered drawdown regime must be assessed. It is possible that early, experimental drawdown may make food sources available to wildlife without negatively affecting the wetland vegetation community and plant species diversity, hence benefiting both wildlife and the water quality of the San Joaquin River.

\subsection{San Joaquin River Management}

Better coordination of agricultural and wetland releases with reservoir releases of good quality snow-melt water on the east-side of the SJR Basin has been suggested as a means of improving SJR water quality for all beneficial uses (Quinn and Delamore, 1994; Karkoski, Quinn and Grober, 1995; Quinn et al., 1997; Quinn and Karkoski, 1998). Studies have shown positive results of a demonstration project of real-time monitoring and management of agricultural drainage and east-side reservoir releases that forecasts the assimilative capacity for salinity on the SJR (Quinn and Karkoski, 1998) The real-time wetland water quality management project builds upon this program to coordinate seasonal wetland drainage with the assimilative capacity of the SJR.

In 1990, Assembly Bill AB 3603 authorized the creation of the SJRMP, along with an advisory council. The advisory council was required to identify problems facing the SJR system and prepare a plan that would identify solutions for improvement, restoration, and enhancement of the currently degraded conditions. AB 3603 initiated a consensus-based effort to solve water-use problems within the SJR system.

The SJRMP covers a regional area along the SJR from Friant Dam downstream through the northern boundary of the South Delta Water Agency and all other tributaries of the SJR up to the first major dam. The major tributaries are the Merced, Tuolumne and Stanislaus Rivers. Minor tributaries include agricultural returns from the east and west sides, environmental areas such as the Grassland Wetland Area (primarily Mud and Salt Sloughs) as well as smaller creeks like Orestimba Creek.

The SJRMP Water Quality Subcommittee installed and demonstrated a San Joaquin River Real-Time Water Quality Management Network on a pilot scale. This network is used to 
enable participants to make informed water management decisions regarding the SJR Basin. It integrates the system's water quality monitoring stations, each equipped with water quality and quantity instrumentation, and provides data to a computer model (SJRIO-DAY) that facilitates interpretation of the raw data collected (Quinn, 1997).

The San Joaquin River Real-Time Water Quality Management Program used telemetered stream stage, salinity data and computer models to simulate and forecast water quality conditions along the lower SJR. The primary goal of the program was to eliminate or reduce the frequency of water quality violations, thereby reducing the number and/or magnitude of high quality releases made specifically to meet SJR salinity objectives.

The main objective of the current project was to facilitate the control and timing of wetland and agricultural drainage, in coordination with east-side reservoir operators, to coincide with periods when dilution flow is sufficient to meet Vernalis salinity objectives. By reducing the frequency of violations of Vernalis EC objectives, the project may reduce the number and/or magnitude of high quality releases (e.g., releases of Stanislaus River flows from New Melones Reservoir) performed specifically for meeting Vernalis EC objectives (Quinn and Karkoski, 1998; Grober et al., 1995). Other specific objectives and benefits include a reduction in conflicts between reservoir operators, wetlands managers, and agricultural drainers in meeting Vernalis salinity objectives; improved SJR and Bay-Delta water quality for agricultural, drinking water, industrial, and recreational beneficial uses; expanded and improved monitoring stations with telemetered streamflow, temperature and EC sensors capable of delivering real-time information; and increased understanding and management of activities that affect SJR water quality .

\subsection{Previous Modeling Approaches}

Watershed modeling is an important tool in integrated basin management. There are an abundance of qualified models developed for hydrologic purposes. However, many do not incorporate adequate water quality components (Arnold et al, 1998). If these watershed models are to be used for environmental applications, water quality along with hydrology must be considered. One of the first salts and water modeling projects utilized dynamic 
simulation of salinity and other water pollutants such as pesticide residues in the Klamath River Basin, California (Woods and Orlob, 1963). Other early modeling efforts included consumptive use equations for water quality parameters in the Sacramento River Basin,

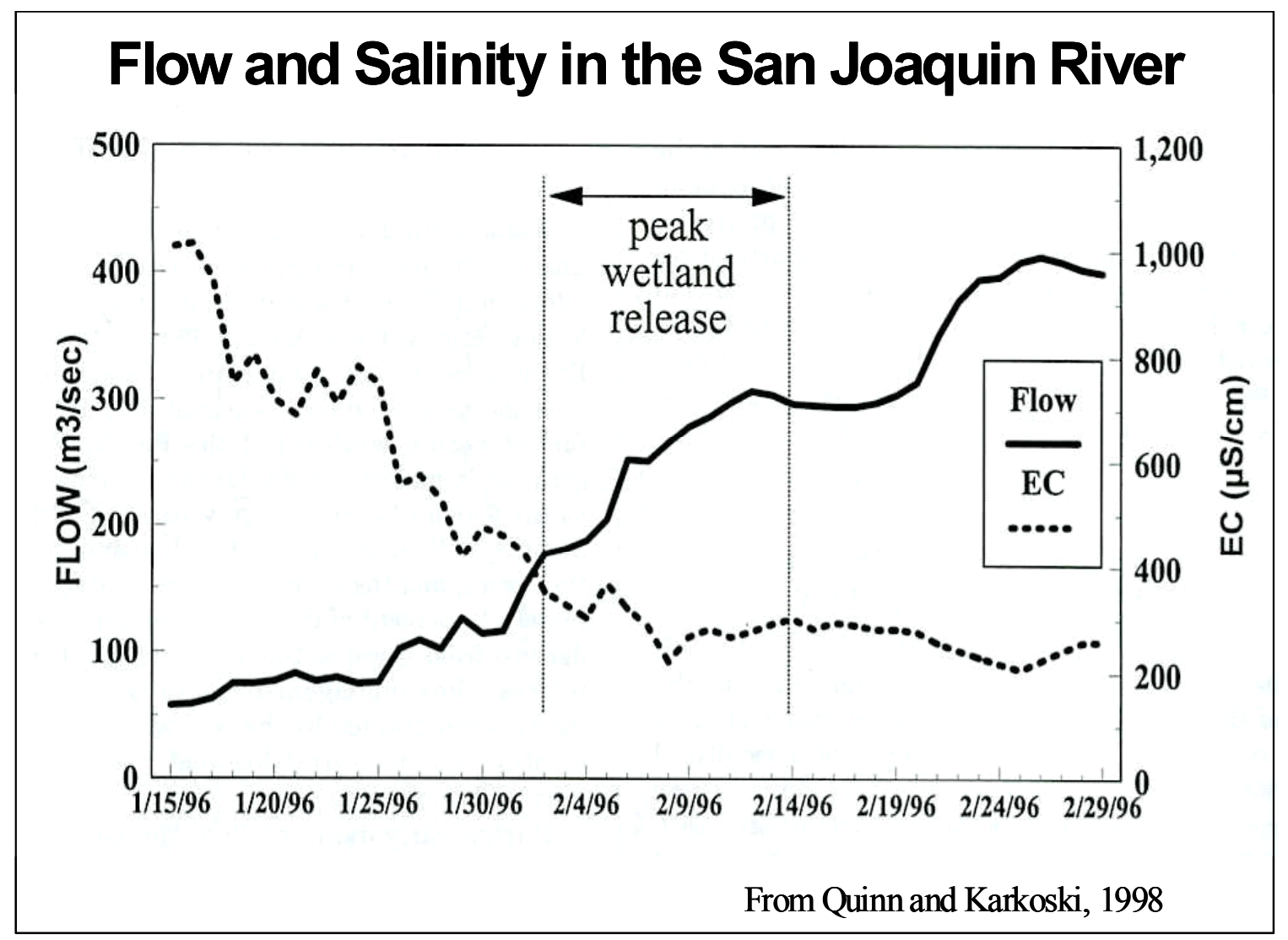

Figure 3.2 Flow and electrical conductivity in the San Joaquin River between January 15 and March 1, 1996.

California (Woods, 1967); linear and multiple regression for salinity impacts on irrigated agriculture in the Lower San Joaquin Basin, California (California Department of Water Resources, 1969); and elemental analyses for salt balances in the Upper Santa Ana River Basin, California (Water Resources Engineers, 1969). Box models for salts and water include mass-balance calculations to estimate TDS and $\mathrm{N}$ waste loading from irrigated agriculture (Bay-Valley Consultants, 1974; Tanji, 1977; Aragues et al., 1985); a comprehensive macro-scale simulation/ mathematical model to estimate hydrology and salinity for large catchment basins (U.S. Bureau of Reclamation, 1977) and a dual-type salinity box model for the separate isoclines in the Black Sea (Karaka et al., 1999). 
More recently, modeling attempts have focused on entire systems. A basin-scale modeling is described as a water resource planning tool in New Zealand watershed Basins (Cooper and Bottcher, 1993). The model, BNZ (Basin-New Zealand), utilizes algorithms similar to those in CREAMS (Chemicals, Runoff, and Erosion from Agricultural Management Systems) developed by the U.S. Department of Agriculture (Knisel, 1980). Several research studies applied dual type box models to describe the layered salinity flux in the Black Sea (Karaka et al., 1999). Recent studies have compared several methods for training artificial neural networks for use in salinity forecasting and other aspects of water resources planning and management.

The literature contains several examples of applying real-time data acquisition to planning and operations modeling. Real-time control of power plant cooling water discharges utilizing optimization models that incorporate stochastic data along with climatic factors were simulated in order to ascertain compliance with temperature standards (Krajewski et al., 1993). A real-time modeling approach was applied to wastewater treatment operations and suggest adaptive management schemes so that facilities' management can better adapt and operate efficiently (Novotny et al., 1992).

In the San Joaquin River Basin, a mass balance model is currently in use to predict the assimilative capacity of the San Joaquin River. This model, the San Joaquin River InputOutput Daily Model (SJRIODAY), calculates daily flows and concentrations of TDS for a 60-mile $(96 \mathrm{~km})$ reach of the San Joaquin River from Lander Avenue to Vernalis. Using real-time flow and EC data from five major tributaries and several small tributaries, daily flow calculations are performed using hydrologic routing techniques. The data are used to establish initial conditions for model runs and to generate two-week forecasts of flow and EC (Quinn et al., 1997; Quinn and Karkoski, 1998). The accuracy of the SJRIO forecasts is greatest when east side reservoir releases and estimates of agricultural and wetland releases are available. Through collaboration and a water quality monitoring network, most reservoir releases and the large agricultural entities are tied into the San Joaquin Real-Time monitoring network (Quinn and Karkoski, 1998). 
The WWQM created for this project complements this previous work by providing a prediction tool for wetland releases from the GWD. Coordinating the salt load from the NGWD with the SJR's assimilative capacity requires forecast results from SJRIODAY to be used as inputs into the WWQM. The WWQM estimates the salt loads that can be expected from the wetland releases. These values then are compared to the SJR assimilative capacity, providing a quantitative impact assessment tool for managing salinity in the SJR.

\subsection{The Wetland Water Quality Model}

The WWQM is a salt and water balance box-type model designed to assist coordination of salt loading from regional wetlands the assimilative capacity for salts the San Joaquin River. This box model is similar to other salinity box models (for example, salinity models of the Black Sea) in that it calculates salinity through a weighted contribution from all inputs, outputs and changes in storage (Karaka et al., 1999). However, the unpredictability of managed systems such as the seasonal wetlands in the GWD makes this model more complex than ones used previously. The WWQM somewhat overcomes this through its ability to be updated and calibrated on a daily basis. The WWQM was developed to organize field monitoring data, land use data, and wetland BMPs into a salt and water balance forecasting model. The WWQM continually tracks the weighted flow and salinity contributions into and out of the box (Figure 3.3). The salinity in the box can be calculated at any time using the salt balance equation below :

$\mathrm{EC}_{\mathrm{Dt}}=$

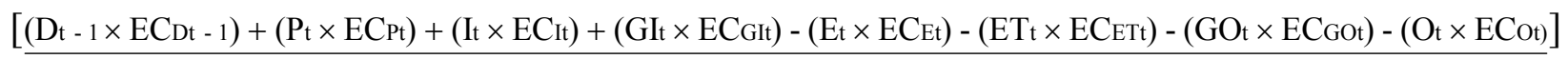

$\left[\left(\mathrm{Dt}_{\mathrm{t}-1}+\mathrm{P}_{\mathrm{t}}+\mathrm{It}_{\mathrm{t}}+\mathrm{GIt}_{\mathrm{t}}-\mathrm{Et}_{\mathrm{t}}-\mathrm{ET}_{\mathrm{t}}-\mathrm{GO}_{\mathrm{t}}-\mathrm{Ot}\right)\right]$

(3)

Where $E C_{X t}$ is the salinity measured as electrical conductivity for parameter $X$ at time $t$ $[\mu \mathrm{S} / \mathrm{cm}] ; D$ is the end of day depth [in]; $P$ is precipitation [in]; $I$ is inflow [in]; $G I$ is the groundwater inflow seepage [in]; $E$ is the evaporation [in]; ET is the evaporation [in]; $G O$ is the groundwater outflow seepage [in]; and $O$ is the wetland outflow [in].

This model assists wetland managers in their efforts to make timely decisions (i.e. when to begin wetland drawdown) regarding return flows to the SJR. A real-time wetland water 
quality monitoring network created specifically for this project supplies the data necessary to validate and operate the WWQM. This model was linked with assimilative capacity forecasts for salinity in the SJR. The San Joaquin River Input-Output Daily Model (SJRIODAY) produces weekly assimilative capacity forecasts for salt loads.

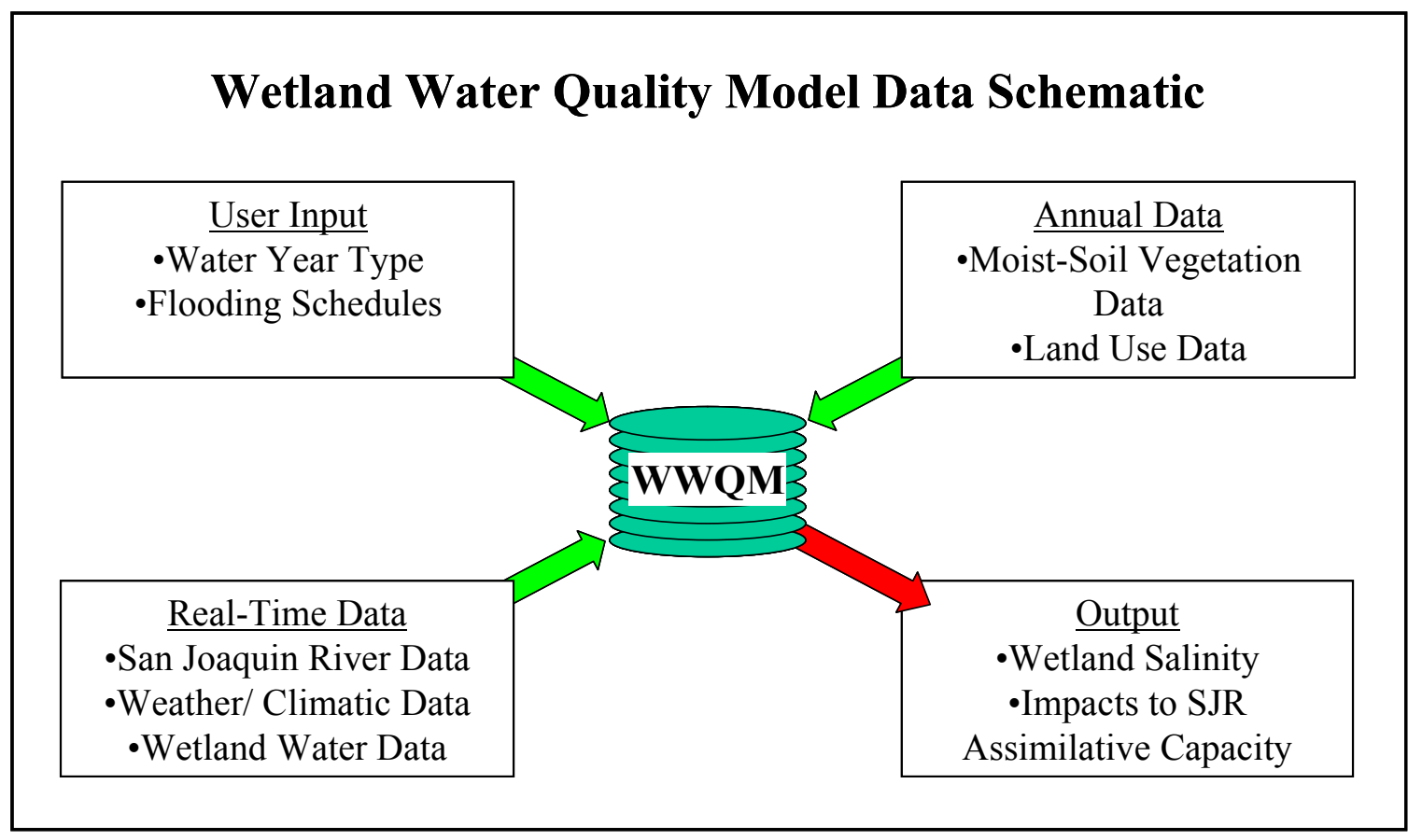

Figure 3.3. Wetland Water Quality Model (WWDM) data schematic.

The purpose of the model was to predict the quantities and qualities of wetland releases by mimicking the wet and dry seasonal cycle that these wetlands experience. The WWQM required time series data inputs of variables such as inflow volume and water quality, residence time, evapotranspiration, evaporation, precipitation, land use, vegetation types and management strategies. The model tracked salinity changes in each of the wetland basins over the flooded season including drawdown (September through April) and incorporates user-defined schedules for wetland drawdown in the spring months to determine salinity loading to the SJR (Figure 3.1).

Using time series data in conjunction with short and long term weather forecasts, the model was used to predict salinity levels in wetland drainage. The real-time drainage salinity monitoring data at each outlet was used to calibrate the model. Once calibrated, the model 
simulated different management strategies to produce experimental drainage schedules of salt loading to the SJR. The WWQM, when used along with the SJR assimilative capacity forecasts, can aid wetland mangers to make better drawdown decisions (Grober et al, 1995; Quinn et al, 1997; Quinn and Karkoski, 1998; Quinn, 1999).

\subsection{Model Development}

The WWQM was developed within Microsoft's ${ }^{\mathrm{TM}}$ two database and file systems, Access ${ }^{\mathrm{TM}}$ and Excel ${ }^{\mathrm{TM}}$. This development scenario was ideal because the Excel ${ }^{\mathrm{TM}}$-based user interface is familiar to wetland managers. Moreover, Excel ${ }^{\mathrm{TM}}$ allows computation and insertion of logic and is supported by the Access ${ }^{\mathrm{TM}}$ database. Access ${ }^{\mathrm{TM}}$ has the ability to support Excel ${ }^{\mathrm{TM}}$ and the monitoring network constructed specifically for this project, and also readily communicates with ArcGISTM 8.X, Environmental Systems Research Institute's (ESRI) latest Geographical Information System (GIS) software package. As a model package, it is an integrated database accounting for many of the individual factors (climatic, management, etc.) that effect wetland salinity in the GWD. The model has been designed to perform historic hydrology simulations as well as seasonal "gaming" alternatives. These gaming alternatives include different wetland drawdown protocols such as (a) early drawdown (critically dry to dry year), (b) traditional drawdown (dry to wet year), (c) late drawdown (wet year), and (d) a pre-flushing option to determine the effects of early salt exports while maintaining desired depths within the wetlands.

The WWQM was designed to predict salt loading from seasonal wetlands in the SJR Basin and interact with the California Department of Water Resources' San Joaquin River real-time water quality forecasting model, SJRIODAY (San Joaquin River Input-Output Daily model), introduced above. SJRIODAY provides water quality forecasts of assimilative capacity for salts in the SJR (Figure 3.4). The WWQM uses SJR assimilative capacity forecasts provided by SJRIODAY as a means of estimating allowable wetland discharge. The WWQM has been designed with flexibility to allow for interactions with the next generation of the SJR water quality model, the Delta Simulation Model II (DSM-2). 
The WWQM's user interface also resides in the Microsoft Excel ${ }^{\mathrm{TM}}$ platform (Figure 3.5) because, as previously noted, there is widespread familiarity with this product among the wetland managers of the GWD. In addition, the model has been designed to allow linkage to GIS software packages such as ARCGIS so results can be viewed and assessed.

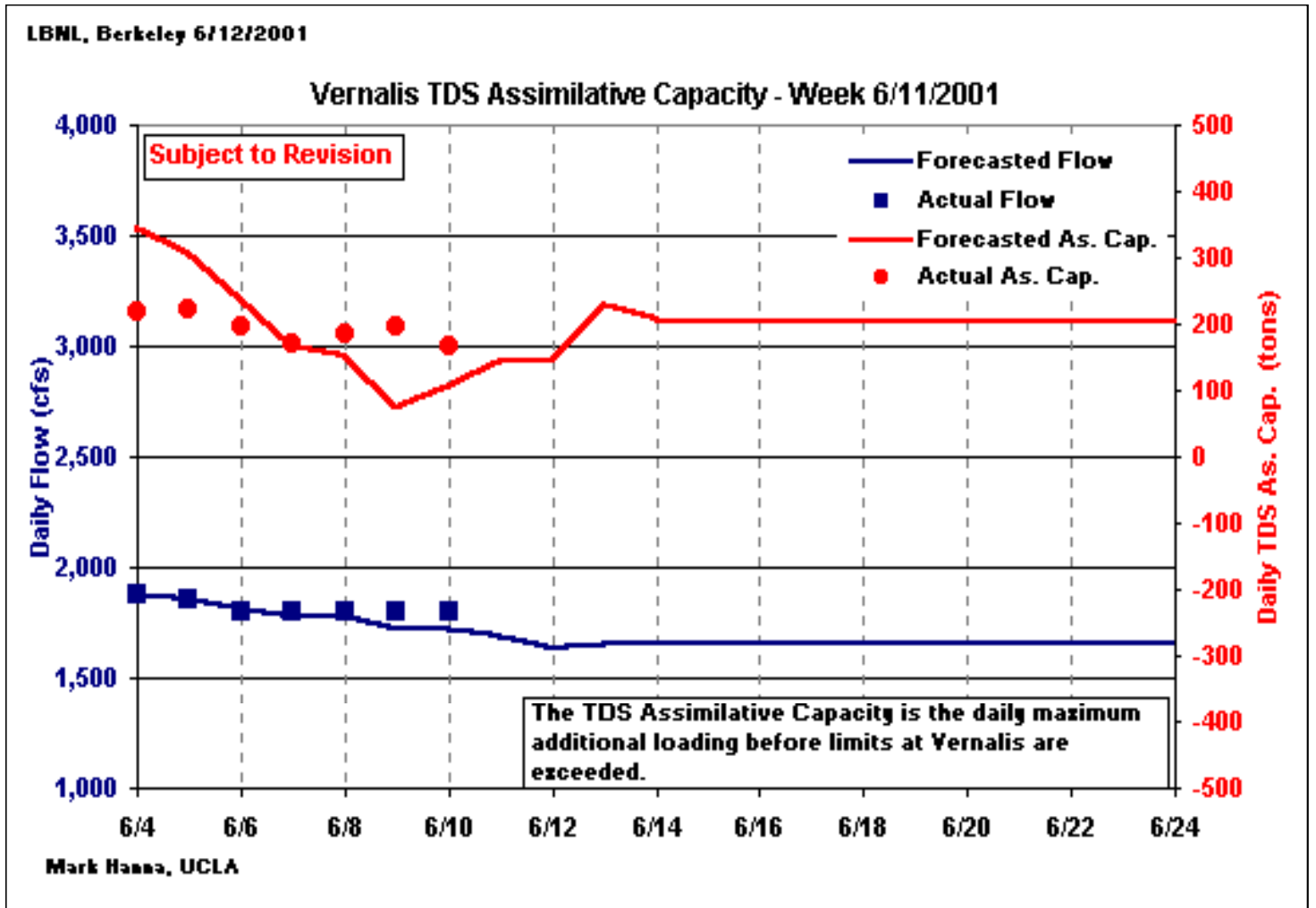

Figure 3.4 Flow and assimilative capacity forecasts on the San Joaquin River for June, 2001 produced by the SJRIODAY Model

The WWQM resides in a file directory called "Model Package" on the computer belonging to the GWD wetland manager. Stored within the directory are several data files required to run the model (Appendix 1 - Wetland Water Quality Model Package). The actual model file, WWQM.xls, contains many links to the various other data files, and constitutes the backbone of the system (Appendix 2 - The Wetland Water Quality Model [WWQM.xls]; and Appendix 3 - Columnar Descriptions of the Wetland Water Quality Model). The two main files that the user needs to run the model are the API.xls (application process interface) and the update.xls files. The API.xls file (Figure 3.5) shows the Wetland Water Quality Model 
user interface which allows the user to input the necessary parameters such as water year type and expected weather conditions. The user then can perform a rudimentary, fine-tuning calibration operation, and view the results. The user also possesses the ability to run some gaming type scenarios in the API.xls file by changing the water year type and/or simulating a "pre-flush" option of the wetlands themselves.

Generally speaking, there are two different classes of wetlands in the Grassland Water District. Those two wetland classes are: seasonal wetlands - wetlands that are flooded for a portion of the year permanent wetlands - wetlands flooded nearly year-round Within the class of seasonal wetlands, there are three different types of wetlands that could be simulated. These are shallow seasonal wetlands, mid-depth seasonal wetlands, and deep seasonal wetlands. The WWQM was developed to simulate mid-depth seasonal wetlands in particular.

The primary reason mid-depth wetlands were chosen to be modeled is because this is the most popular type of wetland -- estimated at greater than 70 percent of the total seasonal wetland area. Wetland managers try to keep the majority of the ponded area between 10 and 12 inches deep. This is the water depth most preferred by desired waterfowl such as mallards (Anas platyrhynchos), green-winged teats (A. crecca), northern pintail (A. acuta) and other dabbling ducks. Accordingly, waterfowl hunters most commonly want to hunt in these types of wetlands (Frederickson and Taylor, 1982, Grober et al 1995, and Smith et al, 1995).

A secondary reason for the selection of mid-depth wetlands is that the hydrology of mid depth wetlands is much easier to understand. Such understanding leads to more accurate modeling. Shallow wetlands tend to have fluctuating aerial extent because they are more susceptible to daily variations in the weather and, as a result, usually have less defined boundaries. Deep wetlands also provide a challenge because they have less well-defined boundaries, and hence their storage volume (due to bottom undulations) is more variable. When draining deep wetlands can produce much more variability in outflow rates. Middepth wetlands, on the other hand, have less variable outflow and better defined boundaries. 


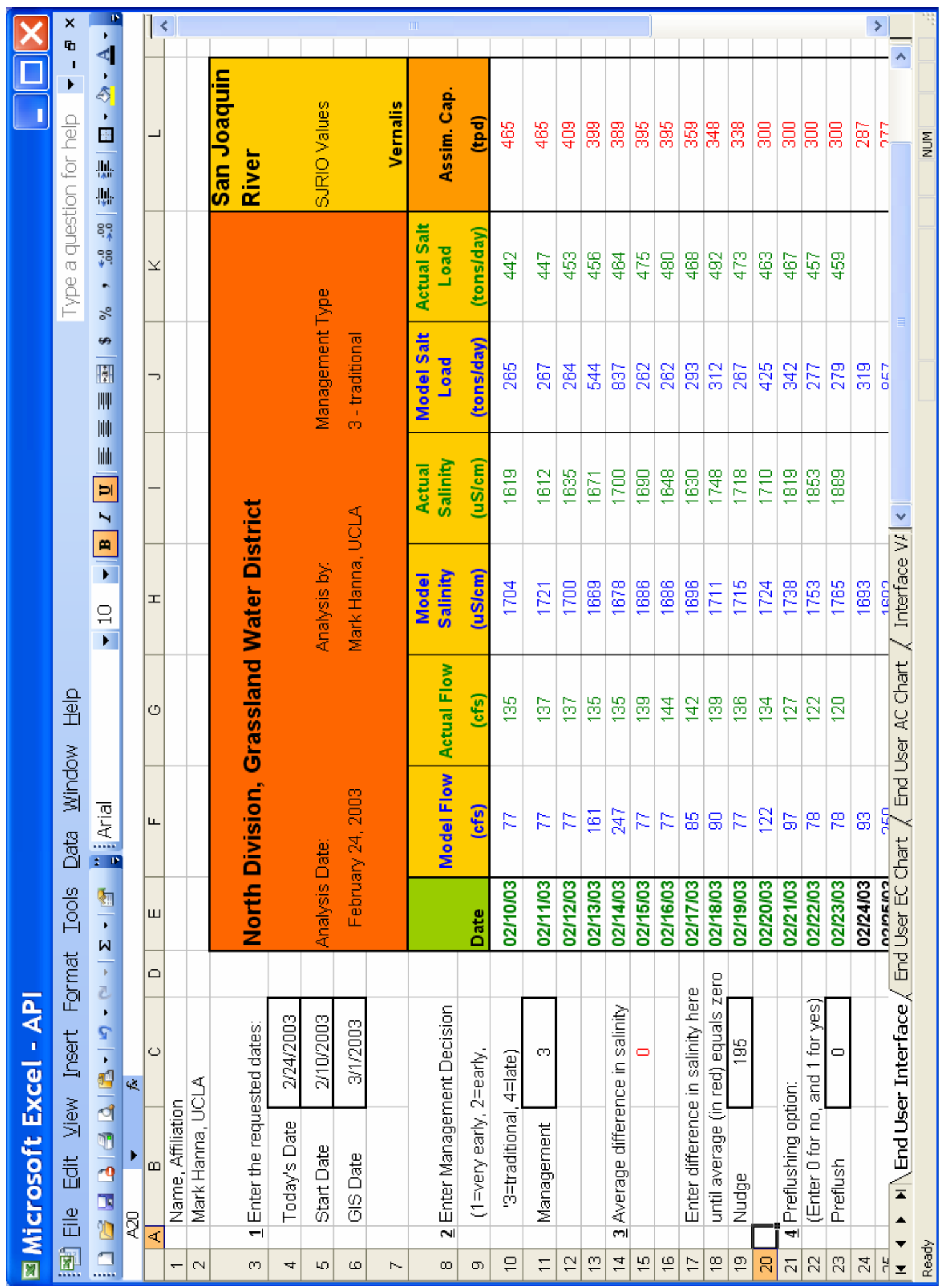

Figure 3.5. Wetland Water Quality Model user interface. 
These boundaries, in the form of levies, are designed to keep the entire wetland unit at a chosen depth. Figure 3.6 shows the Salinas Land \& Cattle Club, a good example of a middepth seasonal wetland unit in the Grasslands Water District.

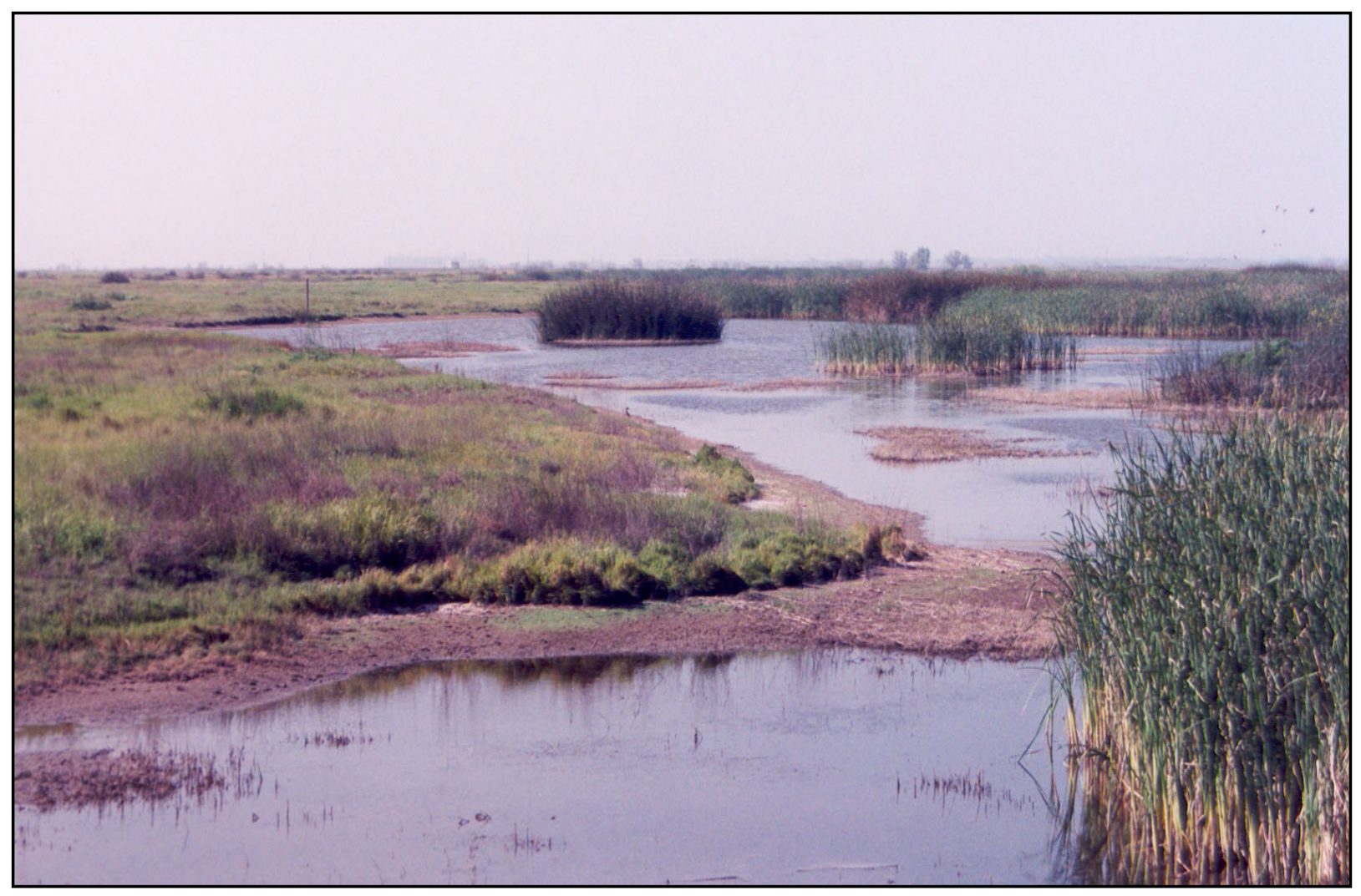

Figure 3.6. The Salinas Land \& Cattle Club, an example of a mid-depth seasonal wetland unit in the Grassland Water District

\subsection{Model Components}

To track wetland conditions as they progress through the flooded season, and monitor their impacts on the SJR, four different analytical worksheets were created within the WWQM. These four components -- wetland management, wetland hydrology, wetland salinity, and San Joaquin River assimilative capacity -- are discussed below.

\subsubsection{Wetland Management}

The WWQM's foundation derives from a combination of accepted wetland "best management practices" (BMPs) for seasonal wetlands. The specific BMP used for the seasonal wetland habitat management component is the recommended flooding regime 
published in "A Guide to Wetland Habitat Management in the Central Valley". This guide was developed, as noted earlier, through a cooperative effort of the California Department of Fish and Game and The California Waterfowl Association (Smith et al., 1995). For seasonal wetlands in California's Central Valley, this guide suggests a flooding regime for optimal wetland management for certain moist-soil plants.

\subsubsection{Model output parameters}

\section{Ai-Target Depth, TD}

The model calculates the average depth, or "target depth", in the wetland unit system based on the management plans named above. The target depth is dictated by date, water year type, and the combination of the wetland percentages delineated as "habitat clubs" $(\% \mathrm{HC})$ and "cattle clubs" (\%CC). Habitat clubs are those that are managed for habitat throughout the year. Cattle clubs, on the other hand, are flooded during hunting season but drained shortly thereafter in order to graze cattle. The model treats the cattle club exactly like a habitat club during fall floodup and throughout the flooded season. However, no matter the water year type, the WWQM initiates drawdown for cattle clubs on February $1^{\text {st }}$ each year. This target depth, which is a combination of the depth for the habitat clubs (HAB) and cattle clubs (CAT), along with their present percentage of the total land, is the controlling factor during the daily time step process within the WWQM

$$
T D_{t}=\left(\% H C \times H A B_{t}\right)+\left(\% C C \times C A T_{t}\right)
$$

Using the "season type" decision variables within the user interface (Figure 3.5), the end user can shift the wetland management timing curve earlier or later, depending upon the user's interpretation of the current year type (extremely dry, dry, normal, and wet). This target depth, calculated for a specific wetland system (i.e. shallow, mid-depth, or deep) and water year type, is then compared to the modeled wetland storage depth, $D$, using the water balance formula in Equation 4). This comparison affects the following day's decisions by either suggesting a need for additional surface water input or that no water is required. 


\subsection{Wetland Hydrology}

\section{Bi-Wetland Storage Depth, D}

The hydrologic modeling within the WWQM considers the water cycle (Figure 3.7) and its associated water balance equation. The water balance equation has been arranged to calculate the wetland storage depth, $D_{t}$, using the following inputs:

$$
D_{t}=D_{t-1}+\sum_{t=1}^{t}\left(I_{t}+P_{t}+G I_{t}-E_{t}-E T_{t}-O_{t}-G O_{t}\right)
$$

where $\mathrm{t}$ is the time step; $D_{t}$ is the end of period storage depth in the wetland units; $I_{t}$ is the wetland inflow; $P_{t}$ is the precipitation that falls within the individual wetland units; $G I_{t}$ is the groundwater inflow to the individual wetland units; $E_{t}$ is the direct evaporation from the open water surfaces within each wetland unit; $E T_{t}$ is the evapotranspiration from the vegetated portions of the wetland units; $O_{t}$ is the combined wetland outflow and operational spill; and $G O_{t}$ is the groundwater inflow / outflow. The Wetland Storage Depth, $D_{t}$, is calculated by starting each iteration with the results from the previous time step's storage depth, $D_{t-1}$. The model then adds and subtracts the daily inputs and outputs for the present time, $t$. The inputs are precipitation $\left(P_{t}\right)$, operational inflow $\left(I_{t}\right)$, and groundwater input $\left(G I_{t}\right)$. The outputs are evaporation $\left(E_{t}\right)$, evapotranspiration $\left(E T_{t}\right)$, outflow $\left(O_{t}\right)$ and groundwater outflow $\left(G O_{t}\right)$.

\section{Bii-Precipitation, $P$}

Precipitation data are measured values. The precipitation data come directly from the California Irrigation Management Information System (CIMIS) website, www.cimis.water.ca.gov, operated by the California Department of Water Resources (DWR). CIMIS publishes daily climatic data recorded at many weather monitoring stations

across California. All precipitation falling within a wetland unit and its associated uplands is assumed captured within the wetland unit itself. The total volume of rainfall, therefore, is the value of precipitation, measured in inches, multiplied over the land area. The closest CIMIS station is located within the former Kesterson Reservoir north of Los Banos.

\section{Biii-Groundwater Inflow, GI}

Lateral groundwater flow and salinity data, if available, can be applied to the WWQM. The WWQM accepts groundwater data through the update files similar to climate and land use 
data. Since groundwater flux data are not available, the model assumes that groundwater inflows and outflows balance and the net contribution to salt balance is zero.

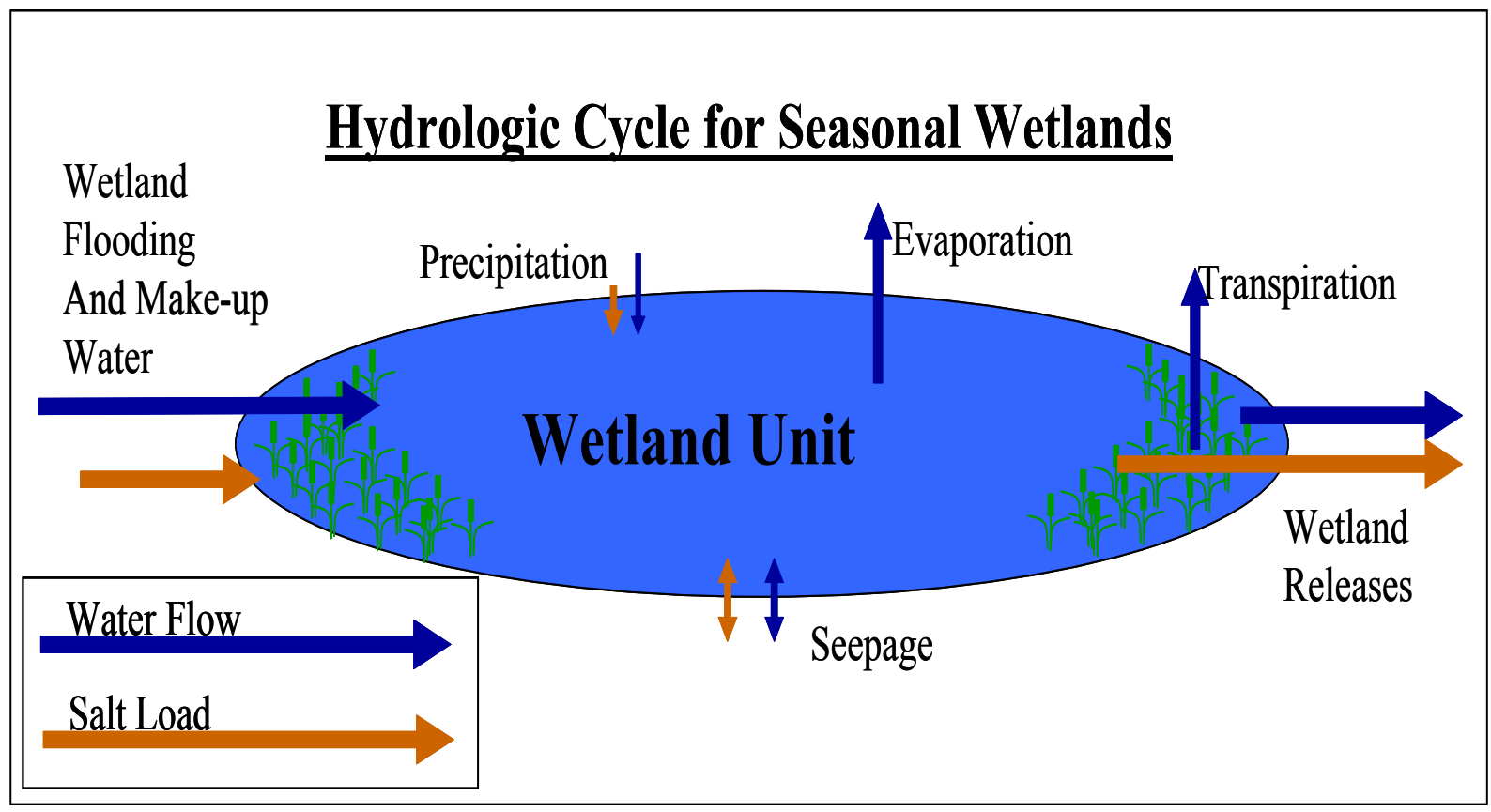

Figure 3.7 - Hydrologic inputs and outputs for seasonal wetlands.

\section{Biv-Surface Water Inflow, I}

Surface water inflow is a model calculated value. It represents all water diverted to the wetlands during flood-up, plus make-up and irrigation water. It is the water added seasonal wetlands to maintain their depth at or near management targets, or to provide summer irrigation water. The net inflow is set equal to the difference between the desired depth and the simulated depth, expressed as a volume. The WWQM assumes zero make-up water when simulated depth is greater the management target. Inflow is accounted for in the model in the following manner. If the previous day's End of Day Storage Depth, $D_{t-1}$, is greater than the current day's target depth, $T D_{t}$, then the current day's inflow, $I_{t}$, equals zero.

$$
\begin{gathered}
\text { If } \mathrm{TD}_{\mathrm{t}}>0 \text {, then } \\
\mathrm{E}_{\mathrm{t}}=(\% \mathrm{OW})\left(\mathrm{E} \text { pan, } \mathrm{t} \mathrm{K}_{\mathrm{p}, \mathrm{t}}\right) \\
\text { otherwise; } \\
\mathrm{E}_{\mathrm{t}}=0
\end{gathered}
$$


However, within the user interface, the user can request a "preflush" option (Figure 3.5) where the model simulates additional fresh water inputs to help flush out the salts. In this case, where the user has selected a positive, non-zero value in the user interface, $I_{t}$ is set equal to the user-defined pre-flush value. The default is 0.4 inches for a period of 30 days, yet this can be changed to whatever is desired with the next release of the update.xls file.

\section{Bv-Evaporation, $E$}

Evaporation is a measured value. The evaporation data are measured by monitoring the drop in water elevation in an open pan. This method is called pan evaporation, $E_{p a n}$. This variable comes directly from the CIMIS website, www.cimis.water.ca.gov, operated by DWR, and must be compensated for local precipitation. These data are updated periodically and delivered to the user in the updatexls file. The evaporation data that is downloaded from CIMIS is manipulated for use in the model by multiplying it by the percentage of open water, $\% O W$, and by a pan coefficient, $K_{p}$. This coefficient is for use in translating corresponding evaporation pan data to the water body of concern.

$$
\begin{gathered}
\text { If } \mathrm{TD}_{\mathrm{t}}>0 \text {, then } \\
\mathrm{E}_{\mathrm{t}}=(\% \mathrm{OW})\left(\mathrm{E}_{\mathrm{pan}, \mathrm{t}} \mathrm{K}_{\mathrm{p}, \mathrm{t}}\right) \\
\text { otherwise; } \\
\mathrm{E}_{\mathrm{t}}=0
\end{gathered}
$$

\section{8}

\section{Bvi-Evapotranspiration, ET}

Evapotranspiration (ET) data are calculated values. Evapotranspiration can be computed in several ways. These options include the Hargreaves method (Hargreaves and Samani, 1985) using temperature as an ET indicator, the Priestley-Taylor approach (Priestley and Taylor, 1972) which uses surface heat flux and large-scale parameters to calculate evaporation and evapo-transpiration, and the Penman-Monteith equation (Monteith, 1965) utilizing many atmospheric components. The Penman-Monteith equation is very robust and is the accepted method if multiple parameters such as vapor pressure, radiation, soil heat flux density, mean daily temperature, and wind speed, are available (Arnold et al., 1998).

CIMIS publishes daily ET data using a modified version of the Penman-Monteith equation for the various climate zones in California. The modification includes a wind function and 
was developed by the University of California, Davis (CIMIS, 2003). CIMIS publishes the data necessary to calculate reference evapotranspiration, but it also calculates and publishes reference evapotranspiration $\left(\mathrm{ET}_{\mathrm{o}}\right)$ using the modified version of the Penman-Monteith equation. This daily ET data can be found on the CIMIS website, www.cimis.water.ca.gov, operated by the DWR. For estimating $E T_{o}\left(E T_{r e f}\right)$, a modified version of the PenmanMonteith equation (Allen et al., 1999) with some fixed parameters was used (Walter et al., 2000 and Itenfisu et al., 2000.). The equation is written as follows:

$$
E T_{\text {ref }}=\frac{0.408 \Delta\left(R_{n}-G\right)+\gamma \frac{C_{n}}{T+273} u_{2}\left(e_{s}-e_{a}\right)}{\Delta+\gamma\left(1+C_{d} u_{2}\right)}
$$

where $\Delta$ is the slope of the saturation vapor pressure at mean air temperature curve $\left[\mathrm{kPa} /{ }^{\circ} \mathrm{C}\right]$; $R_{n}$ is the net radiation $\left[\mathrm{MJ} / \mathrm{m}^{2} \mathrm{~d}\right] ; G$ is the soil heat flux density $\left[\mathrm{MJ} / \mathrm{m}^{2} \mathrm{~d}\right] ; \gamma$ is the psychrometric constant $\left[\mathrm{kPa} /{ }^{\circ} \mathrm{C}\right] ; T$ is the daily mean temperature $\left[{ }^{\circ} \mathrm{C}\right], u_{2}$ is the mean wind speed $[\mathrm{m} / \mathrm{s}]$; and $e_{s}-e_{a}$ is the vapor pressure deficit $[\mathrm{kPa}] . C_{n}$ and $C_{d}$ are given specific values depending on the calculation time step and the reference crop, and are 900 and 0.34, respectively (Snyder et al., 2002). The modified Penman-Monteith equation is accepted widely and as such was chosen by DWR for its agricultural water use calculations, and these published daily values of $\mathrm{ET}_{\mathrm{o}}$ are used in the WWQM. The $\mathrm{ET}_{\mathrm{o}}$ data provided by CIMIS is manipulated for use in the model by multiplying it by a wetland crop coefficient, $K_{c}$, the percentage of emergent vegetation, $\% E V$, and by an osmotic resistance factor, $R$ (Glenn et al, 1995).

$$
\begin{gathered}
\text { If } T D_{t}>0, \text { then, } \\
\mathrm{ET}_{\mathrm{t}}=(\% \mathrm{EV})\left(\mathrm{ET}_{\mathrm{o}, \mathrm{t}} \mathrm{K}_{\mathrm{c}, \mathrm{t}}\right) \mathrm{R}
\end{gathered}
$$

where $E T$ is the total evapotranspiration, $\% E V$ is the percentage of land covered by emergent vegetation, $E T_{o}$ is the reference ET published by CIMIS, $K c$ is the crop coefficient, and $\mathrm{R}$ is the osmotic resistance factor. The crop coefficient, $K c$, is used in translating reference evapotranspiration, $E T_{o}$, into actual evaporation for the vegetation of concern, in this case, emergent vegetation. Values for the $K c$ 's were taken from the several sources and compiled to create a crop coefficient curve (Snyder et al., 2002; USBR, 1993 - Figure 3.8). Although 
there was considerable discrepancy between the other sources regarding the magnitude of the seasonal change, there was a general agreement for the seasonal pattern and range (Hargreaves and Samani, 1985; USBR, 1993). This information has been adapted for the WWQM. The formula for the $K c$ as the season progresses is:

$$
K c=1.05+\frac{\left[\sin \left((x-135) \times \frac{\Pi}{180}\right)\right]}{5}
$$

where $x$ is the julian date. This formula was derived by fitting the sine curve to the interpolated $K c$ curve (Figure 3.8).

Another factor involved in the modeling of ET within the WWQM is salinity effects on plant uptake. Salinity has a marked effect on a plant's ability to take water in through their roots. This phenomenon is referred to as the Osmotic Resistance Factor, $R$. A recent study shows that emergent vegetation is not noticeably affected $(R=1)$ when salinities are below 1,460 EC $(1,100 \mathrm{mg} / \mathrm{L})$. However, when salinities are in the 4,600 EC range $(3,500 \mathrm{mg} / \mathrm{L})$ the growth rate of wetland vegetation decreases to about one-half the normal growth rate $(R=.5)$. When salinities reach $8,000 \mathrm{EC}(6,000 \mathrm{mg} / \mathrm{L})$ and above, the growth of the vegetation stops altogether $(R=0)$ (Glenn et al., 1995). This is incorporated into the model through decision variables, so that if the salinity is below $1460 \mathrm{EC}$, then evapotranspiration is only a function of the modified Penman-Monteith equation (Equation 9), the $K c$ equation (Equation 11) and the percentage of emergent vegetation $(\% E V)$ present in the wetlands. The osmotic resistance factor, $R$, comes into effect when the salinity increases above 1,466 EC. When the salinity is below 1,466 EC, $R=1$, but as salinity increases above 1,466 EC, the decision variable includes the formula derived from the emergent vegetation study described above. The formula for calculating $R$ is as follows:

$$
\begin{gathered}
\text { If } E C D t>1,466, \text { then } \\
R=-0.0002(\mathrm{EC})+1.2263 \\
\text { otherwise } \\
R=1
\end{gathered}
$$




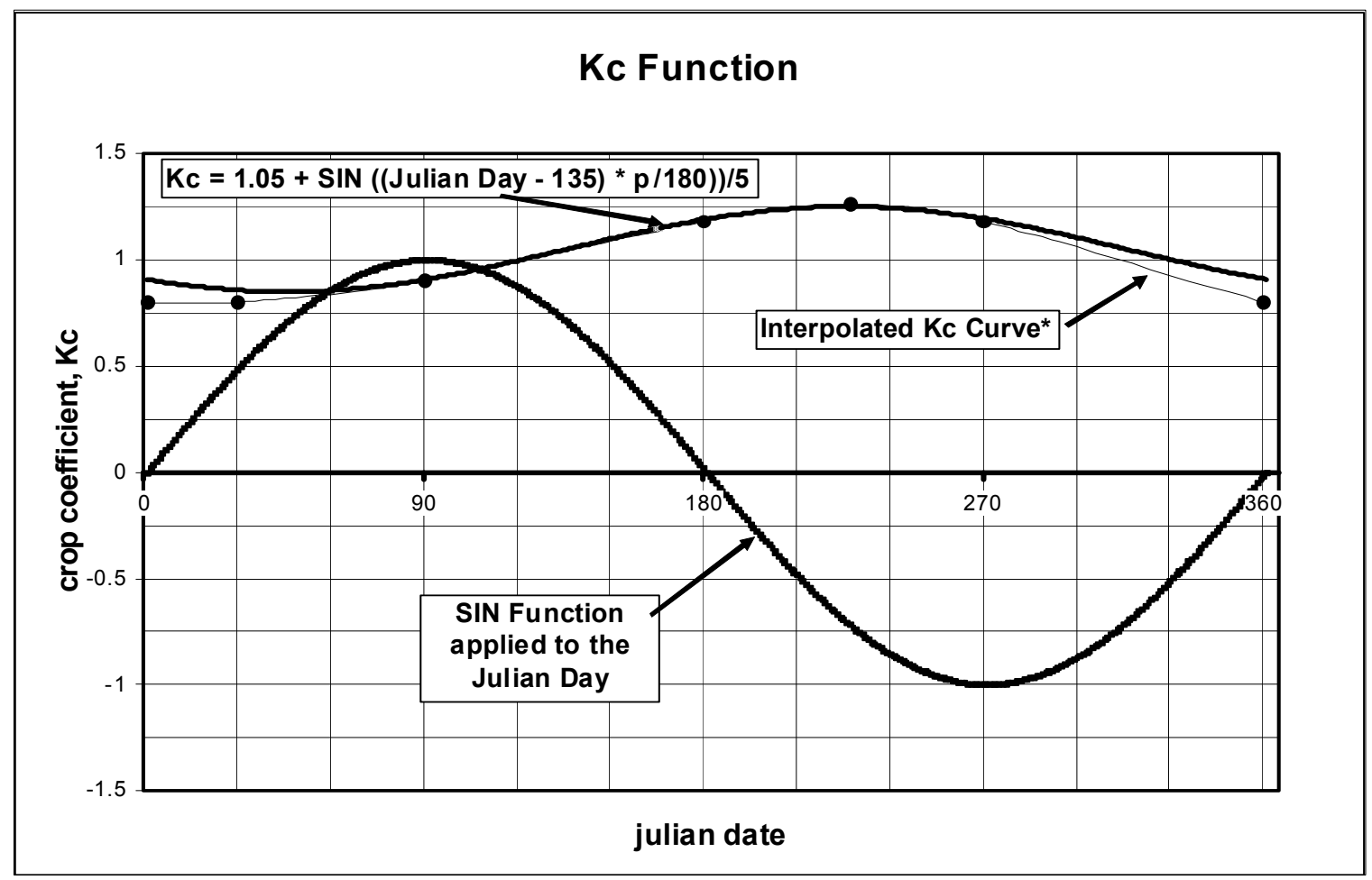

Figure 3.8. The Crop Coefficient, $K c$, for emergent wetland vegetation in the San Joaquin Valley

Bvii - Surface Water Outflow, $O$

Surface water outflow is calculated by the WWQM. While the wetlands are flooded, this value is calculated by adding the operational spill, $O S_{t}$, to the difference, if positive, between the modeled and target depths $\left(D_{t-1}\right.$ and $\left.T D_{t}\right)$. In other words, if the current day's Target Depth is greater than the previous day's wetland storage depth, $D_{t}$, then no major wetland releases will occur, except for operational spill that is automatically released at a rate of $1 \mathrm{cfs}$ per 235 wetland acres.

$$
\begin{gathered}
\text { If } T D_{t}>=D_{t-1} \text {, then, } \\
O S_{t}=1 \mathrm{cfs} / 235 \text { acres (or } 0.1 \text { inches } / \text { day) } \\
\text { Otherwise : } \\
\text { If } T D_{t}<D_{t-1} \text {, then } \\
O_{t}=O S_{t}+D_{t-1}+T D_{t}
\end{gathered}
$$$$
14
$$$$
13 O_{t}=O S_{t}
$$ 
However, if there is a one-fourth inch discrepancy between $D_{t-1}$ and $T D_{t}$.

$$
\begin{gathered}
D_{t-1}-T D_{t},>0.25, \text { then } \\
O_{t}=0.33
\end{gathered}
$$

The upper limit of 0.33 for $O_{t}$ is set because there is a maximum outflow capacity of most wetland flow control structures of $3.3 \mathrm{cfs} / 235$ acres. There is also a depth cutoff of onefourth inch that functions as the threshold to wetland release prompting the model to stop releasing water from the wetlands.

Bviii-Groundwater Outflow, GO

Groundwater outflow and inflow are predicated on having quantitative regional flow data.

\subsection{Wetland Salinity}

$C i-$ Wetland Storage Depth Salinity, $E C_{D}$

The wetland salinity for the end of day storage, $E C_{D t}$, is calculated on a daily basis by using the box model balancing equation detailed above. The box model uses proportional contributions of all inputs and outputs, along with the water and salts remaining from the previous day, and calculates the overall salinity in the ponded water volume, or end of day storage depth, $D_{t}$. The formula used to calculate $E C_{D t}$ was shown above in.

The WWQM logical expression to calculate is:

$$
\begin{gathered}
\text { If } D_{t}<=0 \text {; then } \\
E C_{D t}=0 \\
\text { otherwise, } \\
\text { If } 0<D_{t-1}<1.2 \%, \\
\text { and if } D_{t}>0 \text {; then } \\
E C_{D t}=1.25 E C_{I t}
\end{gathered}
$$

17

18

The assumption that the end of day EC of the depth of water in the wetlands is 1.25 times the EC of the inflow when the wetlands are filling and the depth is between zero and 1.2" comes 
from field observation of initial floodup in wetland units within the GWD. This is a minimal case. If, however, the wetlands are filling (above the 1.2" level) or are completely full, it follows that:

$$
\begin{gathered}
\text { If } D_{t-1}>1.2 \text {, then } \\
E C_{D t} \text { is calculated by : }
\end{gathered}
$$

\subsection{San Joaquin River Assimilative Capacity}

The SJRMP published weekly assimilative capacity forecasts for salts on the SJR, in tons per day during 2001, 2002 and 2003. Current water quality forecasts are merely straight line projections of current data. The website is http:/www.dpla.water.ca.gov/sjd/sjrmp/ index.html. These data are downloaded and delivered to the WWQM users through the update.xls file.

\subsection{Data updating}

Input data are updated and compiled on a weekly or an as-needed schedule into an update spreadsheet, update.xls, and delivered by email to the users of the WWQM.

\subsection{Model Outputs}

The model outputs for the WWQM are wetland flow and salinity. Flow is a much more difficult parameter to model in this system as there are many different wetland managers making decisions on a day-to-day basis. However, the modeled salinity is less variable and less prone to error.

\subsubsection{Wetland Releases - Flow}

Total surface water outflow is calculated using the end of day storage depth, $D_{t}$, measured in units of inches, into a flowrate, $Q_{t}$, measured in units of cubic feet per second [cfs]. This is accomplished by converting the storage depth into the outflow value, $O_{t}$, in inches per day using the conversion factor of 0.042014 to get cubic feet per second, per acre. Multiplying this value by the total acreage serviced by the drainage site returns a total flow rate for the entire wetland drainage basin. 
Ai-Adjusted Flow, A - Flow

The total simulated surface water outflow needs to be calibrated because the flow calculated by the WWQM consistently underestimates the total flow measured leaving the wetland drainage basins. This is most likely due to groundwater seepage, operational losses, evaporative losses, or a combination of these flows. The calculated flow, Flow, is corrected to the adjusted flow, $A-F l o w_{t}$, by dividing it by the percentage difference, $Y \%$, between the calculated values and the measured data.

$$
A-\text { Flow }_{t}=\text { Flow }_{t} / \text { Y\% }
$$

\subsubsection{Wetland Salinity, $\mathrm{EC}_{\mathrm{Dt}}$}

Wetland salinity mass balance model runs rely on the box model developed for the WWQM (Figure 3.3). At any point in time, the model calculates wetland salinity, $E C_{D}[\mathrm{uS} / \mathrm{cm}]$, using the proportional contribution salinity balance model presented above.

$B i-$ Adjusted Wetland Salinity, $A-E C_{D t}$

The simulated wetland salinity needs to be adjusted because the salinity calculated by the WWQM also consistently under estimates the salt concentration in drainage outflow. This underestimate is most likely due to groundwater contributions, residual salts, and bird usage, pond short circuiting or a combination of all factors. In general, the assumption that outlet salinity is equivalent to the mean salt concentration in a seasonal wetland is most likely flawed - in many wetlands short-circuiting of flow can occur and the outflow measured salinity will invariably be less than the calculated salinity. The calculated salinity, $E C_{t}$, is corrected to the adjusted salinity value, $A-E C_{t}$, by dividing it by the average percentage difference, $Y \%$, between the calculated and the actual values.

$$
A-E C_{D t}=E C_{D t} / Z \%
$$

\subsection{Model Application}

The WWQM was first applied to the NGWD as a management tool for the spring drawdown in 2003. The NGWD encompasses roughly 25,000 acres of wetlands and associated uplands

of the 50,000-acre GWD. The 25,000 acres of the NGWD are divided into 70 individually 
owned and managed wetland units ranging in size from 200 to 2000 acres. During the spring drawdown period discussions took place among the wetland managers as to when drawdown should commence. After the GWD Watermaster, Scott Lower, performed a model simulation on 24 February 2003, and results showed moderately high wetland salinity coupled with high San Joaquin River assimilative capacity, he had justification to call for a seasonal wetland drawdown earlier than normal to begin exporting ponded salts. Another model simulation performed on 24 March 2003 showed that although average wetland salinity concentrations had increased, and SJR assimilative capacity had decreased, there still appeared to be sufficient remaining San Joaquin River assimilative capacity to accommodate the residual salt load in the GWD. As it turned out, an unusually wet April increased San Joaquin River assimilative capacity for the later part of April and early May, so that the necessity of accelerating the typical drawdown schedule was muted. No further action was taken to influence the spring drawdown in 2003.

\subsection{Model Input Data Sources}

For future simulations using the Grassland Water District WWQM, input data can be organized into into four categories: fixed data, annually invariant data, annually varying data, and real-time (continuous) data. Fixed data, which do not vary with time, include soil properties, land classifications, wetland acreages, drainage basin surface water deliveries and

Table 3.2 NGWD drainage basin specifications.

\begin{tabular}{|lcccc|}
\hline Drainage Basin & Total Acreage & Wetland Acreage & \% Cattle & $\%$ Habitat \\
\hline Mud Slough & 10,366 & 7,925 & $21 \%$ & $79 \%$ \\
Hollow Tree Drain & 4,150 & 3,409 & $0 \%$ & $100 \%$ \\
S-Lake Drain & 1,644 & 1,390 & $33 \%$ & $67 \%$ \\
Fremont Canal & 705 & 461 & $20 \%$ & $80 \%$ \\
Los Banos Creek & 8,686 & 8,058 & $10 \%$ & $90 \%$ \\
\hline \multicolumn{1}{c}{ TOTALS } & 25,551 & 21,243 & $14.1 \%$ & $85.9 \%$ \\
\hline
\end{tabular}

precipitation and evapotranspiration qualities. Annually invariant data, which are static year to year but vary within a given year, include crop coefficients, best management practices, and water table depth. Annually varying data include precipitation, water year classification, air, water, and soil temperatures, and irrigation and wetland flood-up schedules. Real-time 
(continuous) data include supply water quantity and quality, wetland drainage water quantity and quality, evapotranspiration, precipitation, and San Joaquin River assimilative capacity. Much of the fixed and annually constant data are estimated since intensive monitoring of these wetlands only commenced in water year 2000.

The input data were grouped into the four different WWQM components described above in model development. These components are wetland management, wetland hydrology, wetland salinity, and San Joaquin River Assimilative Capacity.

\subsubsection{Wetland Management}

The NGWD is subdivided into approximately 70 duck clubs or land and cattle clubs. The private clubs of the GWD range in size from 200 to 2000 acres each. Furthermore, each club is divided into a number of units on the basis of management - uplands, seasonal wetlands, semi-permanent wetlands, and permanent wetlands (Figure 3.6). In addition, some clubs belong to State and Federal habitat programs such as the California Department of Fish and Game's Pressley Program, where land owners get paid a per acre fee for managing their wetlands in a habitat-friendly manner. Other management scenarios can include agricultural activities such as grazing cattle. Other land use data include percent open water and percent emergent vegetation. The wetland units in the NGWD that are solely managed for wetland habitat in the GWD comprise approximately $86 \%$ of the wetland acreage, and those that are managed for habitat and cattle grazing comprise the remaining $14 \%$ of the wetland acreage.

For modeling purposes, the individual properties, or wetland units, of the NGWD were grouped according to their respective drainage basins. They were then given a land use classification regarding their management practice type, either a habitat club or a cattle club. Each club was assigned a percent open water value and a percent emergent vegetation value, based on satellite imagery vegetation classification. A surface water source ranking also was determined. This surface water ranking depends on how much water re-use is occurring. All of these data are managed in Microsoft Excel ${ }^{\mathrm{TM}}$ and Microsoft Access ${ }^{\mathrm{TM}}$ database tables so they are able to communicate directly with the WWQM as well as ArcGISTM. 
Table 3.3 - Input data for the WWQM

\begin{tabular}{|c|c|c|c|}
\hline Data Element & Symbol & Units* & Source \\
\hline Time & $t(t-1, t+1)$ & day & na \\
\hline Target Depth & TD & inches & Smith et al, 1995 \\
\hline End of Day Storage Depth & D & inches & calculated \\
\hline Salinity of End of Day Storage Depth & ECD & $\mathrm{uS} / \mathrm{cm}$ & calculated \\
\hline Precipitation & $P$ & inches & CIMIS \\
\hline Inflow & I & inches & calculated \\
\hline Salinity of Inflow & $\mathrm{ECl}$ & $\mathrm{uS} / \mathrm{cm}$ & network \\
\hline Evaporation (from open water) & $\mathrm{E}$ & inches & calculated \\
\hline Pan Evaporation & Ep & $\mathrm{mm}$ & CIMIS (USDA, Station 5) \\
\hline Pan Coefficient & Kp & na & USDA, 2000 \\
\hline Evapotranspiration & ET & inches & calculated \\
\hline Reference Evaporation & ETo & inches & CIMIS \\
\hline Crop Coefficient & $\mathrm{Kc}$ & na & calculated, USBR 1993 \\
\hline Operational Spill & OS & inches & estimated \\
\hline Outflow & 0 & inches & calculated \\
\hline Salinity of Outflow & ECO & $\mathrm{uS} / \mathrm{cm}$ & calculated \\
\hline Groundwater Inflow & $\mathrm{Gl}$ & inches & na \\
\hline Groundwater Outflow & GO & inches & na \\
\hline Desired Depth for Habitat Clubs & $\mathrm{HAB}$ & inches & Smith et al, 1995 \\
\hline Desired Depth for Cattle Clubs & CAT & inches & estimated \\
\hline Percentage of open water wetlands & $\% O W$ & $\%$ & GWD, 2000 \\
\hline Percentage of vegetated wetlands & $\%$ EV & $\%$ & GWD, 2000 \\
\hline Percentage of wetlands managed as Cattle Clubs & $\%$ CC & acres & GWD, 2000 \\
\hline Percentage of wetlands managed under the Habitat Programs & $\% \mathrm{HC}$ & acres & Cal. DFG, 2001 \\
\hline Osmotic Resistance Factor & $\mathrm{R}$ & na & Glenn et al., 1995 \\
\hline
\end{tabular}

Ai-Target Depth, TD

Wetland management scenarios within the WWQM follow the two most prevalent management plans in the GWD. These management plans are for :

- habitat clubs-clubs that are managed throughout the year with wetland habitat as their main consideration,

- cattle clubs-clubs that are managed as waterfowl habitat during duck season, and are used for cattle grazing during the non-hunting season, or

- a combination of the two management plans above.

Both of the above management plans are forced using the recommended schedules outlined in Smith et al., 1995. The difference between the habitat and cattle management plans is that although both plans begin floodup at the same time, the cattle club always begins drawdown 
shortly after the close of duck season. Cattle clubs generally want to experience drawdown earlier than the habitat clubs to promote the growth of grasses for cattle to graze on.

\subsubsection{Wetland Hydrology}

\section{Bi-Wetland Storage Depth, D}

After initial floodup (early to mid-September), the ponds are continually topped-up with a low flow of make-up through each wetland area. The make-up water not only keeps the wetlands "fresh", but also replenishes wetland losses due to direct evaporation, ET, and seepage helps to maintain a desirable depth of between 10 and 12 inches, on average, in a majority of the seasonal wetlands. The WWQM simulates this by continually adding surface water to keep the wetland storage depth, $D$, at the target depth level, $T D$.

\section{Bii-Precipitation, $P$}

Daily data for precipitation, $P$, is readily available from CIMIS. For precipitation in the NGWD, data are downloaded from the CIMIS website for Station 56, Kesterson Reservoir. Kesterson is located just to the northeast of the NGWD, so the data should be representative. These data are delivered to the user in the update.xls file. Precipitation data are downloaded directly into the WWQM from the updatexls file and is applied to the wetlands as a function of total land area.

\section{Biii-Groundwater Inflow, GI}

Many wetlands contain soils with low hydraulic conductivity (high clay content), restricting regional groundwater infiltration (Owen, 1995). Regional gradients are shallow after the initial floodup - hence regional groundwater flow is minor compared to the ponded water volume. It has been noted, however, that in the wetlands of the SJR Basin anecdotal evidence of local groundwater flow is evident. Oftentimes, when a wetland has been drained while adjacent wetlands are still flooded, groundwater rises to near the soil surface in the drained wetland. Because the model's wetland boundary uses sub-basins within an entire wetland complex, this "localized' groundwater flow should have little impact on the model's overall results. In addition, this type of seepage more likely has an impact on the summer irrigation season and/or the following season's floodup. Because of a lack of data and understanding, 
regional groundwater flow was ignored during the 2003 drawdown of the NGWD. However, the WWQM is designed to readily accept groundwater data if available or can be estimated.

\section{Biv-Surface Water Inflow, I}

Inflow to the NGWD is supplied through district canals. The WWQM simulates supply for initial wetland floodup in the fall and for make-up water throughout the flooded season. The inflow, $I$, is calculated by comparing the wetland storage depth, $D$, to the target depth, $T D$, and adding water to $D$ until it equals $T D$. If $T D$ is less than $D$, no inflows are provided.

\section{Bv-Evaporation, $E$}

Because there is no direct evaporation data in close proximity to the NGWD, pan evaporation data was downloaded from the CIMIS website for Station 5, Shafter. Shafter is located south of the NGWD, but is in the same climate zone (zone 10) as signified by the CIMIS website and thus should display similar values to the Los Baños area (CIMIS, 2003). Calculations need to be made to transform the pan evaporation data into wetland. Pan coefficients, $K_{p}$, for use in this adjustment range from 0.6 to 1.3. A value of 0.7 is used in the WWQM because it is the most commonly cited in the scientific literature (Veissman and Lewis, 1996; Dingman, 2002). The formula for evaporation per unit area is:

$$
E / A=\left(E_{p}\right)\left(K_{p}\right)(\% O W)
$$

where $E$ is the calculated evaporation, $A$ is the wetland area in acres, $E_{p}$ is the pan evaporation downloaded from the CIMIS website, $K_{p}$ is the accepted pan coefficient, and $\% \mathrm{OW}$ is the percentage of open water for the individual wetland units. Pan evaporation data are delivered to the user in the update.xls file.

\section{Bvi-Evapotranspiration, ET}

Reference evapotranspiration data, $E T_{o}$, is calculated by CIMIS and is downloaded into the WWQM through the update.xls file. To calculate $E T_{o}$, CIMIS uses the modified PenmanMonteith equation (CIMIS, 2003). The WWQM uses this published data and applies it to the formula used in the WWQM for evapotranspiration per unit area. This equation is 


$$
E T / A=\left(E T_{o}\right)(K c)(\% E V)(R)
$$

where $E T$ is the final evapotranspiration in inches, $A$ is the wetland area in acres, $E T_{o}$ is the reference evapotranspiration calculated using the crop coefficient $K c, \% E V$ is the percentage of emergent vegetation, and $R$ is the osmotic resistance factor.

Bvii - Surface Water Outflow, $O$

Outflow is simulated by the WWQM. While the wetlands are flooded, this value is calculated by adding operational spill, $O S_{t}$, estimated at $1 \mathrm{cfs}$ per 233 acres (Lower, 2003; Poole, 2002), to the difference, if positive, between the target depth, TD, and the calculated wetland storage depth, $D$. For example, if the current day's Target Depth is greater than the previous day's wetland storage depth, $D_{t}$, then no wetland releases will occur other than operational spill.

\section{Bviii - Groundwater Outflow, GO}

See the Groundwater Inflow section above for a description of the groundwater portion of the WWQM for the GWD.

\subsubsection{Wetland Salinity, ECD}

The salinity of the wetland storage depth, $D$, is called the wetland salinity, $E C D$. It is calculated using the box model formula described in the model development section.

\subsubsection{San Joaquin River Assimilative Capacity}

San Joaquin River data, including flows, salinity, and assimilative capacity are accessed and downloaded through the California Department of Water Resources' website at:

http://wwwdpla.water.ca.gov/sjd/waterquality/realtime/index.html .

The data are compiled from real-time water quality monitoring stations on the main stem of the SJR. Forecast values are accessed from the same location, but are compiled using the DWR's assimilative capacity forecast model, SJRIODAY (San Joaquin River Input Output Daily model). These data are available to the users in the update.xls file, and populate the user interface for comparison with the forecasted NGWD salinity exports. 


\subsection{Model Simulations and Model Results}

The WWQM was prepared to simulate and forecast operations in the wetlands of the NGWD beginning in September 2002, during fall floodup. All data were inserted into the update file (update.xls) to conform to the model's format and time step. In addition, the real-time monitoring data from the wetlands, as well as for the SJR forecast data for assimilative capacity, required linkages into the model. For graphically viewing the model results, a results table was built into a Microsoft Access ${ }^{\text {TM }}$ database. This results table and database provides the application process interface between the Microsoft Excel ${ }^{\mathrm{TM}}$ spreadsheet model and ArcGIS, the geographic information system (GIS) chosen for this application. A GIS database was created to provide visual representations of the data such as salinity concentration maps, data tables, and time series graphs, providing the functionality of a graphical user interface for data querying and presentation.

To associate the model with the wetlands of the NGWD, the individual wetland units were arranged into their unique drainage basins. Other associated land use information necessary to operate the model was also supplied. This information includes land area, wetland area, management practices, surface water sources, and percent vegetation versus open water. Each wetland unit was then given a ranking based on the proportion of first use and re-use of surface water supply. This task was performed with several wetland managers and the GWD water master. Each drainage basin then was assigned values from the compilations of the individual wetland unit values for supply ranking, percent vegetation and open water. These drainage basins then were modeled individually within the WWQM.

\subsection{Calibration}

Objectives for the calibration period were to avoid changing model parameters (such as $E T$, $K c$, acreages, etc) to best "fit the curve and to simulate salinity concentration build-up as closely as possible. If errors occurred, it was better for the model to over-predict than underpredict, because conservatism in salinity predictions is beneficial to the receiving waters. A third goal was to have the model more closely follow the actual salinity curve during times when wetland drawdown may have been occurring. 
A recurring difficulty in modeling seasonal wetlands is that, although there is one water master overseeing the entire GWD, there are at times more than 70 individual wetland mangers making decisions that impact salt concentrations in the wetland management areas. A salt and water balance model cannot uniformly forecast the behavior of all the wetland managers. Calibration runs determined that a correction factor of 0.8 should be applied to modeled EC values to account for a general underestimation of salinity concentrations. This underestimation is likely the result of smaller inflows and outflows that were not modeled, groundwater interactions, salt residues from prior operations, wetland short-circuiting and other factors not accounted for in the model.

Flooded Season 2000 - 2001

During the calibration period, the WWQM closely simulated wetland salinity for the NGWD (Figure 3.9). The year was classified as a dry/normal year even though there was a total of 7.72 inches of rain (Table 3.2). Rainfall of 7.72 inches falls within the range to be classified as a normal year (Table 3.5 ). The data and early model simulations suggested an early 


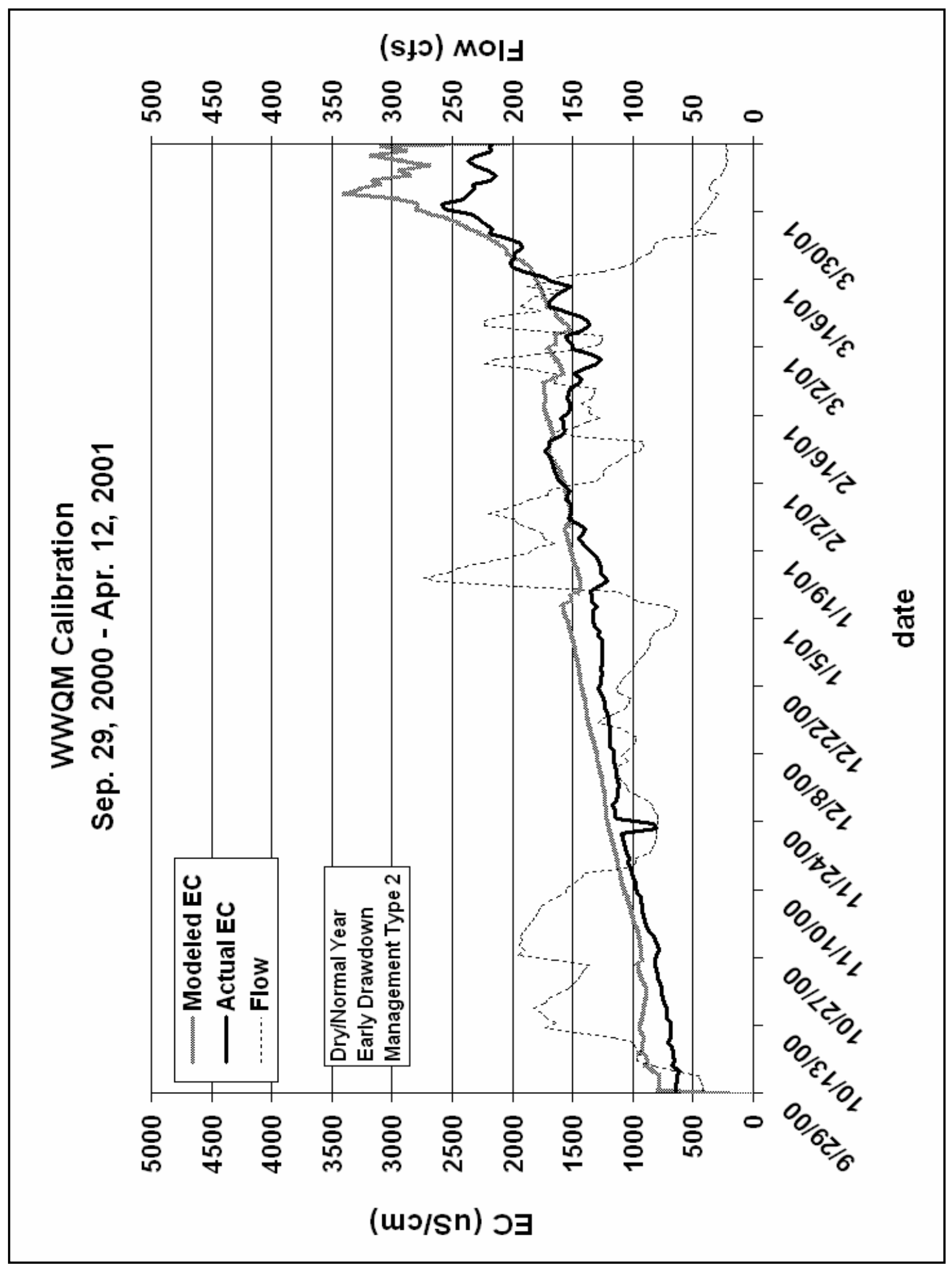

Figure 3.9 Results from WWQM calibration runs for Sep. 29, 2000 to Apr. 12, 2001. Modeled EC shows relatively good agreement with actual EC measurements. 
drawdown (Table 3.1) as in dryer years, since soil moisture and temperature optimal for germinating desirable moist-soil vegetation tend to occur earlier. The management classification was set to Early (type 2 in the WWQM). Results showed that, despite an unexpected dip in actual salinity in mid- to late November, the model overestimated the actual salinity on average by $20 \%$. After the November anomalous fall in measured salinity, the model and actual salinity values quickly converged to within $6.8 \%$ of each other. The deviation between the model and the actual then increases rapidly at the end of the model season because, when wetland drawdown rates for the NGWD drop below $100 \mathrm{cfs}$ (near the assumed baseflow of $1 \mathrm{cfs} / 235$ acres), there tends to be a marked increase in model wetland salinity.

Table 3.2 - Annual average rainfall from 1988 to 2003

\begin{tabular}{|c|c|}
\hline Water Year ${ }^{1}$ & Totals \\
\hline $88-89$ & 6.45 \\
\hline $89-90$ & 9.29 \\
\hline $90-91$ & 8.35 \\
\hline $91-92$ & 9.33 \\
\hline $92-93$ & 8.3 \\
\hline $93-94$ & 2.27 \\
\hline $94-95$ & 13.19 \\
\hline $95-96$ & 11.98 \\
\hline $96-97$ & 11.68 \\
\hline $97-98$ & 21.3 \\
\hline $98-99$ & 12.54 \\
\hline $99-00$ & 7.8 \\
\hline $00-01$ & 7.72 \\
\hline 01-02 & 7.37 \\
\hline $02-03$ & 8.26 \\
\hline \multicolumn{2}{|c|}{${ }^{1}$ Water Year is Oct 1 -Sep 30} \\
\hline
\end{tabular}


Table 3.3 - Description of water year type.

\begin{tabular}{|c|c|c|}
\hline Year Type & \begin{tabular}{|c} 
Interva \\
From
\end{tabular} & $\begin{array}{c}\text { Interval } \\
\text { To }\end{array}$ \\
\hline Critically Dry & \multicolumn{2}{|c|}{ below 5.5} \\
\hline Dry & 5.5 & 7.6 \\
\hline Normal & 7.6 & 11.8 \\
\hline Wet & \multicolumn{2}{|c|}{ above 11.8} \\
\hline
\end{tabular}

\section{Seasonal Wetland Management Drawdown Practice}

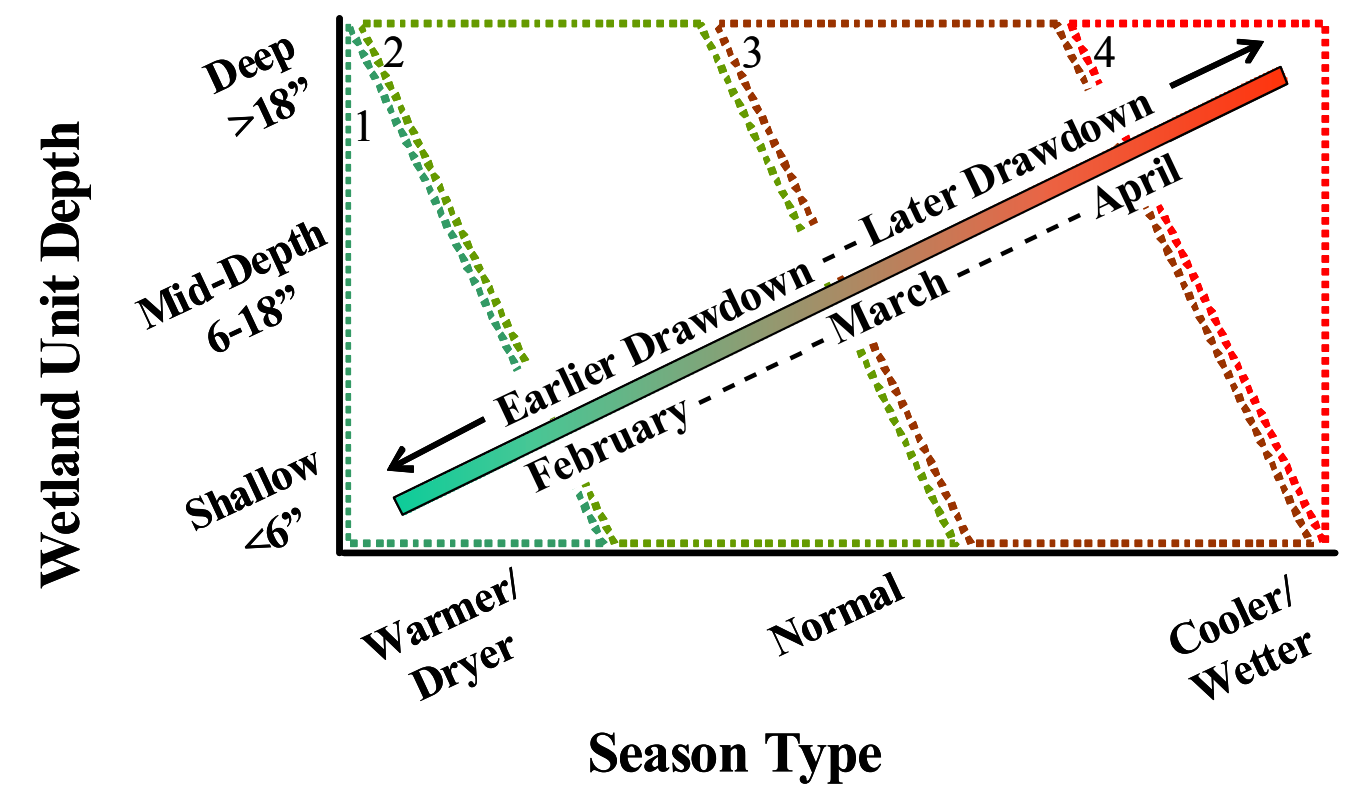

1 Earliest Drawdown, WWQM Type 13 Traditional Drawdown, WWQM Type 3 2 Earlier Drawdown, WWQM Type 24 Late Drawdown, WWQM Type 4

Figure 3.10 Seasonal wetland management practice with year types incorporated.

Although the model consistently overestimated wetland salinity (Figure 3.9), for management purposes the values were acceptable because a slight overestimation adds a factor of safety to the model. Figure 3.11 again shows the propensity for the model to deviate diverge from measured data as salinity increases above $2000 \mathrm{uS} / \mathrm{cm}$. 


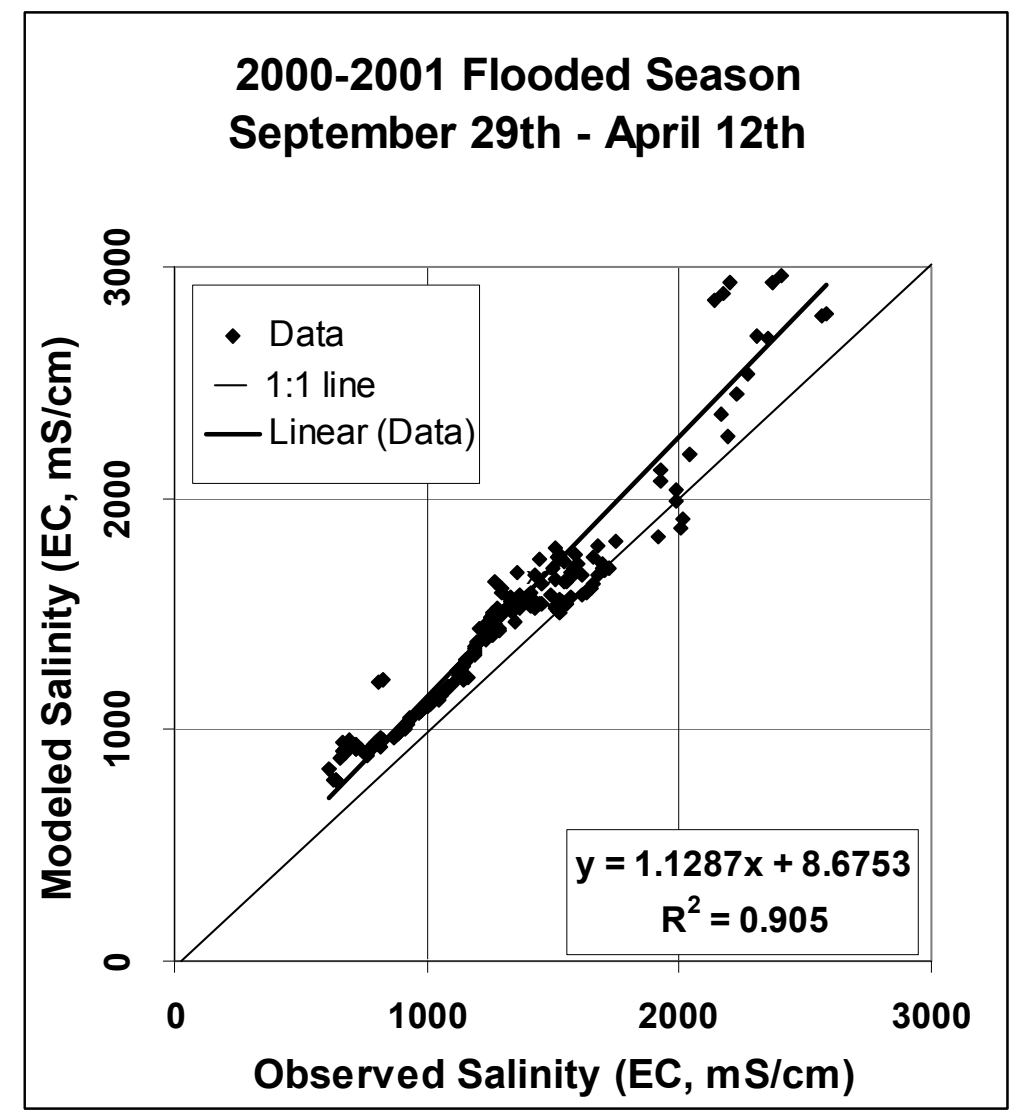

Figure 3.11 Accuracy of modeled versus observed salinity for the 2000-2001 flooded season.

\section{Flooded Season 2001 - 2002}

During the second year's validation period, the simulation did not perform as well as during the prior year. Throughout much of the modeled season, the WWQM underestimated the actual salinity. However, by the end of the model season, the modeled salinity was on average below the measured data by only 13\% (Figure 3.12). The year was classified a dry year because there was a total of 7.37 inches of rain (Table 3.2). Such a total falls on the high end of the guidelines for a dry year classification (Table 3.3). Because the determination was dry, the management type was set at Very Early (type 1 in the WWQM, Figure 3.10). Results showed that although the model results deviated from measured data, during times of higher flow and during times of increased export, simulated and observed values agree. In addition, during the period of managed drawdown (March), the modeled 


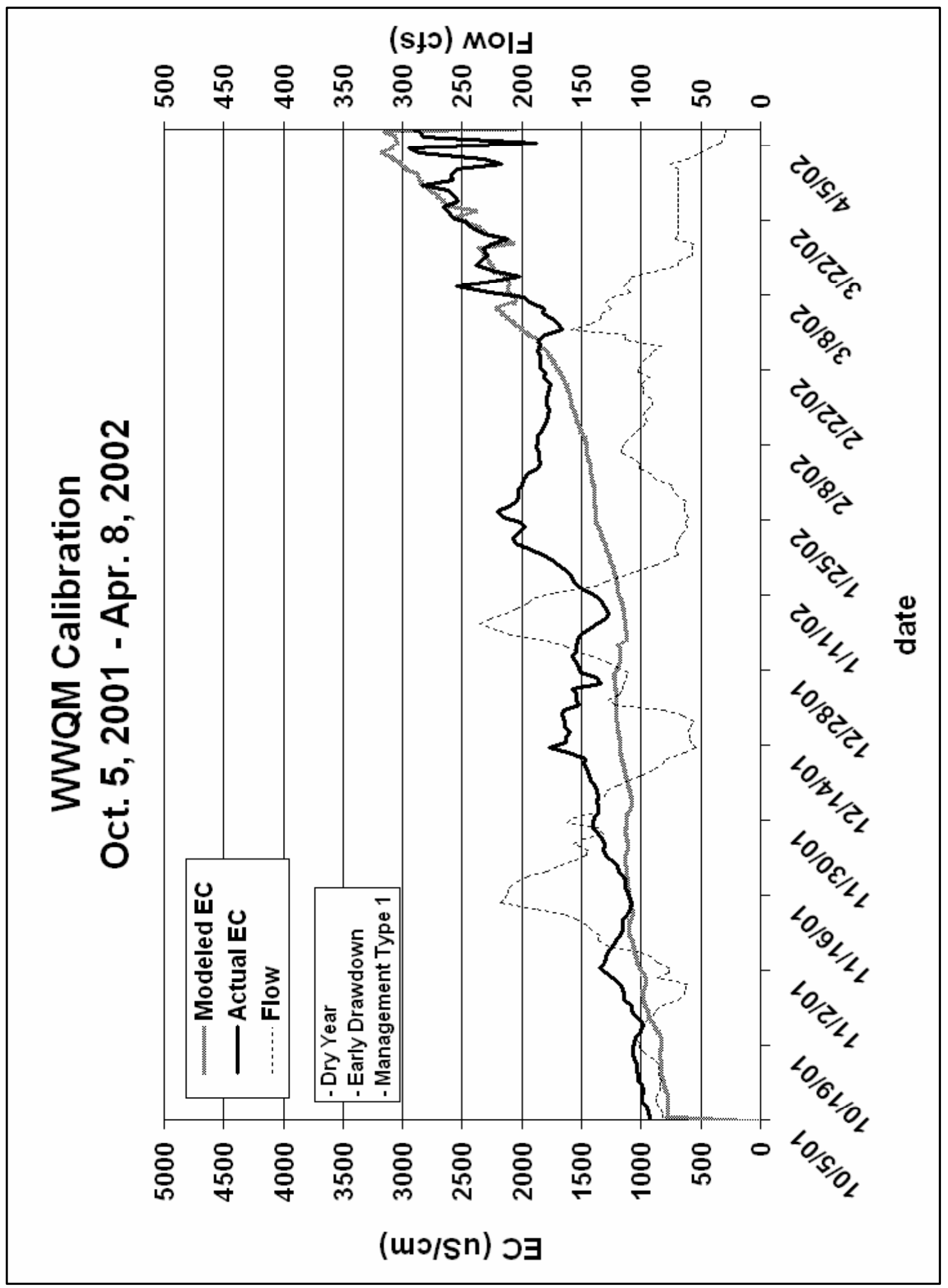

Figure 3.12 - Results from WWQM calibration runs for Oct. 5, 2001 through Apr. 8, 2002. The model underestimates actual salinity by an average of $13 \%$. 


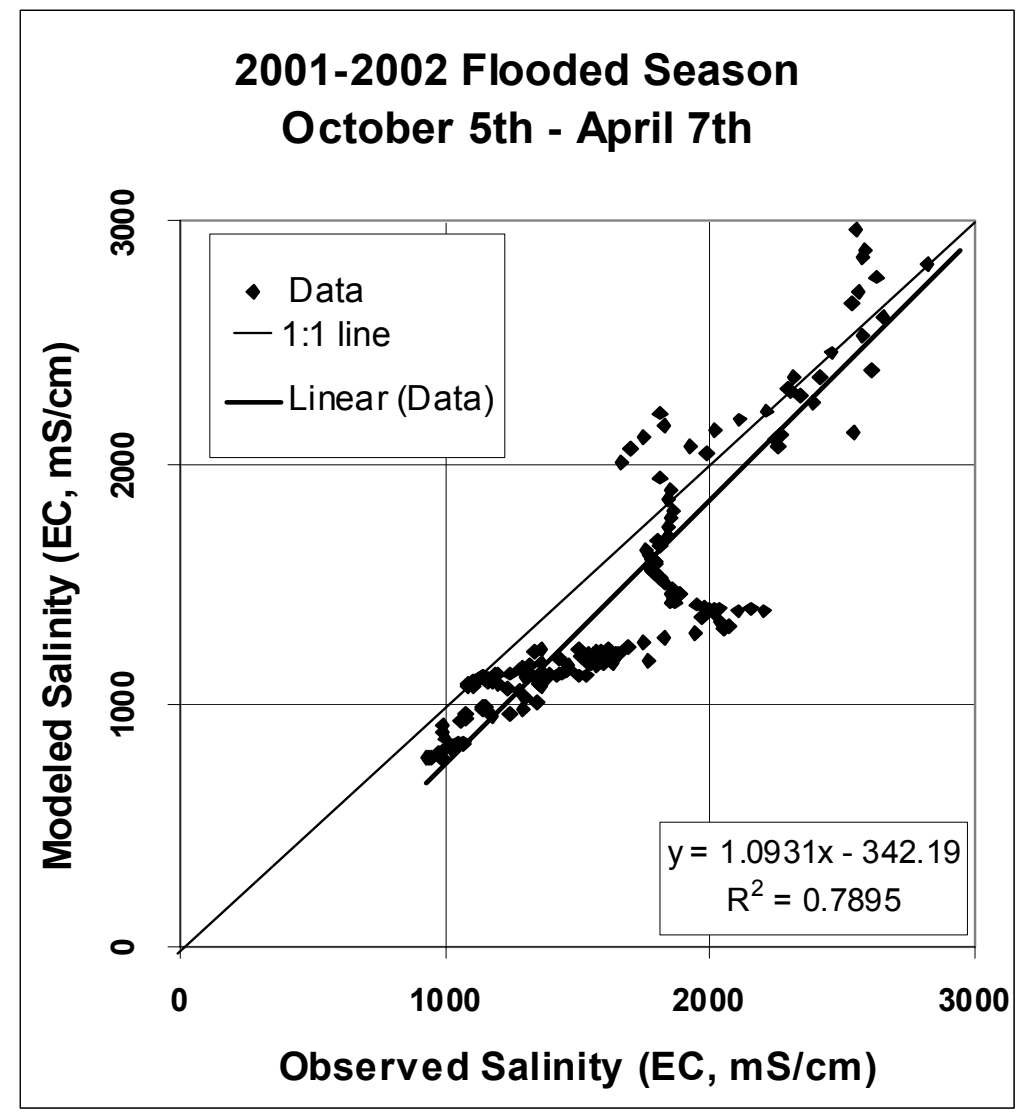

Figure 3.13 Accuracy of modeled versus observed salinity for the 2001-2002 flooded season.

values tracked the actual values very closely (Figure 3.12). Again, when the flows dropped below $100 \mathrm{cfs}$ the model began to deviate more significantly. However, the graphs show that the forecast was valid throughout the period until pond salinity rose above 2,500 EC (Figure $3.13)$.

\subsection{Analysis of Model Results}

Flooded Season 2002 - 2003

For the entire model season, the modeled salinity underestimated measured salinity. A user interface was built that incorporated a "nudging" function to address this systematic bias. The nudging function takes the difference in the modeled and actual salinity during the prior two weeks of the model run and shifts the modeled curve upwards or downwards to match the actual wetland salinity data. 
During the application year's simulation period, the WWQM once again underestimated the actual salinity. This time it underestimated it by an average of $14.4 \%$ (Figure 3.14 ). The water year type was classified a normal year because, by the time the first model run was performed in late February, almost six inches of rain had fallen and more was forecasted to arrive. Because the determination was for a normal year type, the management type was set at Traditional (type 3 in the WWQM). Results showed that although the model slightly overestimated the actual salinity throughout the year, during the traditional drawdown period (late March to early April), the modeled and observed salinity values had converged (Figure $3.15)$.

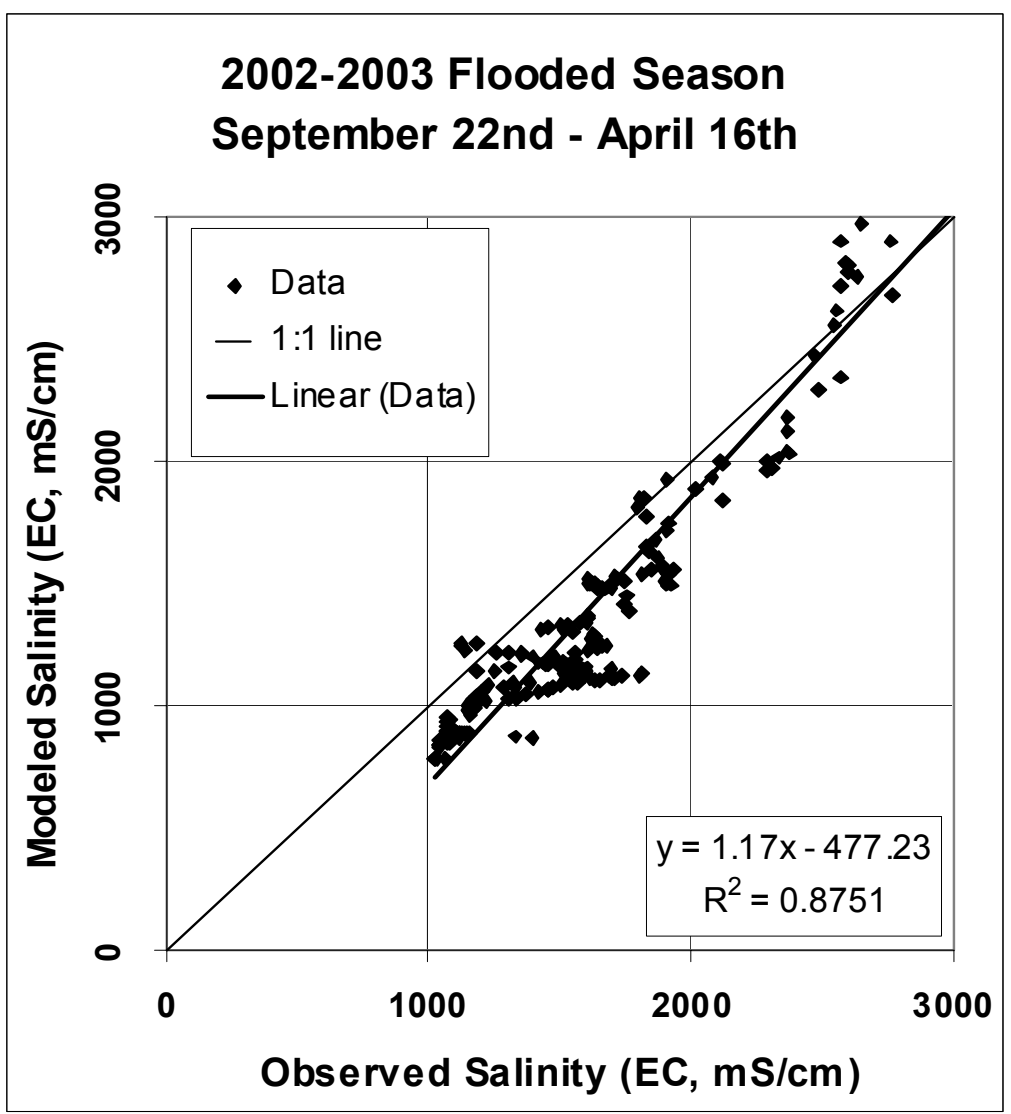

Figure 3.15 - 2002-2003 flooded season scattergram. 


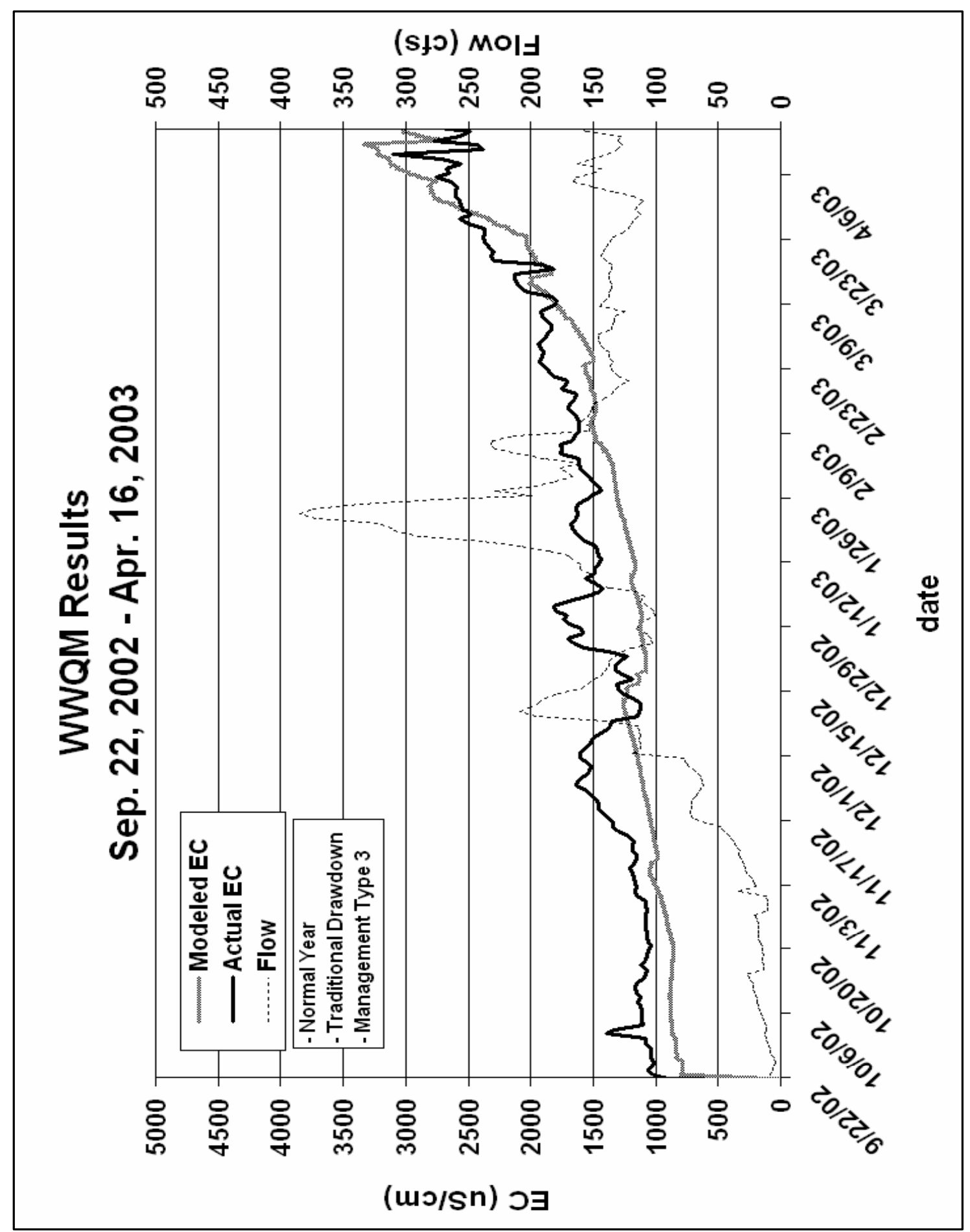

Figure 3.14 Results from WWQM calibration run from Sep. 22, 2002 through Apr. 16, 2003. The model again underestimates actual EC measurements, but by an average of $14 \%$ 
On 24 February 24 2003, a preliminary model simulation produced a 2-week forecast of the salinity of the NGWD wetlands. After updating the model with data from the real-time wetland water quality monitoring network, the SJRMP, and CIMIS, the model predicted that the wetland salinity would increase from approximately 1800 EC to above 2000 EC in the next two weeks (Table 3.4 and Figure 3.16). In addition, data from the SJRIO2 forecast predicted the assimilative capacity for salts in the SJR should remain acceptable for wetland drawdown for at least one week and peaking in early April (Figure 3.17). These results prompted the GWD to encourage wetland managers to either begin drawdown within five days, or hold off drawdown until a week or two of low assimilative capacities could move through the SJR system (Figure 3.16).

Table 3.4 - Tabular results of February 24, 2003 model application.

\begin{tabular}{|c|c|c|c|c|c|c|c|}
\hline \multicolumn{7}{|c|}{ North Division, Grassland Water District } & \multirow{3}{*}{\begin{tabular}{|c|}
$\begin{array}{c}\text { San Joaquin River } \\
\text { S.JRIO Values } \\
\text { Vernalis }\end{array}$ \\
$\begin{array}{c}\text { Assim. Cap. } \\
\text { (tpd) }\end{array}$
\end{tabular}} \\
\hline \multicolumn{2}{|c|}{$\begin{array}{l}\text { Analysis Date: } \\
\text { February 24, } 2003\end{array}$} & \multicolumn{3}{|c|}{$\begin{array}{l}\text { Analysis by: } \\
\text { Mark Hanna, UCLA }\end{array}$} & & & \\
\hline Date & \begin{tabular}{|c}
$\begin{array}{c}\text { Model Flow } \\
\text { (cfs) }\end{array}$ \\
\end{tabular} & \begin{tabular}{|c|}
$\begin{array}{c}\text { Actual Flow } \\
\text { (cfs) }\end{array}$ \\
\end{tabular} & \begin{tabular}{|c|}
$\begin{array}{c}\text { Model Salinity } \\
\text { (uS } / \mathrm{cm})\end{array}$ \\
\end{tabular} & \begin{tabular}{|c|}
$\begin{array}{c}\text { Actual Salinity } \\
\text { (uS } / \mathrm{cm})\end{array}$ \\
\end{tabular} & \begin{tabular}{|c}
$\begin{array}{c}\text { Model Salt Load } \\
\text { (tons iday) }\end{array}$ \\
\end{tabular} & \begin{tabular}{|c|}
$\begin{array}{c}\text { Actual Salt Load } \\
\text { (tons/day) }\end{array}$ \\
\end{tabular} & \\
\hline $02 / 10 / 03$ & 77 & 135 & 1751 & 1619 & 272 & 442 & 465 \\
\hline $02 / 11 / 03$ & 77 & 137 & 1767 & 1612 & 275 & 447 & 465 \\
\hline $02 / 12 / 03$ & 77 & 137 & 1744 & 1635 & 271 & 453 & 409 \\
\hline $02 / 13 / 03$ & 83 & 135 & 1715 & 1671 & 288 & 456 & 399 \\
\hline $02 / 14 / 03$ & 160 & 135 & 1724 & 1700 & 559 & 464 & 389 \\
\hline $02 / 15 / 03$ & 77 & 139 & 1729 & 1690 & 269 & 475 & 395 \\
\hline $02 / 16 / 03$ & 77 & 144 & 1726 & 1648 & 268 & 480 & 395 \\
\hline $02 / 17 / 03$ & 77 & 142 & 1733 & 1630 & 269 & 468 & 359 \\
\hline $02 / 18 / 03$ & 77 & 139 & 1747 & 1748 & 272 & 492 & 348 \\
\hline $02 / 19 / 03$ & 77 & 136 & 1748 & 1718 & 272 & 473 & 338 \\
\hline $02 / 20 / 03$ & 77 & 134 & 1757 & 1710 & 273 & 463 & 300 \\
\hline $02 / 21 / 03$ & 77 & 127 & 1770 & 1819 & 275 & 467 & 300 \\
\hline $02 / 22 / 03$ & 77 & 122 & 1782 & 1853 & 277 & 457 & 300 \\
\hline $02 / 23 / 03$ & 77 & 120 & 1793 & 1889 & 279 & 459 & 300 \\
\hline $02 / 24 / 03$ & 87 & & 1728 & & 305 & & 287 \\
\hline $02 / 25 / 03$ & 250 & & 1729 & & 876 & & 277 \\
\hline $02 / 26 / 03$ & 250 & & 1747 & & 885 & & 267 \\
\hline $02 / 27 / 03$ & 160 & & 1767 & & 573 & & 257 \\
\hline $02 / 28 / 03$ & 77 & & 1786 & & 278 & & 280 \\
\hline $03 / 01 / 03$ & 77 & & 1806 & & 281 & & 280 \\
\hline $03 / 02 / 03$ & 77 & & 1830 & & 284 & & 325 \\
\hline $03 / 03 / 03$ & 77 & & 1855 & & 288 & & 447 \\
\hline $03 / 04 / 03$ & 77 & & 1871 & & 291 & & 341 \\
\hline $03 / 05 / 03$ & 77 & & 1900 & & 295 & & 203 \\
\hline $03 / 06 / 03$ & 77 & & 1930 & & 300 & & 125 \\
\hline $03 / 07 / 03$ & 77 & & 1959 & & 305 & & 82 \\
\hline 03/08/03 & 77 & & 1987 & & 309 & & 50 \\
\hline $03 / 09 / 03$ & 77 & & 2021 & & 314 & & 27 \\
\hline
\end{tabular}




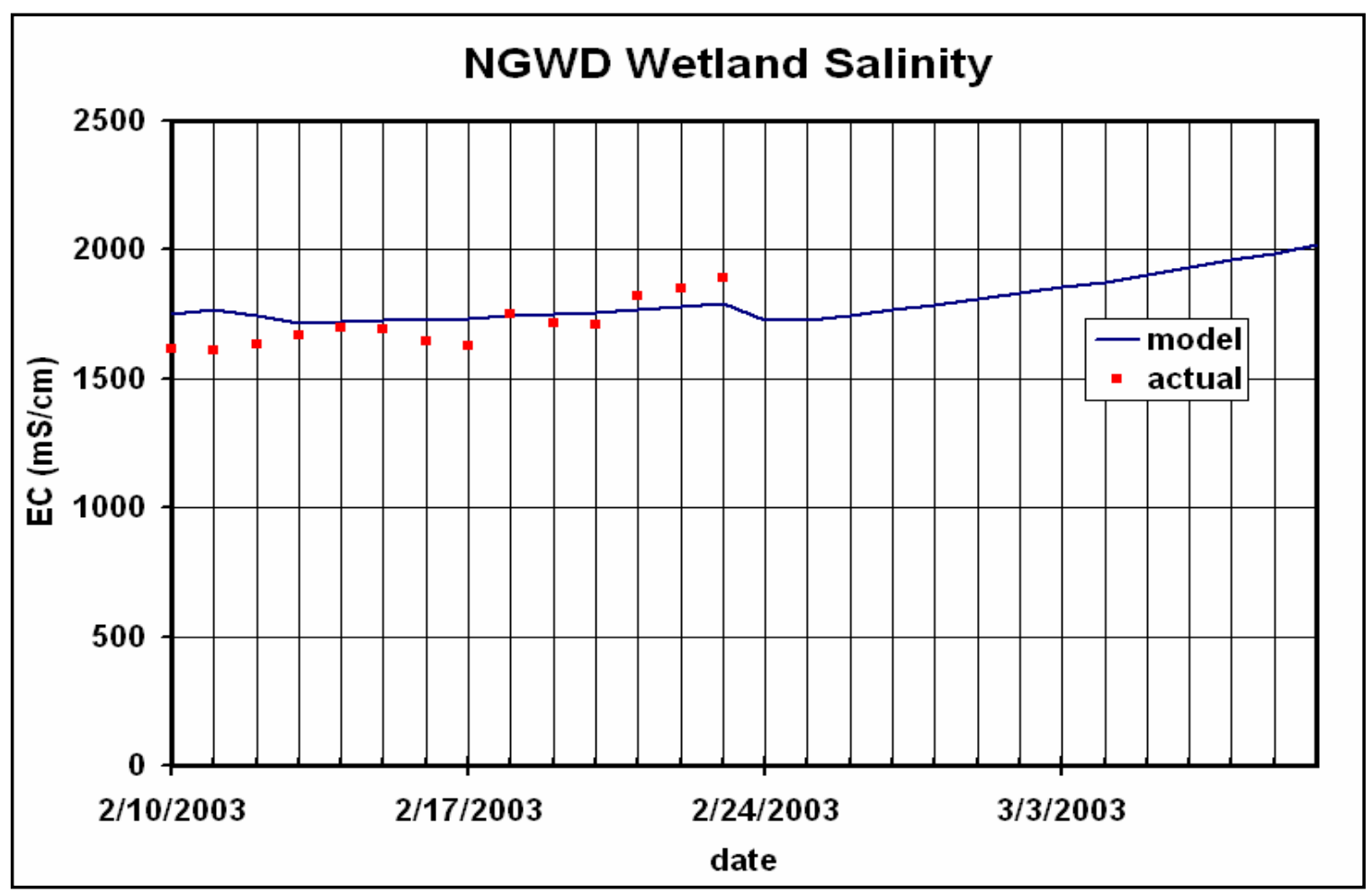

Figure 3.16 Comparison of modeled versus observed EC from February 24, 2003 model application.

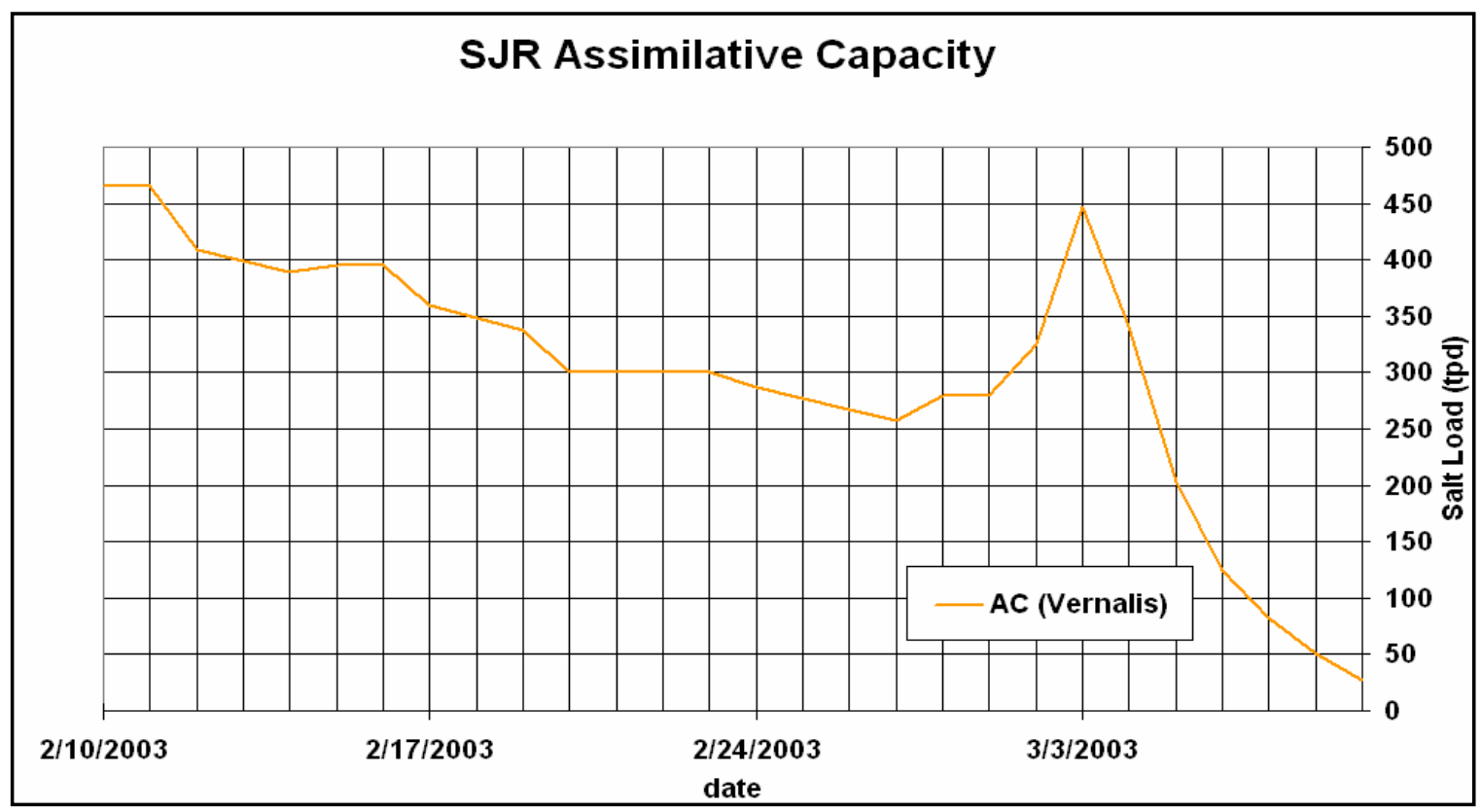

Figure 3.17 Results of SJRIO assimilative capacity forecast incorporating February 24, 2003 model application results. 
On 24 March 2003 a second model simulation was performed and again wetland salinities were predicted to increase, this time from $2300 \mathrm{EC}$ to $3000 \mathrm{EC}$ (Table 3 and Figure 3.18). In addition, the SJRIO forecast, published on 24 March, predicted assimilative capacity for salt in the SJR to increase from 140 tons per day to over 200 tons per day in the next two weeks (Figure 3.18). These results prompted the GWD to encourage wetland managers that had not yet completed drawdown to continue to do so through early April, yet by this time most clubs had finished spring drawdow (Figure 3.14).

Table 3.5 - Tabular results of March 24, 2003 model application

\begin{tabular}{|c|c|c|c|c|c|c|c|}
\hline \multicolumn{7}{|c|}{ North Division, Grassland Water District } & \multirow{3}{*}{\begin{tabular}{|c|}
$\begin{array}{l}\text { San Joaquin Rivel } \\
\text { S.JRIO Values } \\
\text { Vernalis }\end{array}$ \\
$\begin{array}{c}\text { Assim. Cap. } \\
\text { (tpd) }\end{array}$
\end{tabular}} \\
\hline \multicolumn{3}{|c|}{$\begin{array}{l}\text { Analysis Date: } \\
\text { March 24, } 2003\end{array}$} & \multicolumn{4}{|c|}{$\begin{array}{l}\text { Analysis by: } \\
\text { Scott Lower, GWD }\end{array}$} & \\
\hline Date & \begin{tabular}{|l} 
Model Flow \\
(cfs)
\end{tabular} & $\begin{array}{c}\text { Actual Flow } \\
\text { (cfs) }\end{array}$ & $\begin{array}{c}\text { Model Salinity } \\
\text { (US } / \mathrm{cm})\end{array}$ & $\begin{array}{c}\text { Actual Salinity } \\
\text { (uS } / \mathrm{cm})\end{array}$ & \begin{tabular}{|c|} 
Model Salt Load \\
(tons/day)
\end{tabular} & \begin{tabular}{|c} 
Actual Salt Load \\
(tons/day)
\end{tabular} & \\
\hline \begin{tabular}{|l|}
$03 / 10 / 03$ \\
\end{tabular} & 77 & 138 & 2007 & 1820 & 312 & 508 & 16 \\
\hline $03 / 11 / 03$ & 77 & 131 & 2037 & 2019 & 317 & 535 & 16 \\
\hline $03 / 12 / 03$ & 77 & 127 & 2080 & 2078 & 323 & 534 & 124 \\
\hline $03 / 13 / 03$ & 77 & 130 & 2131 & 2110 & 331 & 555 & 137 \\
\hline $03 / 14 / 03$ & 77 & 128 & 2127 & 2123 & 331 & 550 & 134 \\
\hline $03 / 15 / 03$ & 105 & 156 & 2010 & 2123 & 428 & 670 & 134 \\
\hline $03 / 16 / 03$ & 250 & 160 & 2017 & 1811 & 1022 & 586 & 135 \\
\hline $03 / 17 / 03$ & 250 & 146 & 2095 & 1905 & 1061 & 563 & 136 \\
\hline $03 / 18 / 03$ & 77 & 141 & 2182 & 2296 & 339 & 655 & 136 \\
\hline $03 / 19 / 03$ & 77 & 138 & 2219 & 2314 & 345 & 646 & 135 \\
\hline $03 / 20 / 03$ & 77 & 110 & 2249 & 2293 & 350 & 510 & 134 \\
\hline $03 / 21 / 03$ & 77 & 100 & 2268 & 2339 & 353 & 473 & 134 \\
\hline $03 / 22 / 03$ & 77 & 87 & 2292 & 2367 & 356 & 417 & 133 \\
\hline $03 / 23 / 03$ & 77 & 87 & 2257 & 2379 & 351 & 419 & 133 \\
\hline $03 / 24 / 03$ & 77 & & 2323 & & 361 & & 140 \\
\hline $03 / 25 / 03$ & 77 & & 2348 & & 365 & & 140 \\
\hline $03 / 26 / 03$ & 77 & & 2405 & & 374 & & 140 \\
\hline $03 / 27 / 03$ & 77 & & 2434 & & 378 & & 170 \\
\hline $03 / 28 / 03$ & 77 & & 2503 & & 389 & & 177 \\
\hline $03 / 29 / 03$ & 77 & & 2596 & & 404 & & 177 \\
\hline $03 / 30 / 03$ & 77 & & 2649 & & 412 & & 177 \\
\hline $03 / 31 / 03$ & 77 & & 2729 & & 424 & & 177 \\
\hline $04 / 01 / 03$ & 77 & & 2753 & & 428 & & 135 \\
\hline $04 / 02 / 03$ & 77 & & 2795 & & 435 & & 150 \\
\hline $04 / 03 / 03$ & 77 & & 2812 & & 437 & & 150 \\
\hline $04 / 04 / 03$ & 77 & & 2819 & & 438 & & 150 \\
\hline $04 / 05 / 03$ & 77 & & 3002 & & 467 & & 220 \\
\hline $04 / 06 / 03$ & 77 & & 3142 & & 488 & & 220 \\
\hline
\end{tabular}




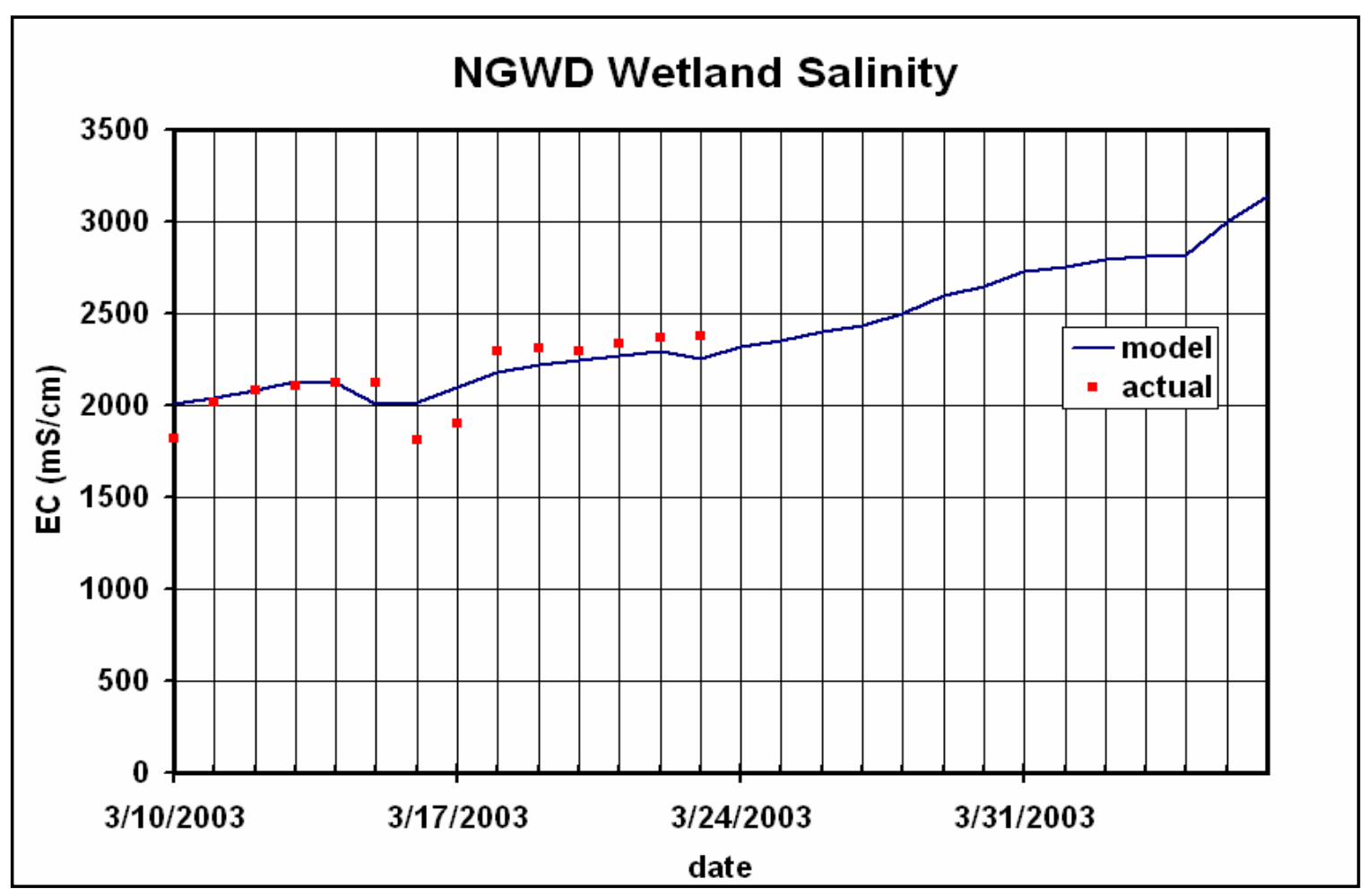

Figure 3.18 Comparison of modeled versus observed EC from March 24, 2003 model application.

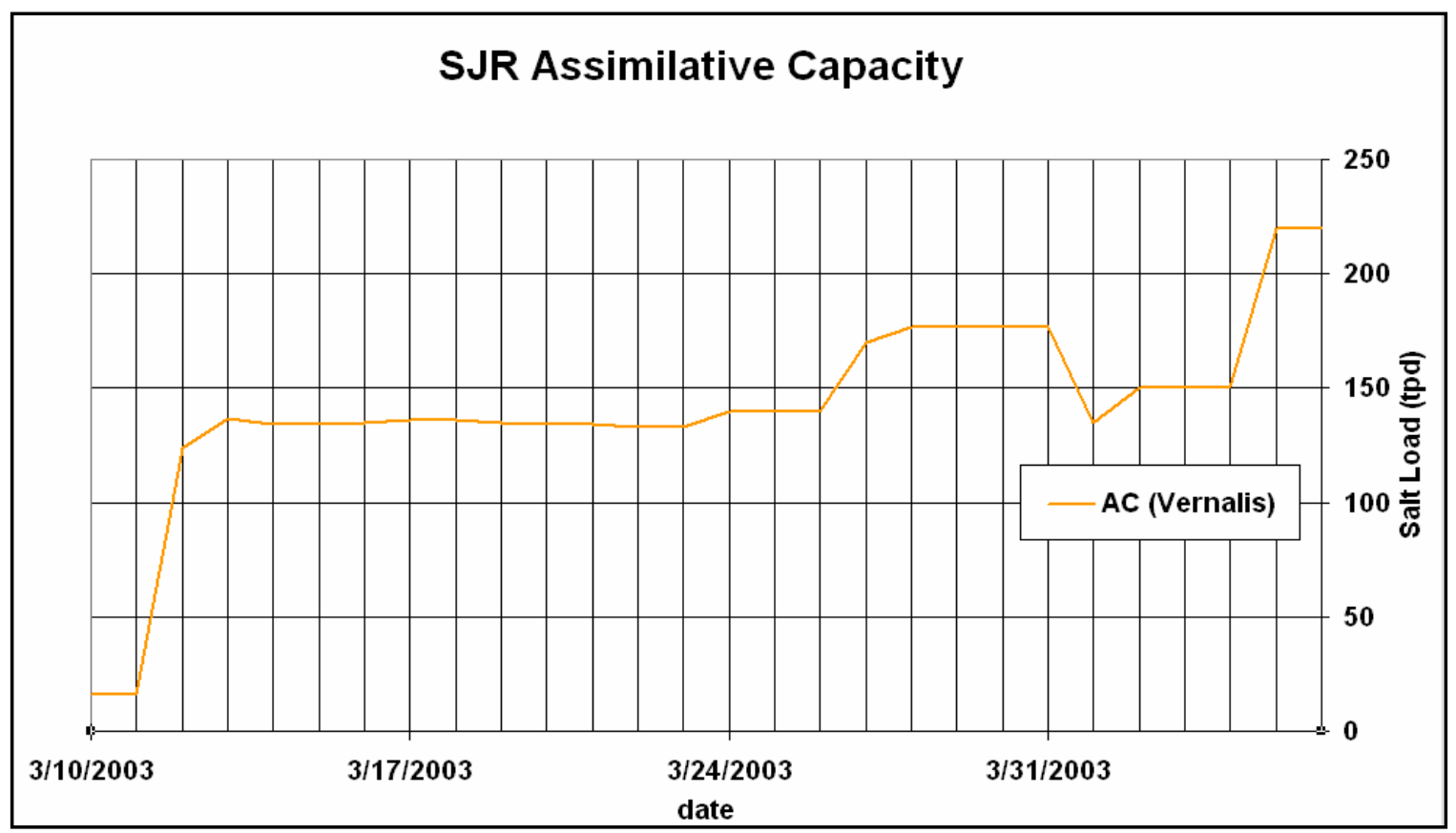

Figure 3.19 Results of SJRIO assimilative capacity forecast incorporating February 24, 2003 model application results 


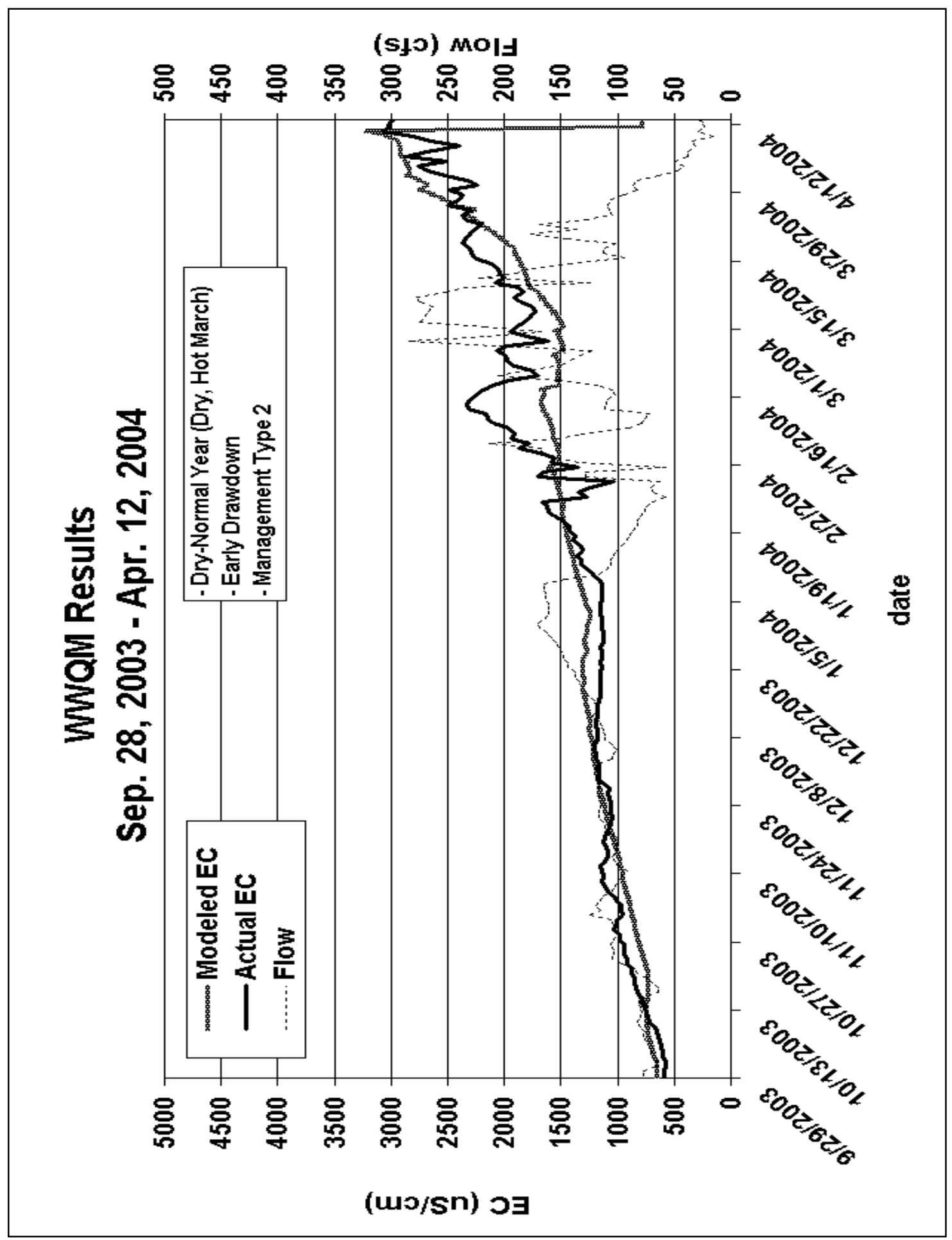

Figure 3.20 Results from WWQM calibration runs for Sep. 28, 2003 through Apr. 12, 2004 
Flooded Season 2003 - 2004

During the 2003-2004 flooded season, the model performed similarly to previous years. Due to 7.07 inches of rainfall, 2003-2004 was classified as a dry year and an early drawdown schedule was modeled. On average, the model predicted EC values within $16 \%$ of actual values, although the model was more accurate during the first part of the season (Figure 3.20). Between $9 / 29 / 03$ and $1 / 21 / 03$, including the flood-up period, modeled values of EC were within $10 \%$, on average, of actual values. This accuracy declined during the second half of the season, where modeled values were within approximately $23 \%$ of measured data. However, in contrast to previous years, this error was almost equally positive and negative. Thus, for the 2003-2004 season, the model did not show the same bias towards underestimating EC. In fact, during the important drawdown period, the model overestimated EC, resulting in a conservative estimate of wetland EC concentrations. Although error should be minimized, wetland managers prefer to base management decisions on conservative estimates of EC so as not to exceed the assimilative capacity of the San Joaquin River.

\subsection{Discussion}

The WWQM provided valuable information that can be used to inform wetland management decisions in the Grasslands Water District. Although daily values of wetland EC include some error, the model does a good job of capturing trends in flow and EC during the flooded season. This information can be very useful to a wetland manager who is trying to determine the appropriate drawdown schedule. In addition, when the WWQM was linked to the SJR forecasting model, SJRIODAY, it becomes an extremely useful tool. The SJRMP produces weekly forecasts of river assimilative capacity and posts them on the Internet at http://wwwdpla.water.ca.gov/sjd/waterquality/realtime/index.html. These data were automatically loaded into the update file that is electronically distributed to users of the WWQM. This linkage of SJRIO assimilative capacity forecasts and the salinity forecasts produced by the WWQM provide decision support to the wetland mangers of the GWD. 
A geographical information system was built within ARCGISTM to complement the WWQM and allow the wetland managers of the GWD to visually analyze salinity concentrations from the seasonal wetlands within the GWD. There is an automatic database link between the WWQM results and the access database that powers the GIS, allowing the most current data to be visualized and archived. Archiving data of the GIS allows good record keeping for review of prior decisions made.

GWD staff will need to work closely with the managers of the individual wetland units to provide information in a timely fashion to reduce the impact of salt export on the SJR. These wetland management decisions will need to be tempered with consideration of any harm management activities might have, but the flexibility demonstrated in the system, no matter how slight, must be used when conditions on the River demand it.

\subsection{Future work}

Future work should be directed at reducing the error in the modeled values of wetland EC. Although the model includes all of the major flow and salt inputs and outputs, there are a few minor sources and sinks that merit further investigation. For example, some of the minor inflows were neglected or flows were estimated in the model. In addition, as described above, groundwater interactions were neglected in this version of the model (although the model was built to accommodate groundwater data). Although the wetland is most likely in a steady-state relationship with the groundwater for most of the flooded season, and losses of flow and salt to groundwater can therefore be neglected, it is likely that these interactions are significant during flood-up and drawdown. However, including losses to groundwater will result in a decrease in EC concentration and will not address the issue of underestimation. One possible reason for the underestimation of EC concentration in the wetland is the simplification of salt dynamics in the water column as well as interactions at the soil-water interface during flood-up and drawdown. Further research, coupled with applying concepts

from existing knowledge, is necessary in order to adequately understand and model these complex processes. 


\section{CHAPTER 4 REMOTE SENSING HABITAT ASSESSMENT METHODOLOGY}

\subsection{Introduction}

Assessing the impact of management decisions on intensively managed wetland habitat is an important component of the land management process. Any management decision support system that can impact the wetlands' ecological health and/or distribution of habitat requires a means of estimating these impacts accurately. By combining recent advances in imagery and computing technologies with industry standard environmental survey methods, a Remote Sensing Habitat Assessment Methodology (RHAM), with the capability to accurately and efficiently estimate moist soil plant abundance and habitat quality over large regions, was developed.

The RHAM utilizes very-high-resolution satellite images and pattern recognition data processing tools to identify and characterize various vegetation communities in both temporal and spatial domains. Very-high-resolution commercial satellite data has become increasingly affordable and accessible for scientific applications. Major vendors of commercial satellite imagery now provide customers with the option to task the satellite according to their needs, allowing them collect data for the study site that is on-target, both spatially and temporally. Several commercial image processing packages are available for the analysis and processing of digital satellite imagery. Computing power continues to increase, minimizing the time and labor costs for image analysis. The RHAM takes advantage of the confluence of these technologies to provide a powerful tool for habitat assessment and quantification of land cover in managed wetlands.

Analysis of satellite imagery to evaluate and quantify habitat and land cover in managed wetlands has multiple benefits. Compared to traditional vegetation survey techniques, satellite imagery requires much less time and labor, while covering a larger area. Rather than the exhaustive on-going field effort that would be required to survey a large area such as NGWD, field work is limited to the time necessary to provide calibration for each image. In fact, while satellite imagery can be used effectively to map large or small areas, it becomes increasingly cost effective for larger study sites. Satellite imagery is also temporally flexible; depending on the variables of interest, image collection can be timed to capture 
different features throughout the growing season. Tracking the changes from one season to the next through the use of multi-temporal imagery can provide valuable feedback to the wetland manager regarding previously made decisions. The satellite imagery is also an

unbiased and spatially consistent data source, reducing concerns of consistency between teams of surveyors, or drifts in field methodology and nomenclature during the field season. As an additional benefit, the fact that satellite imagery is an unbiased and standardized data source creates the potential for study sites to be viewed in a broader context, both regionally and worldwide. Finally, the imagery provides an archival data source, which after its initial use, continues to be available as a historical reference, and can be used in later studies, whose needs may not have been foreseen at the time.

\subsubsection{Background}

For seasonal wetlands in California's Central Valley, management decisions such as scheduling drawdowns and irrigations are made routinely, the timing of which can change from year to year. Habitat assessment is needed to optimize the timing of these changes. Traditional means of habitat assessment such as random sampling or transects for large areas (>1000 acres) are labor intensive (Tatu et al., 1999). In addition, timely data at a high enough resolution is difficult. Moreover, although impact assessment using a fine scale sampling program at the individual pond level could be accomplished, the spatial variations found in larger areas may be missed completely (Link et al., 1994). What is needed is a way to rapidly assess and quantify the various habitat communities at the regional scale, and readily track changes in those communities from year to year (Wiens and Parker, 1995, Shuford et al., 1998; Shuford et al., 1999).

The RHAM was developed for the seasonal wetlands of the Northern Division of Grassland Water District (NGWD) (Figure 4.1) The RHAM performs two major functions for land managers in the NGWD; firstly to catalog the various vegetation communities, both in composition and aerial extent; and secondly to assess changes in these vegetation conditions over time. If the RHAM performs these two functions conjunctively, in both a timely manner and over a large area, it can increase greatly wetland managers' ability to make effective management decisions. 
The RHAM was initially developed in 2002. The methodology has evolved since 2002 to create an improved association of data sources, field collection protocols, and analysis techniques. One example is the choice of satellite imagery vendor. Space Imaging's IKONOS imagery was used for the project in 2003. In 2004, this was replaced with DigitalGlobe's QuickBird imagery, a similar satellite data source with higher spatial resolution. The scheduling of image acquisition has also changed. In 2004, imagery was collected and analyzed for April, May, and June, while in 2003, the analysis proceeded from a single May collection date. The scientific protocol for collection of field data remained the same from year to year, but in 2004, a hand-held data acquisition unit replaced clipboard and worksheets in order to standardize and streamline the data collection process. As a final notable difference, field data was collected over a larger area and more diverse range of habitats in 2004, making possible the accurate characterization of a larger range of environments. Experimentation with a variety of parameters in the RHAM has resulted in a robust and repeatable methodology.

\subsection{Methods}

\subsubsection{Data Acquisition - Imagery}

The RHAM uses various industry-accepted solutions for data source, data collection, and data analysis and processing. The data source that RHAM has developed around is highresolution, multi-spectral imagery. High-resolution satellite imagery generally refers to the recent generation of satellite sensors that are capable of a spatial resolution of less than five meters. A high spatial resolution is necessary to capture the spatial variability of small and irregularly shaped vegetation communities typical of NGWD. Multispectral imagery (as distinct from hyperspectral imagery) denotes imagery with a small number of spectral bands (generally three to seven) that provides data in broad bands in the range of visible and infrared light. In this project, the RHAM was developed for imagery having bands in the blue, green, red and near-infrared (NIR) ranges of light. Multiple vendors provide an acceptable digital image product meeting these requirements. This project utilized two different commercial vendors for the 2003 and 2004. Space Imaging's (Thornton, Colorado)

IKONOS imagery was selected for the 2003 field season. Digital Globe's (Longmont, 
Colorado) QuickBird Imagery was utilized in 2004. The two products are similar; the primary difference is that QuickBird imagery has a higher spatial resolution. A comparison of the spectral and spatial characteristics of these two imagery products is given in Table 4.1.

Table 4.1 Comparison of project imagery. IKONOS imagery was used in 2003; QuickBird was used in 2004. The two products cover similar spectra, however QuickBird imagery has a higher spatial resolution, which makes it possible to resolve smaller objects on the ground.

\begin{tabular}{|c|c|c|}
\hline Color/ Band & $\underline{\text { IKONOS }}$ & $\underline{\text { QuickBird }}$ \\
\hline Blue & $450-520 \mathrm{~nm}$ & $450-520 \mathrm{~nm}$ \\
\hline Green & $530-610 \mathrm{~nm}$ & $520-600 \mathrm{~nm}$ \\
\hline Red & $630-690 \mathrm{~nm}$ & $630-690 \mathrm{~nm}$ \\
\hline NIR & $780-900 \mathrm{~nm}$ & $760-900 \mathrm{~nm}$ \\
\hline Panchromatic & $500-900 \mathrm{~nm}$ & $450-900 \mathrm{~nm}$ \\
\hline Spatial resolution & $4 \mathrm{~m}$ & $2.4 \mathrm{~m}$ \\
& $1 \mathrm{~m}$ panchromatic & $60 \mathrm{~cm}$ panchromatic \\
\hline
\end{tabular}

For both vendors, the images were delivered in the form of GeoTiffs, which are raster files that have been geo-rectified and are ready for processing. For the QuickBird imagery used in the 2004 RHAM, the imagery was also orthorectified prior to processing, resulting in a more spatially accurate product. Imagery was collected for one date in 2003 (May 20) and for three dates in 2004 (April 26, May 14, and June 19.) Image collection was timed to represent different stages of growth throughout the growing season. The late April image would capture seedlings and perennials in wetland basins, and verdant uplands vegetation. It is believed that the maximum growth period for wetland basins occurs immediately following the first summer irrigation, usually late May to early June (Lower, 2003; Poole, 2003). May imagery was timed to coincide with this maximum growth period, and would capture a mix of inflorescence and mature growth in the wetland basins, and a mix of inflorescence, verdant growth, and seeding in the uplands vegetation. June imagery was designed to capture inflorescence, mature growth, and seeding in the wetlands basin, and seeding and senescence 
in the uplands vegetation. Figures 4.1 and 4.2 show the project imagery prior to any image processing. A color stretch is performed on the imagery to enhance contrast and ease of viewing. Even without additional processing, considerable difference between the different times in the growing season can be detected with the naked eye.

\subsubsection{Data Acquisition - Field Data}

For field data collection, the RHAM uses a modification of the California Native Plant Society's (CNPS) Rapid Assessment Protocol (RAP), co-developed by the California DFG (CNPS, 2003). The RAP is accepted widely for similar applications throughout California. The California Native Plant Society, the California Department of Fish and Game, California State Parks, National Parks, other State and Federal agencies, and consulting firms use this methodology to quickly and quantitatively inventory and map vegetation types for several projects throughout California. For example, it is being used in conjunction with a Wildlife Habitat Relationships (WHR) Validation study at Point Reyes National Seashore. It is also being used to inventory and map vegetation for prioritization of conservation sites in the Los Angeles and San Gabriel River watersheds, the San Dieguito River drainage, Napa and Riverside Counties (CNPS, 2003).

The CNPS RAP employs a community-based approach to surveying. In its original format, the CNPS RAP uses a one-page worksheet to rapidly assess large landscapes for a number of important parameters. These parameters include location and distribution of vegetation types and communities, general composition and abundance information on the various plant species, and general site environmental factors. The RAP also provides guidance for identifying the dominant and non-dominant vegetation stands among varying ecosystems, along with varying features such level of community disturbance (CNPS, 2003). The RAP is useful for collecting basic quantitative vegetation and habitat information sufficient for identification and verification of habitats. It can be used for field-based vegetation and habitat mapping and for rapid inventory, validation, and ranking of the full suite of vegetation and habitats in any natural or other management area. Thus, this method can provide wetland and other land use managers with efficient tools for natural resource inventorying and planning (CNPS, 2003). 


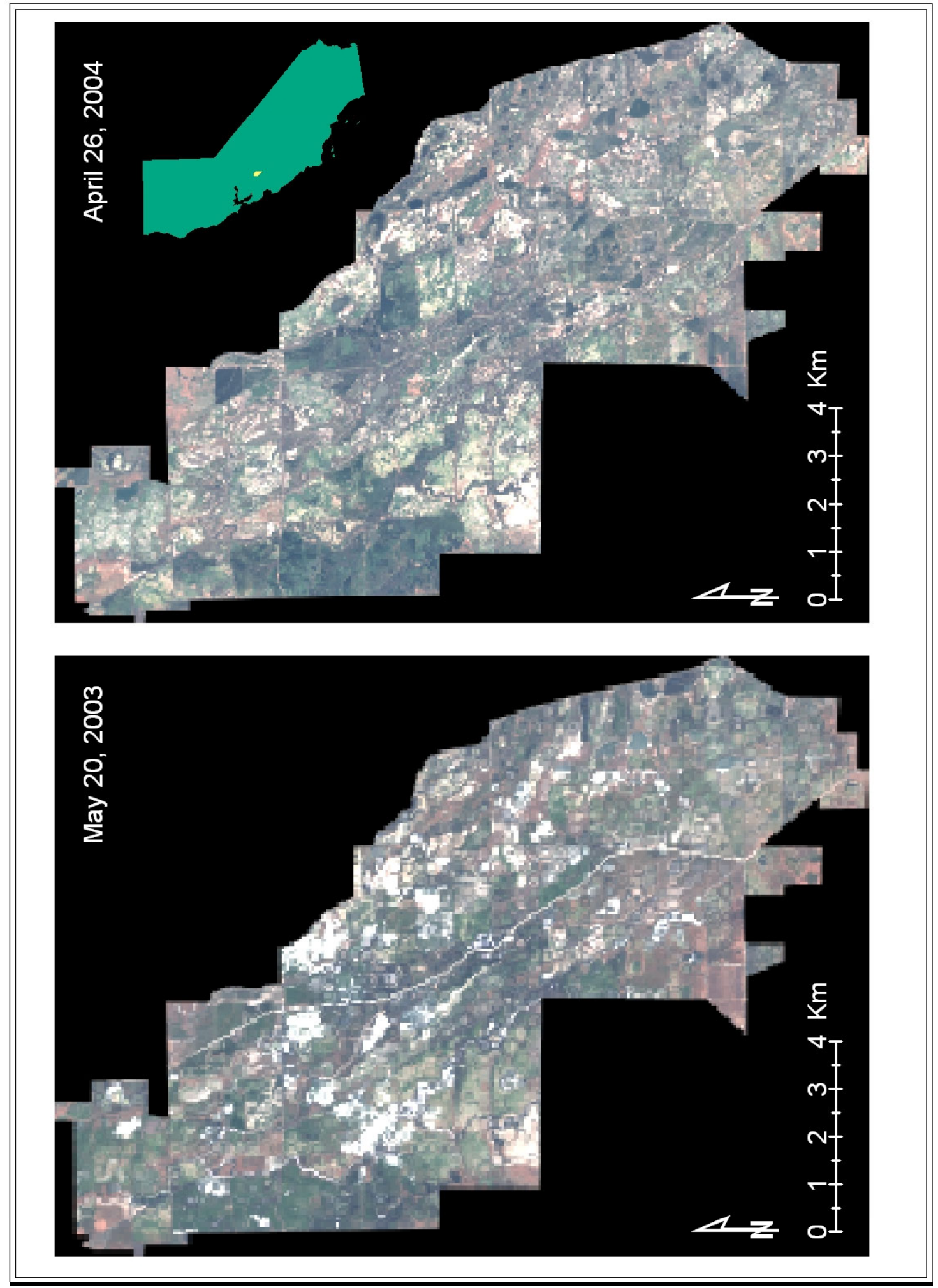

Figure 4.1 Project imagery from May 2003 (IKONOS) and April 2004 (QuickBird). Some areas appear red due to a contrast stretch applied to enhance viewability. White areas on the 2003 image are the result of sun glare on water. Inset shows site location in California. 


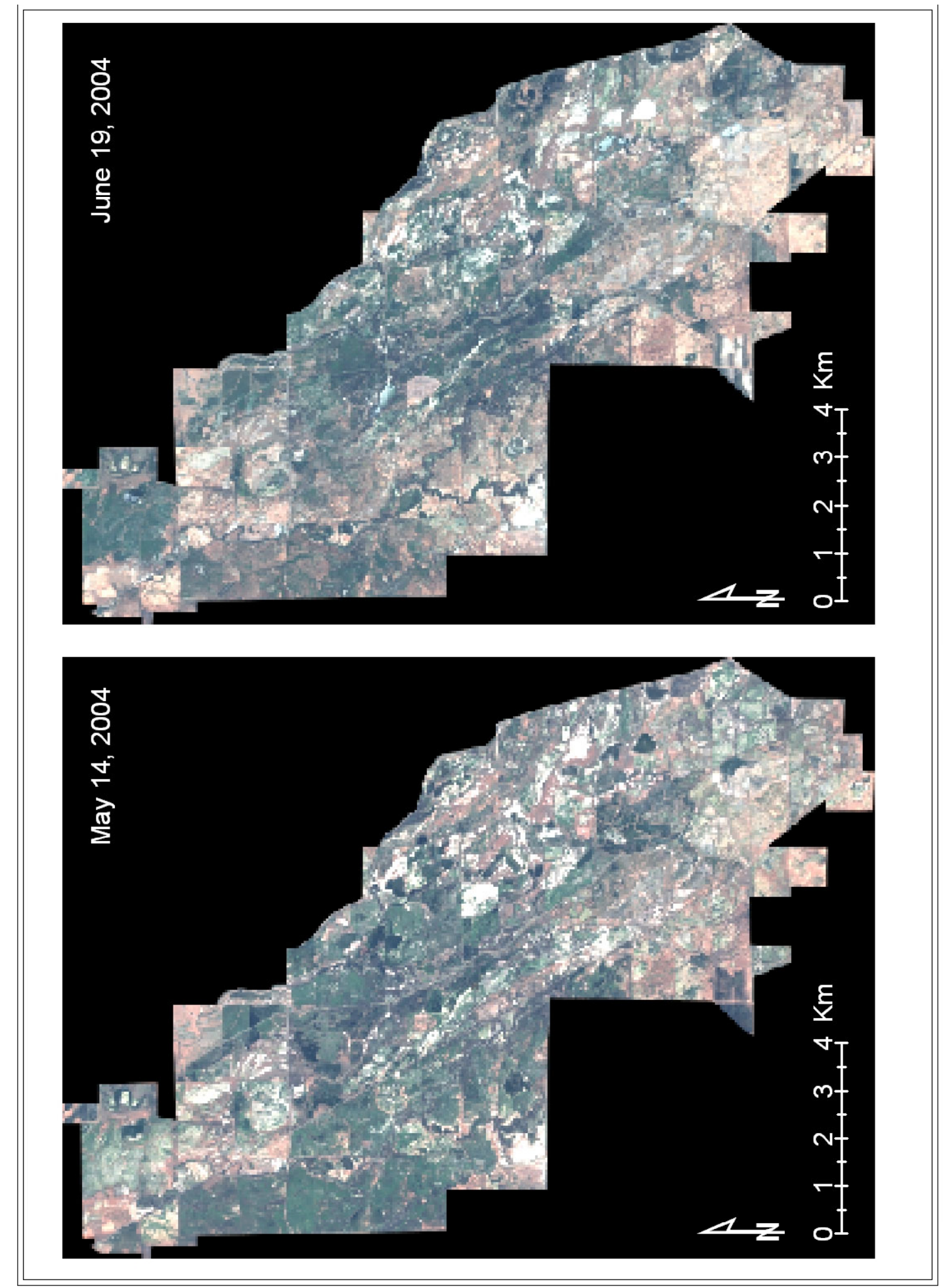

Figure 4.2 Project imagery from May and June (QuickBird). Some areas appear red due to a contrast stretch applied to enhance viewability. The May image appears greener than the June image, due to vegetative senescence already underway in June. 
Minor modifications were made to the protocol that reflected the needs and particular focus of the RHAM. For example, in this project's field surveys, field protocols removed the CNPS's emphasis on native species and placed equal weight on cataloging important nonnative species. Because of the availability of detailed soils maps for the area, the rather timeconsuming soil classification technique used by the RAP was replaced by soil survey data for the purposes of the RHAM. Other minor modifications included the addition of a few new data fields, such as the presence of visible salts, as it was perceived that this could have a significant effect on the spectral response of the pixel. In 2004, the traditional RAP vegetation worksheet was programmed into a hand-held data acquisition system. A Trimble GeoExplorer 3 was programmed with appropriate data fields sufficient to define a community, so that the collection of GPS positions would be automatically tied to attribute data for each plant community. The vegetation database was programmed with predefined pull-down menus wherever possible, in order to standardize and streamline the entry of field data. The development of this computer-based data collection system resulted in a substantial increase in the amount of field data collected in 2004.

\subsubsection{Ground Truthing}

Ground truthing of the satellite imagery is the process of collecting in situ data that tie the spectral values in the imagery to land cover in the real world. Ground truth data may be used both as input to the classification process and, once classification is complete, to check the accuracy of interpretation. Ground truth data was collected during the days shortly before, after, or during the satellite fly-over to ensure maximum correlation between field data and the recorded image. Ground truth data was collected primarily at the Salinas Land and Cattle Club (Salinas Club), a privately owned area of approximately 1,600 acres on the western side of NWGD (Figure 4.4). Additional ground truth data was collected in the San Luis National Wildlife Refuge (SLNWR), a property neighboring the eastern side of NGWD.

In 2003, data was collected using a modified CNPS RAP worksheet to collect 33 ground truth points for the May 20 image. In 2004, the development of a computerized data collection system in 2004 permitted an increase in the number of points collected. For the April 26, 2004 image, 176 ground truth points were collected; for the May 14, 2004 image, 
206 ground truth points were collected; and for the June 19, 2004 image, 276 ground truth points were collected. The increasing number of points collected throughout the growing season reflects both an increase in efficiency of data collection and a decrease in the land surface that was flooded. In order to ensure coverage of important species, local refuge managers and wetland biologists assisted in the selection of ground truth locations. Also, to provide for coverage of a range of habitats, ground truth data was collected in all major accessible basins within the Salinas Club and SLNWR. Table 4.2 shows the extensive suite of data collected for one ground truth data point, along with field names from the database and an explanation of each field. 


\section{Table 4.2 - Field data from modified CNPS Rapid Assessment Protocol}

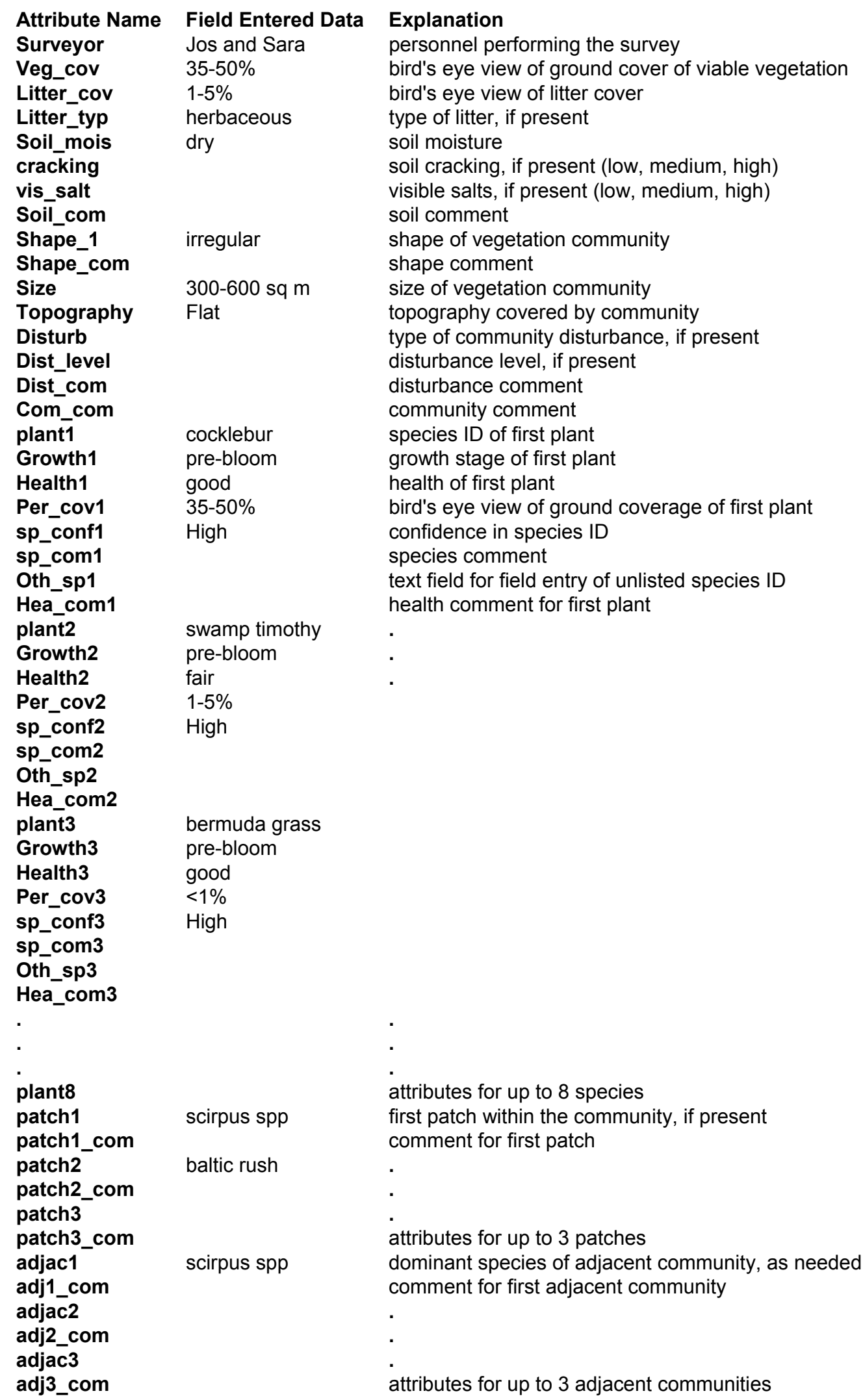




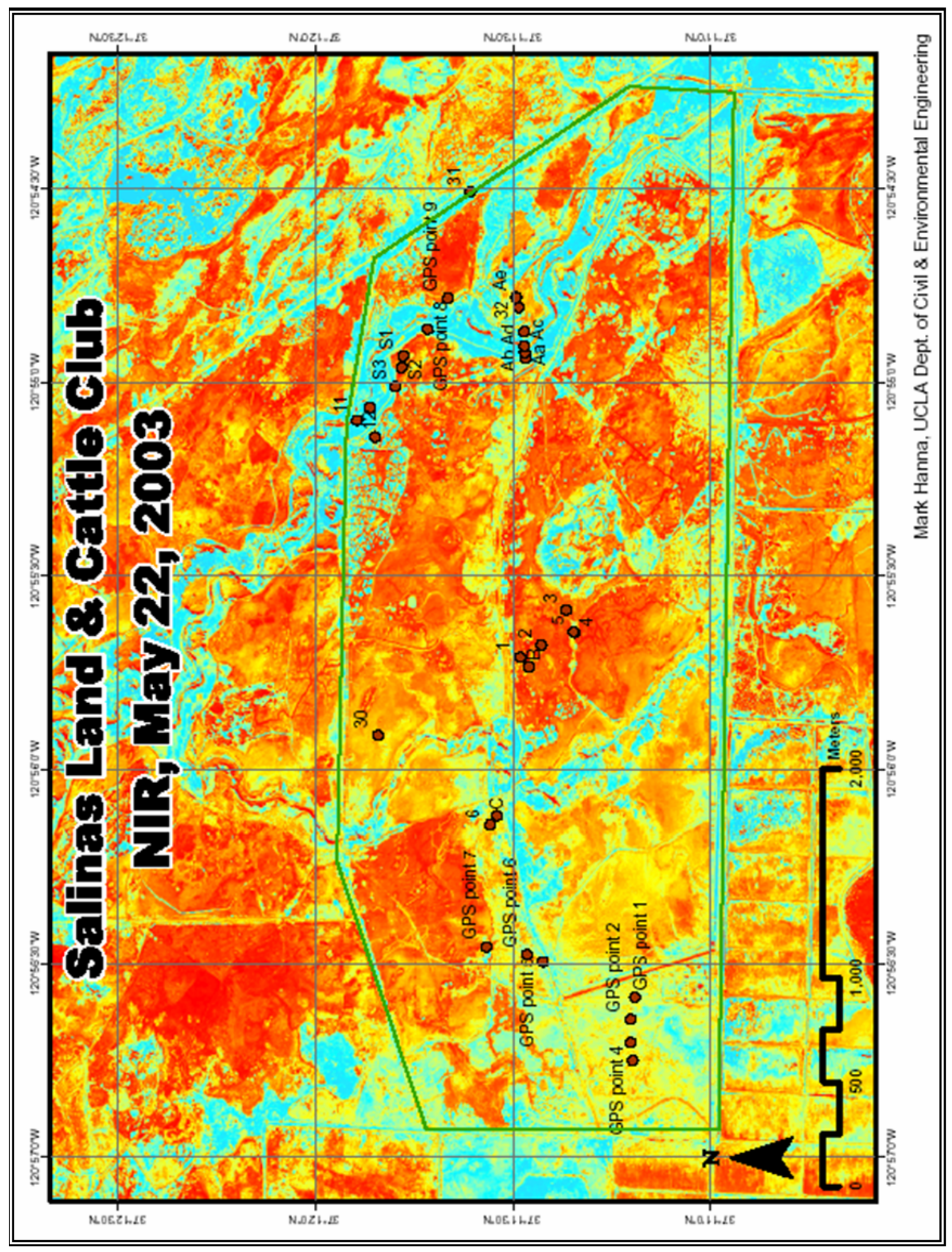

Figure 4.3 2003 Ground truth locations, Salinas Club, Merced County, CA. Field data locations have been overlaid on the near-infrared band of the May 2003 IKONOS imagery. A contrast enhancement has been performed, and regions of verdant vegetation appear red. 


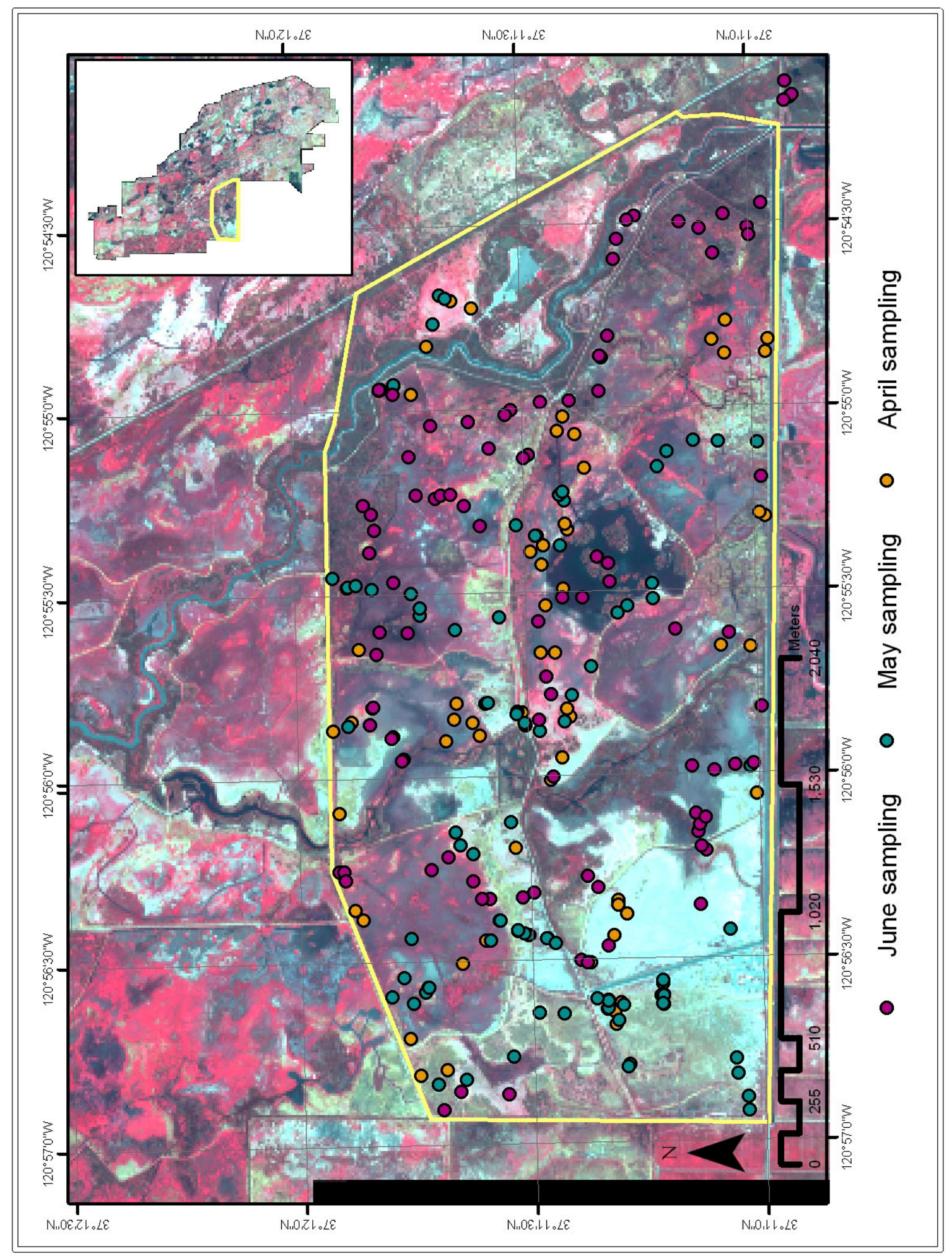

Figure 4.4 2004 Ground truth locations, Salinas Club, Merced County, CA. Field data locations have been overlaid on a false color mapping of the NIR, red, and green bands of May 2004 QuickBird Imagery. Regions of verdant vegetation appear red, water appears dark, and regions of bare, dry soil appear bright. 


\subsubsection{Image Processing}

Image processing and data analysis for the RHAM was performed using commercially available software routines provided by ERDAS Imagine ${ }^{\mathrm{TM}}$ Professional. A number of commercial image processing packages are available which perform comparable analyses. A supervised classification technique - whereby data input by an analyst is used to determine seed values for classes - was selected for classification of the images. Maximum likelihood classification is a standard industry algorithm for projects where adequate ground truth data has been collected. This technique requires the input of "training" data, with which software algorithms define statistically-based spectral bounds for each class. Training data is derived from ground truth points; the analyst defines an area around each ground truth point representative of that community of vegetation, and the image processing software compiles a database of the spectral values for that community. Multiple ground truth points are combined into a robust spectral signature for a single land cover class, and this process is repeated until the analyst has created a signature for all desired land cover classes. After all training data has been entered into the spectral signature file, the classification algorithm is implemented. The algorithm uses the defined spectral signatures to extrapolate from the training pixels to all the pixels in the image. This is a very efficient process, resulting in the extrapolation of data from a few thousand pixels to an entire image comprised of tens of millions of pixels. In the end result, every pixel is assigned to a class - the class it is "most likely" to belong to, even if the pixel's spectral values fall outside the initial seed values for any class.

The start point for classification, a statistical representation of the raw imagery data is shown in Figure 4.5. This figure shows four histograms, one for each spectral band in the imagery for May 14, 2004. The histogram shows the statistical distribution of spectral values. For each band, the spectral values are given on the $\mathrm{X}$-axis, and the number of pixels exhibiting that value is graphed on the Y-axis. Spectral values near the peak of the curve will be represented in the most pixels in the imagery. The histogram describes the statistical distribution of values within a band, but says nothing about the relationships between bands. Therefore, a pixel that is bright (high spectral value) in one band may be dark in another. 

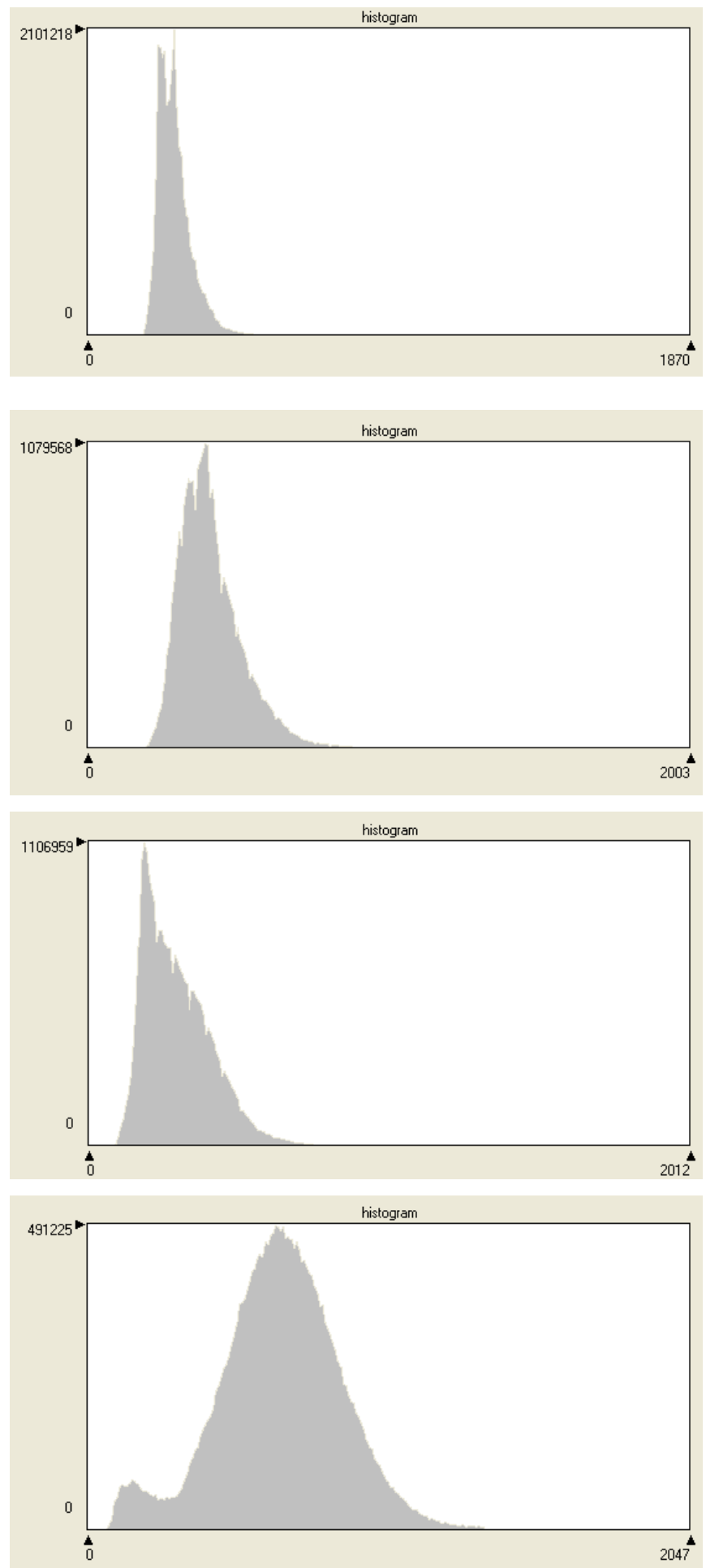

Figure 4.5 Histograms for Bands 1, 2, 3, and 4 (top to bottom) in the May 14, 2004 multispectral imagery. The $\mathrm{X}$-axis displays the spectral value, and the $\mathrm{Y}$-axis displays the number of pixels exhibiting that value in that band. The histograms show the range of spectral values present in the satellite imagery. 
An introduction to the relationship between bands is shown in Figure 4.6. Here, the mean values for the training signatures of three land cover classes - buildings, water, and scirpus spp - are shown for the four multispectral bands. Maximum likelihood classification also accounts for the range and variance of spectral signatures, however, it can be seen in this figure that these three classes may be separable based solely on the mean. Scirpus spp and water have similar means in bands 1,2 , and 3, however, scirpus is significantly brighter in band 4 , due to the response of chlorophyll in this band. These three land cover classes were chosen for ease of illustration. As a general rule, land cover classes comprised of individual plant species will appear more similar and will be more challenging to separate.

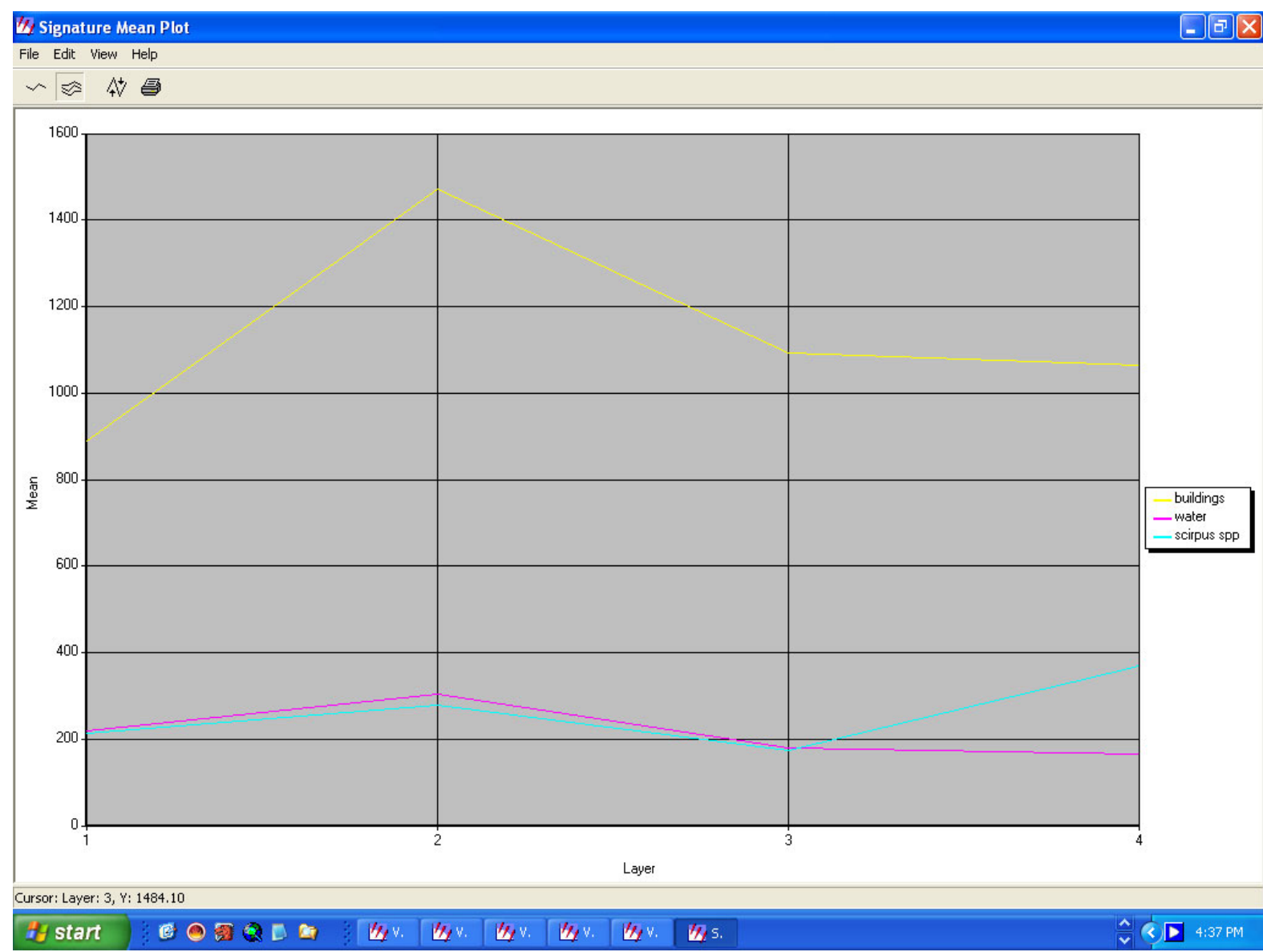

Figure 4.6 Mean values of the training signatures of three land cover classes in the May 14, 2004 imagery. Buildings are considerably brighter in all four bands. Water and scirpus spp take on similar mean values in bands 1, 2, and 3 (blue, green, and red), however scirpus spp is brighter in band 4 (near-infrared.) 
An example of creating a single training signature is shown in Figure 4.7, and the final spectral signature file for 2004 is shown in Figure 4.8. Note that the statistical description of each class is too complex to display in this simple view. The color patches and RGB values shown in the signature file correspond to the average tone of that land cover type, as it is displayed in the working window.

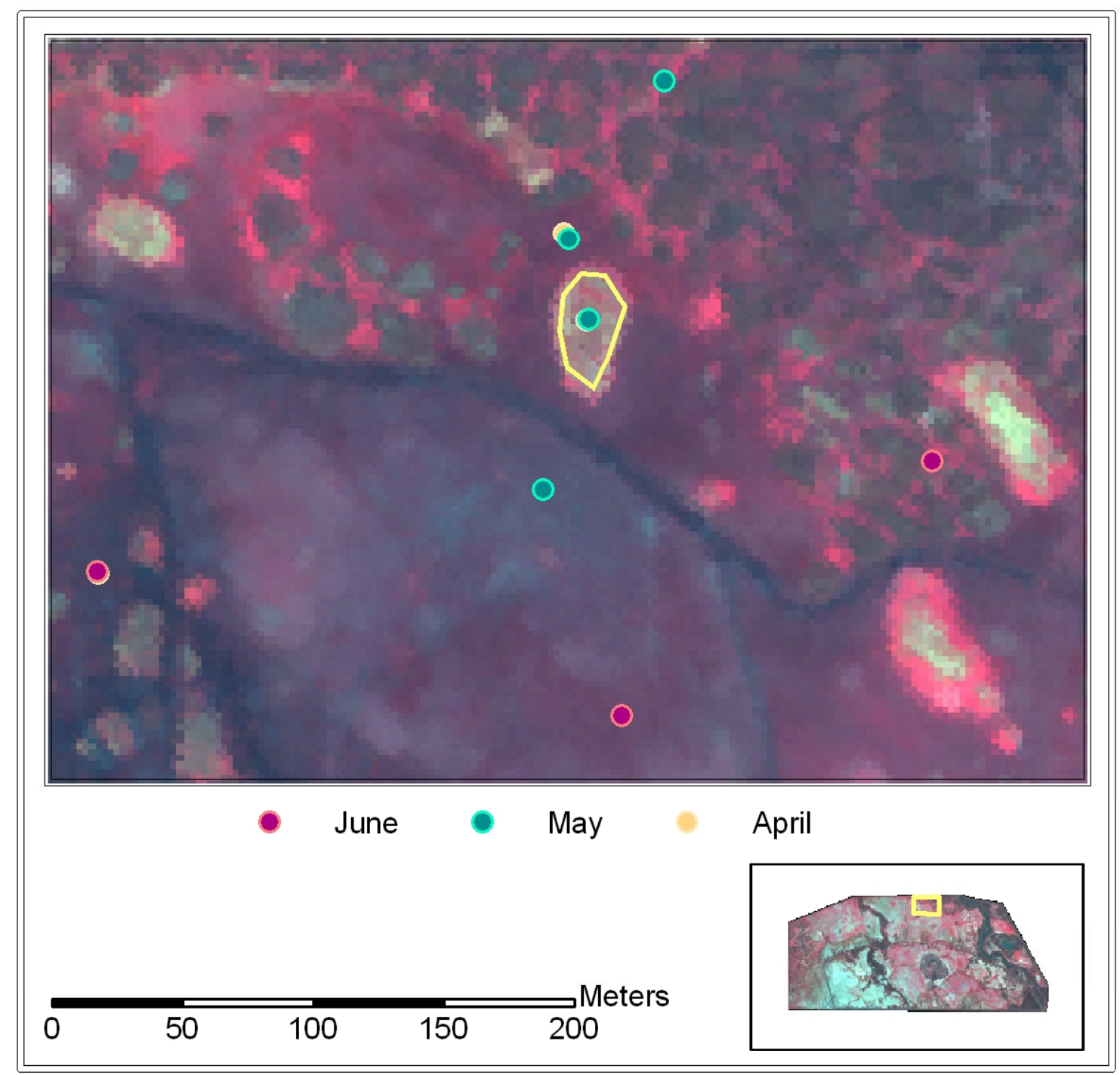

Figure 4.7 Example of training signature delineation. Training signatures are collected in the areas surrounding ground truth points. While the ground truth point represents only a single pixel location, this may be extrapolated to the surrounding area via visual inspection and use of field collected attributes such as community size and shape. It is desirable to maximize the number of pixels included in each spectral signature, as this leads to a more robust statistical description of the class. 


\begin{tabular}{|c|c|c|c|c|c|c|c|c|c|c|c|c|c|c|c|}
\hline \multicolumn{13}{|c|}{ F. Signature Editor (14may04_final.sig) } & - & $\square$ & $\times$ \\
\hline \multicolumn{16}{|c|}{ 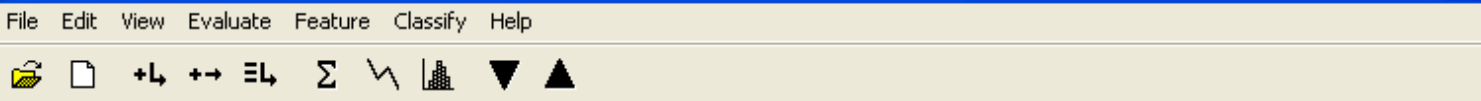 } \\
\hline Class \# & $>$ & Siqnature Name & Color & Red & Green & Blue & Value & Order & Count & Prob. & \begin{tabular}{l|l}
$\mathrm{P}$ & $\mathrm{I}$ \\
\end{tabular} & $\mathrm{H}$ & $\mathrm{A}$ & FS & $\bar{C}$ \\
\hline 1 & $>$ & buildings & & 1.000 & 1.000 & 1.000 & 2 & 5 & 78 & 1.000 & $x \times$ & & $x$ & & \\
\hline 2 & & water & & 0.398 & 0.620 & 0.659 & 16 & 119 & 2881 & 1.000 & $x \mid x$ & & $x$ & & \\
\hline 3 & & scirpus & & 0.537 & 0.593 & 0.647 & 11 & 152 & 1716 & 1.000 & \begin{tabular}{|l|l}
$x$ & $x$ \\
\end{tabular} & 3 & $x$ & & \\
\hline 4 & & bare soil / iodine & & 0.751 & 1.000 & 1.000 & 1 & 158 & 1460 & 1.000 & $x \mid x$ & & $x$ & & \\
\hline 5 & & litter / senescent grass & & 0.789 & 0.808 & 0.788 & 7 & 159 & 1214 & 1.000 & \begin{tabular}{|l|l}
$x$ \\
\end{tabular} & & $x$ & & \\
\hline 6 & & dock5-15 & & 0.738 & 0.753 & 0.754 & 6 & 166 & 101 & 1.000 & $x \mid x$ & & $x$ & & \\
\hline 7 & & moist soil / shallow flooding & & 0.561 & 0.704 & 0.716 & 8 & 176 & 1203 & 1.000 & \begin{tabular}{|l|l}
$x$ \\
\end{tabular} & & $x$ & & \\
\hline 8 & & alkali bulrush5-15 & & 0.712 & 0.776 & 0.777 & 4 & 179 & 38 & 1.000 & $x \mid x$ & $x$ & $x$ & & \\
\hline 9 & & saltgrass - verdant & & 0.926 & 0.722 & 0.706 & 10 & 1 & 11 & 1.000 & \begin{tabular}{|l|l}
$x$ \\
\end{tabular} & $x$ & $x$ & & \\
\hline 10 & & swamp tim0-25 weed0-15 & & 0.856 & 0.929 & 0.880 & 13 & 223 & 378 & 1.000 & $x \mid x$ & & $x$ & & \\
\hline 11 & & mustard & & 0.834 & 0.697 & 0.712 & 74 & 288 & 19 & 1.000 & \begin{tabular}{|l|l}
$x$ \\
\end{tabular} & $x$ & $x$ & & \\
\hline 12 & & pepperweed & & 0.868 & 0.783 & 0.787 & 79 & 293 & 142 & 1.000 & $x \mid x$ & & $x$ & & \\
\hline 13 & & saltgrass $50-75 /$ poison hemlock & & 0.770 & 0.731 & 0.726 & 110 & 330 & 226 & 1.000 & $x \mid x$ & & $\mathrm{x}$ & & \\
\hline 14 & & wild rye5-35-litter0-75/star15-35-litter25-50 & & 0.748 & 0.709 & 0.717 & 111 & 333 & 603 & 1.000 & $x \times$ & & $x$ & & \\
\hline 15 & & smartweed/cocklebur verdant & & 1.000 & 0.698 & 0.683 & 114 & 335 & 1033 & 1.000 & $x \mid x$ & & $x$ & & \\
\hline 16 & & baltic rush / alkali bulrush25-35 & & 0.647 & 0.623 & 0.655 & 116 & 337 & 336 & 1.000 & $x \mid x$ & & $x$ & & \\
\hline 17 & & swamp timothy35-75 & & 0.692 & 0.667 & 0.673 & 138 & 361 & 876 & 1.000 & \begin{tabular}{|l|l}
$x$ \\
\end{tabular} & & $x$ & & \\
\hline 18 & & bermuda grass 25 & & 0.798 & 0.647 & 0.663 & 152 & 375 & 18 & 1.000 & $x \mid x$ & $x$ & $x$ & & \\
\hline 19 & & swamp timothy35-75 / watergrass & & 0.904 & 0.815 & 0.788 & 153 & 376 & 907 & 1.000 & \begin{tabular}{l|l}
$x$ \\
$x$
\end{tabular} & 定 & $x$ & & \\
\hline 20 & & bermuda grass $35-75 /$ water hyacinth & & 1.000 & 0.662 & 0.666 & 154 & 377 & 938 & 1.000 & $x \mid x$ & & $|x|$ & & \\
\hline
\end{tabular}

Figure 4.8 2004 Spectral signature file. Each class is the result of compositing training data for numerous ground truth points. The total number of pixels included in each class is displayed in the "Count" column. The color swatch is derived from the average values of all pixels comprising that class, based on the color mapping used in the display window. Since near-infrared is mapped to red in the display window (as in Figure 4.7), vegetation tends to appear red. The "Red," "Green," and "Blue" columns give the RGB values for the color swatch.

Through a complex process of signature refinement, individual training signatures (Figure 4.7) evolve into the final class signature file that is used to classify the image (Figure 4.8.) The class signatures are based on multiple single signatures added together in proportion to the number of pixels each represents. After signatures are compiled for each class, they are evaluated for separability. There are a number of tools that may be used for this evaluation. Figure 4.9 shows a feature space image for bands 4 (NIR) and 2 (green) and the twodimensional separability of three classes (scirpus, buildings, and water) within this feature space. Figure 4.10 shows a matrix of separability values for ten land cover classes. Separability here is calculated in all four image bands, using a measure of the spectral distance between classes known as transformed divergence. Transformed divergence ranges in value from 0 to 2000, and values over 1500 are considered to be separable. If classes are insufficiently separable, the analyst may choose to combine classes, to add more training data, or to cull some training data before repeating the evaluation of signature separability. 


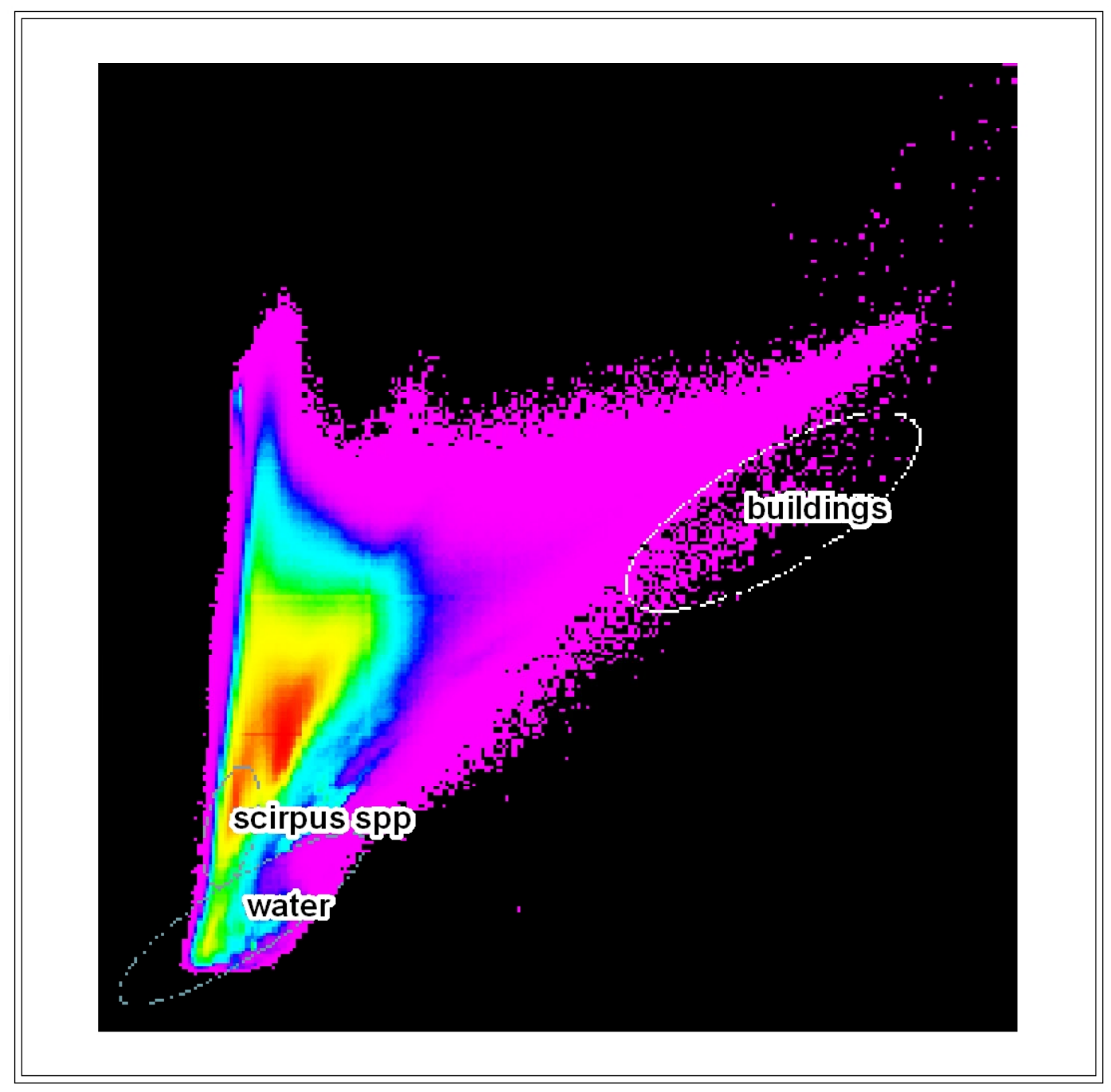

Figure 4.9 Feature space analysis of separability of three land cover classes in bands 2 and 4 of the May 14, 2004 imagery. Band 2 (green) is plotted on the X-axis, and band 4 (near-infrared) is plotted on the Y-axis. The 2-dimensional location of a point on this plot is determined by its spectral value in the two bands. Colors represent the frequency of occurrence of that spectral value combination. Red depicts combinations that occur frequently in the dataset. Violet depicts the combinations that occur least frequently. The class bounds, as determined by training data, of buildings, scirpus spp, and water are plotted on this feature space. The three classes appear to be unambiguously separable in bands 2 and 4 . Furthermore, buildings occupy a sector of feature space not represented in too many pixels. Scirpus spp, by contrast, is centered about a red sector. This could indicate either a predominance of scirpus in the image, or a predominance of land cover classes that reflect a signal similar to scirpus spp. 


\begin{tabular}{|c|c|c|c|c|c|c|c|c|c|c|}
\hline Weparability CellArray & & & & & & & & & & - $\square$ \\
\hline $\begin{array}{l}\text { Distance Measure: Transformed Divergen } \\
\text { Using Layers: } 1234 \\
\text { Taken } 4 \text { at a time } \\
\text { Best Average Separability: } 1982.05 \\
\text { Combination: } 1234\end{array}$ & & & & & & & & & & \\
\hline Siqnature Name & 1 & 2 & 3 & 4 & 5 & 6 & 7 & 8 & 9 & 10 \\
\hline buildings 1 & 0 & 2000 & 2000 & 1999.96 & 2000 & 2000 & 2000 & 2000 & 2000 & 2000 \\
\hline water 2 & 2000 & 0 & 1999.38 & 2000 & 2000 & 2000 & 1990.71 & 2000 & 2000 & 2000 \\
\hline scirpus 3 & 2000 & 1999.38 & 0 & 2000 & 2000 & 2000 & 1998.22 & 1995.68 & 2000 & 2000 \\
\hline bare soil / iodine 4 & 1999.96 & 2000 & 2000 & 0 & 1998.01 & 2000 & 2000 & 2000 & 2000 & 1871.37 \\
\hline litter / senescent grass 5 & 2000 & 2000 & 2000 & 1998.01 & 0 & 1883.28 & 2000 & 1994.58 & 2000 & 1578.49 \\
\hline dock5-15 6 & 2000 & 2000 & 2000 & 2000 & 1883.28 & 0 & 2000 & 1958.67 & 2000 & 1980.31 \\
\hline moist soil / shallow flooding 7 & 2000 & 1990.71 & 1998.22 & 2000 & 2000 & 2000 & 0 & 1996.2 & 2000 & 1999.97 \\
\hline alkali bulrush5-15 8 & 2000 & 2000 & 1995.68 & 2000 & 1994.58 & 1958.67 & 1996.2 & 0 & 2000 & 1947.27 \\
\hline saltgrass - verdant 9 & 2000 & 2000 & 2000 & 2000 & 2000 & 2000 & 2000 & 2000 & 0 & 2000 \\
\hline swamp tim0-25 weed0-15 10 & 2000 & 2000 & 2000 & \begin{tabular}{|l|}
1871.37 \\
\end{tabular} & 1578.49 & 1980.31 & 1999.97 & 1947.27 & 2000 & 0 \\
\hline
\end{tabular}

Figure 4.10 Separability matrix showing transformed divergence values for the first ten land cover classes from the spectral signature file. Values over 1900 are considered to indicate excellent separability; values greater than 1700 represent good separability; values greater than 1500 are considered adequately separable. The matrix shows the separability of pairs of classes. For example, the value in row 1 and column 2 would indicate an excellent separability between buildings and water. Classes that are not adequately separable will result in pixels misclassified as the other member of the pair.

\subsection{Results}

Following the spring 2003 wetland drawdown, the RHAM was applied to North Grassland Water District (NGWD). Maximum likelihood classification was performed on bands 1 (blue) and 4 (NIR) of the 2003 imagery for the Salinas Club. Two bands were selected in order to limit the processing time for classification. Bands 1 and 4 were selected since preliminary analysis indicated that most of the information in the imagery was contained in the spectral values for these bands. The initial classification result for the Salinas Club is shown in Figure 4.11. 


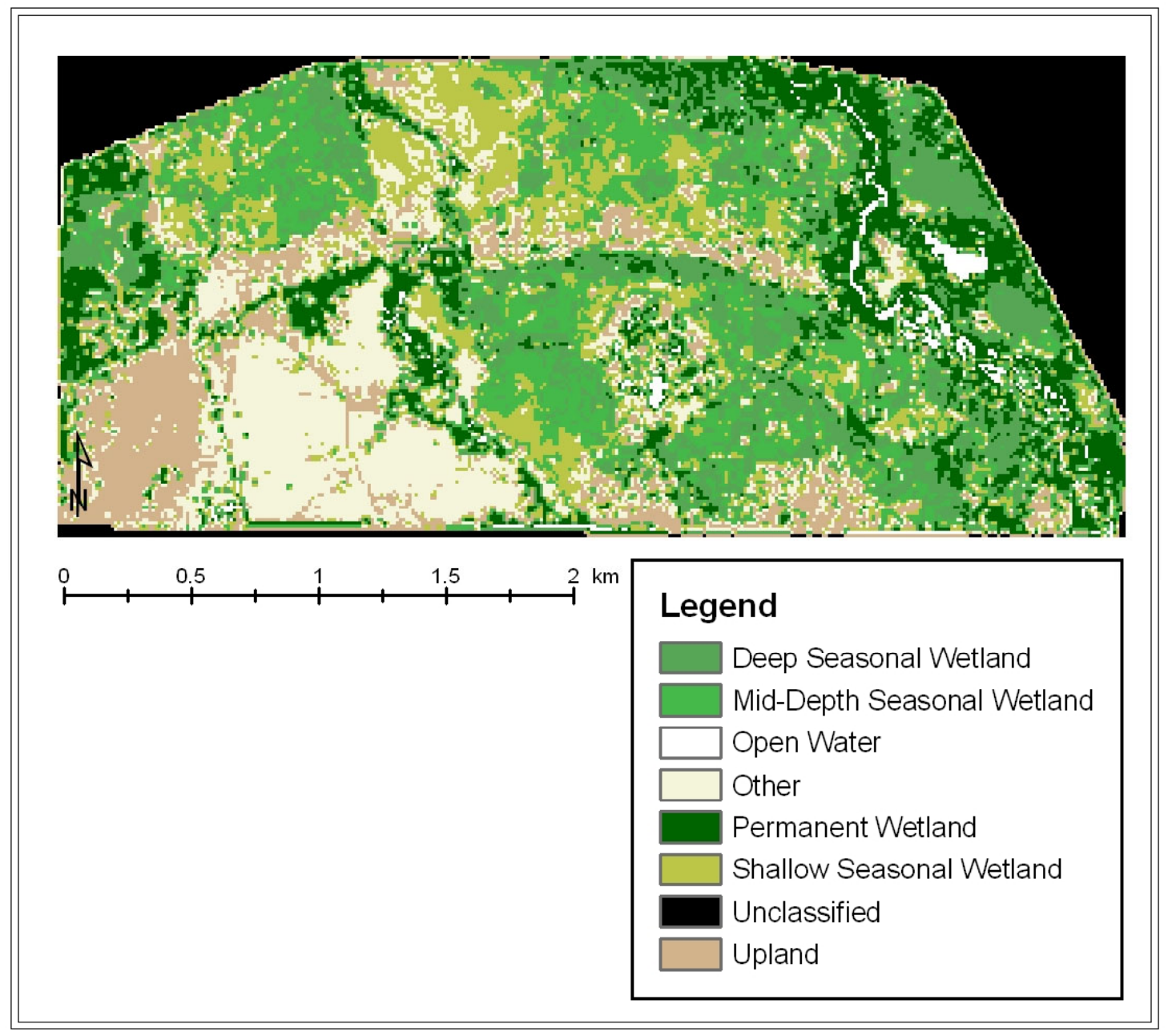

Figure 4.11 2003 maximum likelihood classification result for Salinas Club, Merced County, CA. As expected, the map shows extensive tracts of deep, mid-depth, and shallow seasonal wetlands. The "Other" category includes very shallow seasonal wetlands, salt flats, bare soil, and improvements such as roads and buildings. Unclassified pixels are limited to areas falling outside the study site.

This map was assessed for accuracy through quantitative review by the Salinas Club wetland manager. After several iterations, a final map for the Salinas Club was produced. The spectral signature file used in the final iteration was then applied to the entire NGWD. The result of the maximum likelihood classification of NGWD is shown in Figure 4.12. Reapplying the spectral signature file to the entire NGWD image produced a wetland vegetation and land use map complete with total acreage for each class (Figure 4.13; Table 4.3). 


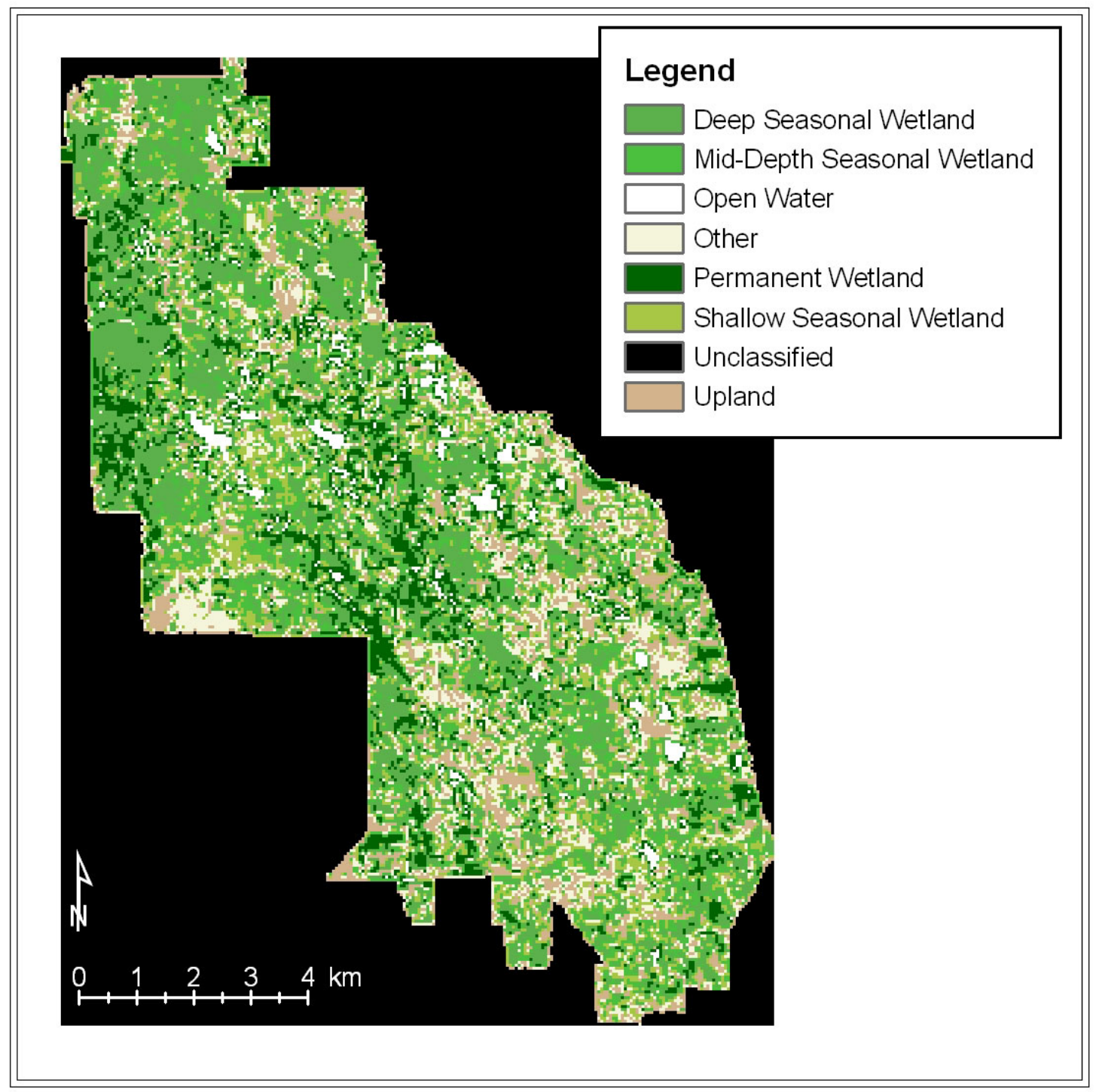

Figure 4.12 2003 maximum likelihood classification of NGWD, Merced County, CA. Classification of the entire area was based on a spectral signature file developed for Salinas Club. The development of the spectral signature file was based on ground truth data at 33 point locations. Using statistically based image processing techniques, this map shows information extrapolated from a few hundred pixels to millions of pixels.

In the final map, the classifications combine similar reflectance signatures. Shallow, middepth, and deep seasonal wetlands were grouped into a single classification called "Seasonal Wetlands." The emergent vegetation indicative of semi-permanent and permanent wetlands facilitated their merging into a single classification called "Semi-Permanent to Permanent Wetlands." The uplands and open water classifications were distinct enough on their own, 
and thus remained as individual classes named "Uplands" and "Open Water." Finally, for purposes of improved accuracy, the three classes for salt flats, bare soil, and improvements, were merged into the single classification called "Other." Performing this process on subsequent images, changes in the aerial extents of the land use classifications can be tracked. Analyzing the changes through comparison with previously made management decisions, impacts may be assigned to various land use activities (Holland, 1986, Fredrickson, 1991).

Of the roughly 25,000 acres in the NGWD, the RHAM estimated that on 20 May 2003, approximately 6,225 acres (25\%) were upland, 10,725 acres (43\%) were seasonal wetlands, and 4,750 acres (19\%) were semi-permanent and permanent wetlands. The remaining 3,400 acres $(14 \%)$ fall in the open water or "other" categories. Other includes very shallow seasonal wetlands, salt flats, bare soil, and improvements such as roads and buildings. These results are useful as a snapshot in time of the quantity and quality of the habitat in the NGWD.

Table 4.3 Land use acreages for the Salinas Land \& Cattle Club and the North Grassland Water District

\section{Wetland Land Use Classification in the Grassland Water District May 20, 2003}

\begin{tabular}{|c|c|c|c|c|}
\hline Land Use Category & \multicolumn{2}{|c|}{ Salinas Club $\sim 1,600$ acres } & \multicolumn{2}{|c|}{ North GWD 25,100 acres } \\
\hline Uplands & 325 & & acleag & $\%$ of total \\
\hline Upranas & 305 & $20 \%$ & 6225 & $25 \%$ \\
\hline Seasonal Wetlands & 700 & $44 \%$ & 10725 & $43 \%$ \\
\hline Semi-Permanent Wetlands & 325 & $20 \%$ & 4750 & $19 \%$ \\
\hline Open Water & 50 & $3 \%$ & 1700 & $7 \%$ \\
\hline Other ${ }^{3}$ & 200 & $13 \%$ & 1700 & $7 \%$ \\
\hline
\end{tabular}

${ }^{1}$ Seasonal Wetlands include shallow, mid-depth and deep wetlands

${ }^{2}$ Semi-Permanent Wetland classification includes permanent and riparian wetlands

${ }^{3}$ The "other" classification includes very shallow seasonal wetlands, salt flats, bare soil, and improvements 


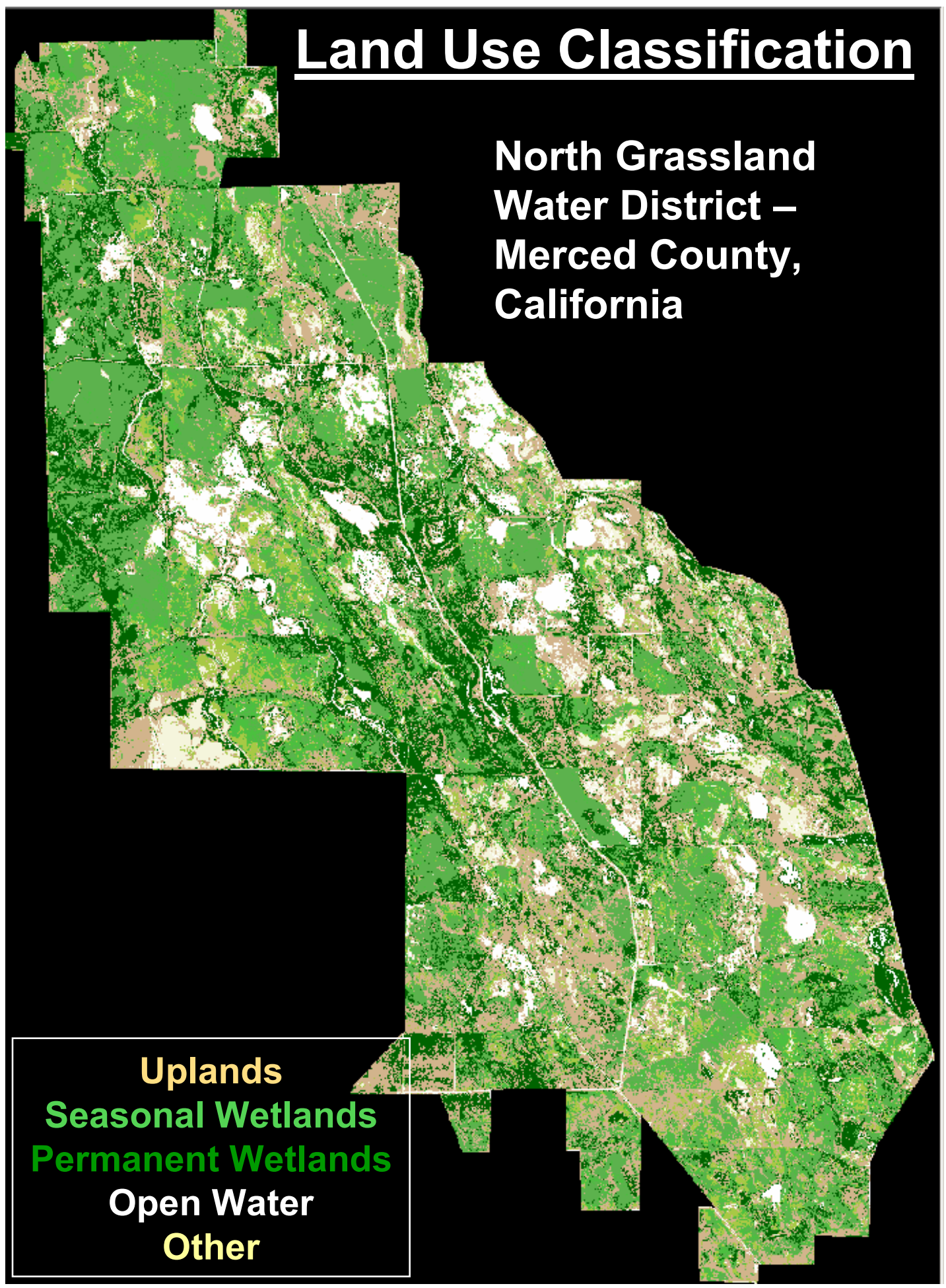

Figure 4.13 Final map showing delineation of entire North Grassland Water District into major land use categories. The map represents the distribution of land use on May 20, 2003. 
In 2004, based on the increased quantity of ground truth data, the RHAM was used to derive additional land cover classes from the imagery. Figures 4.14 and 4.15 shows the result of the classification for the April, May, and June images. Additional land cover classes include non-vegetative categories such as "buildings" and "shallow flooding", wetland basin categories such as "scirpus" and "dense swamp timothy", and finally uplands categories such as "mustard" and "pepperweed." Table 4.4 shows the change in distribution of land cover classes across April, May, and June 2004.

Table 4.4 2004 land use percentages for the North Grassland Water District. The table shows significant changes in dominance of certain moist soil plants. Percentages of plant species represent verdant growth only. Plants that are no longer producing chlorophyll will be represented in the litter/senescent grass category, which increases substantially toward the end of the growing season.

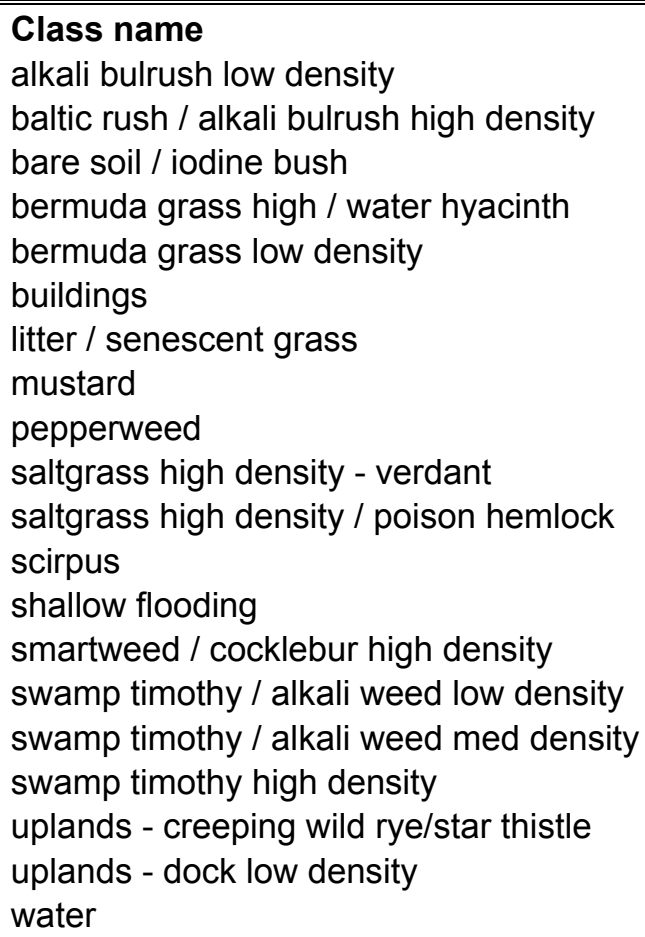

TOTALS:

\begin{tabular}{|rrr|} 
April 2004 & May 2004 & June 2004 \\
$2.9 \%$ & $4.2 \%$ & $4.4 \%$ \\
$0.0 \%$ & $9.0 \%$ & $7.7 \%$ \\
$11.6 \%$ & $7.1 \%$ & $9.1 \%$ \\
$1.0 \%$ & $5.9 \%$ & $5.1 \%$ \\
$0.0 \%$ & $0.8 \%$ & $0.5 \%$ \\
$0.0 \%$ & $0.2 \%$ & $0.0 \%$ \\
$10.5 \%$ & $7.1 \%$ & $20.2 \%$ \\
$0.0 \%$ & $0.3 \%$ & $0.2 \%$ \\
$16.7 \%$ & $4.1 \%$ & $3.0 \%$ \\
$0.1 \%$ & $1.0 \%$ & $0.9 \%$ \\
$9.4 \%$ & $6.3 \%$ & $4.7 \%$ \\
$1.5 \%$ & $6.0 \%$ & $3.3 \%$ \\
$4.7 \%$ & $2.2 \%$ & $1.0 \%$ \\
$1.6 \%$ & $2.7 \%$ & $0.9 \%$ \\
$5.0 \%$ & $6.8 \%$ & $11.9 \%$ \\
$3.6 \%$ & $7.8 \%$ & $2.2 \%$ \\
$13.8 \%$ & $7.3 \%$ & $2.3 \%$ \\
$10.2 \%$ & $12.7 \%$ & $14.8 \%$ \\
$1.3 \%$ & $3.8 \%$ & $6.2 \%$ \\
$6.0 \%$ & $4.8 \%$ & $1.5 \%$ \\
$100.0 \%$ & $100.0 \%$ & $100.0 \%$ \\
\hline
\end{tabular}




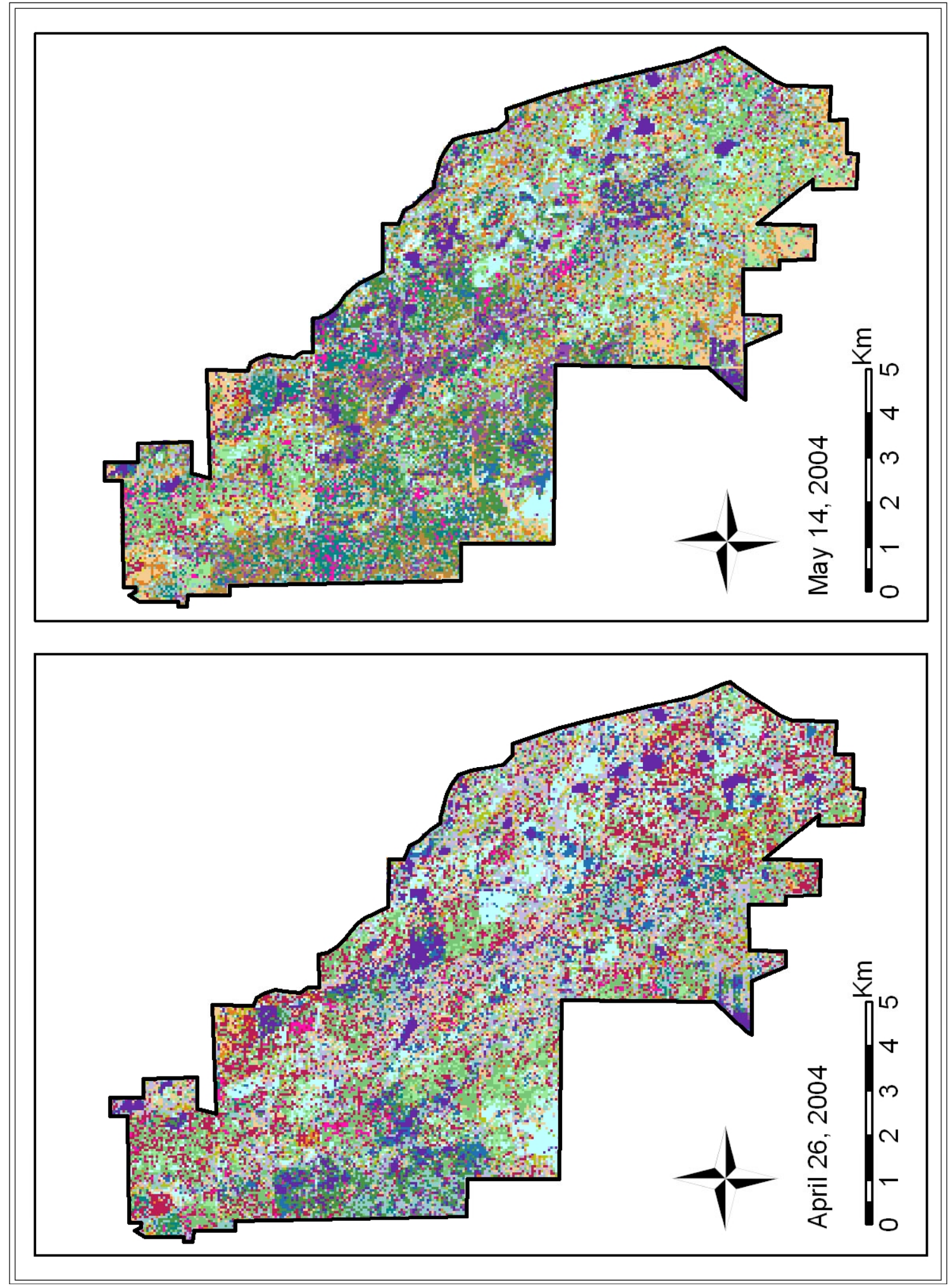

Figure 4.14 April and May 2004 maximum likelihood classification of NGWD. Increasing areas of swamp timothy can be seen near the north and south boundaries of the district. 


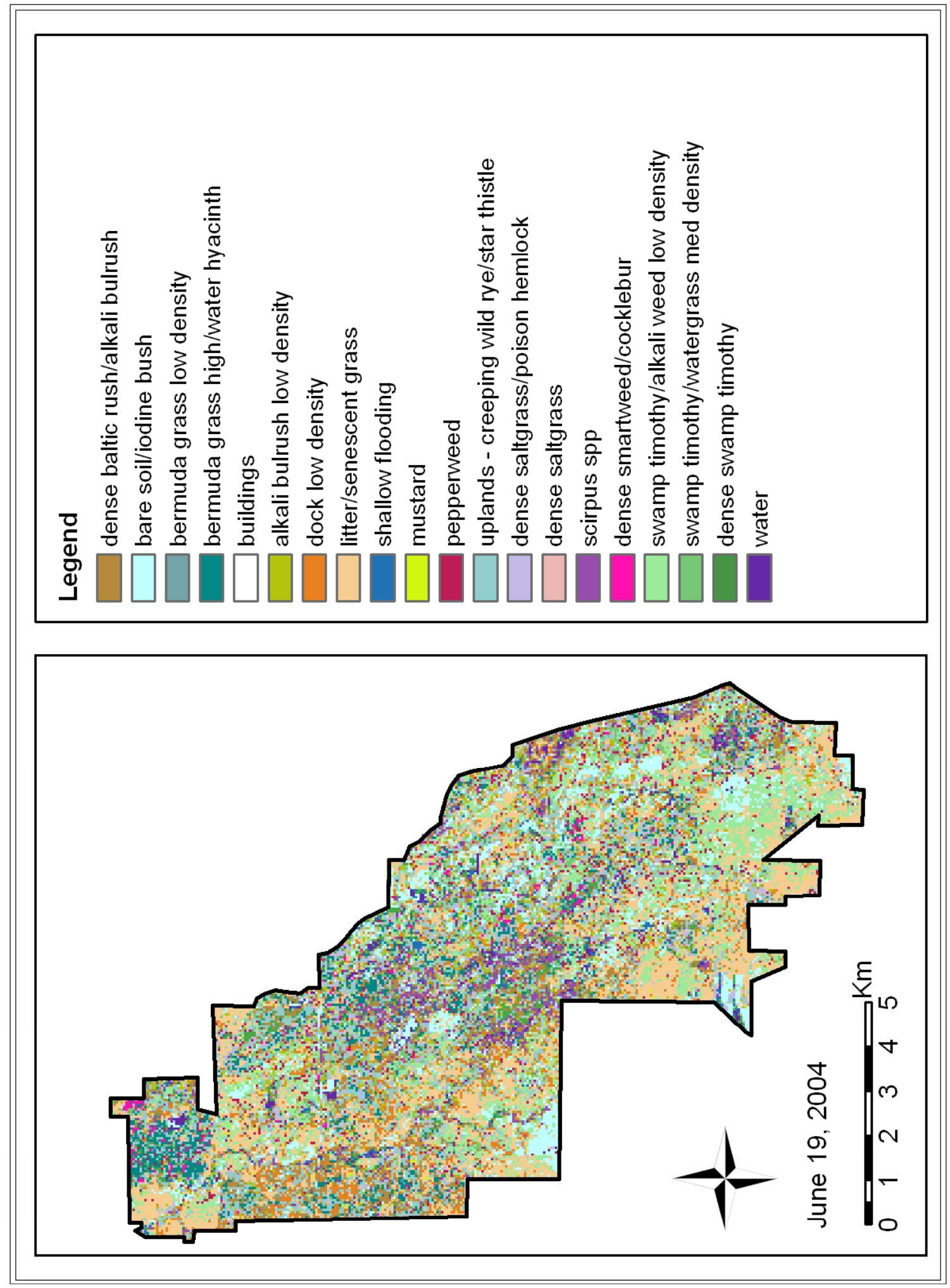

Figure 4.15 June 2004 maximum likelihood classification of NGWD. Decreased verdant swamp timothy and increased litter and senescence indicate a shift toward seed production. 


\subsubsection{Spectral Analysis Assessment}

The table provides reasonable results for the land cover classes. Several notable trends, such as a decrease of open water and an increase in senescent grasses throughout the growing season, provide confidence in the extended application of the spectral signature to the whole of NGWD. The progressive decrease in dense swamp timothy, accompanied by an increase in low and medium density swamp timothy, likely reflects the life stage of the plant. As chlorophyll production wanes, and the plant moves into seeding and senescence, it appears to the satellite to occupy the landscape at a lower density. A few classes, such as pepperweed, show some unexpected variability that could likely be eliminated with continued refinement of the spectral signatures. Continued development of spectral signatures specifically for the months of April and June would also likely improve the accuracy of classification for those months.

Spectral signatures were validated for the 2003 application of the RHAM through a process of comparing land cover classification with the raw imagery from which it was derived. Comparison of the classified imagery with the raw imagery indicated that the extents and locations of known vegetative communities were well-represented. As shown in Figure 4.16 below, the classification does an excellent job of conforming to the boundaries of vegetative communities.

For the 2004 application of the RHAM, accuracy of land cover classes was spot-checked during post-classification assessment using check points reserved from the ground truth data especially for this purpose. During field data processing, ground truth data was divided into subsets characterized by the dominance of an individual plant species or other land cover class. Each ground truth point was then randomly assigned to serve either as a training point or as a check point. Slightly less than half of all field data points were assigned to check point status. Using visual inspection, land cover classes appear to correlate adequately with check points. It would be beneficial to further validate the RHAM by incorporating a quantitative means of assessing accuracy. 


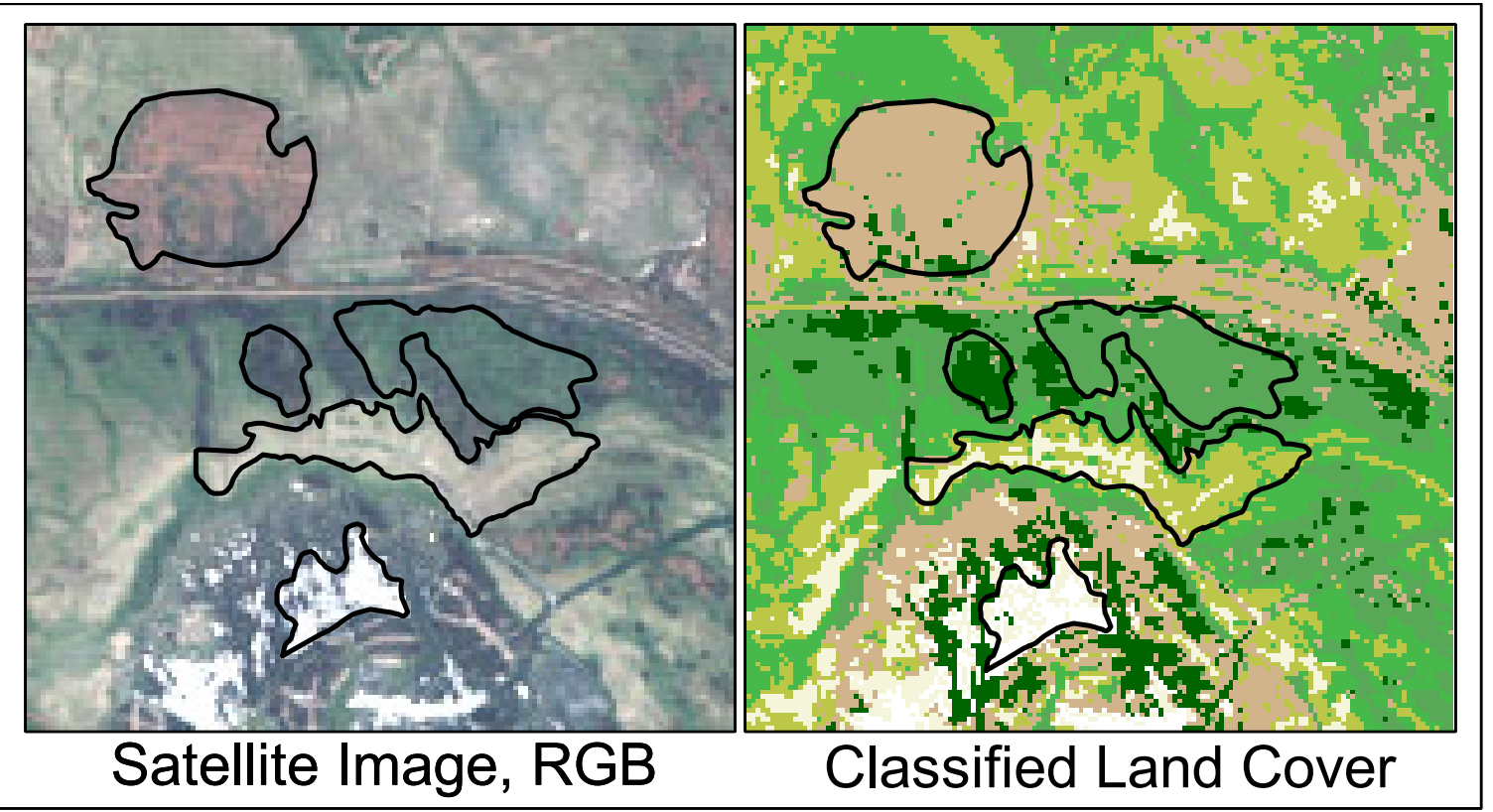

Figure 4.16 Spectral signature validation, 2003 RHAM. Nearly homogenous areas are delineated on the raw imagery and on the classified land cover map. Areas classified as uplands, permanent wetlands, open water, deep seasonal wetlands, and shallow seasonal wetlands all are apparent on the raw imagery.

\subsection{Discussion}

The RHAM described in this chapter can contribute to resource management programs in the Central Valley of California. Salinity TMDL's and other actions to control salt and nutrient loading from managed wetlands may have an impact on wetland hydroperiod, as drawdown is adjusted to match the San Joaquin River's assimilative capacity. The RHAM provides a tool to assess the long-term impact of these adaptive management strategies on the wetland resource. Results from this methodology may help provide a scientific basis for estimation of water needs of the moist-soil vegetation in managed seasonal wetlands. This research promotes better use of existing water resources to maximize wetland benefit with the possibility of long-term water saving.

From the waterfowl habitat perspective, this methodology has the potential to support the goals of the Central Valley Habitat Joint Venture (CVHJV). The CVHJV was established through a coalition of public, private, and nonprofit organizations to protect and restore 
wetlands and waterfowl populations in California's Central Valley. Functions of the CVHJV that the RHAM can promote are :

1. Enhancing habitat quality, not just quantity, particularly with regard to winter habitat for feeding birds;

2. Providing guidance for wetland managers on how to maximize productivity of their units;

3. Developing methods to maximize the efficiency of water use and enhance water quality, while concurrently developing realistic guidelines as to how much water is really needed, and when it is needed, for wetland dependent wildlife activities;

4. Providing a decision support tool and evaluation mechanism to promote wetland enhancement efforts of partners in the CVHJV. (The CVHJV has typically focused on acquisition and restoration of wetlands since it has proven difficult to assess or quantify habitat enhancement quantitatively.)

Given the wide range in seed production in Central Valley seasonal wetlands (200-1200 lbs/ac of moist soil seeds) wetland management for waterfowl habitat still appears to be an uncertain science in theory and in practice. The RHAM provides a reliable method that can be used at a valley-wide scale for evaluating management practices (Naylor, 2002, Eadie, 2003). The RHAM can also indirectly assist wetland managers in the more efficient use of water resources by helping to determine water use requirements for moist soil vegetation management. 


\section{CHAPTER 5 ESTIMATING SOIL SALINITY IN WETLANDS}

\subsection{Background}

Soil salinity is an important conservation and environmental problem in wetlands of the San Joaquin Basin. Salinity affects plant germination and development, and can lead to significant increases in salt tolerant species' populations, thereby creating imbalances in the wetland ecosystem. Consequently, it can also influence fauna diversity, such as invertebrate, fish, and bird. Thus, it is important to evaluate the extent and variability of soil salinity on those wetlands in order to develop sound planning and management practices for improving long-term habitat health and restoring wetlands.

Measurement methods such as the four-electrode probes and soil sampling are generally applied to determine soil salinity; however, these methods require extensive data collection and laboratory analyses that are very slow, labor-intensive, and expensive. Recently, remote sensing technologies have become easier to use for surveying salt-affected lands. Among those techniques, the electromagnetic induction (EM) method has been very efficient in rapidly collecting salinity information in soil systems (Ceuppens et al., 1997; Hendrickx et al.). Furthermore, the EM technology generally provides better and faster estimates of soil salinity than direct methods (Sudduth et al., 1999). The principle of the EM technique is based on the fact that electrical conductance increases with salinity. The instrument generates a primary electromagnetic field in the soil, which in turn creates a secondary field. The ratio of both fields correlates with the depth-weighted electrical conductivity (EC) in the volume of soil below the EM sensor (Slavish, 1990). Since solid soil particles and rock material have very low EC (McNeill, 1980), the instrument response is primarily influenced by the electrolyte concentration of the soil water, i.e., salinity.

\subsection{Objective of the Study}

The objective of the study was to assess and map soil salinity in wetlands of the Grassland Water District (Salinas Club) and the San Luis National Wildlife Refuge (NWR), located in the San Joaquin River Basin, using the EM technique. 


\subsection{Methodology}

Soil salinity surveys were conducted in April 2004 on selected lands of the San Luis National Wildlife Refuge (SLNWR), thereafter defined as San Luis Refuge, and the Salinas Club. Maps showing the locations of the surveys are presented in Figures 1 and 2. Two sites were surveyed at each wetland. Selection of the sites was based on representative soil conditions and vegetation population, as well as locations of previous ground plant identification. In June 2003, salinity surveys were also performed at the Salinas Club on the same sites

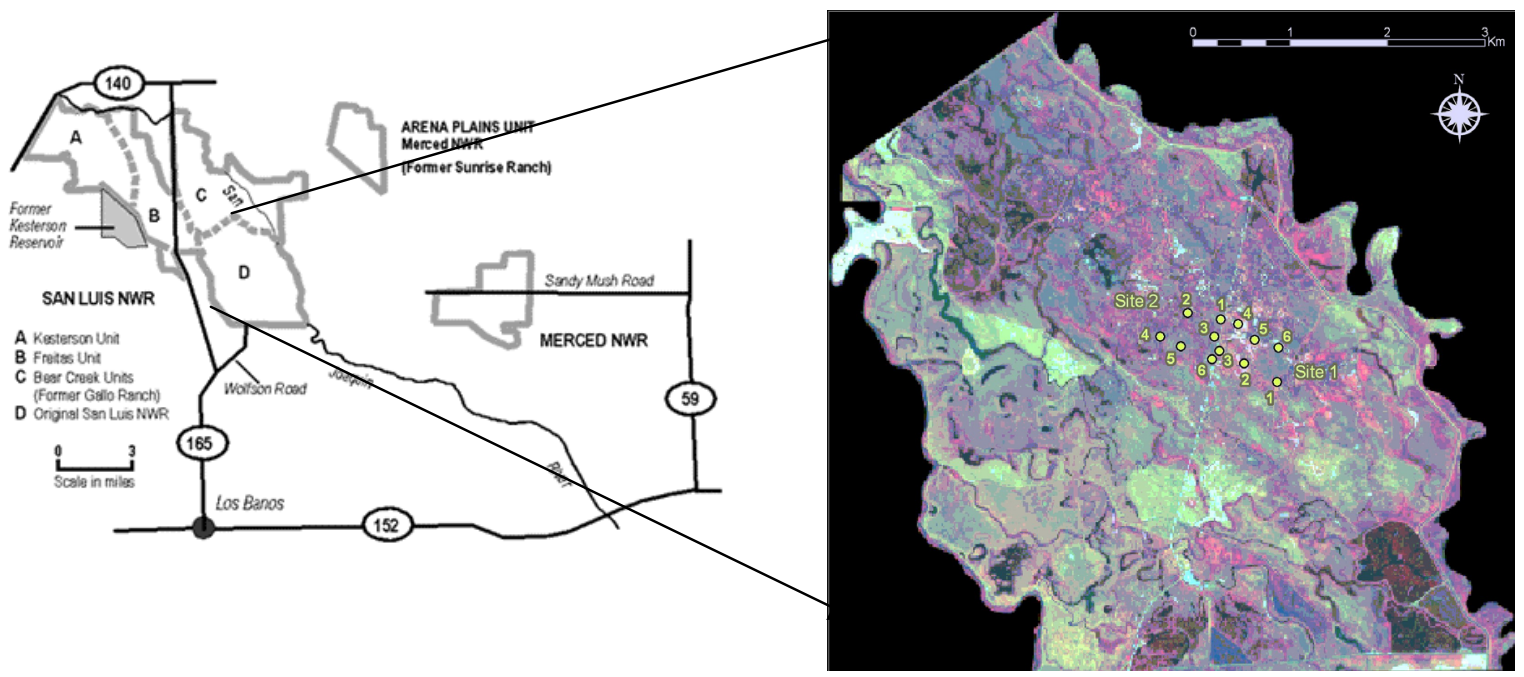

Figure 5.1. Location of sites surveyed at the SLNWR San Luis Unit

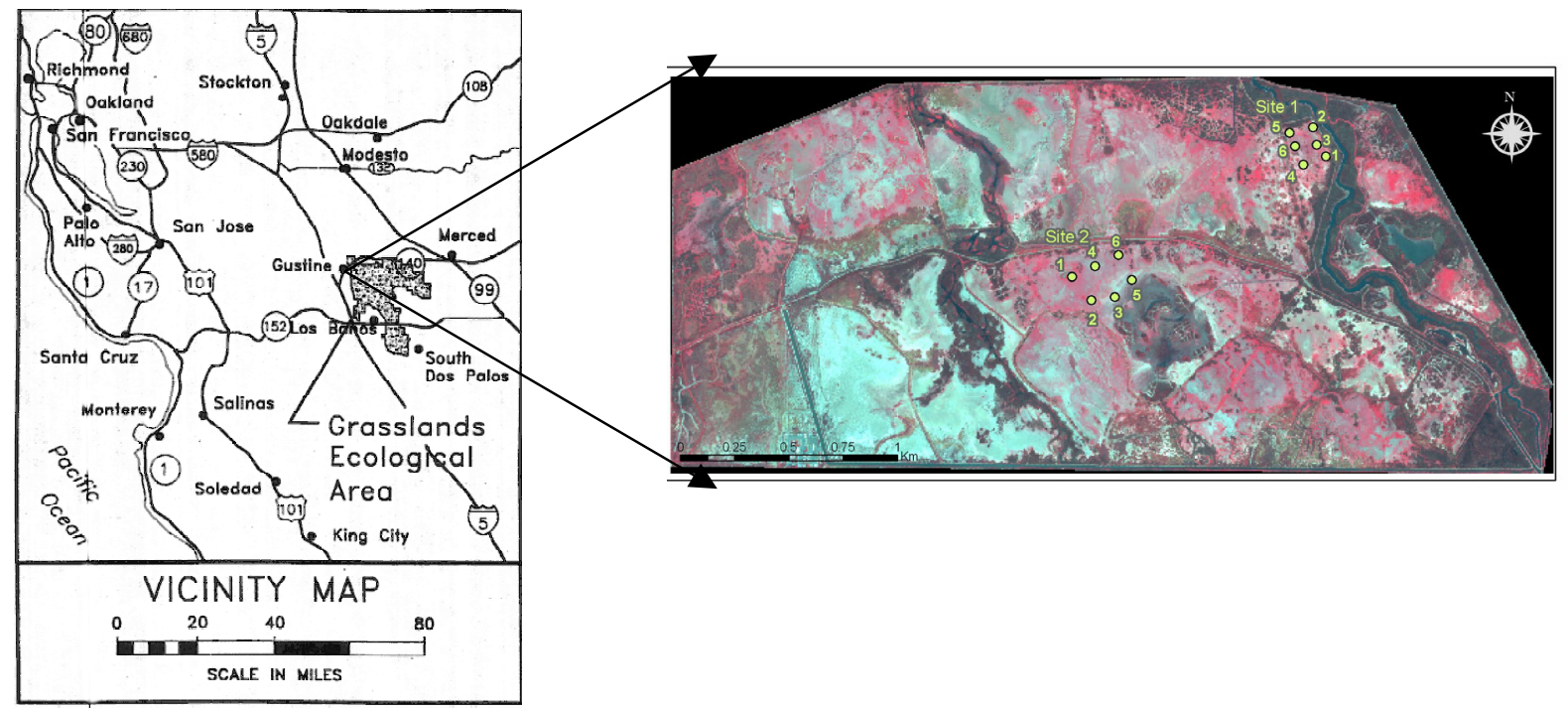

Figure 5.2. Location of sites surveyed at the Salinas Club 
The salinity surveys were conducted using a mobilized system available at the California State University, Fresno. This system comprised a geographical positioning system (GPS) and a dual EM-38 meter (Geonics Ltd) placed in a carrier-sled that was attached at the rear of an ATV and operated in both horizontal and vertical modes, providing bulk salinity estimates of both shallow (top 6 inches) and deep (top 6 feet) soils. Such system allowed for rapid salinity measurements (about 2 hours per survey), after initial setup, at both wetlands. The EM and GPS data were collected along transects spaced 150 to $300 \mathrm{ft}$ apart, depending on the extent of vegetation cover, and recorded simultaneously to a laptop computer. After the surveys, the data were analyzed using ESAP (Lesch and Rhoades, 1999) and a soil sampling plan was developed to calibrate the EM data.

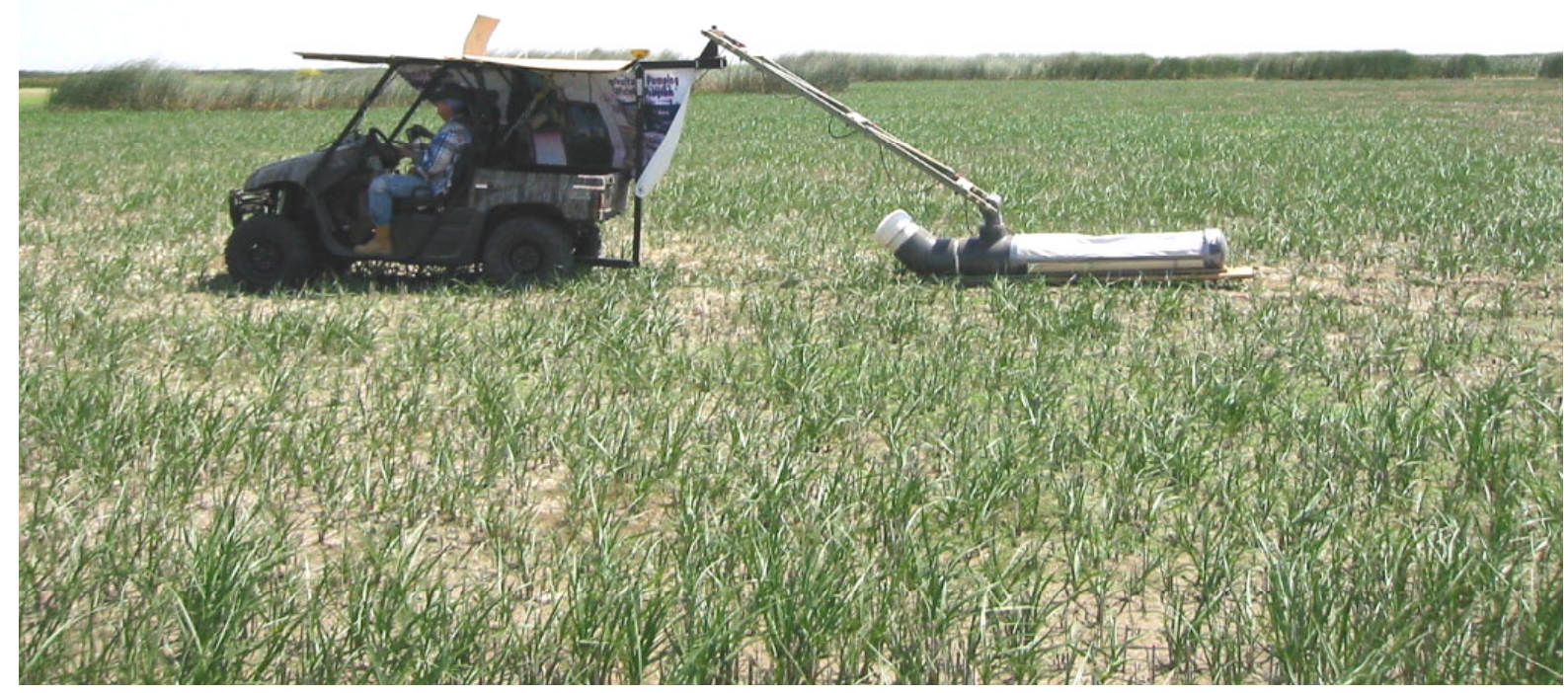

Figure 5.3 EM-38 dual mode meter (Geonics Ltd) placed in a carrier-sled that was attached at the rear of an ATV. Horizontal and vertical aligned coupled meters provide sensing of near-surface bulk salinity (top 6 inches) and deeper bulk salinity (up to 6 feet).

For each survey, the sampling plan comprised 6 locations that were spatially representative of the entire survey area. Ground truthing soil sampling was then conducted at each site. Soil 
samples were collected at 0-6" and 6-12" depths (associated with horizontal and vertical EM38 alignments of the dual instrument) and then analyzed for EC, moisture, texture, and total dissolved solids (TDS) following standard analytical methods (Rhoades, 1996). Based on the EM data and laboratory analyses, maps of soil salinity were generated for each site surveyed using GIS (Environmental System Research Institute, 1996). The San Luis NWR was included because of the large differences in moist soil plant diversity between the Refuge and the private duck clubs within Grassland Water District

\subsection{Results}

Table 5.1 presents the EC levels of soils sampled at the San Luis Refuge and Salinas Club. Sampling locations at each site are shown in Figures 5.1 and 5.2. Soil EC at the San Luis Refuge ranged from 0.4 to $19.8 \mathrm{dS} / \mathrm{m}$, indicating a high degree of variability across the surveyed areas. The EC levels were relatively lower at site 1 as compared to site 2 . Typically, higher EC values were observed in the first six inches of the soil profile in site 1, which could suggest lower drainage of water. At the Salinas Club, similar variability in the EC data was observed (1.3 to $18.3 \mathrm{dS} / \mathrm{m})$.

Table 5.1. Soil electrical conductivity $(\mathrm{dS} / \mathrm{m})$ for samples collected on all surveyed sites.

\begin{tabular}{|c|c|c|c|c|c|}
\hline \multirow{2}{*}{$\begin{array}{l}\text { Sampling } \\
\text { location }\end{array}$} & \multirow[t]{2}{*}{ Depth } & \multicolumn{2}{|c|}{ San Luis Refuge } & \multicolumn{2}{|c|}{ Salinas Club } \\
\hline & & Site 1 & Site 2 & Site 1 & Site 2 \\
\hline 1 & $\begin{array}{c}0-6 " \\
6-12 "\end{array}$ & $\begin{array}{l}12.2 \\
8.69\end{array}$ & $\begin{array}{l}3.34 \\
3.57\end{array}$ & $\begin{array}{l}13.6 \\
14.4\end{array}$ & $\begin{array}{l}4.38 \\
1.34\end{array}$ \\
\hline 2 & $\begin{array}{c}0-6 " \\
6-12 "\end{array}$ & $\begin{array}{l}3.80 \\
4.31\end{array}$ & $\begin{array}{l}1.86 \\
2.64\end{array}$ & $\begin{array}{l}6.75 \\
5.14\end{array}$ & $\begin{array}{l}5.42 \\
5.24\end{array}$ \\
\hline 3 & $\begin{array}{c}0-6 " \\
6-12 "\end{array}$ & $\begin{array}{l}2.02 \\
0.42\end{array}$ & $\begin{array}{l}4.21 \\
1.57\end{array}$ & $\begin{array}{l}6.71 \\
4.85\end{array}$ & $\begin{array}{l}18.3 \\
18.2\end{array}$ \\
\hline "'m"' & $\begin{array}{c}0-6 " \\
6-12 "\end{array}$ & $\begin{array}{l}2.28 \\
1.31\end{array}$ & $\begin{array}{l}7.54 \\
9.52\end{array}$ & $\begin{array}{l}4.19 \\
5.44\end{array}$ & $\begin{array}{l}3.91 \\
4.37\end{array}$ \\
\hline 5 & $\begin{array}{c}0-6 " \\
6-12 "\end{array}$ & $\begin{array}{l}1.67 \\
0.94\end{array}$ & $\begin{array}{l}19.8 \\
21.1\end{array}$ & $\begin{array}{l}3.28 \\
1.45\end{array}$ & $\begin{array}{l}8.41 \\
2.21\end{array}$ \\
\hline 6 & $\begin{array}{c}0-6 " \\
6-12 "\end{array}$ & $\begin{array}{l}1.44 \\
0.65\end{array}$ & $\begin{array}{l}6.63 \\
2.21\end{array}$ & $\begin{array}{l}4.12 \\
3.44\end{array}$ & $\begin{array}{l}4.63 \\
2.31\end{array}$ \\
\hline
\end{tabular}

The texture data indicated that the soils were loamy to clayey. The average EC values of the six samples collected at 0-6" and 6-12" depths in site 2 of the San Luis Refuge and sites 1 and 2 of the Salinas Club were comparable (Table 5.2). Site 1 at the San Luis Refuge exhibited 
the lowest average EC levels for both depths; all EC data were below $9 \mathrm{dS} / \mathrm{m}$. A high variability in the EC data was observed for all sites and depths, as indicated by the large standard deviations.

Table 5.2. Statistics for EC analyzed on all soil samples collected in 2004.

\begin{tabular}{|l|c|c|c|c|c|}
\hline Site & Depth & Mean & Std. dev. & Minimum & Maximum \\
\hline SLR, site 1 & $0-6 "$ & 3.90 & 4.14 & 1.44 & 12.2 \\
\hline & 6-12" & 2.72 & 3.25 & 0.42 & 8.69 \\
\hline SLR, site 2 & $0-6 "$ & 7.23 & 6.51 & 1.86 & 19.8 \\
\hline & $6-12 "$ & 6.76 & 7.58 & 1.57 & 21.1 \\
\hline SC, site 1 & $0-6 "$ & 6.44 & 3.8 & 3.2 & 13.6 \\
\hline & $6-12 "$ & 5.79 & 4.49 & 1.4 & 14.4 \\
\hline SC, site 2 & $0-6 "$ & 7.50 & 5.51 & 3.90 & 18.3 \\
\hline & 6-12" & 5.61 & 6.33 & 1.34 & 18.2 \\
\hline
\end{tabular}

$\mathrm{SLR}=$ San Luis Refuge, $\mathrm{SC}=$ Salinas Club

Table 5.3 shows the TDS results obtained from the soil analyses conducted on all samples. The TDS values followed the same trend observed with EC. The highest TDS values were observed in site 2 at the Salinas Club.

Table 5.3. Statistics for TDS analyzed on all soil samples collected in 2004.

\begin{tabular}{|l|c|c|c|c|c|}
\hline Site & Depth & Mean & Std. dev. & Minimum & Maximum \\
\hline SLR, site 1 & $0-6 "$ & 3138 & 2984 & 1300 & 9017 \\
\hline & $6-12 "$ & 2186 & 2436 & 467 & 6200 \\
\hline SLR, site 2 & $0-6 ”$ & 5967 & 5726 & 1480 & 16860 \\
\hline & $6-12 "$ & 6106 & 8096 & 350 & 21425 \\
\hline SC, site 1 & $0-6 "$ & 5537 & 4184 & 1620 & 12680 \\
\hline & $6-12 ”$ & 5087 & 4776 & 1880 & 14660 \\
\hline SC, site 2 & $0-6 "$ & 6330 & 4657 & 2960 & 14740 \\
\hline & $6-12 "$ & 4720 & 5923 & 1200 & 16600 \\
\hline
\end{tabular}

$\mathrm{SLR}=$ San Luis Refuge, $\mathrm{SC}=$ Salinas Club.

These soil laboratory data were used to calibrate the EM measurements and estimate soil salinity over the surveyed areas. For each site, the correlations between measured TDS and calculated conductivity data were above 0.8 , suggesting a high degree of survey reliability and accuracy for salinity estimation. The soil salinity levels estimated at 0-6" and 6-12" depths for the surveyed areas in 2004 at the San Luis Refuge are presented in Figures 5.3 and 5.4. The contour maps indicate that the soil salinity levels were generally higher in site 2 . Greater 
salinity was also observed at 0-6" depth as compared to the lower depths for both sites, suggesting that drainage could be poor on those sites. At site 1, the soil salinity was greatest in the western part of the surveyed area, and decreased gradually in a north-west direction. At site 2 , salinity was variable across the surveyed area. The greatest salinity problems were encountered in the south and north-east sections. Figures 5.5 and 5.6 show the soil salinity distribution at the two sites surveyed at the Salinas Club in 2004. The salinity levels did not exceed $16 \mathrm{dS} / \mathrm{m}$ at those locations

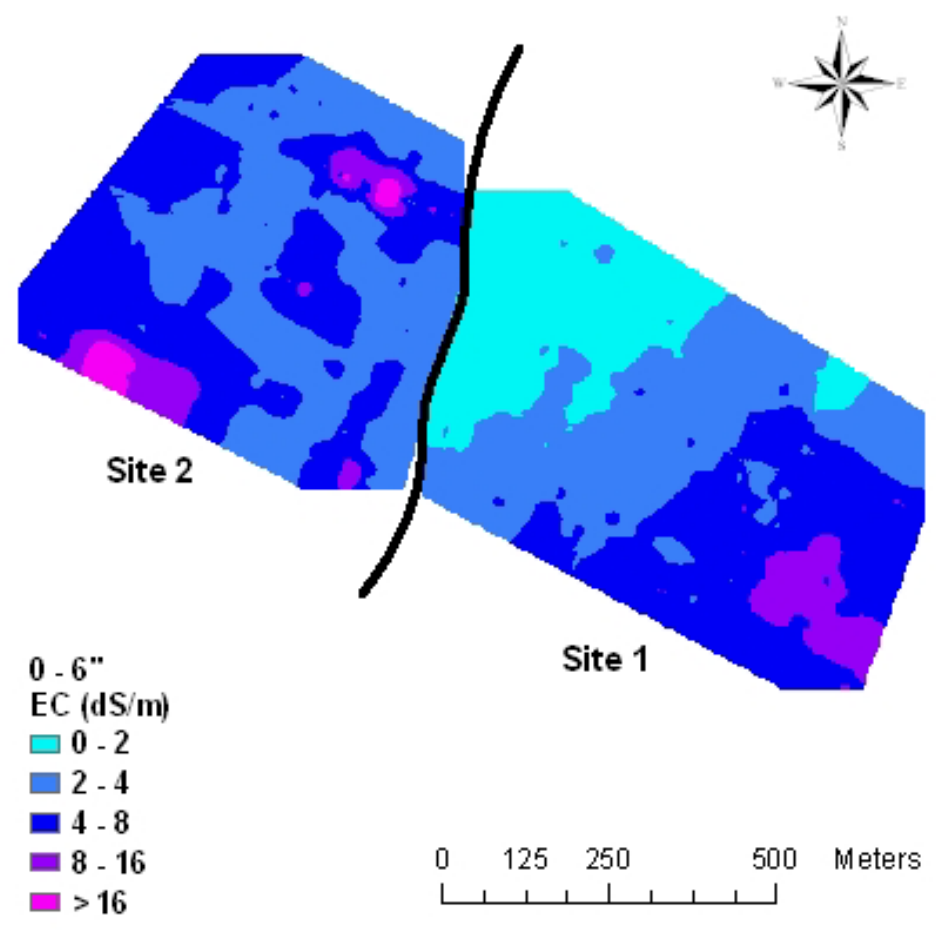

Figure 5.4. Soil salinity estimated at 0-6" depth on two sites surveyed at the San Luis Refuge in 2004

Although the salinity levels were not as variable as those observed at the San Luis Refuge, the salinity distribution was quite different between the 0-6" and 6-12" depths. On both sites, the salinity was higher at the soil surface (0-6"). At site 2 , the soil salinity levels remained mostly between 4 to $8 \mathrm{dS} / \mathrm{m}$ on surface, indicating low spatial variability in the surveyed area. However, at 6-12" depth, the site exhibited greater spatial variability with salinity values ranging from 0.3 to $15.7 \mathrm{dS} / \mathrm{m}$. 
In 2003, salinity surveys were also conducted at the Salinas Club on the same sites. Soil samples were collected at 0-12" for calibration of the EM measurements. Table 5.4 presents the statistics for EC and TDS analyzed on soils collected at the Salinas Club. Compared to 2004, the EC and TDS levels observed the previous years were higher in both sites; however the salinity variability was lower across the surveyed areas.

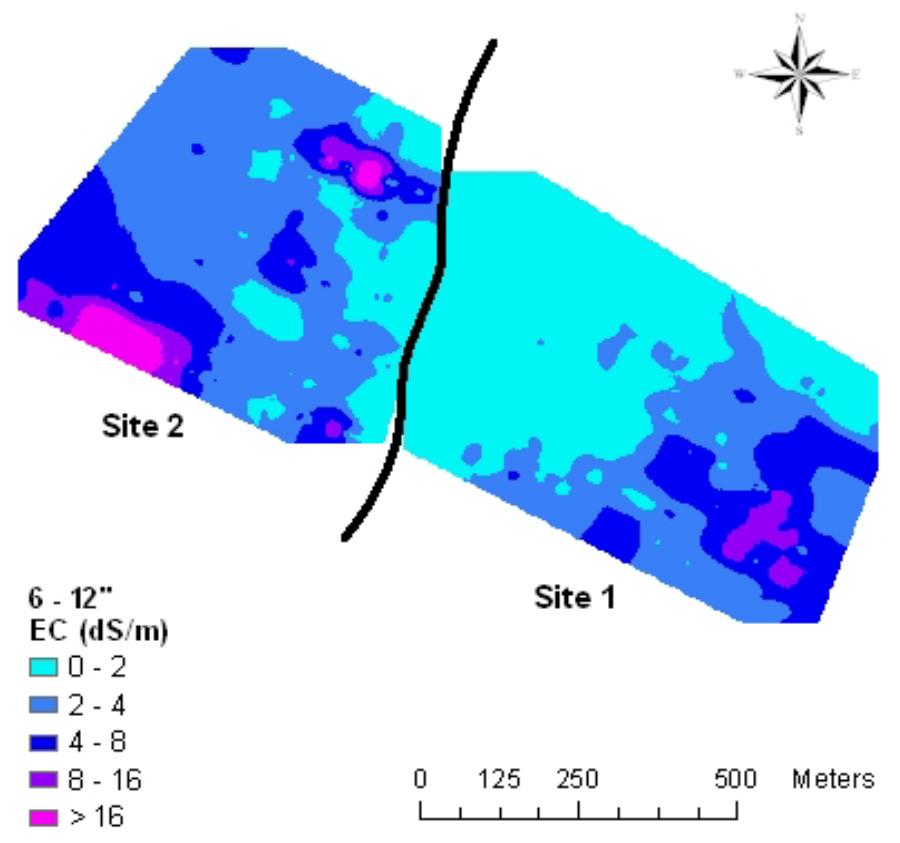

Figure 5.5 Soil salinity estimated at 6-12" depth on two sites surveyed at the San Luis Refuge in 2004
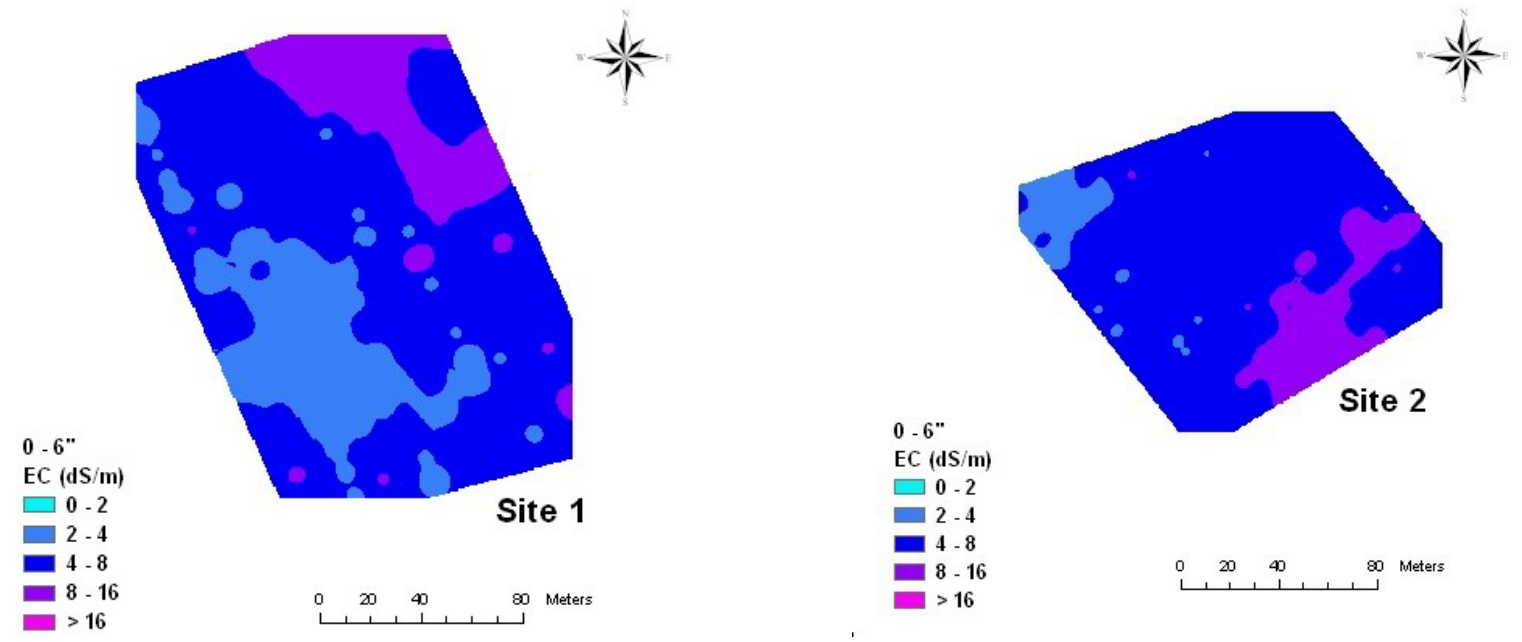

Figure 5.6. Soil salinity estimated at 0-6" depth on two sites surveyed at the Salinas Club in 2004. 


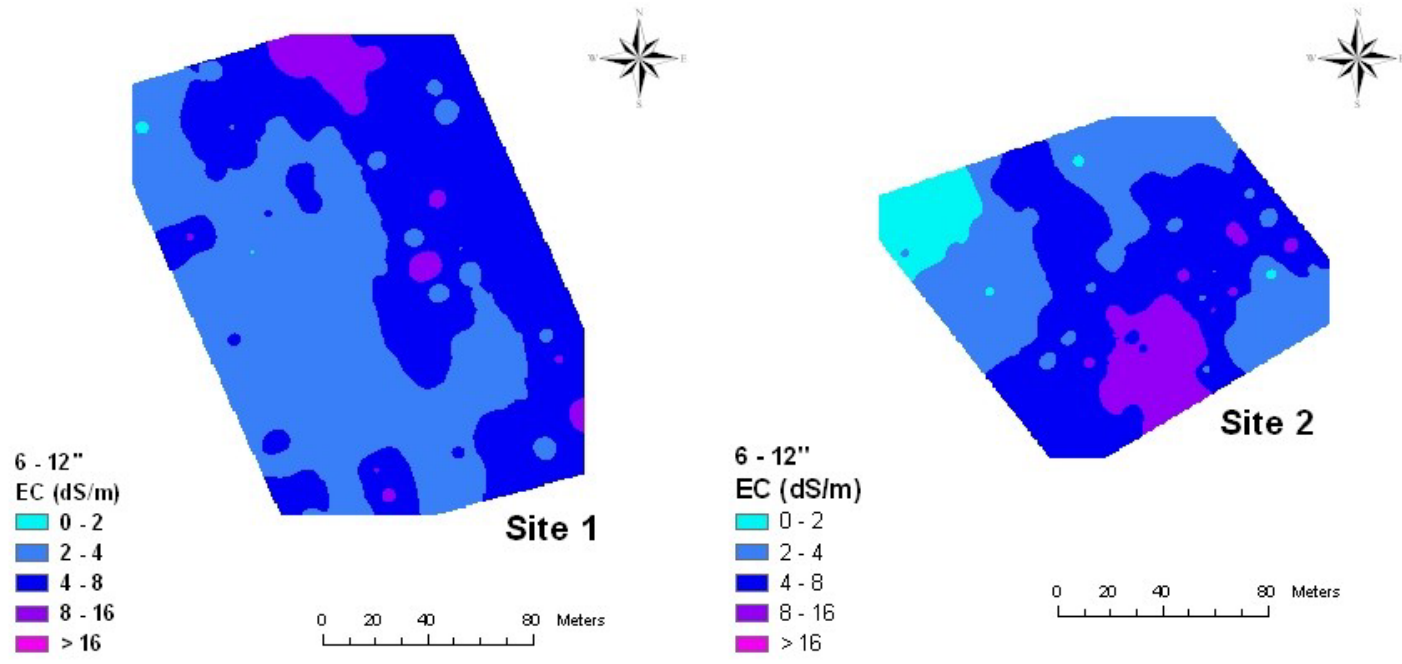

Figure 5.7. Soil salinity estimated at 6-12" depth on two sites surveyed at the Salinas Club in 2004.

Data analyses indicated a high degree of survey reliability and accuracy for predicting salinity levels on both sites. The soil salinity maps generated at each site are presented in Figures 5.7 and 5.8. The mobile system was not used for conducting the 2003 salinity surveys at the Salinas Club; thus, the surveys were performed on smaller areas. Site 1 showed a very uniform salinity pattern, with values ranging from 8 to $16 \mathrm{dS} / \mathrm{m}$. At site 2 , a higher salinity variability was observed across the survey area. However, the salinity levels were lower than $8 \mathrm{dS} / \mathrm{m}$ in most areas.

Table 5.4. Statistics for EC and TDS analyzed on all soil samples collected in 2003 at the Salinas Club.

\begin{tabular}{|l|c|c|c|c|c|}
\hline Site & Depth & Mean & Std. dev. & Minimum & Maximum \\
\hline EC - site 1 & $0-12 ”$ & 11.0 & 2.5 & 8.4 & 14.8 \\
\hline EC - site 2 & $0-12 "$ & 4.4 & 0.8 & 3.3 & 5.7 \\
\hline & $12-24 ”$ & 6.7 & 3.1 & 2.0 & 10.6 \\
\hline TDS - site 1 & $0-12 "$ & 9235 & 2333 & 6797 & 12780 \\
\hline TDS - site 2 & $0-12 "$ & 3334 & 690 & 2453 & 4385 \\
\hline & $12-24 ”$ & 5376 & 2628 & 1381 & 8830 \\
\hline
\end{tabular}

$\mathrm{SLR}=$ San Luis Refuge, $\mathrm{SC}=$ Salinas Club 

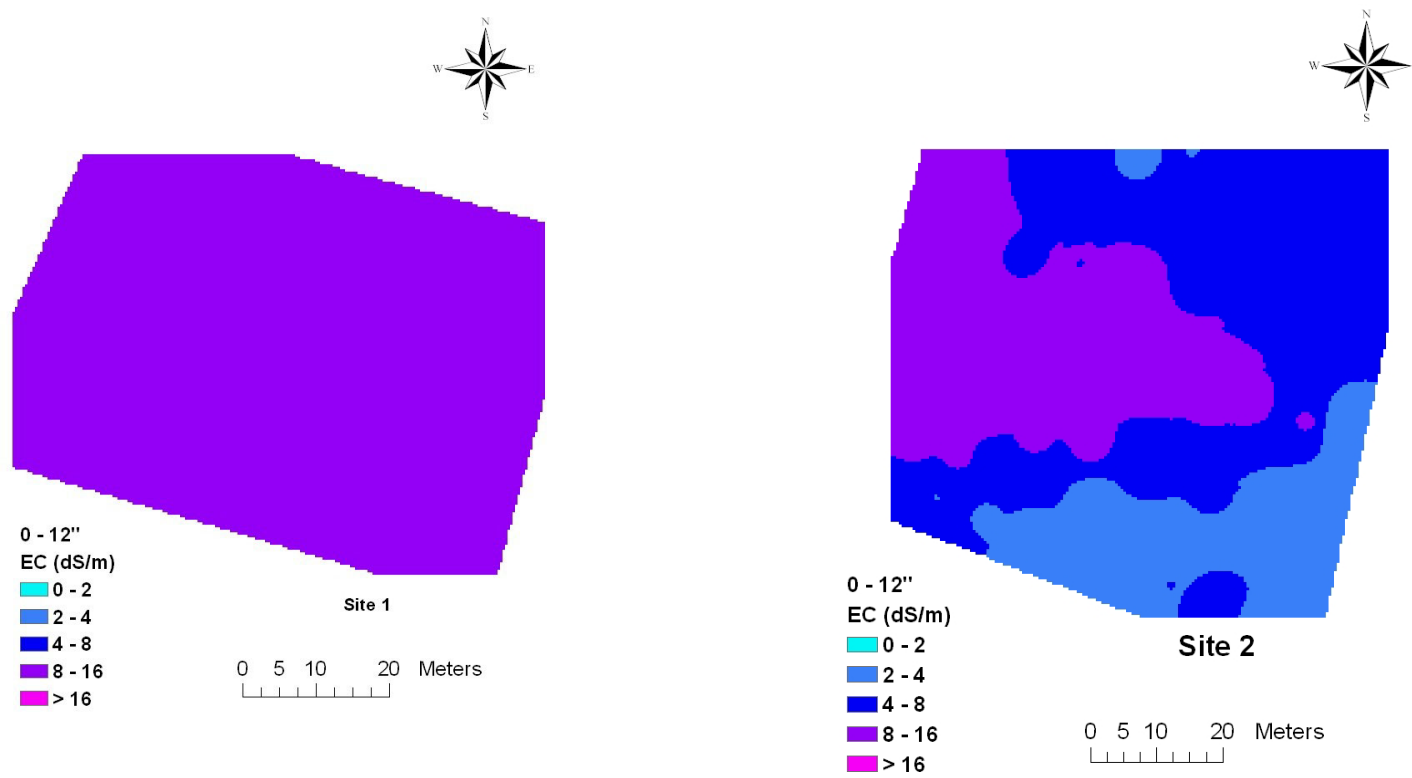

Figure 5.8. Soil salinity estimated at 0-12" depth on two sites surveyed at the Salinas Club in 2003

\subsection{Conclusions}

The results of the study indicated that the EM technique was very effective to accurately assess soil salinity distribution across the surveyed areas of the San Luis Refuge and Salinas Club wetlands. The soil profile shapes (regular or inverted), indicative of drainage management practices, could be suggested from the salinity surveys and soil sampling at various depths. The EM surveys indicated that the soil salinity levels were relatively high on both wetlands, and particularly at the San Luis Refuge at site 2. Therefore, it is advisable to improve drainage management practices on those wetlands to increase flora and fauna diversity and ameliorate wetland habitat.

The soil salinity survey technique described in this section, when combined with the remote sensing methodology described in Chapter 4 should form the basis of a physically-based (as opposed to biologically based) assessment of baseline conditions in advance of a wetlandwide strategy of real-time management of seasonal drainage. These techniques will allow wetland managers to document any long-term changes in wetland soil salinity conditions and take appropriate management actions to avoid the type of damage to the wetland resource that 
occurred in the Southern Division of the Grassland Water District. Changes in the health of the wetland resource occurs slowly and insidiously requiring a quantitative approach to assessment. The techniques described in Chapters 4 and 5 should be further refined to improve their accuracy and reduce their cost. 


\section{CHAPTER 6 CONCLUSIONS}

\subsection{Summary}

The Real-Time Adaptive Wetland Water Quality Management Research Project was designed to better manage the seasonal wetland drainage contribution to San Joaquin River salinity. To accomplish this project goal decision support tools were developed to improve understanding of seasonal wetland salt mass balance and to assess potential impacts on habitat quality of actions to improve water quality in the San Joaquin River. The tools developed for this project include:

1. A real-time flow and salinity data acquisition network for use in seasonal wetlands;

2. A wetland water quality model focusing on salt exports from the Grassland Water District to the San Joaquin River;

3. Results from theoretical application of adaptive wetland drawdown schedules for better coordination with the salt assimilative capacity of the San Joaquin River.

4. A remote habitat assessment methodology for measuring the impacts of alternative wetland drawdown schedules on moist-soil plant production.

These decision support tools provide a resource to wetland managers to adaptively respond to San Joaquin River salt discharge opportunities while maximizing long-term wetland function and habitat value. Adaptive management can be defined as "changing or altering management decisions based on past or current conditions, either physical or political" (Chess et al., 2000). The Decision Support System (DSS) assists in the computation of GWD wetland water requirements including an estimation of wetland salinity loads in seasonal wetlands. The DSS was designed to interact with the existing SJR water quality forecasting model, SJRIODAY, to allow the partition of assimilative capacity among the wetland releases (Quinn and Hanna, 2003).

Decision Support Systems are becoming more important to ecosystem managers. As the habitat value of the GWD increases so do the impacts of their decisions. As concerns over water quality conditions in the San Joaquin River increase - tools that combine information from several disciplines allow general practitioners to make better informed decisions (Chess et al., 2000; Young et al., 2000). For further details of the decision support system utilizing a former version of the WWQM, see Appendix 4 - Quinn, N. W. T., and W. M. Hanna, 2003. 
A decision support system for adaptive real-time management of seasonal wetlands in California. Environmental Modelling and Software, Volume 18, Issue 6.

\subsection{GWD -Project Geographic Information System}

The results from modeling scenarios were automatically loaded into a Microsoft Access database for use with Geographic Information System (GIS) software. The GIS assists the wetland manager develop salinity forecasts salinities on individual wetlands (Figure 2) allowing drainage from each to be scheduled. Included in the GIS, for each wetland unit, are useful information to the water master. This information includes:

1. the name of the wetland unit;

2. the wetland unit's owner's name and phone number;

3. the location of the wetland unit and its upstream and downstream neighbors;

4. the water supply and drainage canals, including the drainage basin;

5. the total area, total wetland area, and total upland area;

6. the total water and salt remaining on the property;

7. the management goals, either habitat or cattle club;

8. satellite, mapped, and schematic images of the wetland unit; and

9. contact phone numbers where the wetland manager can be reached.

This information will allow GWD staff to quickly ascertain wetlands where salinity is accumulating fastest, whether they will be draining earlier (cattle club) or later (habitat club), what drainage basin this may impact, and who to contact when decisions are made.

\subsection{Discussion}

The research performed for this project has provided several useful results that can be immediately applied to wetland "best management practices" (BMP). Results from the research have shown that real-time data acquisition is feasible in seasonal wetlands 


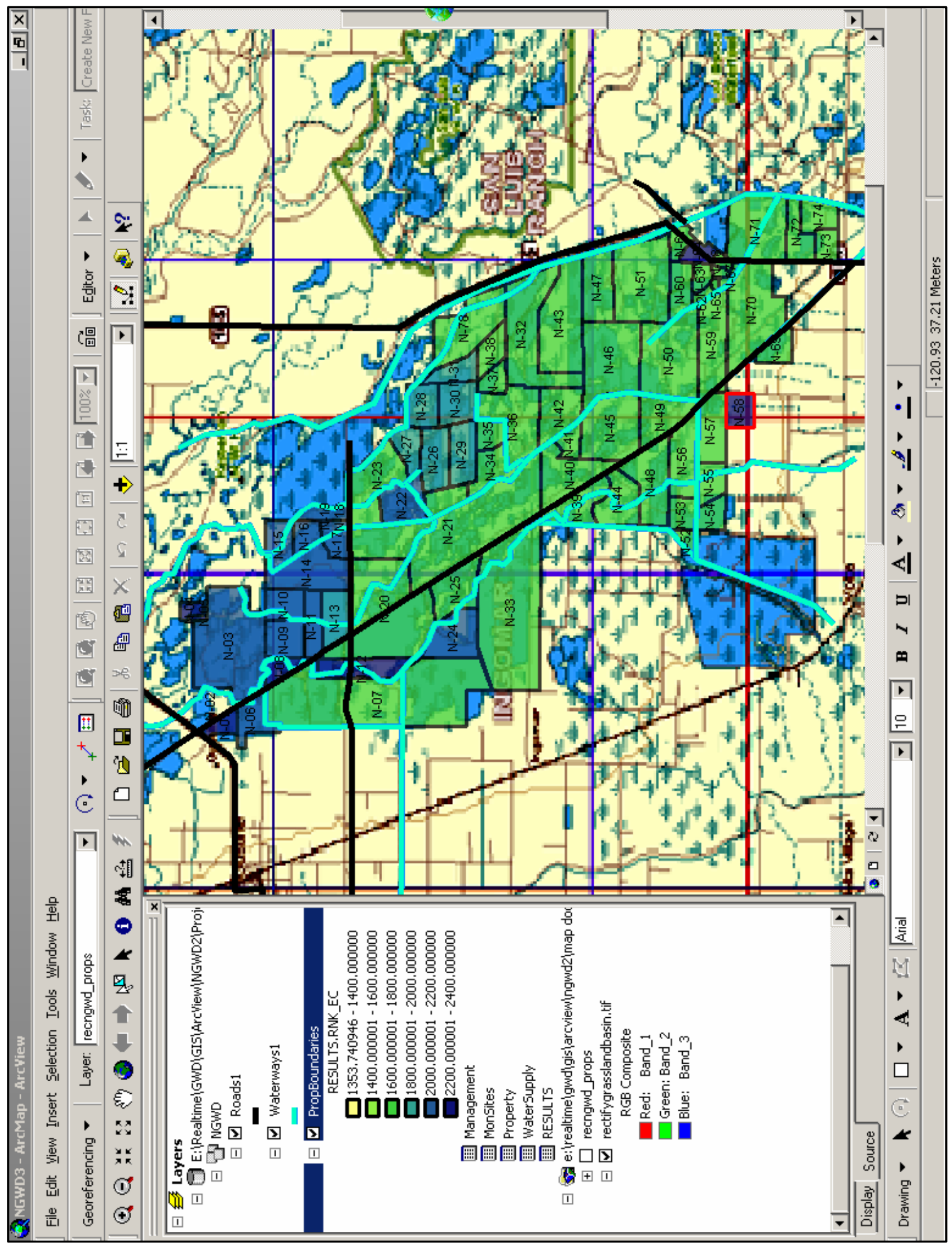

Figure 6.1 Geographical Information System (GIS) for the North Grassland Water District 
and can meet regulatory requirements under EPA mandated TMDL's. The same data can also be used to develop and run a wetland water quality model, providing the capability to forecast wetland salinity levels during the drawdown period. These forecasts, when compared to the San Joaquin River assimilative capacity forecasts for salts, can help decision makers adaptively manage salt export. Use of remote sensing techniques to monitor moist soil plant impacts and mobile salinity sensors to map longer term soil salinity impacts - a methodology has been created to aid the development of sustainable best management practices.

Information obtained through this project will be transferable and of significant value to all wetlands in the Grassland Ecological Area including State and Federally managed wetlands. The successful implementation of this combined monitoring, experimentation and evaluation program can provide the basis for adaptive management of wetland drainage throughout the entire 70,000 hectare Grassland Ecological Area. The project will involve local landowners, duck club operators, and managers of State and Federal refuges in the Grassland Basin. Although this pilot project has concentrated on the 20,000 hectares that comprise the GWD, the goal of the project is to disseminate the findings of the project more widely. The Grassland Water District has a successful history of local involvement through the District newsletter high school and college-level educational outreach programs; and "Wild on Wetland" days which educate the public about the benefits and techniques of wetland management.

Currently there are three types of wetland management strategies practiced in the Grassland Water District. These are:

1. Habitat Clubs; Duck Clubs enrolled in the Pressley Program;

2. Cattle Clubs; Duck Clubs that graze cattle in the non-hunting season

3. Clubs that follow a variety of management plans.

Habitat clubs are clubs that are enrolled in a habitat management reimbursement program or manage their lands in a similar manner. An example of a habitat management reimbursement program is the California Department of Fish and Game's Pressley Program. 
The Pressley Program pays the landowner approximately $\$ 20$ per acre for every acre managed under their habitat guidelines. These types of management practices usually promote a later drawdown into late March to early April. Cattle club managers manage their lands in the off-season for cattle grazing. Because of this use, managers tend to drain their wetlands early to promote the growth of grasses. The remaining clubs have no clear goal or precise management strategy. These clubs should be the first priority for applying this DSS to meet their goals, whatever those goals may be. It must be understood that although the GWD is a seasonal contributor of salts to the San Joaquin River, there are other such entities that may also be able to improve their operations.

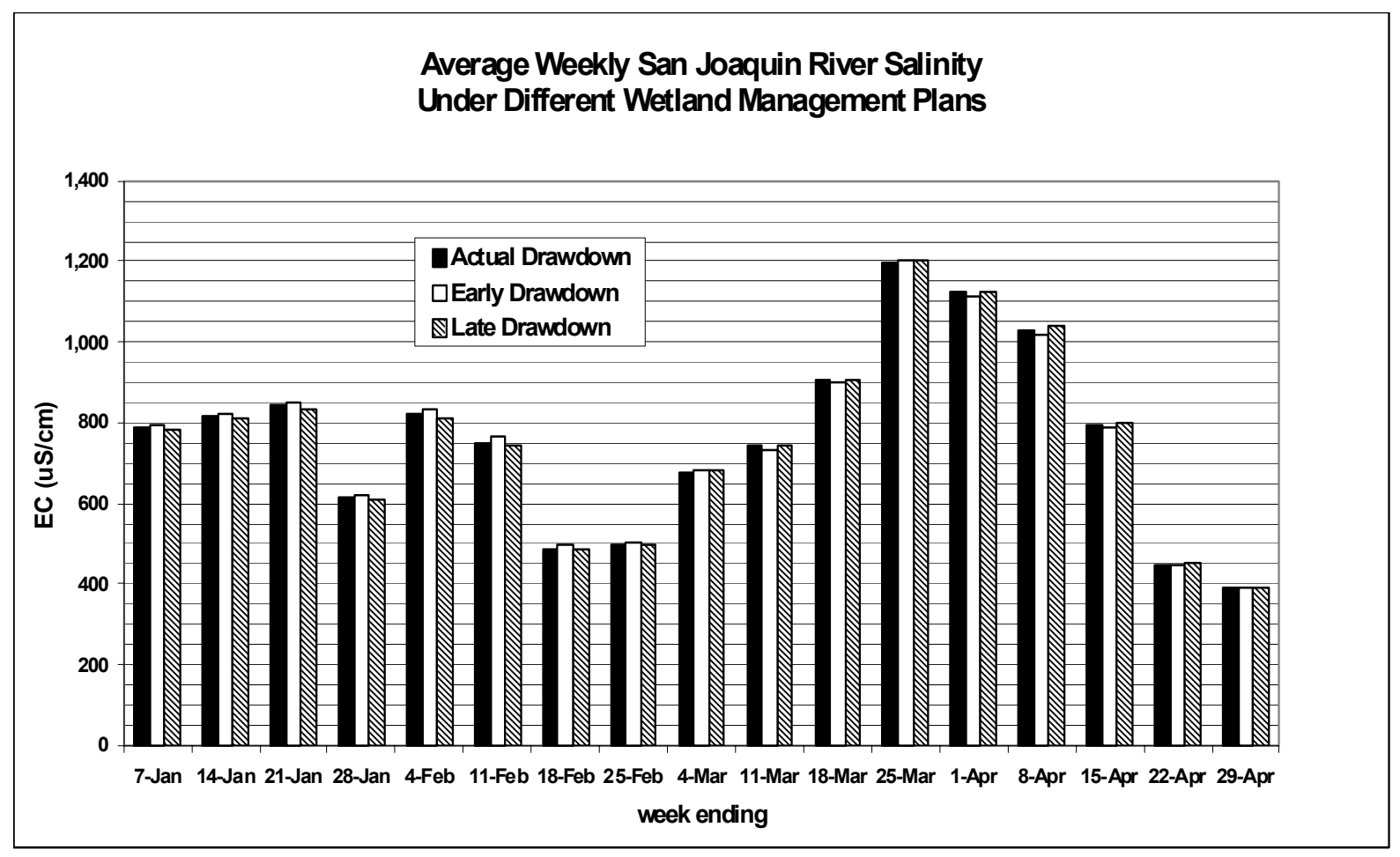

Figure 6.2 Modeled San Joaquin River salinity under different drawdown schedules.

This project has demonstrated the ability to coordinate wetland drainage activities contributing to water quality impairments the San Joaquin River. If a basin-wide effort, combining the activities of environmental, agricultural, municipal and industrial interests is implemented, water quality compliance with environmental objectives in the San Joaquin River is possible. 


\subsection{REFERENCES}

Allen, R.G., L.S. Pereira, D. Raes, and M. Smith. 1999. Crop evapotranspiration: Guidelines for computing crop water requirements. FAO Irrigation and Drainage Paper 56, FAO, Rome.

Aragues, R., Tanji, K.K., Quilez, D., Alberto, F., Faci, J., Machin, J., Arrue, J.L. 1985. Calibration and verification of an irrigation return hydrosalinity model. Irrigation Science, Vol. 6.

Arnold, J.G., Srinivasan, R., Muttiah, R.S., and Williams, J.R. 1998. Large Area Hydrologic Modeling and Assessment, Part I: Model Development. Journal of the American Water Resources Association, Vol. 34, No. 1

Bay-Valley Consultants. 1971. Recommended water quality management plan. Sacramento River Basin, San Joaquin River Basin, Sacramento-San Joaquin Delta. Report to the California State Water Resources Control Board.

Bundy, R.M. 1997. Hydrology influences on vegetation response in a managed moist-soil impoundment. Master's Thesis, University of Missouri-Columbia.

California Department of Water Resources. 1969. Lower San Joaquin River water quality investigation. Bulletin No. 143-5. Dept. of Water Resources, Sacramento.

California Environmental Protection Agency, 2002. Total Maximum Daily Load for Salinity and Boron in the Lower San Joaquin River. Staff report by the Regional Water Quality Control Board, Central Valley Region.

CNPS, 2003. California Native Plant Society, Vegetation Sampling Program, Sampling Protocols and Projects. http://www.cnps.org, Sacramento, CA

Campbell, M.B. 1988. Ownership and recreational use of wetlands in the Grassland Water District and refuges of the Central San Joaquin Valley. Federal-State San Joaquin Valley Drainage Program, U.S. Bureau of Reclamation.

Chess, Caron; Billie Jo Hance, Ginger Gibson, 2000 Adaptive Participation In Watershed Management. Journal of Soil and Water Conservation vol 55, no 3.

Clemmens, A.J., T.L. Wahl, M.G. Bos, and J.A. Replogle. 2001. Water Measurement With Flumes And Weirs, ILRI Publication 58 (2001).

CRWQCB, 2000. Review of selenium concentrations in wetland water supply channels in the Grassland watershed. California Regional Water Quality Control Board, Jeanne Chilcott, CRWQCB, Sacramento, CA 95827 
Cogswell, H.L. 1977. Water Birds of California. California Natural History Guides:40. University of California Press. 399 pages.

Comiso, J. 1995. Unsupervised classification of arctic sea ice using neural network. International Geoscience and Remote Sensing Symposium, Firenze, Italy. Ppg. 414-418

Cooper, A.B., Bottcher, A.B. 1993. Basin-scale modeling as a tool for water-resource planning. Journal of Water Resources Planning and Management, Vol. 119, No. 3.

Ceuppens, J., M.C.S. Wopereis, and K.M. Miézan. 1997. Soil salinization processes in rice irrigation schemes in the Senegal River Delta. Soil Sci. Soc. Am. J. 61:1122-1130.

Eadie, J., 2003. Conversation regarding remote sensing of Central Valley Wetlands and the possible use with the CVJHV. Davis, CA, April 29, 2003

Environmental System Research Institute. 1996. ArcView GIS. Environmental System Research Institute, Inc. Cambridge, England.

Fredrickson, L. 1991. Strategies for Water Level Manipulations in Moist-Soil Systems. United States Fish and Wildlife Leaflet 13.4.6, of the Waterfowl Management Handbook

Fredrickson, L.H.,Taylor T.S. 1982. Management of seasonally flooded impoundments for wildlife. Resource Publication 148. U.S. Dept. of the Interior, Fish and Wildlife Service, Washington, D.C.

Glenn, E., Thompson, T.L., Frye, R., Riley, J., Baumgartner, D. 1995. Effects of salinity on growth and evapotranspiration of Typha domingensis Pers. Aquatic Botany, Vol. 52, ppg. $75-91$

Grassland Water District, 2001. Land Use and Economics Study, Grassland Ecological Area, Merced County, California. Report prepared by Thomas Reid Associates, Palo Alto, CA, and Strong Associates, Oakland, CA. July, 2001.

Grassland Water District. 1986. Ecological and Water Management Characterization of Grassland Water District. California State Water Resources Control Board and Central Valley Water Quality Control Board. Prepared by the Grassland Water District and the Grassland Water Task Force with assistance from Jones \& Stokes Associates, Inc., Summers Engineering, Inc., Stoddard \& Associates. 61 pp.

Grober, L.F., Karkoski J., Poole T. 1995. Water quality impact of wetlands on San Joaquin River, California, paper no. 00149 In T.G. Cleveland [ed.], Advances in the development and use of models in water resources: Proceedings of the American Water Resources Association held in Houston, Texas, November 5-10, 1995. Department of Civil and Environmental Engineering, University of Houston, Houston, Texas. 
Hendrickx, J.M.H., B. Baerends, Z.I. Raza, M. Sadig, and M.A. Chaudhry. 1992. Soil salinity assessment by electromagnetic induction of irrigated lands. Soil Sci. Soc. Am. J. 56:1933-1941.

Isola, C.R. 1998. Habitat use by foraging waterbirds in the Grasslands of California's Northern San Joaquin Valley. Master's Thesis, California State University, Humboldt.

Itenfisu, D., R.L. Elliot, R.G. Allen and I.A. Walter. 2000. Comparison of Reference Evapotranspiration Calculations across a Range of Climates. Proc. of the National Irrigation Symposium, November 2000, Phoenix, AZ, American Society of Civil Engineers, Environmental and Water Resources Institute, New York, NY

Karaka, M., Wirth, A., Ghil, M. 1999. A box model for the paleoceanography of the Black Sea. Geophysical Research Letters, Vol. 26, No. 4.

Knisel, W.G. 1980. CREAMS, A field scale model for Chemicals, Runoff, and Erosion from Agricultural Management Systems. USDA Conservation Research Report No. 26, U.S. Dept. of Agriculture, Washington, D.C.

Lesch, S.M., and J.D. Rhoades. 1999. ESAP-95 Software Package Version 2.01R. USDAARS, George E. Brown Jr. Salinity Laboratory, Riverside, CA.

Letey, J. 2001. Salinity, drainage, toxics continue to plague agricultural activities. Currents: A Newsletter of the UC Center for Water Resources, Vol 2, No. 1.

Link, W.A., Barker, R.J., Sauer, J.R., Droege, S. 1994. Within-site variability in surveys of wildlife populations. Ecology, Vol. 74, No. 5.

Lower, T., 2001. Conversation regarding wetland flow through and make-up water for the seasonal wetlands in the Grassland Water District. Los Banos, California. September 2001

Lower, S., 2003. Conversation regarding wetland drawdowns, irrigations, and peak vegetative periods in the wetlands of the Grassland Water District. Los Banos, CA, April 23,2003

Mason, H.L. 1969. A Flora of the Marshes of California. University of California Press. 879 pages.

McNeill, J.D. 1980. Electrical conductivity of soils and rocks. Tech. Note TN-5. Geonics Ltd., Mississauga, ON, Canada.

Mushet, D.M., Euliss, Jr., N.H., Harris, S.W. 1992. Effects of irrigation on seed production and vegetative characteristics of four moist-soil plants on impounded wetlands in California. Wetlands, Vol. 12, No. 3. 
Naylor, L. 2002. Evaluating Moist-Soil Seed Production and Management in Central Valley Wetlands to Determine Habitat Needs for Waterfowl. M.S. Thesis, University of California, Davis. 85 ppg.

Novotny, V., Capodaglio, A., Jones, H. 1992. Real-time control of wastewater treatment operations. Water Science and Technology, Vol. 256, No. 4-5

Orlob, G.T., Ghorbanzadeh, A. 1981. Impact of water resource development on salinization of semi-arid lands. Agricultural Water Management, Vol. 4.

Oster, J.D., Rhoades, J.D. 1975. Calculated drainage water compositions and salt burdens resulting from irrigation with river waters in the Western United States. Journal of Environmental Quality, Vol. 4, No. 1.

Owen, C.R. 1995. Water budget and flow patterns in an urban wetland. Journal of Hydrology, Vol. 169, ppg. 171-187

Ozesmi, S., Bauer, M., 2002. Satellite remote sensing of wetlands. Wetlands Ecology and Management. Vol. 10, ppg. 381-402

Poole, T., 2003. Conversation regarding wetland drawdowns, irrigations, and peak vegetative periods in the wetlands of the Grassland Water District. Los Banos, CA, April 23, 2003

Quinn, N.W.T., Chen, C.W., Grober, L.F., Kipps, J., Cummings, E. 1997. Computer model improves real-time management of water quality. California Agriculture, Vol. 51, No. 5.

Quinn, N. W. T., and W. M. Hanna, 2003. A decision support system for adaptive real-time management of seasonal wetlands in California. Environmental Modelling and Software, Volume 18, Issue 6, ppg. 503-511

Quinn, N.W.T., Karkoski, J. 1998. Real-time management of water quality in the San Joaquin River Basin, California. American Water Resources Association, Vol. 34, No. 6.

Quinn, N.W.T., 1999. A Decision Support System for Real-Time Management of Water Quality in the San Joaquin River. California Environmental Software Systems. Environmental Information and Decision Support $3{ }^{\text {rd }}$ International Symposium on Environmental Software Systems (ISESS'99). Edited by Ralf Denzer, David A. Swayne, Martin Purvis, and Gerald Schimak. Publisher: Kluwer Academic Publishers, Massachusetts.

Rhoades, J.D. 1996. Salinity: Electrical conductivity and total dissolved salts. In D.L. Sparks (Ed.) Methods of Soil Analysis, Part 3 Chemical Methods. American Society of Agronomy, Madison, WI.

Rosenberg, K. V., Sillett, T. S. 1991 Shorebird use of agricultural fields and mini-refuges in Louisiana's rice country. Final Report, Louisiana State University, Museum of Natural Science. 
Rundel, P.W., Vankat, J.L., 1989. Chaparral communities and ecosystems. In: Keeley, S. (Ed.) The California Chaparral, Paradigms Reexamined. Los Angeles County Museum of Natural History, Los Angeles, pp. 127-139.

Shuford, W.D., Humphrey, J.M., Nur, N. 1999. Surveys of nesting terns and cormorants in California's Central Valley in 1998. Final report of Point Reyes Bird Observatory. Contribution No. 722 of PRBO.

Shuford, W.D., Page, G.W., Kjelmyr, J.E. 1998. Patterns and dynamics of shorebird use of California's Central Valley. The Condor, Vol. 100.

Sibley, D.A. 2000. National Audubon Society: The Sibley Guide to Birds. Alfred A. Knopf, Inc. Publishers, New York, New York. 544 pages.

Small, A. 1974. The Birds of California. Collier Books (Macmillan Publishing), New York, New York. 310 Pages.

Smith, W.D., Rollins, G.L., Shinn, R.L. 1995. A Guide to Wetland Habitat Management in the Central Valley. California Dept. of Fish and Game, California Waterfowl Ass., Sacramento, CA. 34 pp.

Snyder, R.L., Orang, M., Matyac, S., and Eching, S., 2002. Reference Crop Evapotranspiration. Published by the California Irrigation Management Information System (CIMIS) at http://www.cimis.water.ca.gov/ Copyright - Regents of the University of California.

Stoddard \& Associates, 1998. Water management plan for Grassland Water District. Report for the Grassland Water District, Los Banos, CA. 72 pp.

Sudduth, K.A., N.R. Kitchen, and S.T. Drummond. June 1999. Soil conductivity sensing on clay pans: comparison of electromagnetic induction and direct methods. In Geonics Limited (Ed) Applications of electromagnetic methods: Agriculture. Geonics Ltd., Mississauga, ON, Canada.

Swanson, G.A. 1988. Aquatic Habitats of Breeding Waterfowl. In: Hook et al. (Eds.) Ecology and Management of Wetlands, Vol. 1: Ecology of Wetlands. Timber Press, Portland, Oregon. 592 pp.

Tanji, K.K. 1977. A conceptual hydrosalinity model for predicting salt load in irrigation return flows. In: Dregne, H.E. (Ed.), Managing saline water for irrigation, Texas Tech. University, Lubbock, Texas. pp. 49-65.

Tatu, K., Kimothi, M.M., Parihar, J.S. 1999. Remote sensing based habitat availability model (HAM) - A tool for quick-look assessment of wetlands as waterbird habitats. Indian Forrester, October, 1999. Pages $1004-1017$. 
Tanji, K. K. 1977. A conceptual hydrosalinity model for predicting salt load in irrigation return flows. pages 49-70. In: Proceedings of the International Salinity Conference, Texas Tech University, Lubbock, TX

Tedeschi, A., Beltran, Aragues. 2001. Irrigation management and hydrosalinity balance in a semi-arid area of the middle Ebro river basin (Spain). Agricultural Water Management, Vol. 49, pp. 31-50

USBR, 1993. "Review of Wetland Evapotranspiration Literature." Prepared for the Bureau of Reclamation, Lower Colorado Region by Gearheart, R., R., Norman, L. Finger, and D. Titus. Humboldt State University. Arcata California.

USFWS - United States Fish and Wildlife Service. Handout for Information on the Pacific Flyway.

USFWS, 1999. Wetlands of California's Great Central Valley. Poster prepared by Division of Habitat Conservation, Branch of Habitat Assessment. Interior - Geological Survey, Reston, Virginia

U.S. Bureau of Reclamation. 1977. Prediction of mineral quality of irrigation return flow, Vo. 111, simulation model of conjunctive use and water quality for a river system or basin. User's manual, EPA-600/2-77-179c. U.S. Environmental Protection Agency. 285 pp.

Waldemark, J. 1996. An automated procedure for cluster analysis of multivariate satellite data. International Conference EANN "Solving engineering problems with neural networks: Proceedings of the International Conference EANN, London, England. Vol. 1, ppg 237-240

Walter, I.A., R.G. Allen, R. Elliott, M.E. Jensen, D. Itenfisu, B. Mecham, T.A. Howell, R. Snyder, P. Brown, S. Echings, T. Spofford, M. Hattendorf, R.H. Cuenca, J.L. Wright, D. Martin. 2000. ASCE's Standardized Reference Evapotranspiration Equation. Proc. of the Watershed Management 2000 Conference, June 2000, Ft. Collins, CO, American Society of Civil Engineers, St. Joseph, MI.

Walters, C., Korman, J., Stevens, L., and Gold, B. 1999. Ecosystem Modeling for Evaluation of Adaptive Management Policies in the Grand Canyon. Conservation Ecology. Vol. 4, No. 2

Water Resources Engineers, Inc. 1969. An investigation of salt balance in the Upper Santa Ana River Basin. Final Report to the California Dept. of Water Resources. 198 pp.

Wiens, J.A., Parker, K.R. 1995. Analyzing the effects of accidental environmental im pacts: approaches and assumptions. Ecological Applications, Vol. 5, No. 4.

Woods, P.C. 1967. Management of hydrologic systems for water quality control. Water Resources Center Contribution No. 121, University of California. 121 pp. 
Woods, P.C., Orlab, G.T. 1963. The Lost River System: A water quality management investigation. Water Resources Center Contribution No. 68, University of California. 54 $\mathrm{pp}$

Young, W.J., Lam, D.C.L., Ressel, V., and Wong, I.W. 2000. Development of an environmental flows decision support system. Environmental Modelling \& Software. Vol. 15, ppg. 257-265 


\section{APPENDICES}

\section{APPENDIX 1 WETLAND WATER QUALITY MODEL PACKAGE}

The wetland water quality model consists of several interactive spreadsheets that are linked to either the real-time water quality network, or the California Irrigation Management Information System (CIMIS) operated by the California Department of Water Resources (DWR) and the USDA.

\section{WWQM.xls}

This is the water and salt balance model that takes all the input data and produces an output estimation of wetland EC. This estimated wetland EC is then read into a results file that uses a water supply source ranking as a multiplier to get the individual wetland units' ECs.

\section{GWD input.xls}

This is the main water quality and quantity data file. This file contains daily drainage water quantity and quality, in columnar form, from both the real-time network (updated weekly to biweekly) as well as from GWD daily grab samples (updated monthly to bi-monthly). This file serves as input data for the WWQM.xls. (9/1/95 - present, depending on location).

\section{RESULTS.xls}

This is the results file that is the output of the WWQM.xls. It tabulates the GWD ID and the water quality ranking and uses it as a multiplier to estimate (calculate) the individual properties EC from the model results. This file serves as input file populating the fields in the Access Database being read into ArcGIS. ArcGIS takes this information and shades the individual properties according to the estimated EC of the wetlands.

\section{Wetland Habitat Management.xls}

This file contains annually static data based on recommendations from the California Water Fowl Association and is adapted from Smith et al. 1995 "A Guide to Wetland Habitat Management in the Central Valley". This file is used as input data to the WWQM.xls. (September 1 - August 31) 


\section{AssimCapCalcs.xls}

This file contains the actual calculations between the assimilative capacity of the SJR at Vernalis with and without the NGWD input. It also has the ability to load modeled values from both SJRIO and WWQM to produce expected assimilative capacity values for the SJR at Vernalis. This file is from $10 / 1 / 98$ to present and is updated periodically by request by Ernie Taylor of the California Department of Water Resources at etaylor@water.ca.gov.

\section{API.xls}

This file contains the user interface. It has functionality to input the water year type (fore forecasting purposes) and various management scenarios (preflushing, early drawdown, late drawdown). As well, this file accesses the latest SJRIO assimilative capacity forecasts for the San Joaquin River for easy comparison of gaming scenarios.

\section{Update.xls}

This file contains the data necessary to run the WWQM. This data included fall under all four categories; static, annually constant, annually varying, and real-time. The file itself is organized in such a way that all necessary data elements are easily updated. For the updates to take effect, the user needs only to move the most recent "update[date].xls" spreadsheet into the proper working directory. Below is a description of the various data available in the update file, organized into separate worksheets. These worksheets are as follows:

Pan and Crop Coefficients - The crop and pan coefficients worksheet contains pan coefficients $(\mathrm{Kp})$ and crop coefficients $(\mathrm{Kc})$ for the calculation of daily evaporation (from open water) and evapotranspiration (from vegetated areas of wetlands).

Flood Schedules - The Flood Schedules worksheet contains the data that drives all surface water flows. These data include wetland habitat management schedules, preflushing option schedules, and inflow EC. The first of this data are the wetland habitat management schedules for the San Joaquin Valley and have been adjusted for four different water type years, very dry, dry, normal, and wet. In addition, this file contains data for wetland habitat management schedules modified for wetland areas under the dual use of running cattle and 
have been adjusted for the four different water type years, very dry, dry, normal, and wet. This file also includes the data that runs the preflushing option for the WWQM to run different scenarios (see description for API.xls above). Lastly, this file contains the EC values for the delivery water (Inflow EC, see Model Column Description section, below). At present there is no data set on the inflow EC, only a rough profile from sporadic grab samples. The reason for the lack of quality data for the inflow volume and EC is that the Volta Wasteway monitoring station that monitors the delivery water for more than $80 \%$ of the NGWD has been repeatedly vandalized since installation.

Station 5, E - The Station 5 worksheet contains daily pan evaporation data for weather station number 5, located in Shafter, California (operated by the USDA). The file gives only estimates because the station is not located within the project area, however it is located within the same type of climate zone as defined by CIMIS. In addition, data is extrapolated every 5 to 15 days as there is no easy way to get the quantity of water added to replenish the pan when levels get low. This file serves as input data for the WWQM.xls. This file can be updated daily from the web at http://www.cimis.water.ca.gov/. (8/31/96 - present)

Station 56, ET, P - The Station 56 worksheet contains daily climate data for weather station number 56, located in Los Baños, California (Kesterson Wildlife Refuge). Data being used from this file include ETo and precipitation to calculate the water and salt balance in the wetland units. This file serves as input data for the WWQM.xls. This file can be updated daily from at http://www.cimis.water.ca.gov/. (8/31/96 - present)

Assumptions - The Assumptions worksheet contains the data assumptions necessary to operate the WWQM. These data include assumptions for groundwater $(\mathrm{GW})$, operational spill (OS), wetland depth (WD), areal precipitation (P), evaporation (E), and evapotranspiration (ET), water balance theory, percent wetland vegetation coverage, and the minimum depth requirements. The assumptions are as follows:

GW - The model is designed to easily incorporate groundwater data as it becomes available. As of now, the model assumes no net groundwater inflow or outflow during a typical season. 
OS - The operational spill portion of the model was originally estimated at $1 \mathrm{cfs}$ per 200 acres (or 0.12 inches of water per day per acre)(pers. comm.. Scott Lower, 2002, Tim Taylor, 2000). During the calibration process, this number was updated to 1 cfs per 235 acres (or 0.10 inches of water per day per acre).

D - The assumption is stated that the most recent, accepted guide to wetland management practices for the region, is followed by the wetland managers in the NGWD.

$\mathbf{P}$ - The assumption is stated that the precipitation input to the WWQM is that precipitation falling directly onto the wetland area.

$\mathbf{E}$ - The assumption is stated that evaporation output from the wetland occurs from the portions of the wetland that are open water (unvegetated areas).

ET - The assumption is stated that evapotranspiration output from the wetland occurs from only the portions of the wetland that are vegetated.

Other - In addition, it is assumed that there are no dissolved solids in $\mathrm{E}, \mathrm{ET}$, and $\mathrm{P}(\mathrm{EC}=0.0$ $\mathrm{mS} / \mathrm{cm}$ ). That the water balance theory that inflow minus outflow equals the change in storage holds true for these wetlands. The assumptions are made for the percent coverage and percent open water for the wetlands of the NGWD. This value can be greatly improved with further research such as edge detection and pattern recognition techniques applied to aerial photographs. The assumption is made that after the wetland depth drops below a certain level (1.2 in) that drainage stops.

Land Use - The land use worksheet contains data relating to the acreages of the wetlands and the use of those wetlands. Acreages are given for wetland acres, total acres, acres within a specific drainage, and acres managed for solely habitat or for both habitat and raising cattle. This file is a compilation of information from two other spreadsheets, GWD Acreages 12_18_98.xls (from GWD) and pressley.xls (from DFG), as well as discussions with wetland managers. A brief description of the two spreadsheets is below. The GWD Acreages 
12_18_98.xls file contains information pertaining to individual properties including GWD ID, Property Name, total acreage, flooded acreage, supply water source, drainage basin, current owner, former owner, federal tract ID, identifier if map is available, water supply quality ranking, and meta data. The pressley.xls file contains information regarding duck clubs participation in the Pressley Program, i.e. clubs that have agreements to manage their lands primarily as wetland habitat. This information includes GWD ID, Property Name, County, Acres under the program, phase of program, funding source, execution date, expiration date, annual budget, contact name, and contact phone.

Metadata - The metadata worksheet contains background information for many of the data contain in the model package, as well as calculations and conversions for the model itself 


\section{APPENDIX 2 THE WETLAND WATER QUALITY MODEL}

(WWQM.XLS)

Note: Traditional drawdown (Type 3, normal year) selected for entire model run shown.

\begin{tabular}{|c|c|c|c|c|c|c|c|c|c|c|c|c|c|c|c|c|c|c|c|c|c|c|}
\hline \multirow{2}{*}{ Time-Step } & \multicolumn{5}{|l|}{ 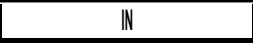 } & \multicolumn{6}{|c|}{ OUT } & \multicolumn{3}{|c|}{ Management } & \multicolumn{4}{|c|}{ MODELOUTPUT } & \multicolumn{4}{|c|}{ NGWD COMPOSTEDDATA } \\
\hline & $\begin{array}{l}\text { Precip } \\
\text { inches }\end{array}$ & & & inches & $\begin{array}{l}E C(\text { Cif } \\
\text { wSCm }\end{array}$ & $\begin{array}{l}\text { Evap. (open } \\
\text { water) } \\
\text { inchess }\end{array}$ & $\begin{array}{c}\text { ET } \\
\text { (veg. areas) } \\
\text { inches }\end{array}$ & $\begin{array}{l}\text { OpSpill } \\
\text { incles }\end{array}$ & $\begin{array}{c}\text { Outflow } \\
\text { inmes }\end{array}$ & & $\begin{array}{c}\text { EC(gw) } \\
\text { wscm }\end{array}$ & \begin{tabular}{|l} 
Depth \\
(hab) \\
inches
\end{tabular} & $\begin{array}{l}\text { Dephth } \\
\text { (CC) }\end{array}$ & $\begin{array}{l}\text { Endoff } \\
\text { Day } \\
\text { inches }\end{array}$ & $\begin{array}{l}\text { Flow } \\
(\mathrm{css})\end{array}$ & $\begin{array}{l}\mathrm{Adj} . \\
\text { Flow } \\
\text { (cs) }\end{array}$ & $\begin{array}{l}\text { EC } \\
\text { WSCm }\end{array}$ & $\begin{array}{c}\text { Adj EC } \\
\text { SSCEm }\end{array}$ & & $\begin{array}{l}\text { ersonnel } \\
\text { Ee }(1 . \mathrm{sicm})\end{array}$ & & \\
\hline 83112000 & 0.00 & 0 & 0 & 0.00 & 500 & 0.00 & 0.00 & 0.00 & 0.00 & 0 & 0 & 0.00 & 0.00 & 0.00 & & & 0 & 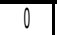 & 12 & 1192 & 12 & 109 \\
\hline 91112000 & 0.00 & 0 & 0 & 0.00 & 500 & 0.00 & 0.00 & 0.00 & 0.00 & n & 0 & 0.00 & 0.00 & 0.00 & 0 & 0 & 0 & 0 & 10 & 1185 & 10 & 1185 \\
\hline 9/22000 & 0.00 & 0 & 0 & 0.00 & 500 & 0.00 & 0.00 & 0.00 & 0.00 & 0 & 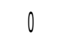 & 0.00 & 0.00 & 0.00 & 0 & 0 & 0 & 0 & $g$ & 1200 & 9 & 1200 \\
\hline 9/32000 & 0.00 & 0 & 0 & 0.00 & 500 & 0.00 & 0.00 & 0.00 & 0.00 & 0 & 0 & 0.00 & 0.00 & 0.00 & n & 0 & 0 & 0 & 0 & 1122 & 9 & 1122 \\
\hline 9412000 & 0.00 & 0 & 0 & 0.00 & 500 & 0.00 & 0.00 & 0.00 & 0.00 & 0 & 0 & 0.00 & 0.00 & 0.00 & 0 & 0 & 0 & 0 & 8 & 1000 & 8 & 1000 \\
\hline 952000 & 0.00 & 0 & 0 & 0.00 & 500 & 0.00 & 0.00 & 0.00 & 0.00 & 0 & 0 & 0.00 & 0.00 & 0.00 & 0 & 0 & 0 & & 10 & 1000 & 10 & 1000 \\
\hline 96120000 & 0.00 & 0 & 0 & 0.00 & 500 & 0.00 & 0.00 & 0.00 & 0.00 & 0 & 0 & 0.00 & 0.00 & 0.00 & 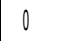 & 0 & 0 & & & 900 & 12 & 900 \\
\hline 972000 & 0.00 & 0 & 0 & 0.00 & 500 & 0.00 & 0.00 & 0.00 & 0.00 & 0 & 0 & 0.00 & 0.00 & 0.00 & 0 & 0 & 0 & & 14 & 871 & 14 & 871 \\
\hline 9/822000 & 0.00 & 0 & 0 & 0.00 & 500 & 0.00 & ne & 0.00 & 0.00 & 0 & 0 & 0.00 & 0.00 & 0.00 & 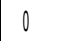 & 0 & 0 & & 1 & 880 & 15 & 880 \\
\hline 99192000 & 0.00 & 0 & 0 & 0.00 & 500 & 0.00 & 0.00 & 0.00 & 0.00 & 0 & 0 & 0.00 & 0.00 & 0.00 & 0 & & 0 & & 1 & 903 & & 903 \\
\hline 910102000 & 0.00 & 0 & 0 & 0.00 & 500 & 0.00 & 0.00 & 0.00 & 0.00 & 0 & 0 & 0.00 & 0.00 & 0.00 & 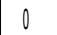 & 0 & 0 & 0 & 11 & 41 & $\pi$ & 741 \\
\hline 9/1112000 & 0.00 & 0 & 0 & 0.00 & 500 & 0.00 & 0.00 & 0.00 & 0.00 & 0 & 0 & 0.00 & 0.00 & 0.00 & 0 & 0 & 0 & & 15 & 747 & 15 & 747 \\
\hline 9/122000 & 0.00 & 0 & 0 & 0.00 & 500 & 0.00 & 0.00 & 0.00 & 0.00 & 0 & & 0.00 & 0.00 & 0.00 & 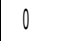 & & 0 & & & 700 & & 700 \\
\hline 2000 & 0.00 & 0 & 0 & 0.00 & 500 & 0.00 & 0.00 & 0.00 & 0.00 & 0 & & 0.00 & 0.00 & 0.00 & & & & & & 100 & & 700 \\
\hline 2000 & 0.00 & 0 & 0 & 0.00 & 500 & 0.00 & 0.00 & 0.00 & 0.00 & 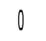 & 0 & 0.00 & 0.00 & 0.00 & 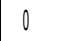 & & 0 & & & 700 & 10 & 700 \\
\hline$|2000|$ & 0.00 & 0 & 0 & 0.00 & 500 & 000 & & 0.00 & 000 & 0 & n & 0.00 & 0.00 & 0.00 & 0 & & 0 & & 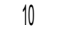 & 00 & ) & 700 \\
\hline 9/1612000 & 0.00 & 0 & 0 & 0.00 & 500 & 0.00 & 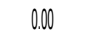 & 0.00 & 0.00 & 0 & & 0.00 & 0.00 & 0.00 & 0 & 0 & 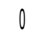 & & 1 & 0 & $\pi$ & 700 \\
\hline 720000 & 0.00 & 0 & 0 & 0.00 & 500 & 0.00 & 0.00 & 0.00 & 0.00 & 0 & 0 & 0.00 & 0.00 & 0.00 & 0 & 0 & 0 & & 10 & 100 & 10 & 700 \\
\hline 9/18/2000 & 0.00 & 0 & 0 & 0.0 & 50 & 0.00 & 0.00 & 0.00 & vid & 0 & & 0.00 & 0.00 & 0.00 & 0 & 0 & 0 & & & 19 & & 719 \\
\hline 9/192000 & 0.00 & 0 & 0 & 0.0 & 50 & 0.00 & 0.00 & 0.00 & 0.4 & 0 & & 0.00 & 0.00 & 0.00 & & & & & & 13 & & , \\
\hline $9 / 2$ & 0.00 & 0 & 0 & 0.00 & 500 & 0.00 & & 0.00 & 0.00 & 0 & & 0.00 & 0.00 & .00 & & & 0 & & & 626 & Lv & 626 \\
\hline 00 & 0.00 & 0 & 0 & 0.36 & 50 & 0.32 & & 0.10 & 0 & 0 & 0 & 0.36 & 0.36 & 0.00 & 9 & 77 & 0 & & & 650 & 24 & 650 \\
\hline 912212000 & 0.00 & 0 & 0 & 0. & 50 & 0.29 & & 0.10 & 0.10 & 0 & & 0.71 & 0.71 & 0.26 & & 77 & 625 & & & 0 & 25 & 650 \\
\hline 912312000 & 0.00 & 0 & 0 & 0.81 & 500 & 0.2 & & 0.1 & 0.10 & 0 & & 1.07 & 1.07 & 0.59 & $g$ & 77 & 625 & & & 650 & 35 & 650 \\
\hline 9/2422000 & 0.00 & 0 & 0 & 0.83 & 50 & 0.1 & 0.0 & 0.10 & 0. & 0 & 0 & 1.42 & 1.42 & 1.11 & gl & 77 & 626 & & 4 & 612 & & 612 \\
\hline 912512000 & 0.00 & 0 & 0 & 0.6 & 50 & 0.1 & 0.0 & 0.10 & 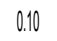 & 0 & & 1.78 & 1.78 & 1.43 & g. & 77 & 625 & & & 12 & & 612 \\
\hline 912612000 & 0.00 & 0 & 0 & 0.71 & 500 & 0.14 & 0.0 & 0.10 & 0.10 & 0 & & 2.13 & 2.13 & 1.81 & gl & 77 & 648 & & & 16 & 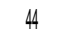 & 010 \\
\hline 12000 & 0.00 & 0 & 0 & 0. & 50 & 0.22 & & 0.10 & 0.10 & 0 & & 2.49 & 2.49 & 2.09 & af & 77 & 688 & & & 16 & 44 & 616 \\
\hline 912822000 & 0.00 & 8 & 0 & 0. & 50 & 0.3 & & 0.10 & 0.10 & n & & 2.84 & 2.84 & 2.37 & & 77 & 732 & & & 12 & 43 & 642 \\
\hline 9129212000 & 0.00 & 0 & 0 & 0.8 & 50 & 0.2 & & 0.10 & 0.1 & 0 & & 3.20 & 3.20 & 2.81 & $g$ & 77 & 737 & & & +0 & & 640 \\
\hline 9/3012000 & 0.00 & 0 & 0 & 0. & 50 & 0.1 & 0.0 & 0.11 & 0. & 0 & & 6 & 3.56 & 3.26 & gl & 77 & 728 & & & 639 & & 639 \\
\hline 101112000 & 0.00 & 0 & 0 & 0. & 50 & 0.1 & 0.0 & 0.10 & 0 & 0 & & 3.91 & 3.91 & 3.59 & g) & 77 & 731 & & & 638 & & 638 \\
\hline 10222000 & 0.00 & 0 & 0 & 0. & 500 & 0.16 & 0.0 & 0.1 & 0.10 & 0 & & 4.27 & 4.27 & 3.92 & 90 & 77 & 737 & & 45 & 628 & 45 & 628 \\
\hline 10332000 & 0.00 & 0 & 0 & 0. & 50 & 0.2 & & 0.10 & 0.10 & 0 & & 4.62 & 4.62 & 4.24 & 9 & 77 & 746 & & 66 & 14 & 66 & 614 \\
\hline 12000 & 0.00 & 0 & 0 & 0. & 50 & 0.2 & & 0.10 & . & 0 & & 4.98 & 4.98 & 4.52 & 90 & 77 & 763 & & & 675 & 83 & 675 \\
\hline 10552000 & 0.00 & 0 & 0 & 0.8 & 50 & 0. & & 01 & 0.1 & 0 & & 5.33 & 5.33 & 5.05 & 90 & 77 & 750 & & & 600 & $v_{11}$ & 600 \\
\hline 106612000 & 0.00 & 0 & 0 & 0.6 & 50 & 0.2 & & 0 & 0. & 0 & & 5.69 & 5.69 & 5.3 & 90 & 77 & 758 & & & 2 & $\pi$ & 662 \\
\hline 2000 & 0.00 & 0 & 0 & 0. & 50 & 0.3 & 0.1 & 0.1 & 0. & 0 & & 6.04 & 6.04 & 5.56 & 90 & 77 & 775 & & vit & 60 & | & 666 \\
\hline 22000 & 0.00 & 0 & 0 & 0.8 & 50 & & 0.0 & 0.10 & 0.10 & 0 & & 6.40 & 6.40 & 6.12 & 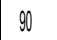 & 77 & 761 & & 98 & 674 & 98 & 674 \\
\hline 0000 & 0.00 & 0 & 0 & 0.4 & 50 & 0 & & 0.1 & 0.10 & 0 & & 6.76 & 6.76 & 6.40 & 9 & 77 & 765 & & & 680 & 100 & 707 \\
\hline 1010102000 & 0.29 & 0 & 0 & 0. & 0 & & & 0 & 0 & 0 & & 7.11 & 7.11 & 6.94 & 90 & 77 & 754 & & & 663 & 116 & 686 \\
\hline 12000 & 0.13 & 0 & 0 & 0.53 & 50 & 0.33 & & $v_{i}$ & 0.10 & 0 & 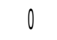 & 7.47 & 7.47 & 7.15 & 90 & 77 & 761 & & 147 & 652 & 147 & 691 \\
\hline 101222000 & 0.01 & 0 & 0 & 0.68 & 500 & 0 & & 011 & 0.1 & 0 & 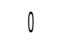 & 7.82 & 7.82 & 7.37 & 90 & 77 & 773 & 96 & 110 & 661 & 173 & 691 \\
\hline 2000 & 0.00 & 0 & 0 & 0.81 & 50 & 0 & & 0. & 0 & 0 & 0 & 8.18 & 8.18 & 7.82 & 90 & 77 & 770 & & 04 & 664 & 164 & 690 \\
\hline 0000 & 0.00 & 0 & 0 & 0.71 & 50 & 0.10 & 0.05 & 0.1 & 0.10 & 0 & 0 & 8.53 & 8.53 & 8.28 & ${ }^{30}$ & 77 & 761 & $y_{0}$ & $1 / 2$ & 684 & 172 & 715 \\
\hline Discove & 0.00 & 0 & 0 & 0.60 & 50 & 0.05 & & vit. & 0.10 & 0 & & 8.89 & 8.89 & 8.68 & 90 & 77 & 752 & & 10 & 684 & 176 & 717 \\
\hline 1016162000 & 0.00 & 0 & 0 & 0.56 & 30 & 0.09 & 0.00 & $v_{1}$ & viv & . & & 9.24 & 9.24 & 9.00 & 0 & II & 749 & & ToL & 682 & 182 & 120 \\
\hline 1017712000 & 0.00 & 0 & 0 & 0.60 & 500 & 0.12 & 0.05 & 0.1 & 0.10 & 0 & 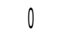 & 9.60 & 9.60 & 9.32 & 30 & 77 & 747 & ori & $\pi / 0$ & 695 & 173 & 738 \\
\hline 1018182000 & 0.00 & 0 & 0 & 0.63 & 500 & 0.02 & 0.06 & 0.10 & 0.10 & 0 & 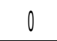 & 9.96 & 9.96 & 9.78 & 90 & 77 & 737 & 921 & 170 & 703 & 170 & 754 \\
\hline
\end{tabular}


Note: Traditional drawdown (Type 3, normal year) selected for entire model run shown.

\begin{tabular}{|c|c|c|c|c|c|c|c|c|c|c|c|c|c|c|c|c|c|c|c|c|c|c|}
\hline Time-Step & \multicolumn{5}{|c|}{$\mathbb{N}$} & \multicolumn{6}{|c|}{ OUT } & \multicolumn{3}{|c|}{ Management } & \multicolumn{4}{|c|}{ MODEL OUTPUT } & \multicolumn{4}{|c|}{ NGWD COMPOSITE DATA } \\
\hline Date & $\begin{array}{l}\text { Precip } \\
\text { inches }\end{array}$ & $\begin{array}{l}\text { GW } \\
\text { inches }\end{array}$ & $\begin{array}{l}E C(g W) \\
u S(c m\end{array}$ & $\begin{array}{l}\text { Op. Inflow } \\
\text { inches }\end{array}$ & & $\begin{array}{c}\text { Evap. (open } \\
\text { water) } \\
\text { inches }\end{array}$ & $\begin{array}{c}\text { ET } \\
\text { (veg, areas) } \\
\text { inches }\end{array}$ & $\begin{array}{c}\text { Op Spill } \\
\text { inches }\end{array}$ & $\begin{array}{c}\text { Outflow } \\
\text { inches }\end{array}$ & & $\begin{array}{l}\text { EC(gW) } \\
\text { uS }(\mathrm{cm}\end{array}$ & $\begin{array}{l}\text { Depth } \\
\text { (hab) } \\
\text { inches }\end{array}$ & $\begin{array}{l}\text { Depth } \\
\text { (CC) }\end{array}$ & $\begin{array}{l}\text { Endof } \\
\text { Day } \\
\text { inches }\end{array}$ & $\begin{array}{l}\text { Flow } \\
(\mathrm{cts})\end{array}$ & $\begin{array}{l}\text { Adj. } \\
\text { Flow } \\
(c t s)\end{array}$ & $\begin{array}{l}\text { EC } \\
\text { US } \mathrm{Cm}\end{array}$ & $\begin{array}{c}\text { Adj], EC } \\
\text { USCCm }\end{array}$ & $\begin{array}{l}\text { GWDP } \\
Q(d f s)\end{array}$ & $\begin{array}{l}\text { ersonnel } \\
E C(u S / \mathrm{cm})\end{array}$ & $\begin{array}{l}\text { Real-Tim } \\
Q(c \text { cis })\end{array}$ & $\begin{array}{l}\text { e Network } \\
\text { EC (uSSCm) }\end{array}$ \\
\hline 10/19/200 & 0.00 & 0 & 0 & 0.53 & 500 & 0.07 & 0.05 & 0.10 & 0.10 & 0 & 0 & 10.31 & 10.31 & 10.09 & 90 & 77 & 734 & 917 & 162 & 699 & 162 & 761 \\
\hline 1020202000 & 0.00 & 0 & 0 & 0.58 & 500 & 0.09 & 0.05 & 0.10 & 0.10 & 0 & 0 & 10.67 & 10.67 & 10.42 & 90 & 77 & 731 & 913 & 153 & 726 & 153 & 767 \\
\hline 102112000 & 0.00 & 0 & 0 & 0.24 & 750 & 0.12 & 0.09 & 0.10 & 0.10 & 0 & 0 & 10.67 & 10.67 & 10.36 & 90 & 77 & 746 & 932 & 149 & 726 & 149 & 775 \\
\hline 102212000 & 0.00 & 0 & 0 & 0.31 & 750 & 0.09 & 0.08 & 0.10 & 0.10 & 0 & 0 & 10.67 & 10.67 & 10.39 & 90 & 77 & 758 & 948 & 145 & 736 & 145 & 795 \\
\hline 102312000 & 0.00 & 0 & 0 & 0.27 & 750 & 0.07 & 0.05 & 0.10 & 0.10 & 0 & 0 & 10.67 & 10.67 & 10.45 & 90 & 77 & 767 & 958 & 143 & 762 & 143 & 799 \\
\hline 101242000 & 0.00 & 0 & 0 & 0.22 & 750 & 0.02 & 0.05 & 0.10 & 0.10 & 0 & 0 & 10.67 & 10.67 & 10.49 & 90 & 77 & 772 & 964 & 141 & 772 & 141 & 809 \\
\hline 102512000 & 0.00 & 0 & 0 & 0.17 & 750 & 0.12 & 0.03 & 0.10 & 0.10 & 0 & 0 & 10.67 & 10.67 & 10.41 & 90 & 77 & 783 & 979 & 136 & 750 & 136 & 812 \\
\hline 102612000 & 0.73 & 0 & 0 & 0.26 & 750 & 0.10 & 0.00 & 0.10 & 0.10 & 0 & 0 & 10.67 & 10.67 & 11.19 & 90 & 77 & 751 & 939 & 165 & 777 & 165 & 812 \\
\hline $1027 / 2000$ & 0.00 & 0 & 0 & 0.00 & 750 & 0.12 & 0.02 & 0.10 & 0.33 & 0 & 0 & 10.67 & 10.67 & 10.72 & 295 & 250 & 761 & 951 & 195 & 771 & 195 & 808 \\
\hline 102812000 & 0.19 & 0 & 0 & 0.00 & 750 & 0.07 & 0.02 & 0.10 & 0.16 & 0 & 0 & 10.67 & 10.67 & 10.67 & 142 & 121 & 757 & 946 & 190 & 792 & 190 & 788 \\
\hline 10129120 & 0.10 & 0 & 0 & 0.00 & 750 & 0.16 & 0.01 & 0.10 & 0.10 & 0 & 0 & 10.67 & 10.67 & 10.49 & 92 & 78 & 763 & 954 & 194 & 795 & 194 & 796 \\
\hline 10130120 & 0.00 & 0 & 0 & 0.17 & 750 & 0.04 & 0.02 & 0.10 & 0.10 & 0 & 0 & 10.67 & 10.67 & 10.50 & 90 & 77 & 768 & 960 & 192 & 801 & 192 & 811 \\
\hline 10311200 & 0.01 & 0 & 0 & 0.16 & 750 & 0.03 & 0.04 & 0.10 & 0.10 & 0 & 0 & 10.67 & 10.67 & 10.50 & 90 & 77 & 772 & 965 & 193 & 815 & 193 & 828 \\
\hline 111111200 & 0.00 & 0 & 0 & 0.16 & 1000 & 0.07 & 0.03 & 0.10 & 0.10 & 0 & 0 & 10.67 & 10.67 & 10.47 & 90 & 77 & 783 & 979 & 190 & 857 & 190 & 869 \\
\hline 111222000 & 0.00 & 0 & 0 & 0.20 & 1000 & 0.05 & 0.03 & 0.10 & 0.10 & 0 & 0 & 10.67 & 10.67 & 10.49 & 90 & 77 & 793 & 991 & 187 & 857 & 187 & 886 \\
\hline $11 / 3 / 2000$ & 0.01 & 0 & 0 & 0.18 & 1000 & 0.06 & 0.03 & 0.10 & 0.10 & 0 & 0 & 10.67 & 10.67 & 10.48 & 90 & 77 & 803 & 1004 & 183 & 883 & 183 & 899 \\
\hline $1114 \mid 20$ & 0.00 & 0 & 0 & 0.19 & 1000 & 0.05 & 0.03 & 0.10 & 0.10 & 0 & 0 & 10.67 & 10.67 & 10.49 & 90 & 77 & 813 & 1016 & 180 & 898 & 180 & 911 \\
\hline $11 / 515200$ & 0.00 & 0 & 0 & 0.18 & 1000 & 0.06 & 0.03 & 0.10 & 0.10 & 0 & 0 & 10.67 & 10.67 & 10.48 & 90 & 77 & 823 & 1029 & 178 & 912 & 178 & 924 \\
\hline $11 / 612000$ & 0.00 & 0 & 0 & 0.19 & 1000 & 0.05 & 0.06 & 0.10 & 0.10 & 0 & 0 & 10.67 & 10.67 & 10.46 & 90 & 77 & 834 & 1043 & 176 & 911 & 176 & 926 \\
\hline 117712000 & 0.00 & 0 & 0 & 0.21 & 1000 & 0.03 & 0.04 & 0.10 & 0.10 & 0 & 0 & 10.67 & 10.67 & 10.50 & 90 & 77 & 843 & 1054 & 170 & 911 & 170 & 929 \\
\hline 1118122000 & 0.00 & 0 & 0 & 0.17 & 1000 & 0.06 & 0.04 & 0.10 & 0.10 & 0 & 0 & 10.67 & 10.67 & 10.47 & 90 & 77 & 853 & 1066 & 162 & 912 & 162 & 933 \\
\hline $11 / 91200$ & 0.00 & 0 & 0 & 0.19 & 1000 & 0.05 & 0.04 & 0.10 & 0.10 & 0 & 0 & 10.67 & 10.67 & 10.48 & 90 & 77 & 863 & 1078 & 156 & 935 & 156 & 965 \\
\hline & 0.00 & 0 & 0 & 0.19 & 1000 & 0.05 & 0.02 & 0.10 & 0.10 & 0 & 0 & 10.67 & 10.67 & 10.50 & 90 & 77 & 871 & 1088 & 154 & 957 & 154 & 977 \\
\hline & 0.00 & 0 & 0 & 0.17 & 1000 & 0.07 & 0.03 & 0.10 & 0.10 & 0 & 0 & 10.67 & 10.67 & 10.46 & 90 & 77 & 882 & 1102 & 148 & 966 & 148 & 981 \\
\hline 11/1212 & 0.00 & 0 & 0 & 0.21 & 1000 & 0.04 & 0.03 & 0.10 & 0.10 & 0 & 0 & 10.67 & 10.67 & 10.50 & 90 & 77 & 890 & 1112 & 143 & 992 & 143 & 999 \\
\hline $11 / 13 / 20$ & 0.12 & 0 & 0 & 0.17 & 1000 & 0.08 & 0.03 & 0.10 & 0.10 & 0 & 0 & 10.67 & 10.67 & 10.58 & 90 & 77 & 892 & 1115 & 139 & 992 & 139 & 1012 \\
\hline $111 / 142000$ & 0.01 & 0 & 0 & 0.09 & 1000 & 0.12 & 0.03 & 0.10 & 0.10 & 0 & 0 & 10.67 & 10.67 & 10.43 & 90 & 77 & 905 & 1131 & 105 & 994 & 105 & 1023 \\
\hline 11/15/2000 & 0.00 & 0 & 0 & 0.24 & 1000 & 0.03 & 0.02 & 0.10 & 0.10 & 0 & 0 & 10.67 & 10.67 & 10.52 & 90 & 77 & 911 & 1138 & 98 & 1025 & 98 & 1043 \\
\hline $11 / 161200$ & 0.00 & 0 & 0 & 0.14 & 1000 & 0.06 & 0.02 & 0.10 & 0.10 & 0 & 0 & 10.67 & 10.67 & 10.49 & 90 & 77 & 919 & 1148 & 98 & 998 & 98 & 1030 \\
\hline $11 / 177 / 2000$ & 0.00 & 0 & 0 & 0.18 & 1000 & 0.02 & 0.03 & 0.10 & 0.10 & 0 & 0 & 10.67 & 10.67 & 10.52 & 90 & 77 & 924 & 1155 & 80 & 1019 & 86 & 1057 \\
\hline $11 / 18122000$ & 0.00 & 0 & 0 & 0.15 & 1000 & 0.08 & 0.02 & 0.10 & 0.10 & 0 & 0 & 10.67 & 10.67 & 10.46 & 90 & 77 & 935 & 1168 & 84 & 1046 & 84 & 1059 \\
\hline 11/19/2000 & 0.00 & 0 & 0 & 0.21 & 1000 & 0.06 & 0.02 & 0.10 & 0.10 & 0 & 0 & 10.67 & 10.67 & 10.48 & 90 & 77 & 944 & 1180 & 82 & 1057 & 82 & 1076 \\
\hline 1112012000 & 0.00 & 0 & 0 & 0.19 & 1000 & 0.09 & 0.02 & 0.10 & 0.10 & 0 & 0 & 10.67 & 10.67 & 10.46 & 90 & 77 & 954 & 1193 & 80 & 1059 & 80 & 1081 \\
\hline 1112112000 & 0.02 & 0 & 0 & 0.21 & 1000 & 0.09 & 0.01 & 0.10 & 0.10 & 0 & 0 & 10.67 & 10.67 & 10.48 & 90 & 77 & 963 & 1204 & 80 & 1073 & 80 & 1097 \\
\hline 1112222000 & 0.00 & 0 & 0 & 0.18 & 1000 & 0.09 & 0.01 & 0.10 & 0.10 & 0 & 0 & 10.67 & 10.67 & 10.47 & 90 & 77 & 973 & 1216 & 80 & 784 & 80 & 809 \\
\hline 11123/2000 & 0.00 & 0 & 0 & 0.20 & 1000 & 0.04 & 0.02 & 0.10 & 0.10 & 0 & 0 & 10.67 & 10.67 & 10.51 & 90 & 77 & 978 & 1223 & 79 & 795 & 79 & 823 \\
\hline 1112412000 & 0.00 & 0 & 0 & 0.16 & 1000 & 0.04 & 0.00 & 0.10 & 0.10 & 0 & 0 & 10.67 & 10.67 & 10.52 & 90 & 77 & 982 & 1228 & 79 & 1123 & 79 & 1141 \\
\hline $11125 / 2000$ & 0.00 & 0 & 0 & 0.14 & 1000 & 0.02 & 0.00 & 0.10 & 0.10 & 0 & 0 & 10.67 & 10.67 & 10.54 & 90 & 77 & 985 & 1231 & 79 & 1134 & 79 & 1152 \\
\hline $11126 / 2000$ & 0.00 & 0 & 0 & 0.13 & 1000 & 0.04 & 0.00 & 0.10 & 0.10 & 0 & 0 & 10.67 & 10.67 & 10.53 & 90 & 77 & 989 & 1236 & 83 & 1119 & 83 & 1150 \\
\hline $11127 / 2000$ & 0.00 & 0 & 0 & 0.14 & 1000 & 0.00 & 0.01 & 0.10 & 0.10 & 0 & 0 & 10.67 & 10.67 & 10.55 & 90 & 77 & 990 & 1237 & 84 & 1133 & 84 & 1165 \\
\hline 1112812000 & 0.00 & 0 & 0 & 0.11 & 1000 & 0.01 & 0.00 & 0.10 & 0.10 & 0 & 0 & 10.67 & 10.67 & 10.56 & 90 & 77 & 991 & 1239 & 88 & 1105 & 88 & 1142 \\
\hline 11129/2000 & 0.06 & 0 & 0 & 0.11 & 1000 & 0.05 & 0.01 & 0.10 & 0.10 & 0 & 0 & 10.67 & 10.67 & 10.57 & 90 & 77 & 992 & 1240 & 97 & 1090 & 97 & 1131 \\
\hline $11 / 3012000$ & 0.00 & 0 & 0 & 0.10 & 1000 & 0.04 & 0.02 & 0.10 & 0.10 & 0 & 0 & 10.67 & 10.67 & 10.50 & 90 & 77 & 998 & 1248 & 104 & 1097 & 104 & 1128 \\
\hline 121112000 & 0.00 & 0 & 0 & 0.17 & 1250 & 0.04 & 0.01 & 0.10 & 0.10 & 0 & 0 & 10.67 & 10.67 & 10.51 & 90 & 77 & 1007 & 1259 & 105 & 1097 & 105 & 1119 \\
\hline 121222000 & 0.00 & 0 & 0 & 0.16 & 1250 & 0.01 & 0.01 & 0.10 & 0.10 & 0 & 0 & 10.67 & 10.67 & 10.54 & 90 & 77 & 1013 & 1266 & 109 & 1112 & 109 & 1132 \\
\hline 121312000 & 0.00 & 0 & 0 & 0.12 & 1250 & 0.04 & 0.01 & 0.10 & 0.10 & 0 & 0 & 10.67 & 10.67 & 10.51 & 90 & 77 & 1021 & 1276 & 112 & 1113 & 112 & 1135 \\
\hline 121412000 & 0.00 & 0 & 0 & 0.15 & 1250 & 0.03 & 0.01 & 0.10 & 0.10 & 0 & 0 & 10.67 & 10.67 & 10.52 & 90 & 77 & 1028 & 1285 & 114 & 1114 & 114 & 1141 \\
\hline $12 / 512000$ & 0.00 & 0 & 0 & 0.15 & 1250 & 0.03 & 0.01 & 0.10 & 0.10 & 0 & 0 & 10.67 & 10.67 & 10.53 & 90 & 77 & 1035 & 1294 & 112 & 1114 & 112 & 1144 \\
\hline 122612000 & 0.00 & 0 & 0 & 0.14 & 1250 & 0.02 & 0.01 & 0.10 & 0.10 & 0 & 0 & 10.67 & 10.67 & 10.53 & 90 & 77 & 1041 & 1302 & 104 & 1129 & 104 & 1156 \\
\hline
\end{tabular}


Note: Traditional drawdown (Type 3, normal year) selected for entire model run shown.

\begin{tabular}{|c|c|c|c|c|c|c|c|c|c|c|c|c|c|c|c|c|c|c|c|c|c|c|}
\hline \multirow{2}{*}{$\begin{array}{r}\text { Time-Step } \\
\text { Date }\end{array}$} & \multicolumn{5}{|c|}{$\mathbb{N}$} & \multicolumn{6}{|c|}{ OUT } & \multicolumn{3}{|c|}{ Management } & \multicolumn{4}{|c|}{ MODELOUTPUT } & \multicolumn{4}{|c|}{ NGWD COMPOSTIE DATA } \\
\hline & $\begin{array}{c}\text { Precip } \\
\text { inches }\end{array}$ & & & & & $\begin{array}{l}\text { Evap. lopen } \\
\text { waterl) } \\
\text { inches }\end{array}$ & $\begin{array}{c}\text { ET } \\
\text { (veg, areas) } \\
\text { inches }\end{array}$ & $\begin{array}{l}\text { Op Spill } \\
\text { inches }\end{array}$ & $\begin{array}{l}\text { Outllow } \\
\text { incheses }\end{array}$ & & $\begin{array}{c}E C(g w) \\
\omega S \mathrm{~cm}\end{array}$ & $\begin{array}{l}\text { Depth } \\
\text { (hab) } \\
\text { inches }\end{array}$ & $\begin{array}{l}\text { Depth } \\
\text { (CC) }\end{array}$ & $\begin{array}{c}\text { Endof } \\
\text { Day } \\
\text { inches }\end{array}$ & $\begin{array}{l}\text { Flow } \\
(\mathrm{cos})\end{array}$ & $\begin{array}{l}\mathrm{Adj} . \\
\text { Flow } \\
(\mathrm{cos})\end{array}$ & $\begin{array}{l}\text { EC } \\
\text { USCm }\end{array}$ & $\begin{array}{c}\mathrm{Adj} \text {, EC } \\
\text { uSCm }\end{array}$ & $\begin{array}{l}\text { GWOP } \\
Q_{(\text {cess }}\end{array}$ & ersonnel & $\begin{array}{l}\text { Real|'Tim } \\
Q(\text { ctis }\end{array}$ & 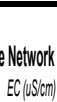 \\
\hline 127712000 & 0.00 & 0 & 0 & 0.14 & 1250 & 0.04 & 0.01 & 0.10 & 0.10 & 0 & 0 & 10.67 & 10.67 & 10.52 & 90 & 77 & 1049 & 1311 & 109 & 1126 & 109 & 1155 \\
\hline 12812000 & 0.00 & 0 & 0 & 0.15 & 1250 & 0.03 & 0.01 & 0.10 & 0.10 & 0 & 0 & 10.67 & 10.67 & 10.52 & 90 & 77 & 1056 & 1320 & 105 & 1148 & 105 & 1163 \\
\hline 12922000 & 0.00 & 0 & 0 & 0.14 & 1250 & 0.03 & 0.01 & 0.10 & 0.10 & 0 & 0 & 10.67 & 10.67 & 10.53 & 90 & 77 & 1062 & 1328 & 100 & 1177 & 100 & 1192 \\
\hline 1211020000 & 0.00 & 0 & 0 & 0.14 & 1250 & 0.03 & 0.01 & 0.10 & 0.10 & 0 & 0 & $\mid 10.67$ & 10.67 & 10.52 & 90 & 77 & 1069 & 1337 & 98 & 11886 & 98 & 1190 \\
\hline 121112000 & 0.00 & 0 & 0 & 0.14 & 1250 & 0.03 & 0.01 & 0.10 & 0.10 & 0 & 0 & 10.67 & 10.67 & 10.52 & 90 & 77 & 1076 & 1345 & 98 & 11866 & 98 & 1192 \\
\hline 121122000 & 0.00 & 0 & 0 & 0.14 & 1250 & 0.06 & 0.02 & 0.10 & 0.10 & 0 & 0 & 10.67 & 10.67 & 10.49 & 90 & 77 & 1086 & 1357 & 104 & 1179 & 104 & 1189 \\
\hline 12132000 & 0.00 & 0 & 0 & 0.17 & 1250 & 0.04 & 0.02 & 0.10 & 0.10 & 0 & 0 & 10.67 & 10.67 & 10.51 & 90 & 77 & 1095 & 1368 & 110 & 1182 & 110 & 1189 \\
\hline 1214142000 & 0.00 & 0 & 0 & 0.16 & 1250 & 0.04 & 0.01 & 0.10 & 0.10 & 0 & 0 & 10.67 & 10.67 & 10.51 & 90 & 77 & 1103 & 1378 & 129 & 1167 & 129 & 1201 \\
\hline 12152000 & 0.00 & 0 & 0 & 0.16 & 1250 & 0.03 & 0.02 & 0.10 & 0.10 & 0 & 0 & 10.67 & 10.67 & 10.52 & 90 & 77 & 1110 & 1387 & 125 & 1159 & 125 & 1200 \\
\hline 1216162000 & 0.00 & 0 & 0 & 0.15 & 1250 & 0.02 & 0.00 & 0.10 & 0.10 & 0 & 0 & 10.67 & 10.67 & 10.54 & 90 & 77 & 1115 & 1394 & 114 & 1172 & 114 & 1213 \\
\hline 12117172000 & 0.01 & 0 & 0 & 0.13 & 1250 & 0.01 & 0.02 & 0.10 & 0.10 & 0 & 0 & 10.67 & 10.67 & 10.55 & 90 & 77 & 1119 & 1398 & 106 & 1174 & 106 & 1233 \\
\hline 1211822000 & 0.01 & 0 & 0 & 0.12 & 1250 & 0.02 & 0.01 & 0.10 & 0.10 & 0 & 0 & 10.67 & 10.67 & 10.54 & 90 & 77 & 1123 & 1403 & 103 & 1175 & 103 & 1231 \\
\hline 121192000 & 0.01 & 0 & 0 & 0.12 & 1250 & 0.04 & 0.02 & 0.10 & 0.10 & 0 & 0 & 10.67 & 10.67 & 10.52 & 90 & 77 & 1129 & 1411 & 102 & 1194 & 102 & 1247 \\
\hline 1220020000 & 0.00 & 0 & 0 & 0.14 & 1250 & 0.02 & 0.01 & 0.10 & 0.10 & 0 & 0 & 10.67 & 10.67 & 10.53 & 90 & 77 & 1134 & 1418 & 112 & 1209 & 112 & 1264 \\
\hline 122112000 & 0.00 & 0 & 0 & 0.14 & 1250 & 0.06 & 0.02 & 0.10 & 0.10 & 0 & 0 & 10.67 & 10.67 & 10.49 & 90 & 77 & 1144 & 1430 & 114 & 1202 & 114 & 1283 \\
\hline 1222222000 & 0.00 & 0 & 0 & 0.18 & 1250 & 0.03 & 0.02 & 0.10 & 0.10 & 0 & 0 & 10.67 & 10.67 & 10.51 & 90 & 77 & 1152 & 1439 & 110 & 1203 & 110 & 1270 \\
\hline 122232000 & 0.00 & 0 & 0 & 0.15 & 1250 & 0.03 & 0.01 & 0.10 & 0.10 & 0 & 0 & 10.67 & 10.67 & 10.52 & 90 & 77 & 1158 & 1447 & 108 & 1211 & 108 & 1269 \\
\hline 1224242000 & 0.00 & 0 & 0 & 0.15 & 1250 & 0.02 & 0.01 & 0.10 & 0.10 & 0 & 0 & 10.67 & 10.67 & 10.54 & 90 & 77 & 1162 & 1453 & 104 & 1197 & 104 & 1254 \\
\hline 122552000 & 0.00 & 0 & 0 & 0.13 & 1250 & 0.02 & 0.01 & 0.10 & 0.10 & 0 & 0 & 10.67 & 10.67 & 10.53 & 90 & 77 & 1167 & 1459 & 100 & 1236 & 100 & 1271 \\
\hline 1226612000 & 0.00 & 0 & 0 & 0.14 & 1250 & 0.04 & 0.02 & 0.10 & 0.10 & 0 & 0 & 10.67 & 10.67 & 10.51 & 90 & 77 & 1174 & 1468 & 98 & 1220 & 98 & 1252 \\
\hline 1222712000 & 0.00 & 0 & 0 & 0.16 & 1250 & 0.03 & 0.01 & 0.10 & 0.10 & 0 & 0 & 10.67 & 10.67 & 10.52 & 90 & 77 & 1180 & 1476 & 94 & 1229 & 94 & 1253 \\
\hline 1222822000 & 0.00 & 0 & 0 & 0.15 & 1250 & 0.03 & 0.02 & 0.10 & 0.10 & 0 & 0 & 10.67 & 10.67 & 10.52 & 90 & 77 & 1187 & 1483 & 91 & 1229 & 91 & 1255 \\
\hline 1222922000 & 0.00 & 0 & 0 & 0.15 & 1250 & 0.04 & 0.02 & 0.10 & 0.10 & 0 & 0 & 10.67 & 10.67 & 10.51 & 90 & 77 & 1194 & 1492 & 88 & 1225 & 88 & 1255 \\
\hline 1233012000 & 0.00 & 0 & 0 & 0.16 & 1250 & 0.04 & 0.01 & 0.10 & 0.10 & 0 & 0 & 10.67 & 10.67 & 10.52 & 90 & 77 & 1200 & 1500 & 86 & 1237 & 86 & 1258 \\
\hline 1233112000 & 0.00 & 0 & 0 & 0.15 & 1250 & 0.03 & 0.01 & 0.10 & 0.10 & 0 & 0 & 10.67 & 10.67 & 10.52 & 90 & 77 & 1205 & 1507 & 86 & 1237 & 80 & 1261 \\
\hline 11112001 & 0.00 & 0 & 0 & 0.14 & 1500 & 0.04 & 0.01 & 0.10 & 0.10 & 0 & 0 & $\mid 10.67$ & 10.67 & 10.51 & 90 & 77 & 1215 & 1519 & 84 & 1259 & 84 & 1289 \\
\hline 1122001 & 0.01 & 0 & 0 & 0.15 & 1500 & 0.04 & 0.01 & 0.10 & 0.10 & 0 & 0 & 10.67 & 10.67 & 10.52 & 90 & 77 & 1224 & 1530 & 80 & 1243 & 80 & 1276 \\
\hline 1/32001 & 0.00 & 0 & 0 & 0.14 & 1500 & 0.04 & 0.02 & 0.10 & 0.10 & 0 & 0 & 10.67 & 10.67 & 10.51 & 90 & 77 & 1234 & 1543 & 70 & 1271 & 70 & 1324 \\
\hline 14142001 & 0.00 & 0 & 0 & 0.15 & 1500 & 0.03 & 0.02 & 0.10 & 0.10 & 0 & 0 & 10.67 & 10.67 & 10.52 & 90 & 77 & 1244 & 1555 & 66 & 1279 & 66 & 1336 \\
\hline 1552001 & 0.00 & 0 & 0 & 0.15 & 1500 & 0.04 & 0.02 & 0.10 & 0.10 & 0 & 0 & $\mid 10.67$ & 10.67 & 10.51 & 90 & 77 & 1254 & 1567 & 64 & 12266 & 64 & 1330 \\
\hline 16162001 & 0.00 & 0 & 0 & 0.16 & 1500 & 0.04 & 0.02 & 0.10 & 0.10 & 0 & 0 & 10.67 & 10.67 & 10.51 & 90 & 77 & 1264 & 1580 & 63 & 1264 & 63 & 1334 \\
\hline 17720041 & 0.00 & 0 & 0 & 0.16 & 1500 & 0.05 & 0.01 & 0.10 & 0.10 & 0 & 0 & 10.67 & 10.67 & 10.50 & 90 & 77 & 1275 & 1594 & 72 & 1245 & 72 & 1297 \\
\hline 18820011 & $\mid 0.72$ & 0 & 0 & 0.16 & 1500 & 0.03 & 0.01 & 0.10 & 0.10 & 0 & 0 & 10.67 & 10.67 & 11.25 & 90 & 77 & 1215 & 1510 & 97 & 1265 & 97 & 1344 \\
\hline |1920001| & 0.00 & 0 & 0 & 0.00 & 1500 & 0.02 & 0.01 & 0.10 & 0.33 & 0 & 0 & 10.67 & 10.67 & 10.89 & 295 & 250 & 12218 & 1523 & 103 & 1272 & 103 & 1340 \\
\hline 1/1102001 & $\mid 0.47$ & 0 & 0 & 0.00 & 1500 & 0.05 & 0.00 & 0.10 & 0.33 & 0 & 0 & 10.67 & 10.67 & 10.98 & 200 & 247 & 1179 & 1474 & 115 & 1277 & 115 & 1347 \\
\hline 1/1112001| & $\mid 0.28$ & 0 & 0 & 0.00 & 1500 & 0.03 & 0.01 & 0.10 & 0.33 & 0 & 0 & 10.67 & 10.67 & 10.90 & 295 & 250 & 1156 & 1445 & 196 & 1221 & 196 & 1285 \\
\hline 1/1220011 & 0.06 & 0 & 0 & 0.00 & 1500 & 0.03 & 0.01 & 0.10 & 0.33 & 0 & 0 & $\mid 10.67$ & 10.67 & 10.59 & 295 & 250 & 1155 & 1443 & 261 & 1176 & 261 & 1208 \\
\hline 1/1/32001 & 0.00 & 0 & 0 & 0.07 & 1500 & 0.03 & 0.02 & 0.10 & 0.10 & 0 & 0 & 10.67 & 10.67 & 10.52 & 90 & 77 & 1162 & 1452 & 274 & 1213 & 274 & 1227 \\
\hline $1 / 1412001$ & 0.00 & 0 & 0 & 0.14 & 1500 & 0.02 & 0.01 & 0.10 & 0.10 & 0 & 0 & 10.67 & 10.67 & 10.53 & 90 & 77 & 1170 & 1463 & 253 & 1227 & 253 & 1263 \\
\hline 1/1/512001 & 0.00 & 0 & 0 & 0.14 & 1500 & 0.05 & 0.02 & 0.10 & 0.10 & 0 & 0 & 10.67 & 10.67 & 10.49 & 90 & 77 & 1183 & 1478 & 246 & 1214 & 246 & 1271 \\
\hline 1/1/62001 & 0.00 & 0 & 0 & 0.17 & 1500 & 0.03 & 0.02 & 0.10 & 0.10 & 0 & 0 & 10.67 & 10.67 & 10.51 & 90 & 77 & 1194 & 1492 & 225 & 1212 & 225 & 1282 \\
\hline $1 / 17712001$ & 0.00 & 0 & 0 & 0.15 & 1500 & 0.03 & 0.02 & 0.10 & 0.10 & 0 & 0 & 10.67 & 10.67 & 10.52 & 90 & 77 & 1204 & 1505 & 206 & 1208 & 206 & 1295 \\
\hline $1 / 11812001$ & 0.00 & 0 & 0 & 0.15 & 1500 & 0.03 & 0.02 & 0.10 & 0.10 & 0 & 0 & 10.67 & 10.67 & 10.51 & 90 & 77 & 1214 & 1517 & 187 & 1246 & 187 & 1333 \\
\hline 1/1912001 & 0.00 & 0 & 0 & 0.15 & 1500 & 0.03 & 0.01 & 0.10 & 0.10 & 0 & 0 & 10.67 & 10.67 & 10.53 & 90 & 77 & 1223 & 1528 & 181 & 1285 & 181 & 1370 \\
\hline 112012001 & 0.00 & 0 & 0 & 0.14 & 1500 & 0.04 & 0.02 & 0.10 & 0.10 & 0 & 0 & 10.67 & 10.67 & 10.51 & 90 & 77 & 1233 & 1542 & 165 & 1312 & 165 & 1415 \\
\hline 121212001 & 0.00 & 0 & 0 & 0.16 & 1500 & 0.02 & 0.01 & 0.10 & 0.10 & 0 & 0 & 10.67 & 10.67 & 10.53 & 90 & 77 & 1241 & 1552 & 174 & 1326 & 174 & 1447 \\
\hline 12222001 & 0.00 & 0 & 0 & 0.14 & 1500 & 0.04 & 0.02 & 0.10 & 0.10 & 0 & 0 & 10.67 & 10.67 & 10.51 & 90 & 77 & 1252 & 1565 & 175 & 1319 & 175 & 1417 \\
\hline 1/2320011 & 0.02 & 0 & 0 & 0.16 & 1500 & 0.06 & 0.02 & 0.10 & 0.10 & 0 & 0 & 10.67 & 10.67 & 10.51 & 90 & 77 & 1263 & 1579 & 185 & 1245 & 185 & 1399 \\
\hline 124212001 & $\mid 0.33$ & 0 & 0 & 0.16 & 1500 & 0.03 & 0.01 & 0.10 & 0.10 & 0 & 0 & 10.67 & 10.67 & 10.85 & 90 & 77 & 1239 & 1549 & 195 & 1312 & 195 & 1400 \\
\hline
\end{tabular}

Note: Traditional drawdown (Type 3, normal year) selected for entire model run shown. 


\begin{tabular}{|c|c|c|c|c|c|c|c|c|c|c|c|c|c|c|c|c|c|c|c|c|c|c|}
\hline \multirow{2}{*}{\begin{tabular}{|r|} 
Time-Step \\
Date \\
\end{tabular}} & \multicolumn{5}{|c|}{$\mathbb{N}$} & \multicolumn{6}{|c|}{ OUT } & \multicolumn{3}{|c|}{ Management } & \multicolumn{4}{|c|}{ MODELOUTPUT } & \multicolumn{4}{|c|}{ NGWD COMPOSTEDDATA } \\
\hline & $\begin{array}{l}\text { Precip } \\
\text { inchess }\end{array}$ & & $\begin{array}{l}\text { EC(gw) } \\
\text { wiscm }\end{array}$ & $\begin{array}{l}\text { Op. Intlor } \\
\text { inchers }\end{array}$ & & $\begin{array}{l}\text { Evap. (open } \\
\text { waterl) } \\
\text { inches }\end{array}$ & $\begin{array}{c}\text { ET } \\
\text { (veg. areas) } \\
\text { incheses }\end{array}$ & $\begin{array}{l}\text { Op Spill } \\
\text { inches }\end{array}$ & $\begin{array}{l}\text { Outtlow } \\
\text { inches }\end{array}$ & $\begin{array}{l}\text { GW } \\
\text { inches }\end{array}$ & $\begin{array}{c}\text { EC(gw) } \\
\text { wscm }\end{array}$ & \begin{tabular}{|l} 
Dephth \\
(hab) \\
inches
\end{tabular} & $\begin{array}{l}\text { Depth } \\
\text { (CC) }\end{array}$ & $\begin{array}{l}\text { Endof } \\
\text { Day } \\
\text { inthes }\end{array}$ & $\begin{array}{l}\text { Flow } \\
\left(c c^{2}\right)\end{array}$ & $\begin{array}{l}\mathrm{Adj} . \\
\text { Flow } \\
\text { (ct) }\end{array}$ & $\begin{array}{l}\text { EC } \\
\text { USCm }\end{array}$ & $\begin{array}{c}\text { Adj, EC } \\
\text { USCOC }\end{array}$ & & $\begin{array}{c}\text { ersonnel } \\
\text { EEC (uscm) }\end{array}$ & $\begin{array}{c}\text { Real-Tim } \\
Q(\text { cts })\end{array}$ & $\begin{array}{l}\text { e Network } \\
\text { EC (LSCOm }\end{array}$ \\
\hline 125512001 & 0.34 & 0 & 0 & 0.00 & 1500 & 0.04 & 0.02 & 0.10 & 0.29 & 0 & 0 & \begin{tabular}{|l|l|}
10.67 \\
\end{tabular} & 10.67 & 10.85 & 255 & 217 & 1211 & 1514 & 199 & 1424 & 199 & 1530 \\
\hline 112012001 & 0.01 & 0 & 0 & 0.00 & 1500 & 0.05 & 0.02 & 0.10 & 0.33 & 0 & 0 & 10.67 & 9.60 & 10.47 & 295 & 250 & 1218 & 1523 & 220 & 1448 & 220 & 1516 \\
\hline 112712001 & 0.00 & 0 & 0 & 0.00 & 1500 & 0.04 & 0.02 & 0.10 & 0.20 & 0 & 0 & 10.67 & 8.53 & 10.21 & 179 & 152 & 1225 & 1531 & 206 & 1426 & 206 & 1511 \\
\hline 12822001 & 0.00 & 0 & 0 & 0.01 & 1500 & 0.04 & 0.02 & 0.10 & 0.10 & 0 & 0 & 10.67 & 7.47 & 10.06 & 90 & 77 & 1232 & 1540 & 194 & 1414 & 194 & 1511 \\
\hline 129012001 & 0.01 & 0 & 0 & 0.01 & 1500 & 0.04 & 0.02 & 0.10 & 0.10 & 0 & 0 & 10.67 & 6.40 & 9.91 & 90 & 77 & 1239 & 1549 & 186 & 1403 & 186 & 1552 \\
\hline 13012001 & 0.00 & 0 & 0 & 0.00 & 1500 & 0.04 & 0.02 & 0.10 & 0.10 & 0 & 0 & 10.67 & 5.33 & 9.75 & 90 & 77 & 1247 & 1558 & 171 & 1415 & 171 & 1540 \\
\hline $1 / 312001$ & 0.00 & 0 & 0 & 0.01 & 1500 & 0.02 & 0.02 & 0.10 & 0.10 & 0 & 0 & 10.67 & 4.27 & 9.62 & 90 & 77 & 1253 & 1566 & 170 & 1428 & 170 & 1528 \\
\hline 21112001 & 0.00 & 0 & 0 & 0.00 & 1750 & 0.04 & 0.01 & 0.10 & 0.11 & 0 & 0 & 10.67 & 3.20 & 9.46 & 96 & 81 & 1280 & 1575 & 154 & 1467 & 154 & 1567 \\
\hline 2222001 & 0.00 & 0 & 0 & 0.00 & 1750 & 0.04 & 0.02 & 0.10 & 0.10 & 0 & 0 & 10.67 & 2.13 & 9.30 & 90 & 77 & 1268 & 1585 & 130 & 1475 & 130 & 1617 \\
\hline 2332001 & 0.00 & 0 & 0 & 0.01 & 1750 & 0.05 & 0.03 & 0.10 & 0.10 & 0 & 0 & 10.67 & 1.07 & 9.14 & 90 & 77 & 1279 & 1598 & 124 & 1510 & 124 & 1634 \\
\hline 242001 & 0.00 & 0 & 0 & 0.02 & 1750 & 0.04 & 0.03 & 0.10 & 0.10 & 0 & 0 & 10.67 & 0.00 & 8.99 & 90 & 77 & 1220 & 1612 & 124 & 1523 & 124 & 1653 \\
\hline 2552001 & 0.00 & 0 & 0 & 0.17 & 1750 & 0.05 & 0.03 & 0.10 & 0.10 & 0 & 0 & 10.67 & 0.00 & 8.99 & 90 & 77 & 1308 & 1635 & 120 & 1547 & 120 & 1661 \\
\hline 2612001 & 0.00 & 0 & 0 & 0.17 & 1750 & 0.08 & 0.04 & 0.10 & 0.10 & 0 & 0 & 10.67 & 0.00 & 8.94 & 90 & 77 & 1335 & 1668 & 112 & 1546 & 112 & 1674 \\
\hline 2712001 & 0.00 & 0 & 0 & 0.22 & 1750 & 0.05 & 0.05 & 0.10 & 0.10 & 0 & 0 & 10.67 & 0.00 & 8.96 & 90 & 77 & 1300 & 1700 & 106 & 1571 & 106 & 1700 \\
\hline 2882001 & 0.00 & 0 & 0 & 0.20 & 1000 & 0.06 & 0.03 & 0.10 & 0.10 & 0 & 0 & 10.67 & 0.00 & 8.98 & 90 & 77 & 1365 & 1706 & 94 & 1600 & 94 & 1723 \\
\hline 2912001 & 0.11 & 0 & 0 & 0.19 & 1000 & 0.07 & 0.01 & 0.10 & 0.10 & 0 & 0 & 10.67 & 0.00 & 9.09 & 90 & 77 & 1355 & 1694 & 91 & 1567 & 91 & 1699 \\
\hline 21010201 & 0.08 & 0 & 0 & 0.07 & 1000 & 0.03 & 0.01 & 0.10 & 0.10 & 0 & 0 & 10.67 & 0.00 & 9.09 & 90 & 77 & 1349 & 1686 & 92 & 1567 & 92 & 1700 \\
\hline 21112001 & 0.21 & 0 & 0 & 0.07 & 1000 & 0.04 & 0.01 & 0.10 & 0.10 & 0 & 0 & 10.67 & 0.00 & 9.22 & 90 & 77 & 1328 & 1659 & 149 & 1426 & 149 & 1612 \\
\hline 2122001 & 0.00 & 0 & 0 & 0.00 & 1000 & 0.03 & 0.02 & 0.10 & 0.16 & 0 & 0 & 10.67 & 0.00 & 9.02 & 140 & 119 & 1334 & 1667 & 163 & 1407 & 163 & 1570 \\
\hline 2132001 & 0.01 & 0 & 0 & 0.04 & 1000 & 0.02 & 0.02 & 0.10 & 0.10 & 0 & 0 & 10.54 & 0.00 & 8.92 & 90 & 77 & 1338 & 1672 & 147 & 1449 & 147 & 1577 \\
\hline 21412001 & 0.00 & 0 & 0 & 0.03 & 1000 & 0.05 & 0.03 & 0.10 & 0.10 & 0 & 0 & 10.42 & 0.00 & 8.78 & 90 & 77 & 1348 & 1685 & 137 & 1484 & 137 & 1582 \\
\hline 21552001 & 0.00 & 0 & 0 & 0.07 & 1000 & 0.06 & 0.02 & 0.10 & 0.10 & 0 & 0 & 10.30 & 0.00 & 8.66 & 90 & 77 & 1358 & 1698 & 128 & 1507 & 128 & 1597 \\
\hline 21616001 & 0.00 & 0 & 0 & 0.08 & 1000 & 0.06 & 0.04 & 0.10 & 0.10 & 0 & 0 & 10.18 & 0.00 & 8.55 & 90 & 77 & 1370 & 17713 & 136 & 1446 & 136 & 1529 \\
\hline 211712001 & 0.00 & 0 & 0 & 0.09 & 1000 & 0.04 & 0.00 & 0.10 & 0.10 & 0 & 0 & 10.06 & 0.00 & 8.49 & 90 & 77 & 1373 & 1717 & 135 & 1442 & 135 & 1519 \\
\hline 21182001 & 0.06 & 0 & 0 & 0.00 & 1000 & 0.07 & 0.02 & 0.10 & 0.13 & 0 & 0 & 9.85 & 0.00 & 8.33 & 115 & 98 & 1380 & 1725 & 143 & 1445 & 143 & 1529 \\
\hline 21912001 & 0.18 & 0 & 0 & 0.00 & 1000 & 0.04 & 0.02 & 0.10 & 0.14 & 0 & 0 & 9.65 & 0.00 & 8.31 & 128 & 109 & 1363 & 1704 & 134 & 1478 & 134 & 1547 \\
\hline 220012001 & 0.00 & 0 & 0 & 0.00 & 1000 & 0.02 & 0.02 & 0.10 & 0.30 & 0 & 0 & 9.44 & 0.00 & 7.98 & 267 & 227 & 1369 & 1711 & 132 & 1471 & 132 & 1538 \\
\hline 22212001 & 0.05 & 0 & 0 & 0.00 & 1000 & 0.05 & 0.02 & 0.10 & 0.14 & 0 & 0 & 9.24 & 0.00 & 7.81 & 127 & 108 & 1373 & 1717 & 131 & 1452 & 131 & 1526 \\
\hline 222212001 & 0.14 & 0 & 0 & 0.00 & 1000 & 0.07 & 0.02 & 0.10 & 0.15 & 0 & 0 & 9.04 & 0.00 & 7.71 & 137 & 117 & 1368 & 1710 & 165 & 1380 & 165 & 1448 \\
\hline 22320001 & 0.40 & 0 & 0 & 0.00 & 1000 & 0.06 & 0.02 & 0.10 & 0.22 & 0 & 0 & 8.83 & 0.00 & 7.81 & 197 & 167 & 1321 & 1651 & 163 & 1365 & 163 & 1432 \\
\hline 224212001 & 0.45 & 0 & 0 & 0.00 & 1000 & 0.01 & 0.01 & 0.10 & 0.33 & 0 & 0 & 8.63 & 0.00 & 7.91 & 295 & 250 & 1258 & 1572 & 164 & 1339 & 164 & 1495 \\
\hline 22552001 & 0.00 & 0 & 0 & 0.00 & 1000 & 0.02 & 0.03 & 0.10 & 0.33 & 0 & 0 & 8.43 & 0.00 & 7.53 & 295 & 250 & 1267 & 1584 & 188 & 1251 & 188 & 1407 \\
\hline 22602001 & 0.00 & 0 & 0 & 0.00 & 1000 & 0.04 & 0.02 & 0.10 & 0.33 & 0 & 0 & 8.22 & 0.00 & 7.13 & 205 & 250 & 1279 & 1599 & 223 & 1180 & 223 & 1297 \\
\hline 22712001 & 0.00 & 0 & 0 & 0.00 & 1000 & 0.06 & 0.04 & 0.10 & 0.33 & 0 & 0 & 8.02 & 0.00 & 6.70 & 295 & 250 & 1301 & 1026 & 214 & 1156 & 214 & 1266 \\
\hline 228212001 & 0.00 & 0 & 0 & 0.01 & 1000 & 0.08 & 0.04 & 0.10 & 0.10 & 0 & 0 & 7.81 & 0.00 & 6.49 & 90 & 77 & 1326 & 1658 & 179 & 1251 & 179 & 1356 \\
\hline 31112001 & 0.00 & 0 & 0 & 0.05 & 600 & 0.08 & 0.03 & 0.10 & 0.10 & 0 & 0 & 7.61 & 0.00 & 6.33 & 90 & 77 & 1343 & 1678 & 144 & 1461 & 144 & 1500 \\
\hline 322001 & 0.24 & 0 & 0 & 0.03 & 600 & 0.04 & 0.01 & 0.10 & 0.10 & 0 & 0 & 7.41 & 0.00 & 6.45 & 90 & 77 & 1307 & 1634 & 128 & 1405 & 128 & 1506 \\
\hline 332001 & 0.12 & 0 & 0 & 0.00 & 600 & 0.06 & 0.01 & 0.10 & 0.33 & 0 & 0 & 7.20 & 0.00 & 6.17 & 295 & 250 & 1299 & 1623 & 126 & 1395 & 126 & 1545 \\
\hline 3412001 & 0.21 & 0 & 0 & 0.00 & 600 & 0.19 & 0.01 & 0.10 & 0.26 & 0 & 0 & 7.00 & 0.00 & 5.92 & 230 & 195 & 1302 & 1627 & 126 & 1350 & 126 & 1553 \\
\hline 3522001 & 0.55 & 0 & 0 & 0.00 & 600 & 0.04 & 0.01 & 0.10 & 0.19 & 0 & 0 & 6.80 & 0.00 & 6.24 & 167 & 142 & 1216 & 1519 & 182 & 1238 & 182 & 1429 \\
\hline 3612001 & 0.00 & 0 & 0 & 0.00 & 600 & 0.05 & 0.02 & 0.10 & 0.33 & 0 & 0 & 6.59 & 0.00 & 5.84 & 295 & 250 & 1231 & 1539 & 223 & 1201 & 223 & 1363 \\
\hline 3712001 & 0.00 & 0 & 0 & 0.00 & 600 & 0.07 & 0.04 & 0.10 & 0.33 & 0 & 0 & 6.39 & 0.00 & 5.40 & 295 & 250 & 1258 & 1573 & 223 & 1222 & 223 & 1371 \\
\hline 3812001 & 0.00 & 0 & 0 & 0.00 & 600 & 0.08 & 0.04 & 0.10 & 0.19 & 0 & 0 & 6.19 & 0.00 & 5.09 & 167 & 142 & 1289 & 1611 & 209 & 1303 & 209 & 1452 \\
\hline 3912001 & 0.01 & 0 & 0 & 0.04 & 600 & 0.09 & 0.02 & 0.10 & 0.10 & 0 & 0 & 5.98 & 0.00 & 4.94 & 90 & 77 & 1309 & 1636 & 177 & 1486 & 177 & 1572 \\
\hline 310102001 & 0.00 & 0 & 0 & 0.02 & 600 & 0.07 & 0.04 & 0.10 & 0.10 & 0 & 0 & 5.78 & 0.00 & 4.75 & 90 & 77 & 1338 & 1673 & 193 & 1469 & 193 & 1700 \\
\hline 311112001 & 0.00 & 0 & 0 & 0.04 & 600 & 0.08 & 0.04 & 0.10 & 0.10 & 0 & 0 & 5.57 & 0.00 & 4.57 & 90 & 77 & 1367 & 1709 & 187 & 1510 & 187 & 1695 \\
\hline 31122001 & 0.00 & 0 & 0 & 0.04 & 600 & 0.11 & 0.05 & 0.10 & 0.10 & 0 & 0 & 5.37 & 0.00 & 4.36 & 90 & 77 & 1409 & 1761 & 181 & 1468 & 181 & 1656 \\
\hline $3 / 132001$ & 0.00 & 0 & 0 & 0.08 & 600 & 0.08 & 0.05 & 0.10 & 0.10 & 0 & 0 & 5.17 & 0.00 & 4.21 & 90 & 77 & 1438 & 1798 & 156 & 1448 & 156 & 1589 \\
\hline 31412001 & 0.00 & 0 & 0 & 0.05 & 600 & 0.09 & 0.05 & 0.10 & 0.10 & 0 & 0 & 4.96 & 0.00 & 4.02 & 90 & 77 & 1480 & 1850 & 188 & 1399 & 188 & 1512 \\
\hline
\end{tabular}

Note: Traditional drawdown (Type 3, normal year) selected for entire model run shown. 


\begin{tabular}{|c|c|c|c|c|c|c|c|c|c|c|c|c|c|c|c|c|c|c|c|c|c|c|}
\hline \multirow{2}{*}{$\begin{array}{r}\text { Time-Step } \\
\text { Date }\end{array}$} & \multicolumn{5}{|c|}{$\mathbb{N}$} & \multicolumn{6}{|c|}{ OUT } & \multicolumn{3}{|c|}{ Management } & \multicolumn{4}{|c|}{ MODEL OUTPUT } & \multicolumn{4}{|c|}{ NGWD COMPOSTEEDATA } \\
\hline & $\begin{array}{l}\text { Precip } \\
\text { inchess }\end{array}$ & & $\begin{array}{l}\text { EC(gw) } \\
\text { uscm }\end{array}$ & $\begin{array}{l}\text { Op. Inflow } \\
\text { incheles }\end{array}$ & & $\begin{array}{c}\text { Evap. (opel } \\
\text { water) } \\
\text { incleses }\end{array}$ & $\begin{array}{c}\text { ET } \\
\text { (veg. areas) } \\
\text { inches }\end{array}$ & $\begin{array}{c}\text { OpSpill } \\
\text { inches }\end{array}$ & $\begin{array}{l}\text { Outflow } \\
\text { inches }\end{array}$ & $\begin{array}{l}\text { GW } \\
\text { inchles }\end{array}$ & $\begin{array}{l}\mathrm{EC}(\mathrm{gw}) \\
{ }_{\mathrm{SSCm}}\end{array}$ & $\begin{array}{l}\text { Depth } \\
\text { (hab) } \\
\text { inches }\end{array}$ & $\begin{array}{l}\text { Dephth } \\
\text { (CC) }\end{array}$ & $\begin{array}{l}\text { Endof } \\
\text { Day } \\
\text { inches }\end{array}$ & $\begin{array}{l}\text { Flow } \\
\text { (ds) }\end{array}$ & $\begin{array}{l}\mathrm{Adj} . \\
\text { Flow } \\
\text { (cts) }\end{array}$ & $\begin{array}{l}\text { EC } \\
\text { USSCm }\end{array}$ & $\begin{array}{c}\text { Adj, EC } \\
\text { USCOC }\end{array}$ & $\begin{array}{l}\text { GWD } \\
\text { a(sis) }\end{array}$ & $\begin{array}{l}\text { ersonnel } \\
\text { EC (lss(m) })\end{array}$ & $\begin{array}{l}\text { Real-Jim } \\
Q(\text { cts) }\end{array}$ & 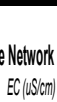 \\
\hline 31152001 & 0.00 & 0 & 0 & 0.17 & 600 & 0.08 & 0.03 & 0.10 & 0.10 & 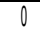 & 0 & 4.88 & 0.00 & 3.97 & 90 & 77 & 1485 & 1856 & 170 & 1579 & 170 & 1679 \\
\hline 31162001 & 0.00 & 0 & 0 & 0.15 & 600 & 0.07 & 0.06 & 0.10 & 0.10 & 0 & 0 & 4.80 & 0.00 & 3.89 & 90 & 77 & 1501 & 1877 & 100 & 1654 & 160 & 1745 \\
\hline 31772001 & 0.00 & 0 & 0 & 0.16 & 600 & 0.09 & 0.05 & 0.10 & 0.10 & 0 & 0 & 4.72 & 0.00 & 3.82 & 90 & 77 & 1517 & 1896 & 124 & 1806 & 124 & 1915 \\
\hline 31182001 & 0.00 & 0 & 0 & 0.17 & 600 & 0.10 & 0.05 & 0.10 & 0.10 & 0 & 0 & 4.64 & 0.00 & 3.72 & 90 & 77 & 1540 & 1925 & 108 & 1845 & 108 & 2004 \\
\hline 31922001 & 0.00 & 0 & 0 & 0.19 & 600 & 0.10 & 0.05 & 0.10 & 0.10 & 0 & 0 & 4.56 & 0.00 & 3.65 & 90 & 77 & 1558 & 1948 & 98 & 1862 & 98 & 2015 \\
\hline 320212001 & 0.00 & 0 & 0 & 0.19 & 600 & 0.15 & 0.05 & 0.10 & 0.10 & 0 & 0 & 4.47 & 0.00 & 3.54 & 90 & 77 & 1596 & 1996 & 95 & 1821 & 95 & 1987 \\
\hline 32112001 & 0.00 & 0 & 0 & 0.23 & 600 & 0.13 & 0.05 & 0.10 & 0.10 & 0 & 0 & 4.39 & 0.00 & 3.49 & 90 & 77 & 1613 & 2016 & 86 & 1853 & 86 & 1988 \\
\hline 32220001 & 0.00 & 0 & 0 & 0.21 & 600 & 0.09 & 0.05 & 0.10 & 0.10 & 0 & 0 & 4.31 & 0.00 & 3.46 & 90 & 77 & 1619 & 2024 & 83 & 1839 & 83 & 1925 \\
\hline 323232001 & 0.00 & 0 & 0 & 0.12 & 600 & 0.09 & 0.05 & 0.10 & 0.10 & 0 & 0 & 4.16 & 0.00 & 3.33 & 90 & 77 & 1653 & 2007 & 82 & 1812 & 82 & 1928 \\
\hline 32412001 & 0.00 & 0 & 0 & 0.12 & 600 & 0.10 & 0.06 & 0.10 & 0.10 & 0 & 0 & 4.01 & 0.00 & 3.19 & 90 & 77 & 1605 & 2119 & 74 & 1900 & 74 & 2038 \\
\hline 32552001 & 0.00 & 0 & 0 & 0.13 & 600 & 0.12 & 0.05 & 0.10 & 0.10 & 0 & 0 & 3.87 & 0.00 & 3.05 & 90 & 77 & 1749 & 2187 & 31 & 1948 & 31 & 2189 \\
\hline 326612001 & 0.00 & 0 & 0 & 0.15 & 600 & 0.13 & 0.07 & 0.10 & 0.10 & 0 & 0 & 3.72 & 0.00 & 290 & 90 & 77 & 1810 & 2263 & 51 & 2027 & 51 & 2164 \\
\hline 32712001 & 0.00 & 0 & 0 & 0.17 & 600 & 0.12 & 0.07 & 0.10 & 0.10 & 0 & 0 & 3.57 & 0.00 & 2.78 & 90 & 77 & 1801 & 2327 & 48 & 2078 & 48 & 2232 \\
\hline 32882001 & 0.00 & 0 & 0 & 0.16 & 600 & 0.12 & 0.07 & 0.10 & 0.10 & 0 & 0 & 3.42 & 0.00 & 2.65 & 90 & 77 & 1920 & 2400 & 44 & 2116 & 44 & 2275 \\
\hline 329912001 & 0.00 & 0 & 0 & 0.16 & 600 & 0.15 & 0.08 & 0.10 & 0.10 & 0 & 0 & 3.27 & 0.00 & 2.49 & 90 & 77 & 2013 & 2516 & 42 & 2167 & 42 & 2351 \\
\hline 3302001 & 0.00 & 0 & 0 & 0.20 & 600 & 0.13 & 0.08 & 0.10 & 0.10 & 0 & 0 & 3.13 & 0.00 & 2.38 & 90 & 77 & 2073 & 2592 & 38 & 2407 & 38 & 2562 \\
\hline 33112001 & 0.00 & 0 & 0 & 0.18 & 600 & 0.12 & 0.07 & 0.10 & 0.10 & 0 & 0 & 2.98 & 0.00 & 2.27 & 90 & 77 & 2132 & 2065 & 35 & 2480 & 35 & 2585 \\
\hline 41112001 & 0.00 & 0 & 0 & 0.16 & 600 & 0.19 & 0.07 & 0.10 & 0.10 & 0 & 0 & 2.83 & 0.00 & 2.07 & 90 & 77 & 2223 & 2887 & 32 & 2288 & 32 & 2003 \\
\hline 4220001 & 0.00 & 0 & 0 & 0.23 & 600 & 0.35 & 0.07 & 0.10 & 0.10 & 0 & 0 & 2.68 & 0.00 & 1.79 & 90 & 77 & 2660 & 3325 & 29 & 2198 & 29 & 2368 \\
\hline 432001 & 0.00 & 0 & 0 & 0.39 & 600 & 0.23 & 0.06 & 0.10 & 0.10 & 0 & 0 & 2.53 & 0.00 & 1.78 & 90 & 77 & 2649 & 3311 & 37 & 1843 & 37 & 2323 \\
\hline 4412001 & 0.00 & 0 & 0 & 0.34 & 600 & 0.12 & 0.06 & 0.10 & 0.10 & 0 & 0 & 2.47 & 0.00 & 1.84 & 90 & 77 & 2538 & 3173 & 35 & 1859 & 35 & 2328 \\
\hline 452001 & 0.00 & 0 & 0 & 0.23 & 600 & 0.12 & 0.07 & 0.10 & 0.10 & 0 & 0 & 2.40 & 0.00 & 1.77 & 90 & 77 & 2569 & 3212 & 33 & 1855 & 33 & 2191 \\
\hline 4662001 & 0.12 & 0 & 0 & 0.24 & 600 & 0.10 & 0.02 & 0.10 & 0.10 & 0 & 0 & 2.33 & 0.00 & 1.90 & 90 & 77 & 2351 & 2939 & 27 & 1887 & 27 & 2137 \\
\hline 47712001 & 0.04 & 0 & 0 & 0.05 & 600 & 0.07 & 0.04 & 0.10 & 0.10 & 0 & 0 & 2.27 & 0.00 & 1.78 & 90 & 77 & 2400 & 3008 & 25 & 1980 & 25 & 2203 \\
\hline 4882001 & 0.18 & 0 & 0 & 0.11 & 600 & 0.08 & 0.04 & 0.10 & 0.10 & 0 & 0 & 2.20 & 0.00 & 1.85 & 90 & 77 & 2236 & 2795 & 23 & 2096 & 23 & 2311 \\
\hline 4920201 & 0.05 & 0 & 0 & 0.00 & 600 & 0.09 & 0.06 & 0.10 & 0.12 & 0 & 0 & 2.13 & 0.00 & 1.63 & 107 & 91 & 2398 & 2997 & 21 & 2198 & 21 & 2373 \\
\hline 411020201 & 0.00 & 0 & 0 & 0.14 & 600 & 0.12 & 0.07 & 0.10 & 0.10 & 0 & 0 & 2.07 & 0.00 & 1.48 & 90 & 77 & 2553 & 3191 & 22 & 2082 & 22 & 2304 \\
\hline 41112001 & 0.04 & 0 & 0 & 0.24 & 600 & 0.06 & 0.03 & 0.10 & 0.10 & 0 & 0 & 2.00 & 0.00 & 1.56 & 90 & 77 & 2362 & 2953 & 21 & 2000 & 21 & 2175 \\
\hline 41122001 & 0.00 & 0 & 0 & 0.10 & 600 & 0.08 & 0.07 & 0.10 & 0.10 & 0 & 0 & 1.93 & 0.00 & 1.41 & 90 & 77 & 2492 & 3116 & 23 & 1965 & 23 & 2185 \\
\hline $4 / 132001$ & 0.00 & 0 & 0 & 0.19 & 600 & 0.09 & 0.07 & 0.10 & 0.10 & 0 & 0 & $\mid 1.87$ & 0.00 & 1.34 & 90 & 77 & 2521 & 3152 & 21 & 1952 & 21 & 2133 \\
\hline 411412001 & 0.00 & 0 & 0 & 0.20 & 600 & 0.11 & 0.06 & 0.10 & 0.10 & 0 & 0 & 1.80 & 0.00 & 1.27 & 90 & 77 & 2564 & 3206 & 19 & 1911 & 19 & 2129 \\
\hline 41/52001 & 0.00 & 0 & 0 & 0.22 & 600 & 0.12 & 0.07 & 0.10 & 0.10 & 0 & 0 & 1.73 & 0.00 & 1.19 & 90 & 77 & 2023 & 3278 & 17 & 1782 & 17 & 1982 \\
\hline 41162000 & 0.00 & 0 & 0 & 0.24 & 600 & 0.18 & 0.08 & 0.10 & 0.10 & 0 & 0 & 1.67 & 0.00 & 1.07 & 90 & 77 & 750 & 938 & 16 & 1769 & 16 & 1952 \\
\hline 41772001 & 0.00 & 0 & 0 & 0.30 & 600 & 0.12 & 0.07 & 0.10 & 0.10 & 0 & 0 & 1.60 & 0.00 & 1.08 & 90 & 77 & 750 & 938 & 17 & 1774 & 17 & 1917 \\
\hline 411820001 & 0.00 & 0 & 0 & 0.24 & 600 & 0.19 & 0.07 & 0.10 & 0.10 & 0 & 0 & 1.53 & 0.00 & 0.96 & 90 & 77 & 750 & 938 & 19 & 1737 & 19 & 1984 \\
\hline 419192001 & 0.00 & 0 & 0 & 0.30 & 600 & 0.14 & 0.04 & 0.10 & 0.10 & 0 & 0 & 1.47 & 0.00 & 0.98 & 90 & 77 & 750 & 938 & 22 & 1516 & 22 & 1713 \\
\hline 42012001 & 0.38 & 0 & 0 & 0.22 & 600 & 0.11 & 0.02 & 0.10 & 0.10 & 0 & 0 & 1.40 & 0.00 & 1.35 & 90 & 77 & 750 & 938 & 24 & 1304 & 24 & 1461 \\
\hline 42112001 & 0.00 & 0 & 0 & 0.00 & 600 & 0.08 & 0.05 & 0.10 & 0.31 & 0 & 0 & 1.33 & 0.00 & 0.91 & 273 & 232 & 964 & 1205 & 24 & 1198 & 24 & 1400 \\
\hline 42222001 & 0.00 & 0 & 0 & 0.18 & 600 & 0.12 & 0.07 & 0.10 & 0.10 & 0 & 0 & $\mid 1.27$ & 0.00 & 0.80 & 90 & 77 & 750 & 938 & 33 & 1179 & 33 & 1350 \\
\hline 423212001 & 0.00 & 0 & 0 & 0.23 & 600 & 0.14 & 0.08 & 0.10 & 0.10 & 0 & 0 & 1.20 & 0.00 & 0.72 & 90 & 77 & 750 & 938 & 32 & 1144 & 32 & 1331 \\
\hline 424242001 & 0.00 & 0 & 0 & 0.26 & 600 & 0.15 & 0.08 & 0.10 & 0.10 & 0 & 0 & 1.13 & 0.00 & 0.63 & 90 & 77 & 750 & 938 & 31 & 1071 & 31 & 1265 \\
\hline 425212001 & 0.00 & 0 & 0 & 0.28 & 600 & 0.18 & 0.09 & 0.10 & 0.10 & 0 & 0 & 1.07 & 0.00 & 0.54 & 90 & 77 & 750 & 938 & 31 & 1000 & 31 & 11886 \\
\hline 42612001 & 0.00 & 0 & 0 & 0.31 & 600 & 0.18 & 0.10 & 0.10 & 0.10 & 0 & 0 & 1.00 & 0.00 & 0.48 & 90 & 77 & 750 & 938 & 30 & 1013 & 30 & 1235 \\
\hline 427272001 & 0.00 & 0 & 0 & 0.32 & 600 & 0.18 & 0.09 & 0.10 & 0.10 & 0 & 0 & 0.93 & 0.00 & 0.43 & 90 & 77 & 750 & 938 & 26 & 1119 & 26 & 1403 \\
\hline 42812001 & 0.00 & 0 & 0 & 0.31 & 600 & 0.18 & 0.08 & 0.10 & 0.10 & 0 & 0 & 0.87 & 0.00 & 0.39 & 90 & 77 & 750 & 938 & 25 & 1088 & 25 & 1334 \\
\hline 429212001 & 0.00 & 0 & 0 & 0.30 & 600 & 0.15 & 0.10 & 0.10 & 0.10 & 0 & 0 & 0.80 & 0.00 & 0.34 & 90 & 77 & 750 & 938 & 25 & 1032 & 25 & 1202 \\
\hline 43002001 & 0.00 & 0 & 0 & 0.29 & 600 & 0.16 & 0.10 & 0.10 & 0.10 & 0 & 0 & 0.73 & 0.00 & 0.27 & 90 & 77 & 750 & 938 & 24 & 963 & 24 & 1154 \\
\hline 51112001 & 0.00 & 0 & 0 & 0.30 & 600 & 0.22 & 0.13 & 0.10 & 0.10 & 0 & 0 & 0.67 & 0.00 & 0.13 & 90 & 77 & 750 & 938 & 28 & 914 & 28 & 1117 \\
\hline 5222001 & 0.00 & 0 & 0 & 0.39 & 600 & 0.20 & 0.16 & 0.10 & 0.10 & 0 & 0 & 0.60 & 0.00 & 0.06 & 90 & 77 & 750 & 938 & 27 & 889 & 27 & 1093 \\
\hline
\end{tabular}


Note: Traditional drawdown (Type 3, normal year) selected for entire model run shown.

\begin{tabular}{|c|c|c|c|c|c|c|c|c|c|c|c|c|c|c|c|c|c|c|c|c|c|c|}
\hline Time-Step & \multicolumn{5}{|c|}{$\mathbb{N}$} & \multicolumn{6}{|c|}{ OUT } & \multicolumn{3}{|c|}{ Management } & \multicolumn{4}{|c|}{ MODEL OUTPUT } & \multicolumn{4}{|c|}{ NGWD COMPOSTE DATA } \\
\hline Date & $\begin{array}{l}\text { Precip } \\
\text { inches }\end{array}$ & $\begin{array}{l}\text { GW } \\
\text { inches }\end{array}$ & $\begin{array}{l}E C(g w) \\
\omega S(c m)\end{array}$ & $\begin{array}{l}\text { Op. Intlow } \\
\text { inches }\end{array}$ & $\begin{array}{l}\text { EClifi } \\
\text { uS } \mathrm{cm}\end{array}$ & $\begin{array}{c}\text { Evap. lopen } \\
\text { water) } \\
\text { inches }\end{array}$ & $\begin{array}{c}\text { ET } \\
\text { (veg, areas) } \\
\text { inches }\end{array}$ & $\begin{array}{c}\text { Op Spill } \\
\text { inches }\end{array}$ & $\begin{array}{c}\text { Outflow } \\
\text { inches }\end{array}$ & & $\begin{array}{c}E C(g W) \\
\text { uSlcm }\end{array}$ & $\begin{array}{l}\text { Depth } \\
\text { (hab) } \\
\text { inches } \\
\end{array}$ & $\begin{array}{l}\text { Depth } \\
\text { (CC) }\end{array}$ & $\begin{array}{l}\text { End of } \\
\text { Day } \\
\text { inches }\end{array}$ & $\begin{array}{l}\text { Flow } \\
(\mathrm{d} / \mathrm{s})\end{array}$ & $\begin{array}{l}\text { Adj. } \\
\text { Flow } \\
(c t s)\end{array}$ & $\begin{array}{l}\text { EC } \\
\text { US } \mathrm{Cm}\end{array}$ & $\begin{array}{c}\text { Adj, EC } \\
\text { uS } / \mathrm{cm}\end{array}$ & $\begin{array}{l}\text { GWDP } \\
Q\left(d f^{\prime}\right)\end{array}$ & $\begin{array}{l}\text { ersonnel } \\
\text { EC ( }(\mathrm{s} \mathrm{cm})\end{array}$ & \begin{tabular}{|c} 
Real|Tin \\
$Q($ cts $)$
\end{tabular} & $\begin{array}{l}\text { e Network } \\
\text { EC }(u S / \mathrm{cm}) \text { ) }\end{array}$ \\
\hline $5 / 3 / 2001$ & 0.00 & 0 & 0 & 0.68 & 600 & 0.20 & 0.11 & 0.10 & 0.10 & 0 & 0 & 0.87 & 0.00 & 0.33 & 90 & 77 & 750 & 938 & 27 & 841 & 27 & 1064 \\
\hline $5 / 42001$ & 0.00 & 0 & 0 & 0.64 & 600 & 0.20 & 0.11 & 0.10 & 0.10 & 0 & 0 & 1.13 & 0.00 & 0.56 & 90 & 77 & 750 & 938 & 24 & 892 & 24 & 1002 \\
\hline $5 / 512001$ & 0.00 & 0 & 0 & 1.01 & 600 & 0.21 & 0.10 & 0.10 & 0.10 & 0 & 0 & 1.83 & 0.00 & 1.16 & 90 & 77 & 750 & 938 & 36 & 918 & 36 & 1068 \\
\hline 56162001 & 0.00 & 0 & 0 & 1.02 & 600 & 0.22 & 0.10 & 0.10 & 0.10 & 0 & 0 & 2.53 & 0.00 & 1.76 & 90 & 77 & 750 & 938 & 89 & 932 & 89 & 1000 \\
\hline $57 / 12001$ & 0.00 & 0 & 0 & 0.65 & 600 & 0.21 & 0.11 & 0.10 & 0.10 & 0 & 0 & 2.80 & 0.00 & 1.98 & 90 & 77 & 815 & 1018 & 77 & 939 & 77 & 981 \\
\hline 51812001 & 0.00 & 0 & 0 & 0.11 & 600 & 0.22 & 0.11 & 0.10 & 0.10 & 0 & 0 & 2.43 & 0.00 & 1.66 & 90 & 77 & 996 & 1245 & 19 & 1126 & 19 & 1300 \\
\hline 5/912001 & 0.00 & 0 & 0 & 0.11 & 600 & 0.26 & 0.12 & 0.10 & 0.10 & 0 & 0 & 2.07 & 0.00 & 1.30 & 90 & 77 & 1353 & 1692 & 30 & 890 & 30 & 1382 \\
\hline 51102001 & 0.00 & 0 & 0 & 0.16 & 600 & 0.28 & 0.11 & 0.10 & 0.10 & 0 & 0 & 1.70 & 0.00 & 0.97 & 90 & 77 & 1965 & 2457 & 16 & 1119 & 16 & 1365 \\
\hline $5 / 112001$ & 0.00 & 0 & 0 & 0.17 & 600 & 0.24 & 0.11 & 0.10 & 0.10 & 0 & 0 & 1.33 & 0.00 & 0.69 & 90 & 77 & 750 & 938 & 14 & 1186 & 14 & 1375 \\
\hline 51222001 & 0.00 & 0 & 0 & 0.19 & 600 & 0.20 & 0.07 & 0.10 & 0.10 & 0 & 0 & 1.03 & 0.00 & 0.51 & 90 & 77 & 750 & 938 & 15 & 1133 & 15 & 1414 \\
\hline $5 / 132001$ & 0.00 & 0 & 0 & 0.12 & 600 & 0.19 & 0.10 & 0.10 & 0.10 & 0 & 0 & 0.73 & 0.00 & 0.25 & 90 & 77 & 750 & 938 & 21 & 1107 & 21 & 1301 \\
\hline $5 / 1412001$ & 0.00 & 0 & 0 & 0.13 & 600 & 0.20 & 0.10 & 0.10 & 0.10 & 0 & 0 & 0.43 & 0.00 & 0.00 & 90 & 77 & 0 & 0 & 34 & 1121 & 34 & 1267 \\
\hline $5 / 1512001$ & 0.00 & 0 & 0 & 0.11 & 600 & 0.18 & 0.09 & 0.10 & 0.10 & 0 & 0 & 0.13 & 0.00 & 0.00 & 90 & 77 & 0 & 0 & 46 & 1127 & 46 & 1284 \\
\hline $5 / 1612001$ & 0.00 & 0 & 0 & 0.00 & 600 & 0.00 & 0.00 & 0.00 & 0.00 & 0 & 0 & 0.00 & 0.00 & 0.00 & 0 & 0 & 0 & 0 & 52 & 1121 & 52 & 1261 \\
\hline $5 / 17 / 2001$ & 0.00 & 0 & 0 & 0.00 & 600 & 0.00 & 0.00 & 0.00 & 0.00 & 0 & 0 & 0.00 & 0.00 & 0.00 & 0 & 0 & 0 & 0 & 46 & 1176 & 46 & 1239 \\
\hline 511822001 & 0.00 & 0 & 0 & 0.00 & 600 & 0.00 & 0.00 & 0.00 & 0.00 & 0 & 0 & 0.00 & 0.00 & 0.00 & 0 & 0 & 0 & 0 & 54 & 1148 & 54 & 1181 \\
\hline $5 / 19 / 2001$ & 0.00 & 0 & 0 & 0.00 & 600 & 0.00 & 0.00 & 0.00 & 0.00 & 0 & 0 & 0.00 & 0.00 & 0.00 & 0 & 0 & 0 & 0 & 50 & 1172 & 50 & 1199 \\
\hline 512012001 & 0.00 & 0 & 0 & 0.00 & 600 & 0.00 & 0.00 & 0.00 & 0.00 & 0 & 0 & 0.00 & 0.00 & 0.00 & 0 & 0 & 0 & 0 & 62 & 1161 & 62 & 1206 \\
\hline $5 / 2112001$ & 0.00 & 0 & 0 & 0.00 & 600 & 0.00 & 0.00 & 0.00 & 0.00 & 0 & 0 & 0.00 & 0.00 & 0.00 & 0 & 0 & 0 & 0 & 48 & 1179 & 48 & 1256 \\
\hline 5/2212001 & 0.00 & 0 & 0 & 0.00 & 600 & 0.00 & 0.00 & 0.00 & 0.00 & 0 & 0 & 0.00 & 0.00 & 0.00 & 0 & 0 & 0 & 0 & 43 & 1179 & 43 & 1271 \\
\hline 5/23/2001 & 0.00 & 0 & 0 & 0.00 & 600 & 0.00 & 0.00 & 0.00 & 0.00 & 0 & 0 & 0.00 & 0.00 & 0.00 & 0 & 0 & 0 & 0 & 39 & 1167 & 39 & 1231 \\
\hline 5/2412001 & 0.00 & 0 & 0 & 0.00 & 600 & 0.00 & 0.00 & 0.00 & 0.00 & 0 & 0 & 0.00 & 0.00 & 0.00 & 0 & 0 & 0 & 0 & 27 & 1274 & 27 & 1347 \\
\hline $5 / 25 / 2001$ & 0.00 & 0 & 0 & 0.00 & 600 & 0.00 & 0.00 & 0.00 & 0.00 & 0 & 0 & 0.00 & 0.00 & 0.00 & 0 & 0 & 0 & 0 & 23 & 1278 & 23 & 1286 \\
\hline $5 / 2612001$ & 0.00 & 0 & 0 & 0.00 & 600 & 0.00 & 0.00 & 0.00 & 0.00 & 0 & 0 & 0.00 & 0.00 & 0.00 & 0 & 0 & 0 & 0 & 16 & 1300 & 16 & 1272 \\
\hline 5/27/2001 & 0.00 & 0 & 0 & 0.00 & 600 & 0.00 & 0.00 & 0.00 & 0.00 & 0 & 0 & 0.00 & 0.00 & 0.00 & 0 & 0 & 0 & 0 & 38 & 989 & 38 & 1116 \\
\hline 5/28122001 & 0.00 & 0 & 0 & 0.00 & 600 & 0.00 & 0.00 & 0.00 & 0.00 & 0 & 0 & 0.00 & 0.00 & 0.00 & 0 & 0 & 0 & 0 & 44 & 1050 & 44 & 1037 \\
\hline 5/29/2001 & 0.00 & 0 & 0 & 0.00 & 600 & 0.00 & 0.00 & 0.00 & 0.00 & 0 & 0 & 0.00 & 0.00 & 0.00 & 0 & 0 & 0 & 0 & 24 & 1075 & 24 & 1055 \\
\hline 5/3012001 & 0.00 & 0 & 0 & 0.00 & 600 & 0.00 & 0.00 & 0.00 & 0.00 & 0 & 0 & 0.00 & 0.00 & 0.00 & 0 & 0 & 0 & 0 & 24 & 1067 & 24 & 1115 \\
\hline $5 / 3112001$ & 0.00 & 0 & 0 & 0.00 & 600 & 0.00 & 0.00 & 0.00 & 0.00 & 0 & 0 & 0.00 & 0.00 & 0.00 & 0 & 0 & 0 & 0 & 20 & 1150 & 20 & 1207 \\
\hline 6112001 & 0.00 & 0 & 0 & 0.00 & 600 & 0.00 & 0.00 & 0.00 & 0.00 & 0 & 0 & 0.00 & 0.00 & 0.00 & 0 & 0 & 0 & 0 & 13 & 1162 & 13 & 1290 \\
\hline 6/222001 & 0.00 & 0 & 0 & 0.00 & 600 & 0.00 & 0.00 & 0.00 & 0.00 & 0 & 0 & 0.00 & 0.00 & 0.00 & 0 & 0 & 0 & 0 & 13 & 1212 & 13 & 1472 \\
\hline 6/3/2001 & 0.00 & 0 & 0 & 0.92 & 600 & 0.24 & 0.13 & 0.10 & 0.10 & 0 & 0 & 1.07 & 0.00 & 0.44 & 90 & 77 & 750 & 938 & 18 & 1211 & 18 & 1449 \\
\hline 6/412001 & 0.00 & 0 & 0 & 1.39 & 600 & 0.20 & 0.14 & 0.10 & 0.10 & 0 & 0 & 2.13 & 0.00 & 1.40 & 90 & 77 & 750 & 938 & 18 & 1247 & 18 & 1518 \\
\hline $6 / 512001$ & 0.00 & 0 & 0 & 1.35 & 600 & 0.25 & 0.14 & 0.10 & 0.10 & 0 & 0 & 3.20 & 0.00 & 2.25 & 90 & 77 & 779 & 974 & 14 & 1221 & 14 & 1393 \\
\hline $6 / 612001$ & 0.00 & 0 & 0 & 1.41 & 600 & 0.20 & 0.13 & 0.10 & 0.10 & 0 & 0 & 4.27 & 0.00 & 3.23 & 90 & 77 & 781 & 977 & 13 & 1092 & 13 & 1289 \\
\hline 61712001 & 0.00 & 0 & 0 & 0.55 & 600 & 0.21 & 0.14 & 0.10 & 0.10 & 0 & 0 & 4.40 & 0.00 & 3.33 & 90 & 77 & 831 & 1039 & 15 & 1093 & 15 & 1330 \\
\hline 61812001 & 0.00 & 0 & 0 & 0.00 & 600 & 0.23 & 0.14 & 0.10 & 0.23 & 0 & 0 & 3.73 & 0.00 & 2.73 & 202 & 172 & 975 & 1219 & 12 & 1058 & 12 & 1321 \\
\hline 6/912001 & 0.00 & 0 & 0 & 0.00 & 600 & 0.25 & 0.13 & 0.10 & 0.20 & 0 & 0 & 3.07 & 0.00 & 2.15 & 180 & 153 & 1211 & 1514 & 12 & 1133 & 12 & 1319 \\
\hline 61102001 & 0.00 & 0 & 0 & 0.00 & 600 & 0.26 & 0.14 & 0.10 & 0.19 & 0 & 0 & 2.40 & 0.00 & 1.56 & 172 & 146 & 1701 & 2126 & 13 & 1185 & 13 & 1378 \\
\hline $6 / 1112001$ & 0.00 & 0 & 0 & 0.00 & 600 & 0.24 & 0.13 & 0.10 & 0.18 & 0 & 0 & 1.73 & 0.00 & 1.02 & 158 & 135 & 2989 & 3737 & 14 & 1221 & 14 & 1221 \\
\hline 601222001 & 0.00 & 0 & 0 & 0.00 & 600 & 0.23 & 0.15 & 0.10 & 0.21 & 0 & 0 & 1.07 & 0.00 & 0.43 & 180 & 158 & 750 & 938 & 12 & 1175 & 12 & 1173 \\
\hline $6 / 132001$ & 0.00 & 0 & 0 & 0.25 & 600 & 0.22 & 0.17 & 0.10 & 0.10 & 0 & 0 & 0.80 & 0.00 & 0.19 & 90 & 77 & 750 & 938 & 10 & 1170 & 10 & 1200 \\
\hline $6 / 142001$ & 0.00 & 0 & 0 & 0.27 & 600 & 0.25 & 0.13 & 0.10 & 0.10 & 0 & 0 & 0.53 & 0.00 & 0.00 & 90 & 77 & 0 & 0 & 10 & 1170 & 10 & 1221 \\
\hline $6 / 1512001$ & 0.00 & 0 & 0 & 0.23 & 600 & 0.25 & 0.14 & 0.10 & 0.10 & 0 & 0 & 0.27 & 0.00 & 0.00 & 90 & 77 & 0 & 0 & $g$ & 1194 & $g$ & 1203 \\
\hline 6/1612001 & 0.00 & 0 & 0 & 0.00 & 600 & 0.00 & 0.00 & 0.00 & 0.00 & 0 & 0 & 0.00 & 0.00 & 0.00 & 0 & 0 & 0 & 0 & 10 & 1110 & 10 & 1142 \\
\hline 601712001 & 0.00 & 0 & 0 & 0.00 & 600 & 0.00 & 0.00 & 0.00 & 0.00 & 0 & 0 & 0.00 & 0.00 & 0.00 & 0 & 0 & 0 & 0 & 12 & 1117 & 12 & 1175 \\
\hline $6 / 1812001$ & 0.00 & 0 & 0 & 0.00 & 600 & 0.00 & 0.00 & 0.00 & 0.00 & 0 & 0 & 0.00 & 0.00 & 0.00 & 0 & 0 & 0 & 0 & 13 & 1119 & 13 & 1073 \\
\hline 6/19/2001 & 0.00 & 0 & 0 & 0.00 & 600 & 0.00 & 0.00 & 0.00 & 0.00 & 0 & 0 & 0.00 & 0.00 & 0.00 & 0 & 0 & 0 & 0 & 15 & 1057 & 15 & 1157 \\
\hline 612012001 & 0.00 & 0 & 0 & 0.00 & 600 & 0.00 & 0.00 & 0.00 & 0.00 & 0 & 0 & 0.00 & 0.00 & 0.00 & 0 & 0 & 0 & 0 & 14 & 1075 & 14 & 1332 \\
\hline
\end{tabular}


Note: Traditional drawdown (Type 3, normal year) selected for entire model run shown.

\begin{tabular}{|c|c|c|c|c|c|c|c|c|c|c|c|c|c|c|c|c|c|c|c|c|c|c|}
\hline \multirow[b]{2}{*}{$|c|$} & & \multicolumn{6}{|c|}{ OUT } & \multicolumn{3}{|c|}{ Management } & \multicolumn{4}{|c|}{ MODEL OUTPUT } & \multicolumn{4}{|c|}{ NGWD COMPOSITE DATA } \\
\hline & $\begin{array}{l}\text { Precip } \\
\text { inches }\end{array}$ & $\begin{array}{l}\text { GW } \\
\text { inches }\end{array}$ & $\begin{array}{c}E C(g \mathrm{gl}) \\
\mathrm{uS}(\mathrm{cm})\end{array}$ & $\begin{array}{c}\text { Op. Inflow } \\
\text { inches }\end{array}$ & $\begin{array}{l}\text { EC(ii) } \\
\text { uS }(\mathrm{cm})\end{array}$ & $\begin{array}{c}\text { Evap. lopen } \\
\text { water) } \\
\text { inches }\end{array}$ & $\begin{array}{c}\text { ET } \\
\text { (veg, areas) } \\
\text { inches }\end{array}$ & $\begin{array}{c}\text { Op Spill } \\
\text { inches }\end{array}$ & $\begin{array}{c}\text { Outflow } \\
\text { inches }\end{array}$ & & $\begin{array}{c}E C(g W) \\
u S(c m\end{array}$ & $\begin{array}{l}\text { Depth } \\
\text { (hab) } \\
\text { inches } \\
\end{array}$ & $\begin{array}{l}\text { Depth } \\
\text { (CC) }\end{array}$ & $\begin{array}{c}\text { End of } \\
\text { Day } \\
\text { inches } \\
\end{array}$ & $\begin{array}{l}\text { Flow } \\
\text { (cts) }\end{array}$ & $\begin{array}{l}\mathrm{Adj}, \\
\text { Flow } \\
(\mathrm{cts})\end{array}$ & $\begin{array}{c}E C \\
\text { USCm }\end{array}$ & $\begin{array}{c}\text { Adj, EC } \\
\text { US }(\mathrm{cm}\end{array}$ & $\begin{array}{l}\text { GWD } \\
Q(c f s)\end{array}$ & $\begin{array}{l}\text { ersonnel } \\
\text { EC (uSScm) }\end{array}$ & $\begin{array}{l}\text { Real|Fin } \\
Q(c+s)\end{array}$ & EC(uSCom) \\
\hline 612112001 & 0.00 & 0 & $\overline{0}$ & 0.00 & 600 & 0.00 & 0.00 & 0.00 & 0.00 & 0 & $\overline{0}$ & 0.00 & 0.00 & 0.00 & 0 & 0 & 0 & 0 & 12 & 1096 & 12 & 1260 \\
\hline 612212001 & 0.00 & 0 & 0 & 0.00 & 600 & 0.00 & 0.00 & 0.00 & 0.00 & 0 & 0 & 0.00 & 0.00 & 0.00 & . & 0 & 0 & 0 & $\pi$ & 1109 & 11 & 1248 \\
\hline 612312001 & 0.00 & 0 & 0 & 0.00 & 600 & 0.00 & 0.00 & 0.00 & 0.00 & 0 & 0 & 0.00 & 0.00 & 0.00 & . & 0 & 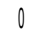 & . & 0 & 1138 & 0 & 1211 \\
\hline 612412001 & 0.00 & 0 & 0 & 0.00 & 600 & 0.00 & 0.00 & 0.00 & 0.00 & 0 & 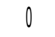 & 0.00 & 0.00 & 0.00 & . & 0 & 0 & 0 & 1 & 1129 & 1 & 1191 \\
\hline 612512001 & 0.00 & 0 & 0 & 0.00 & 600 & 0.00 & 0.00 & 0.00 & 0.00 & 0 & . & 0.00 & 0.00 & 0.00 & 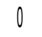 & 0 & 0 & 0 & 1 & 945 & 1 & 1241 \\
\hline 612612001 & 0.00 & 0 & 0 & 0.00 & 600 & 0.00 & 0.00 & 0.00 & 0.00 & 0 & 0 & 0.00 & 0.00 & 0.00 & 0 & 0 & 0 & 0 & 1 & 1236 & 1 & 1269 \\
\hline $6 / 2712001$ & 0.00 & 0 & 0 & 0.00 & 600 & 0.00 & 0.00 & 0.00 & 0.00 & 0 & 0 & 0.00 & 0.00 & 0.00 & 0 & . & 0 & 0 & . & 1217 & 6 & 1267 \\
\hline 612812001 & 0.00 & 0 & 0 & 0.00 & 600 & 0.00 & 0.00 & 0.00 & 0.00 & 0 & 0 & 0.00 & 0.00 & 0.00 & 0 & . & 0 & 0 & . & 1233 & o & 1266 \\
\hline 612912001 & 0.00 & 0 & 0 & 0.00 & 600 & 0.00 & 0.00 & 0.00 & 0.00 & 0 & ? & 0.00 & 0.00 & 0.00 & 0 & 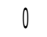 & 0 & 0 & 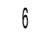 & 1233 & 6 & 1257 \\
\hline $6 / 3012001$ & 0.00 & 0 & 0 & 0.00 & 600 & 0.00 & 0.00 & 0.00 & 0.00 & 0 & 0 & 0.00 & 0.00 & 0.00 & 0 & 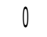 & 0 & 0 & 6 & 1233 & 6 & 1249 \\
\hline 71112001 & 0.00 & 0 & 0 & 0.00 & 600 & 0.00 & 0.00 & 0.00 & 0.00 & 0 & ? & 0.00 & 0.00 & 0.00 & 0 & , & 0 & 0 & 7 & 950 & 7 & 973 \\
\hline 71212001 & 0.00 & 0 & 0 & 0.00 & 600 & 0.00 & 0.00 & 0.00 & 0.00 & 0 & 0 & 0.00 & 0.00 & 0.00 & 0 & 0 & 0 & 0 & 7 & 900 & 7 & 927 \\
\hline $7 / 3 / 2001$ & 0.00 & 0 & 0 & 0.00 & 600 & 0.00 & 0.00 & 0.00 & 0.00 & 0 & 0 & 0.00 & 0.00 & 0.00 & 0 & $v$ & 0 & 0 & 1 & 936 & 7 & 964 \\
\hline $7 / 412001$ & 0.00 & 0 & 0 & 0.00 & 600 & 0.00 & 0.00 & 0.00 & 0.00 & 0 & v & 0.00 & 0.00 & 0.00 & 0 & 0 & 0 & 0 & 1 & 971 & 1 & 1001 \\
\hline $7 / 5 / 2001$ & 0.00 & 0 & 0 & 0.00 & 600 & 0.00 & 0.00 & 0.00 & 0.00 & 0 & v & 0.00 & 0.00 & 0.00 & 0 & 0 & 0 & 0 & 7 & 957 & 1 & 1000 \\
\hline $76 / 2001$ & 0.00 & 0 & 0 & 0.00 & 600 & 0.00 & 0.00 & 0.00 & 0.00 & 0 & 0 & 0.00 & 0.00 & 0.00 & 0 & 0 & 0 & 0 & 0 & 1017 & 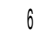 & 1075 \\
\hline 77712001 & 0.00 & 0 & 0 & 0.00 & 600 & 0.00 & 0.00 & 0.00 & 0.00 & 0 & 0 & 0.00 & 0.00 & 0.00 & 0 & 0 & 0 & 0 & 6 & 1017 & 0 & 1083 \\
\hline 71812001 & 0.00 & 0 & 0 & 0.00 & 600 & 0.00 & 0.00 & 0.00 & 0.00 & 0 & 0 & 0.00 & 0.00 & 0.00 & 0 & 0 & 0 & 0 & 7 & 1029 & 1 & 1090 \\
\hline $7|9| 2001$ & 0.00 & 0 & 0 & 0.00 & 600 & 0.00 & 0.00 & 0.00 & 0.00 & 0 & 0 & 0.00 & 0.00 & 0.00 & 0 & 0 & 0 & 0 & 7 & 1029 & 1 & 1092 \\
\hline 711012001 & 0.00 & 0 & 0 & 0.00 & 600 & 0.00 & 0.00 & 0.00 & 0.00 & 0 & 0 & 0.00 & 0.00 & 0.00 & 0 & 0 & 0 & $v$ & 1 & 1043 & 1 & 1087 \\
\hline $7 / 1112001$ & 0.00 & 0 & 0 & 0.00 & 600 & 0.00 & 0.00 & 0.00 & 0.00 & 0 & 0 & 0.00 & 0.00 & 0.00 & 0 & 0 & 0 & 0 & 8 & 1050 & 8 & 1083 \\
\hline 711222001 & 0.00 & 0 & 0 & 0.00 & 600 & 0.00 & 0.00 & 0.00 & 0.00 & 0 & 0 & 0.00 & 0.00 & 0.00 & 0 & 0 & 0 & 0 & 8 & 1050 & 0 & 1080 \\
\hline 711 & 0.00 & 0 & 0 & 0.14 & 600 & 0.21 & 13 & 0.10 & 0.10 & 0 & 0 & 0.17 & 0.00 & 0.00 & 90 & 77 & 0 & n & 8 & 1050 & & 100 \\
\hline 711 & 0.00 & 0 & 0 & 0.29 & 600 & 0.23 & 14 & 0.10 & 0.1 & 0 & 0 & 0.33 & 0.00 & 0.00 & 90 & 77 & 0 & 0 & $g$ & 1056 & & 1103 \\
\hline $7 / 15120$ & 0.00 & 0 & 0 & 0.43 & 600 & 0.23 & 0.12 & 0.10 & 0.10 & 0 & 0 & 0.50 & 0.00 & 0.00 & 90 & 7 & 0 & 0 & & 1060 & & 1107 \\
\hline 711612001 & 0.00 & 0 & 0 & 0.57 & 600 & 0.20 & 0.12 & 0.10 & 0.10 & 0 & 0 & 0.67 & 0.00 & 0.15 & 90 & 77 & 750 & 93 & 9 & 1078 & 9 & 1107 \\
\hline $7117 / 2001$ & 0.00 & 0 & 0 & 0.57 & 600 & 0.18 & 0.12 & 0.10 & 0.10 & 0 & 0 & 0.83 & 0.00 & 0.31 & 90 & 77 & 750 & 93 & 43 & 705 & 43 & 712 \\
\hline $7 / 118 / 2001$ & 0.00 & 0 & 0 & 0.55 & 600 & 0.18 & 0.13 & 0.10 & 0.10 & 0 & 0 & 1.00 & 0.00 & 0.45 & 90 & 77 & 750 & 93 & 14 & 814 & 1. & 830 \\
\hline $7 / 191 / 2001$ & 0.00 & 0 & 0 & 0.56 & 600 & 0.20 & 0.14 & 0.10 & 0.10 & 0 & 0 & 1.17 & 0.00 & 0.57 & 90 & 77 & 750 & 938 & 15 & 800 & 15 & 877 \\
\hline 712012001 & 0.00 & 0 & 0 & 0.58 & 600 & 0.19 & 0.13 & 0.10 & 0.10 & 0 & 0 & 1.33 & 0.00 & 0.72 & 90 & 77 & 750 & 938 & 15 & 913 & 15 & 934 \\
\hline $7 / 2112001$ & 0.00 & 0 & 0 & 0.57 & 600 & 0.19 & 0.12 & 0.10 & 0.10 & 0 & 0 & 1.50 & 0.00 & 0.88 & 90 & 77 & 750 & 938 & 14 & 1014 & 14 & 1063 \\
\hline 712212001 & 0.00 & 0 & 0 & 0.56 & 600 & 0.19 & 0.13 & 0.10 & 0.10 & 0 & 0 & 1.67 & 0.00 & 1.01 & 90 & 77 & 750 & 93 & 13 & 935 & 10 & 1036 \\
\hline $7 / 23 / 2001$ & 0.00 & 0 & 0 & 0.56 & 600 & 0.21 & 0.14 & 0.10 & 0.10 & 0 & 0 & 1.83 & 0.00 & 1.12 & 90 & 77 & 750 & 93 & 19 & 913 & 19 & 932 \\
\hline 712412001 & 0.00 & 0 & 0 & 0.59 & 600 & 0.22 & 0.14 & 0.10 & 0.10 & 0 & 0 & 2.00 & 0.00 & 1.26 & 90 & 77 & 750 & & 14 & 1196 & 14 & 1225 \\
\hline 712512001 & 0.00 & 0 & 0 & 0.31 & 600 & 0.19 & 12 & 0.10 & 0.1 & 0 & 0 & 83 & 0.00 & 1.15 & 90 & 77 & 933 & & 10 & 1800 & 13 & 1800 \\
\hline 712612001 & 0.00 & 0 & 0 & 0.28 & 60 & 10 & 10 & 0.10 & 0.1 & 0 & 0 & 1.67 & 0.00 & 1.02 & 90 & 77 & 750 & & 10 & 2350 & & 2350 \\
\hline 712712001 & 0.00 & 0 & 0 & 0.27 & ou & 0.20 & 0.13 & 0.10 & 0.10 & 0 & & 1.50 & 0.00 & 0.86 & 90 & 77 & 750 & & 10 & 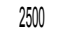 & & 2500 \\
\hline 71281200 & 0.00 & 0 & 0 & 0.29 & 600 & 0.21 & 0.14 & 0.10 & 0.1 & 0 & 0 & 1.33 & 0.00 & 0.70 & 90 & 77 & 750 & 93 & 10 & 2500 & 10 & 2500 \\
\hline $7129 / 2001$ & 0.00 & 0 & 0 & 0.30 & 60 & 0.26 & 0.15 & 0.10 & 0.10 & 0 & 0 & 1.11 & 0.00 & 0.49 & 90 & 77 & 750 & & 10 & 2400 & 10 & 2400 \\
\hline $7 / 3012001$ & 0.00 & 0 & 0 & 0.37 & 600 & 0.19 & 0.13 & 0.10 & 0.10 & 0 & 0 & 1.00 & 0.00 & 0.45 & 90 & 77 & 750 & 08 & 9 & 2100 & 9 & 2100 \\
\hline $7 / 3112001$ & 0.00 & 0 & 0 & 0.27 & 600 & 0.18 & 0.12 & 0.10 & 0.10 & 0 & ? & 0.83 & 0.00 & 0.32 & 90 & 77 & 750 & 938 & 8 & 2000 & 8 & 2000 \\
\hline 81112001 & 0.00 & 0 & 0 & 0.26 & 600 & 0.20 & 0.13 & 0.10 & 0.10 & 0 & ? & 0.67 & 0.00 & 0.14 & 90 & 77 & 750 & 938 & 8 & 1700 & 8 & 1700 \\
\hline 81212001) & 0.00 & 0 & 0 & 0.29 & 600 & 0.20 & 0.14 & 0.10 & 0.10 & 0 & 0 & 0.50 & 0.00 & 0.00 & 90 & 77 & 0 & 0 & 7 & 1600 & 7 & 1600 \\
\hline $8 / 132001$ & 0.00 & 0 & 0 & 0.29 & 600 & 0.20 & 0.13 & 0.10 & 0.10 & 0 & ? & 0.33 & 0.00 & 0.00 & 90 & 77 & 0 & 0 & 6 & 1500 & 6 & 1500 \\
\hline 8412001 & 0.00 & 0 & 0 & 0.14 & 600 & 0.21 & 0.12 & 0.10 & 0.10 & 0 & 0 & 0.17 & 0.00 & 0.00 & 90 & 77 & 0 & 0 & 6 & 1450 & 0 & 1450 \\
\hline 8152001 & 0.00 & 0 & 0 & 0.00 & 600 & 0.00 & 0.00 & 0.00 & 0.00 & 0 & 0 & 0.00 & 0.00 & 0.00 & 0 & 0 & 0 & 0 & 6 & 1450 & 6 & 1450 \\
\hline 81612001 & 0.00 & 0 & 0 & 0.00 & 600 & 0.00 & 0.00 & 0.00 & 0.00 & 0 & 0 & 0.00 & 0.00 & 0.00 & 0 & 0 & 0 & 0 & 5 & 1400 & 5 & 1400 \\
\hline 87712001 & 0.00 & 0 & 0 & 0.00 & 600 & 0.00 & 0.00 & 0.00 & 0.00 & 0 & 0 & 0.00 & 0.00 & 0.00 & 0 & 0 & 0 & 0 & 5 & 1350 & 5 & 1350 \\
\hline 88120001 & 0.00 & 0 & 0 & 0.00 & 600 & 0.00 & 0.00 & 0.00 & 0.00 & 0 & 0 & 0.00 & 0.00 & 0.00 & 0 & 0 & 0 & 0 & 4 & 1350 & 4 & 1350 \\
\hline
\end{tabular}


Note: Traditional drawdown (Type 3, normal year) selected for entire model run shown.

\begin{tabular}{|c|c|c|c|c|c|c|c|c|c|c|c|c|c|c|c|c|c|c|c|c|c|c|}
\hline Time-Step & \multicolumn{5}{|c|}{$\mathbb{N}$} & \multicolumn{6}{|c|}{ OUT } & \multicolumn{3}{|c|}{ Management } & \multicolumn{4}{|c|}{ MODEL OUTPUT } & \multicolumn{4}{|c|}{ NGWD COMPOSTE DATA } \\
\hline Date & $\begin{array}{l}\text { Precip } \\
\text { inches }\end{array}$ & $\begin{array}{l}\text { GW } \\
\text { inches }\end{array}$ & $\begin{array}{l}E C(\mathrm{gN}) \\
\text { uScm }\end{array}$ & $\begin{array}{l}\text { Op. Intlow } \\
\text { inches }\end{array}$ & $\begin{array}{l}\text { EClifi } \\
\text { uS } \mathrm{cm}\end{array}$ & $\begin{array}{c}\text { Evap. lopen } \\
\text { water) } \\
\text { inches }\end{array}$ & $\begin{array}{c}\text { ET } \\
\text { (veg, areas) } \\
\text { inches }\end{array}$ & $\begin{array}{c}\text { Op Spill } \\
\text { inches }\end{array}$ & $\begin{array}{c}\text { Outflow } \\
\text { inches }\end{array}$ & & $\begin{array}{c}E C(g W) \\
\text { uSlcm }\end{array}$ & $\begin{array}{l}\text { Depth } \\
\text { (hab) } \\
\text { inches }\end{array}$ & $\begin{array}{l}\text { Depth } \\
\text { (CC) }\end{array}$ & $\begin{array}{l}\text { End of } \\
\text { Day } \\
\text { inches }\end{array}$ & $\begin{array}{l}\text { Flow } \\
(\mathrm{d} / \mathrm{s})\end{array}$ & $\begin{array}{l}\text { Adj. } \\
\text { Flow } \\
(c t s)\end{array}$ & $\begin{array}{l}\text { EC } \\
\text { US } \mathrm{Cm}\end{array}$ & $\begin{array}{c}\text { Adj, EC } \\
\text { uS } / \mathrm{cm}\end{array}$ & $\begin{array}{l}\text { GWDP } \\
Q\left(d f^{\prime}\right)\end{array}$ & $\begin{array}{l}\text { ersonnel } \\
\text { EC (wSCm) }\end{array}$ & \begin{tabular}{|c} 
Real|Tin \\
$Q($ cts $)$
\end{tabular} & $\begin{array}{l}\text { e Network } \\
\text { EC (uSC cm) }\end{array}$ \\
\hline 81912001 & 0.00 & 0 & 0 & 0.00 & 600 & 0.00 & 0.00 & 0.00 & 0.00 & 0 & 0 & 0.00 & 0.00 & 0.00 & 0 & 0 & 0 & 0 & 5 & 1300 & 5 & 1300 \\
\hline 81102001 & 0.00 & 0 & 0 & 0.00 & 600 & 0.00 & 0.00 & 0.00 & 0.00 & 0 & 0 & 0.00 & 0.00 & 0.00 & 0 & 0 & 0 & 0 & 7 & 1250 & 7 & 1250 \\
\hline 81112001 & 0.00 & 0 & 0 & 0.00 & 600 & 0.00 & 0.00 & 0.00 & 0.00 & 0 & 0 & 0.00 & 0.00 & 0.00 & 0 & 0 & 0 & 0 & 7 & 1250 & 7 & 1250 \\
\hline 81222001 & 0.00 & 0 & 0 & 0.00 & 600 & 0.00 & 0.00 & 0.00 & 0.00 & 0 & 0 & 0.00 & 0.00 & 0.00 & 0 & 0 & 0 & 0 & 8 & 1200 & 8 & 1200 \\
\hline $8 / 132001$ & 0.00 & 0 & 0 & 0.00 & 600 & 0.00 & 0.00 & 0.00 & 0.00 & 0 & 0 & 0.00 & 0.00 & 0.00 & 0 & 0 & 0 & 0 & 8 & 1100 & 8 & 1100 \\
\hline 81142001 & 0.00 & 0 & 0 & 0.00 & 600 & 0.00 & 0.00 & 0.00 & 0.00 & 0 & 0 & 0.00 & 0.00 & 0.00 & 0 & 0 & 0 & 0 & $g$ & 1100 & $g$ & 1100 \\
\hline $8 / 1512001$ & 0.00 & 0 & 0 & 0.00 & 600 & 0.00 & 0.00 & 0.00 & 0.00 & 0 & 0 & 0.00 & 0.00 & 0.00 & 0 & 0 & 0 & 0 & $g$ & 1100 & $g$ & 1100 \\
\hline 811612001 & 0.00 & 0 & 0 & 0.00 & 600 & 0.00 & 0.00 & 0.00 & 0.00 & 0 & 0 & 0.00 & 0.00 & 0.00 & 0 & 0 & 0 & 0 & 10 & 1163 & 10 & 1171 \\
\hline $8177 / 2001$ & 0.00 & 0 & 0 & 0.00 & 600 & 0.00 & 0.00 & 0.00 & 0.00 & 0 & 0 & 0.00 & 0.00 & 0.00 & 0 & 0 & 0 & 0 & 10 & 1163 & 10 & 1164 \\
\hline 811812001 & 0.00 & 0 & 0 & 0.00 & 600 & 0.00 & 0.00 & 0.00 & 0.00 & 0 & 0 & 0.00 & 0.00 & 0.00 & 0 & 0 & 0 & 0 & 12 & 1208 & 12 & 1219 \\
\hline 8/19/2001 & 0.00 & 0 & 0 & 0.00 & 600 & 0.00 & 0.00 & 0.00 & 0.00 & 0 & 0 & 0.00 & 0.00 & 0.00 & 0 & 0 & 0 & 0 & 11 & 1255 & 11 & 1266 \\
\hline 82012001 & 0.00 & 0 & 0 & 0.00 & 600 & 0.00 & 0.00 & 0.00 & 0.00 & 0 & 0 & 0.00 & 0.00 & 0.00 & 0 & 0 & 0 & 0 & 15 & 1250 & 15 & 1261 \\
\hline 812112001 & 0.00 & 0 & 0 & 0.00 & 600 & 0.00 & 0.00 & 0.00 & 0.00 & 0 & 0 & 0.00 & 0.00 & 0.00 & 0 & 0 & 0 & 0 & 14 & 1239 & 14 & 1246 \\
\hline 812212001 & 0.00 & 0 & 0 & 0.00 & 600 & 0.00 & 0.00 & 0.00 & 0.00 & 0 & 0 & 0.00 & 0.00 & 0.00 & 0 & 0 & 0 & 0 & 16 & 1269 & 16 & 1275 \\
\hline 812312001 & 0.00 & 0 & 0 & 0.00 & 600 & 0.00 & 0.00 & 0.00 & 0.00 & 0 & 0 & 0.00 & 0.00 & 0.00 & 0 & 0 & 0 & 0 & 18 & 1272 & 18 & 1272 \\
\hline 812412001 & 0.00 & 0 & 0 & 0.00 & 600 & 0.00 & 0.00 & 0.00 & 0.00 & 0 & 0 & 0.00 & 0.00 & 0.00 & 0 & 0 & 0 & 0 & 16 & 1325 & 16 & 1330 \\
\hline 812512001 & 0.00 & 0 & 0 & 0.00 & 600 & 0.00 & 0.00 & 0.00 & 0.00 & 0 & 0 & 0.00 & 0.00 & 0.00 & 0 & 0 & 0 & 0 & 17 & 1268 & 17 & 1300 \\
\hline 812612001 & 0.00 & 0 & 0 & 0.00 & 600 & 0.00 & 0.00 & 0.00 & 0.00 & 0 & 0 & 0.00 & 0.00 & 0.00 & 0 & 0 & 0 & 0 & 16 & 1263 & 16 & 1298 \\
\hline $8127 / 2001$ & 0.00 & 0 & 0 & 0.00 & 600 & 0.00 & 0.00 & 0.00 & 0.00 & 0 & 0 & 0.00 & 0.00 & 0.00 & 0 & 0 & 0 & 0 & 15 & 1220 & 15 & 1286 \\
\hline 812812001 & 0.00 & 0 & 0 & 0.00 & 600 & 0.00 & 0.00 & 0.00 & 0.00 & 0 & 0 & 0.00 & 0.00 & 0.00 & 0 & 0 & 0 & 0 & 13 & 1108 & 13 & 1168 \\
\hline $8129 / 2001$ & 0.00 & 0 & 0 & 0.00 & 600 & 0.00 & 0.00 & 0.00 & 0.00 & 0 & 0 & 0.00 & 0.00 & 0.00 & 0 & 0 & 0 & 0 & 16 & 1047 & 16 & 1119 \\
\hline $8 / 3012001$ & 0.00 & 0 & 0 & 0.00 & 600 & 0.00 & 0.00 & 0.00 & 0.00 & 0 & 0 & 0.00 & 0.00 & 0.00 & 0 & 0 & 0 & 0 & 23 & 1046 & 23 & 1118 \\
\hline $8 / 312001$ & 0.00 & 0 & 0 & 0.00 & 500 & 0.00 & 0.00 & 0.00 & 0.00 & 0 & 0 & 0.00 & 0.00 & 0.00 & 0 & 0 & 0 & 0 & 19 & 1024 & 19 & 1117 \\
\hline 9112001 & 0.00 & 0 & 0 & 0.00 & 500 & 0.00 & 0.00 & 0.00 & 0.00 & 0 & 0 & 0.00 & 0.00 & 0.00 & 0 & 0 & 0 & 0 & 7 & 1000 & 7 & 1000 \\
\hline 9/222001 & 0.00 & 0 & 0 & 0.00 & 500 & 0.00 & 0.00 & 0.00 & 0.00 & 0 & 0 & 0.00 & 0.00 & 0.00 & 0 & 0 & 0 & 0 & 7 & 1000 & 7 & 1000 \\
\hline 9/3/2001 & 0.00 & 0 & 0 & 0.00 & 500 & 0.00 & 0.00 & 0.00 & 0.00 & 0 & 0 & 0.00 & 0.00 & 0.00 & 0 & 0 & 0 & 0 & 8 & 900 & 8 & 900 \\
\hline 91412001 & 0.00 & 0 & 0 & 0.00 & 500 & 0.00 & 0.00 & 0.00 & 0.00 & 0 & 0 & 0.00 & 0.00 & 0.00 & 0 & 0 & 0 & 0 & 8 & 900 & 8 & 900 \\
\hline $9 / 5 / 2001$ & 0.00 & 0 & 0 & 0.00 & 500 & 0.00 & 0.00 & 0.00 & 0.00 & 0 & 0 & 0.00 & 0.00 & 0.00 & 0 & 0 & 0 & 0 & 8 & 900 & 8 & 900 \\
\hline 91612001 & 0.00 & 0 & 0 & 0.00 & 500 & 0.00 & 0.00 & 0.00 & 0.00 & 0 & 0 & 0.00 & 0.00 & 0.00 & 0 & 0 & 0 & 0 & 12 & 900 & 12 & 900 \\
\hline $9 / 712001$ & 0.00 & 0 & 0 & 0.00 & 500 & 0.00 & 0.00 & 0.00 & 0.00 & 0 & 0 & 0.00 & 0.00 & 0.00 & 0 & 0 & 0 & 0 & 20 & 900 & 20 & 900 \\
\hline 918/2001 & 0.00 & 0 & 0 & 0.00 & 500 & 0.00 & 0.00 & 0.00 & 0.00 & 0 & 0 & 0.00 & 0.00 & 0.00 & 0 & 0 & 0 & 0 & 26 & 850 & 26 & 850 \\
\hline 9/9/2001 & 0.00 & 0 & 0 & 0.00 & 500 & 0.00 & 0.00 & 0.00 & 0.00 & 0 & 0 & 0.00 & 0.00 & 0.00 & 0 & 0 & 0 & 0 & 30 & 850 & 30 & 850 \\
\hline 911022001 & 0.00 & 0 & 0 & 0.00 & 500 & 0.00 & 0.00 & 0.00 & 0.00 & 0 & 0 & 0.00 & 0.00 & 0.00 & 0 & 0 & 0 & 0 & 30 & 850 & 30 & 850 \\
\hline 9/1112001 & 0.00 & 0 & 0 & 0.00 & 500 & 0.00 & 0.00 & 0.00 & 0.00 & 0 & 0 & 0.00 & 0.00 & 0.00 & 0 & 0 & 0 & 0 & 25 & 850 & 25 & 850 \\
\hline 9/1222001 & 0.00 & 0 & 0 & 0.00 & 500 & 0.00 & 0.00 & 0.00 & 0.00 & 0 & 0 & 0.00 & 0.00 & 0.00 & 0 & 0 & 0 & 0 & 8 & 900 & 8 & 900 \\
\hline 9/13/2001 & 0.00 & 0 & 0 & 0.00 & 500 & 0.00 & 0.00 & 0.00 & 0.00 & 0 & 0 & 0.00 & 0.00 & 0.00 & 0 & 0 & 0 & 0 & 22 & 950 & 22 & 950 \\
\hline 9/1412001 & 0.00 & 0 & 0 & 0.00 & 500 & 0.00 & 0.00 & 0.00 & 0.00 & 0 & 0 & 0.00 & 0.00 & 0.00 & 0 & 0 & 0 & 0 & 5 & 950 & 5 & 950 \\
\hline 9/15/2001 & 0.00 & 0 & 0 & 0.00 & 500 & 0.00 & 0.00 & 0.00 & 0.00 & 0 & 0 & 0.00 & 0.00 & 0.00 & 0 & 0 & 0 & 0 & 11 & 873 & 11 & 992 \\
\hline 9/16/2001 & 0.00 & 0 & 0 & 0.00 & 500 & 0.00 & 0.00 & 0.00 & 0.00 & 0 & 0 & 0.00 & 0.00 & 0.00 & 0 & 0 & 0 & 0 & 11 & 873 & 11 & 989 \\
\hline 9/17/2001 & 0.00 & 0 & 0 & 0.00 & 500 & 0.00 & 0.00 & 0.00 & 0.00 & 0 & 0 & 0.00 & 0.00 & 0.00 & 0 & 0 & 0 & 0 & 11 & 873 & 11 & 983 \\
\hline 9/18/2001 & 0.00 & 0 & 0 & 0.00 & 500 & 0.00 & 0.00 & 0.00 & 0.00 & 0 & 0 & 0.00 & 0.00 & 0.00 & 0 & 0 & 0 & 0 & 11 & 855 & 11 & 970 \\
\hline 9/19/2001 & 0.00 & 0 & 0 & 0.00 & 500 & 0.00 & 0.00 & 0.00 & 0.00 & 0 & 0 & 0.00 & 0.00 & 0.00 & 0 & 0 & 0 & 0 & 13 & 846 & 13 & 959 \\
\hline 912012001 & 0.00 & 0 & 0 & 0.00 & 500 & 0.00 & 0.00 & 0.00 & 0.00 & 0 & 0 & 0.00 & 0.00 & 0.00 & 0 & 0 & 0 & 0 & 16 & 838 & 16 & 954 \\
\hline $9 / 212001$ & 0.00 & 0 & 0 & 0.36 & 500 & 0.18 & 0.09 & 0.10 & 0.10 & 0 & 0 & 0.36 & 0.36 & 0.00 & 90 & 77 & 0 & 0 & 21 & 838 & 21 & 957 \\
\hline 912212001 & 0.00 & 0 & 0 & 0.71 & 500 & 0.18 & 0.08 & 0.10 & 0.10 & 0 & 0 & 0.71 & 0.71 & 0.35 & 90 & 77 & 625 & 781 & 23 & 843 & 23 & 956 \\
\hline $9 / 23 / 2001$ & 0.00 & 0 & 0 & 0.72 & 500 & 0.16 & 0.07 & 0.10 & 0.10 & 0 & 0 & 1.07 & 1.07 & 0.73 & 90 & 77 & 625 & 781 & 28 & 827 & 28 & 940 \\
\hline 9/2412001 & 0.13 & 0 & 0 & 0.69 & 500 & 0.16 & 0.08 & 0.10 & 0.10 & 0 & 0 & 1.42 & 1.42 & 1.21 & 90 & 77 & 625 & 781 & 27 & 833 & 27 & 938 \\
\hline 9/25/2001 & 0.00 & 0 & 0 & 0.56 & 500 & 0.17 & 0.08 & 0.10 & 0.10 & 0 & 0 & 1.78 & 1.78 & 1.42 & 90 & 77 & 680 & 850 & 28 & 843 & 28 & 941 \\
\hline 912612001 & 0.00 & 0 & 0 & 0.71 & 500 & 0.14 & 0.08 & 0.10 & 0.10 & 0 & 0 & 2.13 & 2.13 & 1.81 & 90 & 77 & 690 & 862 & 28 & 854 & 28 & 943 \\
\hline
\end{tabular}


Note: Traditional drawdown (Type 3, normal year) selected for entire model run shown.

\begin{tabular}{|c|c|c|c|c|c|c|c|c|c|c|c|c|c|c|c|c|c|c|c|c|c|c|}
\hline Time-Step & \multicolumn{5}{|c|}{$\mathbb{N}$} & \multicolumn{6}{|c|}{ OUT } & \multicolumn{3}{|c|}{ Management } & \multicolumn{4}{|c|}{ MODEL OUTPUT } & \multicolumn{4}{|c|}{ NGWD COMPOSTE DATA } \\
\hline Date & $\begin{array}{l}\text { Precip } \\
\text { inches }\end{array}$ & $\begin{array}{l}\text { GW } \\
\text { inches }\end{array}$ & $\begin{array}{l}\text { EC(gN) } \\
\text { uScm }\end{array}$ & $\begin{array}{l}\text { Op. Intlow } \\
\text { inches }\end{array}$ & $\begin{array}{l}E C(\text { if } \\
u S(c m\end{array}$ & $\begin{array}{c}\text { Evap. (open } \\
\text { water) } \\
\text { inches }\end{array}$ & $\begin{array}{c}\text { ET } \\
\text { (veg, areas) } \\
\text { inches }\end{array}$ & $\begin{array}{c}\text { Op Spill } \\
\text { inches }\end{array}$ & $\begin{array}{l}\text { Outflow } \\
\text { inches }\end{array}$ & & $\begin{array}{l}E C(\mathrm{gW}) \\
\mathrm{uS}(\mathrm{cm}\end{array}$ & $\begin{array}{l}\text { Depth } \\
\text { (hab) } \\
\text { inches }\end{array}$ & $\begin{array}{l}\text { Depth } \\
\text { (CC) }\end{array}$ & $\begin{array}{c}\text { End of } \\
\text { Day } \\
\text { inches }\end{array}$ & $\begin{array}{l}\text { Flow } \\
(\mathrm{cts})\end{array}$ & $\begin{array}{l}\text { Adj. } \\
\text { Flow } \\
(c t s)\end{array}$ & $\begin{array}{l}\text { EC } \\
\mathrm{US} / \mathrm{Cm}\end{array}$ & $\begin{array}{l}\text { Adj], EC } \\
\text { uSCCm }\end{array}$ & $\begin{array}{l}\text { GWDP } \\
Q(d f s)\end{array}$ & $\begin{array}{l}\text { ersonnel } \\
\text { EC (usicm) }\end{array}$ & $\begin{array}{l}\text { Real } \mid \cdot \text { in } \\
Q(c i s)\end{array}$ & $\begin{array}{l}\text { e Network } \\
\text { EC (uS } c \text { cm) }\end{array}$ \\
\hline 9/27/2001 & 0.00 & 0 & 0 & 0.68 & 500 & 0.19 & 0.09 & 0.10 & 0.10 & 0 & 0 & 2.49 & 2.49 & 2.12 & 90 & 77 & 714 & 893 & 36 & 858 & 36 & 941 \\
\hline 9/28/2001 & 0.00 & 0 & 0 & 0.73 & 500 & 0.17 & 0.09 & 0.10 & 0.10 & 0 & 0 & 2.84 & 2.84 & 2.49 & 90 & 77 & 722 & 903 & 41 & 859 & 41 & 942 \\
\hline 9/29/2001 & 0.00 & 0 & 0 & 0.71 & 500 & 0.14 & 0.08 & 0.10 & 0.10 & 0 & 0 & 3.20 & 3.20 & 2.88 & 90 & 77 & 723 & 904 & 41 & 859 & 41 & 948 \\
\hline 9/3012001 & 0.00 & 0 & 0 & 0.68 & 500 & 0.14 & 0.08 & 0.10 & 0.10 & 0 & 0 & 3.56 & 3.56 & 3.23 & 90 & 77 & 726 & 907 & 41 & 859 & 41 & 959 \\
\hline 10112001 & 0.00 & 0 & 0 & 0.68 & 500 & 0.16 & 0.10 & 0.10 & 0.10 & 0 & 0 & 3.91 & 3.91 & 3.55 & 90 & 77 & 735 & 918 & 66 & 809 & 66 & 884 \\
\hline 10222001 & 0.00 & 0 & 0 & 0.72 & 500 & 0.17 & 0.09 & 0.10 & 0.10 & 0 & 0 & 4.27 & 4.27 & 3.91 & 90 & 77 & 740 & 925 & 89 & 754 & 89 & 816 \\
\hline $10 / 312001$ & 0.00 & 0 & 0 & 0.72 & 500 & 0.17 & 0.09 & 0.10 & 0.10 & 0 & 0 & 4.02 & 4.62 & 4.26 & 90 & 77 & 744 & 931 & 94 & 815 & 94 & 880 \\
\hline $10 / 42001$ & 0.00 & 0 & 0 & 0.72 & 500 & 0.21 & 0.08 & 0.10 & 0.10 & 0 & 0 & 4.98 & 4.98 & 4.59 & 90 & 77 & 753 & 941 & 87 & 848 & 87 & 930 \\
\hline $10 / 512001$ & 0.00 & 0 & 0 & 0.75 & 500 & 0.15 & 0.07 & 0.10 & 0.10 & 0 & 0 & 5.33 & 5.33 & 5.02 & 90 & 77 & 747 & 934 & 82 & 855 & 82 & 933 \\
\hline 106612001 & 0.00 & 0 & 0 & 0.67 & 500 & 0.10 & 0.06 & 0.10 & 0.10 & 0 & 0 & 5.69 & 5.69 & 5.42 & 90 & 77 & 740 & 925 & 82 & 848 & 82 & 942 \\
\hline 107712001 & 0.00 & 0 & 0 & 0.62 & 500 & 0.11 & 0.06 & 0.10 & 0.10 & 0 & 0 & 6.04 & 6.04 & 5.77 & 90 & 77 & 737 & 921 & 85 & 848 & 85 & 948 \\
\hline 101812001 & 0.00 & 0 & 0 & 0.63 & 500 & 0.11 & 0.06 & 0.10 & 0.10 & 0 & 0 & 6.40 & 6.40 & 6.12 & 90 & 77 & 734 & 917 & 87 & 853 & 87 & 988 \\
\hline 10912001 & 0.00 & 0 & 0 & 0.63 & 500 & 0.13 & 0.08 & 0.10 & 0.10 & 0 & 0 & 6.76 & 6.76 & 6.44 & 90 & 77 & 735 & 918 & 87 & 853 & 87 & 997 \\
\hline 1010102001 & 0.00 & 0 & 0 & 0.67 & 500 & 0.12 & 0.06 & 0.10 & 0.10 & 0 & 0 & 7.11 & 7.11 & 6.82 & 90 & 77 & 732 & 915 & 84 & 877 & 84 & 979 \\
\hline 1011122001 & 0.00 & 0 & 0 & 0.64 & 500 & 0.10 & 0.06 & 0.10 & 0.10 & 0 & 0 & 7.47 & 7.47 & 7.20 & 90 & 77 & 728 & 910 & 84 & 877 & 84 & 996 \\
\hline 1012122001 & 0.00 & 0 & 0 & 0.02 & 500 & 0.12 & 0.08 & 0.10 & 0.10 & 0 & 0 & 7.82 & 7.82 & 7.52 & 90 & 77 & 728 & 910 & 83 & 889 & 83 & 1029 \\
\hline 10/13/2001 & 0.00 & 0 & 0 & 0.66 & 500 & 0.11 & 0.06 & 0.10 & 0.10 & 0 & 0 & 8.18 & 8.18 & 7.90 & 90 & 77 & 726 & 907 & 85 & 878 & 85 & 1028 \\
\hline 10/14/2001 & 0.00 & 0 & 0 & 0.63 & 500 & 0.11 & 0.06 & 0.10 & 0.10 & 0 & 0 & 8.53 & 8.53 & 8.27 & 90 & 77 & 723 & 904 & 85 & 878 & 85 & 1041 \\
\hline 10/15/2001 & 0.00 & 0 & 0 & 0.62 & 500 & 0.11 & 0.06 & 0.10 & 0.10 & 0 & 0 & 8.89 & 8.89 & 8.81 & 90 & 77 & 722 & 902 & 85 & 866 & 85 & 1035 \\
\hline 1016162001 & 0.00 & 0 & 0 & 0.63 & 500 & 0.14 & 0.06 & 0.10 & 0.10 & 0 & 0 & 9.24 & 9.24 & 8.95 & 90 & 77 & 722 & 902 & 90 & 874 & 90 & 1054 \\
\hline 10171/2001 & 0.00 & 0 & 0 & 0.65 & 500 & 0.12 & 0.05 & 0.10 & 0.10 & 0 & 0 & 9.60 & 9.60 & 9.33 & 90 & 77 & 720 & 899 & 97 & 859 & 97 & 1068 \\
\hline 1018122001 & 0.00 & 0 & 0 & 0.63 & 500 & 0.11 & 0.05 & 0.10 & 0.10 & 0 & 0 & 9.96 & 9.96 & 9.70 & 90 & 77 & 717 & 897 & 102 & 868 & 102 & 1069 \\
\hline 1019122001 & 0.00 & 0 & 0 & 0.62 & 500 & 0.09 & 0.04 & 0.10 & 0.10 & 0 & 0 & 10.31 & 10.31 & 10.09 & 90 & 77 & 713 & 891 & 102 & 875 & 102 & 1057 \\
\hline 1012012001 & 0.00 & 0 & 0 & 0.58 & 500 & 0.07 & 0.05 & 0.10 & 0.10 & 0 & 0 & 10.67 & 10.67 & 10.44 & 90 & 77 & 710 & 887 & 105 & 871 & 105 & 1048 \\
\hline 102112001 & 0.00 & 0 & 0 & 0.23 & 750 & 0.09 & 0.05 & 0.10 & 0.10 & 0 & 0 & 10.67 & 10.67 & 10.42 & 90 & 77 & 721 & 901 & 101 & 841 & 101 & 1007 \\
\hline 1012212001 & 0.00 & 0 & 0 & 0.25 & 750 & 0.10 & 0.05 & 0.10 & 0.10 & 0 & 0 & 10.67 & 10.67 & 10.41 & 90 & 77 & 732 & 915 & 97 & 844 & 97 & 992 \\
\hline 10123212001 & 0.00 & 0 & 0 & 0.25 & 750 & 0.11 & 0.06 & 0.10 & 0.10 & 0 & 0 & 10.67 & 10.67 & 10.40 & 90 & 77 & 744 & 930 & 96 & 849 & 96 & 993 \\
\hline 1024242001 & 0.00 & 0 & 0 & 0.27 & 750 & 0.09 & 0.06 & 0.10 & 0.10 & 0 & 0 & 10.67 & 10.67 & 10.41 & 90 & 77 & 755 & 944 & 90 & 921 & 90 & 1061 \\
\hline 10125/2001 & 0.00 & 0 & 0 & 0.25 & 750 & 0.08 & 0.04 & 0.10 & 0.10 & 0 & 0 & 10.67 & 10.67 & 10.45 & 90 & 77 & 764 & 955 & 88 & 933 & 88 & 1076 \\
\hline 102612001 & 0.00 & 0 & 0 & 0.22 & 750 & 0.09 & 0.04 & 0.10 & 0.10 & 0 & 0 & 10.67 & 10.67 & 10.43 & 90 & 77 & 773 & 967 & 82 & 941 & 82 & 1075 \\
\hline 10127/2001 & 0.00 & 0 & 0 & 0.24 & 750 & 0.11 & 0.04 & 0.10 & 0.10 & 0 & 0 & 10.67 & 10.67 & 10.42 & 90 & 77 & 784 & 979 & 69 & 1013 & 69 & 1146 \\
\hline 1012812001 & 0.00 & 0 & 0 & 0.25 & 750 & 0.08 & 0.04 & 0.10 & 0.10 & 0 & 0 & 10.67 & 10.67 & 10.45 & 90 & 77 & 792 & 990 & 64 & 1011 & 64 & 1144 \\
\hline 10129/2001 & 0.00 & 0 & 0 & 0.22 & 750 & 0.06 & 0.02 & 0.10 & 0.10 & 0 & 0 & 10.67 & 10.67 & 10.49 & 90 & 77 & 796 & 996 & 63 & 1041 & 63 & 1158 \\
\hline 10/3012001 & 0.51 & 0 & 0 & 0.18 & 750 & 0.01 & 0.02 & 0.10 & 0.10 & 0 & 0 & 10.67 & 10.67 & 11.05 & 90 & 77 & 769 & 962 & 62 & 1039 & 62 & 1178 \\
\hline 10/3112001 & 0.00 & 0 & 0 & 0.00 & 750 & 0.04 & 0.04 & 0.10 & 0.33 & 0 & 0 & 10.67 & 10.67 & 10.65 & 295 & 250 & 775 & 969 & 80 & 1000 & 86 & 1244 \\
\hline 1111112001 & 0.00 & 0 & 0 & 0.02 & 1000 & 0.05 & 0.04 & 0.10 & 0.10 & 0 & 0 & 10.67 & 10.67 & 10.48 & 90 & 77 & 782 & 978 & 77 & 1125 & 77 & 1295 \\
\hline 111222001 & 0.00 & 0 & 0 & 0.19 & 1000 & 0.05 & 0.03 & 0.10 & 0.10 & 0 & 0 & 10.67 & 10.67 & 10.48 & 90 & 77 & 792 & 990 & 77 & 1194 & 77 & 1352 \\
\hline $11 / 3 / 2001$ & 0.00 & 0 & 0 & 0.19 & 1000 & 0.07 & 0.04 & 0.10 & 0.10 & 0 & 0 & 10.67 & 10.67 & 10.46 & 90 & 77 & 804 & 1005 & 86 & 1137 & 86 & 1310 \\
\hline 11/412001 & 0.00 & 0 & 0 & 0.21 & 1000 & 0.02 & 0.04 & 0.10 & 0.10 & 0 & 0 & 10.67 & 10.67 & 10.50 & 90 & 77 & 813 & 1016 & 92 & 1159 & 92 & 1298 \\
\hline $11 / 5152001$ & 0.00 & 0 & 0 & 0.16 & 1000 & 0.06 & 0.04 & 0.10 & 0.10 & 0 & 0 & 10.67 & 10.67 & 10.47 & 90 & 77 & 823 & 1029 & 103 & 1107 & 103 & 1278 \\
\hline 11/6/12001 & 0.00 & 0 & 0 & 0.20 & 1000 & 0.07 & 0.04 & 0.10 & 0.10 & 0 & 0 & 10.67 & 10.67 & 10.46 & 90 & 77 & 835 & 1043 & 127 & 1095 & 127 & 1238 \\
\hline 1117/2001 & 0.00 & 0 & 0 & 0.20 & 1000 & 0.07 & 0.04 & 0.10 & 0.10 & 0 & 0 & 10.67 & 10.67 & 10.46 & 90 & 77 & 846 & 1058 & 136 & 1085 & 136 & 1207 \\
\hline 1118122001 & 0.00 & 0 & 0 & 0.21 & 1000 & 0.06 & 0.03 & 0.10 & 0.10 & 0 & 0 & 10.67 & 10.67 & 10.47 & 90 & 77 & 857 & 1072 & 135 & 1071 & 135 & 1181 \\
\hline 11/91/2001 & 0.00 & 0 & 0 & 0.20 & 1000 & 0.08 & 0.03 & 0.10 & 0.10 & 0 & 0 & 10.67 & 10.67 & 10.46 & 90 & 77 & 869 & 1086 & 141 & 1066 & 141 & 1159 \\
\hline 11/10122001 & 0.33 & 0 & 0 & 0.21 & 1000 & 0.09 & 0.03 & 0.10 & 0.10 & 0 & 0 & 10.67 & 10.67 & 10.78 & 90 & 77 & 859 & 1074 & 146 & 1047 & 146 & 1161 \\
\hline 111/1112001 & 0.00 & 0 & 0 & 0.00 & 1000 & 0.04 & 0.03 & 0.10 & 0.21 & 0 & 0 & 10.67 & 10.67 & 10.49 & 189 & 161 & 865 & 1082 & 154 & 1012 & 154 & 1154 \\
\hline 11/12222001 & 0.46 & 0 & 0 & 0.17 & 1000 & 0.01 & 0.00 & 0.10 & 0.10 & 0 & 0 & 10.67 & 10.67 & 11.01 & 90 & 77 & 840 & 1051 & 165 & 969 & 165 & 1116 \\
\hline 11/1312001 & 0.00 & 0 & 0 & 0.00 & 1000 & 0.04 & 0.02 & 0.10 & 0.33 & 0 & 0 & 10.67 & 10.67 & 10.62 & 295 & 250 & 845 & 1057 & 189 & 959 & 189 & 1089 \\
\hline 11/1/42001 & 0.00 & 0 & 0 & 0.05 & 1000 & 0.04 & 0.01 & 0.10 & 0.10 & 0 & 0 & 10.67 & 10.67 & 10.51 & 90 & 77 & 851 & 1063 & 218 & 939 & 218 & 1085 \\
\hline
\end{tabular}


Note: Traditional drawdown (Type 3, normal year) selected for entire model run shown.

\begin{tabular}{|c|c|c|c|c|c|c|c|c|c|c|c|c|c|c|c|c|c|c|c|c|c|c|}
\hline \multirow[b]{2}{*}{ Date } & \multicolumn{5}{|c|}{$\mathbb{N}$} & \multicolumn{6}{|c|}{ OUT } & \multicolumn{3}{|c|}{ Management } & \multicolumn{4}{|c|}{ MODEL OUTPUT } & \multicolumn{4}{|c|}{ NGWD COMPOSTIE DATA } \\
\hline & $\begin{array}{l}\text { Precip } \\
\text { inches }\end{array}$ & $\begin{array}{l}\text { GW } \\
\text { inches }\end{array}$ & $\begin{array}{c}E C(g \mathrm{gl}) \\
\mathrm{uS}(\mathrm{cm})\end{array}$ & $\begin{array}{l}\text { Op. Inflow } \\
\text { inches }\end{array}$ & & $\begin{array}{c}\text { Evap. lopen } \\
\text { water) } \\
\text { inches }\end{array}$ & $\begin{array}{c}\text { ET } \\
\text { (veg, areas) } \\
\text { inches }\end{array}$ & $\begin{array}{c}\text { Op Spill } \\
\text { inches }\end{array}$ & $\begin{array}{c}\text { Outflow } \\
\text { inches }\end{array}$ & & $\begin{array}{l}\text { EC(gN) } \\
\text { USScm }\end{array}$ & $\begin{array}{l}\text { Depth } \\
\text { (hab) } \\
\text { inches } \\
\end{array}$ & $\begin{array}{l}\text { Depth } \\
\text { (CC) }\end{array}$ & $\begin{array}{c}\text { End of } \\
\text { Day } \\
\text { inches }\end{array}$ & $\begin{array}{l}\text { Flow } \\
\text { (dis) }\end{array}$ & $\begin{array}{l}\mathrm{Adj}, \\
\text { Flow } \\
(\mathrm{cts})\end{array}$ & $\begin{array}{c}E C \\
\text { USCm }\end{array}$ & $\begin{array}{c}\text { Adj, EC } \\
\text { US }(\mathrm{cm}\end{array}$ & $\begin{array}{l}\text { GWDP } \\
Q(c f s)\end{array}$ & $\begin{array}{l}\text { arsonnel } \\
\text { EC (uSicm) }\end{array}$ & $\begin{array}{l}\text { Real|Fin } \\
Q(c+s)\end{array}$ & $\begin{array}{l}\text { e Network } \\
\text { EC }(u S \mathrm{~cm})\end{array}$ \\
\hline 11/1/5/2001 & 0.00 & $\overline{0}$ & $\overline{0}$ & 0.16 & 1000 & 0.05 & 0.02 & 0.10 & 0.10 & 0 & 0 & 10.67 & 10.67 & 10.50 & 90 & 77 & 858 & 1073 & 214 & 985 & 214 & 1101 \\
\hline 11/1/6/2001 & 0.00 & 0 & 0 & 0.17 & 1000 & 0.03 & 0.02 & 0.10 & 0.10 & 0 & 0 & 10.67 & 10.67 & 10.51 & 90 & 77 & 865 & 1081 & 212 & 1004 & 212 & 1115 \\
\hline 11/177/2001 & 0.01 & 0 & 0 & 0.15 & 1000 & 0.04 & 0.00 & 0.10 & 0.10 & 0 & 0 & 10.67 & 10.67 & 10.53 & 90 & 77 & 869 & 1087 & 211 & 1003 & 211 & 1135 \\
\hline 11/118122001 & 0.00 & 0 & 0 & 0.13 & 1000 & 0.02 & 0.01 & 0.10 & 0.10 & 0 & 0 & 10.67 & 10.67 & 10.53 & 90 & 77 & 874 & 1092 & 204 & 1041 & 204 & 1137 \\
\hline 11/19/2001 & 0.01 & 0 & 0 & 0.13 & 1000 & 0.04 & 0.01 & 0.10 & 0.10 & 0 & 0 & 10.67 & 10.67 & 10.52 & 90 & 77 & 879 & 1099 & 195 & 1042 & 195 & 1149 \\
\hline 1112012001 & 0.00 & 0 & 0 & 0.14 & 1000 & 0.03 & 0.01 & 0.10 & 0.10 & 0 & 0 & 10.67 & 10.67 & 10.53 & 90 & 77 & 884 & 1105 & 179 & 1071 & 179 & 1185 \\
\hline 1112112001 & 0.01 & 0 & 0 & 0.14 & 1000 & 0.03 & 0.00 & 0.10 & 0.10 & 0 & 0 & 10.67 & 10.67 & 10.54 & 90 & 77 & 888 & 1110 & 167 & 1093 & 167 & 1201 \\
\hline 1122212001 & 0.02 & 0 & 0 & 0.13 & 1000 & 0.02 & 0.01 & 0.10 & 0.10 & 0 & 0 & 10.67 & 10.67 & 10.55 & 90 & 77 & 891 & 1113 & 156 & 1104 & 156 & 1247 \\
\hline 1112312001 & 0.00 & 0 & 0 & 0.12 & 1000 & 0.05 & 0.02 & 0.10 & 0.10 & 0 & 0 & 10.67 & 10.67 & 10.50 & 90 & 77 & 897 & 1122 & 146 & 1132 & 146 & 1295 \\
\hline 11124212001 & 0.49 & 0 & 0 & 0.17 & 1000 & 0.06 & 0.01 & 0.10 & 0.10 & 0 & 0 & 10.67 & 10.67 & 10.98 & 90 & 77 & 873 & 1091 & 145 & 1196 & 145 & 1314 \\
\hline 11125/2001 & 0.00 & 0 & 0 & 0.00 & 1000 & 0.04 & 0.01 & 0.10 & 0.33 & 0 & 0 & 10.67 & 10.67 & 10.60 & 295 & 250 & 877 & 1096 & 157 & 1203 & 157 & 1308 \\
\hline 1112612001 & 0.00 & 0 & 0 & 0.06 & 1000 & 0.03 & 0.02 & 0.10 & 0.10 & 0 & 0 & 10.67 & 10.67 & 10.51 & 90 & 77 & 882 & 1103 & 149 & 1209 & 149 & 1328 \\
\hline 11127/2001 & 0.00 & 0 & 0 & 0.15 & 1000 & 0.05 & 0.02 & 0.10 & 0.10 & 0 & 0 & 10.67 & 10.67 & 10.49 & 90 & 77 & 890 & 1112 & 132 & 1195 & 132 & 1357 \\
\hline 1112812001 & 0.07 & 0 & 0 & 0.17 & 1000 & 0.03 & 0.00 & 0.10 & 0.10 & 0 & 0 & 10.67 & 10.67 & 10.60 & 90 & 77 & 889 & 1112 & 136 & 1194 & 136 & 1403 \\
\hline 11129/2001 & 0.17 & 0 & 0 & 0.06 & 1000 & 0.00 & 0.01 & 0.10 & 0.10 & 0 & 0 & 10.67 & 10.67 & 10.72 & 90 & 77 & 880 & 1100 & 162 & 1155 & 162 & 1399 \\
\hline 11/30122001 & 0.00 & 0 & 0 & 0.00 & 1000 & 0.03 & 0.01 & 0.10 & 0.16 & 0 & 0 & 10.67 & 10.67 & 10.52 & 139 & 118 & 884 & 1105 & 157 & 1160 & 157 & 1390 \\
\hline 12112001 & 0.10 & 0 & 0 & 0.15 & 1250 & 0.01 & 0.00 & 0.10 & 0.10 & 0 & 0 & 10.67 & 10.67 & 10.65 & 90 & 77 & 883 & 1104 & 137 & 1189 & 137 & 1360 \\
\hline 1222222001 & 0.04 & 0 & 0 & 0.01 & 1250 & 0.05 & 0.01 & 0.10 & 0.10 & 0 & 0 & 10.67 & 10.67 & 11.15 & 90 & 77 & 849 & 1061 & 135 & 1182 & 135 & 1362 \\
\hline $12 / 312001$ & 0.02 & 0 & 0 & 0.00 & 1250 & 0.04 & 0.02 & 0.10 & 0.33 & 0 & 0 & 10.67 & 10.67 & 10.77 & 295 & 250 & 852 & 1065 & 137 & 1182 & 137 & 1368 \\
\hline 121412001 & 0.00 & 0 & 0 & 0.00 & 1250 & 0.03 & 0.02 & 0.10 & 0.21 & 0 & 0 & 10.67 & 10.67 & 10.51 & 180 & 158 & 857 & 1071 & 131 & 1182 & 131 & 1358 \\
\hline 12/512001 & 0.00 & 0 & 0 & 0.15 & 1250 & 0.03 & 0.00 & 0.10 & 0.10 & 0 & 0 & 10.67 & 10.67 & 10.53 & 90 & 77 & 865 & 1081 & 128 & 1193 & 128 & 1371 \\
\hline 1216122001 & 0.00 & 0 & 0 & 0.13 & 1250 & 0.04 & 0.02 & 0.10 & 0.10 & 0 & 0 & 10.67 & 10.67 & 10.51 & 90 & 77 & 874 & 1093 & 119 & 1206 & 119 & 1390 \\
\hline 127712001 & 0.00 & 0 & 0 & 0.16 & 1250 & 0.04 & 0.01 & 0.10 & 0.10 & 0 & 0 & 10.67 & 10.67 & 10.52 & 90 & 77 & 884 & 1105 & 110 & 1225 & 110 & 1420 \\
\hline 121812001 & 0.01 & 0 & 0 & 0.15 & 1250 & 0.02 & 0.01 & 0.10 & 0.10 & 0 & 0 & 10.67 & 10.67 & 10.54 & 90 & 77 & 892 & 1115 & 99 & 1224 & 99 & 1435 \\
\hline 129/2001 & 0.01 & 0 & 0 & 0.13 & 1250 & 0.03 & 0.01 & 0.10 & 0.10 & 0 & 0 & 10.67 & 10.67 & 10.54 & 90 & 77 & 899 & 1123 & 89 & 1235 & 89 & 1460 \\
\hline 1210102001 & 0.00 & 0 & 0 & 0.13 & 1250 & 0.04 & 0.02 & 0.10 & 0.10 & 0 & 0 & 10.67 & 10.67 & 10.51 & 90 & 77 & 908 & 1135 & 82 & 1245 & 82 & 1478 \\
\hline 1211122001 & 0.00 & 0 & 0 & 0.16 & 1250 & 0.04 & 0.02 & 0.10 & 0.10 & 0 & 0 & 10.67 & 10.67 & 10.51 & 90 & 77 & 918 & 1148 & 79 & 1280 & 79 & 1467 \\
\hline 1212122001 & 0.00 & 0 & 0 & 0.16 & 1250 & 0.03 & 0.01 & 0.10 & 0.10 & 0 & 0 & 10.67 & 10.67 & 10.52 & 90 & 77 & 927 & 1159 & 64 & 1451 & 64 & 1605 \\
\hline 121132001 & 0.00 & 0 & 0 & 0.15 & 1250 & 0.02 & 0.01 & 0.10 & 0.10 & 0 & 0 & 10.67 & 10.67 & 10.53 & 90 & 77 & 935 & 1169 & 54 & 1465 & 54 & 1772 \\
\hline 121412001 & 0.19 & 0 & 0 & 0.14 & 1250 & 0.03 & 0.02 & 0.10 & 0.10 & 0 & 0 & 10.67 & 10.67 & 10.71 & 90 & 77 & 930 & 1162 & 58 & 1391 & 58 & 1635 \\
\hline 121152001 & 0.00 & 0 & 0 & 0.00 & 1250 & 0.03 & 0.02 & 0.10 & 0.14 & 0 & 0 & 10.67 & 10.67 & 10.51 & 128 & 109 & 934 & 1168 & 59 & 1393 & 59 & 1634 \\
\hline 1216122001 & 0.00 & 0 & 0 & 0.16 & 1250 & 0.03 & 0.01 & 0.10 & 0.10 & 0 & 0 & 10.67 & 10.67 & 10.53 & 90 & 77 & 943 & 1178 & 60 & 1385 & 60 & 1596 \\
\hline 12117/2001 & 0.05 & 0 & 0 & 0.14 & 1250 & 0.03 & 0.00 & 0.10 & 0.10 & 0 & 0 & 10.67 & 10.67 & 10.58 & 90 & 77 & 946 & 1183 & 58 & 1453 & 58 & 1640 \\
\hline 1211812001 & 0.01 & 0 & 0 & 0.09 & 1250 & 0.04 & 0.00 & 0.10 & 0.10 & 0 & 0 & 10.67 & 10.67 & 10.53 & 90 & 77 & 952 & 1190 & 56 & 1518 & 56 & 1645 \\
\hline 1211922001 & 0.01 & 0 & 0 & 0.14 & 1250 & 0.01 & 0.00 & 0.10 & 0.10 & 0 & 0 & 10.67 & 10.67 & 10.57 & 90 & 77 & 956 & 1194 & 66 & 1458 & 66 & 1660 \\
\hline 1220022001 & 0.11 & 0 & 0 & 0.10 & 1250 & 0.05 & 0.01 & 0.10 & 0.10 & 0 & 0 & 10.67 & 10.67 & 10.61 & 90 & 77 & 956 & 1195 & 81 & 1467 & 81 & 1647 \\
\hline 122112001 & 0.10 & 0 & 0 & 0.06 & 1250 & 0.01 & 0.01 & 0.10 & 0.10 & 0 & 0 & 10.67 & 10.67 & 10.65 & 90 & 77 & 951 & 1189 & 122 & 1288 & 122 & 1521 \\
\hline 1222212001 & 0.04 & 0 & 0 & 0.01 & 1250 & 0.03 & 0.00 & 0.10 & 0.10 & 0 & 0 & 10.67 & 10.67 & 10.57 & 90 & 77 & 951 & 1189 & 127 & 1300 & 127 & 1546 \\
\hline 1222312001 & 0.00 & 0 & 0 & 0.09 & 1250 & 0.03 & 0.01 & 0.10 & 0.10 & 0 & 0 & 10.67 & 10.67 & 10.53 & 90 & 77 & 957 & 1196 & 118 & 1332 & 118 & 1542 \\
\hline 1222420001 & 0.00 & 0 & 0 & 0.14 & 1250 & 0.02 & 0.01 & 0.10 & 0.10 & 0 & 0 & 10.67 & 10.67 & 10.54 & 90 & 77 & 964 & 1204 & 116 & 1342 & 116 & 1576 \\
\hline 12253/2001 & 0.01 & 0 & 0 & 0.13 & 1250 & 0.01 & 0.00 & 0.10 & 0.10 & 0 & 0 & 10.67 & 10.67 & 10.56 & 90 & 77 & 968 & 1209 & 114 & 1350 & 114 & 1343 \\
\hline 1226612001 & 0.00 & 0 & 0 & 0.10 & 1250 & 0.01 & 0.00 & 0.10 & 0.10 & 0 & 0 & 10.67 & 10.67 & 10.55 & 90 & 77 & 971 & 1214 & 112 & 1365 & 112 & 1368 \\
\hline 12227/2001 & 0.01 & 0 & 0 & 0.11 & 1250 & 0.02 & 0.01 & 0.10 & 0.10 & 0 & 0 & 10.67 & 10.67 & 10.55 & 90 & 77 & 976 & 1220 & 111 & 1368 & 111 & 1510 \\
\hline 12212822001 & 0.37 & 0 & 0 & 0.11 & 1250 & 0.01 & 0.00 & 0.10 & 0.10 & 0 & 0 & 10.67 & 10.67 & 10.92 & 90 & 77 & 953 & 1191 & 119 & 1356 & 119 & 1524 \\
\hline 122129/2001 & 0.26 & 0 & 0 & 0.00 & 1250 & 0.00 & 0.00 & 0.10 & 0.33 & 0 & 0 & 10.67 & 10.67 & 10.85 & 295 & 250 & 934 & 1168 & 127 & 1350 & 127 & 1549 \\
\hline 12/3012001 & 0.11 & 0 & 0 & 0.00 & 1250 & 0.01 & 0.00 & 0.10 & 0.28 & 0 & 0 & 10.67 & 10.67 & 10.67 & 254 & 215 & 927 & 1158 & 142 & 1371 & 142 & 1575 \\
\hline 123112001 & 0.00 & 0 & 0 & 0.00 & 1250 & 0.03 & 0.00 & 0.10 & 0.10 & 0 & 0 & 10.67 & 10.67 & 10.53 & 91 & 78 & 930 & 1162 & 154 & 1344 & 154 & 1540 \\
\hline 11112002 & 0.01 & 0 & 0 & 0.14 & 1500 & 0.03 & 0.00 & 0.10 & 0.10 & 0 & 0 & 10.67 & 10.67 & 10.54 & 90 & 77 & 939 & 1174 & 163 & 1335 & 163 & 1544 \\
\hline $1 / 212002$ & 0.96 & 0 & 0 & 0.12 & 1500 & 0.03 & 0.00 & 0.10 & 0.10 & 0 & 0 & 10.67 & 10.67 & 11.49 & 90 & 77 & 887 & 1109 & 182 & 1304 & 182 & 1533 \\
\hline
\end{tabular}


Note: Traditional drawdown (Type 3, normal year) selected for entire model run shown.

\begin{tabular}{|c|c|c|c|c|c|c|c|c|c|c|c|c|c|c|c|c|c|c|c|c|c|c|}
\hline Time-Step & & \multicolumn{6}{|c|}{ OUT } & \multicolumn{3}{|c|}{ Management } & \multicolumn{4}{|c|}{ MODEL OUTPUT } & \multicolumn{4}{|c|}{ NGWD COMPOSTED DATA } \\
\hline Date & $\begin{array}{l}\text { Precip } \\
\text { inches }\end{array}$ & $\begin{array}{l}\text { GW } \\
\text { inches }\end{array}$ & $\begin{array}{c}E C(g \mathrm{gl}) \\
\mathrm{uS}(\mathrm{cm})\end{array}$ & $\begin{array}{l}\text { Op. Inflow } \\
\text { inches }\end{array}$ & & $\begin{array}{c}\text { Evap. lopen } \\
\text { water) } \\
\text { inches }\end{array}$ & $\begin{array}{c}\text { ET } \\
\text { (veg, areas) } \\
\text { inches }\end{array}$ & $\begin{array}{c}\text { Op Spill } \\
\text { inches }\end{array}$ & $\begin{array}{c}\text { Outflow } \\
\text { inches }\end{array}$ & & $\begin{array}{c}E C(g W) \\
\text { uS }(\mathrm{cm}\end{array}$ & $\begin{array}{l}\text { Depth } \\
\text { (hab) } \\
\text { inches }\end{array}$ & $\begin{array}{l}\text { Depth } \\
\text { (CC) }\end{array}$ & $\begin{array}{l}\text { End of } \\
\text { Day } \\
\text { inches }\end{array}$ & $\begin{array}{l}\text { Flow } \\
(d s)\end{array}$ & $\begin{array}{l}\text { Adj. } \\
\text { Flow } \\
\text { (cts) }\end{array}$ & $\begin{array}{l}\text { EC } \\
\text { US } \mathrm{cm}\end{array}$ & $\begin{array}{c}\text { Adj, EC } \\
\text { uS } / \mathrm{cm}\end{array}$ & $\begin{array}{l}\text { GWDP } \\
Q(d s)\end{array}$ & $\begin{array}{l}\text { ersonnel } \\
E C(\text { (uS } \mathrm{cm})\end{array}$ & $\begin{array}{l}\text { Real } \mid \text { Tin } \\
Q(d s i)\end{array}$ & $\begin{array}{l}\text { e Network } \\
\text { EC (uSC } \mathrm{cm})\end{array}$ \\
\hline TIJILV & 0.00 & 0 & 0 & 0.00 & 1500 & 0.02 & 0.02 & 0.10 & 0.33 & 0 & 0 & 10.67 & 10.67 & 11.13 & 295 & 250 & 891 & 1113 & 210 & 1249 & 210 & 1510 \\
\hline 1/42002 & 0.01 & 0 & 0 & 0.00 & 1500 & 0.03 & 0.01 & 0.10 & 0.33 & 0 & 0 & 10.67 & 10.67 & 10.77 & 295 & 250 & 893 & 1116 & 221 & 1217 & 221 & 1442 \\
\hline 1/512002 & 0.00 & 0 & 0 & 0.00 & 1500 & 0.02 & 0.00 & 0.10 & 0.20 & 0 & 0 & 10.67 & 10.67 & 10.55 & 183 & 155 & 895 & 1118 & 235 & 1166 & 235 & 1369 \\
\hline $1 / 612002$ & 0.01 & 0 & 0 & 0.12 & 1500 & 0.01 & 0.00 & 0.10 & 0.10 & 0 & 0 & 10.67 & 10.67 & 10.56 & 90 & 77 & 902 & 1128 & 227 & 1166 & 227 & 1294 \\
\hline $17 / 12002$ & 0.01 & 0 & 0 & 0.11 & 1500 & 0.02 & 0.01 & 0.10 & 0.10 & 0 & 0 & 10.67 & 10.67 & 10.54 & 90 & 77 & 910 & 1138 & 214 & 1188 & 214 & 1280 \\
\hline 18122002 & 0.01 & 0 & 0 & 0.12 & 1500 & 0.01 & 0.01 & 0.10 & 0.10 & 0 & 0 & 10.67 & 10.67 & 10.56 & 90 & 77 & 918 & 1147 & 204 & 1203 & 204 & 1296 \\
\hline 19122002 & 0.02 & 0 & 0 & 0.11 & 1500 & 0.02 & 0.01 & 0.10 & 0.10 & 0 & 0 & 10.67 & 10.67 & 10.56 & 90 & 77 & 924 & 1156 & 194 & 1295 & 194 & 1327 \\
\hline 1/11022002 & 0.00 & 0 & 0 & 0.11 & 1500 & 0.05 & 0.01 & 0.10 & 0.10 & 0 & 0 & 10.67 & 10.67 & 10.51 & 90 & 77 & 935 & 1169 & 189 & 1287 & 189 & 1364 \\
\hline $1 / 1112002$ & 0.00 & 0 & 0 & 0.16 & 1500 & 0.02 & 0.00 & 0.10 & 0.10 & 0 & 0 & 10.67 & 10.67 & 10.55 & 90 & 77 & 945 & 1182 & 172 & 1283 & 172 & 1436 \\
\hline $1 / 1212002$ & 0.00 & 0 & 0 & 0.12 & 1500 & 0.00 & 0.00 & 0.10 & 0.10 & 0 & 0 & 10.67 & 10.67 & 10.56 & 90 & 77 & 952 & 1190 & 138 & 1357 & 138 & 1535 \\
\hline 1/11322002 & 0.00 & 0 & 0 & 0.11 & 1500 & 0.02 & 0.00 & 0.10 & 0.10 & 0 & 0 & 10.67 & 10.67 & 10.55 & 90 & 77 & 959 & 1199 & 128 & 1382 & 128 & 1571 \\
\hline 1/1/42002 & 0.00 & 0 & 0 & 0.12 & 1500 & 0.03 & 0.00 & 0.10 & 0.10 & 0 & 0 & 10.67 & 10.67 & 10.54 & 90 & 77 & 968 & 1209 & 116 & 1416 & 116 & 1592 \\
\hline 1/1/512002 & 0.00 & 0 & 0 & 0.13 & 1500 & 0.02 & 0.02 & 0.10 & 0.10 & 0 & 0 & 10.67 & 10.67 & 10.53 & 90 & 77 & 977 & 1221 & 104 & 1418 & 104 & 1620 \\
\hline 1/16122002 & 0.00 & 0 & 0 & 0.14 & 1500 & 0.04 & 0.01 & 0.10 & 0.10 & 0 & 0 & 10.67 & 10.67 & 10.52 & 90 & 77 & 988 & 1236 & 87 & 1498 & 87 & 1698 \\
\hline 1/177/2002 & 0.00 & 0 & 0 & 0.15 & 1500 & 0.04 & 0.02 & 0.10 & 0.10 & 0 & 0 & 10.67 & 10.67 & 10.51 & 90 & 77 & 1001 & 1252 & 79 & 1553 & 79 & 1751 \\
\hline 1/11812002 & 0.00 & 0 & 0 & 0.16 & 1500 & 0.04 & 0.02 & 0.10 & 0.10 & 0 & 0 & 10.67 & 10.67 & 10.51 & 90 & 77 & 1014 & 1267 & 69 & 1604 & 69 & 1826 \\
\hline 1/1992002 & 0.00 & 0 & 0 & 0.15 & 1500 & 0.04 & 0.02 & 0.10 & 0.10 & 0 & 0 & 10.67 & 10.67 & 10.50 & 90 & 77 & 1027 & 1284 & 71 & 1630 & 71 & 1944 \\
\hline 112012002 & 0.00 & 0 & 0 & 0.16 & 1500 & 0.05 & 0.02 & 0.10 & 0.10 & 0 & 0 & 10.67 & 10.67 & 10.50 & 90 & 77 & 1041 & 1301 & 70 & 1714 & 70 & 2055 \\
\hline 1/21212002 & 0.02 & 0 & 0 & 0.16 & 1500 & 0.04 & 0.02 & 0.10 & 0.10 & 0 & 0 & 10.67 & 10.67 & 10.53 & 90 & 77 & 1052 & 1315 & 68 & 1729 & 68 & 2075 \\
\hline 12212002 & 0.00 & 0 & 0 & 0.14 & 1500 & 0.05 & 0.03 & 0.10 & 0.10 & 0 & 0 & 10.67 & 10.67 & 10.49 & 90 & 77 & 1065 & 1331 & 66 & 1677 & 66 & 2036 \\
\hline 112312002 & 0.00 & 0 & 0 & 0.17 & 1500 & 0.05 & 0.03 & 0.10 & 0.10 & 0 & 0 & 10.67 & 10.67 & 10.49 & 90 & 77 & 1080 & 1350 & 62 & 1683 & 62 & 1976 \\
\hline 1124212002 & 0.00 & 0 & 0 & 0.18 & 1500 & 0.05 & 0.02 & 0.10 & 0.10 & 0 & 0 & 10.67 & 10.67 & 10.50 & 90 & 77 & 1094 & 1367 & 63 & 1659 & 63 & 2012 \\
\hline 1125/2002 & 0.00 & 0 & 0 & 0.17 & 1500 & 0.05 & 0.02 & 0.10 & 0.10 & 0 & 0 & 10.67 & 10.67 & 10.50 & 90 & 77 & 1108 & 1385 & 60 & 1779 & 60 & 2158 \\
\hline 112612002 & 0.12 & 0 & 0 & 0.02 & 1500 & 0.03 & 0.01 & 0.10 & 0.10 & 0 & 0 & 10.67 & 9.60 & 10.50 & 90 & 77 & 1102 & 1377 & 64 & 1768 & 64 & 2205 \\
\hline 1/27/2002 & 0.00 & 0 & 0 & 0.00 & 1500 & 0.02 & 0.01 & 0.10 & 0.23 & 0 & 0 & 10.67 & 8.53 & 10.23 & 207 & 176 & 1105 & 1381 & 64 & 1743 & 64 & 2106 \\
\hline 1/28/2002 & 0.00 & 0 & 0 & 0.00 & 1500 & 0.01 & 0.01 & 0.10 & 0.12 & 0 & 0 & 10.67 & 7.47 & 10.09 & 108 & 92 & 1108 & 1385 & 63 & 1752 & 63 & 2037 \\
\hline 1129/2002 & 0.08 & 0 & 0 & 0.00 & 1500 & 0.01 & 0.01 & 0.10 & 0.13 & 0 & 0 & 10.67 & 6.40 & 10.02 & 112 & 95 & 1103 & 1378 & 69 & 1733 & 69 & 2027 \\
\hline 1/3012002 & 0.00 & 0 & 0 & 0.00 & 1500 & 0.03 & 0.01 & 0.10 & 0.21 & 0 & 0 & 10.67 & 5.33 & 9.77 & 184 & 156 & 1108 & 1385 & 73 & 1730 & 73 & 2025 \\
\hline 1/3112002 & 0.00 & 0 & 0 & 0.00 & 1500 & 0.03 & 0.01 & 0.10 & 0.10 & 0 & 0 & 10.67 & 4.27 & 9.62 & 93 & 79 & 1114 & 1392 & 75 & 1729 & 75 & 2000 \\
\hline 21112002 & 0.00 & 0 & 0 & 0.00 & 1750 & 0.05 & 0.01 & 0.10 & 0.10 & 0 & 0 & 10.67 & 3.20 & 9.45 & 92 & 78 & 1121 & 1401 & 88 & 1641 & 88 & 1983 \\
\hline $2|2| 2002$ & 0.00 & 0 & 0 & 0.01 & 1750 & 0.03 & 0.02 & 0.10 & 0.10 & 0 & 0 & 10.67 & 2.13 & 9.31 & 90 & 77 & 1128 & 1410 & 92 & 1710 & 92 & 1958 \\
\hline $2 / 312002$ & 0.04 & 0 & 0 & 0.00 & 1750 & 0.03 & 0.02 & 0.10 & 0.10 & 0 & 0 & 10.67 & 1.07 & 9.20 & 90 & 77 & 1129 & 1412 & 102 & 1659 & 102 & 1869 \\
\hline 241412002 & 0.00 & 0 & 0 & 0.00 & 1750 & 0.04 & 0.01 & 0.10 & 0.14 & 0 & 0 & 10.67 & 0.00 & 9.01 & 128 & 109 & 1136 & 1420 & 102 & 1639 & 102 & 1850 \\
\hline 2,512002 & 0.00 & 0 & 0 & 0.15 & 1750 & 0.05 & 0.02 & 0.10 & 0.10 & 0 & 0 & 10.67 & 0.00 & 8.99 & 90 & 77 & 1155 & 1444 & 107 & 1479 & 107 & 1861 \\
\hline 26612002 & 0.00 & 0 & 0 & 0.17 & 1750 & 0.05 & 0.02 & 0.10 & 0.10 & 0 & 0 & 10.67 & 0.00 & 8.99 & 90 & 77 & 1176 & 1470 & 117 & 1625 & 117 & 1853 \\
\hline 27712002 & 0.15 & 0 & 0 & 0.17 & 1750 & 0.05 & 0.02 & 0.10 & 0.10 & 0 & 0 & 10.67 & 0.00 & 9.14 & 90 & 77 & 1179 & 1474 & 116 & 1627 & 116 & 1884 \\
\hline 28182002 & 0.06 & 0 & 0 & 0.03 & 1000 & 0.06 & 0.03 & 0.10 & 0.10 & 0 & 0 & 10.67 & 0.00 & 9.03 & 90 & 77 & 1184 & 1480 & 113 & 1592 & 113 & 1864 \\
\hline 29192002 & 0.00 & 0 & 0 & 0.13 & 1000 & 0.06 & 0.03 & 0.10 & 0.10 & 0 & 0 & 10.67 & 0.00 & 8.97 & 90 & 77 & 1192 & 1490 & 108 & 1604 & 108 & 1863 \\
\hline 211022002 & 0.00 & 0 & 0 & 0.19 & 1000 & 0.11 & 0.03 & 0.10 & 0.10 & 0 & 0 & 10.67 & 0.00 & 8.92 & 90 & 77 & 1207 & 1508 & 104 & 1573 & 104 & 1832 \\
\hline 21112002 & 0.00 & 0 & 0 & 0.24 & 1000 & 0.07 & 0.03 & 0.10 & 0.10 & 0 & 0 & 10.67 & 0.00 & 8.96 & 90 & 77 & 1214 & 1518 & 98 & 1571 & 98 & 1809 \\
\hline 21122002 & 0.00 & 0 & 0 & 0.20 & 1000 & 0.07 & 0.03 & 0.10 & 0.10 & 0 & 0 & 10.67 & 0.00 & 8.97 & 90 & 77 & 1222 & 1528 & 95 & 1579 & 95 & 1792 \\
\hline 21132002 & 0.00 & 0 & 0 & 0.09 & 1000 & 0.05 & 0.01 & 0.10 & 0.10 & 0 & 0 & 10.54 & 0.00 & 8.90 & 90 & 77 & 1227 & 1534 & 98 & 1566 & 98 & 1783 \\
\hline 21142002 & 0.00 & 0 & 0 & 0.05 & 1000 & 0.05 & 0.02 & 0.10 & 0.10 & 0 & 0 & 10.42 & 0.00 & 8.78 & 90 & 77 & 1237 & 1546 & 95 & 1582 & 95 & 1767 \\
\hline 211522002 & 0.00 & 0 & 0 & 0.07 & 1000 & 0.05 & 0.02 & 0.10 & 0.10 & 0 & 0 & 10.30 & 0.00 & 8.67 & 90 & 77 & 1245 & 1556 & 91 & 1608 & 91 & 1792 \\
\hline 211612002 & 0.02 & 0 & 0 & 0.07 & 1000 & 0.04 & 0.02 & 0.10 & 0.10 & 0 & 0 & 10.18 & 0.00 & 8.60 & 90 & 77 & 1249 & 1501 & 92 & 1606 & 92 & 1794 \\
\hline $2117 / 2002$ & 0.07 & 0 & 0 & 0.04 & 1000 & 0.07 & 0.01 & 0.10 & 0.10 & 0 & 0 & 10.06 & 0.00 & 8.52 & 90 & 77 & 1252 & 1564 & 98 & 1594 & 98 & 1785 \\
\hline 211812002 & 0.00 & 0 & 0 & 0.00 & 1000 & 0.04 & 0.03 & 0.10 & 0.16 & 0 & 0 & 9.85 & 0.00 & 8.29 & 143 & 121 & 1262 & 1578 & 98 & 1576 & 98 & 1768 \\
\hline 211922002 & 0.02 & 0 & 0 & 0.00 & 1000 & 0.08 & 0.01 & 0.10 & 0.11 & 0 & 0 & 9.65 & 0.00 & 8.12 & 94 & 80 & 1273 & 1591 & 99 & 1562 & 99 & 1761 \\
\hline 220012002 & 0.00 & 0 & 0 & 0.00 & 1000 & 0.05 & 0.04 & 0.10 & 0.11 & 0 & 0 & 9.44 & 0.00 & 7.92 & 98 & 83 & 1288 & 1610 & 93 & 1575 & 93 & 1811 \\
\hline
\end{tabular}


Note: Traditional drawdown (Type 3, normal year) selected for entire model run shown.

\begin{tabular}{|c|c|c|c|c|c|c|c|c|c|c|c|c|c|c|c|c|c|c|c|c|c|c|}
\hline & \multirow[b]{2}{*}{$\begin{array}{l}\text { Prec } \\
\text { inche }\end{array}$} & \multirow[b]{2}{*}{$\begin{array}{cc}\text { cip } & \text { GW } \\
\text { es } & \text { inches }\end{array}$} & & \multicolumn{6}{|c|}{ OUT } & \multicolumn{3}{|c|}{ Management } & \multicolumn{4}{|c|}{ MODEL OUTPUT } & \multicolumn{4}{|c|}{ NGWD COMPOSITE DATA } \\
\hline & & & $\begin{array}{c}E C(g \mathrm{gl}) \\
\mathrm{uS}(\mathrm{cm})\end{array}$ & $\begin{array}{c}\text { Op. Inflow } \\
\text { inches }\end{array}$ & $\begin{array}{l}\text { EC(ii) } \\
\text { uS }(\mathrm{cm})\end{array}$ & $\begin{array}{c}\text { Evap. lopen } \\
\text { water) } \\
\text { inches }\end{array}$ & $\begin{array}{c}\text { ET } \\
\text { (veg, areas) } \\
\text { inches }\end{array}$ & $\begin{array}{c}\text { Op Spill } \\
\text { inches }\end{array}$ & $\begin{array}{c}\text { Outflow } \\
\text { inches }\end{array}$ & & $\begin{array}{c}E C(g W) \\
u S(c m\end{array}$ & $\begin{array}{l}\text { Depth } \\
\text { (hab) } \\
\text { inches } \\
\end{array}$ & $\begin{array}{l}\text { Depth } \\
\text { (CC) }\end{array}$ & $\begin{array}{l}\text { End of } \\
\text { Day } \\
\text { inches }\end{array}$ & $\begin{array}{l}\text { Flow } \\
(c t s)\end{array}$ & $\begin{array}{l}\mathrm{Adj}, \\
\text { Flow } \\
(\mathrm{cts})\end{array}$ & $\begin{array}{c}E C \\
\text { US/cm }\end{array}$ & $\begin{array}{c}\mathrm{Adj}, \mathrm{EC} \\
\mathrm{uS} \mathrm{Ccm}\end{array}$ & $Q(c / s)$ & & $Q(c s s)$ & EC(uSCom) \\
\hline 21212002 & 0.00 & 0 & $\overline{0}$ & 0.01 & 1000 & 0.07 & 0.02 & 0.10 & 0.10 & 0 & $\overline{0}$ & 9.24 & 0.00 & 7.75 & 90 & 77 & 1301 & 1627 & 103 & 1563 & 100 & 1802 \\
\hline 212212002 & 0.02 & 0 & 0 & 0.01 & 1000 & 0.09 & 0.02 & 0.10 & 0.10 & 0 & 0 & 9.04 & 0.00 & 7.57 & 90 & 77 & 1318 & 1647 & Tor & 1617 & TV? & 1848 \\
\hline 212312002 & 0.00 & 0 & 0 & 0.02 & 1000 & 0.07 & 0.04 & 0.10 & 0.10 & 0 & 0 & 8.83 & 0.00 & 7.37 & 90 & 77 & 1338 & 1672 & 80 & 1653 & 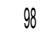 & 1842 \\
\hline 22412002 & 0.00 & 0 & 0 & 0.04 & 1000 & 0.07 & 0.04 & 0.10 & 0.10 & 0 & 0 & 8.63 & 0.00 & 7.20 & 90 & 77 & 1357 & 1696 & 93 & 1683 & 00 & 1852 \\
\hline 212512002 & 0.00 & 0 & 0 & 0.04 & 1000 & 0.08 & 0.03 & 0.10 & 0.10 & 0 & 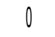 & 8.43 & 0.00 & 7.02 & 90 & 77 & 1377 & 1721 & 0 & 1691 & 0 & 1864 \\
\hline 212612002 & 0.00 & 0 & 0 & 0.04 & 1000 & 0.09 & 0.03 & 0.10 & 0.10 & 0 & . & 8.22 & 0.00 & 6.83 & 90 & 77 & 1401 & 1751 & . & 1672 & 0 & 1849 \\
\hline $2127 / 2002$ & 0.00 & 0 & 0 & 0.05 & 1000 & 0.08 & 0.04 & 0.10 & 0.10 & 0 & 0 & 8.02 & 0.00 & 6.67 & 90 & 77 & 1423 & 1779 & 13 & 1547 & IV & 1858 \\
\hline 212812002 & 0.00 & 0 & 0 & 0.04 & 1000 & 0.10 & 0.05 & 0.10 & 0.10 & 0 & 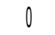 & 7.81 & 0.00 & 6.45 & 90 & 77 & 1456 & 1820 & 13 & 1573 & (V) & 1808 \\
\hline 31112002 & 0.00 & 0 & 0 & 0.08 & 600 & 0.13 & 0.06 & 0.10 & 0.10 & 0 & 0 & 7.61 & 0.00 & 6.24 & 90 & 77 & 1491 & 1863 & 159 & 1451 & 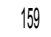 & 1667 \\
\hline 31212002 & 0.00 & 0 & 0 & 0.12 & 600 & 0.16 & 0.04 & 0.10 & 0.10 & 0 & 0 & 7.41 & 0.00 & 6.06 & 90 & 77 & 1525 & 1906 & 141 & 1549 & 141 & 1700 \\
\hline $3 / 3 / 2002$ & 0.00 & 0 & 0 & 0.13 & 600 & 0.14 & 0.04 & 0.10 & 0.10 & 0 & 0 & 7.20 & 0.00 & 5.91 & 90 & 77 & 1551 & 1939 & 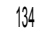 & 1634 & 34 & 1753 \\
\hline 3412002 & 0.00 & 0 & 0 & 0.11 & 600 & 0.11 & 0.04 & 0.10 & 0.10 & 0 & 0 & 7.00 & 0.00 & 5.76 & 90 & 77 & 1576 & 1970 & 3 & 1673 & 133 & 1828 \\
\hline $3 / 512002$ & 0.00 & 0 & 0 & 0.08 & 600 & 0.10 & 0.04 & 0.10 & 0.10 & 0 & 0 & 6.80 & 0.00 & 5.60 & 90 & 77 & 1602 & 2002 & 25 & 1549 & 25 & 1810 \\
\hline $36 / 2002$ & 0.23 & 0 & 0 & 0.07 & 600 & 0.04 & 0.01 & 0.10 & 0.10 & 0 & 0 & 6.59 & 0.00 & 5.74 & 90 & 77 & 1548 & 1934 & 30 & 1626 & 30 & 1928 \\
\hline 37712002 & 0.16 & 0 & 0 & 0.00 & 600 & 0.07 & 0.02 & 0.10 & 0.33 & 0 & 0 & 6.39 & 0.00 & 5.48 & 295 & 250 & 1533 & 1917 & 124 & 1769 & 124 & 1987 \\
\hline 31812002 & 0.00 & 0 & 0 & 0.00 & 600 & 0.08 & 0.04 & 0.10 & 0.27 & 0 & 0 & 6.19 & 0.00 & 5.09 & 237 & 202 & 1572 & 1965 & 109 & 1958 & 09 & 2270 \\
\hline $3 \mid 9 / 2002$ & 0.00 & 0 & 0 & 0.04 & 600 & 0.10 & 0.03 & 0.10 & 0.10 & 0 & 0 & yo & 0.00 & 4.91 & 90 & 77 & 1604 & 2004 & 15 & 1668 & IV & 2548 \\
\hline 311012002 & 0.09 & 0 & 0 & 0.05 & 600 & 0.10 & 0.03 & 0.10 & 0.10 & 0 & 0 & 0 & 0.00 & 4.8 & 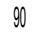 & 77 & 1610 & 2010 & 10 & 1668 & IV & 2250 \\
\hline $3 / 1112002$ & 0.00 & 0 & 0 & 0.00 & 600 & 0.07 & 0.04 & 0.10 & 0.13 & 0 & 0 & 5.57 & 0.00 & 4.5 & 119 & 101 & 1652 & 2005 & 108 & 1642 & 108 & 2019 \\
\hline 311222002 & 0.00 & 0 & 0 & 0.04 & 600 & 0.17 & 0.05 & 0.10 & 0.10 & 0 & 0 & 5.37 & 0.00 & 4.2 & 90 & 77 & 1732 & 216 & 89 & 1943 & 89 & 2215 \\
\hline $3 / 1312002$ & 0.00 & 0 & 0 & 0.15 & 600 & 0.16 & 0.06 & 0.10 & 0.10 & 0 & 0 & 5.17 & 0.00 & 4.1 & 90 & 77 & 1787 & 223 & 69 & 2235 & oy & 2389 \\
\hline $3 / 1412002$ & 0.00 & 0 & 0 & 0.15 & 600 & 0.10 & 0.06 & 0.10 & 0.10 & 0 & o & 4.96 & 0.00 & 4 & 90 & 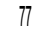 & 1815 & & & 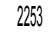 & & 2340 \\
\hline & 0.00 & 0 & 0 & 0.19 & 601 & 0.10 & 0.04 & 010 & 0.1 & 0 & o & 4.88 & 0.00 & 3.9 & 90 & 77 & 1820 & 2275 & & 2190 & 57 & 2294 \\
\hline 311 & 0.00 & 0 & 0 & 0.17 & 60 & DD & nu & 0.10 & 0.1 & 0 & 0 & 4.80 & 0.00 & 3. & 90 & 77 & 1830 & 20 & & 2190 & 57 & 2321 \\
\hline 311 & 0.52 & 0 & 0 & 0.17 & 6II & 0.06 & 0.00 & 0.10 & 01 & 0 & 0 & 4.72 & 0.00 & 4 & $g$ & 77 & 1635 & 20 & & 21 & 56 & 2258 \\
\hline $3 / 18 / 2002$ & 0.00 & 0 & 0 & 0.00 & 60 & 0.09 & 005 & 010 & 03 & 0 & 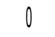 & 4.64 & 0.00 & 3 & 29 & 250 & 1699 & 212 & & 21 & 1 & 2115 \\
\hline 311 & 0.00 & 0 & 0 & 0.00 & 600 & 0.09 & 0.04 & 0.10 & 0.13 & 0 & 0 & 4.56 & 0.00 & 3.6 & 119 & 101 & 1764 & 220 & 69 & 2166 & 69 & 2311 \\
\hline 312012002 & 0.00 & 0 & 0 & 0.16 & 600 & 0.08 & 0.05 & 0.10 & 0.10 & 0 & o & 17 & 0.00 & 3.6 & 90 & 77 & 1774 & 221 & 69 & 2166 & $6 y$ & 2417 \\
\hline 312112002 & 0.00 & 0 & 0 & 0.16 & 600 & 0.12 & 0.05 & 0.10 & 0.10 & 0 & 0 & 4.39 & 0.00 & 3.50 & 90 & 77 & 1806 & 2258 & oy & 2166 & 69 & 2461 \\
\hline 312212002 & 0.00 & 0 & 0 & 0.20 & 600 & 0.13 & 0.03 & 0.10 & 0.10 & 0 & 0 & 4.31 & 0.00 & 3.44 & 90 & 77 & 1824 & 2280 & $6 y$ & 2166 & 69 & 2578 \\
\hline $3 / 23 / 2002$ & 0.13 & 0 & 0 & 0.14 & 600 & 0.04 & 0.03 & 0.10 & 0.10 & 0 & 0 & 16 & 0.00 & 3.53 & 90 & 77 & 1755 & 2194 & 69 & 2166 & by & 2612 \\
\hline 312412002 & 0.00 & 0 & 0 & 0.00 & 600 & 0.10 & 0.05 & 0.10 & 0.18 & 0 & 0 & 4.01 & 0.00 & 3.19 & 163 & 138 & 1849 & 2311 & n & 2166 & $0 y$ & 2653 \\
\hline $3125 / 2002$ & 0.00 & 0 & 0 & 0.13 & 600 & 009 & OOCA & 0.10 & 0.10 & 0 & 0 & 3.87 & 0.00 & 3.09 & 90 & 77 & 1877 & 2346 & $0 y$ & 2166 & 69 & 2540 \\
\hline 312612002 & 0.00 & 0 & 0 & 0.10 & 600 & 010 & 00 & 0.10 & 0.10 & 0 & & 12 & 0.00 & 2.9 & 90 & 77 & 1934 & & & 2160 & 69 & 2500 \\
\hline $3127 / 2002$ & 0.00 & 0 & 0 & 0.13 & 600 & & 0 & 0.10 & 0.1 & 0 & & 3.57 & 0.00 & 2.7 & 90 & 77 & 2004 & & 9 & 216 & 69 & 2628 \\
\hline 312812002 & 0.00 & 0 & 0 & 0.16 & 6 & & & 0.10 & 0.1 & 0 & & 3.42 & 0.00 & 2. & gd & 77 & 2078 & & & 2 & & 2825 \\
\hline & 0.00 & 0 & 0 & 0.18 & & & & 10 & 01 & 0 & & 3.27 & 00 & $?$ & 0 & 77 & 2138 & & & & & 2580 \\
\hline & 0.00 & 0 & 0 & 0.17 & 60 & & 0.0 & 0.1 & 01 & 0 & & 3.13 & 0.00 & 2.3 & 90 & 77 & 2205 & & & & & 2590 \\
\hline $3 / 3112002$ & 0.00 & 0 & 0 & 0.17 & ou & 0.15 & 0.07 & 0.10 & 0.10 & 0 & 0 & 2.98 & 0.00 & 2.2 & $y$ & 77 & 2305 & 288 & 69 & 216 & . & 2551 \\
\hline 4/112002 & 0.00 & 0 & 0 & 0.19 & 600 & 0.15 & 0.07 & 0.10 & 0.10 & 0 & 0 & 2.83 & 0.00 & 2.1 & 90 & 77 & 2392 & 2991 & 76 & 2492 & 76 & 2165 \\
\hline 41212002 & 0.00 & 0 & 0 & 0.19 & 600 & 0.16 & 0.07 & 0.10 & 0.10 & 0 & 0 & 2.68 & 0.00 & 1.98 & 90 & 77 & 2497 & 3122 & 62 & 2581 & 62 & 2320 \\
\hline $4 / 3 / 2002$ & 0.00 & 0 & 0 & 0.20 & 600 & 018 & 0.06 & 0.10 & 0.10 & 0 & 0 & 2.53 & 0.00 & 1.84 & 90 & 77 & 2629 & 3286 & 51 & 2673 & 51 & 2861 \\
\hline 2002 & 0.00 & 0 & 0 & 0.28 & 600 & 13 & 0.05 & 0.10 & 0.10 & 0 & 0 & 2.47 & 0.00 & 1.84 & 90 & 77 & 2576 & 3221 & 43 & 2591 & 43 & 2947 \\
\hline 2002 & 0.00 & 0 & 0 & 0.23 & 600 & 0.11 & 0.04 & 0.10 & 0.10 & 0 & 0 & 2.40 & 0.00 & 1.81 & 90 & 77 & 2549 & 3186 & 33 & 2595 & 33 & 1878 \\
\hline 2002 & 0.00 & 0 & 0 & 0.20 & 600 & 0.10 & 0.06 & 0.10 & 0.10 & 0 & 0 & 2.33 & 0.00 & 1.74 & 90 & 77 & 2562 & 3202 & 30 & 2580 & 30 & 2826 \\
\hline 47712002 & 0.00 & 0 & 0 & 0.20 & 600 & 0.12 & 0.06 & 0.10 & 0.10 & 0 & 0 & 2.27 & 0.00 & 1.67 & 90 & 77 & 2599 & 3249 & 29 & 2597 & 29 & 2849 \\
\hline $48 / 2002$ & 0.00 & 0 & 0 & 0.22 & 600 & 0.16 & 0.07 & 0.10 & 0.10 & 0 & 0 & 2.20 & 0.00 & 1.55 & 90 & 77 & 2713 & 3391 & 28 & 2582 & 28 & 2964 \\
\hline 49/2002 & 0.00 & 0 & 0 & 0.28 & 600 & 0.16 & 0.04 & 0.10 & 0.10 & 0 & 0 & 2.13 & 0.00 & 1.53 & 90 & 77 & 2679 & 3349 & 23 & 2583 & 23 & 2679 \\
\hline 1102002 & 0.00 & 0 & 0 & 0.24 & 600 & 0.07 & 0.07 & 0.10 & 0.10 & 0 & 0 & 2.07 & 0.00 & 1.54 & 90 & 77 & 2589 & 3237 & 27 & 2481 & 27 & 2388 \\
\hline
\end{tabular}


Note: Traditional drawdown (Type 3, normal year) selected for entire model run shown.

\begin{tabular}{|c|c|c|c|c|c|c|c|c|c|c|c|c|c|c|c|c|c|c|c|c|c|c|}
\hline Time-Step & \multicolumn{5}{|c|}{$\mathbb{N}$} & \multicolumn{6}{|c|}{ OUT } & \multicolumn{3}{|c|}{ Management } & \multicolumn{4}{|c|}{ MODEL OUTPUT } & \multicolumn{4}{|c|}{ NGWD COMPOSTE DATA } \\
\hline Date & $\begin{array}{l}\text { Precip } \\
\text { inches }\end{array}$ & $\begin{array}{l}\text { GW } \\
\text { inches }\end{array}$ & $\begin{array}{l}\text { EC(gN) } \\
\text { uScm }\end{array}$ & $\begin{array}{l}\text { Op. Intlow } \\
\text { inches }\end{array}$ & $\begin{array}{l}E C(\text { if } \\
u S(c m\end{array}$ & $\begin{array}{c}\text { Evap. (open } \\
\text { water) } \\
\text { inches }\end{array}$ & $\begin{array}{c}\text { ET } \\
\text { (veg, areas) } \\
\text { inches }\end{array}$ & $\begin{array}{c}\text { Op Spill } \\
\text { inches }\end{array}$ & $\begin{array}{c}\text { Outflow } \\
\text { inches }\end{array}$ & & $\begin{array}{l}\text { EC(gW) } \\
\text { uS }(\mathrm{cm}\end{array}$ & $\begin{array}{l}\text { Depth } \\
\text { (hab) } \\
\text { inches }\end{array}$ & $\begin{array}{l}\text { Depth } \\
\text { (CC) }\end{array}$ & $\begin{array}{l}\text { Endof } \\
\text { Day } \\
\text { inches }\end{array}$ & $\begin{array}{l}\text { Flow } \\
(\mathrm{dss})\end{array}$ & $\begin{array}{l}\text { Adj. } \\
\text { Flow } \\
(c t s)\end{array}$ & $\begin{array}{l}E C \\
U S / C m\end{array}$ & $\begin{array}{c}\text { Adj], EC } \\
\text { USCCm }\end{array}$ & $\begin{array}{l}\text { GWDP } \\
Q(d f s)\end{array}$ & $\begin{array}{l}\text { EC (us } / \mathrm{cm}) \\
\text { annel }\end{array}$ & $\begin{array}{l}\text { Real-Tim } \\
Q(\text { cts })\end{array}$ & $\begin{array}{l}\text { e Network } \\
\text { EC }(u S / \mathrm{cm})\end{array}$ \\
\hline $4 / 1112002$ & 0.00 & 0 & 0 & 0.18 & 600 & 0.14 & 0.07 & 0.10 & 0.10 & 0 & 0 & 2.00 & 0.00 & 1.41 & 90 & 77 & 2726 & 3408 & 29 & 2448 & 29 & 2454 \\
\hline 411222002 & 0.00 & 0 & 0 & 0.25 & 600 & 0.15 & 0.08 & 0.10 & 0.10 & 0 & 0 & 1.93 & 0.00 & 1.33 & 90 & 77 & 2800 & 3500 & 32 & 2313 & 32 & 2368 \\
\hline 4/1322002 & 0.00 & 0 & 0 & 0.27 & 600 & 0.16 & 0.08 & 0.10 & 0.10 & 0 & 0 & 1.87 & 0.00 & 1.27 & 90 & 77 & 2846 & 3558 & 38 & 2168 & 38 & 2387 \\
\hline 4/1412002 & 0.00 & 0 & 0 & 0.28 & 600 & 0.17 & 0.09 & 0.10 & 0.10 & 0 & 0 & 1.80 & 0.00 & 1.19 & 90 & 77 & 2946 & 3682 & 30 & 2243 & 30 & 2360 \\
\hline 41512002 & 0.00 & 0 & 0 & 0.30 & 600 & 0.21 & 0.05 & 0.10 & 0.10 & 0 & 0 & 1.73 & 0.00 & 1.13 & 90 & 77 & 750 & 938 & 22 & 2293 & 22 & 2250 \\
\hline 4/1612002 & 0.00 & 0 & 0 & 0.30 & 600 & 0.16 & 0.07 & 0.10 & 0.10 & 0 & 0 & 1.67 & 0.00 & 1.10 & 90 & 77 & 750 & 938 & 20 & 2285 & 20 & 2130 \\
\hline 41171/2002 & 0.02 & 0 & 0 & 0.28 & 600 & 0.15 & 0.05 & 0.10 & 0.10 & 0 & 0 & 1.60 & 0.00 & 1.10 & 90 & 77 & 750 & 938 & 19 & 2232 & 19 & 2244 \\
\hline 4/18122002 & 0.00 & 0 & 0 & 0.22 & 600 & 0.13 & 0.08 & 0.10 & 0.10 & 0 & 0 & 1.53 & 0.00 & 1.01 & 90 & 77 & 750 & 938 & 20 & 2073 & 20 & 2023 \\
\hline 4/19/2002 & 0.00 & 0 & 0 & 0.25 & 600 & 0.16 & 0.09 & 0.10 & 0.10 & 0 & 0 & 1.47 & 0.00 & 0.91 & 90 & 77 & 750 & 938 & 26 & 1600 & 26 & 2001 \\
\hline 42012002 & 0.00 & 0 & 0 & 0.29 & 600 & 0.18 & 0.08 & 0.10 & 0.10 & 0 & 0 & 1.40 & 0.00 & 0.84 & 90 & 77 & 750 & 938 & 28 & 1634 & 28 & 1960 \\
\hline 42112002 & 0.00 & 0 & 0 & 0.31 & 600 & 0.14 & 0.07 & 0.10 & 0.10 & 0 & 0 & 1.33 & 0.00 & 0.83 & 90 & 77 & 750 & 938 & 34 & 1553 & 34 & 1931 \\
\hline 42212002 & 0.00 & 0 & 0 & 0.26 & 600 & 0.17 & 0.08 & 0.10 & 0.10 & 0 & 0 & 1.27 & 0.00 & 0.74 & 90 & 77 & 750 & 938 & 34 & 1424 & 34 & 2023 \\
\hline 42312002 & 0.00 & 0 & 0 & 0.30 & 600 & 0.20 & 0.09 & 0.10 & 0.10 & 0 & 0 & 1.20 & 0.00 & 0.64 & 90 & 77 & 750 & 938 & 42 & 1423 & 42 & 1548 \\
\hline 42412002 & 0.00 & 0 & 0 & 0.33 & 600 & 0.18 & 0.08 & 0.10 & 0.10 & 0 & 0 & 1.13 & 0.00 & 0.62 & 90 & 77 & 750 & 938 & 39 & 1322 & 39 & 1397 \\
\hline 42512002 & 0.00 & 0 & 0 & 0.30 & 600 & 0.18 & 0.06 & 0.10 & 0.10 & 0 & 0 & 1.07 & 0.00 & 0.57 & 90 & 77 & 750 & 938 & 27 & 1067 & 27 & 1428 \\
\hline 412612002 & 0.15 & 0 & 0 & 0.29 & 600 & 0.06 & 0.05 & 0.10 & 0.10 & 0 & 0 & 1.00 & 0.00 & 0.79 & 90 & 77 & 750 & 938 & 49 & 886 & 49 & 1185 \\
\hline $427 / 2002$ & 0.00 & 0 & 0 & 0.01 & 600 & 0.07 & 0.04 & 0.10 & 0.10 & 0 & 0 & 0.93 & 0.00 & 0.59 & 90 & 77 & 750 & 938 & 49 & 845 & 49 & 1352 \\
\hline 42812002 & 0.00 & 0 & 0 & 0.16 & 600 & 0.11 & 0.07 & 0.10 & 0.10 & 0 & 0 & 0.87 & 0.00 & 0.47 & 90 & 77 & 750 & 938 & 47 & 876 & 47 & 1402 \\
\hline 4/29/2002 & 0.02 & 0 & 0 & 0.22 & 600 & 0.15 & 0.04 & 0.10 & 0.10 & 0 & 0 & 0.80 & 0.00 & 0.41 & 90 & 77 & 750 & 938 & 44 & 910 & 44 & 693 \\
\hline $4 / 302002$ & 0.00 & 0 & 0 & 0.22 & 600 & 0.15 & 0.05 & 0.10 & 0.10 & 0 & 0 & 0.73 & 0.00 & 0.33 & 90 & 77 & 750 & 938 & 30 & 1205 & 30 & 741 \\
\hline 51112002 & 0.00 & 0 & 0 & 0.25 & 600 & 0.09 & 0.08 & 0.10 & 0.10 & 0 & 0 & 0.67 & 0.00 & 0.31 & 90 & 77 & 750 & 938 & 27 & 1183 & 27 & 736 \\
\hline 51212002 & 0.00 & 0 & 0 & 0.21 & 600 & 0.11 & 0.08 & 0.10 & 0.10 & 0 & 0 & 0.60 & 0.00 & 0.22 & 90 & 77 & 750 & 938 & 25 & 1240 & 25 & 944 \\
\hline $5 / 3 / 2002$ & 0.00 & 0 & 0 & 0.52 & 600 & 0.15 & 0.08 & 0.10 & 0.10 & 0 & 0 & 0.87 & 0.00 & 0.41 & 90 & 77 & 750 & 938 & 62 & 840 & 62 & 1097 \\
\hline $5 / 42002$ & 0.00 & 0 & 0 & 0.57 & 600 & 0.16 & 0.09 & 0.10 & 0.10 & 0 & 0 & 1.13 & 0.00 & 0.62 & 90 & 77 & 750 & 938 & 70 & 876 & 70 & 1123 \\
\hline $5 / 512002$ & 0.00 & 0 & 0 & 0.96 & 600 & 0.15 & 0.10 & 0.10 & 0.10 & 0 & 0 & 1.83 & 0.00 & 1.22 & 90 & 77 & 750 & 938 & 69 & 921 & 69 & 1201 \\
\hline $5 / 612002$ & 0.00 & 0 & 0 & 0.96 & 600 & 0.19 & 0.11 & 0.10 & 0.10 & 0 & 0 & 2.53 & 0.00 & 1.78 & 90 & 77 & 782 & 977 & 64 & 979 & 64 & 1325 \\
\hline 51712002 & 0.00 & 0 & 0 & 0.62 & 600 & 0.19 & 0.09 & 0.10 & 0.10 & 0 & 0 & 2.80 & 0.00 & 2.02 & 90 & 77 & 829 & 1036 & 60 & 1076 & 60 & 1476 \\
\hline 51812002 & 0.00 & 0 & 0 & 0.07 & 600 & 0.16 & 0.11 & 0.10 & 0.10 & 0 & 0 & 2.43 & 0.00 & 1.72 & 90 & 77 & 972 & 1215 & 63 & 1120 & 63 & 1499 \\
\hline 5/9/2002 & 0.00 & 0 & 0 & 0.05 & 600 & 0.17 & 0.11 & 0.10 & 0.10 & 0 & 0 & 2.07 & 0.00 & 1.40 & 90 & 77 & 1205 & 1506 & 60 & 1238 & 60 & 1626 \\
\hline 510102002 & 0.00 & 0 & 0 & 0.06 & 600 & 0.16 & 0.10 & 0.10 & 0.10 & 0 & 0 & 1.70 & 0.00 & 1.10 & 90 & 77 & 1555 & 1943 & 45 & 1380 & 45 & 1680 \\
\hline 51112002 & 0.00 & 0 & 0 & 0.05 & 600 & 0.15 & 0.10 & 0.10 & 0.10 & 0 & 0 & 1.33 & 0.00 & 0.79 & 90 & 77 & 750 & 938 & 44 & 1313 & 44 & 1747 \\
\hline 51212002 & 0.00 & 0 & 0 & 0.10 & 600 & 0.17 & 0.09 & 0.10 & 0.10 & 0 & 0 & 1.03 & 0.00 & 0.53 & 90 & 77 & 750 & 938 & 40 & 1334 & 40 & 1651 \\
\hline $5 / 132002$ & 0.00 & 0 & 0 & 0.10 & 600 & 0.22 & 0.11 & 0.10 & 0.10 & 0 & 0 & 0.73 & 0.00 & 0.20 & 90 & 77 & 750 & 938 & 37 & 1388 & 37 & 1431 \\
\hline $5 / 1412002$ & 0.00 & 0 & 0 & 0.18 & 600 & 0.20 & 0.11 & 0.10 & 0.10 & 0 & 0 & 0.43 & 0.00 & 0.00 & 90 & 77 & 0 & 0 & 33 & 1412 & 33 & 1343 \\
\hline $5 / 1512002$ & 0.00 & 0 & 0 & 0.11 & 600 & 0.21 & 0.11 & 0.10 & 0.10 & 0 & 0 & 0.13 & 0.00 & 0.00 & 90 & 77 & 0 & 0 & 31 & 1390 & 31 & 1573 \\
\hline 511612002 & 0.00 & 0 & 0 & 0.00 & 600 & 0.00 & 0.00 & 0.00 & 0.00 & 0 & 0 & 0.00 & 0.00 & 0.00 & 0 & 0 & 0 & 0 & 34 & 1351 & 34 & 943 \\
\hline $5 / 17 / 2002$ & 0.00 & 0 & 0 & 0.00 & 600 & 0.00 & 0.00 & 0.00 & 0.00 & 0 & 0 & 0.00 & 0.00 & 0.00 & 0 & 0 & 0 & 0 & 42 & 1226 & 42 & 673 \\
\hline $5 / 1812002$ & 0.00 & 0 & 0 & 0.00 & 600 & 0.00 & 0.00 & 0.00 & 0.00 & 0 & 0 & 0.00 & 0.00 & 0.00 & 0 & 0 & 0 & 0 & 27 & 1141 & 27 & 801 \\
\hline 5/19/2002 & 0.00 & 0 & 0 & 0.00 & 600 & 0.00 & 0.00 & 0.00 & 0.00 & 0 & 0 & 0.00 & 0.00 & 0.00 & 0 & 0 & 0 & 0 & 13 & 1285 & 13 & 1314 \\
\hline $5 / 2012002$ & 0.00 & 0 & 0 & 0.00 & 600 & 0.00 & 0.00 & 0.00 & 0.00 & 0 & 0 & 0.00 & 0.00 & 0.00 & 0 & 0 & 0 & 0 & 12 & 1583 & 12 & 1938 \\
\hline $5 / 2112002$ & 0.00 & 0 & 0 & 0.00 & 600 & 0.00 & 0.00 & 0.00 & 0.00 & 0 & 0 & 0.00 & 0.00 & 0.00 & 0 & 0 & 0 & 0 & 11 & 1555 & 11 & 1776 \\
\hline 512212002 & 0.00 & 0 & 0 & 0.00 & 600 & 0.00 & 0.00 & 0.00 & 0.00 & 0 & 0 & 0.00 & 0.00 & 0.00 & 0 & 0 & 0 & 0 & 8 & 1619 & 8 & 1781 \\
\hline 512312002 & 0.00 & 0 & 0 & 0.00 & 600 & 0.00 & 0.00 & 0.00 & 0.00 & 0 & 0 & 0.00 & 0.00 & 0.00 & 0 & 0 & 0 & 0 & 8 & 1656 & 8 & 1752 \\
\hline $5 / 242002$ & 0.00 & 0 & 0 & 0.00 & 600 & 0.00 & 0.00 & 0.00 & 0.00 & 0 & 0 & 0.00 & 0.00 & 0.00 & 0 & 0 & 0 & 0 & $g$ & 1433 & 9 & 1612 \\
\hline $5 / 2512002$ & 0.00 & 0 & 0 & 0.00 & 600 & 0.00 & 0.00 & 0.00 & 0.00 & 0 & 0 & 0.00 & 0.00 & 0.00 & 0 & 0 & 0 & 0 & 16 & 1206 & 16 & 1177 \\
\hline $5 / 2612002$ & 0.00 & 0 & 0 & 0.00 & 600 & 0.00 & 0.00 & 0.00 & 0.00 & 0 & 0 & 0.00 & 0.00 & 0.00 & 0 & 0 & 0 & 0 & 21 & 1086 & 21 & 1010 \\
\hline $5 / 27 / 2002$ & 0.00 & 0 & 0 & 0.00 & 600 & 0.00 & 0.00 & 0.00 & 0.00 & 0 & 0 & 0.00 & 0.00 & 0.00 & 0 & 0 & 0 & 0 & 26 & 979 & 26 & 1025 \\
\hline $5 / 2812002$ & 0.00 & 0 & 0 & 0.00 & 600 & 0.00 & 0.00 & 0.00 & 0.00 & 0 & 0 & 0.00 & 0.00 & 0.00 & 0 & 0 & 0 & 0 & 24 & 994 & 24 & 1326 \\
\hline $5 / 2912002$ & 0.00 & 0 & 0 & 0.00 & 600 & 0.00 & 0.00 & 0.00 & 0.00 & 0 & 0 & 0.00 & 0.00 & 0.00 & 0 & 0 & 0 & 0 & 35 & 1140 & 35 & 1464 \\
\hline
\end{tabular}


Note: Traditional drawdown (Type 3, normal year) selected for entire model run shown.

\begin{tabular}{|c|c|c|c|c|c|c|c|c|c|c|c|c|c|c|c|c|c|c|c|c|c|c|}
\hline Time-Step & & \multicolumn{6}{|c|}{ OUT } & \multicolumn{3}{|c|}{ Management } & \multicolumn{4}{|c|}{ MODEL OUTPUT } & \multicolumn{4}{|c|}{ NGWD COMPOSTIE DATA } \\
\hline Date & \begin{tabular}{|c} 
Precip \\
inches
\end{tabular} & $\begin{array}{l}\text { GW } \\
\text { inches }\end{array}$ & $\begin{array}{c}E C(g w) \\
u S C(c m\end{array}$ & $\begin{array}{c}\text { Op. Inflow } \\
\text { inches }\end{array}$ & $\begin{array}{l}\mathrm{EC}(\mathrm{ii}) \\
\mathrm{uS} / \mathrm{cm}\end{array}$ & $\begin{array}{c}\text { Evap. loper } \\
\text { water) } \\
\text { inches }\end{array}$ & $\begin{array}{c}\text { ET } \\
\text { (veg, areas) } \\
\text { inches }\end{array}$ & $\begin{array}{c}\text { Op Spill } \\
\text { inches }\end{array}$ & $\begin{array}{c}\text { Outflow } \\
\text { inches }\end{array}$ & $\begin{array}{l}\text { GW } \\
\text { inches }\end{array}$ & $\begin{array}{c}E C(g W) \\
\text { uS } / \mathrm{cm}\end{array}$ & $\begin{array}{l}\text { Depth } \\
\text { (hab) } \\
\text { inches } \\
\end{array}$ & $\begin{array}{l}\text { Depth } \\
\text { (CC) }\end{array}$ & $\begin{array}{l}\text { End of } \\
\text { Day } \\
\text { inches }\end{array}$ & $\begin{array}{l}\text { Flow } \\
(\mathrm{cts})\end{array}$ & $\begin{array}{l}\text { Adj. } \\
\text { Flow } \\
(d s)\end{array}$ & $\begin{array}{l}\text { EC } \\
\text { USicm }\end{array}$ & $\begin{array}{c}\text { Adj, EC } \\
\text { US } / \mathrm{cm}\end{array}$ & $\begin{array}{l}\text { GWDP } \\
Q\left(d f^{\prime}\right)\end{array}$ & $\begin{array}{l}\text { ersonnel } \\
E C(\omega \mathrm{s}(\mathrm{cm})\end{array}$ & $\begin{array}{c}\text { Real|Tin } \\
Q\left(d f^{\prime}\right)\end{array}$ & $\begin{array}{l}\text { e Network } \\
\text { EC (uS } \mathrm{s}(\mathrm{m}))\end{array}$ \\
\hline $5 / 3012002$ & 0.00 & 0 & 0 & 0.00 & 600 & 0.00 & 0.00 & 0.00 & 0.00 & 0 & 0 & 0.00 & 0.00 & 0.00 & 0 & 0 & 0 & 0 & 27 & 1187 & 27 & 1474 \\
\hline $5 / 3112002$ & 0.00 & 0 & 0 & 0.00 & 600 & 0.00 & 0.00 & 0.00 & 0.00 & 0 & 0 & 0.00 & 0.00 & 0.00 & 0 & 0 & 0 & 0 & 21 & 1238 & 21 & 1337 \\
\hline 6/112002 & 0.00 & 0 & 0 & 0.00 & 600 & 0.00 & 0.00 & 0.00 & 0.00 & 0 & 0 & 0.00 & 0.00 & 0.00 & 0 & 0 & 0 & 0 & 159 & 1459 & 159 & 1789 \\
\hline 61212002 & 0.00 & 0 & 0 & 0.00 & 600 & 0.00 & 0.00 & 0.00 & 0.00 & 0 & 0 & 0.00 & 0.00 & 0.00 & 0 & 0 & 0 & 0 & 141 & 1554 & 141 & 1729 \\
\hline 6/3/2002 & 0.00 & 0 & 0 & 0.92 & 600 & 0.19 & 0.12 & 0.10 & 0.10 & 0 & 0 & 1.07 & 0.00 & 0.51 & 90 & 77 & 750 & 938 & 134 & 1629 & 134 & 1563 \\
\hline 61412002 & 0.00 & 0 & 0 & 1.33 & 600 & 0.15 & 0.13 & 0.10 & 0.10 & 0 & 0 & 2.13 & 0.00 & 1.44 & 90 & 77 & 750 & 938 & 133 & 1683 & 133 & 1190 \\
\hline 61512002 & 0.00 & 0 & 0 & 1.31 & 600 & 0.26 & 0.14 & 0.10 & 0.10 & 0 & 0 & 3.20 & 0.00 & 2.25 & 90 & 77 & 785 & 981 & 124 & 1540 & 124 & 1582 \\
\hline 66612002 & 0.00 & 0 & 0 & 1.42 & 600 & 0.26 & 0.15 & 0.10 & 0.10 & 0 & 0 & 4.27 & 0.00 & 3.15 & 90 & 77 & 799 & 999 & 130 & 1626 & 130 & 1583 \\
\hline 67712002 & 0.00 & 0 & 0 & 0.62 & 600 & 0.25 & 0.14 & 0.10 & 0.10 & 0 & 0 & 4.40 & 0.00 & 3.29 & 90 & 77 & 854 & 1067 & 123 & 1761 & 123 & 1719 \\
\hline 61812002 & 0.00 & 0 & 0 & 0.00 & 600 & 0.24 & 0.17 & 0.10 & 0.18 & 0 & 0 & 3.73 & 0.00 & 2.70 & 164 & 139 & 1018 & 1272 & 109 & 1963 & 109 & 1635 \\
\hline 619:2002 & 0.00 & 0 & 0 & 0.00 & 600 & 0.20 & 0.16 & 0.10 & 0.17 & 0 & 0 & 3.07 & 0.00 & 2.16 & 149 & 127 & 1247 & 1559 & 114 & 1658 & 114 & 1630 \\
\hline $6 / 1012002$ & 0.00 & 0 & 0 & 0.00 & 600 & 0.20 & 0.13 & 0.10 & 0.20 & 0 & 0 & 2.40 & 0.00 & 1.63 & 183 & 155 & 1620 & 2024 & 110 & 1668 & 110 & 1603 \\
\hline $6 / 1112002$ & 0.00 & 0 & 0 & 0.00 & 600 & 0.23 & 0.13 & 0.10 & 0.24 & 0 & 0 & 1.73 & 0.00 & 1.03 & 218 & 185 & 2975 & 3719 & 107 & 1631 & 107 & 1553 \\
\hline 611212002 & 0.00 & 0 & 0 & 0.00 & 600 & 0.23 & 0.13 & 0.10 & 0.21 & 0 & 0 & 1.07 & 0.00 & 0.45 & 192 & 163 & 750 & 938 & 89 & 1876 & 89 & 1523 \\
\hline $6 / 1312002$ & 0.00 & 0 & 0 & 0.23 & 600 & 0.24 & 0.12 & 0.10 & 0.10 & 0 & 0 & 0.80 & 0.00 & 0.23 & 90 & 77 & 750 & 938 & 68 & 1979 & 68 & 1585 \\
\hline $6 / 1412002$ & 0.00 & 0 & 0 & 0.23 & 600 & 0.21 & 0.12 & 0.10 & 0.10 & 0 & 0 & 0.53 & 0.00 & 0.03 & 90 & 77 & 750 & 938 & 68 & 2182 & 68 & 1561 \\
\hline $6 / 1512002$ & 0.00 & 0 & 0 & 0.20 & 600 & 0.19 & 0.12 & 0.10 & 0.10 & 0 & 0 & 0.27 & 0.00 & 0.00 & 90 & 77 & 0 & 0 & 57 & 2115 & 57 & 1675 \\
\hline $6 / 1612002$ & 0.00 & 0 & 0 & 0.00 & 600 & 0.00 & 0.00 & 0.00 & 0.00 & 0 & 0 & 0.00 & 0.00 & 0.00 & 0 & 0 & 0 & 0 & 57 & 2115 & 57 & 1809 \\
\hline $6 / 17 / 2002$ & 0.00 & 0 & 0 & 0.00 & 600 & 0.00 & 0.00 & 0.00 & 0.00 & 0 & 0 & 0.00 & 0.00 & 0.00 & 0 & 0 & 0 & 0 & 56 & 2109 & 56 & 1934 \\
\hline $6 / 18 / 2002$ & 0.00 & 0 & 0 & 0.00 & 600 & 0.00 & 0.00 & 0.00 & 0.00 & 0 & 0 & 0.00 & 0.00 & 0.00 & 0 & 0 & 0 & 0 & 71 & 2146 & 71 & 1962 \\
\hline $6 / 19 / 2002$ & 0.00 & 0 & 0 & 0.00 & 600 & 0.00 & 0.00 & 0.00 & 0.00 & 0 & 0 & 0.00 & 0.00 & 0.00 & 0 & 0 & 0 & 0 & 68 & 2151 & 68 & 1868 \\
\hline 612012002 & 0.00 & 0 & 0 & 0.00 & 600 & 0.00 & 0.00 & 0.00 & 0.00 & 0 & 0 & 0.00 & 0.00 & 0.00 & 0 & 0 & 0 & 0 & 67 & 2149 & 67 & 1933 \\
\hline 612112002 & 0.00 & 0 & 0 & 0.00 & 600 & 0.00 & 0.00 & 0.00 & 0.00 & 0 & 0 & 0.00 & 0.00 & 0.00 & 0 & 0 & 0 & 0 & 60 & 2158 & 60 & 1779 \\
\hline 612212002 & 0.00 & 0 & 0 & 0.00 & 600 & 0.00 & 0.00 & 0.00 & 0.00 & 0 & 0 & 0.00 & 0.00 & 0.00 & 0 & 0 & 0 & 0 & 60 & 2108 & 60 & 1769 \\
\hline $6 / 23 / 2002$ & 0.00 & 0 & 0 & 0.00 & 600 & 0.00 & 0.00 & 0.00 & 0.00 & 0 & 0 & 0.00 & 0.00 & 0.00 & 0 & 0 & 0 & 0 & 57 & 2082 & 57 & 1558 \\
\hline 612412002 & 0.00 & 0 & 0 & 0.00 & 600 & 0.00 & 0.00 & 0.00 & 0.00 & 0 & 0 & 0.00 & 0.00 & 0.00 & 0 & 0 & 0 & 0 & 50 & 1991 & 50 & 1488 \\
\hline 6125$] 2002$ & 0.00 & 0 & 0 & 0.00 & 600 & 0.00 & 0.00 & 0.00 & 0.00 & 0 & 0 & 0.00 & 0.00 & 0.00 & 0 & 0 & 0 & 0 & 45 & 1973 & 45 & 1509 \\
\hline $6 / 2612002$ & 0.00 & 0 & 0 & 0.00 & 600 & 0.00 & 0.00 & 0.00 & 0.00 & 0 & 0 & 0.00 & 0.00 & 0.00 & 0 & 0 & 0 & 0 & 34 & 1996 & 34 & 1587 \\
\hline 612712002 & 0.00 & 0 & 0 & 0.00 & 600 & 0.00 & 0.00 & 0.00 & 0.00 & 0 & 0 & 0.00 & 0.00 & 0.00 & 0 & 0 & 0 & 0 & 34 & 1943 & 34 & 1528 \\
\hline 612812002 & 0.00 & 0 & 0 & 0.00 & 600 & 0.00 & 0.00 & 0.00 & 0.00 & 0 & 0 & 0.00 & 0.00 & 0.00 & 0 & 0 & 0 & 0 & 30 & 1900 & 30 & 1562 \\
\hline $6 / 29 / 2002$ & 0.00 & 0 & 0 & 0.00 & 600 & 0.00 & 0.00 & 0.00 & 0.00 & 0 & 0 & 0.00 & 0.00 & 0.00 & 0 & 0 & 0 & 0 & 28 & 1861 & 28 & 1537 \\
\hline 613012002 & 0.00 & 0 & 0 & 0.00 & 600 & 0.00 & 0.00 & 0.00 & 0.00 & 0 & 0 & 0.00 & 0.00 & 0.00 & 0 & 0 & 0 & 0 & 28 & 1832 & 28 & 1566 \\
\hline 71112002 & 0.00 & 0 & 0 & 0.00 & 600 & 0.00 & 0.00 & 0.00 & 0.00 & 0 & 0 & 0.00 & 0.00 & 0.00 & 0 & 0 & 0 & 0 & 17 & 1485 & 17 & 1111 \\
\hline 71212002 & 0.00 & 0 & 0 & 0.00 & 600 & 0.00 & 0.00 & 0.00 & 0.00 & 0 & 0 & 0.00 & 0.00 & 0.00 & 0 & 0 & 0 & 0 & 13 & 1173 & 13 & 1104 \\
\hline $7 / 3 / 2002$ & 0.00 & 0 & 0 & 0.00 & 600 & 0.00 & 0.00 & 0.00 & 0.00 & 0 & 0 & 0.00 & 0.00 & 0.00 & 0 & 0 & 0 & 0 & 18 & 1183 & 18 & 1294 \\
\hline 71412002 & 0.00 & 0 & 0 & 0.00 & 600 & 0.00 & 0.00 & 0.00 & 0.00 & 0 & 0 & 0.00 & 0.00 & 0.00 & 0 & 0 & 0 & 0 & 18 & 1233 & 18 & 1276 \\
\hline 71512002 & 0.00 & 0 & 0 & 0.00 & 600 & 0.00 & 0.00 & 0.00 & 0.00 & 0 & 0 & 0.00 & 0.00 & 0.00 & 0 & 0 & 0 & 0 & 14 & 1275 & 14 & 1309 \\
\hline 71612002 & 0.00 & 0 & 0 & 0.00 & 600 & 0.00 & 0.00 & 0.00 & 0.00 & 0 & 0 & 0.00 & 0.00 & 0.00 & 0 & 0 & 0 & 0 & 12 & 1217 & 12 & 1231 \\
\hline 77712002 & 0.00 & 0 & 0 & 0.00 & 600 & 0.00 & 0.00 & 0.00 & 0.00 & 0 & 0 & 0.00 & 0.00 & 0.00 & 0 & 0 & 0 & 0 & 16 & 1094 & 16 & 1231 \\
\hline 71812002 & 0.00 & 0 & 0 & 0.00 & 600 & 0.00 & 0.00 & 0.00 & 0.00 & 0 & 0 & 0.00 & 0.00 & 0.00 & 0 & 0 & 0 & 0 & 12 & 1058 & 12 & 1259 \\
\hline 71912002 & 0.00 & 0 & 0 & 0.00 & 600 & 0.00 & 0.00 & 0.00 & 0.00 & 0 & 0 & 0.00 & 0.00 & 0.00 & 0 & 0 & 0 & 0 & 12 & 1008 & 12 & 1330 \\
\hline $7 / 1012002$ & 0.00 & 0 & 0 & 0.00 & 600 & 0.00 & 0.00 & 0.00 & 0.00 & 0 & 0 & 0.00 & 0.00 & 0.00 & 0 & 0 & 0 & 0 & 12 & 1050 & 12 & 1113 \\
\hline $7 / 11112002$ & 0.00 & 0 & 0 & 0.00 & 600 & 0.00 & 0.00 & 0.00 & 0.00 & 0 & 0 & 0.00 & 0.00 & 0.00 & 0 & 0 & 0 & 0 & 13 & 1215 & 13 & 1051 \\
\hline 711122002 & 0.00 & 0 & 0 & 0.00 & 600 & 0.00 & 0.00 & 0.00 & 0.00 & 0 & 0 & 0.00 & 0.00 & 0.00 & 0 & 0 & 0 & 0 & 12 & 1233 & 12 & 1227 \\
\hline $7 / 1132002$ & 0.00 & 0 & 0 & 0.14 & 600 & 0.20 & 0.15 & 0.10 & 0.10 & 0 & 0 & 0.17 & 0.00 & 0.00 & 90 & 77 & 0 & 0 & 10 & 1170 & 10 & 1173 \\
\hline $7 / 1412002$ & 0.00 & 0 & 0 & 0.29 & 600 & 0.22 & 0.15 & 0.10 & 0.10 & 0 & 0 & 0.33 & 0.00 & 0.00 & 90 & 77 & 0 & 0 & 10 & 1170 & 10 & 1244 \\
\hline $7 / 1512002$ & 0.00 & 0 & 0 & 0.43 & 600 & 0.26 & 0.14 & 0.10 & 0.10 & 0 & 0 & 0.50 & 0.00 & 0.00 & 90 & 77 & 0 & 0 & 8 & 1194 & 8 & 1334 \\
\hline $7 / 1612002$ & 0.00 & 0 & 0 & 0.57 & 600 & 0.23 & 0.14 & 0.10 & 0.10 & 0 & 0 & 0.67 & 0.00 & 0.10 & 90 & 77 & 750 & 938 & 10 & 1190 & 10 & 1239 \\
\hline $7 / 117 / 2002$ & 0.00 & 0 & 0 & 0.61 & 600 & 0.22 & 0.14 & 0.10 & 0.10 & 0 & 0 & 0.83 & 0.00 & 0.25 & 90 & 77 & 750 & 938 & 12 & 1117 & 12 & 1113 \\
\hline
\end{tabular}


Note: Traditional drawdown (Type 3, normal year) selected for entire model run shown.

\begin{tabular}{|c|c|c|c|c|c|c|c|c|c|c|c|c|c|c|c|c|c|c|c|c|c|c|}
\hline Time-Step & \multicolumn{5}{|c|}{$\mathbb{N}$} & \multicolumn{6}{|c|}{ OUT } & \multicolumn{3}{|c|}{ Management } & \multicolumn{4}{|c|}{ MODEL OUTPUT } & \multicolumn{4}{|c|}{ NGWD COMPOSTED DATA } \\
\hline Date & $\begin{array}{l}\text { Precip } \\
\text { inches }\end{array}$ & $\begin{array}{l}\text { GW } \\
\text { inches }\end{array}$ & $\begin{array}{c}E C(g \mathrm{gl}) \\
\mathrm{uS}(\mathrm{cm})\end{array}$ & $\begin{array}{l}\text { Op. Intlow } \\
\text { inches }\end{array}$ & $\begin{array}{l}\text { EC(if) } \\
\text { uSCm }\end{array}$ & $\begin{array}{c}\text { Evap. lopen } \\
\text { water) } \\
\text { inches }\end{array}$ & $\begin{array}{c}\text { ET } \\
\text { (veg, areas) } \\
\text { inches }\end{array}$ & $\begin{array}{c}\text { Op Spill } \\
\text { inches }\end{array}$ & $\begin{array}{c}\text { Outflow } \\
\text { inches }\end{array}$ & & $\begin{array}{c}E C(g W) \\
\text { uS }(\mathrm{cm}\end{array}$ & $\begin{array}{l}\text { Depth } \\
\text { (hab) } \\
\text { inches }\end{array}$ & $\begin{array}{l}\text { Depth } \\
\text { (CC) }\end{array}$ & $\begin{array}{l}\text { End of } \\
\text { Day } \\
\text { inches }\end{array}$ & $\begin{array}{l}\text { Flow } \\
\text { (dss) }\end{array}$ & $\begin{array}{l}\text { Adj. } \\
\text { Flow } \\
\text { (cts) }\end{array}$ & $\begin{array}{l}\text { EC } \\
\text { USCm }\end{array}$ & $\begin{array}{c}\text { Adj, EC } \\
\text { uS } / \mathrm{cm}\end{array}$ & $\begin{array}{l}\text { GWDP } \\
Q(d s)\end{array}$ & $\begin{array}{l}\text { ersonnel } \\
E C(\text { (uS } \mathrm{cm})\end{array}$ & \begin{tabular}{|c} 
Real|Tin \\
$Q($ cts $)$
\end{tabular} & $\begin{array}{l}\text { e Network } \\
\text { EC (LSS } \mathrm{cm})\end{array}$ \\
\hline $7 / 11812002$ & 0.00 & 0 & 0 & 0.61 & 600 & 0.23 & 0.14 & 0.10 & 0.10 & 0 & 0 & 1.00 & 0.00 & 0.38 & 90 & 77 & 750 & 938 & 13 & 1119 & 13 & 1030 \\
\hline 7/19/2002 & 0.00 & 0 & 0 & 0.62 & 600 & 0.23 & 0.13 & 0.10 & 0.10 & 0 & 0 & 1.17 & 0.00 & 0.54 & 90 & 77 & 750 & 938 & 15 & 1030 & 15 & 893 \\
\hline 712012002 & 0.00 & 0 & 0 & 0.61 & 600 & 0.23 & 0.14 & 0.10 & 0.10 & 0 & 0 & 1.33 & 0.00 & 0.67 & 90 & 77 & 750 & 938 & 15 & 1057 & 15 & 980 \\
\hline 712112002 & 0.00 & 0 & 0 & 0.62 & 600 & 0.23 & 0.14 & 0.10 & 0.10 & 0 & 0 & 1.50 & 0.00 & 0.82 & 90 & 77 & 750 & 938 & 12 & 1096 & 12 & 1000 \\
\hline 712222002 & 0.00 & 0 & 0 & 0.61 & 600 & 0.23 & 0.13 & 0.10 & 0.10 & 0 & 0 & 1.67 & 0.00 & 0.97 & 90 & 77 & 750 & 938 & 11 & 1109 & 11 & 966 \\
\hline 712312002 & 0.00 & 0 & 0 & 0.01 & 600 & 0.30 & 0.13 & 0.10 & 0.10 & 0 & 0 & 1.83 & 0.00 & 1.04 & 90 & 77 & 750 & 938 & $g$ & 1144 & $g$ & 1042 \\
\hline 712412002 & 0.00 & 0 & 0 & 0.68 & 600 & 0.19 & 0.13 & 0.10 & 0.10 & 0 & 0 & 2.00 & 0.00 & 1.30 & 90 & 77 & 750 & 938 & 8 & 1138 & 8 & 1122 \\
\hline 712512002 & 0.00 & 0 & 0 & 0.27 & 600 & 0.21 & 0.14 & 0.10 & 0.10 & 0 & 0 & 1.83 & 0.00 & 1.12 & 90 & 77 & 985 & 1231 & 7 & 1129 & 7 & 1300 \\
\hline 712612002 & 0.00 & 0 & 0 & 0.31 & 600 & 0.21 & 0.14 & 0.10 & 0.10 & 0 & 0 & 1.67 & 0.00 & 0.98 & 90 & 77 & 750 & 938 & 7 & 1200 & 7 & 1508 \\
\hline 712712002 & 0.00 & 0 & 0 & 0.31 & 600 & 0.21 & 0.15 & 0.10 & 0.10 & 0 & 0 & 1.50 & 0.00 & 0.83 & 90 & 77 & 750 & 938 & 7 & 1236 & 7 & 1398 \\
\hline 712812002 & 0.00 & 0 & 0 & 0.31 & 600 & 0.19 & 0.13 & 0.10 & 0.10 & 0 & 0 & 1.33 & 0.00 & 0.72 & 90 & 77 & 750 & 938 & 6 & 1233 & 6 & 1335 \\
\hline 712912002 & 0.00 & 0 & 0 & 0.28 & 600 & 0.18 & 0.12 & 0.10 & 0.10 & 0 & 0 & 1.17 & 0.00 & 0.60 & 90 & 77 & 750 & 938 & 6 & 1233 & 6 & 1352 \\
\hline 7/3012002 & 0.00 & 0 & 0 & 0.26 & 600 & 0.16 & 0.13 & 0.10 & 0.10 & 0 & 0 & 1.00 & 0.00 & 0.47 & 90 & 77 & 750 & 938 & 6 & 1233 & 6 & 1394 \\
\hline $7 / 312002$ & 0.00 & 0 & 0 & 0.24 & 600 & 0.20 & 0.14 & 0.10 & 0.10 & 0 & 0 & 0.83 & 0.00 & 0.28 & 90 & 77 & 750 & 938 & 4 & 1350 & 4 & 1603 \\
\hline 81112002 & 0.00 & 0 & 0 & 0.29 & 600 & 0.19 & 0.13 & 0.10 & 0.10 & 0 & 0 & 0.67 & 0.00 & 0.15 & 90 & 77 & 750 & 938 & 5 & 1000 & 5 & 1614 \\
\hline 8122002 & 0.00 & 0 & 0 & 0.28 & 600 & 0.21 & 0.13 & 0.10 & 0.10 & 0 & 0 & 0.50 & 0.00 & 0.00 & 90 & 77 & 0 & 0 & 3 & 1000 & 3 & 1626 \\
\hline $8 / 32002$ & 0.00 & 0 & 0 & 0.29 & 600 & 0.23 & 0.13 & 0.10 & 0.10 & 0 & 0 & 0.33 & 0.00 & 0.00 & 90 & 77 & 0 & 0 & 2 & 900 & 2 & 1637 \\
\hline $8 / 42002$ & 0.00 & 0 & 0 & 0.14 & 600 & 0.18 & 0.12 & 0.10 & 0.10 & 0 & 0 & 0.17 & 0.00 & 0.00 & 90 & 77 & 0 & 0 & 2 & 900 & 2 & 1649 \\
\hline $8 / 512002$ & 0.00 & 0 & 0 & 0.00 & 600 & 0.00 & 0.00 & 0.00 & 0.00 & 0 & 0 & 0.00 & 0.00 & 0.00 & 0 & 0 & 0 & 0 & 2 & 900 & 2 & 1600 \\
\hline $8 / 612002$ & 0.00 & 0 & 0 & 0.00 & 600 & 0.00 & 0.00 & 0.00 & 0.00 & 0 & 0 & 0.00 & 0.00 & 0.00 & 0 & 0 & 0 & 0 & 2 & 900 & 2 & 1672 \\
\hline 87712002 & 0.00 & 0 & 0 & 0.00 & 600 & 0.00 & 0.00 & 0.00 & 0.00 & 0 & 0 & 0.00 & 0.00 & 0.00 & 0 & 0 & 0 & 0 & 2 & 900 & 2 & 1684 \\
\hline 81812002 & 0.00 & 0 & 0 & 0.00 & 600 & 0.00 & 0.00 & 0.00 & 0.00 & 0 & 0 & 0.00 & 0.00 & 0.00 & 0 & 0 & 0 & 0 & 2 & 900 & 2 & 1695 \\
\hline $8 / 912002$ & 0.00 & 0 & 0 & 0.00 & 600 & 0.00 & 0.00 & 0.00 & 0.00 & 0 & 0 & 0.00 & 0.00 & 0.00 & 0 & 0 & 0 & 0 & 4 & 900 & 4 & 1707 \\
\hline 81102002 & 0.00 & 0 & 0 & 0.00 & 600 & 0.00 & 0.00 & 0.00 & 0.00 & 0 & 0 & 0.00 & 0.00 & 0.00 & 0 & 0 & 0 & 0 & 5 & 950 & 5 & 1718 \\
\hline $8 / 112002$ & 0.00 & 0 & 0 & 0.00 & 600 & 0.00 & 0.00 & 0.00 & 0.00 & 0 & 0 & 0.00 & 0.00 & 0.00 & 0 & 0 & 0 & 0 & 8 & 950 & 8 & 1730 \\
\hline 81122002 & 0.00 & 0 & 0 & 0.00 & 600 & 0.00 & 0.00 & 0.00 & 0.00 & 0 & 0 & 0.00 & 0.00 & 0.00 & 0 & 0 & 0 & 0 & 13 & 1000 & 13 & 1741 \\
\hline $8 / 132002$ & 0.00 & 0 & 0 & 0.00 & 600 & 0.00 & 0.00 & 0.00 & 0.00 & 0 & 0 & 0.00 & 0.00 & 0.00 & 0 & 0 & 0 & 0 & 19 & 1000 & 19 & 1753 \\
\hline $8 / 142002$ & 0.00 & 0 & 0 & 0.00 & 600 & 0.00 & 0.00 & 0.00 & 0.00 & 0 & 0 & 0.00 & 0.00 & 0.00 & 0 & 0 & 0 & 0 & 21 & 1000 & 21 & 1753 \\
\hline 811522002 & 0.00 & 0 & 0 & 0.00 & 600 & 0.00 & 0.00 & 0.00 & 0.00 & 0 & 0 & 0.00 & 0.00 & 0.00 & 0 & 0 & 0 & 0 & 17 & 1000 & 17 & 1716 \\
\hline 811612002 & 0.00 & 0 & 0 & 0.00 & 600 & 0.00 & 0.00 & 0.00 & 0.00 & 0 & 0 & 0.00 & 0.00 & 0.00 & 0 & 0 & 0 & 0 & $g$ & 1083 & 9 & 1597 \\
\hline $8177 / 2002$ & 0.00 & 0 & 0 & 0.00 & 600 & 0.00 & 0.00 & 0.00 & 0.00 & 0 & 0 & 0.00 & 0.00 & 0.00 & 0 & 0 & 0 & 0 & 8 & 1081 & 8 & 1554 \\
\hline 811812002 & 0.00 & 0 & 0 & 0.00 & 600 & 0.00 & 0.00 & 0.00 & 0.00 & 0 & 0 & 0.00 & 0.00 & 0.00 & 0 & 0 & 0 & 0 & 10 & 1100 & 10 & 1342 \\
\hline 8/19/2002 & 0.00 & 0 & 0 & 0.00 & 600 & 0.00 & 0.00 & 0.00 & 0.00 & 0 & 0 & 0.00 & 0.00 & 0.00 & 0 & 0 & 0 & 0 & 6 & 1233 & 6 & 1455 \\
\hline 812012002 & 0.00 & 0 & 0 & 0.00 & 600 & 0.00 & 0.00 & 0.00 & 0.00 & 0 & 0 & 0.00 & 0.00 & 0.00 & 0 & 0 & 0 & 0 & 7 & 1164 & 7 & 1446 \\
\hline 82112002 & 0.00 & 0 & 0 & 0.00 & 600 & 0.00 & 0.00 & 0.00 & 0.00 & 0 & 0 & 0.00 & 0.00 & 0.00 & 0 & 0 & 0 & 0 & 7 & 993 & 7 & 1413 \\
\hline 82222002 & 0.00 & 0 & 0 & 0.00 & 600 & 0.00 & 0.00 & 0.00 & 0.00 & 0 & 0 & 0.00 & 0.00 & 0.00 & 0 & 0 & 0 & 0 & 8 & 906 & 8 & 1390 \\
\hline 812312002 & 0.00 & 0 & 0 & 0.00 & 600 & 0.00 & 0.00 & 0.00 & 0.00 & 0 & 0 & 0.00 & 0.00 & 0.00 & 0 & 0 & 0 & 0 & 6 & 908 & 6 & 1338 \\
\hline 812412002 & 0.00 & 0 & 0 & 0.00 & 600 & 0.00 & 0.00 & 0.00 & 0.00 & 0 & 0 & 0.00 & 0.00 & 0.00 & 0 & 0 & 0 & 0 & 5 & 950 & 5 & 1293 \\
\hline 812512002 & 0.00 & 0 & 0 & 0.00 & 600 & 0.00 & 0.00 & 0.00 & 0.00 & 0 & 0 & 0.00 & 0.00 & 0.00 & 0 & 0 & 0 & 0 & 4 & 475 & 4 & 1120 \\
\hline 812612002 & 0.00 & 0 & 0 & 0.00 & 600 & 0.00 & 0.00 & 0.00 & 0.00 & 0 & 0 & 0.00 & 0.00 & 0.00 & 0 & 0 & 0 & 0 & 5 & 930 & 5 & 1142 \\
\hline $8127 / 2002$ & 0.00 & 0 & 0 & 0.00 & 600 & 0.00 & 0.00 & 0.00 & 0.00 & 0 & 0 & 0.00 & 0.00 & 0.00 & 0 & 0 & 0 & 0 & 8 & 925 & 8 & 1162 \\
\hline 812812002 & 0.00 & 0 & 0 & 0.00 & 600 & 0.00 & 0.00 & 0.00 & 0.00 & 0 & 0 & 0.00 & 0.00 & 0.00 & 0 & 0 & 0 & 0 & 8 & 881 & 8 & 1087 \\
\hline 8129/2002 & 0.00 & 0 & 0 & 0.00 & 600 & 0.00 & 0.00 & 0.00 & 0.00 & 0 & 0 & 0.00 & 0.00 & 0.00 & 0 & 0 & 0 & 0 & 10 & 885 & 10 & 1089 \\
\hline $8 / 302002$ & 0.00 & 0 & 0 & 0.00 & 600 & 0.00 & 0.00 & 0.00 & 0.00 & 0 & 0 & 0.00 & 0.00 & 0.00 & 0 & 0 & 0 & 0 & 12 & 883 & 12 & 1052 \\
\hline $8 / 312002$ & 0.00 & 0 & 0 & 0.00 & 500 & 0.00 & 0.00 & 0.00 & 0.00 & 0 & 0 & 0.00 & 0.00 & 0.00 & 0 & 0 & 0 & 0 & 13 & 881 & 13 & 1014 \\
\hline 91112002 & 0.00 & 0 & 0 & 0.00 & 500 & 0.00 & 0.00 & 0.00 & 0.00 & 0 & 0 & 0.00 & 0.00 & 0.00 & 0 & 0 & 0 & 0 & 12 & 767 & 12 & 1041 \\
\hline 9/222002 & 0.00 & 0 & 0 & 0.00 & 500 & 0.00 & 0.00 & 0.00 & 0.00 & 0 & 0 & 0.00 & 0.00 & 0.00 & 0 & 0 & 0 & 0 & 12 & 767 & 12 & 1009 \\
\hline 9/3/2002 & 0.00 & 0 & 0 & 0.00 & 500 & 0.00 & 0.00 & 0.00 & 0.00 & 0 & 0 & 0.00 & 0.00 & 0.00 & 0 & 0 & 0 & 0 & 14 & 764 & 14 & 982 \\
\hline 9412002 & 0.00 & 0 & 0 & 0.00 & 500 & 0.00 & 0.00 & 0.00 & 0.00 & 0 & 0 & 0.00 & 0.00 & 0.00 & 0 & 0 & 0 & 0 & 15 & 720 & 15 & 973 \\
\hline
\end{tabular}


Note: Traditional drawdown (Type 3, normal year) selected for entire model run shown.

\begin{tabular}{|c|c|c|c|c|c|c|c|c|c|c|c|c|c|c|c|c|c|c|c|c|c|c|}
\hline \multirow[b]{2}{*}{ te) } & \multirow[b]{2}{*}{$\begin{array}{l}\text { Prec } \\
\text { inche }\end{array}$} & \multirow[b]{2}{*}{$\begin{array}{cc}\text { cip } & \text { GW } \\
\text { es } & \text { inches }\end{array}$} & & \multicolumn{6}{|c|}{ OUT } & \multicolumn{3}{|c|}{ Management } & \multicolumn{4}{|c|}{ MODEL OUTPUT } & \multicolumn{4}{|c|}{ NGWD COMPOSITE DATA } \\
\hline & & & $\begin{array}{c}E C(g \mathrm{gl}) \\
\mathrm{uSC}(\mathrm{cm})\end{array}$ & $\begin{array}{c}\text { Op. Inflow } \\
\text { inches }\end{array}$ & $\begin{array}{l}\text { EC(if) } \\
\text { uSCm }\end{array}$ & $\begin{array}{c}\text { Evap. lopen } \\
\text { water) } \\
\text { inches }\end{array}$ & $\begin{array}{c}\text { ET } \\
\text { (veg, areas) } \\
\text { inches }\end{array}$ & $\begin{array}{c}\text { Op Spill } \\
\text { inches }\end{array}$ & $\begin{array}{c}\text { Outflow } \\
\text { inches }\end{array}$ & & $\begin{array}{c}E C(g W) \\
\text { uS }(\mathrm{cm})\end{array}$ & $\begin{array}{l}\text { Depth } \\
\text { (hab) } \\
\text { inches } \\
\end{array}$ & $\begin{array}{l}\text { Depth } \\
\text { (CC) }\end{array}$ & $\begin{array}{l}\text { End of } \\
\text { Day } \\
\text { inches }\end{array}$ & $\begin{array}{l}\text { Flow } \\
\text { (dss) }\end{array}$ & $\begin{array}{l}\mathrm{Adj}, \\
\text { Flow } \\
(\mathrm{cts})\end{array}$ & $\begin{array}{c}\text { EC } \\
\text { USCm }\end{array}$ & $\begin{array}{c}\text { Adj. EC } \\
\text { uSicm }\end{array}$ & $\begin{array}{l}\text { GWD } \\
Q(d s)\end{array}$ & $\begin{array}{l}\text { ersonnel } \\
\text { EC (uSS } \mathrm{cm})\end{array}$ & $Q$ & EC( (uSC)m \\
\hline 9/5/2002 & 0.00 & 0 & $\overline{0}$ & 0.00 & 500 & 0.00 & 0.00 & 0.00 & 0.00 & 0 & $\overline{0}$ & 0.00 & 0.00 & 0.00 & 0 & 0 & 0 & $\overline{0}$ & 17 & 718 & 17 & 939 \\
\hline 96/2002 & 0.00 & 0 & 0 & 0.00 & 500 & 0.00 & 0.00 & 0.00 & 0.00 & 0 & 0 & 0.00 & 0.00 & 0.00 & . & 0 & 0 & 0 & 10 & 717 & 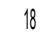 & 906 \\
\hline $97 / 2002$ & 0.00 & 0 & 0 & 0.00 & 500 & 0.00 & 0.00 & 0.00 & 0.00 & 0 & 0 & 0.00 & 0.00 & 0.00 & . & 0 & 0 & 0 & 10 & 716 & 10 & 873 \\
\hline $98 / 2002$ & 0.00 & 0 & 0 & 0.00 & 500 & 0.00 & 0.00 & 0.00 & 0.00 & 0 & 0 & 0.00 & 0.00 & 0.00 & 0 & 0 & 0 & 0 & 19 & 716 & 10 & 841 \\
\hline 9/9/2002 & 0.00 & 0 & 0 & 0.00 & 500 & 0.00 & 0.00 & 0.00 & 0.00 & 0 & 0 & 0.00 & 0.00 & 0.00 & 0 & 0 & 0 & 0 & 21 & 721 & 21 & 817 \\
\hline 9/1012002 & 0.00 & 0 & 0 & 0.00 & 500 & 0.00 & 0.00 & 0.00 & 0.00 & 0 & 0 & 0.00 & 0.00 & 0.00 & 0 & 0 & 0 & 0 & 22 & 727 & 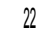 & 824 \\
\hline 9/1112002 & 0.00 & 0 & 0 & 0.00 & 500 & 0.00 & 0.00 & 0.00 & 0.00 & 0 & 0 & 0.00 & 0.00 & 0.00 & 0 & 0 & 0 & 0 & 22 & 727 & 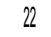 & 834 \\
\hline $9 / 122002$ & 0.00 & 0 & 0 & 0.00 & 500 & 0.00 & 0.00 & 0.00 & 0.00 & 0 & 0 & 0.00 & 0.00 & 0.00 & 0 & . & 0 & 0 & o & 730 & v & 837 \\
\hline 9/13/2002 & 0.00 & 0 & 0 & 0.00 & 500 & 0.00 & 0.00 & 0.00 & 0.00 & 0 & 0 & 0.00 & 0.00 & 0.00 & 0 & 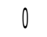 & 0 & . & 26 & 735 & 26 & 849 \\
\hline $9 / 1412002$ & 0.00 & 0 & 0 & 0.00 & 500 & 0.00 & 0.00 & 0.00 & 0.00 & 0 & 0 & 0.00 & 0.00 & 0.00 & 0 & 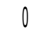 & 0 & 0 & 14 & 786 & 14 & 933 \\
\hline 9/15/2002 & 0.00 & 0 & 0 & 0.00 & 500 & 0.00 & 0.00 & 0.00 & 0.00 & 0 & ? & 0.00 & 0.00 & 0.00 & 0 & . & 0 & 0 & 14 & 786 & 14 & 963 \\
\hline 9/16/2002 & 0.00 & 0 & 0 & 0.00 & 500 & 0.00 & 0.00 & 0.00 & 0.00 & 0 & 0 & 0.00 & 0.00 & 0.00 & 0 & 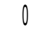 & 0 & 0 & 10 & 790 & 15 & 972 \\
\hline 9/17/2002 & 0.00 & 0 & 0 & 0.00 & 500 & 0.00 & 0.00 & 0.00 & 0.00 & 0 & 0 & 0.00 & 0.00 & 0.00 & 0 & 0 & 0 & 0 & 14 & 796 & 14 & 1000 \\
\hline 9/18/2002 & 0.00 & 0 & 0 & 0.00 & 500 & 0.00 & 0.00 & 0.00 & 0.00 & 0 & 0 & 0.00 & 0.00 & 0.00 & 0 & 0 & 0 & 0 & 15 & 800 & 15 & 1005 \\
\hline 9/19/2002 & 0.00 & 0 & 0 & 0.00 & 500 & 0.00 & 0.00 & 0.00 & 0.00 & 0 & 0 & 0.00 & 0.00 & 0.00 & 0 & 0 & 0 & $v$ & 15 & 800 & 10 & 988 \\
\hline $9 / 2012002$ & 0.00 & 0 & 0 & 0.00 & 500 & 0.00 & 0.00 & 0.00 & 0.00 & 0 & 0 & 0.00 & 0.00 & 0.00 & 0 & 0 & 0 & 0 & 11 & 806 & 17 & 983 \\
\hline 9/21/2002 & 0.00 & 0 & 0 & 0.36 & 500 & 0.17 & 0.10 & 0.10 & 0.10 & 0 & 0 & 0.36 & 0.36 & 0.00 & 90 & 77 & 0 & 0 & 18 & 808 & 10 & 875 \\
\hline $9 / 2212002$ & 0.00 & 0 & 0 & 0.71 & 500 & 0.17 & 0.10 & 0.10 & 0.10 & 0 & $v$ & 0.71 & 0.71 & 0.34 & yo & 77 & 625 & 781 & 18 & 808 & 18 & 1020 \\
\hline $9 / 23 / 2002$ & 0.00 & 0 & 0 & 0.73 & 500 & 0.17 & 0.09 & 0.10 & 0.10 & 0 & 0 & 1.07 & 1.07 & 0.71 & 9u & 77 & 625 & 78 & 18 & 700 & 10 & 1063 \\
\hline 9/2412002 & 0.00 & 0 & 0 & 0.72 & 500 & 0.15 & 0.09 & 0.10 & 0.10 & 0 & 0 & 1.42 & 1.42 & 1.08 & 90 & 11 & 625 & 78 & 10 & 700 & 10 & 1028 \\
\hline 9/25/2002 & 0.00 & 0 & 0 & 0.70 & 500 & 0.20 & 0.10 & 0.10 & 0.10 & 0 & 0 & 1.78 & 1.78 & 1.38 & 90 & 77 & 625 & (1) & Iv & 700 & 19 & 1020 \\
\hline 9/26/2002 & 0.00 & 0 & 0 & 0.76 & 500 & 0.19 & 0.09 & 0.10 & 0.1 & 0 & 0 & 2.13 & 2.13 & 1. & 90 & 11 & 665 & & 21 & 700 & 21 & 1037 \\
\hline 9/227/2002 & 0.00 & 0 & 0 & 0.74 & 500 & 0.15 & 0.06 & 0.10 & 0.10 & 0 & 0 & 2.49 & 2.49 & 2.1 & 90 & 77 & 671 & 87 & 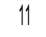 & 78. & 1 & 1039 \\
\hline $9 / 28 / 2002$ & 0.00 & 0 & 0 & 0.67 & 500 & 012 & $\mathrm{AMC}$ & 0.10 & 0.1 & 0 & 0 & 2.84 & 2.84 & 2.59 & 90 & 77 & 668 & & 10 & 725 & & 101 \\
\hline 9/29/2002 & 0.00 & 0 & 0 & 0.61 & 500 & 0.12 & n & 0.10 & 0.1 & 0 & 0 & 3.20 & 3.20 & 2.9 & 90 & 77 & 675 & & & 736 & & 077 \\
\hline 9/3012002 & 0.00 & 0 & 0 & 0.64 & 500 & 0.13 & 0.07 & 0.10 & 0.10 & 0 & 0 & 3.56 & 3.56 & 3.26 & 90 & 77 & 680 & 85 & 12 & 738 & 12 & 1080 \\
\hline 10112002 & 0.00 & 0 & 0 & 0.65 & 500 & 0.15 & 0.11 & 0.10 & 0.10 & 0 & 0 & 3.91 & 3.91 & 3.55 & 90 & 77 & 695 & 86 & 34 & 874 & 34 & 1396 \\
\hline 10222002 & 0.00 & 0 & 0 & 0.71 & 500 & 0.13 & 0.10 & 0.10 & 0.10 & 0 & 0 & 4.27 & 4.27 & 3.93 & 90 & 77 & 700 & 87 & 32 & 878 & 20 & 1326 \\
\hline 10/3/2002 & 0.00 & 0 & 0 & 0.69 & 500 & 0.12 & 0.07 & 0.10 & 0.10 & 0 & 0 & 4.62 & 4.62 & 4.33 & 90 & 77 & 700 & 875 & 31 & 877 & 21 & 1102 \\
\hline $10 / 42002$ & 0.00 & 0 & 0 & 0.65 & 500 & 0.13 & 0.07 & 0.10 & 0.10 & 0 & 0 & 4.98 & 4.98 & 4.68 & 90 & 77 & 701 & 877 & 33 & 873 & 23 & 1108 \\
\hline 101512002 & 0.00 & 0 & 0 & 0.65 & 500 & 0.14 & 0.07 & 0.10 & 0.10 & 0 & 0 & 5.33 & 5.33 & 5.02 & 90 & 77 & 704 & 880 & 37 & 862 & 27 & 1115 \\
\hline 101612002 & 0.00 & 0 & 0 & 0.67 & 500 & 0.14 & 0.07 & 0.10 & 0.10 & 0 & 0 & 5.69 & 5.69 & 5.38 & 90 & 77 & 706 & 883 & 41 & 865 & 28 & 1109 \\
\hline 107712002 & 0.00 & 0 & 0 & 0.67 & 500 & 0.12 & 0.07 & 0.10 & 0.10 & 0 & 0 & 6.04 & 6.04 & 5.75 & 90 & 77 & 706 & 88 & 42 & 861 & 30 & 1120 \\
\hline 101812002 & 0.00 & 0 & 0 & 0.65 & 500 & 0.14 & 0.07 & 0.10 & 0.10 & 0 & 0 & 6.40 & 6.40 & 6.09 & 90 & 77 & 708 & & 45 & 861 & 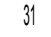 & 1141 \\
\hline 101992002 & 0.00 & 0 & 0 & 0.66 & 500 & 0.15 & 0.06 & 0.10 & 0.10 & 0 & 0 & 6.76 & 6.76 & 6.45 & 90 & 77 & 709 & & $\pi$ & & & 124 \\
\hline |/2002 & 0.00 & 0 & 0 & 0.66 & . & & 00 & 0.10 & 0.10 & 0 & & 7.11 & 7.11 & 6.80 & 90 & 77 & 710 & & 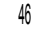 & 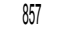 & & 149 \\
\hline & 0.00 & 0 & 0 & 0.67 & 50 & & 0.05 & 0.10 & 0.10 & 0 & & 717 & 7.47 & 7.20 & 90 & 77 & 708 & & 48 & & & 1160 \\
\hline 1212002 & 0.00 & 0 & 0 & 0.63 & 50 & 0.07 & 0.06 & 0.10 & 0.10 & 0 & 0 & 7.82 & 7.82 & 7.59 & 90 & 77 & 703 & 87 & 70 & 849 & vo & 1152 \\
\hline 132002 & 0.00 & 0 & 0 & 0.59 & 500 & 0.09 & 0.06 & 0.10 & 0.10 & 0 & 0 & 8.18 & 8.18 & 7.93 & 90 & 77 & 701 & 07 & 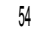 & 0 & 41 & 1090 \\
\hline 142002 & 0.00 & 0 & 0 & 0.60 & 500 & 0.09 & 0.05 & 0.10 & 0.10 & 0 & 0 & 8.53 & 8.53 & 8.29 & 90 & 77 & 699 & 87 & 56 & 841 & 45 & 1076 \\
\hline $15 / 2002$ & 0.00 & 0 & 0 & 0.60 & 500 & 0.10 & 0.06 & 0.10 & 0.10 & 0 & 0 & 8.89 & 8.89 & 8.63 & 90 & 77 & 698 & 873 & 58 & 838 & 48 & 1068 \\
\hline 1612002 & 0.00 & 0 & 0 & 0.62 & 500 & 0.10 & 0.05 & 0.10 & 0.10 & 0 & 0 & 9.24 & 9.24 & 8.99 & 90 & 77 & 696 & 87 & 70 & 854 & 60 & 1118 \\
\hline $17 / 2002$ & 0.00 & 0 & 0 & 0.61 & 500 & 0.07 & 0.05 & 0.10 & 0.10 & 0 & 0 & 9.60 & 9.60 & 9.38 & 90 & 77 & 692 & 865 & 82 & 840 & 10 & 1077 \\
\hline 18/2002 & 0.00 & 0 & 0 & 0.57 & 500 & 0.07 & 0.04 & 0.10 & 0.10 & 0 & 0 & 9.96 & 9.96 & 9.74 & 90 & 77 & 689 & 861 & 84 & 837 & 72 & 1071 \\
\hline $\mid 2002$ & 0.00 & 0 & 0 & 0.57 & 500 & 0.08 & 0.05 & 0.10 & 0.10 & 0 & 0 & 10.31 & 10.31 & 10.08 & 90 & 77 & 687 & 859 & 83 & 818 & 72 & 1056 \\
\hline 10120/2002 & 0.00 & 0 & 0 & 0.58 & 500 & 0.08 & 0.05 & 0.10 & 0.10 & 0 & 0 & 10.67 & 10.67 & 10.44 & 90 & 77 & 685 & 856 & 78 & 810 & 71 & 1043 \\
\hline 1012112002 & 0.00 & 0 & 0 & 0.23 & 750 & 0.08 & 0.05 & 0.10 & 0.10 & 0 & 0 & 10.67 & 10.67 & 10.43 & 90 & 77 & 695 & 869 & 74 & 805 & 70 & 1055 \\
\hline 1012212002 & 0.00 & 0 & 0 & 0.23 & 750 & 0.10 & 0.05 & 0.10 & 0.10 & 0 & 0 & 10.67 & 10.67 & 10.42 & 90 & 77 & 706 & 882 & 67 & 816 & 68 & 1066 \\
\hline 123/2002 & 0.00 & 0 & 0 & 0.24 & 750 & 0.07 & 0.04 & 0.10 & 0.10 & 0 & 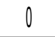 & 10.67 & 10.67 & 10.46 & 90 & 77 & 714 & 893 & 64 & 805 & 65 & 1072 \\
\hline
\end{tabular}


Note: Traditional drawdown (Type 3, normal year) selected for entire model run shown.

\begin{tabular}{|c|c|c|c|c|c|c|c|c|c|c|c|c|c|c|c|c|c|c|c|c|c|c|}
\hline Time-Step & \multicolumn{5}{|c|}{$\mathbb{N}$} & \multicolumn{6}{|c|}{ OUT } & \multicolumn{3}{|c|}{ Management } & \multicolumn{4}{|c|}{ MODEL OUTPUT } & \multicolumn{4}{|c|}{ NGWD COMPOSTIE DATA } \\
\hline Date & $\begin{array}{l}\text { Precip } \\
\text { inches }\end{array}$ & $\begin{array}{l}\text { GW } \\
\text { inches }\end{array}$ & $\begin{array}{l}E C(g w) \\
u S(c m\end{array}$ & $\begin{array}{l}\text { Op. Inflow } \\
\text { inches }\end{array}$ & & $\begin{array}{c}\text { Evap. loper } \\
\text { water) } \\
\text { inches }\end{array}$ & $\begin{array}{c}\text { ET } \\
\text { (veg, areas) } \\
\text { inches }\end{array}$ & $\begin{array}{l}\text { Op Spill } \\
\text { inches }\end{array}$ & $\begin{array}{l}\text { Outflow } \\
\text { inches }\end{array}$ & & $\begin{array}{l}\text { EC(gw) } \\
\text { uSlcm }\end{array}$ & $\begin{array}{l}\text { Depth } \\
\text { (hab) } \\
\text { inches }\end{array}$ & $\begin{array}{l}\text { Depth } \\
\text { (CC) }\end{array}$ & $\begin{array}{l}\text { End of } \\
\text { Day } \\
\text { inches }\end{array}$ & $\begin{array}{l}\text { Flow } \\
(\mathrm{cts})\end{array}$ & $\begin{array}{l}\text { Adj, } \\
\text { Flow } \\
(d s)\end{array}$ & $\begin{array}{l}\text { EC } \\
\text { USSCm }\end{array}$ & $\begin{array}{l}\text { Adj, EC } \\
\text { US/Cm }\end{array}$ & $\begin{array}{l}\text { GWD } \\
Q(c / s)\end{array}$ & $\begin{array}{l}\text { ersonnel } \\
\text { EC ( }(\omega \mathrm{S} C \mathrm{~cm})\end{array}$ & $\begin{array}{c}\text { Real-Tim } \\
Q(\text { dis })\end{array}$ & $\begin{array}{l}\text { le Network } \\
\text { EC }(u s / \mathrm{cm})\end{array}$ \\
\hline 1024120 & 0.00 & 0 & 0 & 0.21 & 750 & 0.05 & 0.03 & 0.10 & 0.10 & 0 & 0 & 10.67 & 10.67 & 10.48 & 90 & 77 & 721 & 901 & 60 & 815 & 62 & 1078 \\
\hline 10125/2002 & 0.00 & 0 & 0 & 0.19 & 750 & 0.04 & 0.04 & 0.10 & 0.10 & 0 & 0 & 10.67 & 10.67 & 10.49 & 90 & 77 & 727 & 909 & 63 & 819 & 63 & 1080 \\
\hline 10126/2002 & 0.00 & 0 & 0 & 0.18 & 750 & 0.05 & 0.04 & 0.10 & 0.10 & 0 & 0 & 10.67 & 10.67 & 10.48 & 90 & 77 & 733 & 917 & 63 & 831 & 63 & 1077 \\
\hline 1012712002 & 0.00 & 0 & 0 & 0.19 & 750 & 0.05 & 0.04 & 0.10 & 0.10 & 0 & 0 & 10.67 & 10.67 & 10.47 & 90 & 77 & 740 & 925 & 67 & 832 & 69 & 1084 \\
\hline $10128 / 2002$ & 0.00 & 0 & 0 & 0.19 & 750 & 0.06 & 0.04 & 0.10 & 0.10 & 0 & 0 & 10.67 & 10.67 & 10.46 & 90 & 77 & 748 & 935 & 69 & 834 & 73 & 1072 \\
\hline 10129/2002 & 0.00 & 0 & 0 & 0.21 & 750 & 0.07 & 0.05 & 0.10 & 0.10 & 0 & 0 & 10.67 & 10.67 & 10.45 & 90 & 77 & 756 & 946 & 71 & 838 & 76 & 1080 \\
\hline 10/3012002 & 0.00 & 0 & 0 & 0.22 & 750 & 0.08 & 0.05 & 0.10 & 0.10 & 0 & 0 & 10.67 & 10.67 & 10.44 & 90 & 77 & 765 & 957 & 76 & 845 & 78 & 1078 \\
\hline 10/3112002 & 0.00 & 0 & 0 & 0.23 & 750 & 0.08 & 0.05 & 0.10 & 0.10 & 0 & 0 & 10.67 & 10.67 & 10.44 & 90 & 77 & 774 & 968 & 90 & 847 & 119 & 1158 \\
\hline $11 / 1 / 12002$ & 0.00 & 0 & 0 & 0.23 & 1000 & 0.07 & 0.05 & 0.10 & 0.10 & 0 & 0 & 10.67 & 10.67 & 10.44 & 90 & 77 & 788 & 985 & 107 & 1115 & 112 & 1166 \\
\hline 111212002 & 0.00 & 0 & 0 & 0.22 & 1000 & 0.07 & 0.04 & 0.10 & 0.10 & 0 & 0 & 10.67 & 10.67 & 10.46 & 90 & 77 & 800 & 1000 & 106 & 1094 & 112 & 1155 \\
\hline $11 / 3 / 2002$ & 0.00 & 0 & 0 & 0.21 & 1000 & 0.05 & 0.03 & 0.10 & 0.10 & 0 & 0 & 10.67 & 10.67 & 10.48 & 90 & 77 & 811 & 1014 & 116 & 1091 & 113 & 1161 \\
\hline 11141200 & 0.00 & 0 & 0 & 0.19 & 1000 & 0.06 & 0.04 & 0.10 & 0.10 & 0 & 0 & 10.67 & 10.67 & 10.46 & 90 & 77 & 822 & 1028 & 115 & 1065 & 113 & 1173 \\
\hline $11 / 5 / 2002$ & 0.00 & 0 & 0 & 0.21 & 1000 & 0.07 & 0.04 & 0.10 & 0.10 & 0 & 0 & 10.67 & 10.67 & 10.46 & 90 & 77 & 834 & 1043 & 116 & 1064 & 113 & 1186 \\
\hline $1116 / 2002$ & 0.00 & 0 & 0 & 0.21 & 1000 & 0.06 & 0.03 & 0.10 & 0.10 & 0 & 0 & 10.67 & 10.67 & 10.48 & 90 & 77 & 845 & 1056 & 118 & 1110 & 115 & 1204 \\
\hline $1117 / 2002$ & 0.52 & 0 & 0 & 0.19 & 1000 & 0.03 & 0.02 & 0.10 & 0.10 & 0 & 0 & 10.67 & 10.67 & 11.03 & 90 & 77 & 821 & 1026 & 142 & 1094 & 141 & 1179 \\
\hline $111 / 12002$ & 0.63 & 0 & 0 & 0.00 & 1000 & 0.03 & 0.00 & 0.10 & 0.33 & 0 & 0 & 10.67 & 10.67 & 11.30 & 295 & 250 & 786 & 983 & 206 & 1108 & 196 & 1151 \\
\hline $11 / 912002$ & 0.00 & 0 & 0 & 0.00 & 1000 & 0.01 & 0.04 & 0.10 & 0.33 & 0 & 0 & 10.67 & 10.67 & 10.93 & 295 & 250 & 790 & 987 & 214 & 1107 & 209 & 1150 \\
\hline $11 / 10200$ & 0.00 & 0 & 0 & 0.00 & 1000 & 0.05 & 0.02 & 0.10 & 0.33 & 0 & 0 & 10.67 & 10.67 & 10.54 & 295 & 250 & 795 & 993 & 206 & 1146 & 201 & 1180 \\
\hline $11 / 11112002$ & 0.01 & 0 & 0 & 0.13 & 1000 & 0.06 & 0.03 & 0.10 & 0.10 & 0 & 0 & 10.67 & 10.67 & 10.49 & 90 & 77 & 803 & 1004 & 195 & 1191 & 194 & 1180 \\
\hline $11 / 1212002$ & 0.01 & 0 & 0 & 0.18 & 1000 & 0.04 & 0.02 & 0.10 & 0.10 & 0 & 0 & 10.67 & 10.67 & 10.52 & 90 & 77 & 810 & 1013 & 188 & 1214 & 189 & 1172 \\
\hline $11 / 113 / 2002$ & 0.00 & 0 & 0 & 0.15 & 1000 & 0.03 & 0.03 & 0.10 & 0.10 & 0 & 0 & 10.67 & 10.67 & 10.50 & 90 & 77 & 818 & 1022 & 177 & 1214 & 178 & 1219 \\
\hline $11 / 1 / 142002$ & 0.00 & 0 & 0 & 0.16 & 1000 & 0.02 & 0.03 & 0.10 & 0.10 & 0 & 0 & 10.67 & 10.67 & 10.52 & 90 & 77 & 824 & 1030 & 157 & 1260 & 160 & 1303 \\
\hline & 0.02 & 0 & 0 & 0.15 & 1000 & 0.02 & 0.00 & 0.10 & 0.10 & 0 & 0 & 10.67 & 10.67 & 10.57 & 90 & 77 & 827 & 1033 & 152 & 1256 & 154 & 1341 \\
\hline & 0.01 & 0 & 0 & 0.10 & 1000 & 0.03 & 0.02 & 0.10 & 0.10 & 0 & 0 & 10.67 & 10.67 & 10.53 & 90 & 77 & 831 & 1039 & 135 & 1234 & 149 & 1340 \\
\hline $11 / 177 / 20$ & 0.00 & 0 & 0 & 0.13 & 1000 & 0.04 & 0.03 & 0.10 & 0.10 & 0 & 0 & 10.67 & 10.67 & 10.50 & 90 & 77 & 838 & 1048 & 139 & 1298 & 144 & 1370 \\
\hline $11 / 18 / 2002$ & 0.00 & 0 & 0 & 0.17 & 1000 & 0.03 & 0.02 & 0.10 & 0.10 & 0 & 0 & 10.67 & 10.67 & 10.52 & 90 & 77 & 845 & 1056 & 134 & 1303 & 141 & 1423 \\
\hline $11 / 199 / 2002$ & 0.00 & 0 & 0 & 0.15 & 1000 & 0.02 & 0.02 & 0.10 & 0.10 & 0 & 0 & 10.67 & 10.67 & 10.52 & 90 & 77 & 850 & 1063 & 132 & 1333 & 138 & 1455 \\
\hline 11/20/2002 & 0.01 & 0 & 0 & 0.14 & 1000 & 0.03 & 0.01 & 0.10 & 0.10 & 0 & 0 & 10.67 & 10.67 & 10.53 & 90 & 77 & 855 & 1069 & 121 & 1397 & 138 & 1455 \\
\hline 1112112002 & 0.00 & 0 & 0 & 0.13 & 1000 & 0.05 & 0.01 & 0.10 & 0.10 & 0 & 0 & 10.67 & 10.67 & 10.50 & 90 & 77 & 863 & 1078 & 118 & 1395 & 132 & 1478 \\
\hline $11 / 22212002$ & 0.00 & 0 & 0 & 0.17 & 1000 & 0.04 & 0.02 & 0.10 & 0.10 & 0 & 0 & 10.67 & 10.67 & 10.51 & 90 & 77 & 870 & 1087 & 121 & 1448 & 127 & 1507 \\
\hline 11/23/2002 & 0.00 & 0 & 0 & 0.16 & 1000 & 0.04 & 0.02 & 0.10 & 0.10 & 0 & 0 & 10.67 & 10.67 & 10.50 & 90 & 77 & 877 & 1096 & 108 & 1434 & 119 & 1550 \\
\hline 1112412002 & 0.00 & 0 & 0 & 0.16 & 1000 & 0.02 & 0.01 & 0.10 & 0.10 & 0 & 0 & 10.67 & 10.67 & 10.54 & 90 & 77 & 881 & 1101 & 100 & 1435 & 102 & 1635 \\
\hline $11 / 25 \mid 2002$ & 0.00 & 0 & 0 & 0.13 & 1000 & 0.04 & 0.02 & 0.10 & 0.10 & 0 & 0 & 10.67 & 10.67 & 10.51 & 90 & 77 & 888 & 1109 & 92 & 1434 & 104 & 1620 \\
\hline $111 / 2612002$ & 0.00 & 0 & 0 & 0.16 & 1000 & 0.04 & 0.02 & 0.10 & 0.10 & 0 & 0 & 10.67 & 10.67 & 10.51 & 90 & 77 & 894 & 1118 & 84 & 1433 & 107 & 1569 \\
\hline $11 / 127 / 2002$ & 0.00 & 0 & 0 & 0.16 & 1000 & 0.03 & 0.02 & 0.10 & 0.10 & 0 & 0 & 10.67 & 10.67 & 10.51 & 90 & 77 & 900 & 1125 & 79 & 1454 & 115 & 1525 \\
\hline $11 \mid 128 / 2002$ & 0.00 & 0 & 0 & 0.15 & 1000 & 0.04 & 0.02 & 0.10 & 0.10 & 0 & 0 & 10.67 & 10.67 & 10.51 & 90 & 77 & 906 & 1133 & 75 & 1442 & 112 & 1520 \\
\hline $111 / 29 \mid 2002$ & 0.00 & 0 & 0 & 0.16 & 1000 & 0.03 & 0.02 & 0.10 & 0.10 & 0 & 0 & 10.67 & 10.67 & 10.51 & 90 & 77 & 912 & 1140 & 68 & 1457 & 107 & 1539 \\
\hline $11 / 13012002$ & 0.00 & 0 & 0 & 0.15 & 1000 & 0.02 & 0.00 & 0.10 & 0.10 & 0 & 0 & 10.67 & 10.67 & 10.54 & 90 & 77 & 915 & 1144 & 68 & 1450 & 100 & 1601 \\
\hline 12112002 & 0.00 & 0 & 0 & 0.12 & 1250 & 0.03 & 0.02 & 0.10 & 0.10 & 0 & 0 & 10.67 & 10.67 & 10.52 & 90 & 77 & 923 & 1154 & 87 & 1443 & 102 & 1603 \\
\hline 122122002 & 0.00 & 0 & 0 & 0.15 & 1250 & 0.03 & 0.02 & 0.10 & 0.10 & 0 & 0 & 10.67 & 10.67 & 10.51 & 90 & 77 & 932 & 1166 & 85 & 1444 & 107 & 1571 \\
\hline 121312002 & 0.00 & 0 & 0 & 0.16 & 1250 & 0.04 & 0.02 & 0.10 & 0.10 & 0 & 0 & 10.67 & 10.67 & 10.51 & 90 & 77 & 942 & 1178 & 90 & 1411 & 112 & 1522 \\
\hline 121412002 & 0.01 & 0 & 0 & 0.16 & 1250 & 0.03 & 0.02 & 0.10 & 0.10 & 0 & 0 & 10.67 & 10.67 & 10.52 & 90 & 77 & 950 & 1188 & 91 & 1427 & 109 & 1514 \\
\hline $12 / 512002$ & 0.00 & 0 & 0 & 0.14 & 1250 & 0.02 & 0.01 & 0.10 & 0.10 & 0 & 0 & 10.67 & 10.67 & 10.53 & 90 & 77 & 957 & 1197 & 95 & 1394 & 115 & 1470 \\
\hline 126612002 & 0.01 & 0 & 0 & 0.13 & 1250 & 0.04 & 0.00 & 0.10 & 0.10 & 0 & 0 & 10.67 & 10.67 & 10.53 & 90 & 77 & 964 & 1205 & 97 & 1372 & 138 & 1402 \\
\hline 127712002 & 0.00 & 0 & 0 & 0.13 & 1250 & 0.03 & 0.01 & 0.10 & 0.10 & 0 & 0 & 10.67 & 10.67 & 10.52 & 90 & 77 & 972 & 1215 & 103 & 1301 & 147 & 1359 \\
\hline 12812002 & 0.00 & 0 & 0 & 0.15 & 1250 & 0.02 & 0.02 & 0.10 & 0.10 & 0 & 0 & 10.67 & 10.67 & 10.53 & 90 & 77 & 980 & 1224 & 108 & 1260 & 150 & 1352 \\
\hline 12912002 & 0.01 & 0 & 0 & 0.14 & 1250 & 0.04 & 0.01 & 0.10 & 0.10 & 0 & 0 & 10.67 & 10.67 & 10.52 & 90 & 77 & 987 & 1234 & 111 & 1247 & 153 & 1139 \\
\hline 12/1012002 & 0.00 & 0 & 0 & 0.14 & 1250 & 0.03 & 0.01 & 0.10 & 0.10 & 0 & 0 & 10.67 & 10.67 & 10.52 & 90 & 77 & 995 & 1244 & 115 & 1222 & 160 & 1131 \\
\hline 12111112002 & 0.01 & 0 & 0 & 0.14 & 1250 & 0.04 & 0.01 & 0.10 & 0.10 & 0 & 0 & 10.67 & 10.67 & 10.53 & 90 & 77 & 1002 & 1253 & 117 & 1235 & 160 & 1126 \\
\hline
\end{tabular}


Note: Traditional drawdown (Type 3, normal year) selected for entire model run shown.

\begin{tabular}{|c|c|c|c|c|c|c|c|c|c|c|c|c|c|c|c|c|c|c|c|c|c|c|}
\hline & \multicolumn{5}{|c|}{$\mathbb{N}$} & \multicolumn{6}{|c|}{ OUT } & \multicolumn{3}{|c|}{ Management } & \multicolumn{4}{|c|}{ MODEL OUTPUT } & \multicolumn{4}{|c|}{ NGWD COMPOSTIE DATA } \\
\hline & $\begin{array}{l}\text { Precip } \\
\text { inches }\end{array}$ & $\begin{array}{l}\text { GW } \\
\text { inches }\end{array}$ & $\begin{array}{c}E C(g \mathrm{gl}) \\
\mathrm{uSC}(\mathrm{cm})\end{array}$ & $\begin{array}{l}\text { Op. Inflow } \\
\text { inches }\end{array}$ & & $\begin{array}{c}\text { Evap. lopen } \\
\text { water) } \\
\text { inches }\end{array}$ & $\begin{array}{c}\text { ET } \\
\text { (veg, areas) } \\
\text { inches }\end{array}$ & $\begin{array}{c}\text { Op Spill } \\
\text { inches }\end{array}$ & $\begin{array}{c}\text { Outflow } \\
\text { inches }\end{array}$ & & $\begin{array}{c}E C(g W) \\
\text { uS }(\mathrm{cm})\end{array}$ & $\begin{array}{l}\text { Depth } \\
\text { (hab) } \\
\text { inches } \\
\end{array}$ & $\begin{array}{l}\text { Depth } \\
\text { (CC) }\end{array}$ & $\begin{array}{l}\text { End of } \\
\text { Day } \\
\text { inches }\end{array}$ & $\begin{array}{l}\text { Flow } \\
(\mathrm{ds})\end{array}$ & $\begin{array}{l}\text { Adj, } \\
\text { Flow } \\
(c t s)\end{array}$ & $\begin{array}{c}\text { EC } \\
\text { USCm }\end{array}$ & $\begin{array}{c}\text { Adj. EC } \\
\text { uSicm }\end{array}$ & $\begin{array}{l}\text { GWDP } \\
Q(d s)\end{array}$ & $\begin{array}{l}\text { asonnel } \\
\text { EC (uS }(\mathrm{cm})\end{array}$ & $\begin{array}{l}\text { Real|Fin } \\
Q(\text { cts })\end{array}$ & $\begin{array}{l}\text { e Network } \\
\text { EC (uSCm) }\end{array}$ \\
\hline 1211212002 & 0.00 & $\overline{0}$ & $\overline{0}$ & 0.14 & 1250 & 0.03 & 0.00 & 0.10 & 0.10 & 0 & 0 & 10.67 & 10.67 & 10.53 & 90 & 77 & 1009 & 1261 & 121 & 1215 & 167 & 1122 \\
\hline 121132002 & 0.12 & 0 & 0 & 0.13 & 1250 & 0.04 & 0.00 & 0.10 & 0.10 & 0 & 0 & 10.67 & 10.67 & 10.65 & 90 & 77 & 1006 & 1257 & 159 & 1211 & 170 & 1186 \\
\hline 121142002 & 0.41 & 0 & 0 & 0.02 & 1250 & 0.03 & 0.01 & 0.10 & 0.10 & 0 & 0 & 10.67 & 10.67 & 10.93 & 90 & 77 & 979 & 1224 & 187 & 1240 & 185 & 1264 \\
\hline 1211522002 & 0.03 & 0 & 0 & 0.00 & 1250 & 0.04 & 0.00 & 0.10 & 0.33 & 0 & 0 & 10.67 & 10.67 & 10.59 & 295 & 250 & 981 & 1226 & 215 & 1288 & 208 & 1303 \\
\hline 1216122002 & 0.88 & 0 & 0 & 0.07 & 1250 & 0.02 & 0.01 & 0.10 & 0.10 & 0 & 0 & 10.67 & 10.67 & 11.41 & 90 & 77 & 926 & 1157 & 223 & 1290 & 239 & 1307 \\
\hline 12117/2002 & 0.29 & 0 & 0 & 0.00 & 1250 & 0.01 & 0.02 & 0.10 & 0.33 & 0 & 0 & 10.67 & 10.67 & 11.34 & 295 & 250 & 909 & 1136 & 225 & 1276 & 288 & 1184 \\
\hline 1211812002 & 0.00 & 0 & 0 & 0.00 & 1250 & 0.02 & 0.02 & 0.10 & 0.33 & 0 & 0 & 10.67 & 10.67 & 10.98 & 295 & 250 & 912 & 1140 & 227 & 1264 & 307 & 1250 \\
\hline 12119/2002 & 0.68 & 0 & 0 & 0.00 & 1250 & 0.10 & 0.01 & 0.10 & 0.33 & 0 & 0 & 10.67 & 10.67 & 11.22 & 295 & 250 & 876 & 1095 & 244 & 1285 & 311 & 1318 \\
\hline 1220022002 & 0.30 & 0 & 0 & 0.00 & 1250 & 0.04 & 0.01 & 0.10 & 0.33 & 0 & 0 & 10.67 & 10.67 & 11.13 & 295 & 250 & 861 & 1076 & 289 & 1256 & 323 & 1325 \\
\hline 122112002 & 0.01 & 0 & 0 & 0.00 & 1250 & 0.02 & 0.01 & 0.10 & 0.33 & 0 & 0 & 10.67 & 10.67 & 10.79 & 295 & 250 & 862 & 1078 & 278 & 1227 & 372 & 1286 \\
\hline 1222212002 & 0.00 & 0 & 0 & 0.00 & 1250 & 0.01 & 0.02 & 0.10 & 0.22 & 0 & 0 & 10.67 & 10.67 & 10.54 & 197 & 167 & 865 & 1081 & 277 & 1256 & 385 & 1229 \\
\hline 1221232002 & 0.01 & 0 & 0 & 0.13 & 1250 & 0.02 & 0.02 & 0.10 & 0.10 & 0 & 0 & 10.67 & 10.67 & 10.54 & 90 & 77 & 872 & 1090 & 273 & 1283 & 374 & 1387 \\
\hline 1221242002 & 0.00 & 0 & 0 & 0.13 & 1250 & 0.02 & 0.00 & 0.10 & 0.10 & 0 & 0 & 10.67 & 10.67 & 10.54 & 90 & 77 & 879 & 1098 & 242 & 1357 & 336 & 1567 \\
\hline 12255/2002 & 0.01 & 0 & 0 & 0.13 & 1250 & 0.02 & 0.00 & 0.10 & 0.10 & 0 & 0 & 10.67 & 10.67 & 10.55 & 90 & 77 & 884 & 1105 & 239 & 1383 & 272 & 1654 \\
\hline 1226612002 & 0.00 & 0 & 0 & 0.11 & 1250 & 0.03 & 0.01 & 0.10 & 0.10 & 0 & 0 & 10.67 & 10.67 & 10.53 & 90 & 77 & 892 & 1114 & 221 & 1401 & 199 & 1695 \\
\hline 12227/2002 & 0.00 & 0 & 0 & 0.14 & 1250 & 0.04 & 0.02 & 0.10 & 0.10 & 0 & 0 & 10.67 & 10.67 & 10.51 & 90 & 77 & 901 & 1126 & 209 & 1434 & 228 & 1578 \\
\hline 1228822002 & 0.15 & 0 & 0 & 0.16 & 1250 & 0.04 & 0.01 & 0.10 & 0.10 & 0 & 0 & 10.67 & 10.67 & 10.66 & 90 & 77 & 900 & 1125 & 201 & 1525 & 197 & 1596 \\
\hline 1212992002 & 0.09 & 0 & 0 & 0.00 & 1250 & 0.03 & 0.01 & 0.10 & 0.10 & 0 & 0 & 10.67 & 10.67 & 10.61 & 90 & 77 & 897 & 1122 & 190 & 1552 & 181 & 1686 \\
\hline 123012002 & 0.07 & 0 & 0 & 0.05 & 1250 & 0.03 & 0.01 & 0.10 & 0.10 & 0 & 0 & 10.67 & 10.67 & 10.60 & 90 & 77 & 898 & 1122 & 175 & 1572 & 167 & 1742 \\
\hline 1231312002 & 0.18 & 0 & 0 & 0.07 & 1250 & 0.03 & 0.01 & 0.10 & 0.10 & 0 & 0 & 10.67 & 10.67 & 10.70 & 90 & 77 & 892 & 1114 & 161 & 1614 & 171 & 1714 \\
\hline 11112003 & 0.01 & 0 & 0 & 0.00 & 1500 & 0.03 & 0.01 & 0.10 & 0.13 & 0 & 0 & 10.67 & 10.67 & 10.53 & 120 & 102 & 895 & 1118 & 153 & 1647 & 176 & 1803 \\
\hline 11222003 & 0.00 & 0 & 0 & 0.13 & 1500 & 0.04 & 0.01 & 0.10 & 0.10 & 0 & 0 & 10.67 & 10.67 & 10.52 & 90 & 77 & 906 & 1133 & 146 & 1674 & 161 & 1811 \\
\hline 1/3/2003 & 0.01 & 0 & 0 & 0.15 & 1500 & 0.02 & 0.01 & 0.10 & 0.10 & 0 & 0 & 10.67 & 10.67 & 10.54 & 90 & 77 & 916 & 1145 & 138 & 1705 & 189 & 1700 \\
\hline 1442003 & 0.01 & 0 & 0 & 0.12 & 1500 & 0.03 & 0.00 & 0.10 & 0.10 & 0 & 0 & 10.67 & 10.67 & 10.54 & 90 & 77 & 925 & 1156 & 132 & 1647 & 208 & 1547 \\
\hline $1 / 512003$ & 0.00 & 0 & 0 & 0.12 & 1500 & 0.01 & 0.01 & 0.10 & 0.10 & 0 & 0 & 10.67 & 10.67 & 10.54 & 90 & 77 & 934 & 1167 & 133 & 1614 & 228 & 1447 \\
\hline $1 / 612003$ & 0.00 & 0 & 0 & 0.13 & 1500 & 0.03 & 0.01 & 0.10 & 0.10 & 0 & 0 & 10.67 & 10.67 & 10.53 & 90 & 77 & 944 & 1180 & 132 & 1578 & 232 & 1423 \\
\hline $177 / 2003$ & 0.01 & 0 & 0 & 0.14 & 1500 & 0.01 & 0.00 & 0.10 & 0.10 & 0 & 0 & 10.67 & 10.67 & 10.56 & 90 & 77 & 952 & 1190 & 141 & 1580 & 231 & 1493 \\
\hline 18122003 & 0.00 & 0 & 0 & 0.11 & 1500 & 0.02 & 0.00 & 0.10 & 0.10 & 0 & 0 & 10.67 & 10.67 & 10.55 & 90 & 77 & 959 & 1199 & 150 & 1521 & 214 & 1558 \\
\hline 19/2003 & 0.11 & 0 & 0 & 0.12 & 1500 & 0.03 & 0.00 & 0.10 & 0.10 & 0 & 0 & 10.67 & 10.67 & 10.64 & 90 & 77 & 960 & 1200 & 153 & 1487 & 153 & 1487 \\
\hline 1/11022003 & 0.41 & 0 & 0 & 0.02 & 1500 & 0.01 & 0.00 & 0.10 & 0.10 & 0 & 0 & 10.67 & 10.67 & 10.96 & 90 & 77 & 933 & 1167 & 153 & 1492 & 153 & 1492 \\
\hline $1 / 1112003$ & 0.01 & 0 & 0 & 0.00 & 1500 & 0.02 & 0.00 & 0.10 & 0.33 & 0 & 0 & 10.67 & 10.67 & 10.61 & 295 & 250 & 935 & 1168 & 159 & 1460 & 159 & 1460 \\
\hline $1 / 1212003$ & 0.01 & 0 & 0 & 0.05 & 1500 & 0.03 & 0.00 & 0.10 & 0.10 & 0 & 0 & 10.67 & 10.67 & 10.54 & 90 & 77 & 940 & 1175 & 154 & 1440 & 154 & 1440 \\
\hline $1 / 1 / 120003$ & 0.01 & 0 & 0 & 0.12 & 1500 & 0.04 & 0.01 & 0.10 & 0.10 & 0 & 0 & 10.67 & 10.67 & 10.52 & 90 & 77 & 950 & 1188 & 152 & 1457 & 152 & 1457 \\
\hline 1/1142003 & 0.01 & 0 & 0 & 0.14 & 1500 & 0.01 & 0.00 & 0.10 & 0.10 & 0 & 0 & 10.67 & 10.67 & 10.56 & 90 & 77 & 958 & 1198 & 151 & 1469 & 151 & 1469 \\
\hline $1 / 1512003$ & 0.00 & 0 & 0 & 0.10 & 1500 & 0.03 & 0.01 & 0.10 & 0.10 & 0 & 0 & 10.67 & 10.67 & 10.53 & 90 & 77 & 967 & 1208 & 149 & 1473 & 149 & 1473 \\
\hline 1/1/612003 & 0.02 & 0 & 0 & 0.14 & 1500 & 0.03 & 0.01 & 0.10 & 0.10 & 0 & 0 & 10.67 & 10.67 & 10.55 & 90 & 77 & 975 & 1219 & 142 & 1557 & 142 & 1557 \\
\hline $1 / 177 / 2003$ & 0.00 & 0 & 0 & 0.12 & 1500 & 0.03 & 0.00 & 0.10 & 0.10 & 0 & 0 & 10.67 & 10.67 & 10.54 & 90 & 77 & 984 & 1229 & 135 & 1613 & 135 & 1613 \\
\hline 1/11812003 & 0.00 & 0 & 0 & 0.13 & 1500 & 0.00 & 0.00 & 0.10 & 0.10 & 0 & 0 & 10.67 & 10.67 & 10.56 & 90 & 77 & 991 & 1238 & 132 & 1648 & 132 & 1648 \\
\hline 1/1912003 & 0.00 & 0 & 0 & 0.11 & 1500 & 0.00 & 0.00 & 0.10 & 0.10 & 0 & 0 & 10.67 & 10.67 & 10.56 & 90 & 77 & 996 & 1245 & 127 & 1666 & 127 & 16660 \\
\hline 112012003 & 0.00 & 0 & 0 & 0.10 & 1500 & 0.01 & 0.00 & 0.10 & 0.10 & 0 & 0 & 10.67 & 10.67 & 10.56 & 90 & 77 & 1002 & 1252 & 122 & 1680 & 122 & 1680 \\
\hline 12112003 & 0.00 & 0 & 0 & 0.11 & 1500 & 0.02 & 0.01 & 0.10 & 0.10 & 0 & 0 & 10.67 & 10.67 & 10.54 & 90 & 77 & 1009 & 1262 & 130 & 1636 & 130 & 1636 \\
\hline 12212003 & 0.00 & 0 & 0 & 0.13 & 1500 & 0.03 & 0.01 & 0.10 & 0.10 & 0 & 0 & 10.67 & 10.67 & 10.53 & 90 & 77 & 1019 & 1274 & 134 & 1621 & 134 & 1621 \\
\hline $1 / 2312003$ & 0.00 & 0 & 0 & 0.14 & 1500 & 0.03 & 0.01 & 0.10 & 0.10 & 0 & 0 & 10.67 & 10.67 & 10.52 & 90 & 77 & 1030 & 1287 & 136 & 1635 & 136 & 1635 \\
\hline $1 / 242003$ & 0.00 & 0 & 0 & 0.14 & 1500 & 0.01 & 0.00 & 0.10 & 0.10 & 0 & 0 & 10.67 & 10.67 & 10.55 & 90 & 77 & 1038 & 1297 & 134 & 1626 & 134 & 1626 \\
\hline $1125 / 2003$ & 0.01 & 0 & 0 & 0.12 & 1500 & 0.03 & 0.00 & 0.10 & 0.10 & 0 & 0 & 10.67 & 10.67 & 10.54 & 90 & 77 & 1045 & 1307 & 137 & 1552 & 137 & 1552 \\
\hline 112612003 & 0.00 & 0 & 0 & 0.00 & 1500 & 0.05 & 0.00 & 0.10 & 0.13 & 0 & 0 & 10.67 & 9.60 & 10.36 & 115 & 98 & 1051 & 1313 & 137 & 1520 & 137 & 1520 \\
\hline $1 / 27 / 2003$ & 0.00 & 0 & 0 & 0.00 & 1500 & 0.02 & 0.01 & 0.10 & 0.10 & 0 & 0 & 10.67 & 8.53 & 10.24 & 90 & 77 & 1054 & 1317 & 142 & 1433 & 142 & 1433 \\
\hline 112812003 & 0.00 & 0 & 0 & 0.00 & 1500 & 0.01 & 0.02 & 0.10 & 0.12 & 0 & 0 & 10.67 & 7.47 & 10.08 & 110 & 94 & 1057 & 1322 & 145 & 1458 & 145 & 1458 \\
\hline 1129/2003 & 0.01 & 0 & 0 & 0.00 & 1500 & 0.05 & 0.02 & 0.10 & 0.12 & 0 & 0 & 10.67 & 6.40 & 9.91 & 104 & 89 & 1064 & 1330 & 146 & 1508 & 146 & 1508 \\
\hline
\end{tabular}


Note: Traditional drawdown (Type 3, normal year) selected for entire model run shown.

\begin{tabular}{|c|c|c|c|c|c|c|c|c|c|c|c|c|c|c|c|c|c|c|c|c|c|c|}
\hline \multirow{2}{*}{\begin{tabular}{r|} 
Time-Step \\
Date
\end{tabular}} & \multicolumn{5}{|c|}{$\mathbb{N}$} & \multicolumn{6}{|c|}{ OUT } & \multicolumn{3}{|c|}{ Management } & \multicolumn{4}{|c|}{ MODEL OUTPUT } & \multicolumn{4}{|c|}{ NGWD COMPOSTEDDATA } \\
\hline & $\begin{array}{l}\text { Precip } \\
\text { inches }\end{array}$ & & ECCgw) & $\begin{array}{l}\text { Dp. Inflor } \\
\text { inchers }\end{array}$ & & $\begin{array}{c}\text { Evap. (opel } \\
\text { waterer) } \\
\text { incless }\end{array}$ & $\begin{array}{c}\text { ET } \\
\text { (veg. areas) } \\
\text { incles }\end{array}$ & $\begin{array}{c}\text { Op Spill } \\
\text { inches }\end{array}$ & $\begin{array}{c}\text { Outflow } \\
\text { inthes }\end{array}$ & $\begin{array}{l}\text { GW } \\
\text { inchles }\end{array}$ & $\begin{array}{l}\mathrm{EC}(\mathrm{gw}) \\
\mathrm{ISC \textrm {cm }}\end{array}$ & \begin{tabular}{|l} 
Depth \\
(habl) \\
inctes
\end{tabular} & $\begin{array}{l}\text { Depth } \\
\text { (CC) }\end{array}$ & $\begin{array}{l}\text { Endo } \\
\text { Day } \\
\text { inches }\end{array}$ & $\begin{array}{l}\text { Flow } \\
\text { (cts) }\end{array}$ & $\begin{array}{l}\text { Adj. } \\
\text { Flow } \\
\text { (cos) }\end{array}$ & $\begin{array}{l}\text { EC } \\
\text { USCm }\end{array}$ & $\begin{array}{c}\text { Adi. EC } \\
\text { ISCOC }\end{array}$ & $\begin{array}{l}\text { GWD } \\
a_{\text {(fs }}\end{array}$ & $\begin{array}{l}\text { Personnel } \\
\text { EC }\left(\mathrm{uscm}^{2}\right)\end{array}$ & $\begin{array}{l}\text { Real-Fim } \\
\text { Q(dis) }\end{array}$ & $\begin{array}{l}\text { e Network } \\
\text { EC (HSCcm) }\end{array}$ \\
\hline 13002003 & 0.01 & 0 & 0 & 0.01 & 1500 & 0.04 & 0.01 & 0.10 & 0.10 & 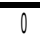 & 0 & 10.67 & 5.33 & 9.77 & 90 & 77 & 1069 & 1336 & 146 & 1530 & 146 & 1530 \\
\hline 13112003 & 0.00 & 0 & 0 & 0.00 & 1500 & 0.04 & 0.00 & 0.10 & 0.11 & 0 & 0 & 10.67 & 4.27 & 9.63 & 100 & 85 & 1072 & 1341 & 135 & 1574 & 135 & 1574 \\
\hline 21112003 & 0.00 & 0 & 0 & 0.00 & 1750 & 0.01 & 0.02 & 0.10 & 0.12 & 0 & 0 & 10.67 & 3.20 & 9.48 & 103 & 88 & 1076 & 1345 & 134 & 16001 & 134 & 1001 \\
\hline 2222003 & 0.00 & 0 & 0 & 0.00 & 1750 & 0.04 & 0.04 & 0.10 & 0.12 & 0 & 0 & 10.67 & 2.13 & 9.28 & 110 & 93 & 1085 & 1356 & 133 & 1609 & 133 & 1009 \\
\hline 23,32003 & 0.00 & 0 & 0 & 0.03 & 1750 & 0.06 & 0.02 & 0.10 & 0.10 & 0 & 0 & 10.67 & 1.07 & 9.12 & 90 & 77 & 1098 & 1372 & 132 & 1613 & 132 & 1613 \\
\hline 2442003 & 0.00 & 0 & 0 & 0.04 & 1750 & 0.05 & 0.03 & 0.10 & 0.10 & 0 & 0 & 10.67 & 0.00 & 8.98 & 90 & 77 & 1110 & 1387 & 125 & 1765 & 125 & 1765 \\
\hline 2552003 & 0.00 & 0 & 0 & 0.18 & 1750 & 0.06 & 0.03 & 0.10 & 0.10 & 0 & 0 & 10.67 & 0.00 & 898 & 90 & 77 & 1133 & 1416 & 145 & 1750 & 145 & 1750 \\
\hline 2662003 & 0.00 & 0 & 0 & 0.18 & 1750 & 0.09 & 0.02 & 0.10 & 0.10 & 0 & 0 & $\mid$\begin{tabular}{|l|}
$\mid 0.67$ \\
\end{tabular} & 0.00 & 8.95 & 90 & 77 & 1159 & 1449 & 142 & 1756 & 142 & 1756 \\
\hline 2772003 & \begin{tabular}{l|l}
3 & 0.00
\end{tabular} & 0 & 0 & 0.21 & 1750 & 0.07 & 0.03 & 0.10 & 0.10 & 0 & 0 & 10.67 & 0.00 & 8.96 & 90 & 77 & 1180 & 1483 & 137 & 16606 & 137 & 16060 \\
\hline 2882003 & \begin{tabular}{l|l}
3 & 0.00
\end{tabular} & 0 & 0 & 0.20 & 1000 & 0.06 & 0.03 & 0.10 & 0.10 & 0 & 0 & 10.67 & 0.00 & 8.97 & 90 & 77 & 1194 & 1492 & 137 & 1647 & 137 & 1647 \\
\hline 2920033 & 0.00 & 0 & 0 & 0.19 & 1000 & 0.06 & 0.03 & 0.10 & 0.10 & 0 & 0 & $\mid 10.67$ & 0.00 & 8.97 & 90 & 77 & 1202 & 1502 & 135 & 1611 & 135 & 1611 \\
\hline 2102003 & 0.00 & 0 & 0 & 0.19 & 1000 & 0.05 & 0.02 & 0.10 & 0.10 & 0 & 0 & 10.67 & 0.00 & 8.99 & 90 & 77 & 1207 & 1509 & 135 & 1619 & 135 & 1619 \\
\hline 21112003 & 0.00 & 0 & 0 & 0.17 & 1000 & 0.11 & 0.02 & 0.10 & 0.10 & 0 & 0 & 10.67 & 0.00 & 8.93 & 90 & 77 & 1221 & 1526 & 137 & 1612 & 137 & 1612 \\
\hline 2122003 & 0.15 & 0 & 0 & 0.23 & 1000 & 0.04 & 0.00 & 0.10 & 0.10 & 0 & 0 & 10.67 & 0.00 & 9.17 & 90 & 77 & 1204 & 1505 & 137 & 1635 & 137 & 1635 \\
\hline 21132003 & 0.26 & 0 & 0 & 0.00 & 1000 & 0.02 & 0.02 & 0.10 & 0.21 & 0 & 0 & 10.54 & 0.00 & 9.18 & 189 & 161 & 1179 & 1474 & 135 & 1671 & 135 & 1671 \\
\hline 21412003 & 0.00 & 0 & 0 & 0.00 & 1000 & 0.03 & 0.02 & 0.10 & 0.33 & 0 & 0 & 10.42 & 0.00 & 8.80 & 290 & 247 & 1180 & 1483 & 135 & 1700 & 135 & 1700 \\
\hline 21152003 & 0.00 & 0 & 0 & 0.04 & 1000 & 0.04 & 0.02 & 0.10 & 0.10 & 0 & 0 & 10.30 & 0.00 & 8.69 & 90 & 77 & 1193 & 1491 & 139 & 1690 & 139 & 1690 \\
\hline 211612003 & 0.09 & 0 & 0 & 0.05 & 1000 & 0.06 & 0.03 & 0.10 & 0.10 & 0 & 0 & 10.18 & 0.00 & 8.65 & 90 & 77 & 1193 & 1491 & 144 & 1648 & 144 & 1648 \\
\hline 211712003 & 0.00 & 0 & 0 & 0.00 & 1000 & 0.04 & 0.02 & 0.10 & 0.11 & 0 & 0 & 10.06 & 0.00 & 8.48 & 101 & 85 & 1201 & 1501 & 142 & 1630 & 142 & 1630 \\
\hline 21182003 & 0.00 & 0 & 0 & 0.00 & 1000 & 0.05 & 0.03 & 0.10 & 0.12 & 0 & 0 & 9.85 & 0.00 & 8.28 & 106 & 90 & 1212 & 1516 & 139 & 1748 & 139 & 1748 \\
\hline 21912003 & 0.07 & 0 & 0 & 0.01 & 1000 & 0.07 & 0.01 & 0.10 & 0.10 & 0 & 0 & 9.65 & 0.00 & 8.17 & 90 & 77 & 1216 & 1520 & 136 & 1718 & 136 & 17718 \\
\hline 22012003 & 0.00 & 0 & 0 & 0.00 & 1000 & 0.02 & 0.02 & 0.10 & 0.16 & 0 & 0 & 9.44 & 0.00 & 7.96 & 143 & 122 & 1223 & 1529 & 134 & 1710 & 134 & 1710 \\
\hline 22112003 & 0.00 & 0 & 0 & 0.00 & 1000 & 0.05 & 0.02 & 0.10 & 0.13 & 0 & 0 & 9.24 & 0.00 & 7.76 & 114 & 97 & 1235 & 1543 & 127 & 1819 & 127 & 1819 \\
\hline 22220033 & 0.00 & 0 & 0 & 0.00 & 1000 & 0.05 & 0.02 & 0.10 & 0.10 & 0 & 0 & 9.04 & 0.00 & 7.59 & 92 & 78 & 1247 & 1558 & 122 & 1853 & 122 & 1853 \\
\hline 222320033 & 0.00 & 0 & 0 & 0.00 & 1000 & 0.03 & 0.02 & 0.10 & 0.10 & 0 & 0 & 8.83 & 0.00 & 7.43 & 92 & 78 & 1256 & 1570 & 120 & 1889 & 120 & 1889 \\
\hline 2242003 & 0.51 & 0 & 0 & 0.00 & 1000 & 0.05 & 0.02 & 0.10 & 0.12 & 0 & 0 & 8.63 & 0.00 & 7.74 & 109 & 93 & 1198 & 1498 & 116 & 1928 & 116 & 1928 \\
\hline 22552003 & 0.08 & 0 & 0 & 0.00 & 1000 & 0.04 & 0.03 & 0.10 & 0.33 & 0 & 0 & 8.43 & 0.00 & 7.43 & 205 & 250 & 1198 & 1497 & 112 & 1907 & 112 & 1907 \\
\hline 22602003 & 0.00 & 0 & 0 & 0.00 & 1000 & 0.05 & 0.03 & 0.10 & 0.33 & 0 & 0 & 8.22 & 0.00 & 7.02 & 295 & 250 & 1212 & 1516 & 116 & 1899 & 116 & 1899 \\
\hline 222712003 & 0.00 & 0 & 0 & 0.00 & 1000 & 0.06 & 0.03 & 0.10 & 0.23 & 0 & 0 & 8.02 & 0.00 & 670 & 206 & 175 & 1229 & 1537 & 113 & 1919 & 113 & 1919 \\
\hline 22882003 & 0.00 & 0 & 0 & 0.01 & 1000 & 0.06 & 0.03 & 0.10 & 0.10 & 0 & 0 & 7.81 & 0.00 & 6.52 & 90 & 77 & 1245 & 1557 & 110 & 1938 & 110 & 1938 \\
\hline 31112003 & 0.00 & 0 & 0 & 0.01 & 600 & 0.07 & 0.03 & 0.10 & 0.10 & 0 & 0 & $\mid 7.61$ & 0.00 & 6.34 & 90 & 77 & 1263 & 1579 & 117 & 1889 & 117 & 1889 \\
\hline 322003 & 0.00 & 0 & 0 & 0.02 & 600 & 0.08 & 0.03 & 0.10 & 0.10 & 0 & 0 & 7.41 & 0.00 & 6.15 & 90 & 77 & 1284 & 1005 & 134 & 1871 & 134 & 1871 \\
\hline 332003 & 0.00 & 0 & 0 & 0.04 & 600 & 0.09 & 0.03 & 0.10 & 0.10 & 0 & 0 & 7.20 & 0.00 & 5.97 & 90 & 77 & 1306 & 1633 & 151 & 1838 & 151 & 1838 \\
\hline 3412003 & 0.00 & 0 & 0 & 0.05 & 600 & 0.07 & 0.02 & 0.10 & 0.10 & 0 & 0 & 7.00 & 0.00 & 5.82 & 90 & 77 & 1321 & 1651 & 166 & 1834 & 166 & 1834 \\
\hline 3522003 & 0.00 & 0 & 0 & 0.02 & 600 & 0.07 & 0.04 & 0.10 & 0.10 & 0 & 0 & 6.80 & 0.00 & 5.63 & 90 & 77 & 1345 & 1682 & 163 & 1870 & 163 & 1870 \\
\hline 3612003 & 0.00 & 0 & 0 & 0.04 & 600 & 0.08 & 0.04 & 0.10 & 0.10 & 0 & 0 & 6.59 & 0.00 & 5.44 & 90 & 77 & 1372 & 1715 & 150 & 1906 & 150 & 1906 \\
\hline 3712003 & 0.00 & 0 & 0 & 0.05 & 600 & 0.08 & 0.04 & 0.10 & 0.10 & 0 & 0 & 6.39 & 0.00 & 5.26 & 90 & 77 & 1398 & 1747 & 144 & 1916 & 144 & 1916 \\
\hline 3820203 & 0.00 & 0 & 0 & 0.05 & 600 & 0.08 & 0.04 & 0.10 & 0.10 & 0 & 0 & 6.19 & 0.00 & 5.09 & 90 & 77 & 1423 & 1779 & 162 & 1832 & 162 & 1832 \\
\hline 392003 & 0.00 & 0 & 0 & 0.04 & 600 & 0.09 & 0.04 & 0.10 & 0.10 & 0 & 0 & 5.98 & 0.00 & 4.91 & 90 & 77 & 1454 & 1817 & 151 & 1796 & 151 & 1796 \\
\hline 31002003 & 0.00 & 0 & 0 & 0.05 & 600 & 0.08 & 0.04 & 0.10 & 0.10 & 0 & 0 & 5.78 & 0.00 & 4.74 & 90 & 77 & 1481 & 1851 & 138 & 1820 & 138 & 1820 \\
\hline 311112003 & 0.00 & 0 & 0 & 0.04 & 600 & 0.08 & 0.03 & 0.10 & 0.10 & 0 & 0 & 5.57 & 0.00 & 4.58 & 90 & 77 & 1509 & 1887 & 131 & 2019 & 131 & 2019 \\
\hline 31122003 & 0.00 & 0 & 0 & 0.04 & 600 & 0.08 & 0.05 & 0.10 & 0.10 & 0 & 0 & \begin{tabular}{|l|l} 
& 5.37
\end{tabular} & 0.00 & 4.38 & 90 & 77 & 1548 & 1935 & 127 & 2078 & 127 & 2078 \\
\hline 31132003 & 0.00 & 0 & 0 & 0.06 & 600 & 0.13 & 0.03 & 0.10 & 0.10 & 0 & 0 & 5.17 & 0.00 & 4.17 & 90 & 77 & 1600 & 2001 & 130 & 2110 & 130 & 2110 \\
\hline 31142003 & 0.13 & 0 & 0 & 0.09 & 600 & 0.11 & 0.05 & 0.10 & 0.10 & 0 & 0 & 4.96 & 0.00 & 4.13 & 90 & 77 & 1593 & 1992 & 128 & 2123 & 128 & 2123 \\
\hline 31152003 & 0.50 & 0 & 0 & 0.06 & 600 & 0.08 & 0.04 & 0.10 & 0.10 & 0 & 0 & 4.88 & 0.00 & 4.47 & 90 & 77 & 1472 & 1839 & 156 & 2123 & 156 & 2123 \\
\hline 31162003 & 0.09 & 0 & 0 & 0.00 & 600 & 0.07 & 0.02 & 0.10 & 0.33 & 0 & 0 & 4.80 & 0.00 & 4.14 & 205 & 250 & 1477 & 1847 & 160 & 1811 & 160 & 1811 \\
\hline 31772003 & 0.00 & 0 & 0 & 0.00 & 600 & 0.09 & 0.06 & 0.10 & 0.19 & 0 & 0 & 4.72 & 0.00 & 3.80 & 166 & 141 & 1541 & 1927 & 146 & 1905 & 146 & 1905 \\
\hline 31182003 & 0.00 & 0 & 0 & 0.18 & 600 & 0.11 & 0.07 & 0.10 & 0.10 & 0 & 0 & 4.64 & 0.00 & 3.70 & 90 & 77 & 1571 & 1964 & 141 & 2296 & 141 & 2296 \\
\hline 3192003 & 0.00 & 0 & 0 & 0.21 & 600 & 0.09 & 0.05 & 0.10 & 0.10 & 0 & 0 & 4.56 & 0.00 & 3.67 & 90 & 77 & 1574 & 1968 & 138 & 2314 & 138 & 2314 \\
\hline
\end{tabular}


Note: Traditional drawdown (Type 3, normal year) selected for entire model run shown.

\begin{tabular}{|c|c|c|c|c|c|c|c|c|c|c|c|c|c|c|c|c|c|c|c|c|c|c|}
\hline \multirow{2}{*}{$\begin{array}{r}\text { Time-Step } \\
\text { Date }\end{array}$} & \multicolumn{5}{|c|}{$\mathbb{N}$} & \multicolumn{6}{|c|}{ OUT } & \multicolumn{3}{|c|}{ Management } & \multicolumn{4}{|c|}{ MODELOUTPUT } & \multicolumn{4}{|c|}{ NGWD CONPOSTEEDATA } \\
\hline & $\begin{array}{l}\text { Precip } \\
\text { inches }\end{array}$ & & ECCgN) & $\begin{array}{l}\text { Dp. Inflor } \\
\text { incheres }\end{array}$ & & $\begin{array}{c}\text { Evap. (opel } \\
\text { waterer) } \\
\text { incless }\end{array}$ & $\begin{array}{c}\text { ET } \\
\text { (veg. areas) } \\
\text { inches }\end{array}$ & $\begin{array}{c}\text { Op Spill } \\
\text { inches }\end{array}$ & $\begin{array}{c}\text { Outflow } \\
\text { inches }\end{array}$ & $\begin{array}{l}\text { GW } \\
\text { incthes }\end{array}$ & $\begin{array}{l}\mathrm{EC}(\mathrm{gw}) \\
\text { UScmon }\end{array}$ & \begin{tabular}{|l} 
Depth \\
(hab) \\
inches
\end{tabular} & $\begin{array}{l}\text { Depth } \\
\text { (CC) }\end{array}$ & $\begin{array}{l}\text { Endof } \\
\text { Day } \\
\text { inthes }\end{array}$ & $\begin{array}{l}\text { Flow } \\
\text { (ds) }\end{array}$ & $\begin{array}{l}\text { Adj. } \\
\text { Flow } \\
\text { (cts) }\end{array}$ & $\begin{array}{l}\text { EC } \\
\text { USCOm }\end{array}$ & $\begin{array}{c}\mathrm{Adj}, \mathrm{EC} \\
\mathrm{IS \textrm {CCm }}\end{array}$ & $\begin{array}{l}\text { GWD } \\
\left.a_{(\text {Cs }}\right)\end{array}$ & $\begin{array}{l}\text { Personnel } \\
\text { EC (uScm) }\end{array}$ & $\begin{array}{l}\text { Real-Fim } \\
\text { Q(fisis) }\end{array}$ & $\begin{array}{l}\text { e Network } \\
\text { EC( (LSC)m }\end{array}$ \\
\hline 32012003 & 0.00 & 0 & 0 & 0.17 & 600 & 0.11 & 0.05 & 0.10 & 0.10 & 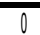 & 0 & 4.47 & 0.00 & 3.58 & 90 & 77 & 1599 & 1999 & 110 & 2293 & 110 & 2293 \\
\hline 3212003 & 0.00 & 0 & 0 & 0.19 & 600 & 0.11 & 0.05 & 0.10 & 0.10 & 0 & 0 & 4.39 & 0.00 & 3.52 & 90 & 77 & 1616 & 2020 & 100 & 2339 & 100 & 2339 \\
\hline 32212003 & 0.00 & 0 & 0 & 0.19 & 600 & 0.10 & 0.05 & 0.10 & 0.10 & 0 & 0 & 4.31 & 0.00 & 3.44 & 90 & 77 & 1635 & 2044 & 87 & 2367 & 87 & 2367 \\
\hline 32320203 & 0.03 & 0 & 0 & 0.13 & 600 & 0.08 & 0.02 & 0.10 & 0.10 & 0 & 0 & 4.16 & 0.00 & 3.41 & 90 & 77 & 1627 & 2034 & 87 & 2379 & 87 & 2379 \\
\hline 3242003 & 0.00 & 0 & 0 & 0.04 & 600 & 0.10 & 0.06 & 0.10 & 0.10 & 0 & 0 & 4.01 & 0.00 & 3.19 & 90 & 77 & 1701 & 2126 & 86 & 2367 & 86 & 2367 \\
\hline 32520003 & 0.00 & 0 & 0 & 0.13 & 600 & 0.11 & 0.05 & 0.10 & 0.10 & 0 & 0 & 3.87 & 0.00 & 3.06 & 90 & 77 & 1746 & 2183 & 82 & 2367 & 82 & 2367 \\
\hline 322012003 & 0.00 & 0 & 0 & 0.14 & 600 & 0.17 & 0.05 & 0.10 & 0.10 & 0 & 0 & 3.72 & 0.00 & 2.87 & 90 & 77 & 1830 & 2288 & 84 & 2490 & 84 & 2490 \\
\hline 32712003 & 0.00 & 0 & 0 & 0.19 & 600 & 0.11 & 0.08 & 0.10 & 0.10 & 0 & 0 & 3.57 & 0.00 & 2.77 & 90 & 77 & 1872 & 2340 & 76 & 2570 & 76 & 2570 \\
\hline 32820033 & \begin{tabular}{l|l}
3 & 0.00
\end{tabular} & 0 & 0 & 0.17 & 600 & 0.15 & 0.06 & 0.10 & 0.10 & 0 & 0 & 3.42 & 0.00 & 2.63 & 90 & 77 & 1945 & 2432 & 68 & 2774 & 68 & 2774 \\
\hline 32912003 & \begin{tabular}{l|l}
3 & 0.00
\end{tabular} & 0 & 0 & 0.18 & 600 & 0.18 & 0.06 & 0.10 & 0.10 & 0 & 0 & 3.27 & 0.00 & 2.47 & 90 & 77 & 2044 & 2555 & 58 & 2550 & 58 & 2550 \\
\hline 3/3012003 & 0.00 & 0 & 0 & 0.22 & 600 & 0.15 & 0.06 & 0.10 & 0.10 & 0 & 0 & 3.13 & 0.00 & 2.37 & 90 & 77 & 2094 & 2617 & 55 & 2555 & 55 & 2555 \\
\hline 33112003 & 0.00 & 0 & 0 & 0.18 & 600 & 0.15 & 0.06 & 0.10 & 0.10 & 0 & 0 & 298 & 0.00 & 2.24 & 90 & 77 & 2177 & 2721 & 53 & 2570 & 53 & 2570 \\
\hline 41112003 & 0.05 & 0 & 0 & 0.19 & 600 & 0.19 & 0.03 & 0.10 & 0.10 & 0 & 0 & 2.83 & 0.00 & 2.16 & 90 & 77 & 2214 & 2768 & 50 & 2715 & 50 & 2595 \\
\hline 421220033 & 0.01 & 0 & 0 & 0.14 & 600 & 0.09 & 0.05 & 0.10 & 0.10 & 0 & 0 & 2.68 & 0.00 & 2.07 & 90 & 77 & 2242 & 2803 & 47 & 2728 & 47 & 2002 \\
\hline 4/32003 & 0.00 & 0 & 0 & 0.10 & 600 & 0.03 & 0.05 & 0.10 & 0.10 & 0 & 0 & 2.53 & 0.00 & 1.99 & 90 & 77 & 2248 & 2810 & 44 & 2650 & 44 & 2594 \\
\hline 44420033 & 0.07 & 0 & 0 & 0.12 & 600 & 0.09 & 0.03 & 0.10 & 0.10 & 0 & 0 & 2.47 & 0.00 & 1.97 & 90 & 77 & 2204 & 2755 & 43 & 2643 & 43 & 2637 \\
\hline 4552003 & 0.00 & 0 & 0 & 0.09 & 600 & 0.10 & 0.06 & 0.10 & 0.10 & 0 & 0 & 2.40 & 0.00 & 1.81 & 90 & 77 & 2317 & 2890 & 47 & 2754 & 47 & 2759 \\
\hline 4662003 & 0.00 & 0 & 0 & 0.20 & 600 & 0.13 & 0.06 & 0.10 & 0.10 & 0 & 0 & 2.33 & 0.00 & 1.71 & 90 & 77 & 2380 & 2975 & 45 & 2221 & 45 & 2648 \\
\hline 4772003 & 0.00 & 0 & 0 & 0.23 & 600 & 0.15 & 0.06 & 0.10 & 0.10 & 0 & 0 & 2.27 & 0.00 & 1.63 & 90 & 77 & 2446 & 3058 & 44 & 2835 & 44 & 2675 \\
\hline 4882003 & 0.00 & 0 & 0 & 0.26 & 600 & 0.15 & 0.07 & 0.10 & 0.10 & 0 & 0 & 2.20 & 0.00 & 1.56 & 90 & 77 & 2492 & 3116 & 39 & 2824 & 39 & 2554 \\
\hline 4992003 & 0.00 & 0 & 0 & 0.27 & 600 & 0.15 & 0.07 & 0.10 & 0.10 & 0 & 0 & 2.13 & 0.00 & 1.51 & 90 & 77 & 2517 & 3146 & 36 & 2840 & 36 & 2716 \\
\hline 41010203 & 0.00 & 0 & 0 & 0.26 & 600 & 0.17 & 0.07 & 0.10 & 0.10 & 0 & 0 & 2.07 & 0.00 & 1.44 & 90 & 77 & 2578 & 3223 & 35 & 2900 & 60 & 3103 \\
\hline 411112003 & 0.00 & 0 & 0 & 0.28 & 600 & 0.17 & 0.04 & 0.10 & 0.10 & 0 & 0 & 200 & 0.00 & 1.40 & 90 & 77 & 2585 & 3231 & 30 & 3160 & 60 & 2376 \\
\hline 41122003 & 0.00 & 0 & 0 & 0.26 & 600 & 0.18 & 0.06 & 0.10 & 0.10 & 0 & 0 & 1.93 & 0.00 & 1.33 & 90 & 77 & 2654 & 3318 & 28 & 2486 & 64 & 2428 \\
\hline $4 / 132003$ & 0.30 & 0 & 0 & 0.28 & 600 & 0.05 & 0.05 & 0.10 & 0.10 & 0 & 0 & 1.87 & 0.00 & 1.71 & 90 & 77 & 2144 & 2680 & 29 & 2507 & 60 & 2769 \\
\hline 414142003 & 0.00 & 0 & 0 & 0.00 & 600 & 0.03 & 0.06 & 0.10 & 0.26 & 0 & 0 & 1.80 & 0.00 & 1.30 & 233 & 198 & 2323 & 2004 & 29 & 2524 & 57 & 2570 \\
\hline 41552003 & 0.00 & 0 & 0 & 0.13 & 600 & 0.08 & 0.06 & 0.10 & 0.10 & 0 & 0 & 1.73 & 0.00 & 1.25 & 90 & 77 & 2407 & 3008 & 29 & 2538 & 57 & 2483 \\
\hline 4/1612003 & 0.05 & 0 & 0 & 0.18 & 600 & 0.14 & 0.05 & 0.10 & 0.10 & 0 & 0 & 1.67 & 0.00 & 1.19 & 90 & 77 & 2419 & 3024 & 29 & 2588 & 57 & 2800 \\
\hline 4417172003 & 0.00 & 0 & 0 & 0.18 & 600 & 0.09 & 0.05 & 0.10 & 0.10 & 0 & 0 & 1.00 & 0.00 & 1.13 & 90 & 77 & 750 & 938 & 29 & 2564 & 62 & 2711 \\
\hline 411822003 & 0.00 & 0 & 0 & 0.18 & 600 & 0.09 & 0.08 & 0.10 & 0.10 & 0 & 0 & 1.53 & 0.00 & 1.05 & 90 & 77 & 750 & 938 & 33 & 2609 & 63 & 2633 \\
\hline 41912003 & 0.00 & 0 & 0 & 0.21 & 600 & 0.12 & 0.07 & 0.10 & 0.10 & 0 & 0 & 1.47 & 0.00 & 0.96 & 90 & 77 & 750 & 938 & 35 & 2557 & 61 & 2468 \\
\hline 42020203 & 0.00 & 0 & 0 & 0.24 & 600 & 0.09 & 0.05 & 0.10 & 0.10 & 0 & 0 & 1.40 & 0.00 & 0.96 & 90 & 77 & 750 & 938 & 36 & 2996 & 64 & 2996 \\
\hline 42112003 & 0.02 & 0 & 0 & 0.18 & 600 & 0.14 & 0.06 & 0.10 & 0.10 & 0 & 0 & 1.33 & 0.00 & 0.80 & 90 & 77 & 750 & 938 & 36 & 2467 & 68 & 2430 \\
\hline 4222003 & 0.02 & 0 & 0 & 0.23 & 600 & 0.11 & 0.06 & 0.10 & 0.10 & 0 & 0 & 1.27 & 0.00 & 0.83 & 90 & 77 & 750 & 938 & 35 & 2340 & 73 & 2264 \\
\hline 423212003 & 0.00 & 0 & 0 & 0.20 & 600 & 0.11 & 0.07 & 0.10 & 0.10 & 0 & 0 & 1.20 & 0.00 & 0.75 & 90 & 77 & 750 & 938 & 35 & 2296 & 75 & 2529 \\
\hline 424242003 & 0.06 & 0 & 0 & 0.23 & 600 & 0.15 & 0.03 & 0.10 & 0.10 & 0 & 0 & 1.13 & 0.00 & 0.76 & 90 & 77 & 750 & 938 & 36 & 2167 & 73 & 2484 \\
\hline 42512003 & 0.00 & 0 & 0 & 0.16 & 600 & 0.15 & 0.06 & 0.10 & 0.10 & 0 & 0 & 1.07 & 0.00 & 0.60 & 90 & 77 & 750 & 938 & 34 & 2112 & 79 & 2230 \\
\hline 42602003 & 0.00 & 0 & 0 & 0.25 & 600 & 0.13 & 0.07 & 0.10 & 0.10 & 0 & 0 & 1.00 & 0.00 & 0.56 & 90 & 77 & 750 & 938 & 35 & 1997 & 100 & 2123 \\
\hline 427272003 & 0.00 & 0 & 0 & 0.25 & 600 & 0.16 & 0.08 & 0.10 & 0.10 & 0 & 0 & 0.93 & 0.00 & 0.46 & 90 & 77 & 750 & 938 & 36 & 1986 & 102 & 2280 \\
\hline 42812003 & 0.22 & 0 & 0 & 0.28 & 600 & 0.11 & 0.07 & 0.10 & 0.10 & 0 & 0 & 0.87 & 0.00 & 0.69 & 90 & 77 & 750 & 938 & 32 & 2031 & 90 & 2517 \\
\hline 42920033 & 0.00 & 0 & 0 & 0.00 & 600 & 0.14 & 0.08 & 0.10 & 0.10 & 0 & 0 & 0.80 & 0.00 & 0.37 & 92 & 79 & 750 & 938 & 29 & 2021 & 87 & 2671 \\
\hline $4 / 3012003$ & 0.00 & 0 & 0 & 0.26 & 600 & 0.13 & 0.08 & 0.10 & 0.10 & 0 & 0 & 0.73 & 0.00 & 0.32 & 90 & 77 & 750 & 938 & 27 & 2015 & 81 & 2791 \\
\hline 51112003 & 0.00 & 0 & 0 & 0.25 & 600 & 0.11 & 0.06 & 0.10 & 0.10 & 0 & 0 & 0.67 & 0.00 & 0.30 & 90 & 77 & 750 & 938 & 27 & 1974 & 74 & 2975 \\
\hline 5222003 & \begin{tabular}{|l|l|} 
\\
\end{tabular} & 0 & 0 & 0.22 & 600 & 0.09 & 0.03 & 0.10 & 0.10 & 0 & 0 & 0.60 & 0.00 & 0.47 & 90 & 77 & 750 & 938 & 26 & 2038 & 73 & 2893 \\
\hline $5 / 322003$ & 0.42 & 0 & 0 & 0.28 & 600 & 0.07 & 0.02 & 0.10 & 0.10 & 0 & 0 & 0.87 & 0.00 & 0.97 & 90 & 77 & 750 & 938 & 27 & 1959 & 73 & 2646 \\
\hline 542003 & 0.00 & 0 & 0 & 0.01 & 600 & 0.11 & 0.06 & 0.10 & 0.10 & 0 & 0 & 1.13 & 0.00 & 0.71 & 90 & 77 & 750 & 938 & 37 & 1992 & 83 & 2376 \\
\hline 5552003 & 0.00 & 0 & 0 & 0.87 & 600 & 0.12 & 0.08 & 0.10 & 0.10 & 0 & 0 & 1.83 & 0.00 & 1.28 & 90 & 77 & 750 & 938 & 37 & 1727 & 90 & 2317 \\
\hline 5612003 & 0.00 & 0 & 0 & 0.90 & 600 & 0.19 & 0.09 & 0.10 & 0.10 & 0 & 0 & 2.53 & 0.00 & 1.79 & 90 & 77 & 783 & 979 & 35 & 1600 & 91 & 2248 \\
\hline 57120033 & 0.00 & 0 & 0 & 0.61 & 600 & 0.14 & 0.07 & 0.10 & 0.10 & 0 & 0 & 2.80 & 0.00 & 2.10 & 90 & 77 & 802 & 1003 & 35 & 1580 & 104 & 2008 \\
\hline
\end{tabular}


Note: Traditional drawdown (Type 3, normal year) selected for entire model run shown.

\begin{tabular}{|c|c|c|c|c|c|c|c|c|c|c|c|c|c|c|c|c|c|c|c|c|c|c|}
\hline \multirow{2}{*}{\begin{tabular}{r|} 
Time-Step \\
Date
\end{tabular}} & \multicolumn{5}{|c|}{$\mathbb{N}$} & \multicolumn{6}{|c|}{ OUT } & \multicolumn{3}{|c|}{ Management } & \multicolumn{4}{|c|}{ MODEL OUTPUT } & \multicolumn{4}{|c|}{ NGWD COMPOSTTEDATA } \\
\hline & $\begin{array}{l}\text { Precip } \\
\text { inches }\end{array}$ & & ECCgw) & $\begin{array}{l}\text { Dp. Inflor } \\
\text { inchers }\end{array}$ & & $\begin{array}{c}\text { Evap. (opel } \\
\text { waterer) } \\
\text { incless }\end{array}$ & $\begin{array}{c}\text { ET } \\
\text { (veg. areas) } \\
\text { incless }\end{array}$ & $\begin{array}{c}\text { Op Spill } \\
\text { inches }\end{array}$ & $\begin{array}{c}\text { Outflow } \\
\text { inthes }\end{array}$ & $\begin{array}{l}\text { GW } \\
\text { incthes }\end{array}$ & $\begin{array}{l}\mathrm{EC}(\mathrm{gw}) \\
\mathrm{ISC \textrm {cm }}\end{array}$ & \begin{tabular}{|l} 
Depth \\
(habl) \\
inctes
\end{tabular} & $\begin{array}{l}\text { Depth } \\
\text { (CC) }\end{array}$ & $\begin{array}{l}\text { Endo } \\
\text { Day } \\
\text { inches }\end{array}$ & $\begin{array}{l}\text { Flow } \\
\text { (cts) }\end{array}$ & $\begin{array}{l}\text { Adj. } \\
\text { Flow } \\
\text { (cos) }\end{array}$ & $\begin{array}{l}\text { EC } \\
\text { USCm }\end{array}$ & $\begin{array}{c}\text { Adi. EC } \\
\text { ISCOC }\end{array}$ & $\begin{array}{l}\text { GWD } \\
a_{\text {(fs }}\end{array}$ & $\begin{array}{l}\text { Personnel } \\
E C(\Delta S C m)\end{array}$ & $\begin{array}{l}\text { Real-Fim } \\
\text { Q(cists }\end{array}$ & $\begin{array}{l}\text { e Network } \\
\text { EC (HSCcm) }\end{array}$ \\
\hline 5812003 & 0.00 & 0 & 0 & 0.00 & 600 & 0.13 & 0.08 & 0.10 & 0.11 & 0 & 0 & 2.43 & 0.00 & 1.78 & 101 & 86 & 915 & 1143 & 32 & 1556 & 104 & 1813 \\
\hline 5992003 & 0.00 & 0 & 0 & 0.00 & 600 & 0.12 & 0.09 & 0.10 & 0.11 & 0 & 0 & 2.07 & 0.00 & 1.47 & 98 & 83 & 1075 & 1343 & 26 & 1508 & 89 & 1588 \\
\hline 5102003 & 0.00 & 0 & 0 & 0.00 & 600 & 0.14 & 0.09 & 0.10 & 0.11 & 0 & 0 & 1.70 & 0.00 & 1.13 & 100 & 85 & 1395 & 1744 & 24 & 1517 & 102 & 1676 \\
\hline 511112003 & 0.00 & 0 & 0 & 0.02 & 600 & 0.16 & 0.10 & 0.10 & 0.10 & 0 & 0 & 1.33 & 0.00 & 0.79 & 90 & 77 & 750 & 938 & 24 & 1508 & 95 & 1680 \\
\hline 51122003 & 0.00 & 0 & 0 & 0.10 & 600 & 0.16 & 0.10 & 0.10 & 0.10 & 0 & 0 & 1.03 & 0.00 & 0.53 & 90 & 77 & 750 & 938 & 32 & 1794 & 88 & 18008 \\
\hline $5 / 132003$ & 0.00 & 0 & 0 & 0.10 & 600 & 0.20 & 0.11 & 0.10 & 0.10 & 0 & 0 & 0.73 & 0.00 & 0.22 & 90 & 77 & 750 & 938 & 25 & 1664 & 75 & 1673 \\
\hline 51412003 & 0.00 & 0 & 0 & 0.15 & 600 & 0.27 & 0.06 & 0.10 & 0.10 & 0 & 0 & 0.43 & 0.00 & 0.00 & 90 & 77 & 0 & 0 & 23 & 1589 & 67 & 1006 \\
\hline 5152003 & 0.00 & 0 & 0 & 0.11 & 600 & 0.17 & 0.11 & 0.10 & 0.10 & 0 & 0 & 0.13 & 0.00 & 0.00 & 90 & 77 & 0 & 0 & 18 & 1450 & 62 & 1639 \\
\hline 51162003 & \begin{tabular}{l|l}
3 & 0.00
\end{tabular} & 0 & 0 & 0.00 & 600 & 0.00 & 0.00 & 0.00 & 0.00 & 0 & 0 & 0.00 & 0.00 & 0.00 & 0 & 0 & 0 & 0 & 16 & 1413 & 65 & 1625 \\
\hline $51 / 7172003$ & \begin{tabular}{l|l}
3 & 0.00
\end{tabular} & 0 & 0 & 0.00 & 600 & 0.00 & 0.00 & 0.00 & 0.00 & 0 & 0 & 0.00 & 0.00 & 0.00 & 0 & 0 & 0 & 0 & 23 & 1500 & 58 & 1492 \\
\hline 51182003 & 0.00 & 0 & 0 & 0.00 & 600 & 0.00 & 0.00 & 0.00 & 0.00 & 0 & 0 & 0.00 & 0.00 & 0.00 & 0 & 0 & 0 & 0 & 20 & 1510 & 58 & 1373 \\
\hline 519192033 & 0.00 & 0 & 0 & 0.00 & 600 & 0.00 & 0.00 & 0.00 & 0.00 & 0 & 0 & 0.00 & 0.00 & 0.00 & 0 & 0 & 0 & 0 & 18 & 1289 & 61 & 1413 \\
\hline 512012003 & 0.00 & 0 & 0 & 0.00 & 600 & 0.00 & 0.00 & 0.00 & 0.00 & 0 & 0 & 0.00 & 0.00 & 0.00 & 0 & 0 & 0 & 0 & 9 & 1589 & 74 & 1404 \\
\hline 521212003 & 0.00 & 0 & 0 & 0.00 & 600 & 0.00 & 0.00 & 0.00 & 0.00 & 0 & 0 & 0.00 & 0.00 & 0.00 & 0 & 0 & 0 & 0 & 17 & 1612 & 72 & 1513 \\
\hline 512212003 & 0.00 & 0 & 0 & 0.00 & 600 & 0.00 & 0.00 & 0.00 & 0.00 & 0 & 0 & 0.00 & 0.00 & 0.00 & 0 & 0 & 0 & 0 & 15 & 1633 & 53 & 1537 \\
\hline 512320033 & 0.00 & 0 & 0 & 0.00 & 600 & 0.00 & 0.00 & 0.00 & 0.00 & 0 & 0 & 0.00 & 0.00 & 0.00 & 0 & 0 & 0 & 0 & 30 & 1527 & 70 & 1456 \\
\hline $5 / 242003$ & 0.00 & 0 & 0 & 0.00 & 600 & 0.00 & 0.00 & 0.00 & 0.00 & 0 & 0 & 0.00 & 0.00 & 0.00 & 0 & 0 & 0 & 0 & 27 & 1530 & 57 & 1368 \\
\hline 51252003 & 0.00 & 0 & 0 & 0.00 & 600 & 0.00 & 0.00 & 0.00 & 0.00 & 0 & 0 & 0.00 & 0.00 & 0.00 & 0 & 0 & 0 & 0 & 21 & 1452 & 55 & 1348 \\
\hline 512612003 & 0.00 & 0 & 0 & 0.00 & 600 & 0.00 & 0.00 & 0.00 & 0.00 & 0 & 0 & 0.00 & 0.00 & 0.00 & 0 & 0 & 0 & 0 & 15 & 1473 & 56 & 1299 \\
\hline 512712003 & 0.00 & 0 & 0 & 0.00 & 600 & 0.00 & 0.00 & 0.00 & 0.00 & 0 & 0 & 0.00 & 0.00 & 0.00 & 0 & 0 & 0 & 0 & 11 & 1427 & 58 & 1292 \\
\hline 512820033 & 0.00 & 0 & 0 & 0.00 & 600 & 0.00 & 0.00 & 0.00 & 0.00 & 0 & 0 & 0.00 & 0.00 & 0.00 & 0 & 0 & 0 & 0 & 21 & 1200 & 65 & 1306 \\
\hline 529212003 & 0.00 & 0 & 0 & 0.00 & 600 & 0.00 & 0.00 & 0.00 & 0.00 & 0 & 0 & 0.00 & 0.00 & 0.00 & 0 & 0 & 0 & 0 & 38 & 1029 & 91 & 1231 \\
\hline 53002003 & 0.00 & 0 & 0 & 0.00 & 600 & 0.00 & 0.00 & 0.00 & 0.00 & 0 & 0 & 0.00 & 0.00 & 0.00 & 0 & 0 & 0 & 0 & 8 & 1338 & 84 & 1264 \\
\hline $5 / 3112003$ & 0.00 & 0 & 0 & 0.00 & 600 & 0.00 & 0.00 & 0.00 & 0.00 & 0 & 0 & 0.00 & 0.00 & 0.00 & 0 & 0 & 0 & 0 & 8 & 1338 & 54 & 1345 \\
\hline 61112003 & 0.00 & 0 & 0 & 0.00 & 600 & 0.00 & 0.00 & 0.00 & 0.00 & 0 & 0 & 0.00 & 0.00 & 0.00 & 0 & 0 & 0 & 0 & 18 & 1056 & 60 & 1313 \\
\hline 6122003 & 0.00 & 0 & 0 & 0.00 & 600 & 0.00 & 0.00 & 0.00 & 0.00 & 0 & 0 & 0.00 & 0.00 & 0.00 & 0 & 0 & 0 & 0 & 18 & 1056 & 61 & 1289 \\
\hline 61322003 & 0.00 & 0 & 0 & 0.92 & 600 & 0.28 & 0.14 & 0.10 & 0.10 & 0 & 0 & 1.07 & 0.00 & 0.39 & 90 & 77 & 750 & 938 & 29 & 972 & 68 & 1289 \\
\hline 6412003 & 0.00 & 0 & 0 & 1.44 & 600 & 0.21 & 0.12 & 0.10 & 0.10 & 0 & 0 & 2.13 & 0.00 & 1.40 & 90 & 77 & 750 & 938 & 36 & 931 & 73 & 1225 \\
\hline 6152003 & 0.00 & 0 & 0 & 1.35 & 600 & 0.25 & 0.12 & 0.10 & 0.10 & 0 & 0 & 3.20 & 0.00 & 2.28 & 90 & 77 & 773 & 967 & 60 & 962 & 86 & 1155 \\
\hline 6662003 & 0.00 & 0 & 0 & 1.39 & 600 & 0.22 & 0.12 & 0.10 & 0.10 & 0 & 0 & 4.27 & 0.00 & 3.22 & 90 & 77 & 779 & 974 & 55 & 955 & 83 & 1196 \\
\hline 6712003 & 0.00 & 0 & 0 & 0.56 & 600 & 0.20 & 0.12 & 0.10 & 0.10 & 0 & 0 & 4.40 & 0.00 & 3.36 & 90 & 77 & 821 & 1027 & 41 & 937 & 74 & 1181 \\
\hline 682003 & 0.00 & 0 & 0 & 0.00 & 600 & 0.20 & 0.12 & 0.10 & 0.25 & 0 & 0 & 3.73 & 0.00 & 2.78 & 226 & 192 & 941 & 1176 & 38 & 932 & 71 & 1161 \\
\hline 6912003 & 0.00 & 0 & 0 & 0.00 & 600 & 0.30 & 0.13 & 0.10 & 0.25 & 0 & 0 & 3.07 & 0.00 & 2.11 & 224 & 191 & 1217 & 1521 & 34 & 944 & 69 & 1133 \\
\hline 61102003 & 0.00 & 0 & 0 & 0.00 & 600 & 0.24 & 0.11 & 0.10 & 0.15 & 0 & 0 & 2.40 & 0.00 & 1.00 & 134 & 114 & 1015 & 2018 & 31 & 919 & 129 & 1140 \\
\hline 601112003 & 0.00 & 0 & 0 & 0.00 & 600 & 0.20 & 0.11 & 0.10 & 0.22 & 0 & 0 & 1.73 & 0.00 & 1.08 & 192 & 163 & 2529 & 3161 & 32 & 944 & 104 & 1261 \\
\hline 61122003 & 0.00 & 0 & 0 & 0.00 & 600 & 0.20 & 0.11 & 0.10 & 0.26 & 0 & 0 & 1.07 & 0.00 & 0.50 & 233 & 198 & 750 & 938 & 34 & 929 & 68 & 1314 \\
\hline 601312003 & 0.00 & 0 & 0 & 0.18 & 600 & 0.19 & 0.12 & 0.10 & 0.10 & 0 & 0 & 0.80 & 0.00 & 0.27 & 90 & 77 & 750 & 938 & 34 & 938 & 58 & 1191 \\
\hline $6 / 142003$ & 0.00 & 0 & 0 & 0.19 & 600 & 0.19 & 0.13 & 0.10 & 0.10 & 0 & 0 & 0.53 & 0.00 & 0.04 & 90 & 77 & 750 & 938 & 34 & 943 & 60 & 1295 \\
\hline $6 / 152003$ & 0.00 & 0 & 0 & 0.19 & 600 & 0.21 & 0.13 & 0.10 & 0.10 & 0 & 0 & 0.27 & 0.00 & 0.00 & 90 & 77 & 0 & 0 & 31 & 958 & 67 & 1301 \\
\hline 611610003 & 0.00 & 0 & 0 & 0.00 & 600 & 0.00 & 0.00 & 0.00 & 0.00 & 0 & 0 & 0.00 & 0.00 & 0.00 & 0 & 0 & 0 & 0 & 31 & 937 & 66 & 1304 \\
\hline 61172003 & 0.00 & 0 & 0 & 0.00 & 600 & 0.00 & 0.00 & 0.00 & 0.00 & 0 & 0 & 0.00 & 0.00 & 0.00 & 0 & 0 & 0 & 0 & 26 & 925 & 63 & 1245 \\
\hline $6 / 1812003$ & 0.00 & 0 & 0 & 0.00 & 600 & 0.00 & 0.00 & 0.00 & 0.00 & 0 & 0 & 0.00 & 0.00 & 0.00 & 0 & 0 & 0 & 0 & 23 & 937 & 54 & 1258 \\
\hline 6/1912003 & 0.00 & 0 & 0 & 0.00 & 600 & 0.00 & 0.00 & 0.00 & 0.00 & 0 & 0 & 0.00 & 0.00 & 0.00 & 0 & 0 & 0 & 0 & 20 & 930 & 50 & 1310 \\
\hline 612012003 & 0.00 & 0 & 0 & 0.00 & 600 & 0.00 & 0.00 & 0.00 & 0.00 & 0 & 0 & 0.00 & 0.00 & 0.00 & 0 & 0 & 0 & 0 & 19 & 924 & 52 & 1286 \\
\hline 61212003 & 0.00 & 0 & 0 & 0.00 & 600 & 0.00 & 0.00 & 0.00 & 0.00 & 0 & 0 & 0.00 & 0.00 & 0.00 & 0 & 0 & 0 & 0 & 19 & 905 & 53 & 1197 \\
\hline 612220033 & 0.00 & 0 & 0 & 0.00 & 600 & 0.00 & 0.00 & 0.00 & 0.00 & 0 & 0 & 0.00 & 0.00 & 0.00 & 0 & 0 & 0 & 0 & 18 & 900 & 65 & 1024 \\
\hline 612322003 & 0.00 & 0 & 0 & 0.00 & 600 & 0.00 & 0.00 & 0.00 & 0.00 & 0 & 0 & 0.00 & 0.00 & 0.00 & 0 & 0 & 0 & 0 & 18 & 917 & 70 & 1019 \\
\hline 61242003 & 0.00 & 0 & 0 & 0.00 & 600 & 0.00 & 0.00 & 0.00 & 0.00 & 0 & 0 & 0.00 & 0.00 & 0.00 & 0 & 0 & 0 & 0 & 18 & 917 & 70 & 947 \\
\hline 612520033 & 0.00 & 0 & 0 & 0.00 & 600 & 0.00 & 0.00 & 0.00 & 0.00 & 0 & 0 & 0.00 & 0.00 & 0.00 & 0 & 0 & 0 & 0 & 18 & 900 & 63 & 1087 \\
\hline
\end{tabular}


Note: Traditional drawdown (Type 3, normal year) selected for entire model run shown.

\begin{tabular}{|c|c|c|c|c|c|c|c|c|c|c|c|c|c|c|c|c|c|c|c|c|c|c|}
\hline \multirow{2}{*}{\begin{tabular}{r|} 
Time-Step \\
Date
\end{tabular}} & \multicolumn{5}{|c|}{$\mathbb{N}$} & \multicolumn{6}{|c|}{ OUT } & \multicolumn{3}{|c|}{ Management } & \multicolumn{4}{|c|}{ MODEL OUTPUT } & \multicolumn{4}{|c|}{ NGWD COMPOSTEDDATA } \\
\hline & $\begin{array}{l}\text { Precip } \\
\text { inches }\end{array}$ & & EC(gN) & $\begin{array}{l}\text { Dp. Inflor } \\
\text { indrotes }\end{array}$ & & $\begin{array}{c}\text { Evap. (opel } \\
\text { waterer) } \\
\text { incless }\end{array}$ & $\begin{array}{c}\text { ET } \\
\text { (veg. areas) } \\
\text { incles }\end{array}$ & $\begin{array}{c}\text { Op Spill } \\
\text { inches }\end{array}$ & $\begin{array}{c}\text { Outflow } \\
\text { inthes }\end{array}$ & $\begin{array}{l}\text { GW } \\
\text { incthes }\end{array}$ & $\begin{array}{l}\mathrm{EC}(\mathrm{gW}) \\
\mathrm{ISCm}\end{array}$ & \begin{tabular}{|l} 
Depth \\
(habl) \\
inctes
\end{tabular} & $\begin{array}{l}\text { Depth } \\
\text { (CC) }\end{array}$ & $\begin{array}{l}\text { Endo } \\
\text { Day } \\
\text { inches }\end{array}$ & $\begin{array}{l}\text { Flow } \\
\text { (cts) }\end{array}$ & $\begin{array}{l}\text { Adj. } \\
\text { Flow } \\
\text { (cos) }\end{array}$ & $\begin{array}{l}\mathrm{EC} \\
\mathrm{US} / \mathrm{Cm}\end{array}$ & $\begin{array}{c}\mathrm{Adj}, \mathrm{EC} \\
\mathrm{ISCO}\end{array}$ & $\begin{array}{l}\text { GWD } \\
\left.a_{\text {(fs }}\right)\end{array}$ & 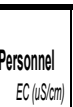 & 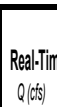 & $\begin{array}{l}\text { e Network } \\
\text { EC (WSCm) }\end{array}$ \\
\hline 626212003 & 0.00 & 0 & 0 & 0.00 & 600 & 0.00 & 0.00 & 0.00 & 0.00 & 0 & 0 & 0.00 & 0.00 & 0.00 & 0 & 0 & 0 & $\overline{0}$ & 20 & 960 & 56 & 1391 \\
\hline 627/2003 & 0.00 & 0 & 0 & 0.00 & 600 & 0.00 & 0.00 & 0.00 & 0.00 & 0 & 0 & 0.00 & 0.00 & 0.00 & 0 & 0 & 0 & 0 & 34 & 903 & 57 & 1503 \\
\hline 628212003 & 0.00 & 0 & 0 & 0.00 & 600 & 0.00 & 0.00 & 0.00 & 0.00 & 0 & 0 & 0.00 & 0.00 & 0.00 & 0 & 0 & 0 & 0 & 40 & 800 & 57 & 1566 \\
\hline 62920203 & 0.00 & 0 & 0 & 0.00 & 600 & 0.00 & 0.00 & 0.00 & 0.00 & 0 & 0 & 0.00 & 0.00 & 0.00 & 0 & 0 & 0 & 0 & 50 & 772 & 55 & 1600 \\
\hline 63012003 & 0.00 & 0 & 0 & 0.00 & 600 & 0.00 & 0.00 & 0.00 & 0.00 & 0 & 0 & 0.00 & 0.00 & 0.00 & 0 & 0 & 0 & 0 & 64 & 784 & 60 & 1544 \\
\hline 71112003 & 0.00 & 0 & 0 & 0.00 & 600 & 0.00 & 0.00 & 0.00 & 0.00 & 0 & 0 & 0.00 & 0.00 & 0.00 & 0 & 0 & 0 & 0 & 43 & 750 & 55 & 1374 \\
\hline 71220033 & 0.00 & 0 & 0 & 0.00 & 600 & 0.00 & 0.00 & 0.00 & 0.00 & 0 & 0 & 0.00 & 0.00 & 0.00 & 0 & 0 & 0 & 0 & 28 & 800 & 73 & 1306 \\
\hline $7 / 320033$ & 0.00 & 0 & 0 & 0.00 & 600 & 0.00 & 0.00 & 0.00 & 0.00 & 0 & 0 & 0.00 & 0.00 & 0.00 & 0 & 0 & 0 & 0 & 19 & 800 & 57 & 1444 \\
\hline $7 / 42003$ & 0.00 & 0 & 0 & 0.00 & 600 & 0.00 & 0.00 & 0.00 & 0.00 & 0 & 0 & 0.00 & 0.00 & 0.00 & 0 & 0 & 0 & 0 & 17 & 800 & 50 & 1548 \\
\hline 7512003 & 0.00 & 0 & 0 & 0.00 & 600 & 0.00 & 0.00 & 0.00 & 0.00 & 0 & 0 & 0.00 & 0.00 & 0.00 & 0 & 0 & 0 & 0 & 17 & 800 & 50 & 1667 \\
\hline 7662003 & 0.00 & 0 & 0 & 0.00 & 600 & 0.00 & 0.00 & 0.00 & 0.00 & 0 & 0 & 0.00 & 0.00 & 0.00 & 0 & 0 & 0 & 0 & 21 & 800 & 51 & 1756 \\
\hline 7712003 & 0.00 & 0 & 0 & 0.00 & 600 & 0.00 & 0.00 & 0.00 & 0.00 & 0 & 0 & 0.00 & 0.00 & 0.00 & 0 & 0 & 0 & 0 & 25 & 800 & 51 & 1768 \\
\hline 7812003 & 0.00 & 0 & 0 & 0.00 & 600 & 0.00 & 0.00 & 0.00 & 0.00 & 0 & 0 & 0.00 & 0.00 & 0.00 & 0 & 0 & 0 & 0 & 27 & 800 & 48 & 1003 \\
\hline 7912003 & 0.00 & 0 & 0 & 0.00 & 600 & 0.00 & 0.00 & 0.00 & 0.00 & 0 & 0 & 0.00 & 0.00 & 0.00 & 0 & 0 & 0 & 0 & 27 & 800 & 44 & 1776 \\
\hline 711020203 & 0.00 & 0 & 0 & 0.00 & 600 & 0.00 & 0.00 & 0.00 & 0.00 & 0 & 0 & 0.00 & 0.00 & 0.00 & 0 & 0 & 0 & 0 & 30 & 800 & 46 & 1399 \\
\hline 711112003 & 0.00 & 0 & 0 & 0.00 & 600 & 0.00 & 0.00 & 0.00 & 0.00 & 0 & 0 & 0.00 & 0.00 & 0.00 & 0 & 0 & 0 & 0 & 30 & 800 & 59 & 1441 \\
\hline 71122003 & 0.00 & 0 & 0 & 0.00 & 600 & 0.00 & 0.00 & 0.00 & 0.00 & 0 & 0 & 0.00 & 0.00 & 0.00 & 0 & 0 & 0 & 0 & 27 & 800 & 52 & 1521 \\
\hline $7 / 1312003$ & 0.00 & 0 & 0 & 0.14 & 600 & 0.21 & 0.15 & 0.10 & 0.10 & 0 & 0 & 0.17 & 0.00 & 0.00 & 90 & 77 & 0 & 0 & 25 & 850 & 49 & 1504 \\
\hline $7 / 1420203$ & 0.00 & 0 & 0 & 0.29 & 600 & 0.20 & 0.15 & 0.10 & 0.10 & 0 & 0 & 0.33 & 0.00 & 0.00 & 90 & 77 & 0 & 0 & 23 & 850 & 52 & 1356 \\
\hline $7 / 152003$ & 0.00 & 0 & 0 & 0.43 & 600 & 0.20 & 0.15 & 0.10 & 0.10 & 0 & 0 & 0.50 & 0.00 & 0.00 & 90 & 77 & 0 & 0 & 38 & 850 & 55 & 1329 \\
\hline $7 / 1612003$ & 0.00 & 0 & 0 & 0.57 & 600 & 0.21 & 0.14 & 0.10 & 0.10 & 0 & 0 & 0.67 & 0.00 & 0.12 & 90 & 77 & 750 & 938 & 49 & 850 & 65 & 1188 \\
\hline 711712003 & 0.00 & 0 & 0 & 0.00 & 600 & 0.19 & 0.15 & 0.10 & 0.10 & 0 & 0 & 0.83 & 0.00 & 0.28 & 90 & 77 & 750 & 938 & 51 & 850 & 74 & 1142 \\
\hline 711820033 & 0.00 & 0 & 0 & 0.58 & 600 & 0.18 & 0.14 & 0.10 & 0.10 & 0 & 0 & 1.00 & 0.00 & 0.44 & 90 & 77 & 750 & 938 & 50 & 850 & 71 & 1165 \\
\hline $7 / 192003$ & 0.00 & 0 & 0 & 0.57 & 600 & 0.17 & 0.16 & 0.10 & 0.10 & 0 & 0 & 1.17 & 0.00 & 0.57 & 90 & 77 & 750 & 938 & 51 & 850 & 75 & 1093 \\
\hline 712020203 & 0.00 & 0 & 0 & 0.57 & 600 & 0.22 & 0.14 & 0.10 & 0.10 & 0 & 0 & 1.33 & 0.00 & 0.68 & 90 & 77 & 750 & 938 & 45 & 900 & 74 & 1196 \\
\hline 721212003 & 0.00 & 0 & 0 & 0.61 & 600 & 0.19 & 0.14 & 0.10 & 0.10 & 0 & 0 & 1.50 & 0.00 & 0.85 & 90 & 77 & 750 & 938 & 45 & 900 & 65 & 1774 \\
\hline 712222003 & 0.00 & 0 & 0 & 0.58 & 600 & 0.19 & 0.14 & 0.10 & 0.10 & 0 & 0 & 1.67 & 0.00 & 1.00 & 90 & 77 & 750 & 938 & 42 & 900 & 65 & 1329 \\
\hline 71232003 & 0.00 & 0 & 0 & 0.57 & 600 & 0.17 & 0.11 & 0.10 & 0.10 & 0 & 0 & 1.83 & 0.00 & 1.20 & 90 & 77 & 750 & 938 & 41 & 900 & 62 & 1334 \\
\hline 71242003 & 0.00 & 0 & 0 & 0.52 & 600 & 0.24 & 0.14 & 0.10 & 0.10 & 0 & 0 & 2.00 & 0.00 & 1.23 & 90 & 77 & 750 & 938 & 40 & 1000 & 62 & 1319 \\
\hline 712520003 & 0.00 & 0 & 0 & 0.34 & 600 & 0.19 & 0.15 & 0.10 & 0.10 & 0 & 0 & 1.83 & 0.00 & 1.13 & 90 & 77 & 950 & 1187 & 39 & 1000 & 55 & 1328 \\
\hline 712612003 & 0.00 & 0 & 0 & 0.30 & 600 & 0.15 & 0.14 & 0.10 & 0.10 & 0 & 0 & \begin{tabular}{|l}
$\mid .67$ \\
|
\end{tabular} & 0.00 & 1.04 & 90 & 77 & 750 & 938 & 39 & 1000 & 69 & 1407 \\
\hline 712712003 & 0.00 & 0 & 0 & 0.25 & 600 & 0.20 & 0.14 & 0.10 & 0.10 & 0 & 0 & 1.50 & 0.00 & 0.85 & 90 & 77 & 750 & 938 & 58 & 900 & 86 & 1291 \\
\hline 712820203 & 0.00 & 0 & 0 & 0.30 & 600 & 0.17 & 0.14 & 0.10 & 0.10 & 0 & 0 & 1.33 & 0.00 & 0.74 & 90 & 77 & 750 & 938 & 52 & 950 & 103 & 1213 \\
\hline 712912003 & 0.00 & 0 & 0 & 0.26 & 600 & 0.19 & 0.13 & 0.10 & 0.10 & 0 & 0 & 1.17 & 0.00 & 0.58 & 90 & 77 & 750 & 938 & 46 & 1000 & 101 & 1152 \\
\hline $7(3012003$ & 0.00 & 0 & 0 & 0.28 & 600 & 0.12 & 0.13 & 0.10 & 0.10 & 0 & 0 & 1.00 & 0.00 & 0.51 & 90 & 77 & 750 & 938 & 21 & 1250 & 74 & 1263 \\
\hline 73112003 & 0.03 & 0 & 0 & 0.21 & 600 & 0.20 & 0.05 & 0.10 & 0.10 & 0 & 0 & 0.83 & 0.00 & 0.39 & 90 & 77 & 750 & 938 & 17 & 1250 & 51 & 1441 \\
\hline 8112003 & 0.00 & 0 & 0 & 0.18 & 600 & 0.19 & 0.10 & 0.10 & 0.10 & 0 & 0 & 0.67 & 0.00 & 0.18 & 90 & 77 & 750 & 938 & 12 & 1250 & 41 & 1445 \\
\hline 8122003 & 0.24 & 0 & 0 & 0.25 & 600 & 0.19 & 0.10 & 0.10 & 0.10 & 0 & 0 & 0.50 & 0.00 & 0.28 & 90 & 77 & 750 & 938 & 6 & 1250 & 55 & 1301 \\
\hline 832003 & 0.00 & 0 & 0 & 0.00 & 600 & 0.20 & 0.13 & 0.10 & 0.10 & 0 & 0 & 0.33 & 0.00 & 0.00 & 90 & 77 & 0 & 0 & 0 & 0 & 61 & 1249 \\
\hline 8442003 & 0.00 & 0 & 0 & 0.14 & 600 & 0.24 & 0.13 & 0.10 & 0.10 & 0 & 0 & 0.17 & 0.00 & 0.00 & 90 & 77 & 0 & 0 & 0 & 0 & 56 & 1191 \\
\hline 852003 & 0.00 & 0 & 0 & 0.00 & 600 & 0.00 & 0.00 & 0.00 & 0.00 & 0 & 0 & 0.00 & 0.00 & 0.00 & 0 & 0 & 0 & 0 & 0 & 0 & 59 & 1239 \\
\hline 8612003 & 0.00 & 0 & 0 & 0.00 & 600 & 0.00 & 0.00 & 0.00 & 0.00 & 0 & 0 & 0.00 & 0.00 & 0.00 & 0 & 0 & 0 & 0 & 0 & 0 & 68 & 1309 \\
\hline 8712003 & 0.00 & 0 & 0 & 0.00 & 600 & 0.00 & 0.00 & 0.00 & 0.00 & 0 & 0 & 0.00 & 0.00 & 0.00 & 0 & 0 & 0 & 0 & 0 & 0 & 60 & 1351 \\
\hline 8812003 & 0.00 & 0 & 0 & 0.00 & 600 & 0.00 & 0.00 & 0.00 & 0.00 & 0 & 0 & 0.00 & 0.00 & 0.00 & 0 & 0 & 0 & 0 & 0 & 0 & 47 & 1338 \\
\hline 892003 & 0.00 & 0 & 0 & 0.00 & 600 & 0.00 & 0.00 & 0.00 & 0.00 & 0 & 0 & 0.00 & 0.00 & 0.00 & 0 & 0 & 0 & 0 & 0 & 0 & 43 & 1688 \\
\hline 81020203 & 0.00 & 0 & 0 & 0.00 & 600 & 0.00 & 0.00 & 0.00 & 0.00 & 0 & 0 & 0.00 & 0.00 & 0.00 & 0 & 0 & 0 & 0 & 0 & 0 & 42 & 1925 \\
\hline 811112003 & 0.00 & 0 & 0 & 0.00 & 600 & 0.00 & 0.00 & 0.00 & 0.00 & 0 & 0 & 0.00 & 0.00 & 0.00 & 0 & 0 & 0 & 0 & 0 & 0 & 40 & 2047 \\
\hline 81122003 & 0.00 & 0 & 0 & 0.00 & 600 & 0.00 & 0.00 & 0.00 & 0.00 & 0 & 0 & 0.00 & 0.00 & 0.00 & 0 & 0 & 0 & 0 & 0 & 0 & 43 & 2011 \\
\hline 81132003 & 0.00 & 0 & 0 & 0.00 & 600 & 0.00 & 0.00 & 0.00 & 0.00 & 0 & 0 & 0.00 & 0.00 & 0.00 & 0 & 0 & 0 & 0 & 0 & 0 & 38 & 2041 \\
\hline
\end{tabular}


Note: Traditional drawdown (Type 3, normal year) selected for entire model run shown.

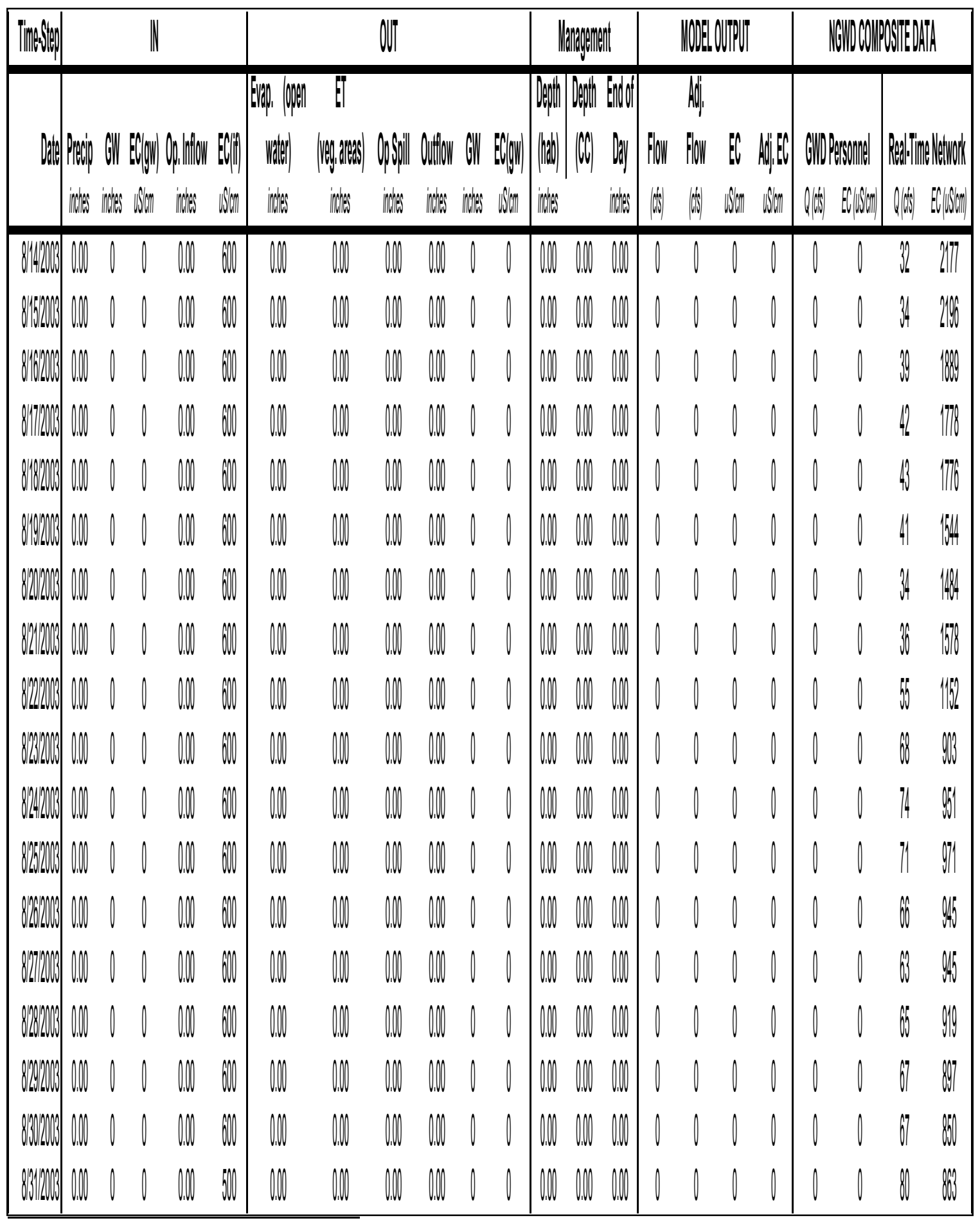




\section{APPENDIX 3 DESCRIPTION OF THE WETLAND WATER QUALITY MODEL (WWQM.xls)}

\section{Column A - Date}

The time-step for the WWQM is flexible, and is dependent upon the resolution of the input data. For the purposes of the real-time wetland water quality management project, the model uses a daily time-step. Use of the daily time-step is made possible by the availability of daily values for precipitation, evaporation, and evapotranspiration. In addition, the SJR salinity forecasts are available in a daily time-step format, and the real-time wetland water quality data being collected for this project, taken at 15-minute intervals, is readily averaged for a daily value. Any desired time-step can be easily used, however, all input data must match the model's time-step.

\section{Column B - Precipitation}

Precipitation data is a measured value. The precipitation data comes directly from the California Irrigation Management Information System (CIMIS) website, www.cimis.water.ca.gov, operated by the California Department of Water Resources (DWR). CIMIS publishes daily climatic data recorded at many weather monitoring stations across California. The monitoring station providing the precipitation data used in the WWQM is station 56 - Los Baños. This data is delivered to the user in the update[date].xls file.

\section{Column C - Groundwater Input}

Although the model has been developed to readily accept groundwater inflow and outflow none was supplied for this project. Many wetlands consist of soils with very low conductivities (clay, silt), so there is little regional groundwater flow into or out of the wetland system (Owen, 1995). It has been noted, however, in the wetlands of the GWD that local groundwater flow is important. Oftentimes, when a wetland has been drained while adjacent wetlands are still flooded, groundwater (usually high in salt content) rises to the surface in the drained wetland. Because the model simulates the entire wetland complex of the NGWD, this "localized' groundwater flow should have little impact on the model's overall results.This type of seepage more likely has an impact on the summer irrigation 
season and/or the following season's flood-up. This aspect of the model could benefit from additional research.

\section{Column D - Groundwater Input Salinity}

Groundwater Input

\section{Column E - Operational Inflow}

Operational inflow is a modeled value. It represents all water manually applied by the wetland managers in the form of flood-up, make-up, and irrigation water, and is calculated here. Inflow is the water added to the wetlands to keep their depth at or near management goals, or to provide summer irrigation water. This value is equal to the difference between the desired depth and the actual (modeled) depth, or make-up water, plus some extra for operational spill. The WWQM assumes zero make-up water when modeled depth is greater than management goals. These management goals are the driving force for this calculation and are based upon the assumption that the Guide to Wetland Management (henceforth "the guide") (Smith et. al, 1995) published through a cooperational effort by the California Waterfowl Association and the California Department of Fish and Game, dictates the general management theory that most wetland managers follow. This value is calculated by taking the desired daily wetland depth and comparing it to the end of day depth that the WWQM calculates. For instance, if the model balances all inputs (precipitation, P; groundwater, Gwin; and operational inflow, I) with all ouputs (evaporation, E; evapotranspiration, ET; groundwater, Gwout; operational spill, S; and outflow, O), and outputs a depth of $101 / 2$ inches, and the guide calls for a depth of 10 2/3 inches, the model asks for an operational inflow for the following day of $1 / 6$ of an inch. The model has programming in this column to first check if the user has asked for additional inflow by a decision variable in the application process interface contained in the file API.xls. This functionality is installed to allow the user to model the effects of a pre-flushing water management option that could be used to export some of the salts in the wetland prior to drawdown. 


\section{Column F - Operational Inflow Salinity}

Operational inflow salinity (EC) is an estimated value. Prior to 2003, the EC curve is was estimated using sporadic grab samples taken over the last few years. During 2003 and afterwards, it will be supplied with real-time data. (The real-time monitoring station installed on the Volta Wasteway has never been fully operational because of numerous episodes of vandalism. The Volta Wasteway feeds the San Luis Holding Reservoir, which supplies over $80 \%$ of the NGWD). Due to the various uncertainties downstream from the monitoring station, this is another area of study that could help reduce the error in the model. The uncertainties include additional inflow and outflow points, precipitation inputs, evaporation and evapotranspiration outputs, etc.)

\section{Column G - Evaporation}

Evaporation data is a measured value. The evaporation data comes directly from the CIMIS website, www.cimis.water.ca.gov, operated by DWR. CIMIS publishes daily climatic data recorded at many weather monitoring stations across California. The monitoring station providing the precipitation data used in the WWQM is station 5 - Shafter. The evaporation data comes from Shafter because it is the nearest location to Los Baños that has a full data set of pan evaporation data that is updated daily. As well, its use is justified because both station 5 and 56 (Los Baños) are located within the same CIMIS climate zone, zone 10 This data is updated periodically and delivered to the user in the update[date].xls file. The evaporation data that is downloaded from CIMIS is manipulated for use in the model by multiplying it by a pan coefficient, $\mathrm{Kp}$.

\section{Column H - Evapotranspiration}

Evapotranspiration data is a measured value. The evapotranspiration data comes directly from the CIMIS website, www.cimis.water.ca.gov, operated by DWR. CIMIS publishes daily climatic data recorded at many weather monitoring stations across California. The monitoring station providing the precipitation data used in the WWQM is station 56 - Los Baños. This data is updated periodically and delivered to the user in the update[date].xls file. The evapotranspiration data is calculated by CIMIS using a modified version of Penman's equation. It also includes a wind function developed by the University of California, Davis 
(CIMIS, 2003). This data is then manipulated for use in the model by multiplying it by a crop coefficient curve and by an osmotic resistance factor (Glenn et al, 1995).

\section{Column I - Operational Spill}

Operational spill data is estimated. It was first assumed to be one cubic foot per second for every 200 acres, however after developing the model it was lowered to one cubic foot per second for every 235 acres (or 0.10 inches of water per day, per acre).

\section{Column J - Outflow}

Outflow data is calculated within the model. While the wetlands are flooded, this value is calculated by adding the operational spill to the difference, if positive, of the end of day depth for day t-1 and the desired depth for day t. There is a depth cutoff, however, of $1 / 4$ inch, that functions as the threshold prompting the model to quit releasing water from the wetlands.

\section{Column K - Groundwater Output}

See description for Column C, "Groundwater Input", above.

\section{Column L - Groundwater Output Salinity}

See description for Column C, "Groundwater Input”, above.

\section{Columns $\mathrm{M}$ and $\mathrm{N}$ - Habitat and Cattle Club Wetland Management Depths}

The habitat wetland management depth and the cattle club wetland management depth data are adapted from Smith et al. 1995 "A Guide to Wetland Habitat Management in the Central Valley". The difference between the two management scenarios is that the habitat clubs manage for habitat throughout the year, whereas the cattle clubs manage for habitat during the hunting season, but drain their wetlands when duck season ends, allowing grasses to grow for cattle grazing. The habitat clubs and cattle clubs make up approximately $86 \%$ and $14 \%$ respectively, of the wetland acreage in the NGWD. This data takes the recommended water management (flooding and irrigation) plans for the three main wetland vegetation species targeted by wetland managers such as smartweed (Polygonum punctatum), 
swamp timothy (Heleochloa schoenoides), and watergrass (Echinochloa crusgalli) and averages them to get one wetland depth value per day, per management scenario.

These two management scenarios are the driving mechanisms for the WWQM. Depending on user input regarding water year type (very dry, dry, normal, and wet), the data is adjusted for the water year. The calculated end of day storage values (see column $\mathrm{O}$, below) are compared to the sum of $86 \%$ of the value for habitat clubs and $14 \%$ of the value for cattle clubs (column N), and the following day's inflow is calculated. If the management goal is less than the calculated end of day storage, outflow consists of the difference between those two plus the operational spill (column I), and the following days inflow (column E) is set to zero. If the management goal is greater than the calculated end of day storage, outflow consists of strictly the operational spill, and the difference, or make-up water, is applied in the following days inflow (column E).

\section{Column O - End of day Depth}

The end of day depth data are calculated by the WWQM by balancing all water inputs and outputs. These data are used in a comparison to the following day's desired depth, which drives the following day's inflow variable. The end of day depth is calculated in the following manner. Beginning with yesterday's (time t-1) end of day storage and adding and subtracting all inputs and outputs for today (time $\mathrm{t}=1$ ) to the end of day storage from time $\mathrm{t}-1$, the model calculates wetland depth at the end of time $t=1$. The model then compares the calculated end of time $t=1$ storage to the desired depth for time $t+1$. If the calculated depth for time $\mathrm{t}=1$ is less than the desired depth of time $\mathrm{t}+1$, Inflow for time $\mathrm{t}+1$ is equal to the difference between the calculated depth at time $\mathrm{t}=1$, and the desired depth at time $\mathrm{t}+1$, plus the estimated operational spill volume. Otherwise, if the calculated depth is greater than the desired depth, inflow is equal to zero.

\section{Column P - Flow}

This column represents one-half of the results. The flow value is calculated by converting the outflow value, $\mathrm{O}_{t}$, with units of inches per day, into a flowrate, $\mathrm{Q}_{\mathrm{t}}$, with units of cubic feet per second [cfs]. This is done by multiplying the outflow value by the total wetland acreage and by the conversion factor of 0.042014 [in/day to cfs/acre]. There is a depth cutoff, 
however, of $1 / 4$ inch, that functions as the threshold prompting the model to quit releasing water from the wetlands.

\section{Column Q - Adjusted Flow}

This column is available to apply a calibration factor calculated from comparing past results of modeled flow data to actual flow data.

\section{Column R - Salinity (EC)}

This column represents the other half of the results. The salinity, or EC, is calculated using a box model routine balancing all salt and water inputs with all salt and water outputs.

\section{Column S - Adjusted Salinity (EC)}

This column is available to apply a calibration factor calculated from comparing past results of modeled EC data to actual EC data. Currently, the model has been underestimating the salinity of the wetlands by roughly $80 \%$. This could be attributed to many things, the most important of which could be ground water, residual salts, bird droppings, and an underestimation of inflow EC.

\section{Columns T through W - NGWD Composite Flow and Salinity (EC) Values}

These four columns are populated with the flow and EC values from (columns T, U) the GWD staff sampling program and from (columns $\mathrm{V}, \mathrm{W}$ ) the real-time network. These values are updated periodically. 


\title{
Appendix 4 - Quinn, N. W. T., and W. M. Hanna, 2003
}

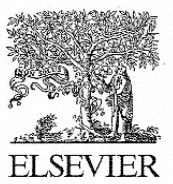

Available online at www.sciencedirect.com

science $\mathcal{W}$ Dinecto

Environmental

\section{A decision support system for adaptive real-time management of seasonal wetlands in California}

\author{
N.W.T. Quinn ${ }^{\mathrm{a}, *}$, W.M. Hanna ${ }^{\mathrm{b}}$ \\ a Berkeley National Laboratory, 1 Cyclotron Road, Building 70A-3317H, Berkeley, CA 94720, USA \\ ${ }^{\mathrm{b}}$ Department of Civil and Environmental Engineering, University of California, Los Angeles, CA 90095, USA
}

Received 15 October 2001; accepted 15 July 2002

\begin{abstract}
This paper describes the development of a comprehensive flow and salinity monitoring system and application of a decision support system (DSS) to improve management of seasonal wetlands in the San Joaquin Valley of California. The Environmental Protection Agency regulates salinity discharges from non-point sources to the San Joaquin River using a procedure known as the total maximum daily load (TMDL) to allocate the assimilative capacity of the river for salt among watershed sources. Management of wetland sources of salt load will require the development of monitoring systems, more integrative management strategies and coordination with other entities. To obtain local cooperation, the Grassland Water District (GWD), whose primary function is to supply surface water to private duck clubs and manage wetlands, needs to communicate to local landowners the likely impacts of salinity regulation on the long-term health and function of wildfowl habitat. The project described in this paper will also provide this information. The models that form the backbone of the DSS, develop salinity balances at both a regional and local scale. The regional scale concentrates on deliveries to and exports from the GWD while the local scale focuses on an individual wetland unit where more intensive monitoring is being conducted. The design of the DSS is constrained to meet the needs of busy wetland managers and is being designed from the bottom up utilizing tools and procedures familiar to these individuals.

(c) 2003 Elsevier Science Ltd. All rights reserved.
\end{abstract}

Keywords: Wetlands; Salinity; Real-time monitoring; Assimilative capacity

\section{Introduction}

The Grassland Water District (GWD) together with the adjacent State and Federal refuges constitute the largest contiguous wetland in the State of California (Fig. 1). The GWD comprises two interconnected units - the northern and southern GWD units-which together provides water to more than 20,000 ha of privately owned wetlands, mostly used as over-wintering habitat for wildfowl on the Pacific Flyway. The Northern GWD (NGWD) is larger in area than the Southern GWD and contains discrete drainage outlets, which provide drainage to distinct subbasins within the NGWD (Fig. 2). For this reason, the NGWD was chosen as the subject of the study described in this paper.

Seasonal wetlands in the GWD are flooded in the fall

${ }^{*}$ Corresponding author. Tel.: +1-510-486-7056; fax: +1-510-4867152.

E-mail address: nwquinn@lbl.gov (N.W.T. Quinn). and drawn-down in the spring to provide habitat for migratory waterfowl, shorebirds, and other wetlanddependent species. Due to alterations in natural hydrology, these wetlands are flooded with Central Valley Project water supplies delivered through GWD canals. In the spring, during the months of March-April, seasonal wetlands are drawn-down to mimic the natural dry cycle of a seasonal wetland. Wetland drawdowns are timed to make seed and invertebrate resources available during peak waterfowl and shorebird migrations and to correspond with optimal germination conditions (primarily soil temperature) to grow naturally occurring moist-soil plants. The seeds of moist-soil plants are recognized as a critical waterfowl food source, providing essential nutrients and energy for wintering and migrating birds (Fredrickson and Taylor, 1982). Optimal timing of wetland flood-up and release has been determined by trial and error for different species of moist-soil plants and for different environmental conditions, although guidelines for these practices are poorly documented. 


\section{San Joaquin River Basin}

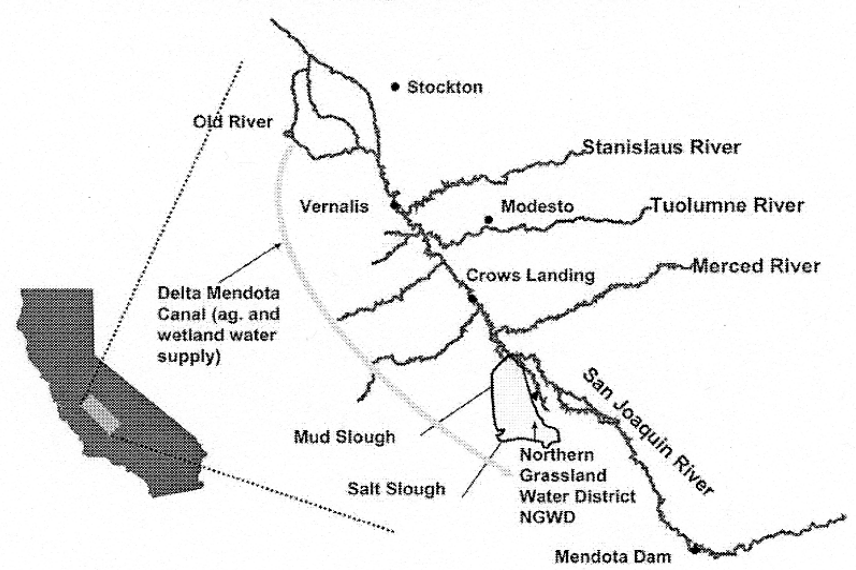

Fig. 1. SJR Basin showing NGWD and the major west-side wetland drainage conveyances Mud and Salt Sloughs. Water supply to agriculture and wetlands in the Grassland subbasin is provided through pumping from the Sacramento-San Joaquin Delta via the Delta Mendota Canal.

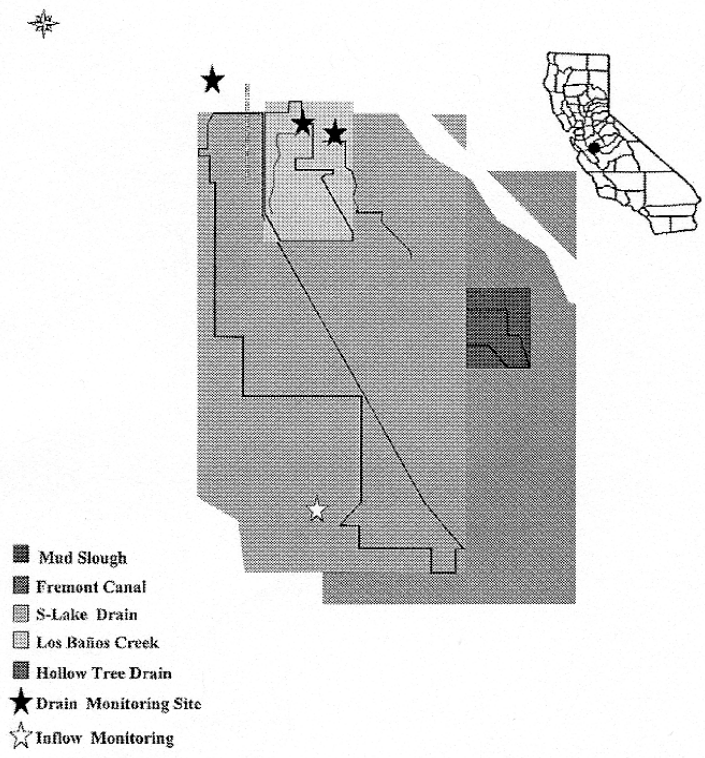

Fig. 2. NGWD showing drainage subbasins and both inflow and drainage monitoring.

\section{Wetland management}

The seasonal wetlands of the GWD are managed to meet habitat requirements by flooding in the fall and releasing their waters in the spring. Spring releases are discharged into tributaries of the Lower San Joaquin River (SJR). These releases, in combination with agricultural drainage that flows through the GWD, contain varying amounts of total dissolved solids (TDS), boron, and selenium. These constituents have been identified as stressors that lead to frequent exceedance of water quality objectives established for the SJR by state and federal agencies.

Research conducted by Grober et al. (1995) suggests that wetland drainage from the GWD could be scheduled to coincide with peak assimilative capacity in the SJR to help improve downstream water quality (Fig. 3). Assimilative capacity in the SJR occurs during periods when the average electrical conductivity (EC) at Vernalis is below the seasonal running average concentration. Fig. 3 shows that the irrigation season EC objective of $700 \mathrm{uS} / \mathrm{cm}$ between April 15 and August 15 each year is frequently violated. Between 1985 and 1998 the EC objective at Vernalis was violated more than $70 \%$ of the time.

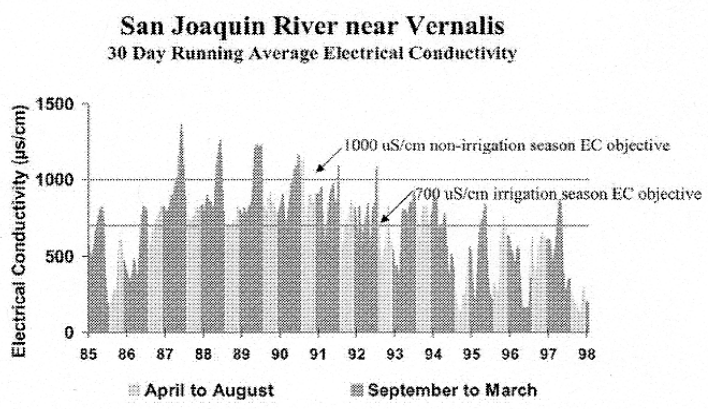

Fig. 3. SJR 30-day running average EC showing periods of assimilative capacity (graph below seasonal objective) and violation (graph above seasonal objective). Over the past 13 years, salinity (EC) objectives have been violated approximately $70 \%$ of the time. 
Increased water supply allocations ie Central Valley Project Improvement Act (CVPIA) - environmental legislation that resulted in a large transfer of water between irrigated agriculture and the environment-have created opportunities to coordinate the release of seasonal wetland drainage with the assimilative capacity of the SJR. Coordinated releases will help to achieve salt and boron water quality objectives and improve fish habitat in the main-stem of the SJR and Sacramento-San Joaquin Delta. Improved scheduling of west-side discharges can assist in avoiding critical time periods for fish rearing and remove an important stressor leading to improvements in the San Joaquin salmon fishery. To date, however, no systematic data collection program has been undertaken to evaluate the short- and long-term consequences of real-time wetland drainage management. Drainage monitoring (Fig. 4), undertaken as part of the project described in this paper, has been undertaken to address this deficiency.

Management of wetland drainage, through scheduling of releases to coincide with periods of SJR assimilative capacity, can help to improve SJR water quality. However, these actions may need to be considered relative to potential biological impacts of changes to traditional wetland management practices. Figs. 5 and 6 show how water management for optimal productivity differs between smartweed and water. Peak assimilative capacity typically occurs between the months of January and April. This time period is often earlier than the traditional wetland drawdown period (March-April). Hence, the response of moist-soil plants and of migratory waterfowl and shorebirds to an altered drawdown regime needs to be assessed. This assessment will

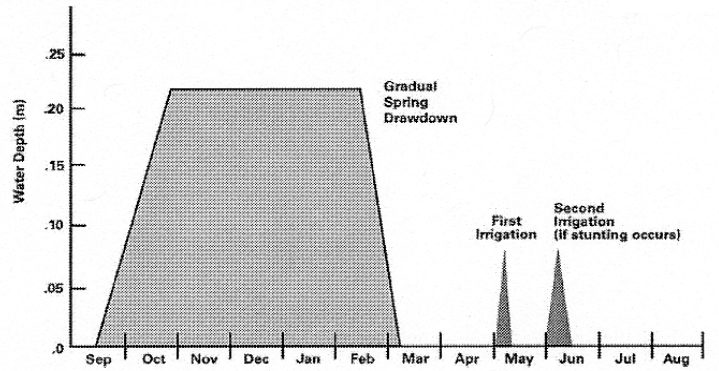

Fig. 5. Wetland flood-up and return flow schedule for smartweed in the Grassland Basin.

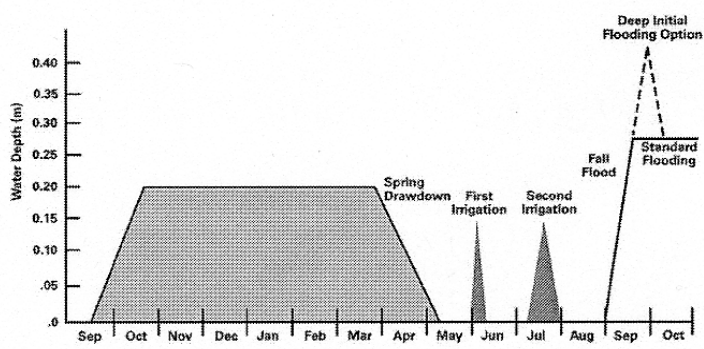

Fig. 6. Wetland flood-up and return flow schedule for watergrass in the Grassland Basin.

identify potential impacts to seed germination rates, waterbird foraging rates, habitat availability, and species diversity and abundance. It is possible that early experimental drawdown may make food sources available to wildlife without negatively affecting wetland vegetation

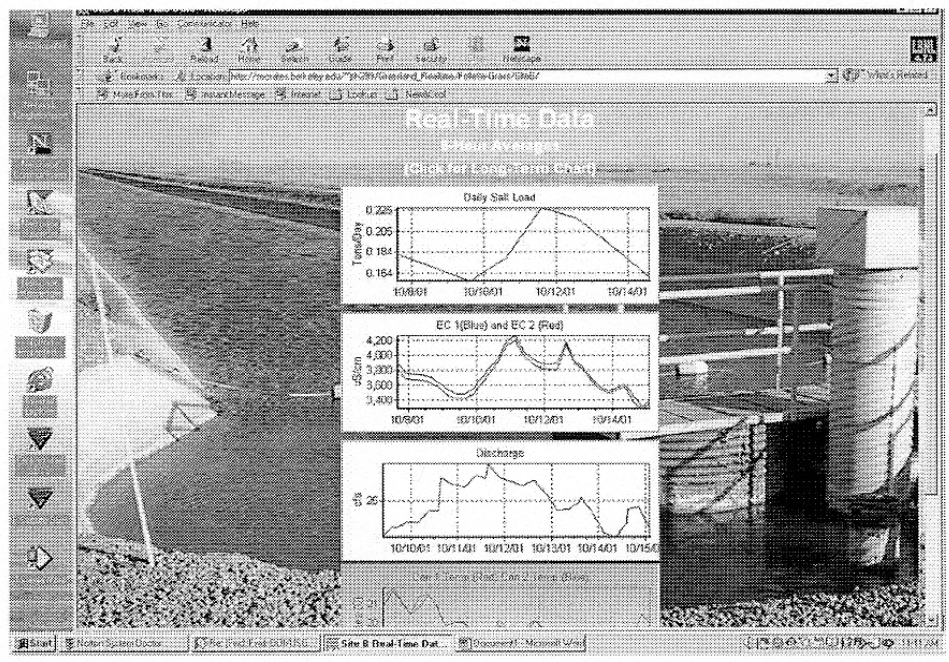

Fig. 4. Example of the real-time data acquisition and reporting system installed at wetland sites and the San Luis Drain. Wetland drainage combines with agricultural drainage in the San Luis Drain (shown above) and the combined flow is discharged to the SJR via Mud Slough. 
community and plant species diversity-hence benefiting both wildlife and the health of the SJR. This ongoing research phase of this project will have considerable technology transfer value to other agencies that operate seasonal wetlands and also discharge constituents of concern to the River.

\section{Water quality management}

As a result of recent landmark environmental legislation that drastically changed water allocations among agricultural, municipal and environmental consumers, increases in water supply have helped to improve the quality of wetland habitat in the Grassland Basin. Additional water allocations, while increasing the flexibility of operation of seasonal wetlands and improving the quality of their return flows, increase the total salt load discharged to the SJR. Exploitation of opportunities to improve coordination of seasonal wetland drainage with the assimilative capacity of the SJR can improve compliance with river water quality objectives (Fig. 3). These objectives were established originally to encourage improvements in the management of agricultural and wetland return flows. These objectives were set to protect downstream riparian irrigators who use the SJR as their sole water supply and to protect the salmon fishery. Wetland releases that contain high salt loads during the months of April coincide with agricultural pre-season irrigation to propagate plant seedlings. Saline water can inhibit germination and reduce crop yields. Salmon can become confused during their annual migration when higher flows emanate from sloughs carrying drainage water than along the main-stem of the SJR.

Better coordination of agricultural and wetland releases with reservoir releases of good quality snowmelt water on the east-side of the San Joaquin Basin has been suggested as a means of improving SJR water quality for all beneficial uses (Karkoski et al., 1995a,b; Quinn and Karkoski, 1998; Quinn et al., 1997). Quinn (1999) described the results of a demonstration project of real-time monitoring and management of agricultural drainage and east-side reservoir releases that forecasts the assimilative capacity for salinity on the SJR (Fig. 7). These forecasts are made weekly based on an analysis of current data at all monitoring stations on a Monday morning in combination with information directly obtained from east-side reservoir operators on the main tributaries, riparian diverters along the main-stem of the SJR and those agricultural drainage districts that continuously monitor their drainage return flows. Wetland real-time water quality management project complements this existing program to coordinate seasonal wetland drainage with the assimilative capacity of the SJR. Since there exists little coordinated monitoring of salt loading leaving the GWD, this project has required the installation of wetland monitoring stations at major drainage outlets from the district (Fig. 2). To allow salt balance modeling, a similar station has been installed at the main GWD inlet at the Volta Wasteway channel. The DSS, described below, was developed to help organize field monitoring data and to allow wetland managers make timely decisions regarding return flows to the SJR. These decisions are aided by the fact that the elements of the DSS will eventually be common for the SJR and wetland salt management projects.

\section{Real-time flow and water quality monitoring}

Flow transducers and EC sensors have been installed at control structures within the GWD (Figs. 2 and 4). These instruments take measurements every $15 \mathrm{~min}$ to provide an accurate measurement of salt loading in to and out of the GWD boundary. Flow and EC data at each site is collected on a battery-powered datalogger that is attached to a phone telemetry system, allowing these data to be accessed $24 \mathrm{~h}$ a day.

Flow measurements at the inlet and most of the outlet sites are being made using a state-of-the-art acoustic velocity transducers. These transducers utilize the Doppler principle whereby during operation, each transducer produces short pulses of sound at a known frequency along two different axes. Sound from the outgoing pulses is reflected ('scattered') in all directions by particulate matter in the water. These return signals have a frequency shift proportional to the velocity of the scattering material. By combining data from both beams, and knowing the relative orientation of those beams, the device measures $2 \mathrm{D}$ velocity in the plane defined by its two acoustic beams. Each transducer is equipped with two stage measurement sensors, a vertical beam and a pressure sensor which, with information on the stream cross-sectional profile and the velocity, is used in the flow computation.

Temperature-compensated EC sensors are being used to obtain real-time salinity and temperature data at each site. EC is a measure of the TDS, or the presence of ions, in the water. When compensation is made for the water temperature, EC readings provide an accurate count for the salinity in the water. Maps have been prepared locating water delivery and drainage turnouts in the GWD drainage system. These maps will document drainage hydrology within individual wetland basins. The location of the monitoring stations has been determined by Global Positioning System (GPS) survey and located on the set of Geographic Information System (GIS) maps of the study area. These monitoring sites are strategically placed within wetland channels so as to allow computation of salt loads in real-time from different sectors of the GWD.

Real-time flow, EC and temperature data from the 
N.W.T. Quinn, W.M. Hanna / Environmental Modelling \& Software 18 (2003) 503-511

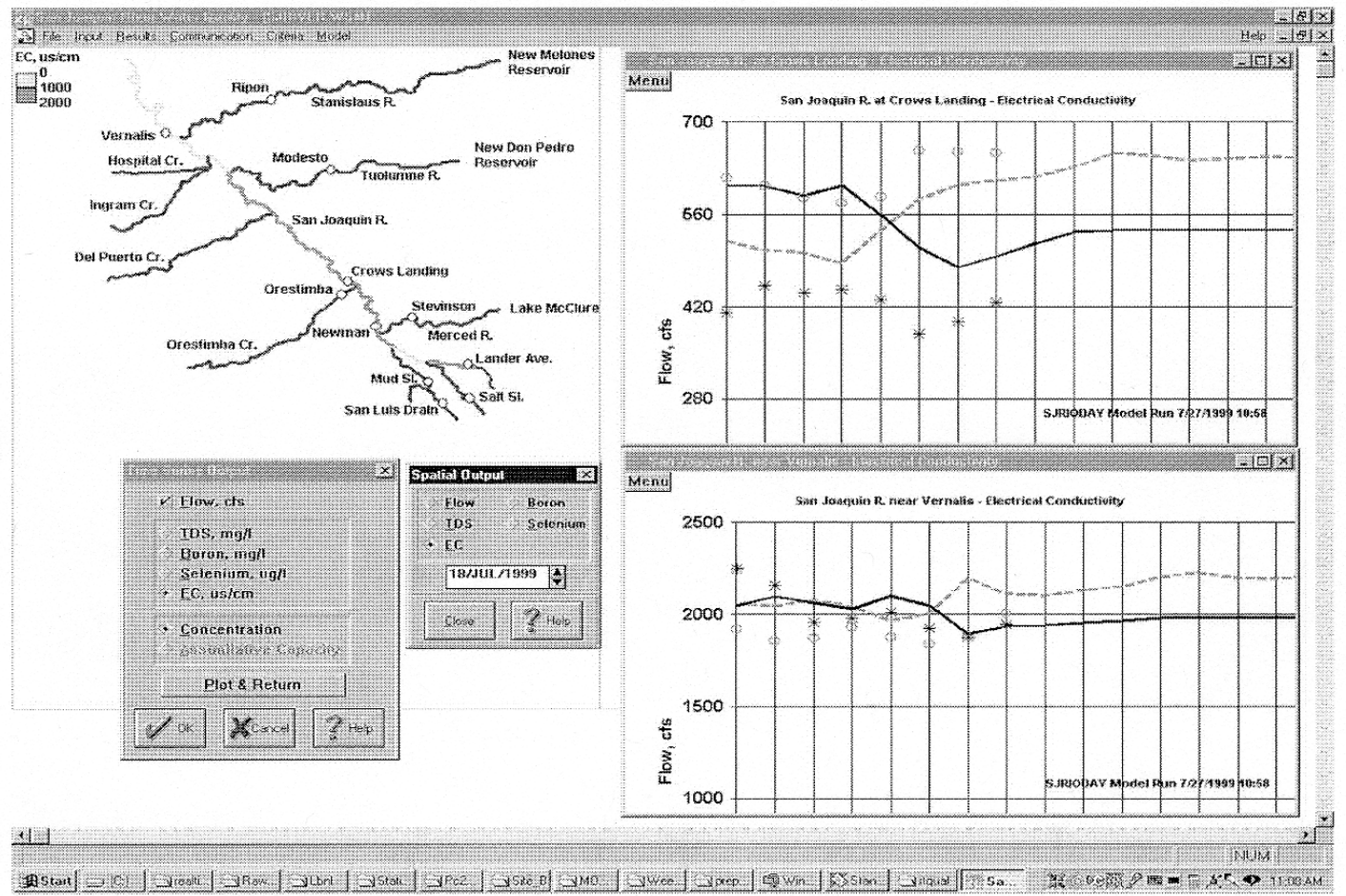

Fig. 7. Graphical user interface for the SJR salinity forecasting model. Wetland drainage enters the SJR through Mud and Salt Sloughs and, when combined with agricultural flows, account for $37 \%$ of the salt load in the SJR at Vernalis.

GWD is provided by e-mail and through a website http://socrates.berkeley.edu/ nwquinn/GrasslandRealtime/Quinn-Grass/ as input to the real-time water quality model of the SJR operated by the SJRMP Water Quality Subcommittee (Fig. 7) http://wwwdpla.water.ca. gov/sjd/waterquality/realtime/index.html. The SJRMP Water Quality Subcommittee has been funded to enhance the existing network of real-time monitoring stations along the main-stem of the SJR and to improve the coordination of agricultural return flows and scheduled east-side fish flows (Quinn et al., 1997). Installation of flow and water quality monitoring equipment and cellular telemetry equipment at key locations in the GWD helps to provide wetland and refuge managers the data necessary to make scheduling decisions. Mean daily salinity loading from the GWD is calculated from the monitoring data and is compared with the daily assimilative capacity determinations on the SJR. Wetland discharge opportunities during the spring months, when the majority of saline discharges from seasonal wetlands occur, is evaluated weekly by the project team, cooperatively with the watermaster and district biologist from the GWD.

\section{Habitat evaluation}

The biological and ecological monitoring and data objectives of the project are to document the effects of changing traditional flood-up and wetland drainage discharge patterns on wetland habitat and bird species (Williams, 1996). Achievement of these objectives will assist in developing adaptive management approaches to optimize wetland habitat conditions while minimizing the negative effects of wetland drainage on the water quality in the SJR.

A program of wetland habitat assessment is proceeding concurrently with the real-time monitoring and water quality management program. Changing the scheduling of wetland drainage to the SJR affects the timing and rate of drawdown of wetland ponds and hence the forage value of the wetlands for migrating and wintering shorebirds and waterfowl. Wetland salinity management measures can also affect the productivity and diversity of vegetation that can be grown in the watershed. The research underway is documenting the impacts of altering traditional wetland management practices and developing guidelines for multi-objective wetland oper- 
ations including forage production, nesting cover establishment and salinity management. The concurrent program of habitat evaluation and salinity management could lead to optimization of wildlife and environmental benefits to the Grassland Basin and SJR.

Wetland habitat monitoring sites have been randomly chosen from available seasonal wetlands within the GWD. These wetlands correspondingly drain into locations where flow and EC monitoring sites are situated. At all wetland study plots, a paired study design is being used to directly assess differences in traditionally drained wetlands vs. non-traditionally drained wetlands. Biological monitoring is being conducted on adjacent traditionally and non-traditionally drained wetlands. The monitoring includes both a waterbird (waterfowl and shorebirds) usage component and a moist-soil plant production component. The waterbird component measures abundance and diversity and determine time-activity budgets of waterbirds through scan sampling and direct observation to assess foraging potential. The moist-soil plant production component determines the impacts, if any, to the vegetation by assessing changes in total plant biomass, percent coverage, and species composition through grid sampling and aerial photography.

\section{DSS design}

The rationale for developing a DSS was to provide a set of analytical tools that assist in computation of GWD wetland water requirements, estimation of wetland salinity load in seasonal wetlands and in the selection of best management practices. A requirement of the DSS was that it be simple in design and intuitive, similar to data management tools typically used by the GWD. GWD staffs spend much of their time in the field and do not have large blocks of time that they can devote to learning new software. The DSS was designed to interact with existing SJR water quality forecasting models and software to allow the partition of river assimilative capacity among the wetland releases.

\section{Water quality model}

The wetland water and salinity model simulates seasonal and permanent wetland management in the GWD and mimics the wet/dry seasonal cycle that these wetlands experience as well as the quantity and water quality of wetland releases. The main objective of the wetland water quality model is to predict the effects of salt loading to the SJR during spring drawdown (JanuaryApril). The model incorporates the weekly water use requirements of the major wetland habitat types in the GWD and the adjacent State and Federal refuges. Mapping of the wetland habitat has been limited to date to discriminating open water areas within the wetland complex. Evapotranspiration from moist-soil plants within the GWD is presently estimated and not specifically modeled owing to lack of field data for model calibration. There are no reliable techniques available using remote sensing technology to quantify the areal extent of the major moist-soil plants and other wetland habitat within the GWD. In spite of these limitations the model tracks salinity changes in each of the wetlands over the winter season and incorporates user-defined schedules for wetland drawdown in the spring months. By running scenarios of different weekly wetland fill and release schedules and annual changes in vegetation type and waterbird usage, managers are able to plan operations to minimize water quality impacts on the SJR while maximizing wildlife benefits.

The current model has been developed as a Microsoft Excel spreadsheet on account of the widespread familiarity with this product among wetland managers in the Grassland Basin. The model has been designed to perform historic hydrology simulations as well as seasonal alternatives (along with sensitivity analyses). Seasonal alternatives include different wetland drawdown protocols such as: (a) early drawdown (critically dry to dry year), (b) traditional drawdown (dry to wet year), (c) late drawdown (wet year), and (d) preflushing. The wetland water quality model has been designed to allow easy linkages to popular software packages such as RAISON and ARCVIEW. In addition, the Excel spreadsheet model has been designed to predict salt loading from the NGWD watershed as well to read salt assimilative capacity output directly from the Department of Water Resources' Delta Simulation Model II (DSM-2). First the wetland water quality model provides wetland outflow quantities and salt loads to DSM-2 at Mud and Salt Sloughs for use in its river forecasts and second, the wetland water quality model uses SJR assimilative capacity forecasts provided by DSM-2 as input.

\subsection{Input data}

Input data for the wetland water quality model fall into four categories; static, annually constant, annually varying, and real-time. Static data, which do not vary with time, include soil properties, land classifications, acreages, drainage basin allocations, and precipitation and ET qualities. Annually constant data, which are static year to year but vary within the year, include crop coefficients (for ET subroutines), best management practices, and water table depth. Annually varying data include precipitation, water year classification, air, water, and soil temperatures, irrigation schedule, and wetland flood-up schedule. Real-time data includes supply water quantity and quality, drainage water quantity and quality, evapotranspiration, precipitation, and SJR assimilative capacity. Much of the static and annually 
constant data are assumptions, since intensive monitoring in these wetlands only commenced in water year 2000. A typical user will not need modify these data, once measured, except for system changes, calibration, or sensitivity analyses.

\subsection{Model runs}

The model was applied to historical northern GWD drainage data collected during the 1998-1999 water year. The NGWD contains the major drainage outlets to the SJR and, since it is geographically separated from the southern GWD by the city of Los Banos, it can be considered as a hydrologically separate system. During the spring of 1999 , NGWD wetland drawdown contributed over $6 \%$ of the total salt load in the SJR at the Crows Landing monitoring station, located downstream of the Mud and Salt Slough discharge points, on the SJR. The Mud Slough discharge to the SJR combines flow and salt loads from Mud Slough (north), Fremont Canal, Los Baños Creek, Hollow Tree Drain, and S-Lake Drain. Fremont Canal alone contributes flows and salt loads of approximately $2 \%$ of the total wetland acreage in the NGWD (GWD, 2001).

Model simulations have been made, comparing SJR flow and water quality at Crows Landing under several different wetland management plans for the drawdown season between January 1999 and April 1999 (Figs. 8 and 9). The different wetland management plans were simulated using calculated wetland water quality. The salt loads generated from this analysis were compared to river assimilative capacity, estimated by the DSM-2 river hydrodynamic model for the same period. The first step of the model run required developing high and low baseline flow and salt load values for the SJR. The high SJR baseline selected was the actual modeled (DSM-2) salt load at Crows Landing. The low SJR baseline was the salt load at Crows Landing assuming zero contribution of flow and salt load from the NGWD.

Once baseline values were established, the wetland water quality model simulated early and late drawdown release scenarios from the NGWD. For these historical model runs, early and late wetland drawdown scenarios were generated by skewing the actual drainage data by $+/-1$ standard deviation. To view the impacts of the alternative wetland management plans, the modeled results were added to the low SJR baseline values. Although the actual NGWD salinity contribution to the SJR was roughly $6 \%$ during the 1999 wetland drawdown season, effects from altered drawdown schedules are apparent.

7.2.1. Scenario 1: baseline values: DSM-2 model values (actual) vs. DSM-2 w/o NGWD contribution

This comparison shows the difference between the actual modeled (DSM-2) SJR qualities and quantities (high baseline) and the SJR had there been no contribution from the NGWD (low baseline).

7.2.1.1. Water quantity Completely removing the NGWD contribution considerably reduced the flow in the SJR at Crows Landing. The reduction in flow ranged from one to almost $11 \%$, with the maximum observed deficit occurring in late March and early April (Fig. 8).

7.2.1.2. Water quality Completely removing the contributions from the NGWD to the SJR had a marked effect by reducing the EC at Crows Landing by more than $4 \%$ during peak wetland withdrawals in February and March (Fig. 9). It is interesting to note that during the week ending March 25th, removing the NGWD contribution actually increased the EC of the SJR at Crows

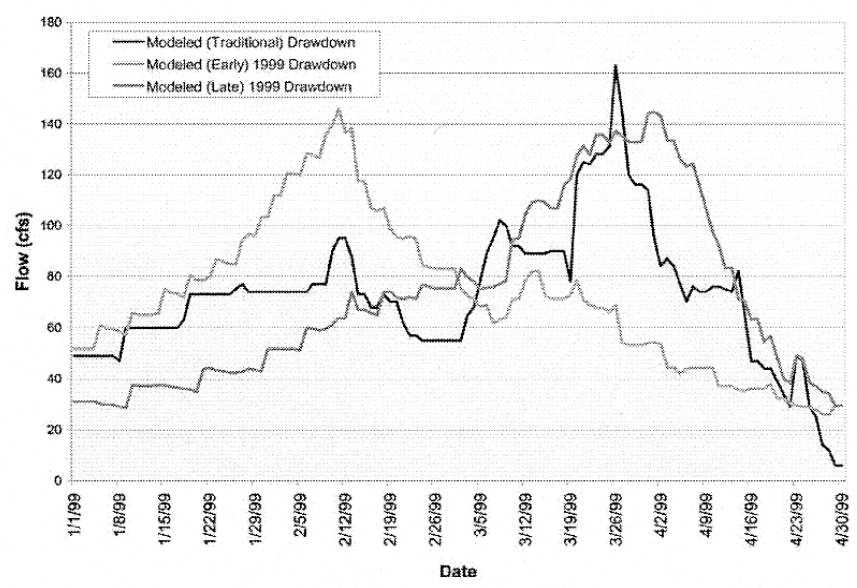

Fig. 8. Comparison of drainage flow for traditional, early and late drawdown scenarios for NGWD. 
N.W.T. Quinn, W.M. Hanna / Environmental Modelling \& Software 18 (2003) 503-511

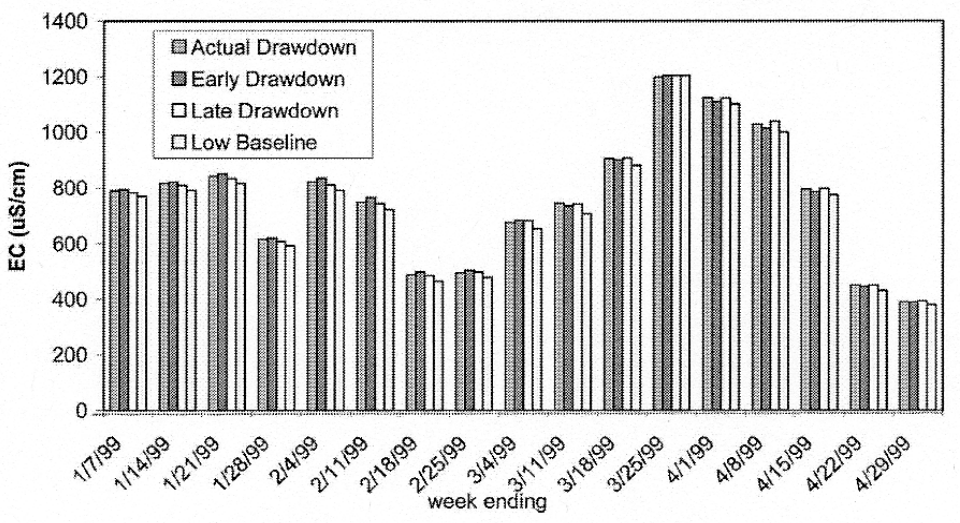

Fig. 9. Average weekly EC at Crows Landing for WY 1999 spring drawdown.

Landing. Further review of the data confirms this, showing that indeed the EC of the SJR was higher during that time than the wetland releases. However, other than that 1 week, removal of the NGWD component decreased the EC, and hence increased the assimilative capacity, of the SJR at Crows Landing.

\subsubsection{Scenario 2: wetland water quality model run 1 -early wetland drawdown}

This comparison is designed to show the difference between the actual modeled (DSM-2) SJR qualities and quantities (high baseline) and the SJR, had there been an early wetland drawdown from the NGWD.

7.2.2.1. Water quantity An early wetland drawdown management plan from the NGWD to the SJR increased the flow in the SJR at Crows Landing during the early months and reduced it in the later months (Fig. 8).

7.2.2.2. Water quality Applying an early wetland drawdown management plan from the NGWD to the SJR had a marked effect by increasing the EC by an average of $1.5 \%$ during the early months (January and February) and by reducing the EC by an average of $2.5 \%$ in the later drawdown months (March and April)-(Fig. 9).

\subsubsection{Scenario 3: wetland water quality model run} 2 -late wetland drawdown

This comparison shows the difference between the actual modeled (DSM-2) SJR qualities and quantities (high baseline) and the SJR, had there been a late wetland drawdown from the NGWD.

7.2.3.1. Water quantity A late wetland drawdown management plan from the NGWD to the SJR did not have as great an impact on the SJR as did the early drawdown management plan. The late drawdown did decrease the flow in the SJR at Crows Landing during the early months and increased it in the later months, however, on average, it did not change the flows by more than $+/-1 \%$ (Fig. 8 )

7.2.3.2. Water quality Because traditional drawdown management plans tend to be later in the season, applying a late wetland drawdown management plan from the NGWD to the SJR did not have as marked an effect on the water quality of the SJR. The late drawdown decreased the EC by an average of $0.5 \%$ during the early months (January and February) and increased the EC by an average of $0.25 \%$ in the later drawdown months (March and April)-(Fig. 9).

\subsection{Analysis}

It was apparent that even though an early withdrawal management plan has the greatest effect on altering the quality of the SJR, this is mainly because wetland managers in the NGWD schedule traditional drawdown later in the season. These simulations will need to be performed on subsequent years to verify the findings from the one drawdown season of 1999.

\subsection{Discussion - adaptive management of wetland releases}

The overall goal of the project is to provide basic monitoring information and to develop decision support tools to allow wetland managers in the GWD to respond to the long-term challenge of improving water quality while maximizing wetland functions and habitat values. The project considers two levels of monitoring and analysis - the first, at the water district scale, will develop inflow and outflow monitoring and a salinity loading mass balance for the entire North-Grasslands region. The second, conducted at the scale of a single duck club, in this case the most progressive and scien- 
tifically managed in the water district, which has designated functional wetland units to attract different bird species and which offers a great diversity of hunting experience. The project is fortunate in having enlisted the cooperation of one of the most innovative wetland managers in the GWD, who has for years been experimenting with different regimes of wetland filling and release - primarily with the objective of optimizing wildfowl habitat under various regimes of water availability and supply water quality. The duck club will benefit by the more intensive level of water flow and quality monitoring while providing the wetland manager a test-bed to observe and evaluate alternative management regimes. More intensive monitoring of a suite of water quality factors is underway at the duck club with including flow, EC, pH, turbidity, dissolved and particulate organic carbon concentrations and biochemical oxygen demand, which provide a comprehensive comparison of management-related impacts.

The synergy between the monitoring and research objectives of our project and the practical aspects of improving wetland function in a climate of increased environmental regulation and control of non-point source discharges provides a unique opportunity for advancement of the art and the science of wildfowl wetland management. By taking this 'pre-emptive' actionthe GWD is seen to be proactive in the eyes of the EPA and the Regional Water Quality Control Board (enforcement division for the EPA), which are presently laying the groundwork for salt load allocation and salinity water quality objectives on the SJR.

\section{Summary}

Information obtained through this project will likely be transferable and of significant value to all wetlands in the grassland ecological area including those wetlands managed by State and Federal wildlife agencies. The successful implementation of this combined monitoring, experimentation and evaluation program will provide the basis for adaptive management of wetland drainage throughout the entire 70,000 ha grassland ecological area. The project will involve local landowners, duck club operators, and managers of State and Federal refuges in the Grassland Basin. Although this pilot project has concentrated on the 20,000 ha that comprise the GWD, the goal of the project is to disseminate the findings of the project more widely. The GWD has a successful history of local involvement through the district newsletter, published monthly; high school and collegelevel educational outreach programs; and through 'Wild on Wetland' days, which help to educate the public about the benefits and techniques of wetland management.

\section{Acknowledgements}

The authors gratefully acknowledge project funding from the US Bureau of Reclamation and the CALFED Bay-Delta Program and project support from Don Marciochi and Scott Lower of the Grassland Water District.

\section{References}

Fredrickson, L.H., Taylor, T.S., 1982. Management of Seasonally Flooded Impoundments for Wildlife. US Department of the Interior, Fish and Wildlife Service, Washington, DC (Resource publication 148).

Grober, L.F., Karkoski, J., Poole, T., 1995. Water quality impact of wetlands on San Joaquin River, California, paper no. 00149. In: Cleveland, T.G. (Ed.), Texas, November 5-10, Advances in the Development and Use of Models in Water Resources: Proceedings of the American Water Resources Association held in Houston. Department of Civil and Environmental Engineering, University of Houston, Houston, TX.

Karkoski, J., Quinn, N.W.T., Grober, L.F., 1995a. The potential for real-time water quality management in the San Joaquin River Basin of California. In: AWRA Annual Conference and Symposium Proceedings, Houston, Texas, July, Advances in Model Use and Development for Water Resources.

Karkoski, J., Quinn, N.W.T., Grober, L.F., Chilcott, J.E., Vargas, A., 1995b. Selenium transport in the grasslands watershed. In: Veterinary Medical Extension Conference, June 1, 2, Sacramento, Selenium in the Environment: Essential Nutrient, Potential Toxicant. Cooperative Extension and U.C. (Poster session).

Quinn, N.W.T., 1999. A decision support system for real-time management of water quality in the San Joaquin River, California Environmental Software Systems. Environmental information and decision support. IFIP TC5 WG5. In: Denzer, R., Swayne, D.A., Purvis, M., Schimak, G. (Eds.), 30 August-2 September, Dunedin, New Zealand, Third International Symposium on Environmental Software Systems (ISESS'99). Kluwer Academic Publishers, Massachusetts.

Quinn, N.W.T., Karkoski, J., 1998. Potential for real time management of water quality in the San Joaquin Basin, California. American Water Resources Association 34 (6).

Quinn, N.W.T., Chen, C.W., Grober, L.F., Kipps, J., Cummings, E., 1997. Computer model improves real-time management of water quality. California Agriculture 51 (5).

Williams, O.E., 1996. Waterbird responses to late winter and early spring drawdowns of moist-soil managed wetlands in California's San Joaquin Valley. MS thesis, Humboldt State University, California, USA. $136 \mathrm{pp}$. 